\title{
Homogeneous and Heterogeneous Chelation-Assisted Ruthenium(II)-Catalyzed C-H Functionalizations
}

\author{
Dissertation
}

for the award of the degree

"Doctor rerum naturalium"

of the Georg-August-Universität Göttingen

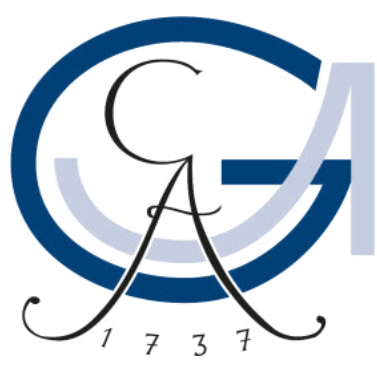

within the

International PhD Program Catalysis for Sustainable Synthesis

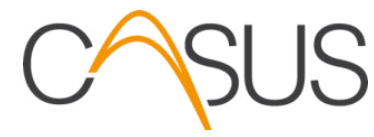

of the Georg-August-University School of Science (GAUSS)

submitted by

\section{Svenja Warratz}

from Marburg

Göttingen 2016 



\section{Thesis Committee}

Prof. Dr. Lutz Ackermann, Institute of Organic and Biomolecular Chemistry

Prof. Dr. Konrad Koszinowski, Institute of Organic and Biomolecular Chemistry

Prof. Dr. Dietmar Stalke, Institute of Inorganic Chemistry

\section{Members of the Examination Board}

Prof. Dr. Lutz Ackermann, Institute of Organic and Biomolecular Chemistry

Prof. Dr. Konrad Koszinowski, Institute of Organic and Biomolecular Chemistry

Prof. Dr. Dietmar Stalke, Institute of Inorganic Chemistry

\section{Further Members of the Examination Board}

Prof. Dr. Sven Schneider, Institute of Inorganic Chemistry

Dr. Shoubhik Das, Institute of Organic and Biomolecular Chemistry

Dr. Franziska Thomas, Institute of Organic and Biomolecular Chemistry

Date of the oral examination: November $18^{\text {th }}, 2016$ 



\section{Acknowledgement}

Zuallererst möchte ich mich ganz herzlich bei meinem Doktorvater Professor L. Ackermann bedanken, der mir die Möglichkeit gegeben hat die vorliegende Arbeit in seinem Arbeitskreis anzufertigen und in dieser Zeit stets mit wertvollen Ratschlägen zur Seite stand. Besonders für die Chance nach Israel zu gehen bin ich sehr dankbar.

Bei Professor K. Koszinowski und Professor D. Stalke möchte ich mich für die Übernahme der Korreferate bedanken. Für die Teilnahme an der Prüfungskomission bedanke ich mich zudem bei Professor S. Schneider, Dr. S. Das und Dr. F. Thomas.

I am very thankful to Professor D. Gelman who gave me the great opportunity to work in his lab. Many thanks also to his group who made my stay in Israel such a special time. Many thanks to Amani, I am very glad that I got to know you.

Besonders möchte ich mich bei den analytischen Abteilungen der Universität Göttingen für die fantastische Arbeit bedanken und ihre Hilfe bei Problemen und vor allem die schnellen Messungen bei dringenden Proben. An dieser Stelle möchte ich mich auch bei Frau Dr. A. C. Stückl für die ESR Messungen bedanken, bei Herrn Dr. K. Simon für die ICP-MS Messungen und bei Julius Scholz und Professor C. Jooss für die Unterstützung bei der Analytik der Sol-Gel Katalysatoren. Vielen Dank an Julia Möhrke für die Messung der TGAs und besonders auch vielen Dank an Benedikt Niepötter, Christian Maaß, Helena Keil und Professor D. Stalke für die Kristallstrukturanalysen.

Bei Gabi, Stefan und Karsten möchte ich mich für die stete Unterstützung bezüglich Verwaltung, EDV und Laborausrüstung bedanken.

Thanks also to all the people who worked on projects with me, it was an honor working with you! Lieben Dank an meine Studenten, die mir mit ihren Startmaterialien sehr geholfen haben.

A huge thanks goes to all my labmates and group members during the years, you made working here so much more fun! Ein ganz großes Dankeschön an Marc, für all die Hilfe, Ideen und Unterstützung während den Jahren hier. Thank you Darko for making me laugh, even though you ruined my crystals. Many thanks also to Suman who helped me so many times and shared his knowledge and ideas with me! Thanks to Hui for helping wherever he could help. Thanks to you Emy, you made me feel welcome in this group from my first day on.

Many thanks to all the people who proofread all my texts and especially to the ones who helped me with this thesis: Alex, Hui, Julian Marc, Mélanie, Michalea and Nicolas.

Ein riesen Dank geht an meine Familie, danke dass ihr mich immer unterstützt habt! Und natürlich an Lars für Alles! 



\section{Contents}

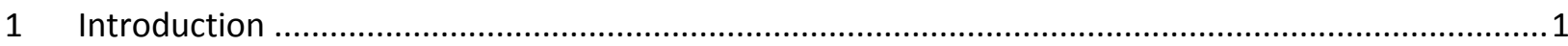

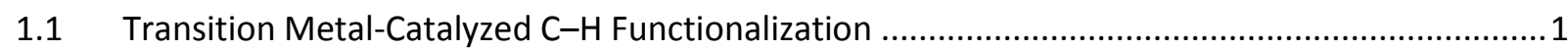

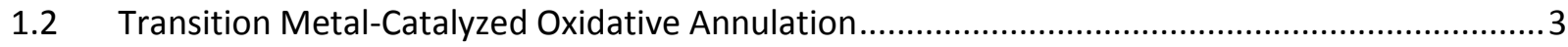

1.3 Direct Arylation Through Ruthenium-Catalyzed C-H Activation........................................... 8

1.4 Ruthenium-Catalyzed Alkylation through C-H Bond Activation ............................................10

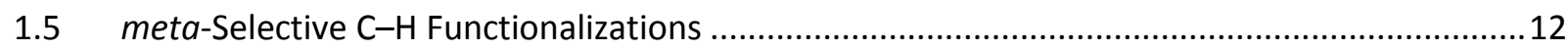

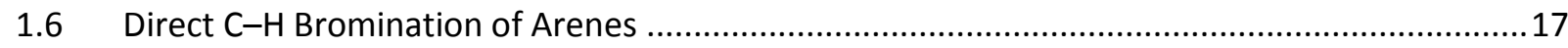

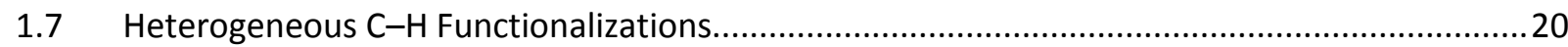

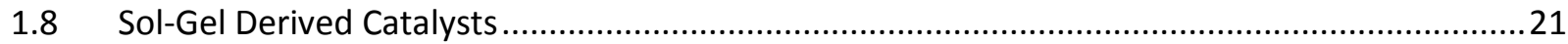

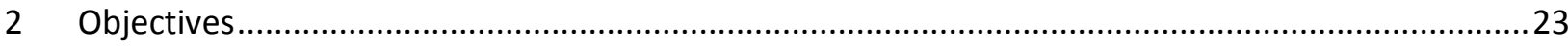

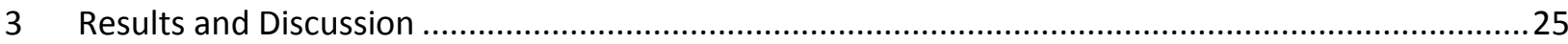

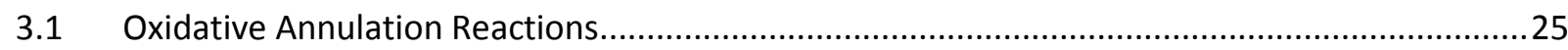

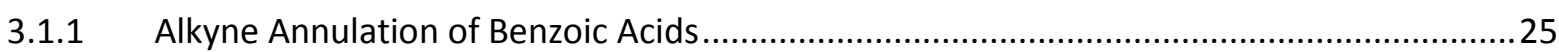

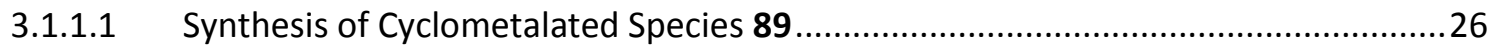

3.1.1.2 Synthesis of Ruthenium(0) Sandwich Complexes 91...........................................28

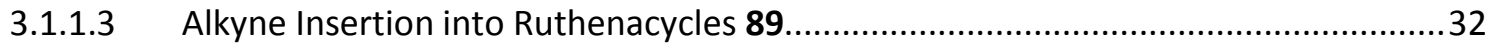

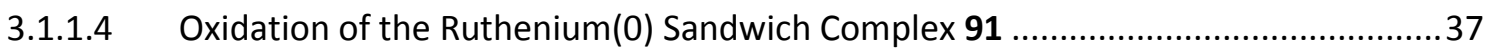

3.1.1.5 Catalytic Reaction and Activity of Isolated Complexes in These ..............................42

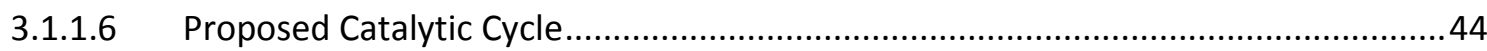

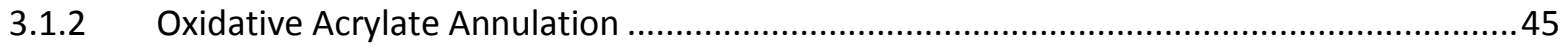

3.1.2.1 Mechanistic Investigations of the Oxidation Mode ..................................................47

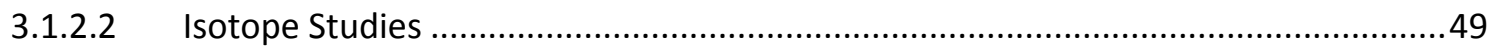

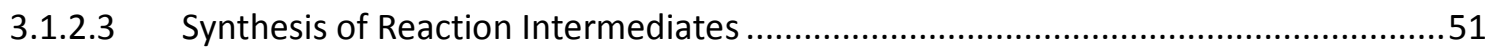

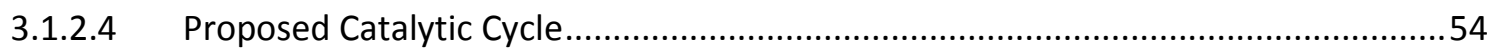

3.2 C-H Arylations Catalyzed by Single-Component Phosphinous Acid Ruthenium(II) Catalysts .....56

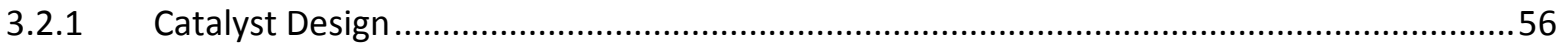


3.2.2 Optimization Studies

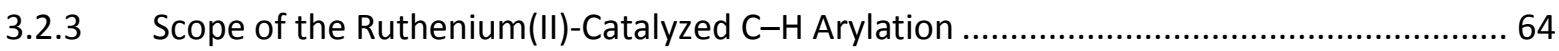

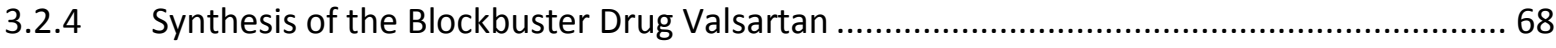

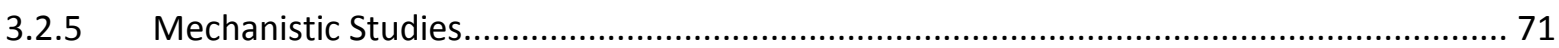

3.3 Ruthenium(II)-Catalyzed meta-C-H Alkylations............................................................

3.3.1 Synthesis of Ruthenium(II) MPAA Complexes....................................................... 74

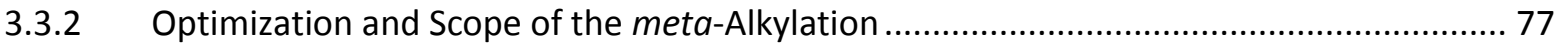

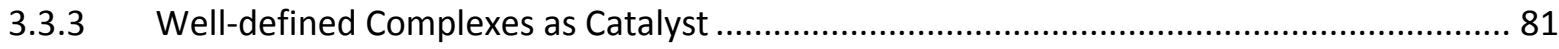

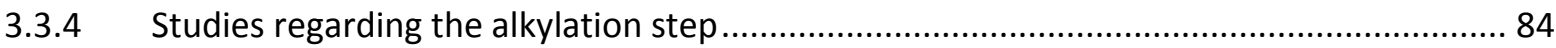

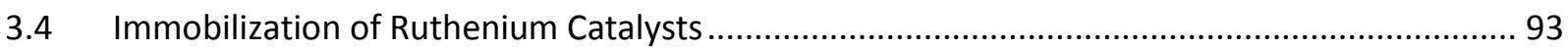

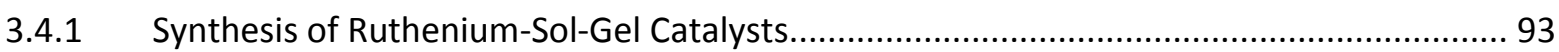

3.4.2 meta-Selective Bromination of Purine Bases ....................................................... 96

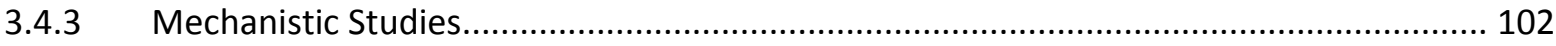

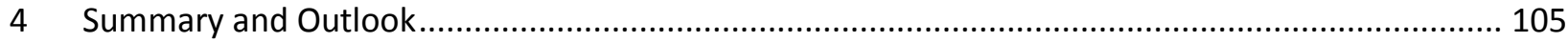

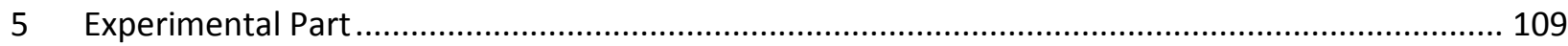

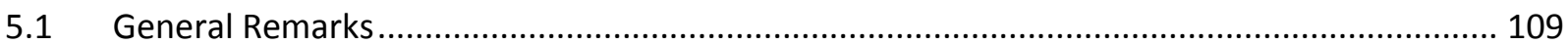

5.2 General Procedures............................................................................................. 113

5.2.1 General Procedure A: Synthesis of Ruthenacycles 89 via C-H Metallation .................. 113

5.2.2 General Procedure B: Synthesis of Ruthenium(0) Sandwich Complex $91 \ldots \ldots \ldots \ldots \ldots \ldots . . . . . . . .114$

5.2.3 General Procedure C: Synthesis of Ruthenium(0) Sandwich Complex 91 via Alkyne

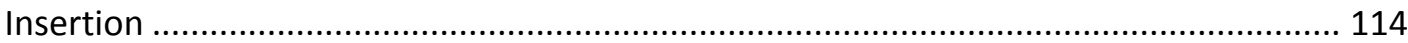

5.2.4 General Procedure D: Synthesis of Phthalides 14 via Ruthenium(II)-Catalyzed Aerobic Alkene Annulation

5.2.5 General Procedure E: Synthesis of Ruthenium(II) Phosphinous Acid Catalysts $\mathbf{8 4}$

5.2.6 General Procedure F: PA-Ruthenium(II)-Catalyzed C-H Arylations of Oxazolines 102.... 115

5.2.7 General Procedure G: PA-Ruthenium(II)-Catalyzed C-H Arylations of Tetrazoles 104.... 115

5.2.8 General Procedure H: Ruthenium(II)-Catalyzed direct meta-Alkylation of Phenylpyridines 32 
5.3 Experimental Procedures and Analytical Data ..................................................................117

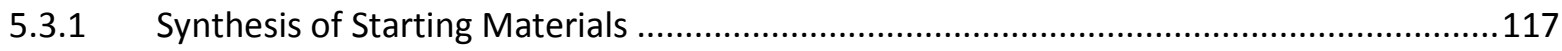

5.3.2 Data for the Ruthenium-catalyzed Oxidative Annulation ................................................118

5.3.2.1 Synthesis of 5-membered Ruthenacycles..............................................................118

5.3.2.2 Synthesis of Ruthenium-Sandwich Complexes ...................................................120

5.3.2.3 Attempted Synthesis of 7-membered Ruthenacycle ..............................................129

5.3.2.4 Oxidation of Sandwich complex 91ba and Release of Isocoumarin ........................132

5.3.2.5 Synthesis of Isocoumarins via Aerobic Ruthenium-Catalyzed Alkyne Annulations.135

5.3.2.6 Ruthenium-catalyzed Phthalide Synthesis.........................................................137

5.3.2.7 $\quad \mathrm{O}_{2}$-uptake Study for the Synthesis of Phthalides...................................................... 140

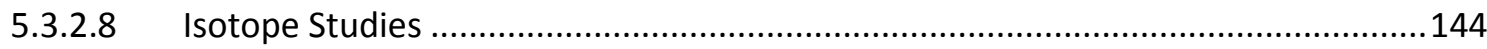

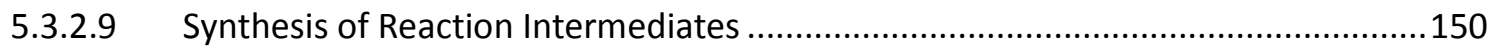

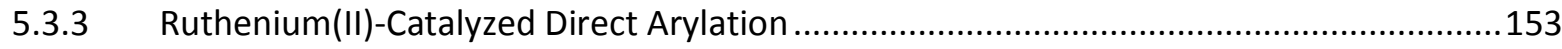

5.3.3.1 Synthesis of Ruthenium(II) Phosphinous Acid Catalysts 84 ..................................153

5.3.3.2 PA-Ruthenium(II)-catalyzed C-H Arylation of Oxazolines .......................................155

5.3.3.3 PA-Ruthenium(II)-catalyzed C-H Arylation of Triazole .............................................163

5.3.3.4 PA-Ruthenium(II)-catalyzed C-H Arylations of Tetrazoles .......................................163

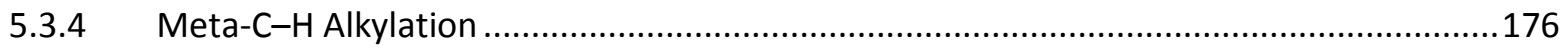

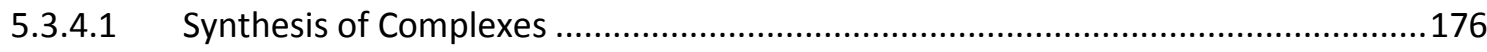

5.3.4.2 Ruthenium(II)-catalyzed direct meta-Alkylation.................................................. 180

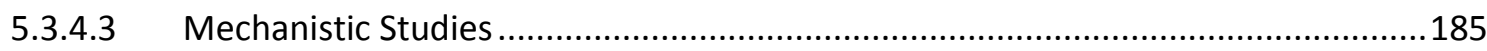

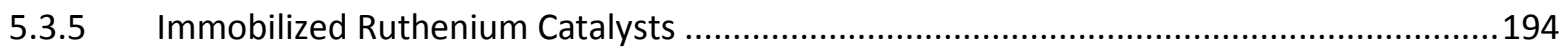

5.3.5.1 meta-Selective C-H Bromination....................................................................... 197

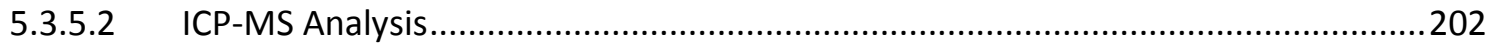

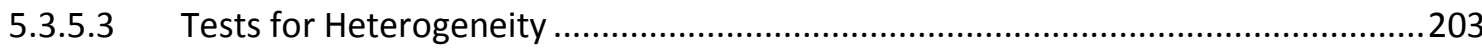

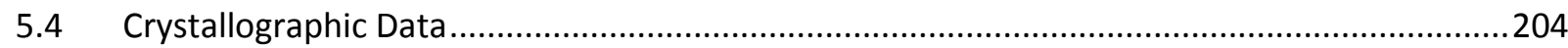

6 Literature. 



\section{List of Abbreviations}

\begin{tabular}{|c|c|}
\hline $\mathrm{Ad}$ & adamantyl \\
\hline Alk & alkyl \\
\hline AMLA & ambiphilic metal-ligand activation \\
\hline $\operatorname{Ar}$ & aryl \\
\hline ATR & attenuated total reflectance \\
\hline $\mathrm{Bn}$ & benzyl \\
\hline $\mathrm{Bu}$ & butyl \\
\hline cat & catalytic \\
\hline CMD & concerted metalation-deprotonation \\
\hline $\operatorname{cod}$ & 1,5-cyclooctadiene \\
\hline $\mathrm{Cp} *$ & 1,2,3,4,5-pentamethylcyclopentadiene \\
\hline CV & cyclic voltammetry \\
\hline DCE & 1,2-dichloroethane \\
\hline DG & directing group \\
\hline DMA & $N, N$-dimethylformamide \\
\hline DMAP & 4-(dimethylamino)pyridin \\
\hline DMSO & dimethylsulfoxide \\
\hline DPPH & 2,2-diphenyl-1-picrylhydrazyl \\
\hline EDG & electron-donating group \\
\hline El & electron ionization \\
\hline equiv & equivalents \\
\hline ESI & electronspray ionization \\
\hline Et & ethyl \\
\hline EWG & electron-withdrawing group \\
\hline $\mathrm{Fc}$ & ferrocene \\
\hline FTICR & Fourier transform ion cyclotron resonance \\
\hline GC-MS & gas chromatography-mass spectrometry \\
\hline Hept & heptyl \\
\hline HFIP & 1,1,1,3,3,3-hexafluoro-2-propanol \\
\hline HMPT & tris(dimethylamino)phosphine \\
\hline HRMS & high resolution mass spectrometry \\
\hline IES & internal electrophilic substitution \\
\hline Ind & indene \\
\hline IR & infrared \\
\hline KIE & kinetic isotope effect \\
\hline L & ligand \\
\hline M & metal \\
\hline Mes & 2,4,6-trimethylphenyl \\
\hline Me & methyl \\
\hline$m$ & meta \\
\hline M.p. & Melting point \\
\hline MPAA & mono- $N$-protected amino acid \\
\hline NBS & $\mathrm{N}$-bromosuccinimide \\
\hline
\end{tabular}




$\begin{array}{ll}\text { NCS } & \text { N-chlorosuccinimide } \\ \text { NIS } & N \text {-iodosuccinimide } \\ \text { NMP } & N \text {-methyl-2-pyrrolidinone } \\ \text { NMR } & \text { nuclear magnetic resonance } \\ o & \text { ortho } \\ p & \text { para } \\ \text { PA } & \text { phosphinous acid } \\ p \text {-cymene } & \text { 4-iso-propyltoluene } \\ \text { PEG } & \text { polyethylene glycol } \\ \text { Ph } & \text { phenyl } \\ \text { Piv } & \text { 2,2-dimethylpropanoyl } \\ \text { pKa } & \text { logarithmic acid dissociation constant } \\ \text { PMP } & \text { para-methoxyphenyl } \\ \text { Pr } & \text { propyl } \\ \text { py } & \text { pyridine } \\ \text { R } & \text { rest } \\ \text { SEAr } & \text { electrophilic aromatic substitution } \\ \text { SET } & \text { single electron transfer } \\ \text { SN1 } & \text { First-order nucleophilic substitution } \\ \text { SN2 } & \text { Second-order nucleophilic substitution } \\ \text { SPO } & \text { secondary phosphine oxide } \\ \text { T } & \text { temperature } \\ t \text {-Am } & \text { 2-methylbut-2-yl } \\ \text { TEMPO } & \text { 2,2,6,6-tetramethylpiperidinyloxyl } \\ \text { Tf } & \text { trifluoromethanesulfonate } \\ \text { THF } & \text { tetrahydrofuran } \\ \text { TM } & \text { transition metal } \\ \text { TMP } & \text { 2,4,6-trimethoxyphenyl } \\ \text { TOF } & \text { time of flight } \\ \text { TON } & \text { turnover number } \\ \text { TS } & \text { transition state } \\ \text { TS } & \text { tosyl } \\ \text { UV } & \text { ultraviolet } \\ & \end{array}$


Introduction

\section{Introduction}

A major goal of chemists nowadays is to develop processes which follow the rules of green chemistry and thus improve the impact on the environment. Anastas and Warner published the twelve principles of green chemistry in 1998 as a guideline for future developments. ${ }^{[1]}$ Catalysis itself is one principle to reduce waste and displays an essential role in modern synthesis.

\subsection{Transition Metal-Catalyzed C-H Functionalization}

The formation of carbon-carbon $(\mathrm{C}-\mathrm{C})$ and carbon-heteroatom ( $\mathrm{C}-\mathrm{Het}$ ) bonds through catalytic processes are key to the design of all kinds of functionalized materials. A breakthrough in this area, the transition metal-catalyzed cross-coupling reactions, was recognized by the Nobel Prize in 2010 and is nowadays a standard technique in industrial syntheses. Even though it offers a great tool for organic chemists, it still displays some room for improvement, especially the necessity for prefunctionalized starting materials is a major drawback. On the contrary, transition metal-catalyzed site-selective functionalization of otherwise inert $\mathrm{C}-\mathrm{H}$ bonds bears the potential for the construction of $\mathrm{C}-\mathrm{C}$ and $\mathrm{C}-\mathrm{Het}$ bonds without pre-functionalization steps. ${ }^{[2]}$ Therefore the production of waste and costs are significantly minimized (Figure 1).

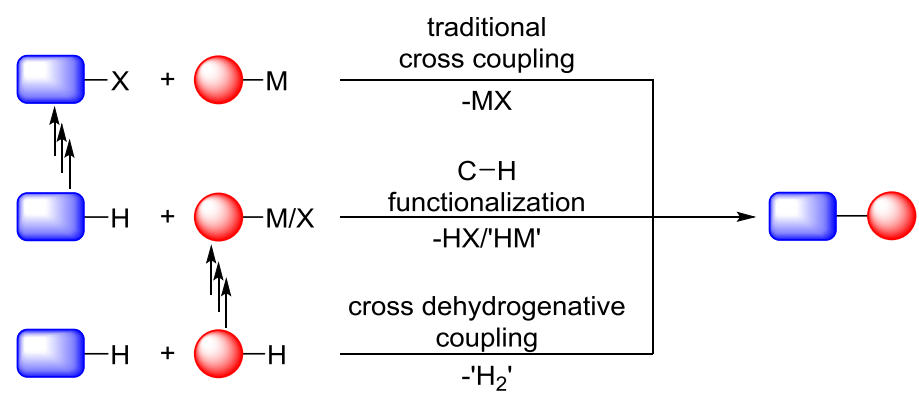

Figure 1. Strategies for $\mathrm{C}-\mathrm{C}$ and $\mathrm{C}-\mathrm{Het}$ bond formation.

The last decades witnessed tremendous achievements in the field of $\mathrm{C}-\mathrm{H}$ functionalization. ${ }^{[3]}$ The key step, the activation of the $\mathrm{C}-\mathrm{H}$ bond can proceed in different fashions depending mainly on the nature of the metal catalyst (Scheme 1). 


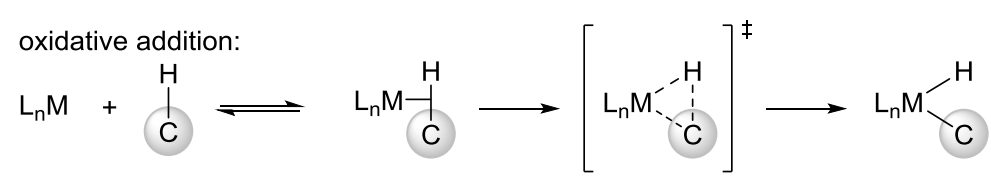

electrophilic substitution:

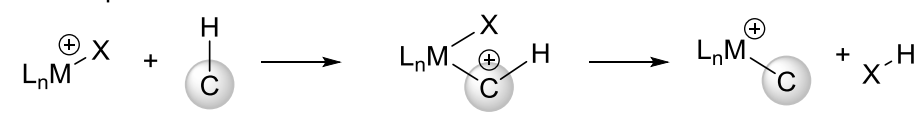

$\mathrm{L}_{n} \mathrm{M}^{-\mathrm{R}}+\underset{\mathrm{C}}{\mathrm{H} \text {-bond metathesis: }} \longrightarrow\left[\mathrm{L}_{n} \mathrm{M}_{-\mathrm{C}^{-}-\mathrm{H}^{-}}^{\mathrm{R}}\right]^{\ddagger} \longrightarrow \mathrm{L}^{\mathrm{M}} \mathrm{C}_{\mathrm{C}}{ }^{+\mathrm{R}^{-}}$

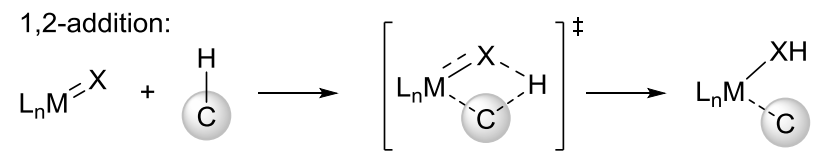

base assisted metalation:

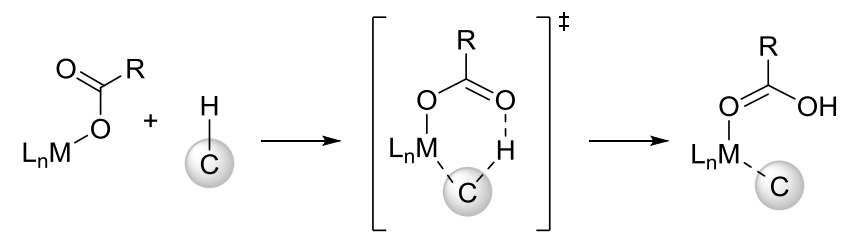

Scheme 1. Plausible mechanisms for transition metal-catalyzed $\mathrm{C}-\mathrm{H}$ activations.

Excluding outer-sphere homolytic pathways, five pathways are generally agreed upon; ${ }^{[4]}$ oxidative addition with electron-rich late transition metals, electrophilic substitution in case of late transitionmetals in higher oxidation states. Early transition-metals, as well as lanthanides are not capable of oxidative addition and tend to proceed via $\sigma$-bond metathesis. Besides that 1,2-addition to unsaturated $\mathrm{M}-\mathrm{X}$ bonds, such as metal imido complexes, are feasible. ${ }^{[5]}$ More recent studies unraveled the importance of an internal base for many $\mathrm{C}-\mathrm{H}$ activation processes; therefore a baseassisted mechanism was studied. Different transition states have been proposed (Figure 2). The concerted metalation-deprotonation $(\mathrm{CMD})^{[6]}$ and ambiphilic metal ligand activation (AMLA) $)^{[7]}$ are based on a six-membered transition state. Whereas a four membered transition state is proposed in case of an internal electrophilic substitution (IES), which was found to be most likely for $\mathrm{C}-\mathrm{H}$ activations enabled by complexes with alkoxy ligands. ${ }^{[8]} \mathrm{A}$ related base-assisted internal electrophilic substitution (BIES) has recently been proposed for electron-rich arenes with acetate or carboxylate ligands. ${ }^{[9]}$ 


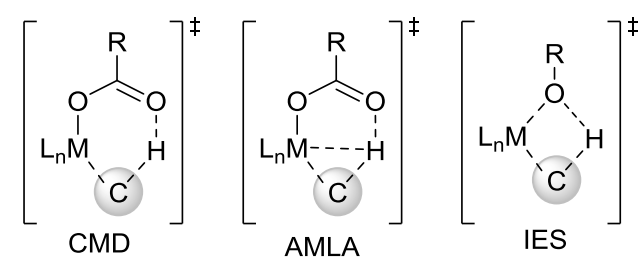

Figure 2. Proposed transition states for the base-assisted metalation.

$\mathrm{C}-\mathrm{H}$ bonds are ubiquitous in organic molecules and very often exhibit similar dissociation energies therefore the distinction of several $\mathrm{C}-\mathrm{H}$ bonds in a molecule is a huge challenge. To overcome this problem two different approaches have been established. The distinction of the bonds is possible by the inherent reactivity of a compound caused by differences in the acidity in heterocycles (Figure 3a), or through chelation-assistance by Lewis basic directing groups (Figure $3 b) .{ }^{[10]}$

a)

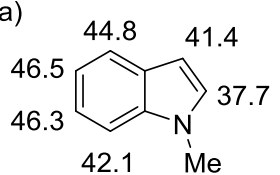

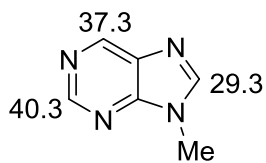

b)

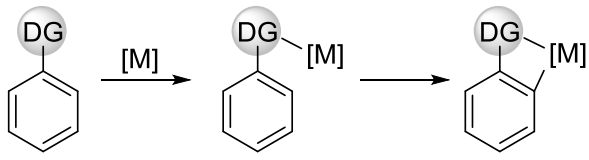

inherent reactivity

pKa-Value

Figure 3. Enabling site-selectivity in $\mathrm{C}-\mathrm{H}$ functionalization.

In molecules with directing groups the Lewis basic atom can coordinate to the metal center and thus bring the metal in close proximity to the ortho-position. To achieve other selectivities different approaches have been adressed which will be discussed in section 1.5.

\subsection{Transition Metal-Catalyzed Oxidative Annulation}

Oxidative annulation reactions are highly valuable tools for the synthesis of decorated heterocyclic compounds. ${ }^{[30]}$ A great advantage of the method lies in the possibility to avoid pre-functionalized starting materials, which immensely reduces the production of waste. Stoichiometric experiments from Maitlis revealed the feasibility of rhodium, iridium and osmium to activate the ortho- $\mathrm{C}\left(\mathrm{sp}^{2}\right)-\mathrm{H}$ bond in benzoic acid to form a five-membered metallacycle. ${ }^{[11]}$ Thereafter, studies by Satoh and Miura showed the potential of rhodium for the catalytic annulation of benzoic acids onto alkynes and alkenes (Scheme 2). ${ }^{[12]}$ 


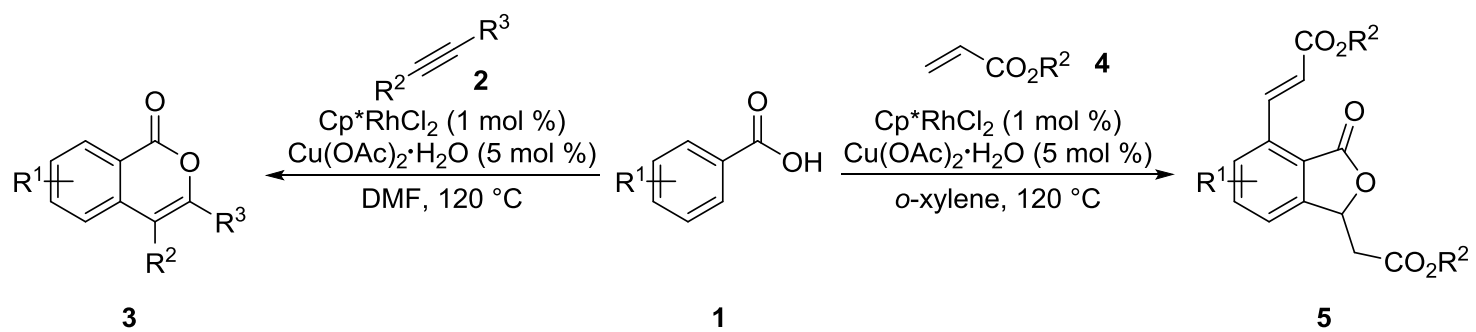

Scheme 2. Rhodium-catalyzed annulation reactions with benzoic acid. ${ }^{[12]}$

The following catalytic cycle was rationalized for the rhodium-catalyzed oxidative $\mathrm{C}-\mathrm{H}$ functionalization (Scheme 3); coordination of benzoic acid to rhodium(III) gives the rhodium benzoate 6 , which subsequently forms the five-membered rhodacycle 7. Migratory alkyne insertion to the seven-membered rhodacycle $\mathbf{8}$ is followed by reductive elimination. The rhodium(I) species is oxidized by copper(II) acetate to regenerate the catalytically active rhodium(III) species. Reoxidation of copper(I) acetate with oxygen allows for the catalytic use of copper(II) acetate with water as the only stoichiometric byproduct.

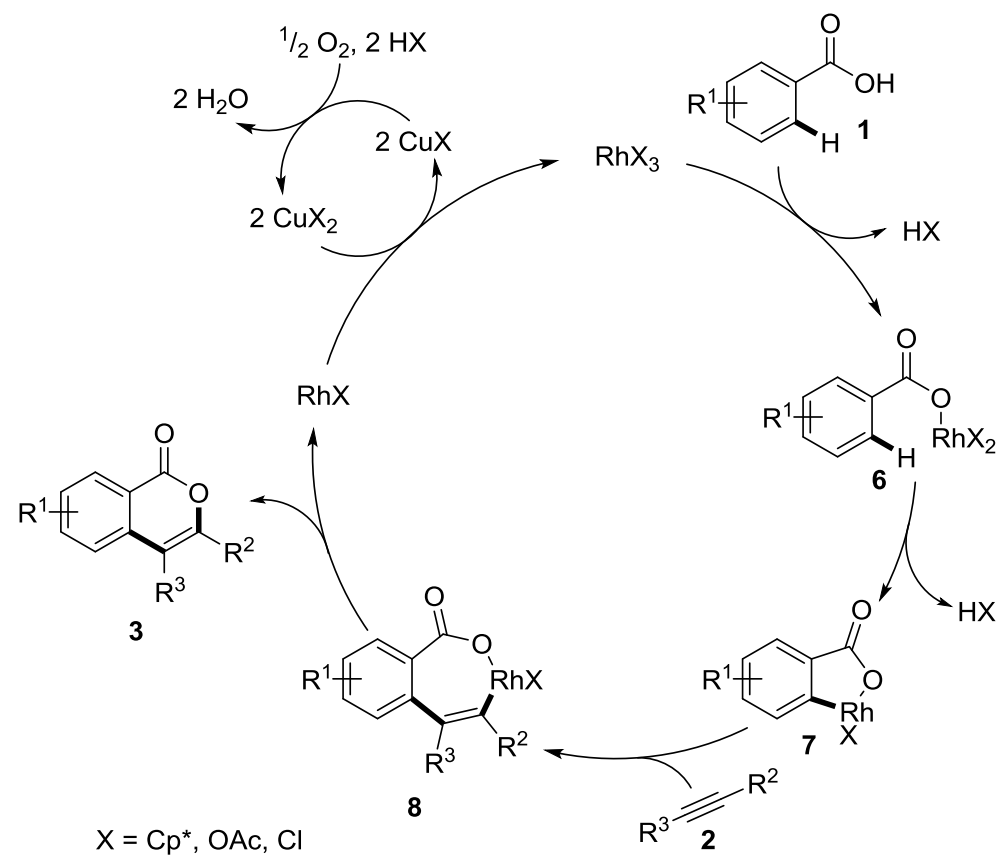

Scheme 3. Proposed mechanism for the rhodium-catalyzed oxidative isocoumarin synthesis, neutral ligands are omitted. ${ }^{[12]}$

The reaction was soon further studied and enabled the efficient synthesis of numerous heterocycles, furthermore the use of different metals from the platinum group was possible. ${ }^{[3 d, 30,13]}$ Regarding the prices of the active metals, the use of ruthenium catalysts is highly desirable. ${ }^{[14]}$ Ackermann 
discovered the first ruthenium-catalyzed oxidative annulation through cleavage of $\mathrm{C}-\mathrm{H}$ bonds, which enabled the synthesis of isoquinolones $10 .{ }^{[15]}$ Key to success was the use of a polar, protic solvent and copper(II) acetate as the oxidant.

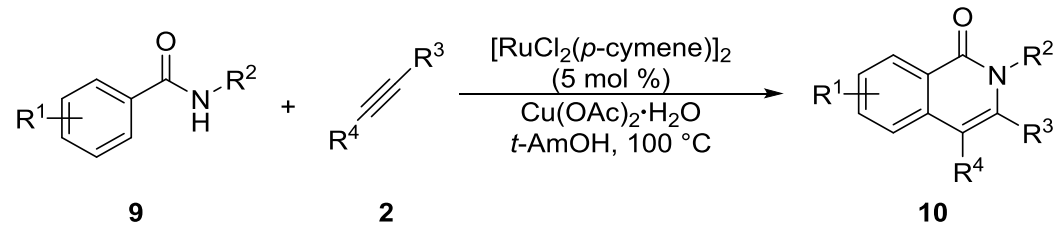

Scheme 4. Ruthenium(II)-catalyzed synthesis of isoquinolones $10 .{ }^{[15]}$

Based on this initial success, several heterocycles were later on synthesized through rutheniumcatalyzed oxidative alkyne annulation (Scheme 5). ${ }^{[30,16]}$

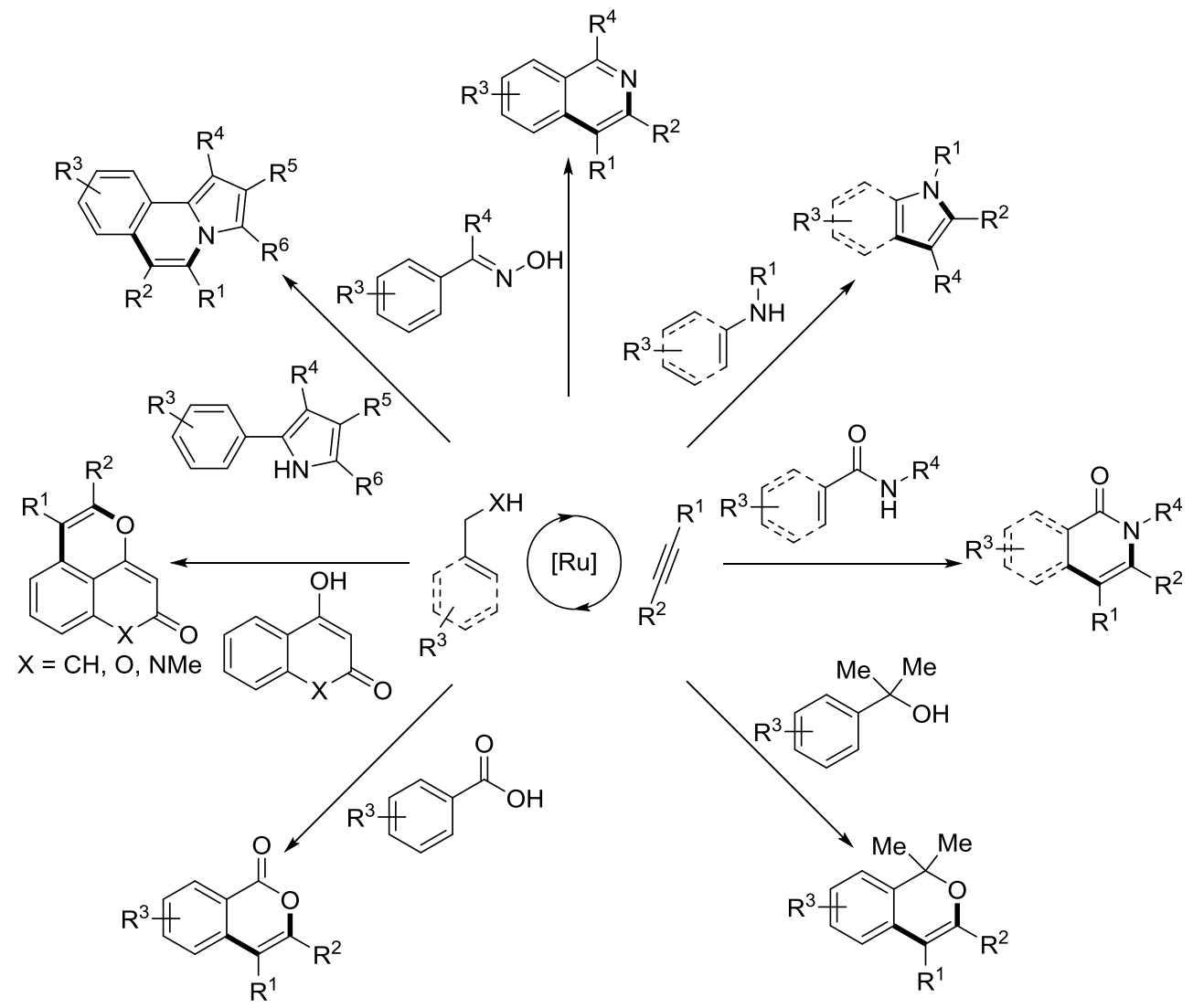

Scheme 5. Synthesis of a manifold of heterocycles by oxidative alkyne annulation.

For the synthesis of isocoumarins $\mathbf{3}^{[17]}$ an in situ formed cationic ruthenium complex proved optimal, the mechanism of this transformation was supposed to proceed similar to the related rhodiumcatalyzed reaction (Scheme 6). 
Introduction

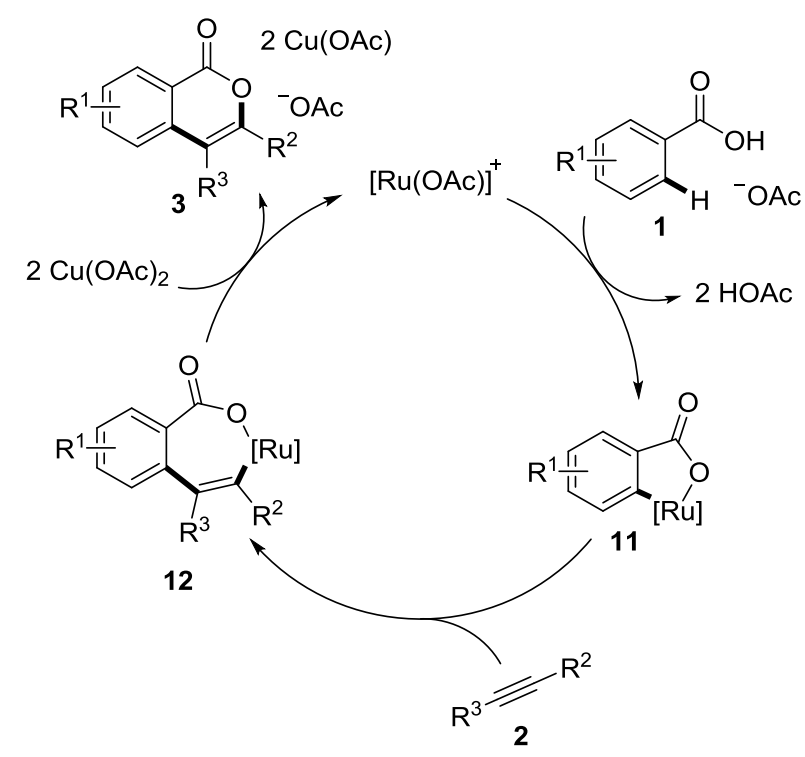

Scheme 6. Proposed catalytic cycle for the ruthenium-catalyzed oxidative isocoumarin synthesis. ${ }^{[17]}$

The cationic complex forms the five-membered ruthenacycle, which then undergoes migratory insertion with an alkyne. The thus formed seven-membered ruthenacycle releases the product through reductive elimination and subsequent oxidation of ruthenium reinstalls the catalytic active cationic ruthenium(II) complex.

Noteworthy is the alkene annulation of benzoic acid, which can be performed in water as benign solvent and furthermore constituted the first alkene annulation through ruthenium-catalyzed oxidative $\mathrm{C}-\mathrm{H}$-functionalization. ${ }^{[18]}$

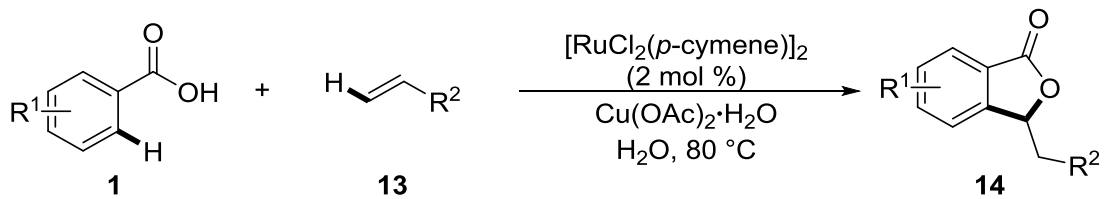

Scheme 7. Ruthenium-catalyzed oxidative synthesis of phthalides. ${ }^{[18]}$

Despite these advances the ruthenium-catalyzed annulations relied on the addition of metal based oxidants such as copper or silver salts and thus produce undesired metal containing byproducts. A huge improvement is the reduction of metal containing oxidant to a catalytic amount, which was realized by Ackermann and his group in the synthesis of pyrrole 16, where oxygen can be used as terminal oxidant. ${ }^{[19]}$ 


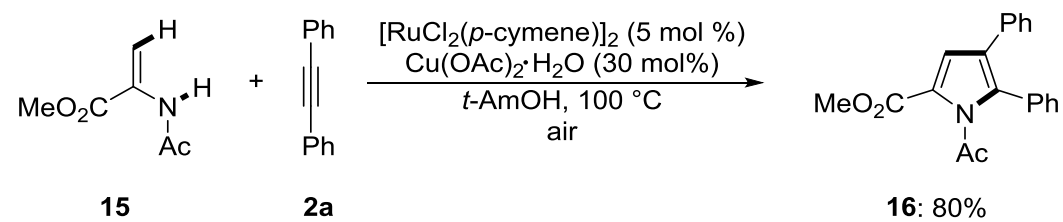

Scheme 8. Ruthenium-catalyzed aerobic pyrrole synthesis. ${ }^{[19]}$

The installation of an internal oxidant on the starting material displayed an alternative way to avoid the use of external metal based oxidants, therefore $\mathrm{N}-\mathrm{O}$ bonds embedded in the directing group were installed. ${ }^{[20]}$ Wang $^{[21]}$ and Ackermann ${ }^{[22]}$ used this approach in the ruthenium-catalyzed alkyne annulation of $\mathrm{N}$-methoxybenzamides $\mathbf{1 7 a}$, it is worth noting that the protocol from Ackermann enabled the direct functionalization of free hydroxamic acids $\mathbf{1 7 b}$, with water as the only byproduct. Furthermore the reaction was performed in water as benign solvent (Scheme 9). Interestingly also in this case catalytic amounts of a carboxylate were essential, which clearly illustrates the carboxylateassisted nature of the $\mathrm{C}-\mathrm{H}$ functionalization.

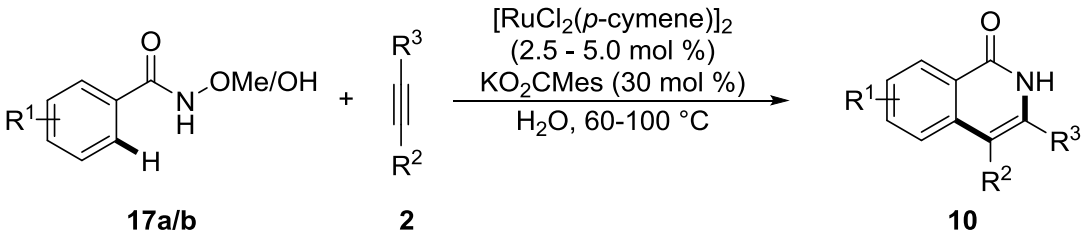

Scheme 9. Alkyne annulation with substrate embedded oxidant. ${ }^{[22]}$

Oxygen is an ideal oxidant, especially in regards of green and sustainable chemistry. Jiao developed a palladium-catalyzed indole synthesis, starting from simple anilines $\mathbf{1 8}$ with oxygen as the sole oxidant (Scheme 10). ${ }^{[23]}$

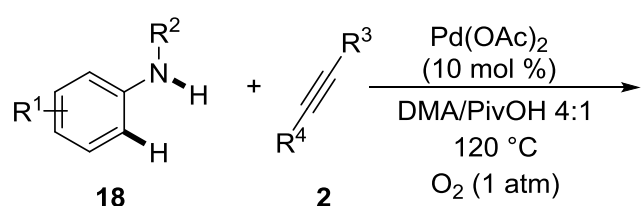

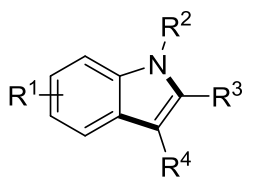

19

Scheme 10. Palladium-catalyzed indole synthesis with $\mathrm{O}_{2}$ as sole oxidant. ${ }^{[23]}$

Furthermore, rhodium-catalyzed annulation reactions with oxygen as sole oxidant were developed for strong $N$-containing directing groups. ${ }^{[24]}$ 
The oxidation of rhodium(I) complex $\mathbf{2 1}$ by oxygen was examined by Huang through the isolation of reaction intermediates and careful study of their reactivity (Scheme 11). ${ }^{[24 c]}$

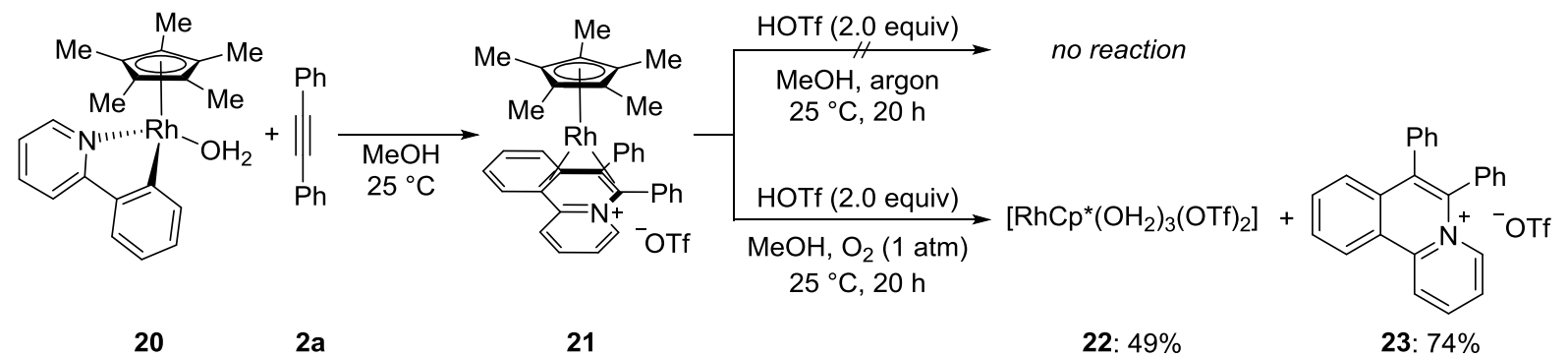

Scheme 11. Synthesis and oxidation of rhodium(I) complex 21. ${ }^{[24]}$

\subsection{Direct Arylation Through Ruthenium-Catalyzed C-H Activation}

Biaryls display a common structural unit in compounds of importance to organic synthesis, biology or material science. ${ }^{[25]}$ Transition metal-catalyzed cross-coupling reactions enable the synthesis of manifold biaryl units and were hence awarded with the Nobel Prize. Unfortunately costly prefunctionalization is required to obtain suitable starting materials, which can be avoided by direct $\mathrm{C}-\mathrm{H}$ functionalization strategies (see also chapter 1.1, page 1).

In early studies $\mathrm{Oi}$ and Inoue developed a catalytic system based on $\left[\mathrm{RuCl}_{2}\left(\mathrm{C}_{6} \mathrm{H}_{6}\right)\right]$ with triphenylphospine as ligand in $\mathrm{N}$-methyl-2-pyrrolidinon. Thus, the arylation of arenes with different $\mathrm{N}$-containing directing groups was enabled. ${ }^{[26]}$ Unfortunately, this catalytic system was later shown to give irreproducible results due to impurities in the solvent NMP. ${ }^{[27]}$

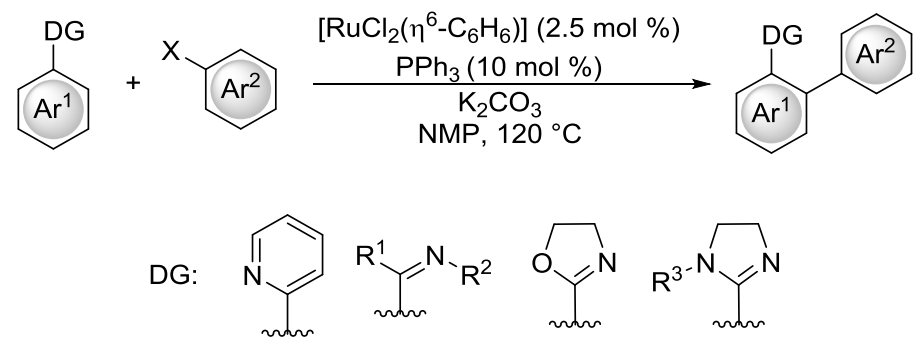

Scheme 12. Ruthenium-catalyzed arylation developed by Oi and Inoue. ${ }^{[26]}$

A huge breakthrough displays the use of bifunctional ligands, which allow for a base-assisted $\mathrm{C}-\mathrm{H}$ activation and facilitates the use of a variety of directing groups. The beneficial effect of these additives could be shown by the group of Ackermann, first with secondary phosphine oxides (SPO) as air stable pre-ligands. $\left.{ }^{[4 a}, 28\right]$ Coordination to a metal center proceeds through trivalent phosphinous acid (PA), which is in solution in equilibrium with the pentavalent SPO 
Introduction

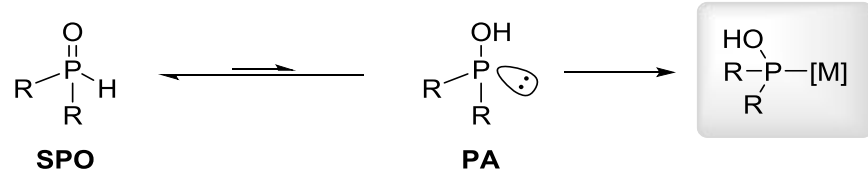

Scheme 13. Equilibrium of SPO and PA and coordination of PA to a metal center.

A thorough screening of various ligands for the direct arylation of triazoles unraveled carboxylates to perform highly efficient in this reaction, some representative examples from the screening are shown in Scheme 14. ${ }^{[29]}$<smiles>COc1ccc(Br)cc1</smiles>

24

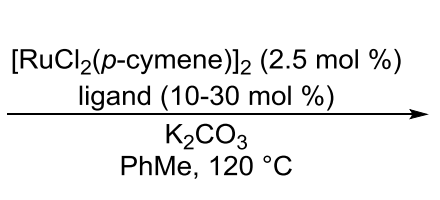

PhMe, $120^{\circ} \mathrm{C}$

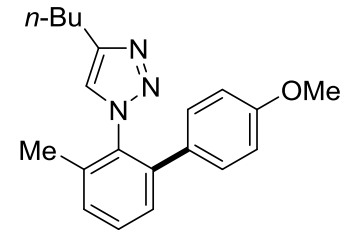

$26 a$

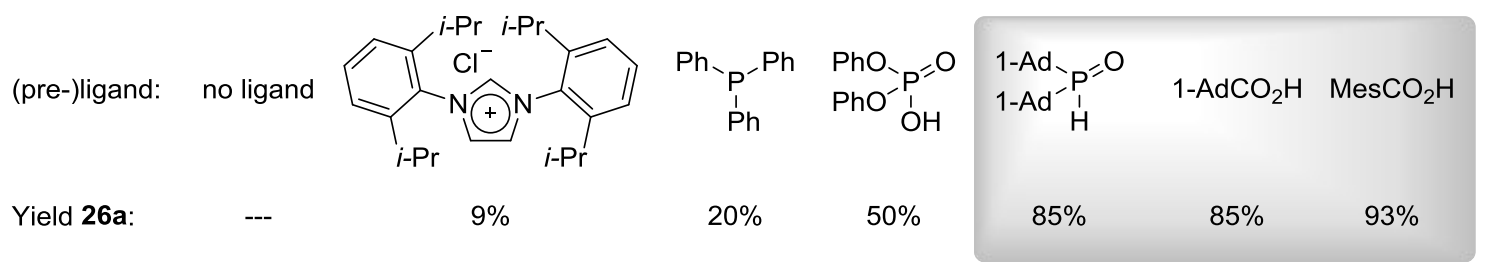

Scheme 14. Ligand effect in the ruthenium-catalyzed arylation of triazoles. ${ }^{[29]}$

The activation mode is proposed to be similar in both cases (Scheme 15).[4a]

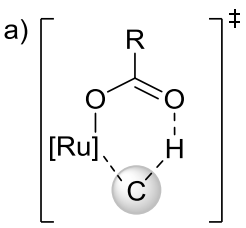

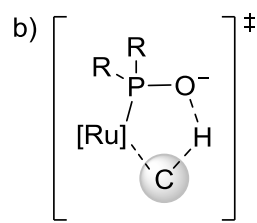

Scheme 15. Base-assisted ruthenation with a) carboxylate and b) PA assistance. ${ }^{[4 a]}$

The group of Anderson ${ }^{[30]}$ could show that for ruthenium(0) complexes the activation of the aryl halide most likely proceeds via oxidative addition at the beginning of the mechanistic cycle followed by $\mathrm{C}-\mathrm{H}$ activation of the arene (Scheme $16 \mathrm{a}$ ). Contrary Ackermann ${ }^{[31]}$ could show that ruthenium(II) complexes undergo $\mathrm{C}-\mathrm{H}$ ruthenation first and no reactivity of the $\left[\mathrm{RuCl}_{2}(p \text {-cymene })\right]_{2}$ complex with aryl halides was observed (Scheme 16b). The activation step of the aryl halide itself was not thoroughly studied and remains thus far unclear. 
a)

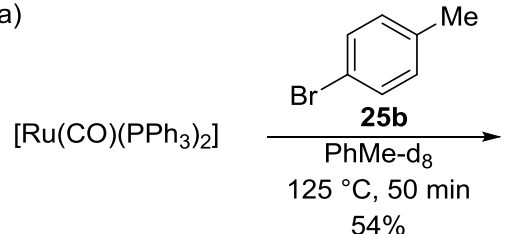

$54 \%$

b)

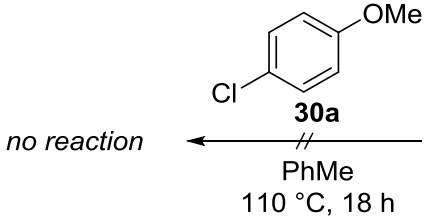

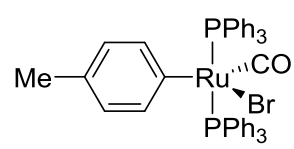

27

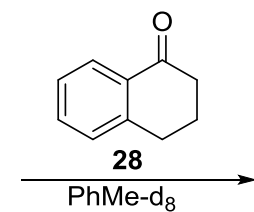

$125^{\circ} \mathrm{C}, 30 \mathrm{~min}$

$99 \%$

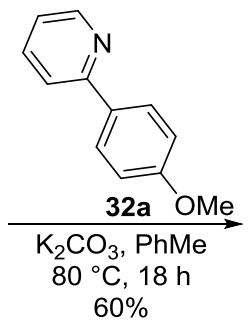

$60 \%$

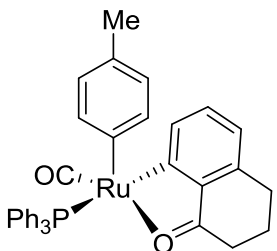

29

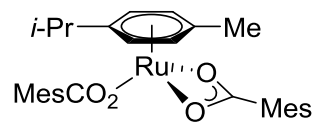

31

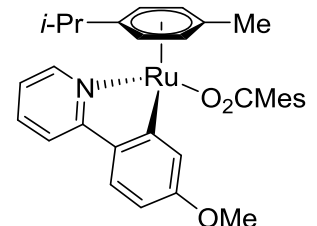

33

Scheme 16. Mechanistic studies regarding ruthenium-catalyzed direct arylations. ${ }^{[30-31]}$

\subsection{Ruthenium-Catalyzed Alkylation through C-H Bond Activation}

The production of alkyl-arenes is conventionally based on Friedel-Craft alkylations, ${ }^{[32]}$ unfortunately the method lacks in generality. ${ }^{[33]}$ The attachment of $n$-alkyl chains continuous to be difficult as the alky halides undergo rearrangement reactions under the applied reaction conditions. Furthermore, alkylation is not possible in meta-position to electron-donating groups and electron-withdrawing groups on the arene hamper the reactivity significantly. In spite of this, tremendous progress has been achieved in the last decades. ${ }^{[33]}$ Alternatively, cross-coupling methods have been developed in the last decades. ${ }^{[34]}$

a) Friedel-Craft alkylation:

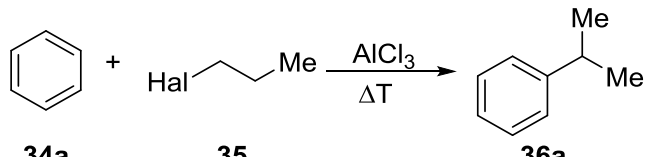

b) Cross-coupling with alkyl halides:

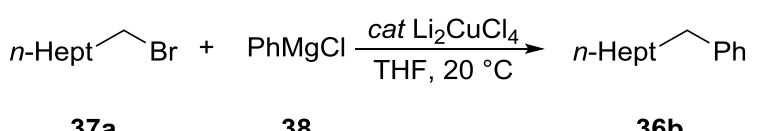

$37 a$
38

$36 \mathrm{~b}$

Scheme 17. Examples for a) the Friedel-Craft alkylation and b) cross-coupling with alkyl halides. ${ }^{[35]}$

To enhance the sustainability of the syntheses of alkyl arenes direct alkylation methods through $\mathrm{C}-\mathrm{H}$ activation have been developed recently (Scheme 18). ${ }^{[36]}$ 
Introduction

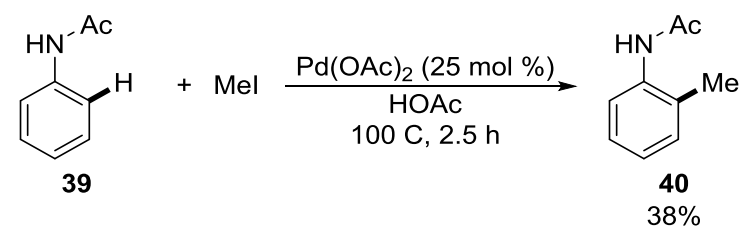

Scheme 18. Early example for palladium-catalyzed alkylation with methyliodide. ${ }^{[37]}$

The first regioselective ruthenium-catalyzed direct C-H alkylation was developed by Lewis in 1986, which proceeds through the formation of a phosphite derived from the starting material $\mathbf{4 1}$ (Scheme 19). ${ }^{[38]}$

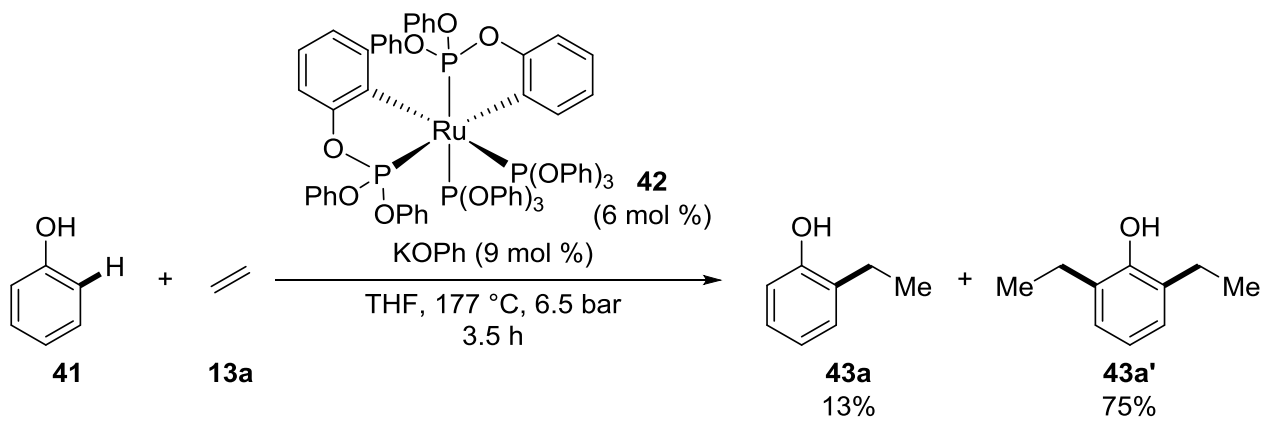

Scheme 19. First ruthenium-catalyzed ortho-alkylation developed by Lewis. ${ }^{[38]}$

A very useful approach for the synthesis of alkyl arenes was introduced by Murai et al. in 1993. Key to success was a ruthenium(0) complex which upon cyclometalation formed a ruthenium-hydride species (Scheme 20). Insertion of the alkene into the $\mathrm{Ru}-\mathrm{H}$ bond followed by reductive elimination delivered the corresponding alkylated arene. ${ }^{[39]}$

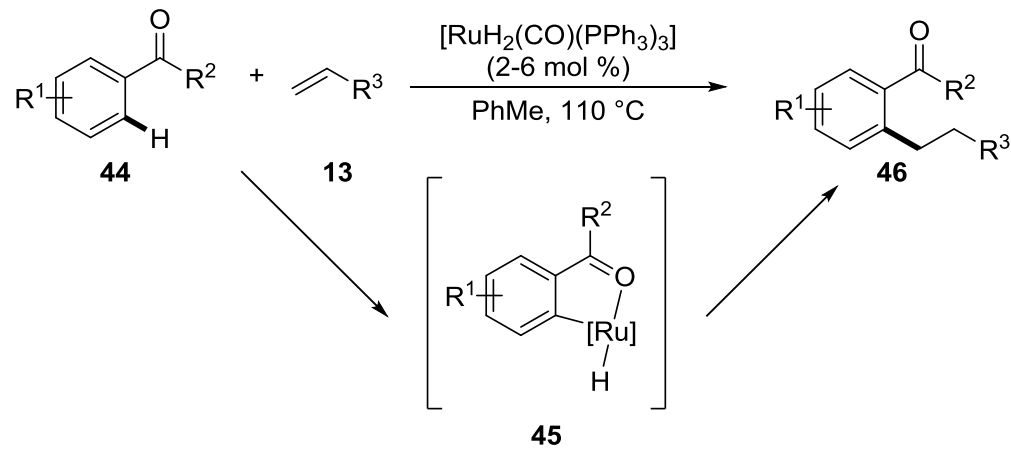

Scheme 20. Hydroarylation of alkenes developed by Murai and coworkers. ${ }^{[39]}$

The hydroarylation was later also achieved with easy to handle and air-stable $\left[\operatorname{RuCl}_{2}(p \text {-cymene })\right]_{2}$ using unactivated alkenes. ${ }^{[40]}$ Recently, $\mathrm{C}-\mathrm{H}$ alkylation was enabled with alkyl halides by the group of 
Ackermann. The developed system allowed for primary alkylation with chlorides, bromides and iodides applying adamantyl carboxylic acid as bulky ligand (Scheme 21). The robustness of the catalytic system set the stage for the efficient transformation of variously decorated arenes and enabled the use of different $N$-containing directing groups. Especially the functionalization of ketimines is worth noting, as it gave access to functionalized anilines. ${ }^{[41]}$

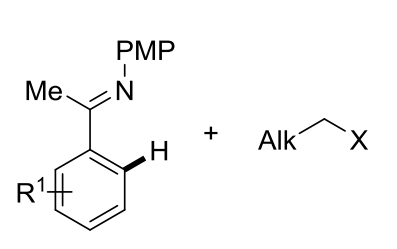

47

37
1. $\left[\mathrm{RuCl}_{2}(p \text {-cymene })\right]_{2}(2.5 \mathrm{~mol} \%)$

$1-\mathrm{AdCO}_{2} \mathrm{H}(30 \mathrm{~mol} \%)$

$\mathrm{K}_{2} \mathrm{CO}_{3}, m$-xylene

$\frac{120^{\circ} \mathrm{C}, 20 \mathrm{~h}}{\text { 2. } \mathrm{ZnCl}_{2}, \mathrm{NaBH}_{3} \mathrm{CN}}$

$\mathrm{MeOH} / \mathrm{THF}$

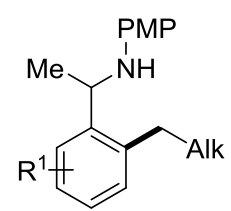

48

Scheme 21. Alkylation with primary alkyl halides 37 , here shown for the alkylation of ketimines $47 .{ }^{[41]}$

Interestingly, when applying secondary alkyl halides the alkylation took place in meta-position, thus opening new possibilities for the synthesis of diversely decorated arenes. ${ }^{[42]}$ Fortunately, the catalytic system was not limited to pyridines as the directing group but allowed for the functionalization of pyrimidines and a variety of azoles.

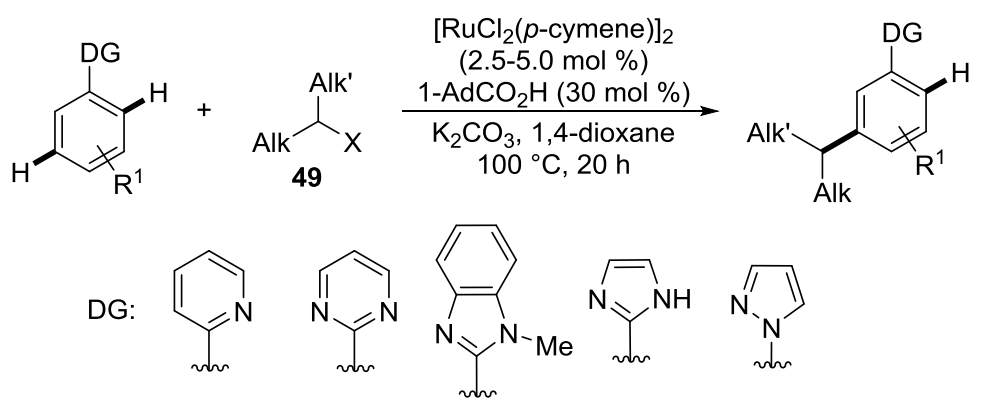

Scheme 22. meta-Selective C-H alkylation with secondary alkyl halides $49 .^{[42]}$

\section{5 meta-Selective C-H Functionalizations}

The site-selectivity in $\mathrm{C}-\mathrm{H}$ functionalization of arenes continues to be a major challenge, as already discussed in chapter 1.1. The introduction of a directing group can facilitate the functionalization in the ortho-position (Scheme 23b). Traditional electrophilic aromatic substitution reactions are in case of electron-donating groups ortho and para-selective and often a product mixture is obtained, while electron-withdrawing groups are more favorably substituted in meta-position but as they are deactivated harsh conditions are usually required (Scheme 23a). 
a) electrophilic aromatic substitution

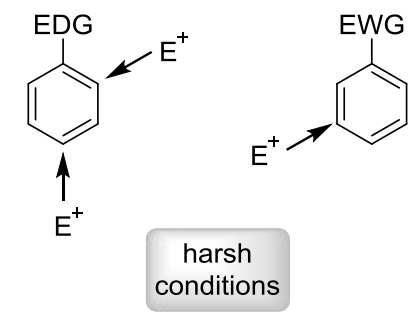

b) proximity induced $\mathrm{C}-\mathrm{H}$ activation<smiles>c1ccc2c(c1)O[Ga]2</smiles>

Scheme 23. Site selectivity in $\mathrm{S}_{\mathrm{E}} \mathrm{Ar}$ and directed $\mathrm{C}-\mathrm{H}$ functionalization.

Cross-coupling reactions can in general provide excellent selectivity, albeit on the cost of prefunctionalization steps and the production of metal-containing stoichiometric byproducts. Also the pre-functionalized starting material needs to be prepared site-selectively. ${ }^{[43]}$

The environmentally- and economically- benign $\mathrm{C}-\mathrm{H}$ functionalization in remote positions proved inherently more difficult than the ortho-directed counterpart and examples are still scarce. ${ }^{[44]}$ To achieve meta-selectivity different approaches have been introduced (Figure 4). ${ }^{[4 a]}$

a) Removable directing group<smiles>[R]c1cccc([Y])c1C(=O)O[W]</smiles>

b) Substrate controlled<smiles>[R]c1cc([R])cc([AlH][Tl])c1</smiles>

d) Catalyst controlled

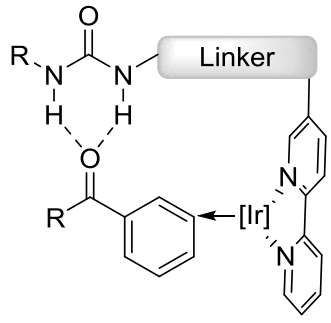

Reversible secondary hydrogen interactions

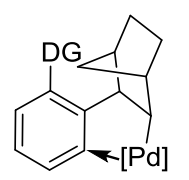

catalytic mediator c) Template-assisted

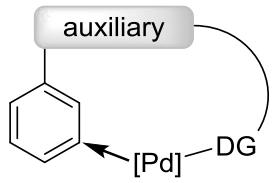

Figure 4. Different approaches to achieve meta-selectivity in $\mathrm{C}-\mathrm{H}$ functionalizations.

Early examples for formal meta functionalization through the removal of a directing group have been shown by the groups from Miura and Satoh (Scheme 24a), ${ }^{[45]}$ as well as Larrosa (Scheme 24b) ${ }^{[46]}$ with rhodium- and palladium-catalyzed functionalizations of benzoic acids $\mathbf{1}$, respectively. But still precious metals as well as over stoichiometric amounts of silver salt were required. 
a)

b) 1

b) $\mathrm{R}$

13

1) $\left[\mathrm{Cp}^{*} \mathrm{RhCl}_{2}\right]_{2}(1.0 \mathrm{~mol} \%)$

$\mathrm{AgOAC}$ DMA, $120^{\circ} \mathrm{C}$
2) $\mathrm{AgOAc}, \mathrm{K}_{2} \mathrm{CO}_{3}$
$160{ }^{\circ} \mathrm{C}$

$\mathrm{R}^{2}$<smiles>[R]c1cccc(/C=C/Br)c1</smiles>

50<smiles>[R]c1[R][14cH]c([AlH2])c([R])c1</smiles>

52

Scheme 24. Early examples for decarboxylative formal meta $\mathrm{C}-\mathrm{H}$ functionalization. ${ }^{[45-46]}$

A recent achievement by the group of Ackermann, enabled decarboxylative formal meta functionalization with only catalytic amounts of ruthenium in the absence of any silver or copper

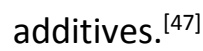

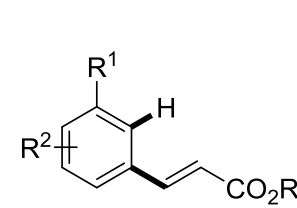

53

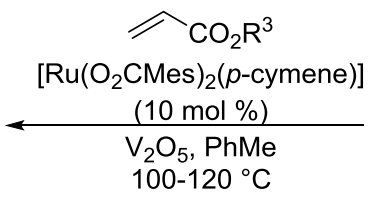

$100-120^{\circ} \mathrm{C}$ \begin{tabular}{c}
$\mathrm{Pd}(\mathrm{OAc})_{2}(2.0 \mathrm{~mol} \%)$ \\
\hline $\mathrm{Ag}_{2} \mathrm{CO}_{3}, \mathrm{AcOH}$ \\
$130^{\circ} \mathrm{C}$
\end{tabular}

51

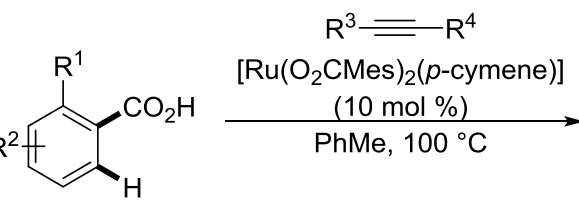

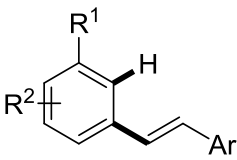

50

Scheme 25. Decarboxylative synthesis of meta-alkenylated arenes in absence of silver or copper salt. ${ }^{[47]}$

Iridium catalysts enabled the meta-borylation of substituted arenes $\mathbf{3 4}$, the selectivity was proposed to be caused by steric repulsions. ${ }^{[48]}$ The strategy was further studied for the silylation ${ }^{[49]}$ of sterically demanding arenes $\mathbf{3 4}$ and is also used in other direct functionalizations. ${ }^{[4 a]}$ But apparently the selectivity is derived from a certain substitution pattern of the substrates and therefore not generally applicable.

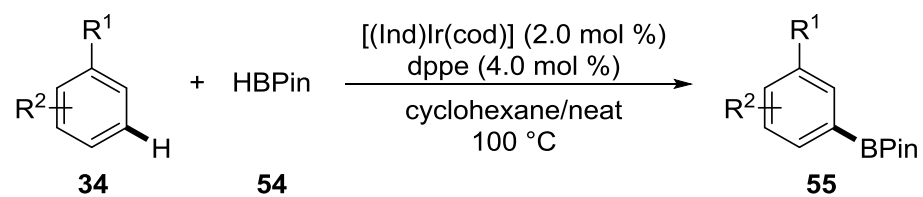

Scheme 26. Early example for meta-selective borylations. ${ }^{[48 b]}$

Recent studies by $\mathrm{Yu}$ and coworkers highlighted the possibility of installing rationally designed directing groups, which puts the metal in close proximity to the meta $\mathrm{C}-\mathrm{H}$ bond. ${ }^{[50]}$ The strategy is based on a U-shaped nitrile containing template, coordinating end-on to palladium (Figure 4c). 
Despite of the progress ${ }^{[44 e, 50-51]}$ that has been achieved often mixtures are obtained and the synthesis and installation of the auxiliary requires additional steps. Recently, Kanai and coworkers ${ }^{[52]}$ elegantly developed an approach based on a linker installed on the ligand which coordinates to the substrate through secondary hydrogen interactions and thus brings iridium in close proximity to the meta-C-H bond (Figure 4d, left).

Another catalytic approach is based on the Catellani reaction, ${ }^{[53]}$ where norbornene acts as transient mediator. Further studies were done to broaden the applicability of the reaction. ${ }^{[54]}$ A recent example from Dong and coworkers showed the high versatility of this approach allowing for the use of amine as directing group. ${ }^{[55]}$

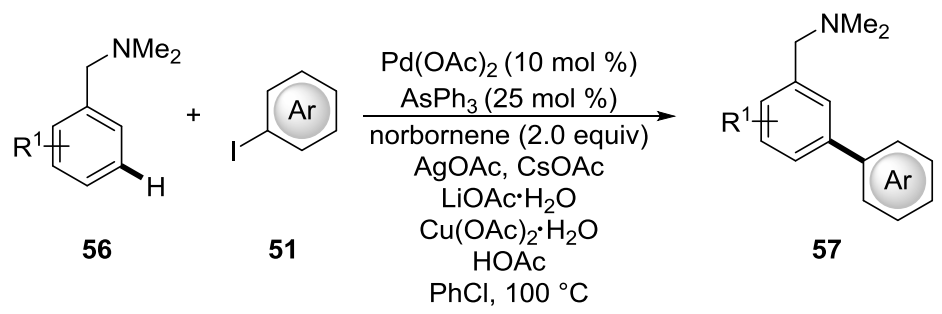

Scheme 27. Recent example for meta-selective $\mathrm{C}-\mathrm{H}$ functionalization with norbornene as transient mediator. ${ }^{[55]}$

The activation of the meta $\mathrm{C}-\mathrm{H}$ bond by cyclometalation represents a promising research area (Figure 4d, right). Early stoichiometric experiments with ruthena- and osmacycles clearly showed the activation of the $\mathrm{C}-\mathrm{H}$ bond para to the $[\mathrm{TM}]-\mathrm{C}$ bond. Chlorination in trace amounts was reported by van Koten in the copper(II)-mediated oxidative coupling of complex 58 (Scheme 28). ${ }^{[56]}$

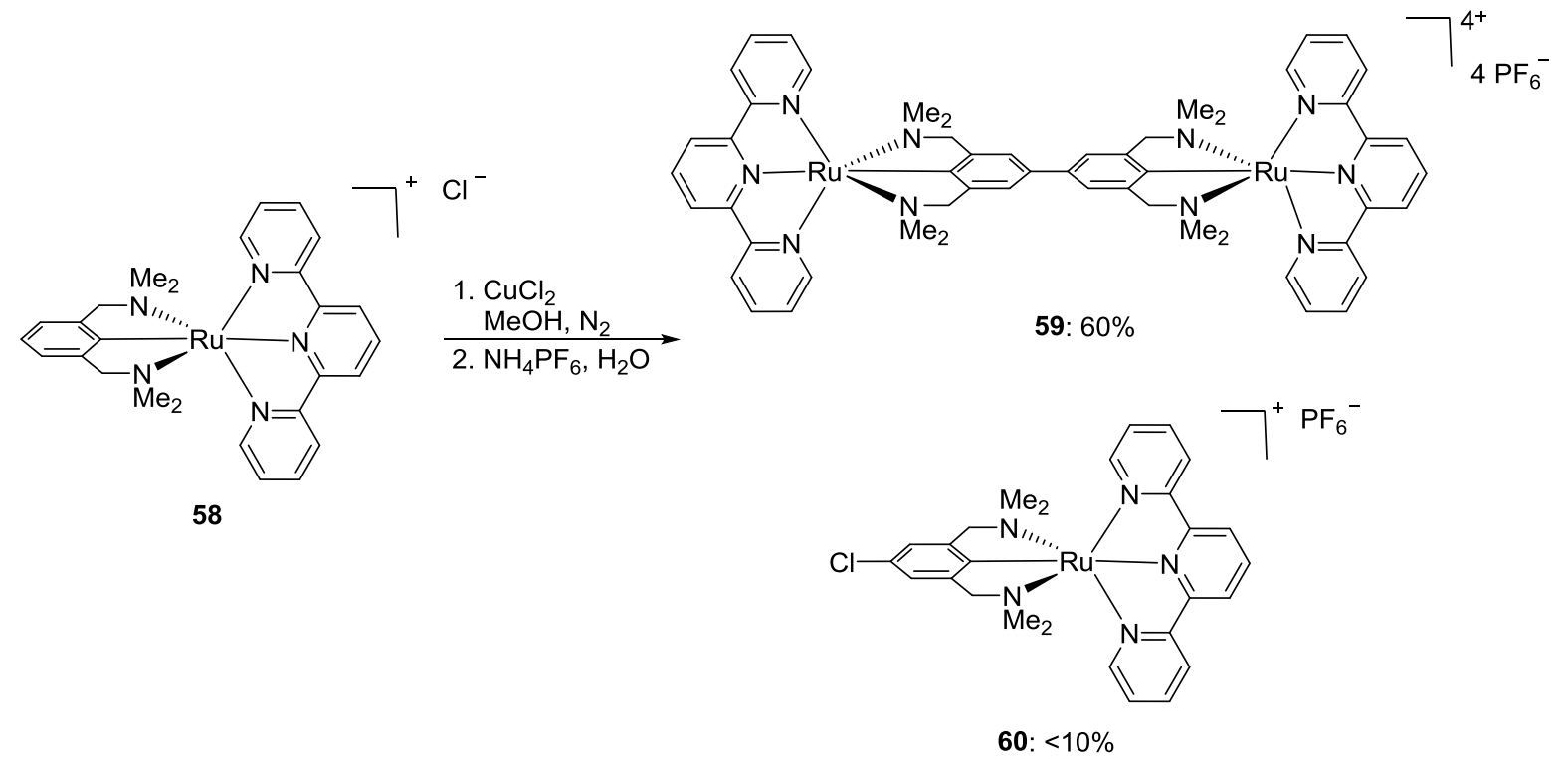

Scheme 28. Preliminary observation of para-selective chlorination of ruthenacycle $58 .{ }^{[56]}$ 
Coudret ${ }^{[57]}$ enabled the bromination and iodination of cycloruthenated phenylpyridine 61 (Scheme 29) followed by a Sonogashira coupling, while Roper and Wright ${ }^{[58]}$ disclosed the bromination and nitration of ruthenium and osmium complexes.

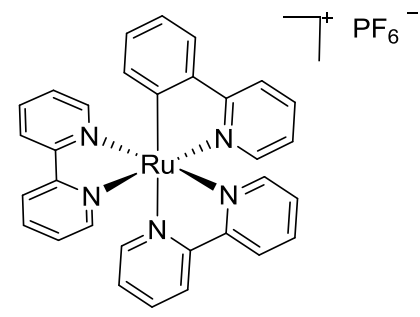

61

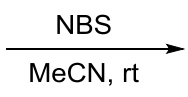

Scheme 29. Bromination para to Ru-C bond on cyclometalated complex $61 .{ }^{[57]}$

Based on these early findings catalytic systems have been developed recently to enable functionalizations in para-position to ruthenium and hence in meta position regarding the ruthenium free product. Frost and coworkers developed a system which enabled meta-sulfonation of phenylpyridines 32 (Scheme 30). ${ }^{[59]}$<smiles>[R]c1ccc([R])c([18OH])c1</smiles>

32

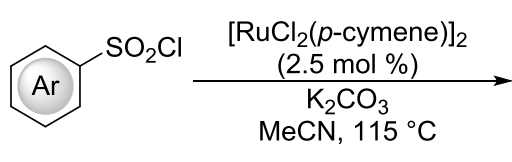

63

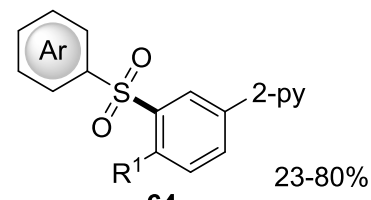

64

Scheme 30. meta-Sulfonation of phenylpyridine. ${ }^{[59]}$

Ackermann and coworker presented the first meta-selective $\mathrm{C}-\mathrm{H}$ alkylation with challenging secondary alkyl halides (Scheme 22). This reaction is especially interesting as primary alkyl halides under similar reaction conditions form the ortho-alkylated product. Preliminary mechanistic studies showed that a radical process is most likely to take place, as radical inhibitors diminished the reactivity of the system. ${ }^{[42]}$ Recent progress has furthermore been made in the course of metaselective bromination ${ }^{[60]}$ and recently also nitration ${ }^{[61]}$ of phenylpyridines. 
Introduction

\subsection{Direct C-H Bromination of Arenes}

Organic halides and particularly bromides are substantial building blocks in organic synthesis, especially in regard of their importance in cross-coupling reactions. ${ }^{[62]}$ Hence, efficient, reliable and environmentally-benign as well as economically-beneficial methods are in strong demand. Direct bromination through site-selective $\mathrm{C}-\mathrm{H}$ bond activation displays a mild method to introduce $\mathrm{C}-\mathrm{Br}$ bonds into a molecule. An early contribution by Sanford and coworkers ${ }^{[63]}$ showed the practicability of the method, albeit with long reaction times (Scheme 31).

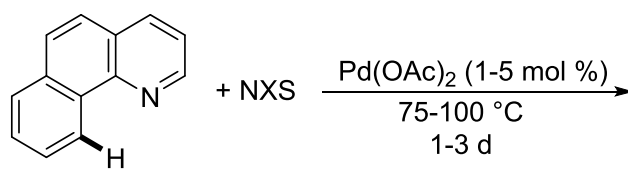

65

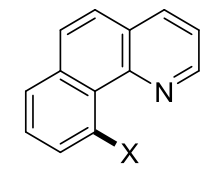

$66 \mathrm{a}=\mathrm{Cl}: 95 \%$ $\mathbf{6 6 b}=\mathrm{Br}: 93 \%$

Scheme 31. Early example for direct halogenation of benzo[h]quinoline (65). ${ }^{[63]}$

Since then several methods have been developed for palladium and rhodium-catalyzed halogenations. ${ }^{[64]}$ Detailed mechanistic studies regarding the chlorination of benzo[h]quinoline (65) suggested a bimetallic palladium(III) complex to be key for the turnover-limiting oxidation (Scheme $32) \cdot{ }^{[65]}$ 


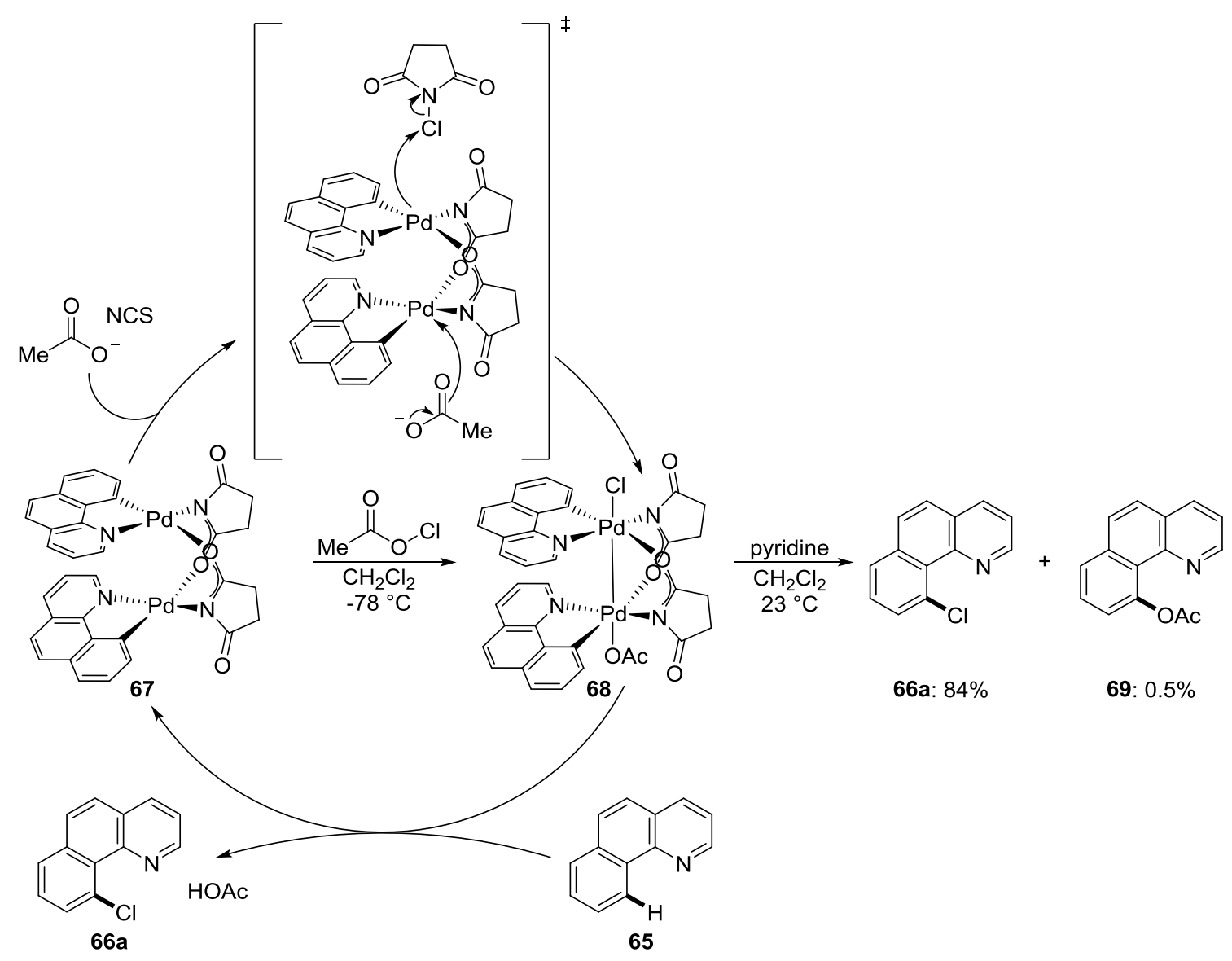

Scheme 32. Mechanistic studies and proposed mechanism for palladium-catalyzed chlorination. ${ }^{[65]}$

An interesting electrochemical approach was reported from Kakiuchi. Thus, hydrogen halides could be used as halogenating agent by oxidation of the halide. ${ }^{[66]}$ Economically interesting is the use of cheaper metals as catalyst, worth mentioning is the development of copper-mediated or catalyzed bromination, ${ }^{[67]}$ the catalytic version was first enabled by $\mathrm{Yu}$ in the halogenation of phenylpyridine 32 (Scheme 33). ${ }^{[68]}$ Furthermore, cobalt offers an attractive alternative. Hence, work from Glorius ${ }^{[69]}$ showed the potential in the iodination of substrates containing pyridine or amide, while bromination was only realized with phenylpyridines 32 (Scheme 33).

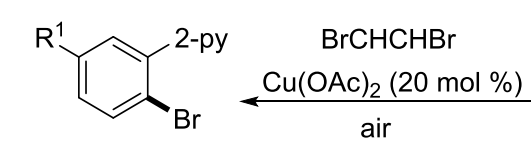

$\mathrm{R}^{1}=\mathrm{H}(\mathbf{7 0 a}): 65 \%$<smiles>[R]c1cccc([R]#N)c1</smiles>

32
NBS

$\left[\mathrm{Cp}{ }^{*} \mathrm{Co}(\mathrm{CO}) \mathrm{I}_{2}\right](10 \mathrm{~mol} \%)$ $\underset{\mathrm{AgSbF}_{6}(20 \mathrm{~mol} \%)}{\mathrm{PivOH}, \mathrm{DCE}}$ $60-100^{\circ} \mathrm{C}$<smiles>[R]c1ccc(Br)c([18OH])c1</smiles>

$\mathrm{R}^{1}=\mathrm{H}(\mathbf{7 0 a}): 45 \%$ $\mathrm{R}^{1}=\mathrm{Me}(\mathbf{7 0 b}): 48 \%$

Scheme 33. Bromination methods catalyzed by copper or cobalt. ${ }^{[68-69]}$ 
Ruthenium-catalyzed halogenation on synthetically useful benzamides $\mathbf{7 1}$ was achieved with userfriendly $\mathrm{Ru}_{3}(\mathrm{CO})_{12}$ as the catalyst. ${ }^{[70]}$<smiles>[H][R16]=NC(=O)c1cc[R1]cc1</smiles>

71

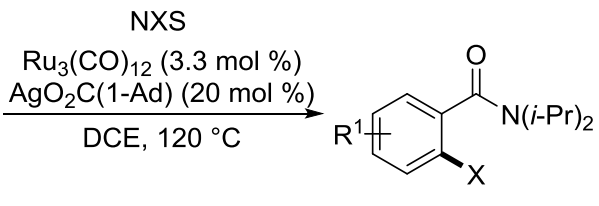

72

$\mathrm{X}=\mathrm{Br}, \mathrm{I}$

Scheme 34. Ruthenium-catalyzed $\mathrm{C}-\mathrm{H}$ halogenation reported by Ackermann. ${ }^{[70]}$

A first heterogeneous method for ortho-selective iodination was developed by Martin-Matude and coworkers based on a palladium/MOF catalyst. ${ }^{[71]}$

All mentioned procedures solely give access to the ortho-products, recently challenging metaselective halogenation has been developed as well. Yu and coworkers reported on an iodination with a template directing the palladium catalyst to the meta-position (Scheme 35$).{ }^{[11 \mathrm{~g}]}$

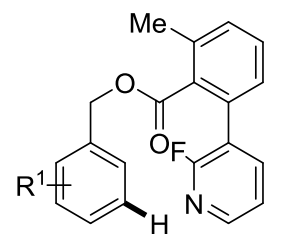

73

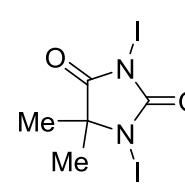

74

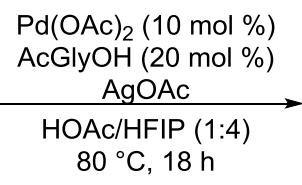

$80{ }^{\circ} \mathrm{C}, 18 \mathrm{~h}$

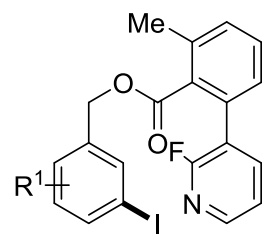

75: $47-77 \%$ m/others $5: 1$ to $>20: 1$

Scheme 35. meta-Selective iodination. ${ }^{[51 g]}$

2015 Greaney ${ }^{[60 a]}$ and Huang ${ }^{[60 b]}$ reported on the meta-selective bromination of phenylpyridines. The selectivity was induced by a ruthenium(II) catalyst (Scheme 36). While Greaney used an carboxylateassisted approach, Huang solely used $\left[\mathrm{RuCl}_{2}(p \text {-cymene })\right]_{2}$. Furthermore, air was crucial in Huangs approach. Besides phenylpyridine 32 also pyrimidyl and pyrazolyl directing groups proved viable.

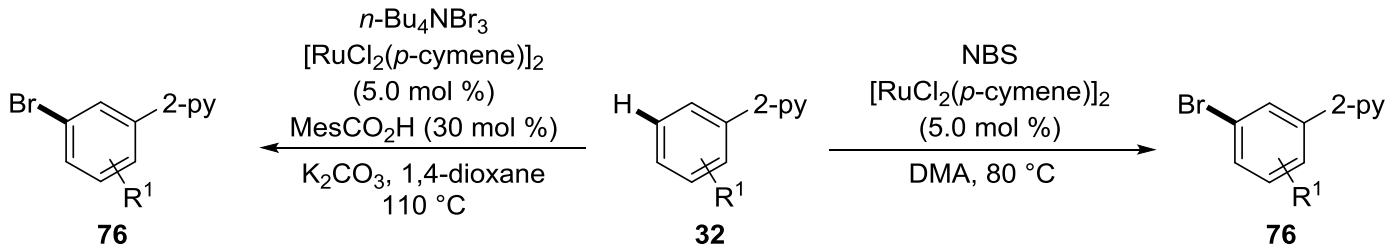

Scheme 36. meta-Bromination through ortho-cyclometallation, developed from Greaney (left) and Huang (right). ${ }^{[60]}$ 
Introduction

\subsection{Heterogeneous C-H Functionalizations}

Heterogeneous catalysis can not only lower the cost of production and the environmental impact due to recyclable catalysts but also reduce the metal incorporation into the products. ${ }^{[72]}$ Thus, combining $\mathrm{C}-\mathrm{H}$ functionalization with heterogeneous catalysis is highly desirable. ${ }^{[73]}$

A very early contribution from Nakamura, Tajima and Sakai showed the reactivity of palladium on charcoal in the phenylation of isoxazoles 77 (Scheme 37). ${ }^{[74]}$

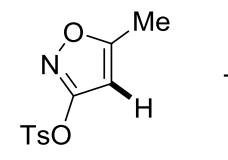

77

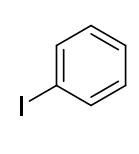

$51 \mathrm{a}$

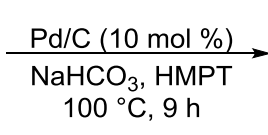

$100{ }^{\circ} \mathrm{C}, 9 \mathrm{~h}$

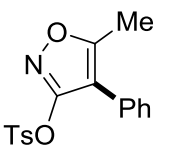

78: $44 \%$

Scheme 37. Phenylation of isoxazoles 77 catalyzed by $\mathrm{Pd} / \mathrm{C} .^{[74]}$

But no studies regarding the recyclability and heterogeneity of the reaction were performed. The nature of a catalytic reaction regarding the homo- or heterogeneity is often complicated to determine, especially catch and release mechanisms or in situ formation of nanoparticles impede a straightforward differentiation. Common control reactions include hot filtration tests, catalyst poisoning with mercury and three-phase tests. ${ }^{[75]}$

A user-friendly method was reported by Kim, Lee and coworkers ${ }^{[76]}$ for the direct arylation of imidazo[1,2-a]pyridine which allowed to recover the catalyst magnetically. It is worth noting that the catalyst could be reused ten times without loss in activity.

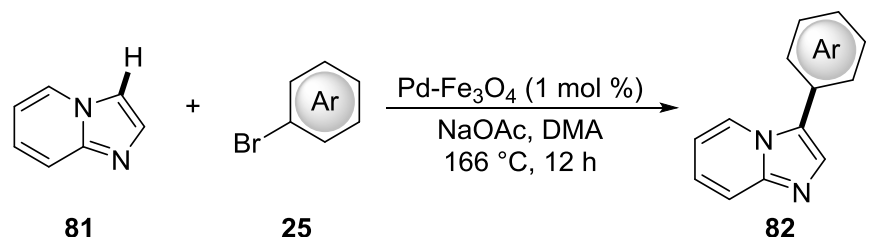

81

25

82

Scheme 38. Direct arylation with a magnetic palladium catalyst. ${ }^{[76]}$

Further progress has been made mainly focusing on the use of palladium catalysts. ${ }^{[73,77]}$ Heterogeneous ruthenium-catalyzed $\mathrm{C}-\mathrm{H}$ bond functionalizations are thus far scarce. ${ }^{[73,78]}$

Notable contributions by Wada, Inoue and coworkers have been achieved using ruthenium supported on cerium(IV) oxide as the catalyst. ${ }^{[78 d, 78 e]}$ Thereby, arylation of benzo[h]quinolone (65) was enabled at $170^{\circ} \mathrm{C}$, reduction of the catalyst in a hydrogen atmosphere in the presence of triphenylphosphine gave access to a more potent catalyst. Hence, the reaction temperature could be 
lowered to $120^{\circ} \mathrm{C}$ or for aryl chlorides to $140{ }^{\circ} \mathrm{C}$ (Scheme 39a). Some leaching of the catalyst was observable but a hot filtration test suggested that indeed the immobilized ruthenium was catalytically active. Furthermore, recycling of the catalyst was possible albeit calcination and reduction of the catalyst had to be performed prior to a new run.

The catalytic system furthermore proved viable for the hydroarylation of vinylsilanes (Scheme 39b).

a)<smiles></smiles>

65

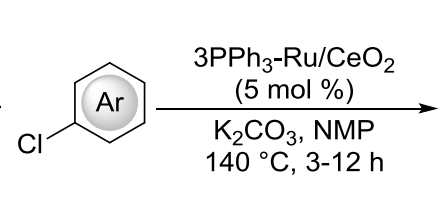

30

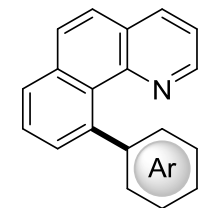

81: $53-98 \%$ recycling procedure:

b)

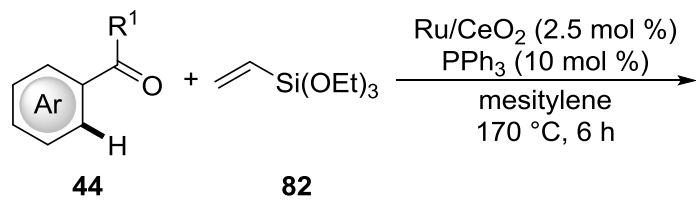<smiles>[R1]C(=O)c1ccccc1CC[SiH2]OCC</smiles>

83: $67-96 \%$

Scheme 39. $\mathrm{Ru} / \mathrm{CeO}_{2}$ catalyzed $\mathrm{C}-\mathrm{H}$ functionalizations. ${ }^{[78 \mathrm{~d}, 78 \mathrm{e}]}$

\subsection{Sol-Gel Derived Catalysts}

Catalysts on support are indispensable for chemical industry, especially for the synthesis of bulk chemicals. Nowadays most supports are based on silica, alumina, carbon or zeolites. Herein silica supported catalysts are discussed. Silica has advantageous properties regarding its low cost, absence of swelling, flexibility to control catalyst properties (i. e. particle size, surface area) and high thermal and chemical stability. The point of zero charge (PZC) is between 2 and 4 and thus it is only slightly acidic under neutral conditions. The principals of the sol-gel process are depicted in Figure $5 .{ }^{[79]}$

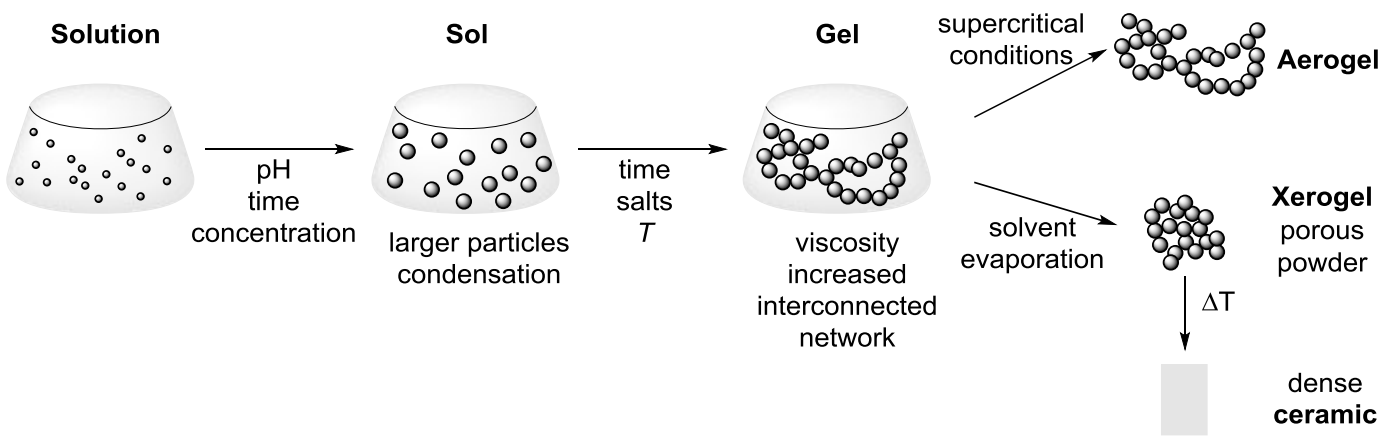

Figure 5. Schematic principle of the sol-gel process. 
Starting from alkoxysilanes, hydrolysis followed by condensation results in the formation of a sol (Scheme 40), a dispersion of these condensed particles.

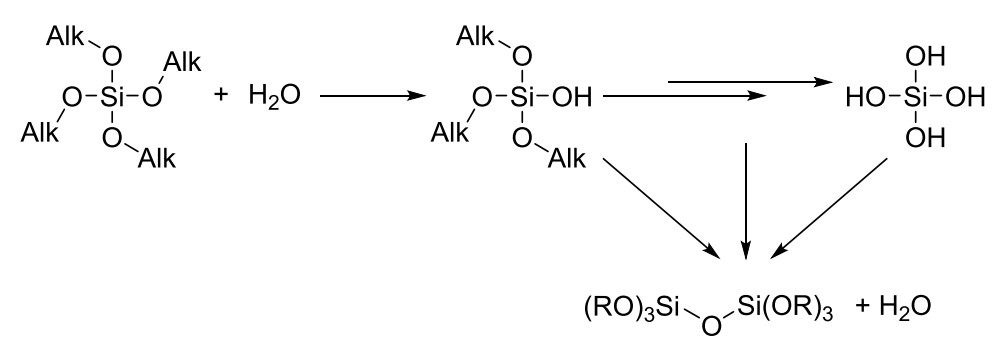

Scheme 40. Sol formation with alkoxysilanes through hydrolysis and condensation reactions.

The next step is the gel formation, in which the particles build a three-dimensional network which encloses a liquid phase. Depending on the drying process different kinds of materials can be obtained. Drying under supercritical conditions leads to the formation of aerogels where the large pores, characteristic for the wet gel, are retained as there is no collapse of the pores due to capillary pressure. If the solvent is removed under ambient pressure the particles shrink caused by partial collapse of the pores resulting in the formation of Xerogels, porous powders. If Xerogels are heated further a dense ceramic will form (Figure 5). ${ }^{[79]}$ To obtain mixed oxides the gel formation can also be performed with two different precursors, for example alkoxysilane and a metal halide, both undergo hydrolization and condensation reactions coincidently to form a mixed gel. ${ }^{[80]}$

The influence of diols ${ }^{[81]}$ on the surface area and the pore size of silica derived from the sol-gel process has already been observed 1986 in the synthesis of ruthenium catalysts for partial benzene hydrogenation. ${ }^{[82]}$ Thus, depending on the diol defined pore sizes and surface areas can be obtained. Furthermore the addition of diols also enhances the reactivity of alkoxysilanes and hence allows for the sol formation under neutral conditions. ${ }^{[83]}$ Further studies showed that polyols also act as reducing agents in the synthesis of metal(0) nanoparticles at high temperatures. ${ }^{[84]}$

Catalysts embedded in silica are broadly used in catalysis, ${ }^{[80,85]}$ for example, in the Fischer-Tropsch synthesis ${ }^{[86]}$ or hydrogenation reactions. ${ }^{[87]}$ 


\section{Objectives}

\section{Objectives}

The selective formation of carbon-carbon ( $\mathrm{C}-\mathrm{C}$ ) and carbon-heteroatom ( $\mathrm{C}-\mathrm{Het}$ ) bonds through transition metal-catalyzed $\mathrm{C}-\mathrm{H}$ bond functionalizations recently emerged as a powerful platform for synthetic chemists. ${ }^{[2]}$ Especially the use of relatively cheap, albeit highly reactive ruthenium catalysts, is highly desirable. ${ }^{[3 e, 30,3 s, 4 a, 88]}$

Recently, alkyne and alkene annulation of benzoic acids $\mathbf{1}$ were developed by Ackermann and coworkers. ${ }^{[17-18,89]}$ Even though the environmental impact is already reduced by preventing the use of pre-functionalized starting materials, the use of metal containing oxidants still represents a major drawback. It was therefore one goal of this thesis to understand the mechanism of these oxidative annulations and to thereby allow for the use of environmentally-benign oxygen as the only oxidant.

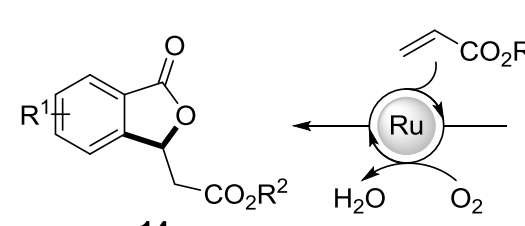

14

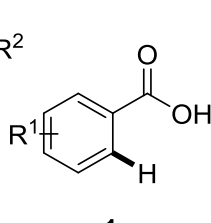

1

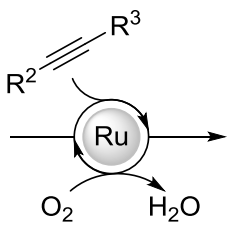

$\mathrm{O}_{2}$

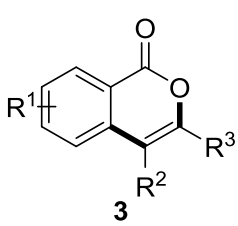

3

Scheme 41. Oxidative alkyne and alkene annulations with $\mathrm{O}_{2}$ as optimal oxidant.

In recent years, the carboxylate-assisted ruthenium(II)-catalyzed $\mathrm{C}-\mathrm{H}$ arylation has underwent tremendous progress. ${ }^{[3 e, 4 a]}$ However, the use of secondary phosphine oxides as pre-ligands has rarely been studied. ${ }^{[28 b, 29,90]}$ Hence, within this thesis studies regarding the mode of activation in the ruthenium(II) phosphinous acid-catalyzed arylation should be performed. In view of the importance for efficient ways to synthesize biaryl units, especially enabling an efficient synthesis of nonpeptidic angiotensin II receptor blockers (ARBs), such as Valsartan, should be developed.

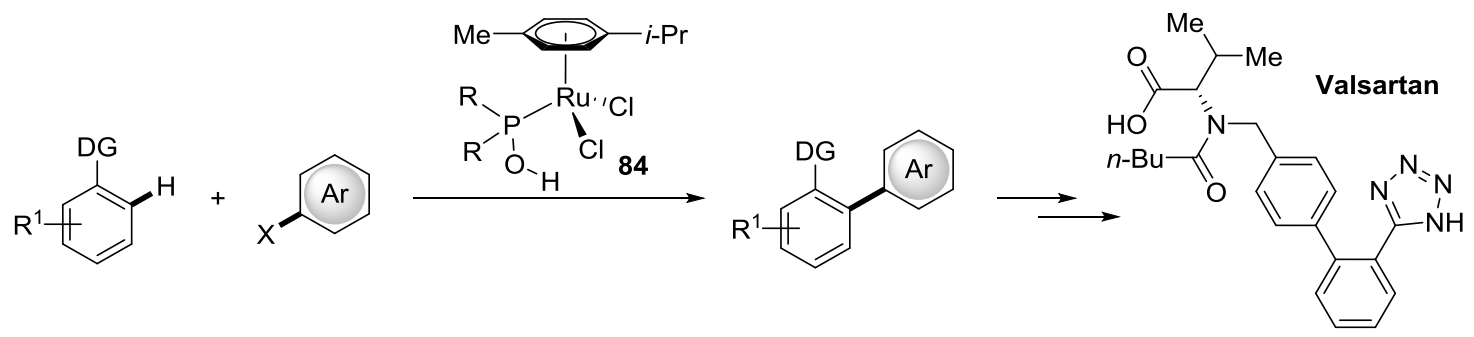

Scheme 42. Direct arylation with well-defined ruthenium(II) phosphinous acid catalysts and potential route to valsartan or other ARBs.

Remote functionalization has only recently been established in the field of $\mathrm{C}-\mathrm{H}$ functionalizations. ${ }^{[44 a,}$ ${ }^{44 b}, 44-$-g] $B a s e d$ on the pioneering studies of Ackermann, ${ }^{[42]}$ the meta-selective tert-alkylation of arenes was to be studied to unravel the mode of activation and enable powerful alkylations of synthetically useful arenes. 


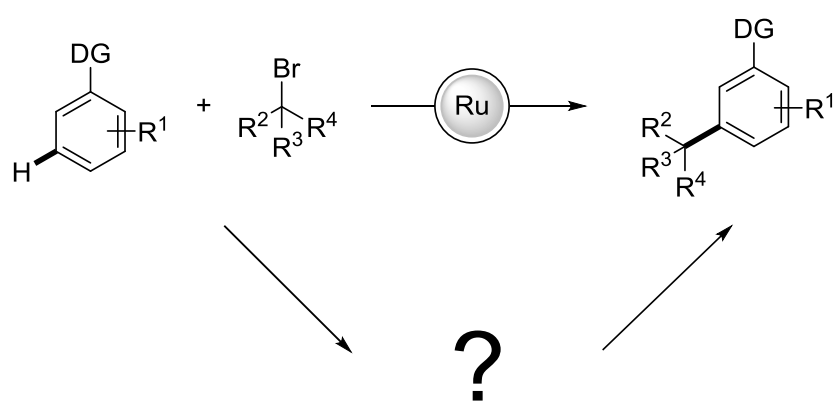

Scheme 43. Exploring the mechanism of meta-selective ruthenium-catalyzed alkylations.

Heterogeneous catalysis offers a huge potential to address the needs of sustainable synthesis, allowing for easy catalyst-product separation and reuse of the catalyst. ${ }^{[73]}$ Thus far, only little is known about heterogeneous ruthenium-catalyzed ${ }^{[78]} \mathrm{C}-\mathrm{H}$ functionalization and nothing about remote functionalizations. Recently, the functionalization of otherwise unreactive $\mathrm{C}-\mathrm{H}$ bonds in purine bases has gained interest, ${ }^{[91]}$ as modified purine bases were found to exhibit biological activity. Hence, studying meta-selective bromination of 6-aryl purines 85 catalyzed by a reusable system was the final major target of this thesis.

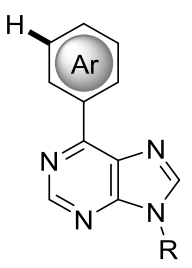

85

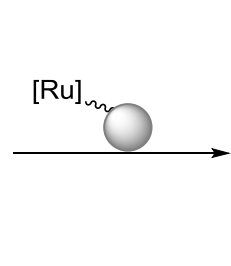

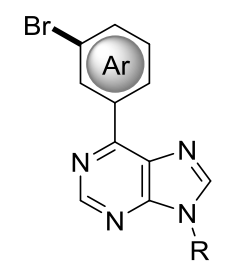

86

Scheme 44. Attempted meta-selective bromination of purine bases with a recyclable catalytic system. 


\section{Results and Discussion}

\subsection{Oxidative Annulation Reactions}

Ruthenium-catalyzed functionalizations of unreactive $\mathrm{C}-\mathrm{H}$ bonds by annulations of substrates bearing $\mathrm{C}-\mathrm{C}$ multiple bonds are powerful tools for the step-economical synthesis of bioactive heterocycles. ${ }^{[3 \mathrm{a}-\mathrm{c}, 3 \mathrm{e}, 3 \mathrm{~g}-\mathrm{l}, 3 \mathrm{o}-\mathrm{t}]}$ These methods avoid the preparation and use of prefunctionalized starting materials by the activation of otherwise inert $\mathrm{C}-\mathrm{H}$ bonds. Despite recent advances, ${ }^{[30]}$ all methods thus far required either the use of additional oxidants, thereby leading to the formation of undesired metal-containing by-products or prefunctionalized starting materials bearing the oxidant.

\subsubsection{Alkyne Annulation of Benzoic Acids}

Heterocycles are ubiquitous structural motifs in natural products, functional materials, crop protecting agents and drugs (Figure 6). ${ }^{[92]}$ This results in a continued strong demand for methods that allow for their efficient synthesis. One of the most general approaches is represented by transition metal-catalyzed annulation of alkynes by ortho-halogen substituted benzoic acid derivatives. ${ }^{[33]}$ Unfortunately, prefunctionalized starting materials are required, thereby limiting the step- and atomeconomy of this approach. ${ }^{[94]}$ In contrast, syntheses via oxidative annulation of alkynes by aromatic acids provides a step and atom economic alternative. While Miura and Satoh elegantly applied a versatile rhodium-catalyst, ${ }^{[12,13 c]}$ less expensive ruthenium(II) complexes proved to be highly efficient and thus allowed for the synthesis of isocoumarins and 2-pyrones. ${ }^{[95]}$

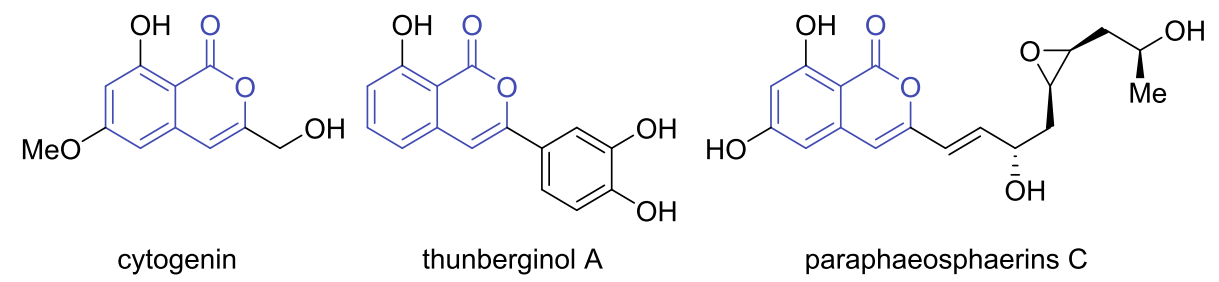

Figure 6. Bioactive compounds and natural products containing isocoumarins.

Both methods require copper acetate as the oxidant. Inspired by the advances in oxidative rhodium catalysis $^{[23-24,96]}$ with strong directing groups, we started to explore the possibilities of using oxygen as the sole oxidant in the ruthenium-catalyzed alkyne annulation of benzoic acids 1 . 


\subsubsection{Synthesis of Cyclometalated Species 91}

At the outset of these studies the cycloruthenation of benzoic acids was investigated to gain a deeper understanding of the individual steps in the reaction. It turned out that the addition of a neutral $\mathrm{N}$ containing ligand, such as pyridine or DMAP is necessary to form a stable 18 valence electron complex. Thus, a complex featuring a neutral sodium benzoate ligand as it was observed for palladium (Scheme 45$)^{[97]}$ seems highly unlikely to be of relevance here.
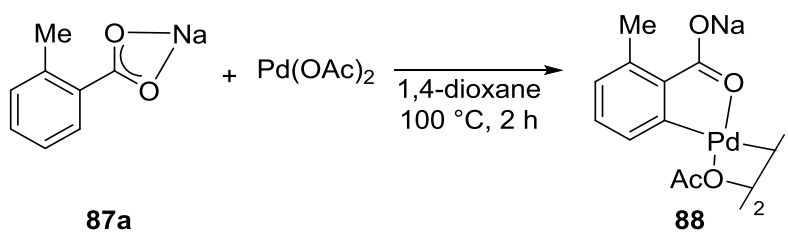

Scheme 45. Palladacycle with benzoate $87 a .{ }^{[97]}$

Direct addition of sodium benzoate was superior compared to the in situ deprotonation of benzoic acid. No complete conversion could be observed with free acids as starting material and separation turned out to be very difficult. Thus, bench-stable complexes could be isolated in case of electrondonating groups (Scheme 46) at ambient temperature. Further experiments indicated that $\mathrm{NEt}_{3}$ can be replaced by $\mathrm{Na}_{2} \mathrm{CO}_{3}$ or $\mathrm{NaOAc}$ without loss of activity, which in some cases made the isolation of pure compounds easier. In case of electron-withdrawing substituents, such as the nitro group but also the fluoro derivative $\mathbf{8 9}$ ea and $\mathbf{8 9 f a , ~ t h e ~ c o m p l e x e s ~ a r e ~ a p p a r e n t l y ~ n o t ~ s t a b l e ~ i n ~ s o l u t i o n ~ u n d e r ~}$ air and could not be isolated in a pure fashion by crystallization. 
$\left[\operatorname{RuCl}_{2}(p \text {-cymene })\right]_{2}+$

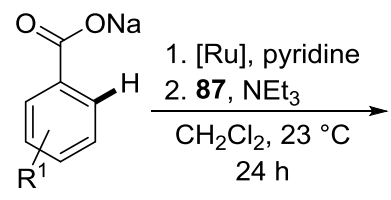

87

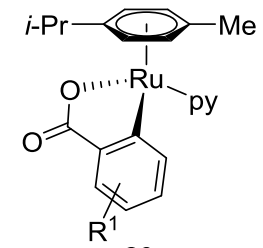

89

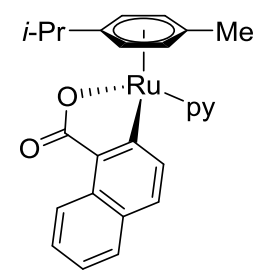

89ba: $71 \%$

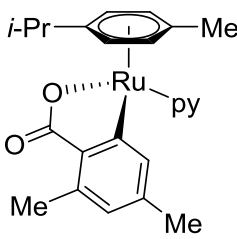

89da: $81 \%[c]$

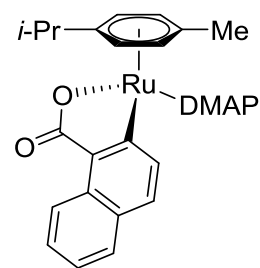

89bb: $85 \%(69 \%)^{[b]}$

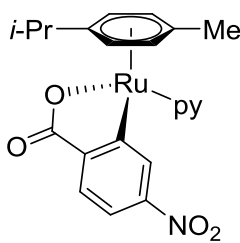

89ea: $65 \%[\mathrm{~d}]$

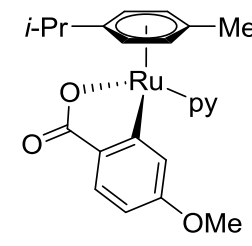

89ca: $70 \%$

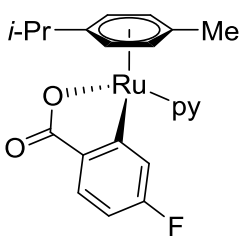

89fa: $65 \%[d]$

[a] Reaction conditions: 1) $\left[\mathrm{RuCl}_{2}(p \text {-cymene })\right]_{2}(0.04 \mathrm{mmol})$, pyridine or DMAP $(0.08 \mathrm{mmol})$, $\mathrm{CH}_{2} \mathrm{Cl}_{2}$ (2 mL), 2 h. 2) 87 (0.20 mmol), $\mathrm{NEt}_{3}$ (0.2 mL). ${ }^{[b]}$ Using $\mathrm{Na}_{2} \mathrm{CO}_{3}$ instead of $\mathrm{NEt}_{3}$. ${ }^{\text {[c] Using }}$ $\mathrm{NaOAC}$ instead of $\mathrm{NEt}_{3}$. ${ }^{[\mathrm{d}]}$ Determined by NMR using 1,4-dimethoxybenzene as internal standard.

Scheme 46. Synthesis of five-membered ruthenacycles 89 . ${ }^{[a]}$

Pre-stirring of the dimeric ruthenium complex $\left[\operatorname{RuCl}_{2}(p \text {-cymene })\right]_{2}$ with the ligand was necessary to pre-form the monomeric complex of the structure $\left[\mathrm{RuCl}_{2}(\mathrm{py} / \mathrm{DMAP})(p\right.$-cymene)] $\mathbf{9 0}$ prior to the addition of benzoic acid. It could indeed be shown that the isolated complex $\left[\mathrm{RuCl}_{2}(\mathrm{py})(p\right.$-cymene)] (90a) showed the same reactivity as the in situ generated system (Scheme 47).

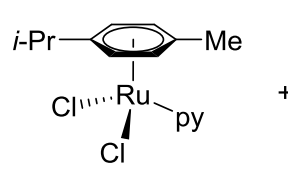

$90 \mathrm{a}$<smiles>COc1ccc(C(=O)O[Na])cc1</smiles>

$87 \mathrm{c}$

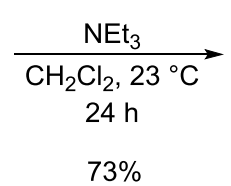

$73 \%$<smiles></smiles>

$89 \mathrm{ca}$

Scheme 47. Cycloruthenation with monomeric ruthenium precursor 90a.

Attempts to stabilize the electron-poor five-membered ruthenacycles 89ea and 89fa with phosphorous ligands, such as $\mathrm{PPh}_{3}, \mathrm{P}\left(2,4,6-\mathrm{OMeC}_{6} \mathrm{H}_{2}\right)_{3}, \mathrm{P}(t-\mathrm{Bu})_{3}$ or $\mathrm{P}\left(\mathrm{NMe}_{2}\right)_{3}$, failed as judged by ${ }^{1} \mathrm{H}$ NMR and ESI-MS analysis. 


\subsubsection{Synthesis of Ruthenium(0) Sandwich Complexes 91}

Surprisingly, the direct reaction of the ruthenium precursor with naphthoic acid (16) and alkyne $\mathbf{2 a}$ yielded the ruthenium(0) sandwich complex 91 (Scheme 48a) instead of a seven-membered ruthenacycle as observed in similar reactions. ${ }^{[98]}$ The addition of pyridine as stabilizing ligand could not prevent the reductive elimination and formation of the ruthenium(0) complex 91 (Scheme $48 \mathrm{~b}$ ). This observation is in accordance with calculations concerning the iridium-catalyzed annulation of benzoic acids by alkynes, in which the sandwich complex is energetically favored over the sevenmembered ring. ${ }^{[99]}$

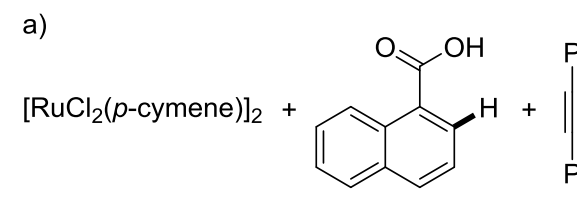

$1 \mathrm{~b}$

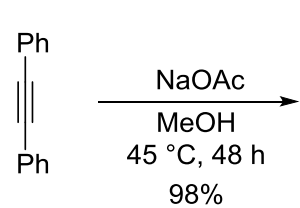

$2 a$

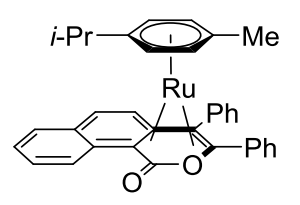

$91 \mathrm{ba}$

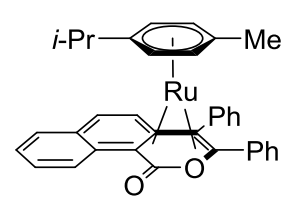

$91 \mathrm{ba}$

b)

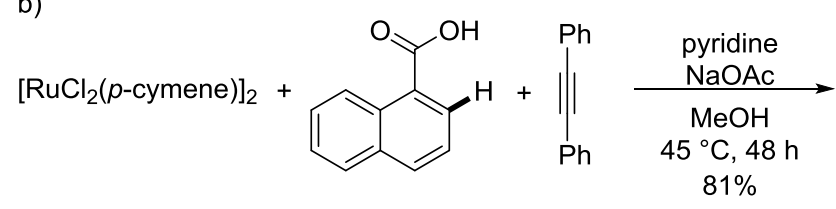

$1 b$

$2 a$

Scheme 48. Unprecedented formation of ruthenium(0) sandwich complex $91 \mathrm{ba}$.

Structurally alike ruthenium(0) sandwich complexes have been isolated before by Pfeffer (Scheme 49) as well as Wang and Li. ${ }^{[100]}$

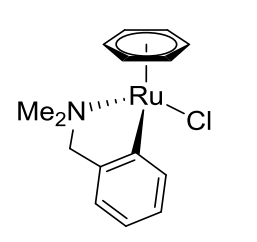

92

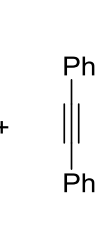

$2 a$

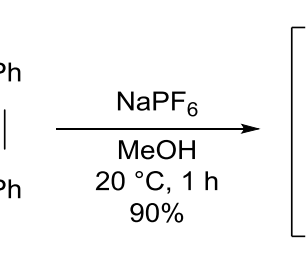

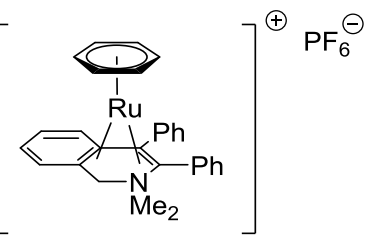

93

Scheme 49. Cationic ruthenium(0) sandwich complex 93 isolated by Pfeffer. ${ }^{[100 b, 100 c]}$

Besides that, ruthenium(II) $)^{[101]}$ sandwich complexes and related rhodium(I) ${ }^{[24 c,}$ 98a] sandwich complexes have been isolated as intermediates in oxidative annulation reactions.

Further investigation of the influence of alkyne substituents led to the smooth formation of ruthenium(0) complexes $\mathbf{9 1}$ for a representative set of alkynes $\mathbf{2}$ (Scheme 50). 


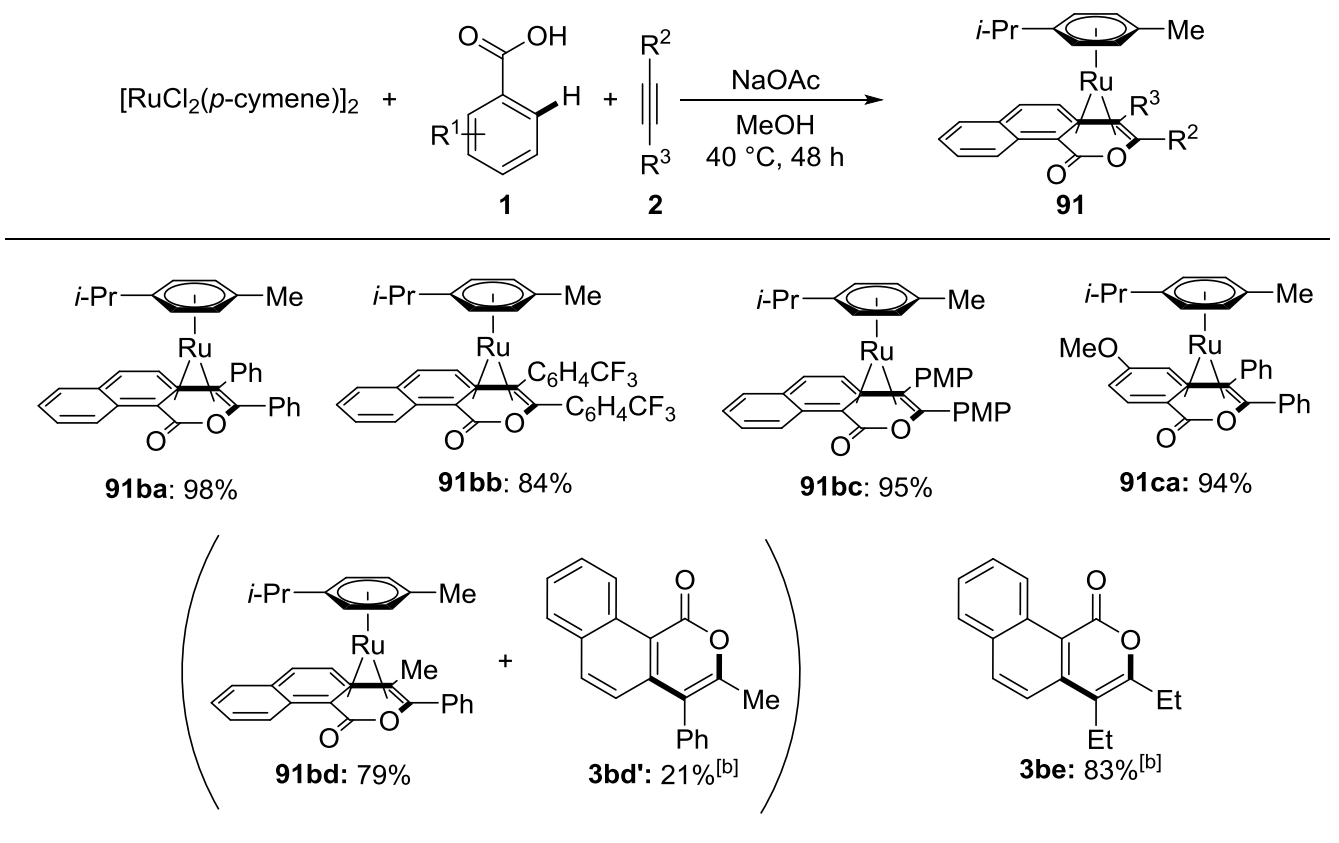

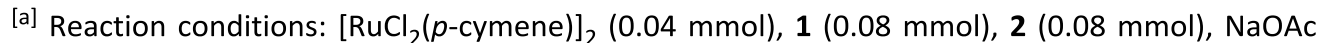
$(0.16 \mathrm{mmol}), \mathrm{MeOH}(2 \mathrm{~mL}), 40^{\circ} \mathrm{C}, 48 \mathrm{~h}$. ${ }^{[b]}$ Elimination product isolated, ${ }^{1} \mathrm{H}$ NMR-spectra of crude product showed the Ru-sandwich complex 91.
}

Scheme 50. Synthesis of diverse ruthenium(0) sandwich complexes 91 . $^{[a]}$

While aromatic substituents led to air- and moisture-stable complexes 91ba, 91bb, 91bc and 91ca the compound derived from alkyl substituted alkyne $\mathbf{2 e}$ provided the elimination product $3 \mathbf{b e}$ after purification under air (Scheme 50). Careful analysis of the reaction mixture by NMR spectroscopy showed that the sandwich complex was formed in all cases but fast oxidation took place for complexes derived from alkyl substituted alkyne $\mathbf{2 e}$ during the purification process under air. The sandwich complex 91be can be isolated through purification under an inert atmosphere (Scheme 54). In case of aryl-alkyl-substituted alkyne $\mathbf{2 d}$ only the complex $\mathbf{9 1 b d}$ with the aromatic ring adjacent to the oxygen proved to be air-stable. This clearly showed the importance of a stabilizing $\pi$-system. Interestingly, the catalytic reaction with the unsymmetrical alkyne $\mathbf{2} \mathbf{d}$ provided a different ratio of isomers of 97:3 (Figure 7) than obtained in the stoichiometric reaction (79:21, Scheme 50 ). This is counterintuitive as the oxidative step seems to be easier for the minor product $\mathbf{3 b d}$ ', which means a higher or equal amount of this product is expected in the catalytic reaction, but the amount of $\mathbf{3} \mathbf{b d}$ ' is clearly higher in case of the stoichiometric reaction, where no oxidation is taking place. 


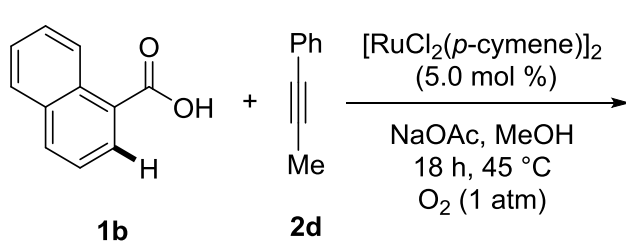

ratio crude mixture: 97

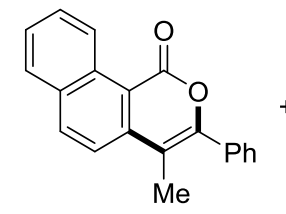

3bd: $59 \%$<smiles>Cc1oc(=O)c2c(ccc3ccccc32)c1-c1ccccc1</smiles>

3bd': $2 \%$

Scheme 51. Catalytic reaction of $1 \mathrm{~b}$ and $\mathbf{2 d}$.

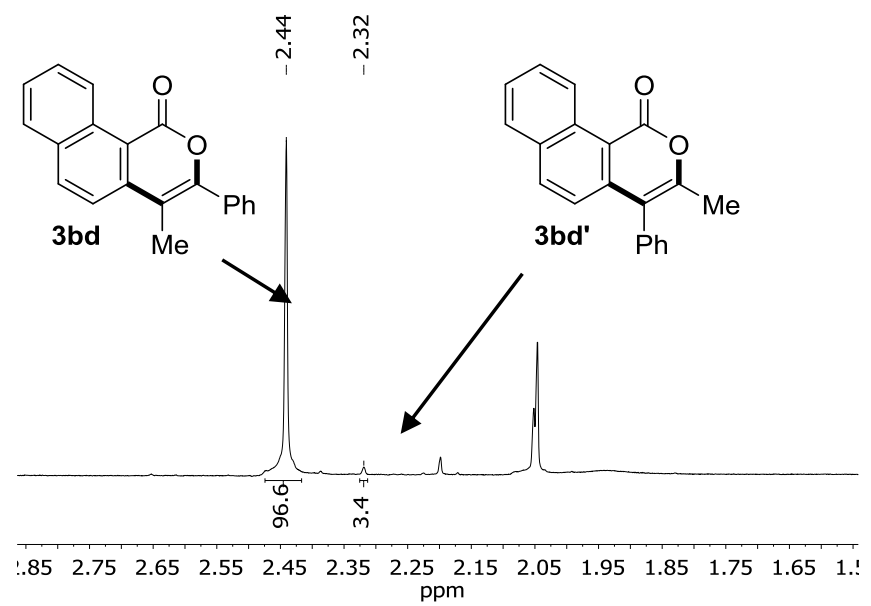

Figure 7. Ratio of $\mathbf{3 b d}$ and $\mathbf{3 b d}$ ' in the catalytic reaction.

A closer look at the reaction conditions can give a possible explanation for this observation. While the stoichiometric reaction has overall an excess of base, the catalytic reaction is slightly acidic due to an excess of the naphthoic acid $\mathbf{1 b}$. As already seen in chapter 3.1.1.1 the base has a crucial role on the formation of the 5-membered ring. Under acidic conditions secondary interactions between the arene on the alkyne and the ruthenium center could be even more important to stabilize the intermediate and thus an even larger amount of compound $\mathbf{3 b d}$ is formed at the end, i. e. the reaction pathway on the left is further destabilized in case of acidic conditions (Scheme 52). 


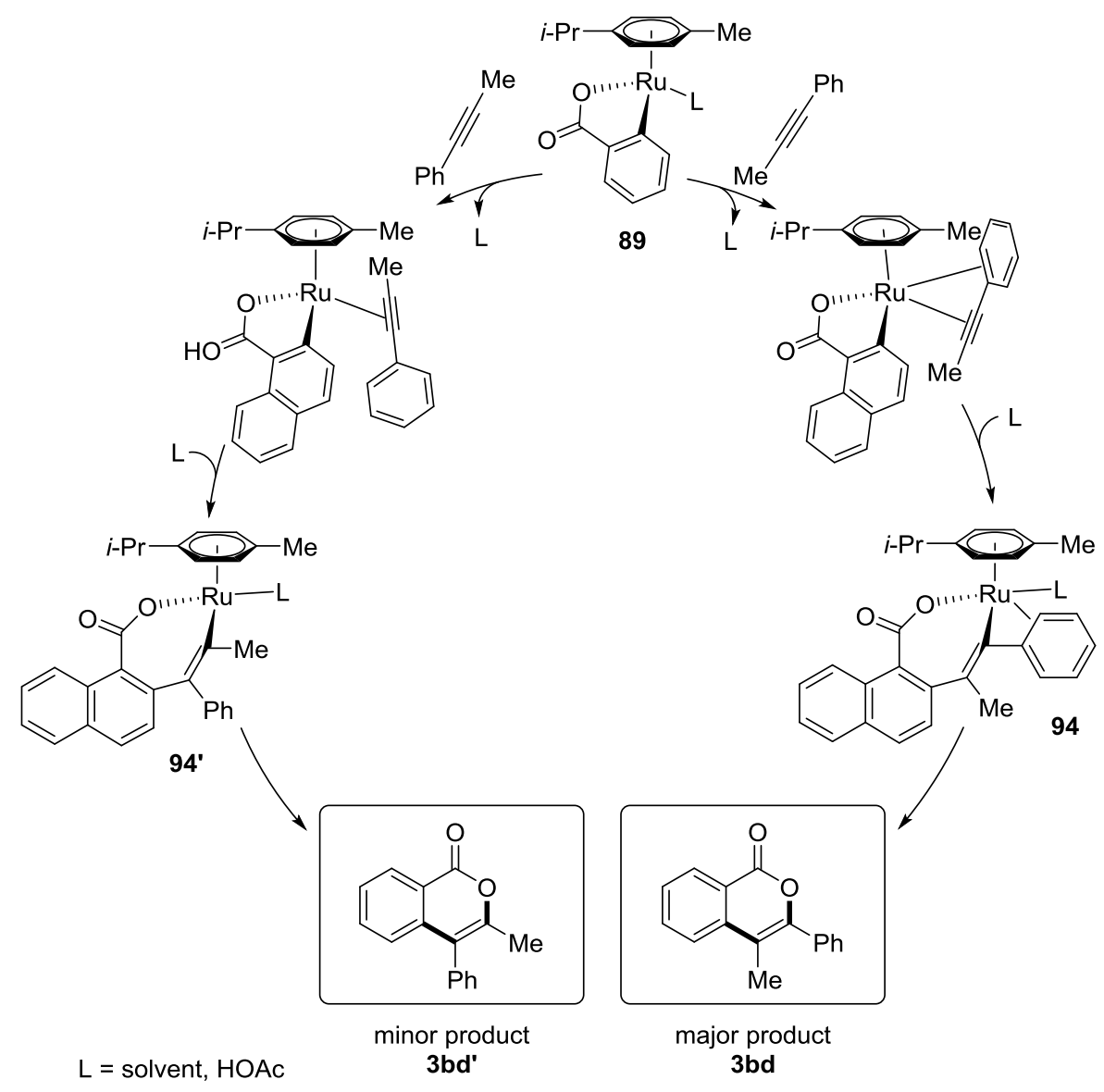

Scheme 52. Conceivable mechanism for the alkyne insertion.

The structure of the obtained sandwich complexes 91 was indicated by NMR analysis which showed aromatic quaternary carbon signals shifted to higher fields. Thus, signals of five quaternary carbon atoms are found in the region between 70 and $110 \mathrm{ppm}$ for the sandwich complex 91ca, whilst for the five-membered ruthenacycle solely the two expected signals originating from the para-cymene ligand can be observed in this region (Figure 8). 

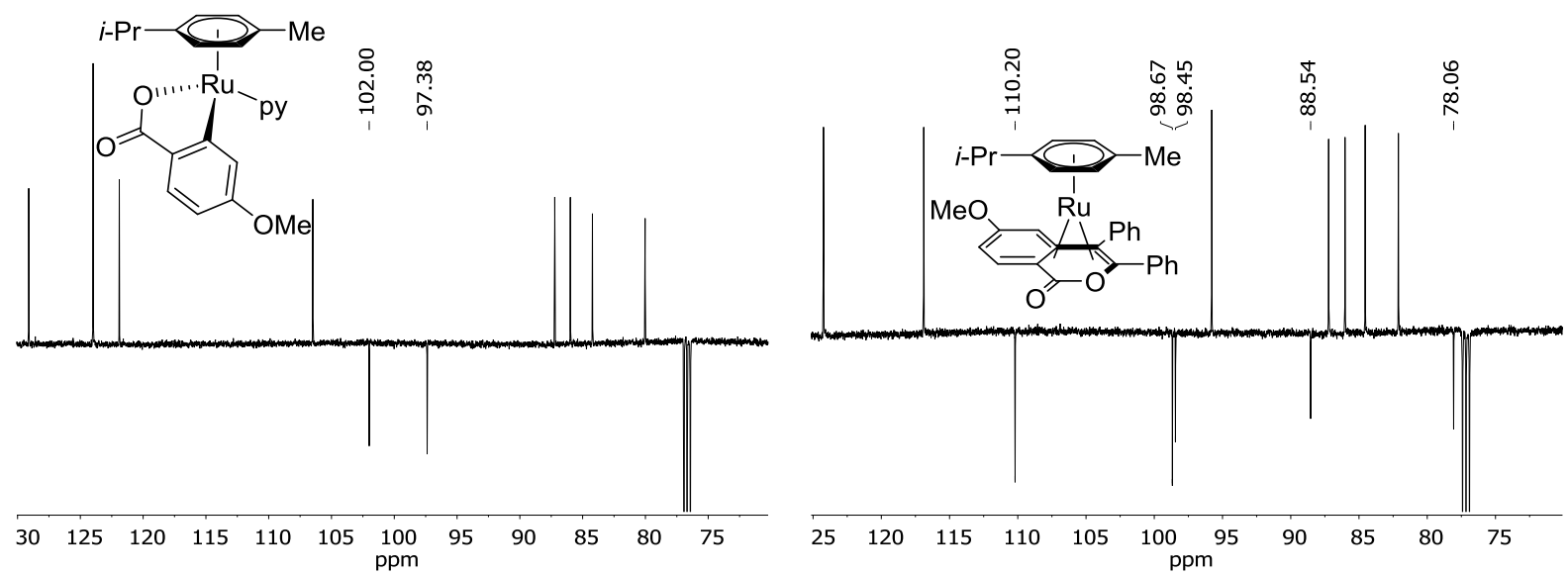

Figure 8. Comparison of ${ }^{13} \mathrm{C}$ NMR spectra of five-membered ring 89ca and sandwich complex $91 \mathrm{ca}$.

Single crystals were obtained by slow diffusion of $n$-hexane into a saturated solution of 91be in tetrahydrofurane. The structure clearly shows the $\eta^{4}$ coordination of the planar fragment (C11-13, C22) and an $\eta^{6}$ coordinated $p$-cymene. ${ }^{[102]}$

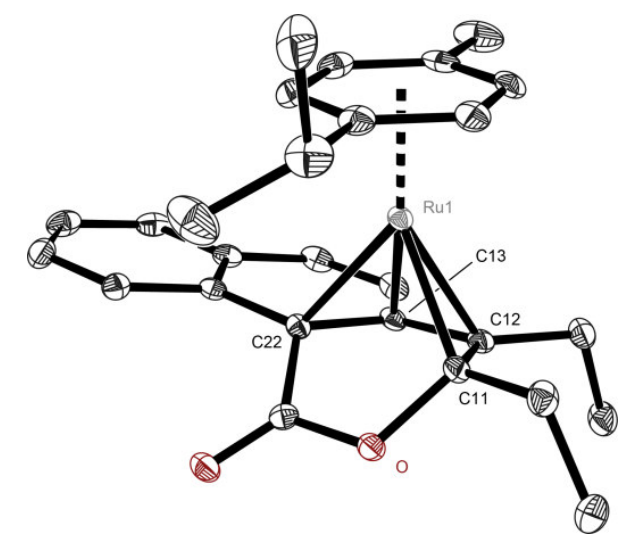

Figure 9. Molecular structure of complex 91be. $\mathrm{H}$ atoms are omitted for clarity. Anisotropic displacement parameters are depicted at the $50 \%$ probability level.

\subsubsection{Alkyne Insertion into Ruthenacycles 89}

In order to study the formation of the proposed seven-membered ring the addition of alkynes to well-defined ruthenacycles $\mathbf{8 9 b b}$ (Figure 10) was investigated in time resolved ${ }^{1} \mathrm{H}$ NMR studies. However, only the direct conversion of the cycloruthenated species 89bb towards the sandwich complex 91 was observed. 

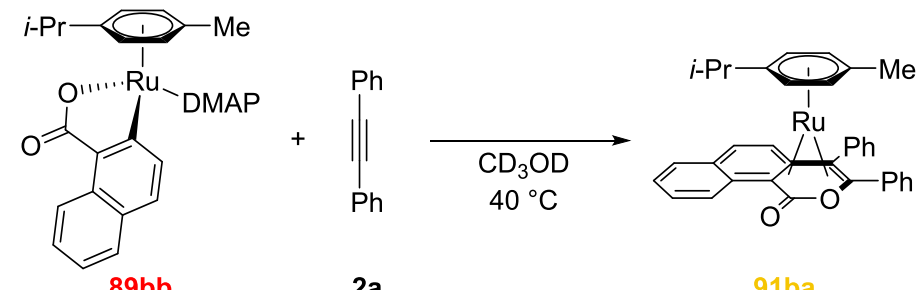

2a

$91 \mathrm{ba}$
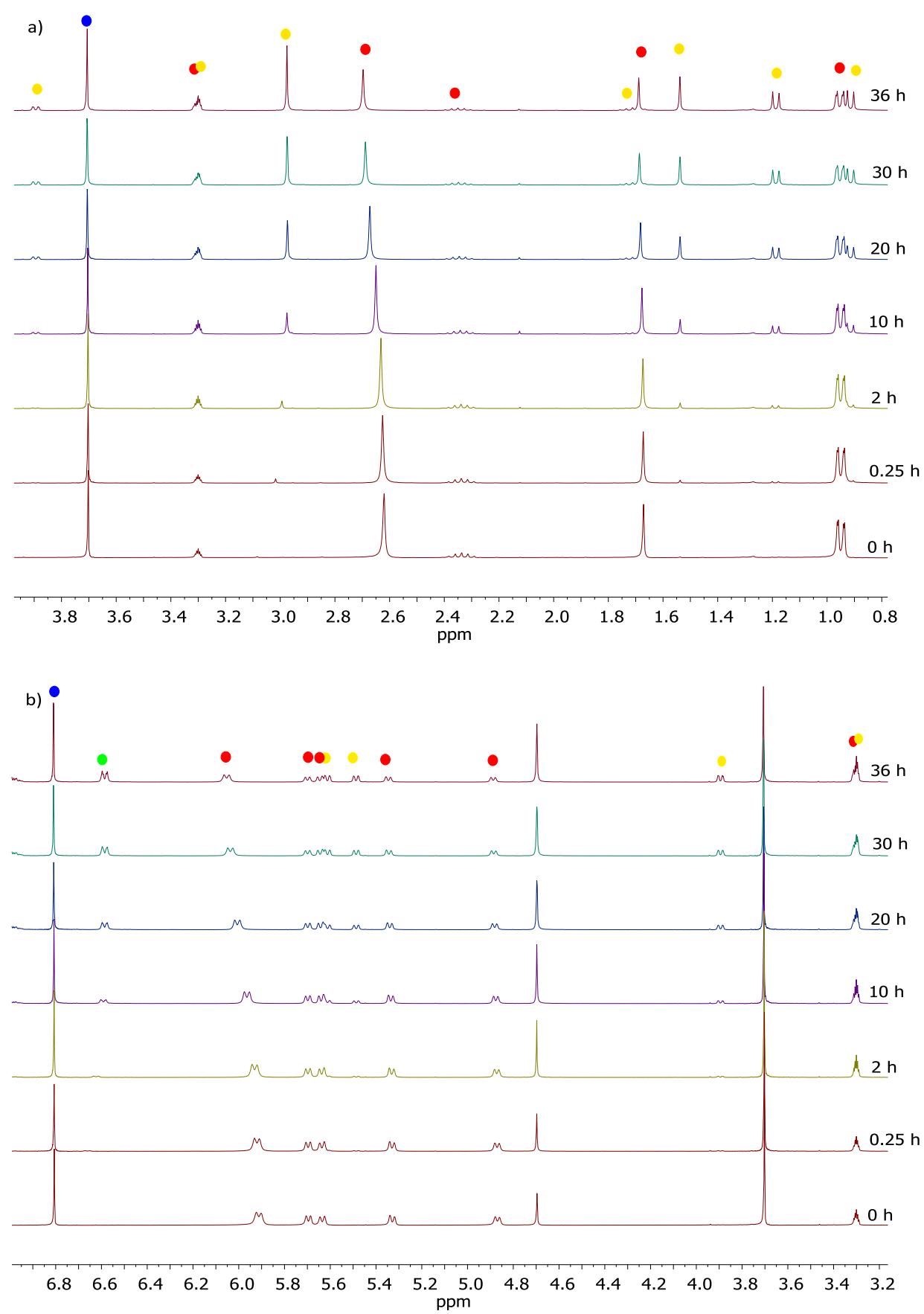

Figure 10. Time resolved ${ }^{1} \mathrm{H}$ NMR study of the insertion of alkyne $2 \mathrm{a}$ into the ruthenacycle $89 \mathrm{bb}$, the blue dot indicates the internal standard 1,4-dimethoxybenzene, the green one free DMAP.

No new resonances besides the one originating from the sandwich complex have been observed. Pfeffer showed for the reaction of $\mathbf{9 2}$ with alkynes that the electronic nature of the alkyne defines if 
the sandwich complex or the seven-membered ring is the more stable intermediate. ${ }^{[100 c, 103]}$ Electronrich alkynes led to the formation of the ruthenium(0) complex 93, whereas electron poor alkynes, such as dimethyl acetylenedicarboxylate (2f), yielded the seven-membered ring 95 (Scheme 53). It is worth noting that no alike ruthenium(0) sandwich compound was observable for complexes bearing para-cymene instead of benzene as $\eta^{6}$-ligand due to reduced stabilities.

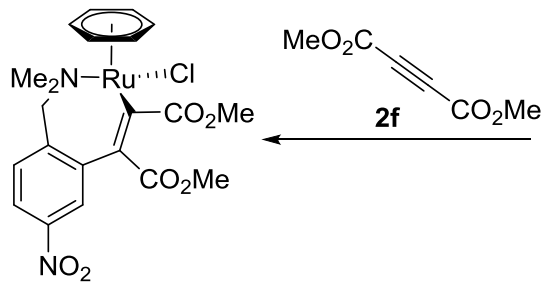

95

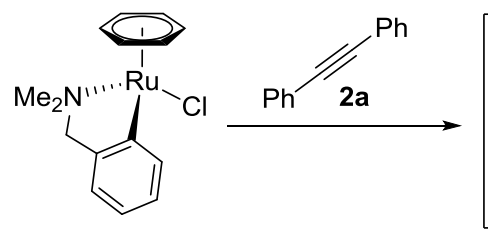

92

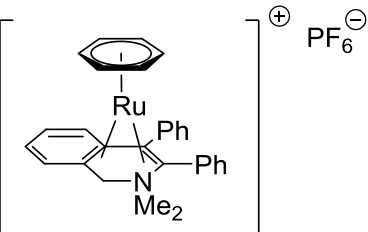

93

Scheme 53. Formation of 7-membered ruthenacycle 95 or ruthenium(0) complex 93 depending on the electronic nature of the alkyne. ${ }^{[100 c, 103]}$

Further investigations showed that the insertion and reductive elimination proceeded relatively fast with the electron-poor alkyne $\mathbf{2} \mathbf{b}$, while the use of electron-rich alkyne $\mathbf{2 c}$ led to longer reaction times. Nonetheless good yields were obtained in both cases. Even though a variation of the electronic character somewhat changed the rate of the alkyne insertion, it could not stabilize the seven-membered ring. In all cases only the immediate formation of the sandwich complex was observed (Scheme 54). Unfortunately, alkyne insertion with the very electron-poor alkyne dimethyl acetylenedicarboxylate (2f) was not successful. A high reaction temperature of $80^{\circ} \mathrm{C}$ was necessary to start a reaction, which was not selective. 


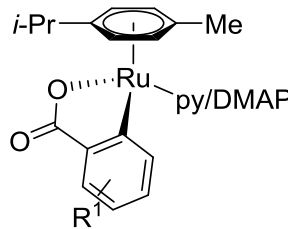

89

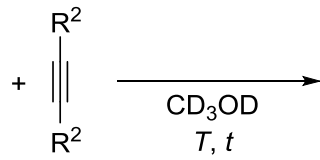

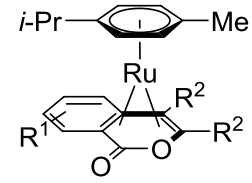

91

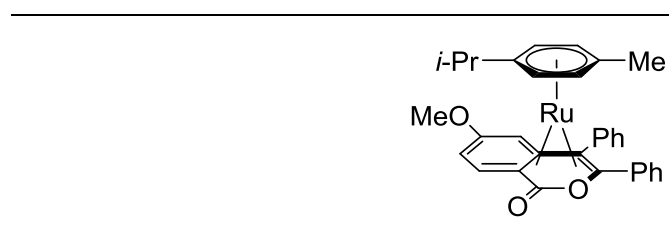

91ca

$71 \%\left(40^{\circ} \mathrm{C}, 20 \mathrm{~h}\right)$

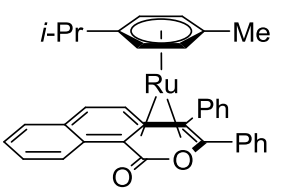

$91 \mathrm{ba}$

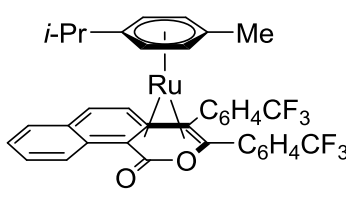

$91 \mathrm{bb}$

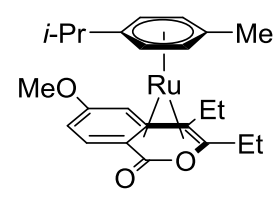

91ce

$75 \%\left(40^{\circ} \mathrm{C}, 18 \mathrm{~h}\right)$

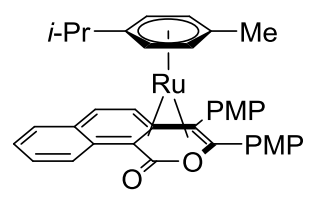

$91 \mathrm{bc}$

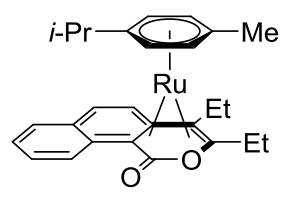

$91 \mathrm{be}$

no full conversion $\left(40^{\circ} \mathrm{C}\right)^{[\mathrm{b}]} \quad 95 \%\left(40^{\circ} \mathrm{C}: 48 \mathrm{~h}, 60^{\circ} \mathrm{C}, 6 \mathrm{~h}\right)^{[\mathrm{b}]}$ $87 \%\left(60^{\circ} \mathrm{C}, 48 \mathrm{~h}\right)^{[\mathrm{b}]}$

$76 \%\left(40{ }^{\circ} \mathrm{C}, 80 \mathrm{~h}\right)^{[\mathrm{b}]}$

$67 \%\left(60^{\circ} \mathrm{C}, 46 \mathrm{~h}\right)^{[\mathrm{b}, \mathrm{c}]}$

[a] Reaction conditions: 89 (0.02 mmol), 2 (0.02 mmol) and 1,4-dimethoxybenzene (standard) in $\mathrm{CD}_{3} \mathrm{OD}(0.6 \mathrm{~mL})$. Yield of isolated product ${ }^{[\mathrm{b}]}$ DMAP was used as ligand instead of pyridine. ${ }^{[\mathrm{c}]}$ Conversion determined by ${ }^{1} \mathrm{H}$ NMR.

Scheme 54: Alkyne insertion into ruthenacycle 91. ${ }^{[a]}$

Also electronic changes at the ligand were only able to influence the overall rate of the reaction. Similarly, increasing the amount of the ligand only inhibited the overall reaction (Scheme 55). For instance, ten equivalents of DMAP shut down the reaction completely at $40^{\circ} \mathrm{C}$. Increasing the temperature or lowering the excess to five equivalents enabled the reaction, albeit with prolonged reaction times and without any hints for the formation of the seven-membered intermediate.
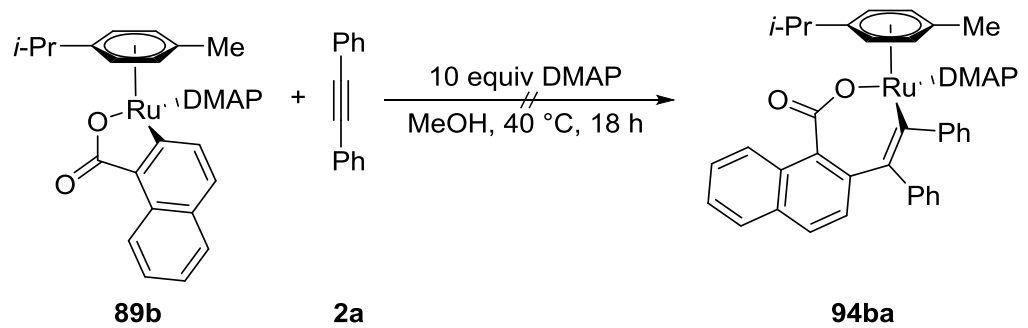

Scheme 55. Attempt to stabilize the proposed intermediate $\mathbf{9 4 b a}$ with an excess of DMAP. 
Attempts to stabilize the proposed seven-membered ruthenacycle via a second directing group on the alkyne $\mathbf{2 g}$ and also an intramolecular attempt with benzoic acid $\mathbf{1 g}$ failed (Scheme 56 ).

a)

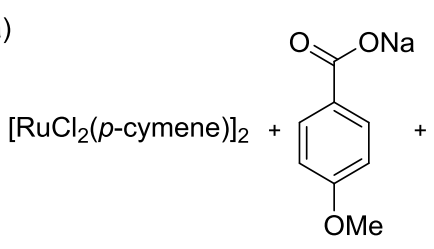

$89 \mathrm{c}$

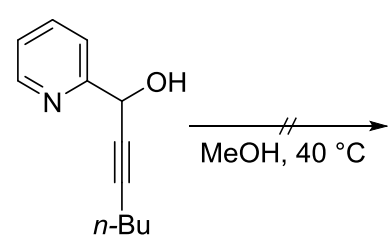

$2 \mathrm{~g}$
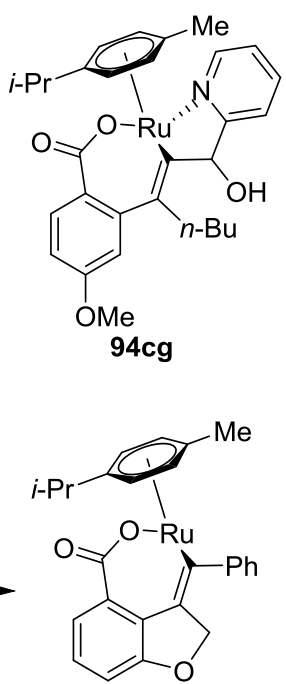

$94 \mathrm{~g}$

$1 \mathrm{~g}$

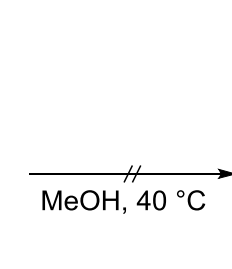

Scheme 56. Attempts for the preparation of the seven-membered ruthenacycles 94 by a) a chelating alkyne or b) an intramolecular approach.

Likewise, neither a non-polar solvent, like benzene, nor a strongly coordinating solvent, like acetonitrile, could stabilize the seven-membered ring. Unfortunately, electron-poor benzoic acids proved unsuitable for the synthesis of the five-membered ruthenacycle. Therefore, the reactivity was tested in the direct reaction starting from $\left[\mathrm{RuCl}_{2}(p \text {-cymene) }]_{2}\right.$ and benzoic acid $\mathbf{1 e}$ (Scheme 57$)$, but also in this case the seven-membered ring $\mathbf{9 4}$ was not detectable. The same holds true for reactions in the presence of phosphine ligands (see also page 27).

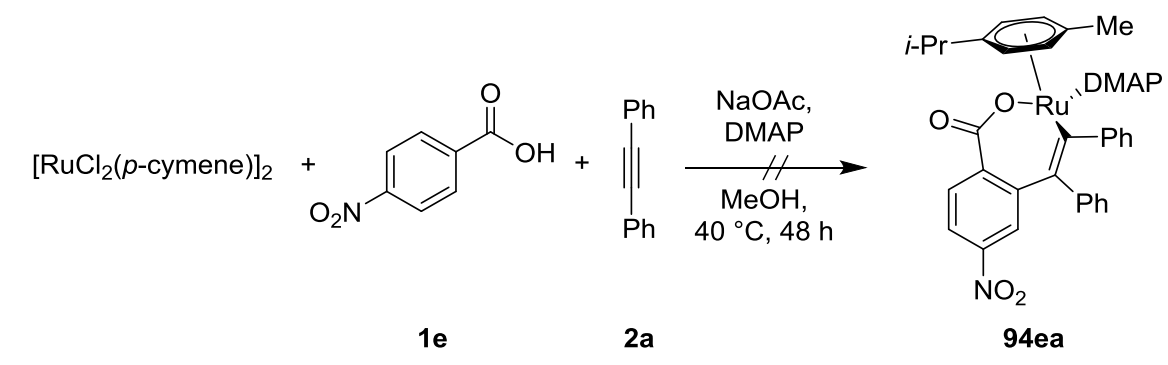

Scheme 57. Attempt to synthesis the seven-membered ruthenacycle with electron-poor acid $\mathbf{1 e .}$

As the isolation of the seven membered ruthenacycle was not possible with the described methods and the species seemed not to be detectable by NMR studies, mass spectrometric studies were 
carried out. For this the alkyne insertion of diphenylacetylene onto ruthenacycle $\mathbf{9 1 b b}$ was stopped before completion of the reaction.

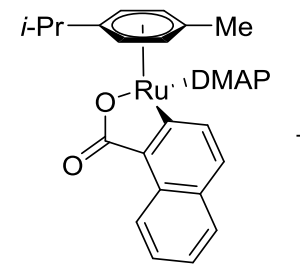

$89 b b$

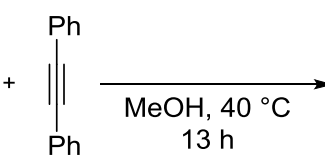

2a

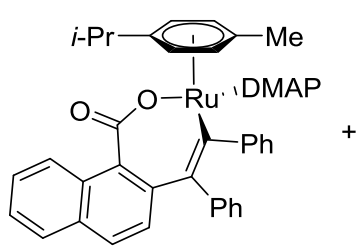

$94 b a$

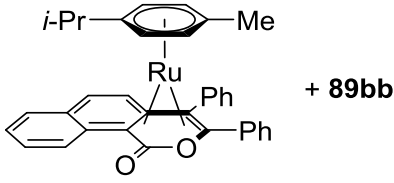

$91 \mathrm{ba}$

Scheme 58. Reaction of $\mathbf{8 9 b b}$ with alkyne $2 \mathrm{a}$ stopped after $13 \mathrm{~h}$ and subjected to ESI-MS.In this case a third compound, besides the starting material $89 \mathrm{bb}$ and the sandwich complex $91 \mathrm{ba}$, was observed, which had both DMAP and diphenylacetylene (2a) attached to the complex (HR-MS (ESI): $m / z=707.2217$ calculated for $\mathrm{C}_{42} \mathrm{H}_{40} \mathrm{~N}_{2} \mathrm{O}_{2} \mathrm{Ru}+\mathrm{H}^{+}$, found: 707.2212). This observation is indicative of the existence of the seven-membered cycle $\mathbf{9 4 b a}$, which is stabilized by the neutral ligand. This $\mathrm{m} / \mathrm{z}$ ratio was not observable when supplying a mixture of $\mathbf{8 9 b b}$ and diphenylacetylene (2a) or the sandwich complex $\mathbf{9 1 b a}$ and DMAP to the measurement. Hence, a formation of the species during the ionization process can be excluded.

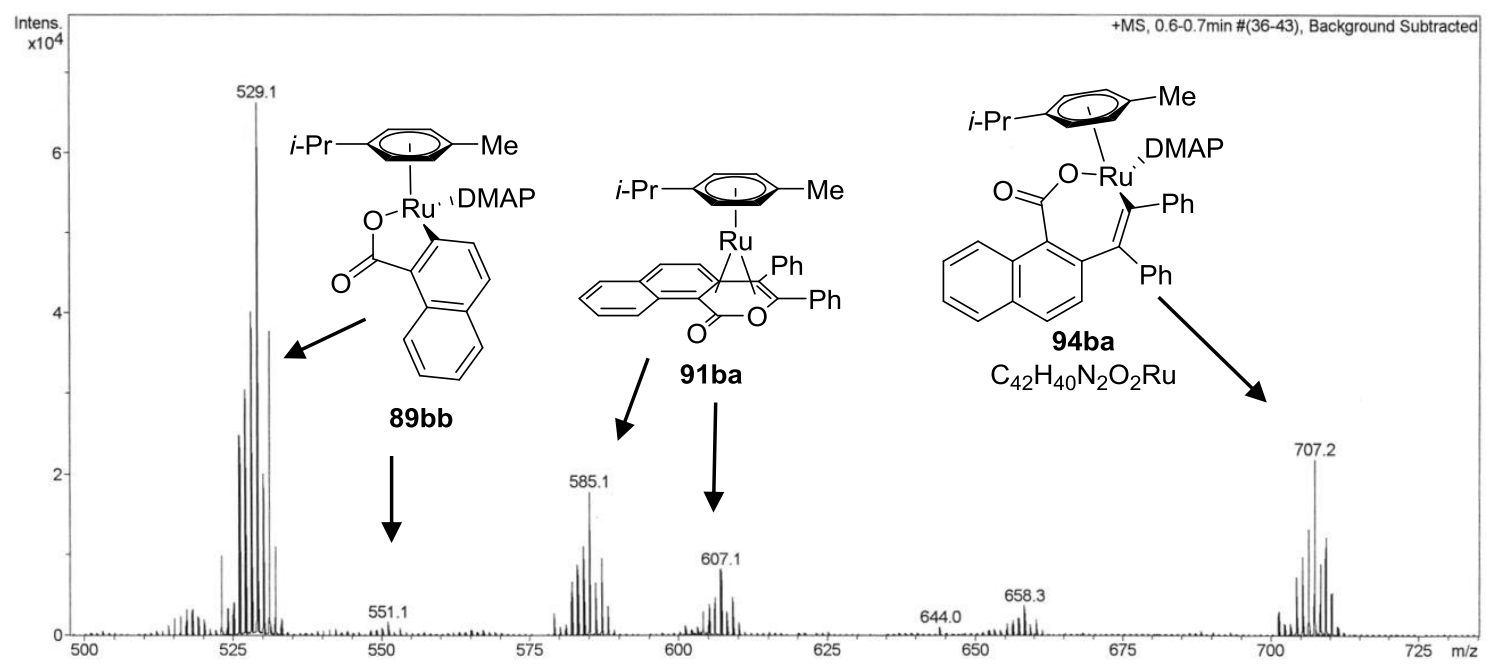

Figure 11. HR-MS spectra of the reaction mixture of the alkyne insertion of alkyne $2 \mathrm{a}$ onto $89 \mathrm{bb}$.

These results indicate that the reductive elimination has to be considerably faster than the insertion of the alkyne.

\subsubsection{Oxidation of the Ruthenium(0) Sandwich Complex 91}

First, the oxidation with $\mathrm{Cu}(\mathrm{OAc})_{2}$ was analyzed. Interestingly, no oxidation was observable when adding solely $\mathrm{Cu}(\mathrm{OAc})_{2}$ to the sandwich complex. Also the addition of sodium naphthoate (87b) and DMAP as ligand to regenerate the five-membered ruthenacycle $\mathbf{8 9} \mathbf{b b}$ did not suffice. The addition of 
$\mathrm{KPF}_{6}$, which was used as additive in the catalytic reaction developed by Ackermann and coworkers, ${ }^{[17]}$ cleanly formed the product and also acetic acid as additive led to product formation in quantitative yield.

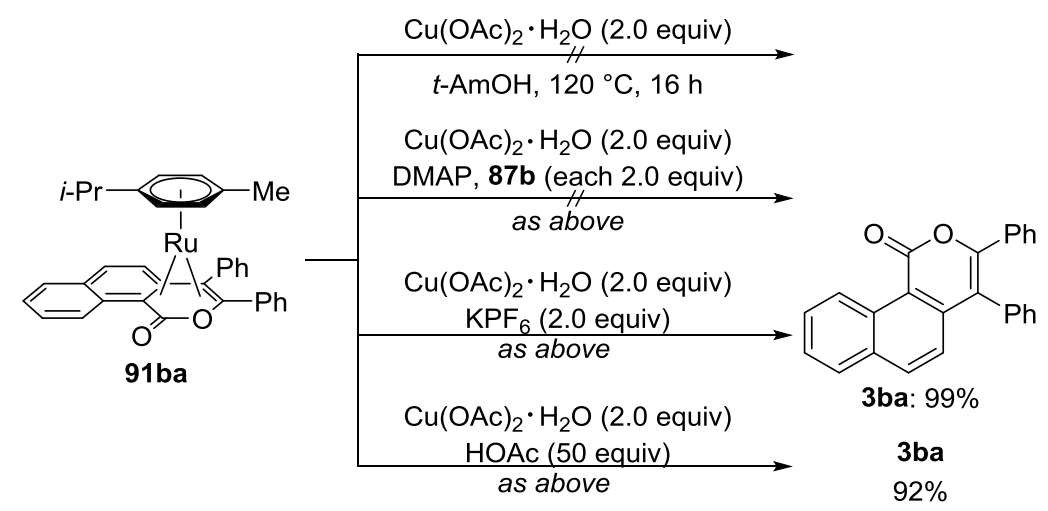

Scheme 59. Oxidation of sandwich complex 91ba with copper acetate as the oxidant.

As the complex 91be and 91ce derived from alkyl substituted alkynes proved to be instable under aerobic conditions, the question arose if oxygen can be used as an environmentally friendly oxidant for the aromatic system as well. Also in this case the simple addition of oxygen did not generate the product or induce any observable reaction, while the addition of acetic acid and oxygen yielded the product 3 ba and also $\left[\mathrm{Ru}(\mathrm{OAc})_{2}(p\right.$-cymene $\left.)\right]$. If the experiment was conducted under air and not under an oxygen enriched atmosphere, a somewhat longer reaction time along with a higher temperature were required. These results show that on the one hand the benzoate $\mathbf{8 7}$ is needed to achieve the cycloruthenation of the benzoic acid $\mathbf{1}$ but on the other hand acetic acid is required for the oxidation of the ruthenium(0) complex 91. Thus, the reaction requires conditions that allow for the formation of the benzoate 87 in the presence of acetic acid.

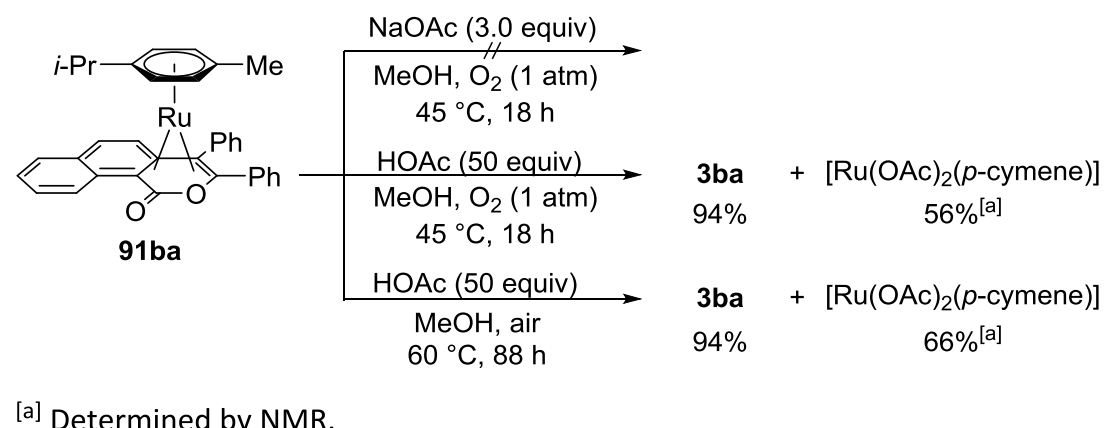

Scheme 60. Oxidation of 91ba applying oxygen as the oxidant. 
The excess of acetic acid is crucial for the oxidation step. If only ten equivalents are used a conversion of only $17 \%$ is observed under otherwise identical conditions. Interestingly, the reactivity increases again when the molarity of the reaction is increased. Thus, moving from a concentration of $0.017 \mathrm{M}$ to $0.068 \mathrm{M}$ the conversion went up to $62 \%$, again under otherwise identical conditions (Scheme 61). This showed that the concentration of acetic acid in solution and not only the overall amount is important for the efficiency of the reaction.

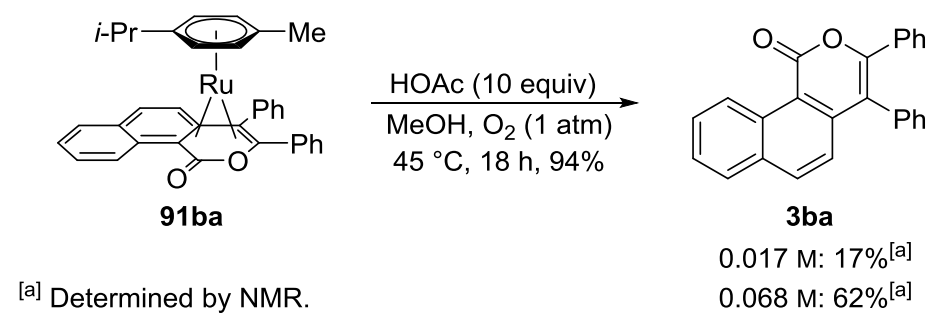

Scheme 61. Influence of the molarity on the oxidation of 91ba.

A reasonable explanation for the crucial role of the acid would be an oxidative addition of acetic acid to ruthenium, but the addition of acetic acid without oxygen did not lead to any reaction (Scheme 62). Hence, an oxidative addition, like it is known for ary ${ }^{[30]}$ and alkyl halides ${ }^{[104]}$ and also aryl ethers, ${ }^{[105]}$ seems to be unlikely. The oxidation simultaneously requires oxygen and acetic acid. The reason for this either lies in a simultaneous process or a reversible first step, in which the addition of the second required chemical shifts the equilibrium to the product side via a nonreversible reaction.

a)

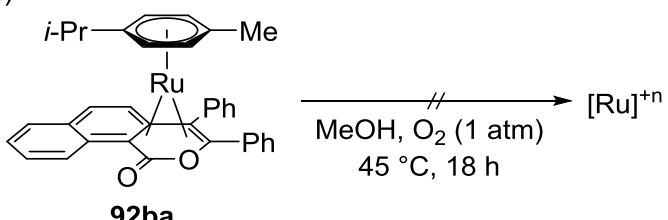

b)

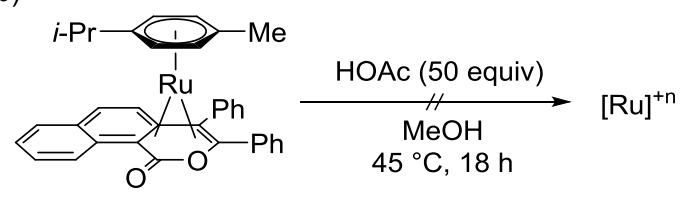

Scheme 62. Role of acetic acid in the oxidation.

Interestingly, when controlling the oxidation process by ${ }^{1} \mathrm{H}$ NMR studies a paramagnetic side product was observed. To further check this observation EPR studies were performed. It turned out that indeed a paramagnetic ruthenium species could be observed. The radical displays orthorhombic features and the g-value suggested that the radical character is most likely not based on the ligand system ( $g_{\text {iso }}=2.41, g_{x} \neq g_{y} \neq g_{z}$ ). Aging of the reaction mixture led to a decrease of the observed radical, while a new organic radical evolves $\left(g=2.006 ; g_{e}=2.002 ; \Delta=0.004\right)$. Ruthenium(l) species are very scarce in the literature ${ }^{[106]}$ and it is therefore most likely that this side product is a result of 
an over oxidation process to ruthenium(III). However, upon subjecting ruthenium(II) acetate complex 96 to the oxidation conditions no paramagnetic species was formed (Scheme 63).

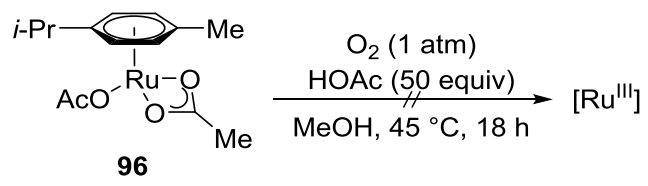

Scheme 63. Attempted oxidation of $\left[\mathrm{Ru}(\mathrm{OAc})_{2}(p\right.$-cymene $\left.)\right]$.

Cyclic voltammetry studies of the sandwich complex were conducted to gain more insight into the oxidation process (Figure 12). The CV studies suggested an irreversible oxidation process in which only one oxidation step was visible. The special role of the acetic acid in the oxidation process can be seen in a decreased oxidation potential in case of the addition of acetic acid.

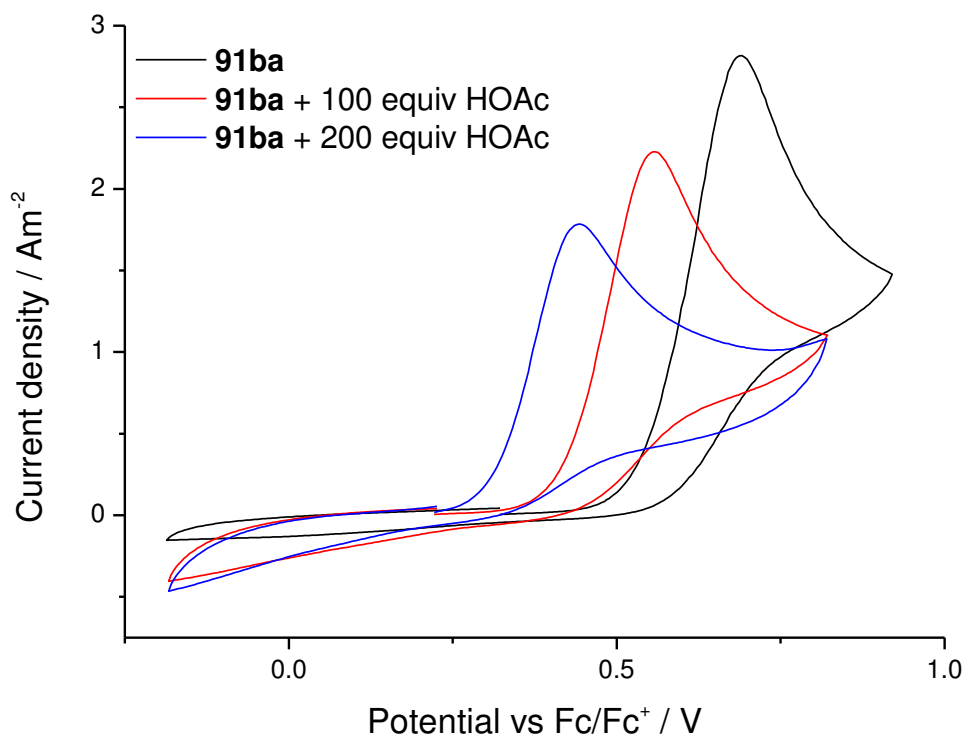

Figure 12. Cyclic voltammogram of ruthenium(0) sandwich complex $91 \mathrm{ba}$.

Interestingly, when adding a large excess of acetic acid a second oxidation process becomes observable, thus strengthening the theory of an over oxidation leading to a paramagnetic ruthenium(III) species (Figure 13). 


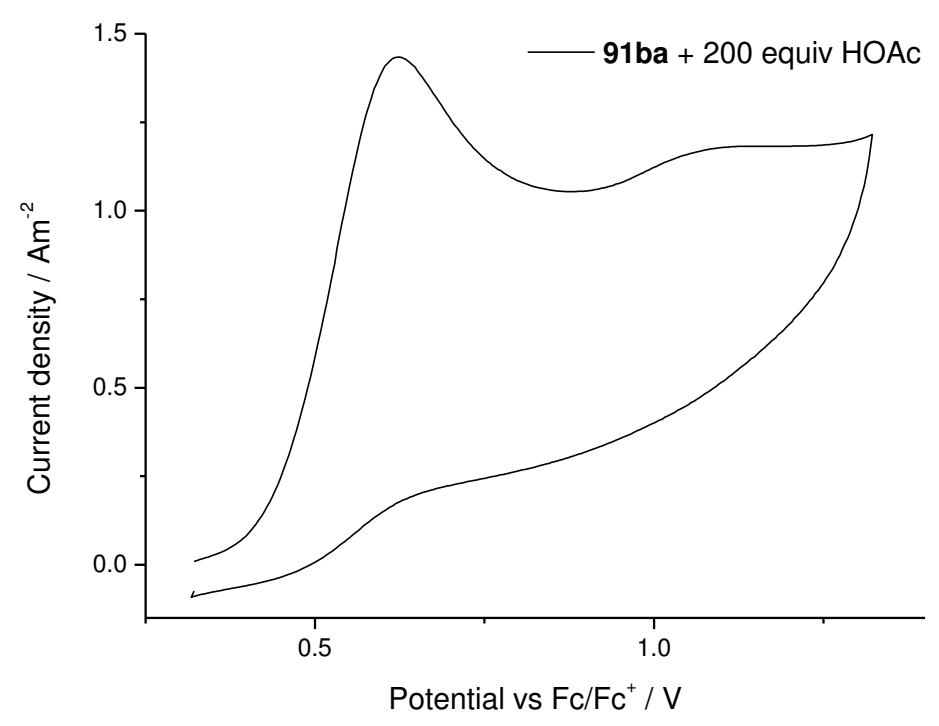

Figure 13. Cyclic voltammogram of ruthenium(0) sandwich complex 91 ba with 200 equivalents acetic acid.

The two following oxidation pathways are reasonable (Scheme 64).

a)
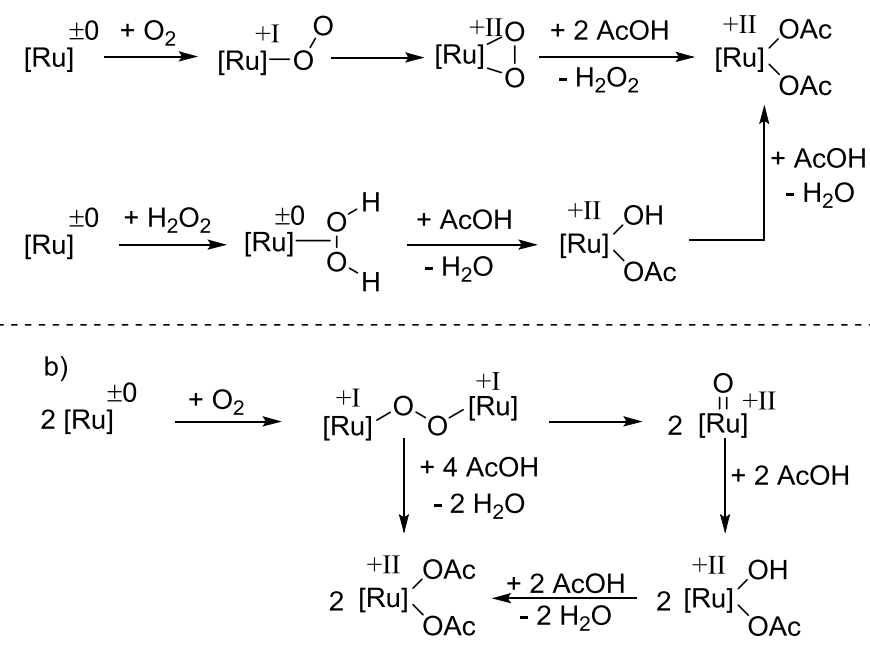

Scheme 64. Possible pathways for the oxidation of the ruthenium(0) sandwich complex 91.

The oxidation itself is probably proceeding via a fast single electron transfer process producing a peroxo ruthenium species, which further reacts to the acetate complex (Scheme 64a). Calculations from $\mathrm{Fu}$, Lin and coworkers ${ }^{[107]}$ regarding the formation of $\mathrm{Ru}(\mathrm{II})$ peroxo species suggested an initial formation of an end-on $\eta^{1}-\mathrm{O}_{2}$ complex. The dangling oxygen atom then attacks the metal to form the side-on $\eta^{2}-\mathrm{O}_{2}$ peroxo species. However, the calculations have not been conducted for $\eta^{6}$-arene 
complexes. The in situ formed hydrogen peroxide is then consumed during oxidation of another ruthenium(0) complex. An alternative would be represented by an oxidation involving two ruthenium centers, forming a dioxygen-bridged complex (Scheme 64b). This may either be directly attacked by acetic acid or split into two oxo-ruthenium species, which subsequently react with acetic acid.

To probe the feasibility of hydrogen peroxide as oxidant, C. Kornhaaß ${ }^{[108]}$ tested it in the catalytic reaction under an inert atmosphere and the product indeed formed in good yield with only one equivalent of hydrogen peroxide (Scheme 65).
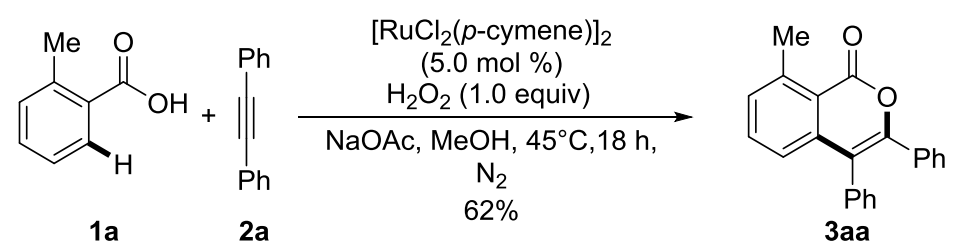

Scheme 65. Ruthenium(II)-catalyzed alkyne annulation with hydrogen peroxide as oxidant.

Nevertheless, a test for hydrogen peroxide with peroxide test stripes after the reaction was negative. The detection limit of these stripes is $1 \mathrm{mg}$ peroxide per liter. The result may either indicate that no hydrogen peroxide is formed during the reaction or that the in situ produced hydrogen peroxide is a better oxidant than oxygen itself and is therefore consumed directly after its formation.

\subsubsection{Catalytic Reaction and Activity of Isolated Complexes in These}

The optimization of the catalytic oxidative alkyne annulations of benzoic acids was performed by $\mathrm{C}$. Kornhaaß. ${ }^{[109]}$ In the course of the present thesis a base screening was performed, showing that acetates performed excellent in the reaction (Table 1, entry 1-4). In case of the in methanol more soluble potassium salts a generally higher yield was obtained (Table 1, entry 3 ).

Table 1. Influence of the base in the oxidative alkyne annulation of benzoic acids $1 a^{[a]}$<smiles>Cc1ccccc1C(=O)O[14CH2]C(F)F</smiles>

1a

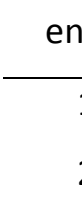

2

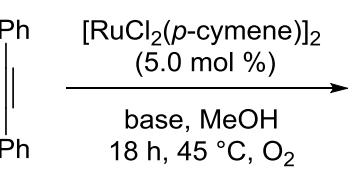

2a

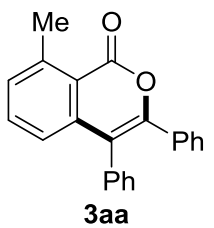

yield / \%

$\mathrm{NaOAc}$

$78^{[\mathrm{b}]}$

3

$\mathrm{KO}_{2} \mathrm{CMes}$

65 
[a] Reaction conditions: 1a $(2.0 \mathrm{mmol}), 2 \mathrm{a}(1.0 \mathrm{mmol})$,

[Ru] (5.0 mol \%), base (1.0 mmol), $\mathrm{MeOH}(0.33 \mathrm{M}), \mathrm{O}_{2}$

(1 atm), $45^{\circ} \mathrm{C}, 18$ h. ${ }^{[b]}$ Performed by C. Kornhaaß.

The standard conditions developed by C. Kornhaa $\aleph^{[109]}$ are as shown in Scheme 66 and the catalytic system proved applicable to diverse (hetero)aromatic acids $\mathbf{1}$ and differently substituted alkynes $\mathbf{2}$.<smiles>[R][CH]C#[R]C(=O)c1c[R17]ccc1[1H]</smiles>

1

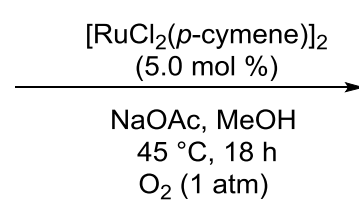

$\mathrm{O}_{2}(1 \mathrm{~atm})$

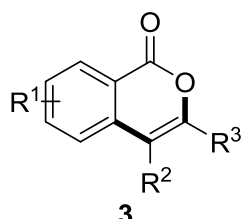

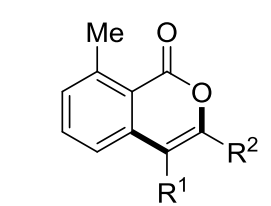

$\mathrm{R}^{1}=\mathrm{R}^{2}=\mathrm{Et}:$ (3ae): $\quad 78 \%$ $\mathrm{R}^{1}=\mathrm{Me}, \mathrm{R}^{2}=\mathrm{Ph}(\mathbf{3 a d}): 79 \%$

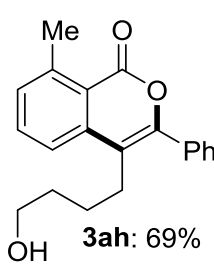<smiles>COc1ccc2c(=O)oc(-c3ccccc3)c(CCCCCl)c2c1</smiles><smiles>CCCCc1oc(=O)c2c3ccccc3n(C)c2c1OCC</smiles>

3lj: $94 \%$

Scheme 66. Optimized conditions and examples for the scope of the oxidative alkyne annulation of acids 1. Reactions performed by C. Kornhaaß. ${ }^{[109]}$

To test if the aforementioned isolated complexes $\mathbf{8 9}$ and $\mathbf{9 1}$ are catalytically competent species in the reaction, they were submitted as catalysts under the previously developed standard reaction conditions with copper acetate as oxidant in the annulation of benzoic acid $\mathbf{1 h}$ with alkyne $\mathbf{2 e}$ (Scheme 67).

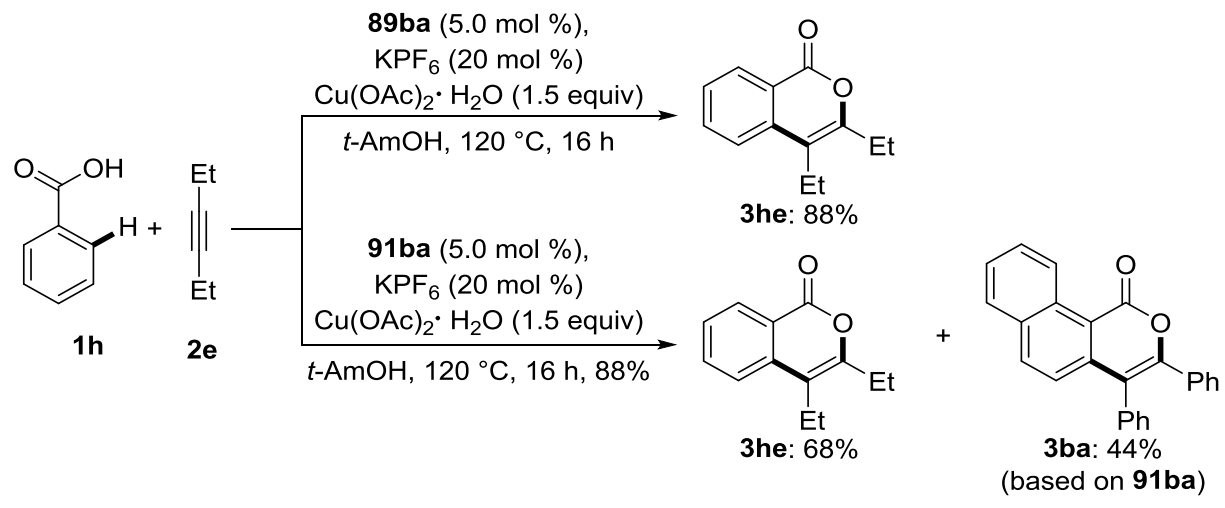

Scheme 67. Catalytic activity of isolated complexes. 
Surprisingly, the yield obtained with the ruthenacycle $89 \mathrm{ba}$ is considerably higher than with the corresponding sandwich complex $91 \mathrm{ba}$. A careful check of the conditions revealed the pyridine ligand attached to metallacycle $\mathbf{8 9 b a}$ to be the only significant difference. Hence, the effect of pyridine in the catalytic reactions was tested and indeed a higher yield was obtained (Scheme 68).

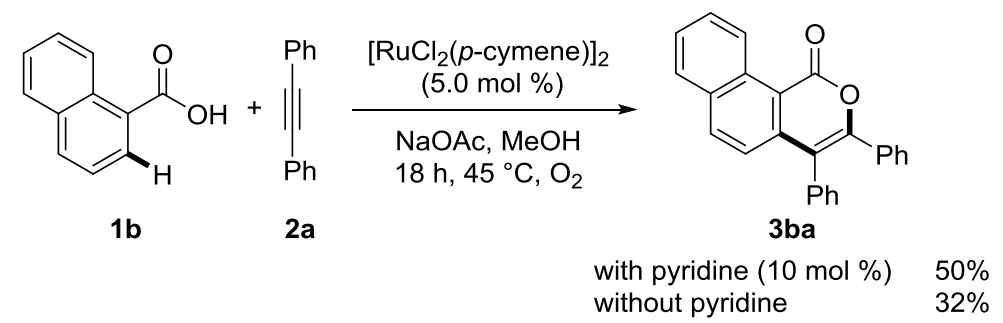

Scheme 68. Ligand effect in the oxidative alkyne annulation of challenging substrate $\mathbf{1 b}$.

The effect of pyridine as additional ligand is only observable for low yielding substrates. Furthermore, the stoichiometry of the ligand to ruthenium is extremely important. In case of an excess of pyridine an inhibition of the reaction was observed.

\subsubsection{Proposed Catalytic Cycle}

The finally proposed mechanism (Scheme 69) involves the formation of the ruthenium(II) acetate complex 96 and a pre-equilibrium between the benzoic acid 1 and sodium acetate, which leads to the in situ formation of sodium benzoate 87 and acetic acid. The ruthenium(II) acetate complex can react with the sodium benzoate 87 via cycloruthenation to yield compound 89 and another equivalent of acetic acid. Kinetic isotope effect (KIE) studies performed by C. Kornhaa $\beta^{[109]}$ revealed this step to be turnover limiting, the ruthenation presumably proceeds isohypsic via an acetate assisted CMD or AMLA ${ }^{[4 a]}$ type process. It is followed by coordination of the alkyne $\mathbf{2}$ and its insertion into the metal-carbon bond yielding the seven-membered ring $\mathbf{9 4}$, which was detected by ESI-MS spectrometry. The ruthenacycle very quickly undergoes reductive elimination to form the ruthenium(0) sandwich complex $\mathbf{9 1}$, which can then be oxidized by molecular oxygen. This oxidation requires the previously formed acetic acid and releases the isocoumarin $\mathbf{3}$, water and the ruthenium(II) acetate complex 96. 


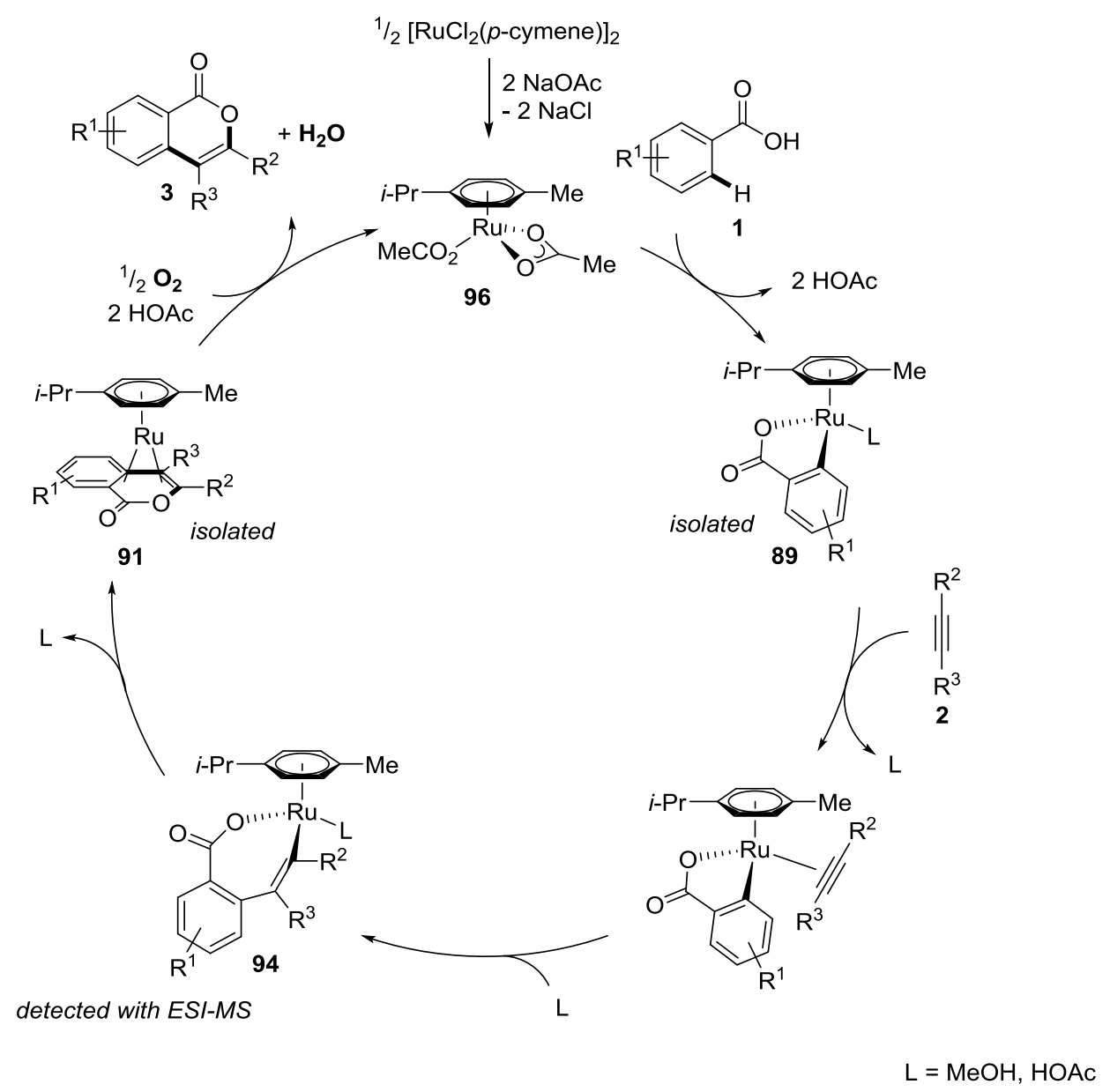

Scheme 69. Proposed catalytic of the ruthenium-catalyzed oxidative alkyne annulation.

\subsubsection{Oxidative Acrylate Annulation}

The aerobic $\mathrm{C}-\mathrm{H}$ functionalization was not limited to alkynes, but also enabled the annulation of benzoic acids 1 with acrylates 4 . The optimization of the reaction conditions was performed by $A$. Bechtoldt and C. Kornhaaß (Scheme 70). ${ }^{[110]}$
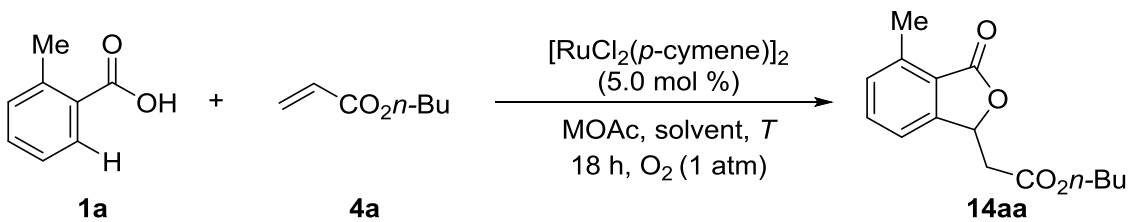

Conditions A: 1a (2.0 mmol), $4 a(1.0 \mathrm{mmol}), \mathrm{CsOAc}(1.0 \mathrm{mmol}), \mathrm{MeOH}(3.0 \mathrm{~mL}), 60^{\circ} \mathrm{C}$. Conditions B: $1 \mathrm{a}(1.0 \mathrm{mmol}), 4 \mathrm{a}(1.5 \mathrm{mmol}), \mathrm{KOAC}(1.1 \mathrm{mmol}), n-\mathrm{BuOH}(3.0 \mathrm{~mL}), 80^{\circ} \mathrm{C}$.

Scheme 70. Optimized conditions for the ruthenium-catalyzed phthalide synthesis. ${ }^{[110]}$ 
Studies within the framework of this thesis showed the necessity of the base and the ruthenium catalyst (Table 2, entry 1-2). It was furthermore possible to decrease the reaction temperature to 37 or even $24^{\circ} \mathrm{C}$, albeit with prolonged reaction times (Table 2, entry 3-4). Applying the acrylate $4 \mathrm{a}$ as solvent did not increase the reactivity at $37^{\circ} \mathrm{C}$ (Table 2 , entry 5).

Table 2. Effect of temperature and necessity of base and catalyst for the alkene annulation. ${ }^{[a]}$

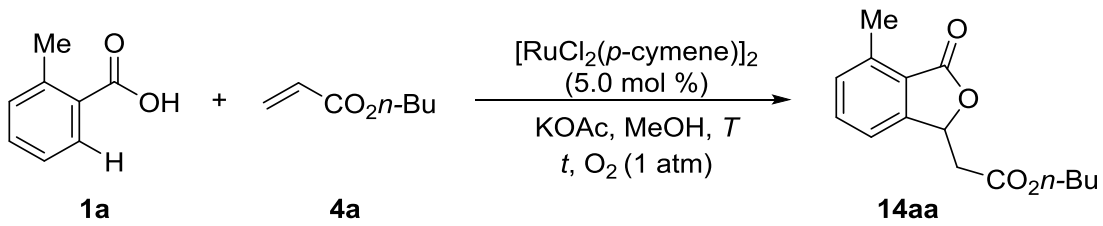

\begin{tabular}{ccccc} 
entry & changes & $\mathrm{T} /{ }^{\circ} \mathrm{C}$ & $\mathrm{t} / \mathrm{h}$ & yield \\
\hline 1 & without KOAc & 60 & 18 & $<5 \%^{\mathrm{b}}$ \\
2 & without [Ru] & 60 & 18 & $<5 \%^{\mathrm{b}}$ \\
3 & --- & 24 & 64 & $53 \%$ \\
4 & --- & 37 & 64 & $82 \%$ \\
5 & Neat, 10 equiv acrylate & 37 & 64 & $38 \%$
\end{tabular}

[a] Reaction conditions: 1a $(1.0 \mathrm{mmol}), 4 a(1.5 \mathrm{mmol}),\left[\mathrm{RuCl}_{2}(p \text {-cymene })\right]_{2}(5.0 \mathrm{~mol} \%)$, $\mathrm{KOAC}$ (1.1 equiv), $\mathrm{MeOH}(3.0 \mathrm{~mL}), \mathrm{O}_{2}$ (1 atm), yield of isolated product. ${ }^{[b]} \mathrm{GC}$ conversion, $n$-dodecane as internal standard.

Some representative examples displaying the scope of the ruthenium-catalyzed aerobic alkene annulation are shown in Scheme 71. Substitutions in all ring positions of the benzoic acid 1 were tolerated as well as functional groups, such as halides.

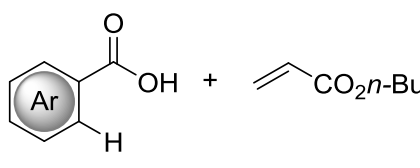

1

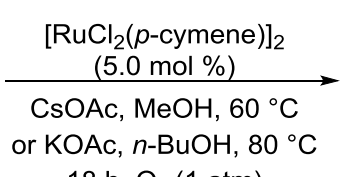

$18 \mathrm{~h}, \mathrm{O}_{2}(1 \mathrm{~atm})$
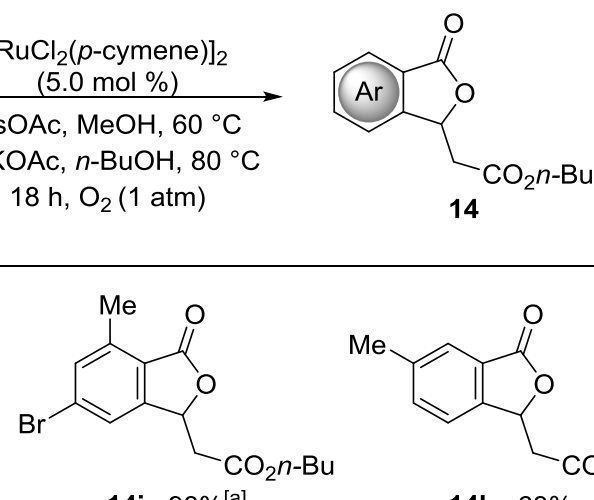

14ja:98\%[a]<smiles>CCOC(=O)CC1OC(=O)c2cc(C)ccc21</smiles>

14ka:63\%

a: Reaction performed by $C$. Kornhaaß

b: Reaction performed by A. Bechtoldt

Scheme 71. Selected examples for the ruthenium(II)-catalyzed acrylate annulation. 


\subsubsection{Mechanistic Investigations of the Oxidation Mode}

Rüping and coworkers ${ }^{[111]}$ proposed that a superoxide anion is the actual in situ produced oxidant in the photoredox-catalyzed alkenylation of phenols. According to their hypothesis the superoxide is formed by the reduction of oxygen by the photoredox catalyst. To check whether this is a likely event in the herein studied oxidation, the standard reaction using potassium superoxide as oxidant under an atmosphere of argon was run. It turned out that the product is formed although in a very low yield (Scheme 72). This indicates that the oxidation during the ruthenium-catalyzed alkene annulations is probably occurring via an alternative route. It cannot be excluded, though, that the low yield is only the outcome of a fast degradation of potassium superoxide at $80^{\circ} \mathrm{C}$ in butanol. During the catalytic reaction $\mathrm{KO}_{2}$ would be formed in situ and would probably be present in only low concentrations and react rapidly with the substrate, potentially giving rise to higher yields.

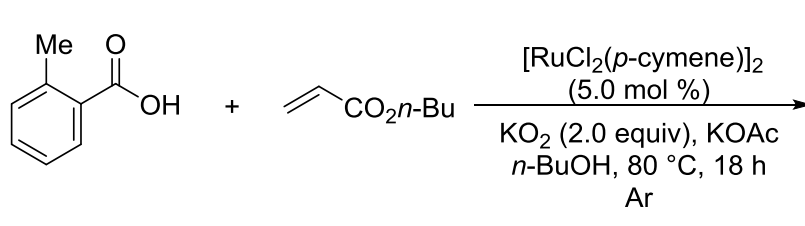

$1 \mathrm{a}$

$4 a$

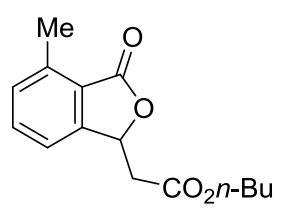

14aa: $13 \%$

Scheme 72. $\mathrm{KO}_{2}$ as oxidant for the ruthenium(II)-catalyzed alkene annulation.

Furthermore, no hydrogen peroxide could be detected in the crude reaction mixture (Scheme 73). This was already the case for the alkyne annulation and could again be caused by the higher efficiency of hydrogen peroxide over oxygen as oxidant or an oxidation pathway excluding the formation of hydrogen peroxide.

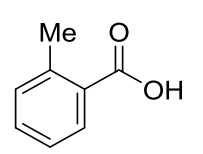

$1 \mathbf{a}$

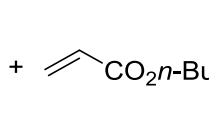

$4 \mathbf{a}$

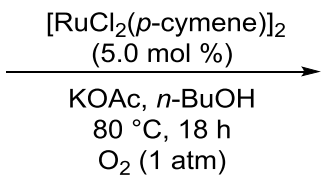

$\mathrm{O}_{2}(1 \mathrm{~atm})$

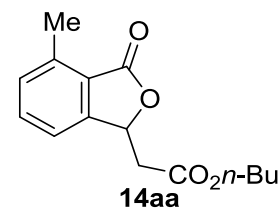

no $\mathrm{H}_{2} \mathrm{O}_{2}$ detectable

Scheme 73. Test for hydrogen peroxide.

The oxygen uptake was measured with a burette filled with oxygen-saturated water. If the reaction is run in $n$-butanol a background oxidation was observed, which can be assigned to the oxidation of $n$ butanol. Therefore, the oxidation of $n$-butanol in the absence of $n$-butyl acrylate under otherwise standard reaction conditions was studied as well. With this correction curve in hand reliable values were obtained for the oxygen uptake (Figure 14). 


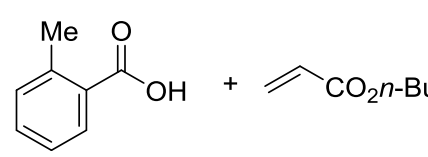

1a

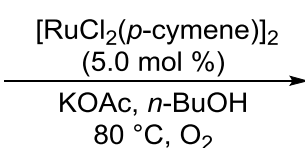

$80^{\circ} \mathrm{C}, \mathrm{O}_{2}$

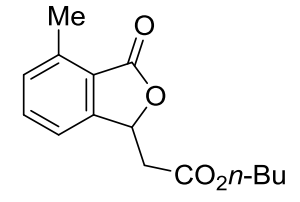

$14 a a$

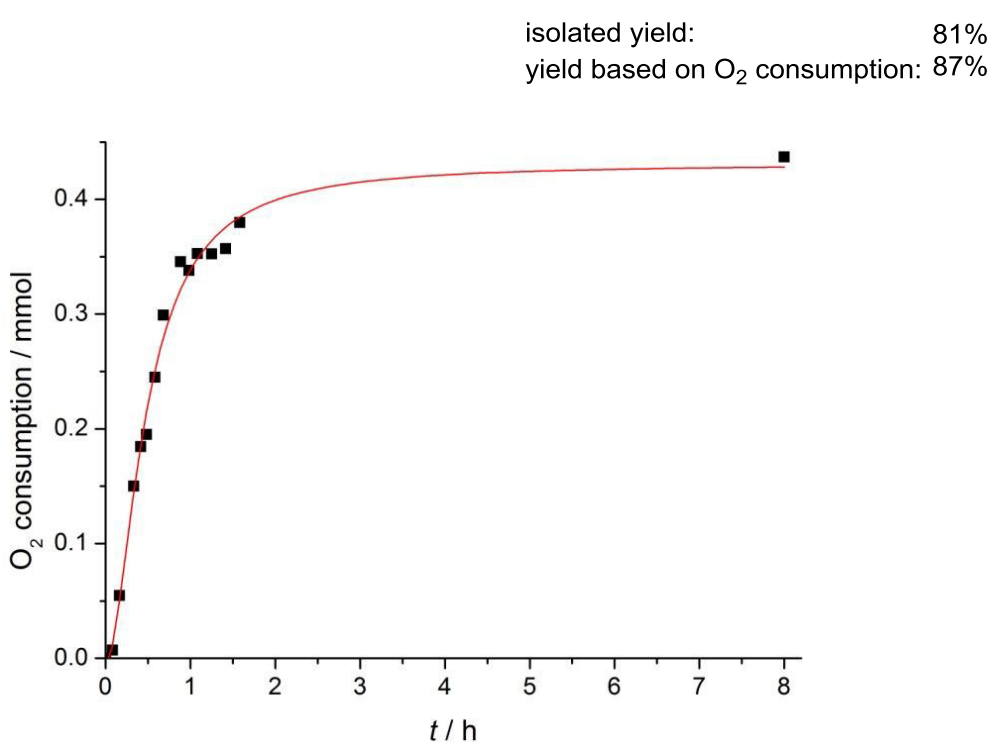

Figure 14. $\mathrm{O}_{2}$ uptake during the ruthenium(II)-catalyzed alkene annulation in butanol.

To rule out errors caused by the oxidation of the solvent, the reaction was also performed neat for further measurements (Figure 15).

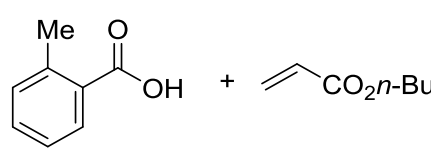

$1 \mathrm{a}$

4a

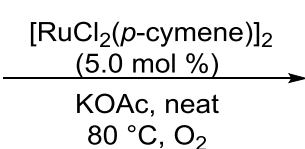

$80^{\circ} \mathrm{C}, \mathrm{O}_{2}$

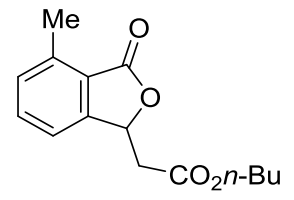

$14 a a$

$$
\begin{array}{lr}
\text { isolated yield: } & 83 \% \\
\text { yield based on } \mathrm{O}_{2} \text { consumption: } 92 \%
\end{array}
$$

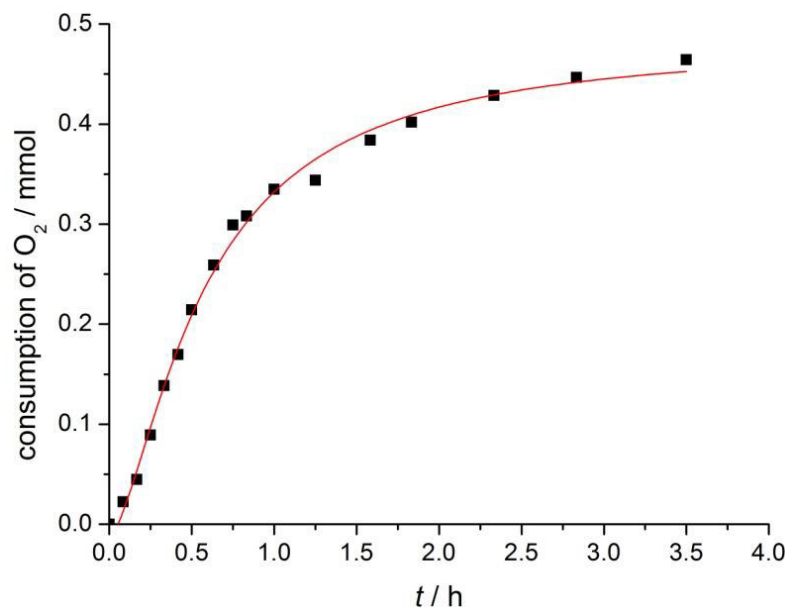

Figure 15. $\mathrm{O}_{2}$ uptake during the ruthenium(II)-catalyzed alkene annulation under neat conditions. 
The studies showed an oxygen-coupled turnover, hence strengthened the hypothesis of an aerobic oxidation process. It furthermore showed the high efficiency of the catalyst with over $90 \%$ conversion within only four hours reaction time.

\subsubsection{Isotope Studies}

Further studies focused on the H/D exchange during the reaction. At the outset of these studies $A$. Bechtoldt ${ }^{[112]}$ could show that no deuterium exchange on the acrylate occurred with $\mathrm{CD}_{3} \mathrm{OD}$ as solvent in the absence of benzoic acid.

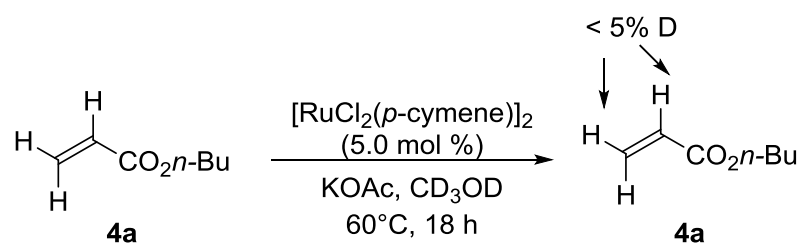

Scheme 74. Control reaction for H/D exchange on acrylate $4 a^{[112]}$

Next, the deuterium exchange in the reaction was investigated, revealing a significant deuterium incorporation in the ortho-position of the starting material $\mathbf{1 h}$ as well as the product $\mathbf{1 4 h a}$ (Scheme 75). In addition small amounts of the alkenylated phthalide 5ha were formed. Deuterium incorporation was furthermore observed in the side chain of $\mathbf{1 4 a a}$ as well as $\mathbf{5 h a}$.<smiles>O=C(O)c1ccccc1</smiles>

$1 \mathrm{~h}$

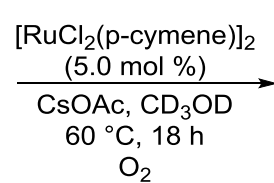

4a

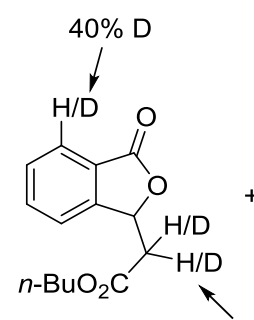

14ha: $64 \% 43 \%$ D

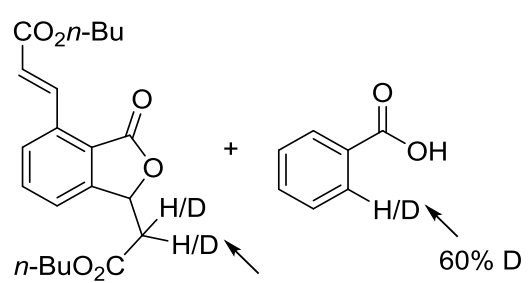

5ha: $19 \% \quad 35 \%$ D $\quad$ 1h: $6 \%$

Scheme 75. $\mathrm{H} / \mathrm{D}$ exchange under standard conditions with $\mathrm{CD}_{3} \mathrm{OD}$.

To check whether the deuterium incorporation in the side chain is due to a reversible oxa-Michael addition, the non-deuterated product $\mathbf{1 4 h a}$ of the reaction was submitted to the reaction conditions using $\mathrm{CD}_{3} \mathrm{OD}$ as solvent and deuterium source (Scheme 76 ). No deuterium incorporation was observed, thus the second alkene addition must be caused by an irreversible $\mathrm{C}-\mathrm{H}$ activation directed 
by the lactone. This exemplifies the potential of esters to function as directing group in this chemistry, albeit first studies with aromatic esters only led to minimal product formation.

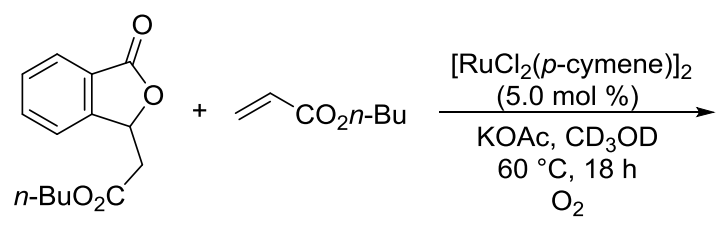

14ha

$4 a$

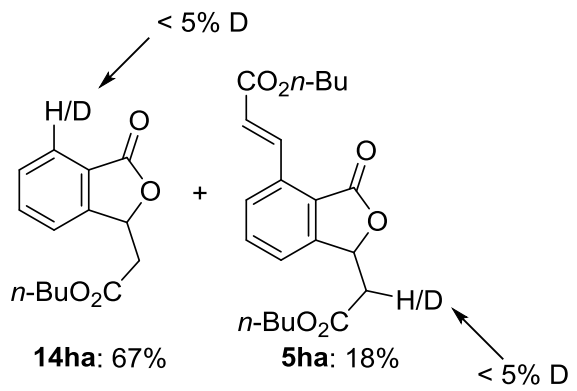

Scheme 76. Attempted H/D scrambling of phthalide 14ha under the reaction conditions.

Toluic acid (1a) was reacted with acrylate $4 \mathrm{a}$ in the presence of phthalide 14 ha (Scheme 77). No H/D scrambling on the phthalide 14ha was observed, while phthalide 14aa showed the expected deuterium incorporation in the side chain. The alkenylated phthalide 5ha was only formed in trace amounts and the $H / D$ exchange was not determinable. This confirms the assumption that the second alkene addition has to be caused by an irreversible $\mathrm{C}-\mathrm{H}$ activation.
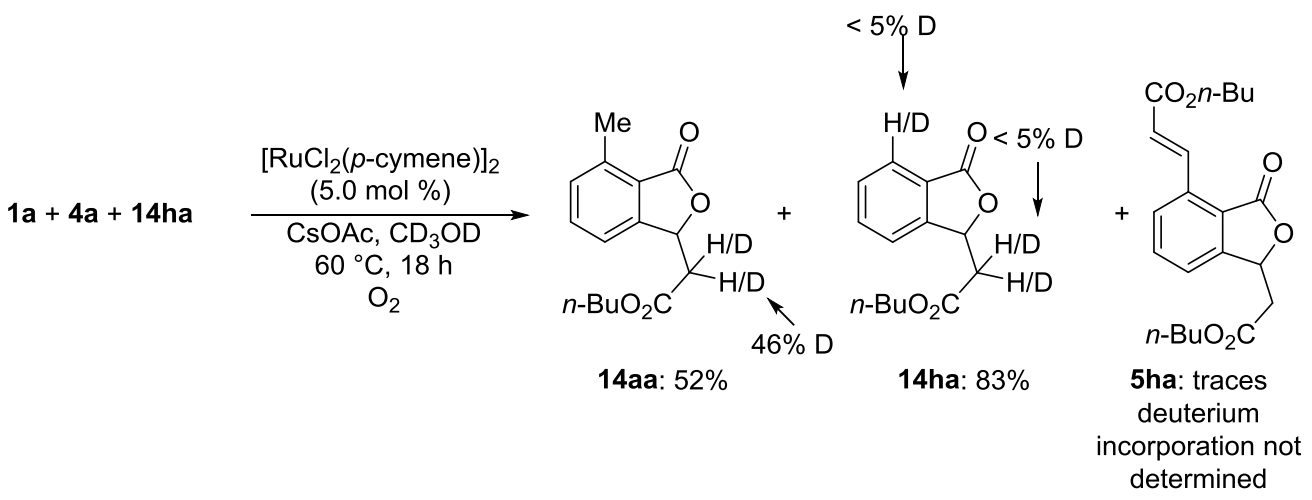

Scheme 77. Deuterium incorporation with phthalide 14 ha as additive.

In order to gain deeper knowledge on the turnover limiting step of the reaction, the kinetic isotope effect was determined by two separate reactions with benzoic acid (1) and deuterated benzoic acid $\left(\left[D_{5}\right]-\mathbf{1}\right)$, respectively (Figure 16$)$. 
<smiles>CC(=O)c1ccccc1</smiles>

$1 \mathrm{~h}$<smiles>O=C(O)c1ccc(Br)cc1</smiles>

$\left[D_{5}\right]-1 h$
$\left[\operatorname{RuCl}_{2}(p \text {-cymene })\right]_{2}$ $(5.0 \mathrm{~mol} \%)$ $\mathrm{KOAc}, n-\mathrm{BuOH}$ $80^{\circ} \mathrm{C}, \mathrm{O}_{2}$

$4 a$<smiles>C=CC(=O)OCC</smiles>

$4 a$<smiles>C[18OH]</smiles>

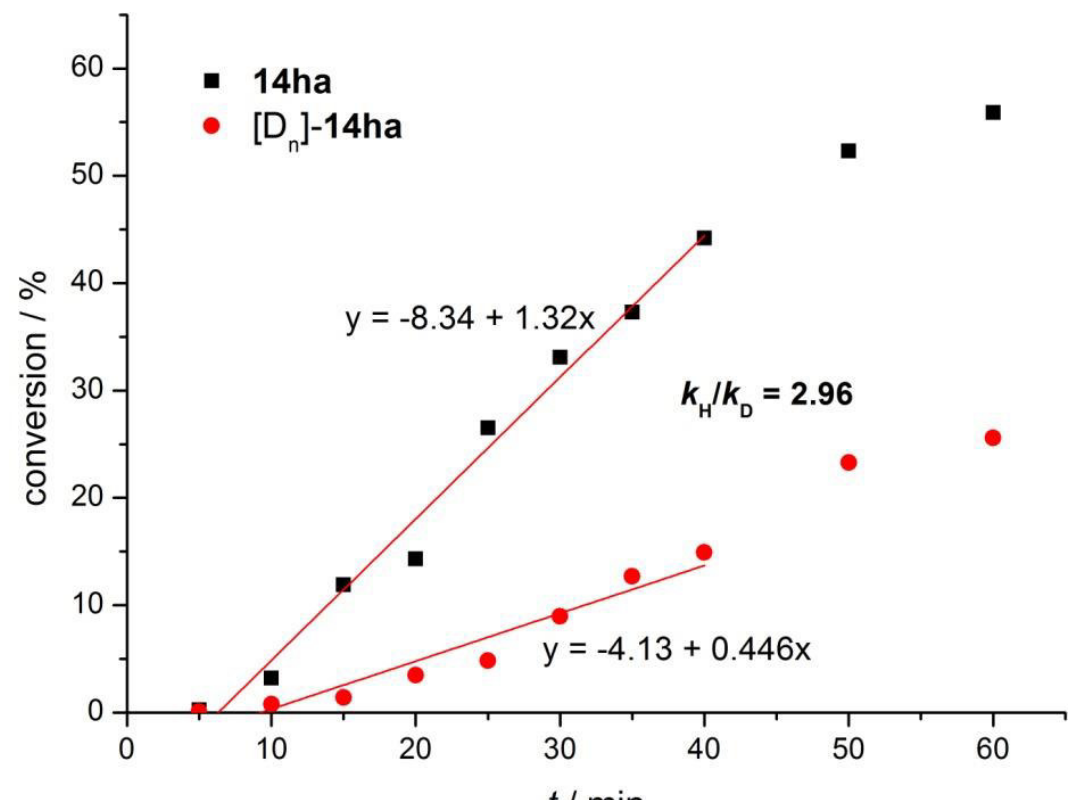

Figure 16. Kinetic isotope effect of the oxidative annulation of benzoic acid (1) with $n$-butyl acrylate (4a).

The KIE of $k_{\mathrm{H}} / k_{\mathrm{D}} \approx 3$ indicates that the cycloruthenation is kinetically relevant. In contrast to the alkyne annulation of benzoic acids, where an analogous cycloruthenation step occurs, H/D scrambling was observed and also higher reaction temperatures were required. Hence, it is more likely that the turnover determining step happens after the cycloruthenation and the concentration of the five-membered ruthenacycle $\mathbf{8 9}$ affects the rate of the turnover determining step.

\subsubsection{Synthesis of Reaction Intermediates}

To obtain deeper knowledge in the reaction mechanism stoichiometric experiments to isolate reaction intermediates were performed. At the beginning the equimolar reaction of all starting materials including $\left[\mathrm{RuCl}_{2}(p \text {-cymene })\right]_{2}$ in the absence of oxygen was investigated. 

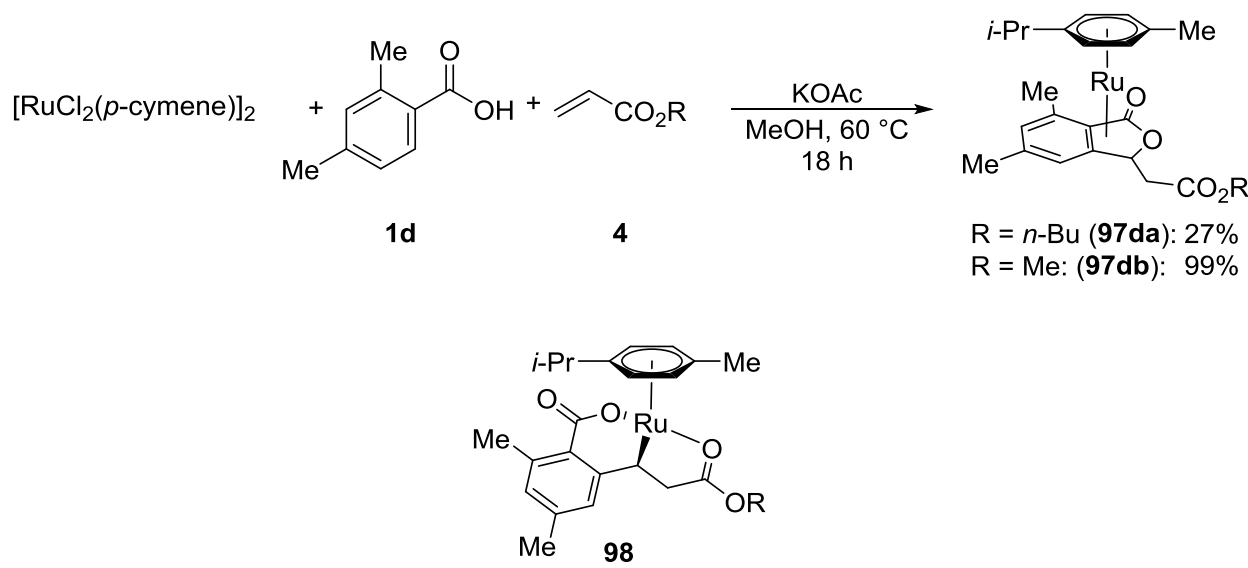

alternative structure of the obtained product

Scheme 78. Stoichiometric Reaction of $\left[\mathrm{RuCl}_{2}(p \text {-cymene })\right]_{2}$, benzoic acid $\mathbf{1 d}$ and acrylate $\mathbf{4}$.

Detailed NMR studies showed that the product is most likely the sandwich complex 987 . It cannot be excluded that the structure is not the ruthenium(II) six-membered ruthenacycle $\mathbf{9 8}$, as both species have the same mass and no suitable crystals for single crystal analysis could be obtained. The carbon NMR gives hints for the formation of such a sandwich complex, though, as highfield shifted quaternary carbon signals are observed (Figure 17) as before for the sandwich complex 91 (compare Figure 8). Furthermore, the resonance of one proton from para-cymene is highfield shifted due to increased electron density (Figure 17), typical for the formation of a ruthenium(0) sandwich species.

กิ

$$
\text { సิำ }
$$

ดे ดั
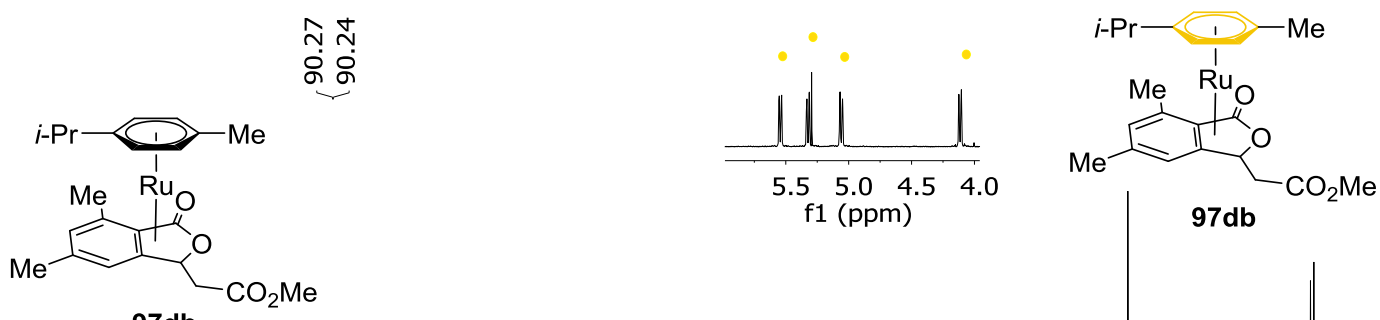

$97 \mathrm{db}$
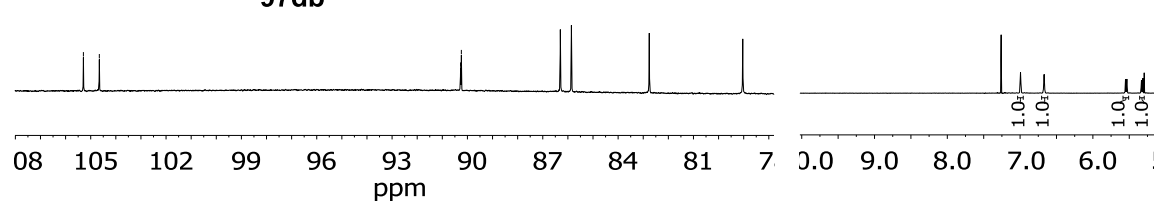

Figure 17. ${ }^{13} \mathrm{C}$ and ${ }^{1} \mathrm{H}$ NMR spectra of the complex $\mathbf{9 7 d b}$.

To study the insertion of the alkene the reaction of $89 \mathrm{da}$ with methyl acrylate was followed by ${ }^{1} \mathrm{H}$ NMR (Figure 18), which unraveled an intermediate to be formed during the reaction. The 
intermediate is most likely the seven-membered ruthenacycle $\mathbf{9 9} \mathbf{d b}$, an isolation of the pure compound was not possible.
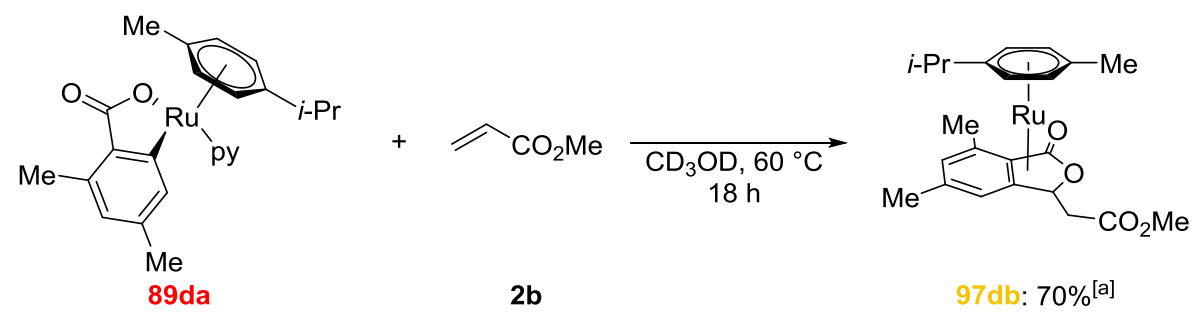

[a] NMR-yield using 1,3,5-trimethoxybenzene as internal standard.
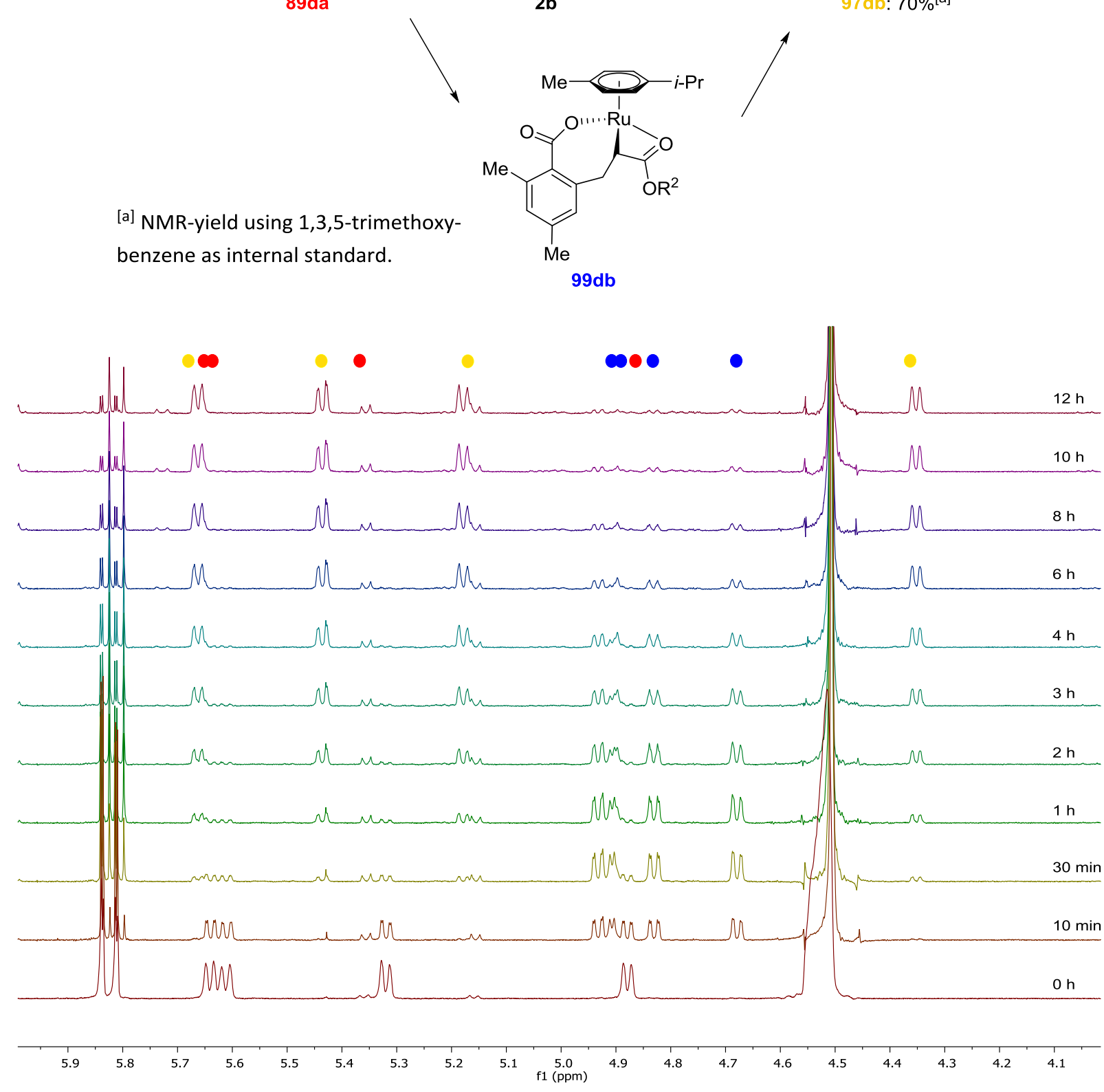

Figure 18. NMR study of the formation of the alkene insertion onto $89 \mathrm{da}$. 
Treatment of complex 97da with oxygen under acidic conditions resulted in the formation of phthalide 14da, analogous to the oxidation of ruthenium(0) isocoumarin sandwich complex 91ba (Scheme 60).

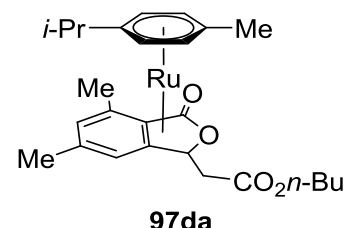

97da

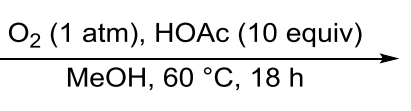

$\mathrm{MeOH}, 60^{\circ} \mathrm{C}, 18 \mathrm{~h} \longrightarrow$

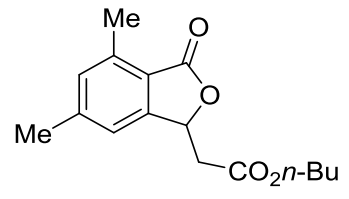

14da

$62 \%$

Scheme 79. Oxidation with release of phthalide $14 \mathrm{da}$.

Analysis of the sandwich complex by CV studies clearly showed no reduction but one oxidation process, thus confirming the isolated complex to be the ruthenium(0) species. Interestingly the addition of acetic acid did not have a significant influence of the oxidation potential (Figure 15).

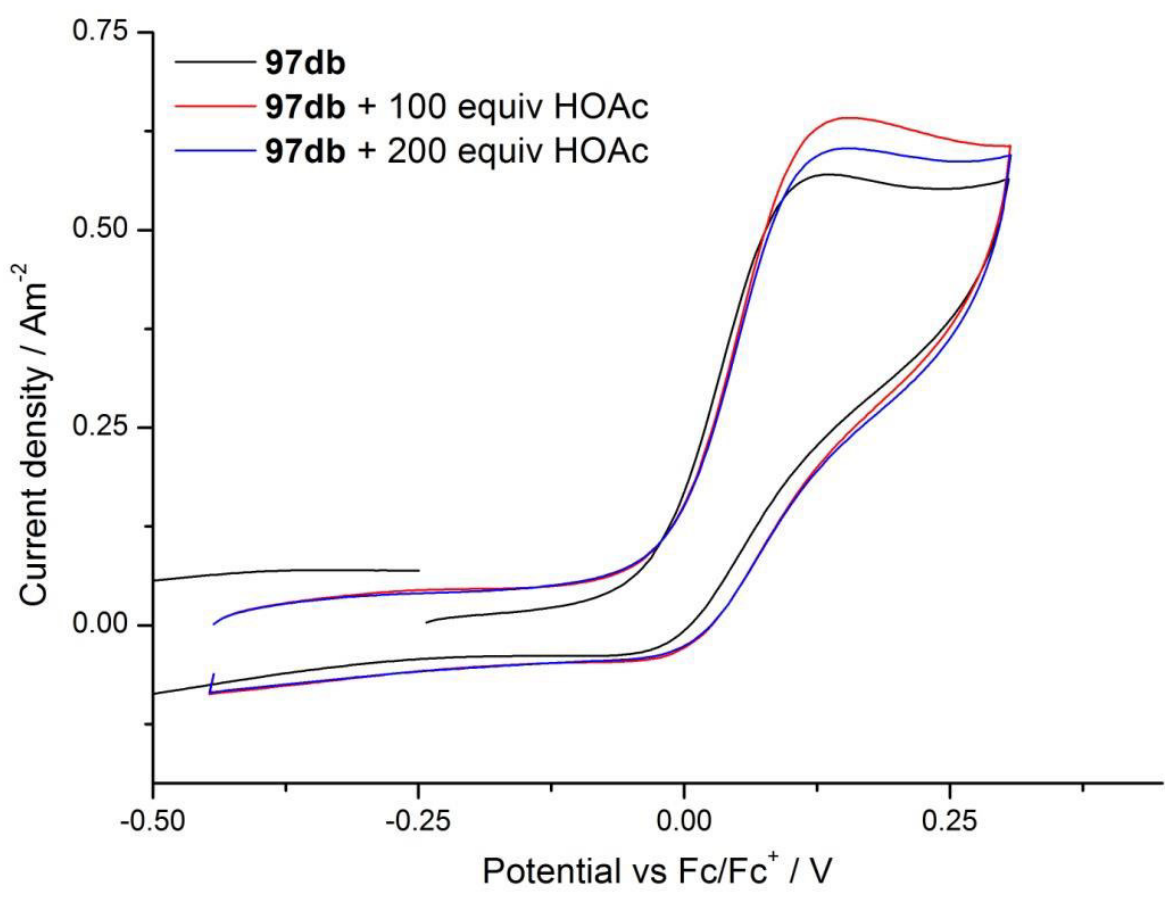

Figure 19. Cyclic voltammogramm of $97 \mathrm{db}$.

\subsubsection{Proposed Catalytic Cycle}

Based on the herein presented mechanistic studies a plausible catalytic cycle is proposed (Scheme 80). A kinetically relevant, isohypsic cycloruthenation with ruthenium(II) bisacetate complex 96 furnishes ruthena(II)cycle 89, along with two equivalents of acetic acid (Scheme 80). Thereafter, 
alkene coordination and migratory insertion generates the 7-membered ruthena(II) cycle 99, whose existence is strongly indicated by the NMR studies of the alkene insertion. Intermediate $\mathbf{9 9}$ probably rearranges to the 6-membered ruthenacycle 98 , the observed deuterium incorporation in the side chain suggested this step to happen via a $\beta$-hydride elimination. Reductive elimination yields the ruthenium(0) sandwich complex $\mathbf{9 7}$, which is supposed to be structurally similar to the sandwich complexes 91 derived from alkynes (see chapter 3.1.1.2). Finally, reoxidation by molecular oxygen in the presence of previously formed acetic acid releases the phthalides $\mathbf{1 4}$ and regenerates the ruthenium(II) acetate complex 96 . The ruthenium(0) oxidation possibly occurs by a single electron transfer process producing a peroxo ruthenium species which further reacts to the catalytically active ruthenium(II) bisacetate $96 .^{[107]}$ In this step, environmentally-benign $\mathrm{H}_{2} \mathrm{O}$ is formed as the sole stoichiometric by-product.

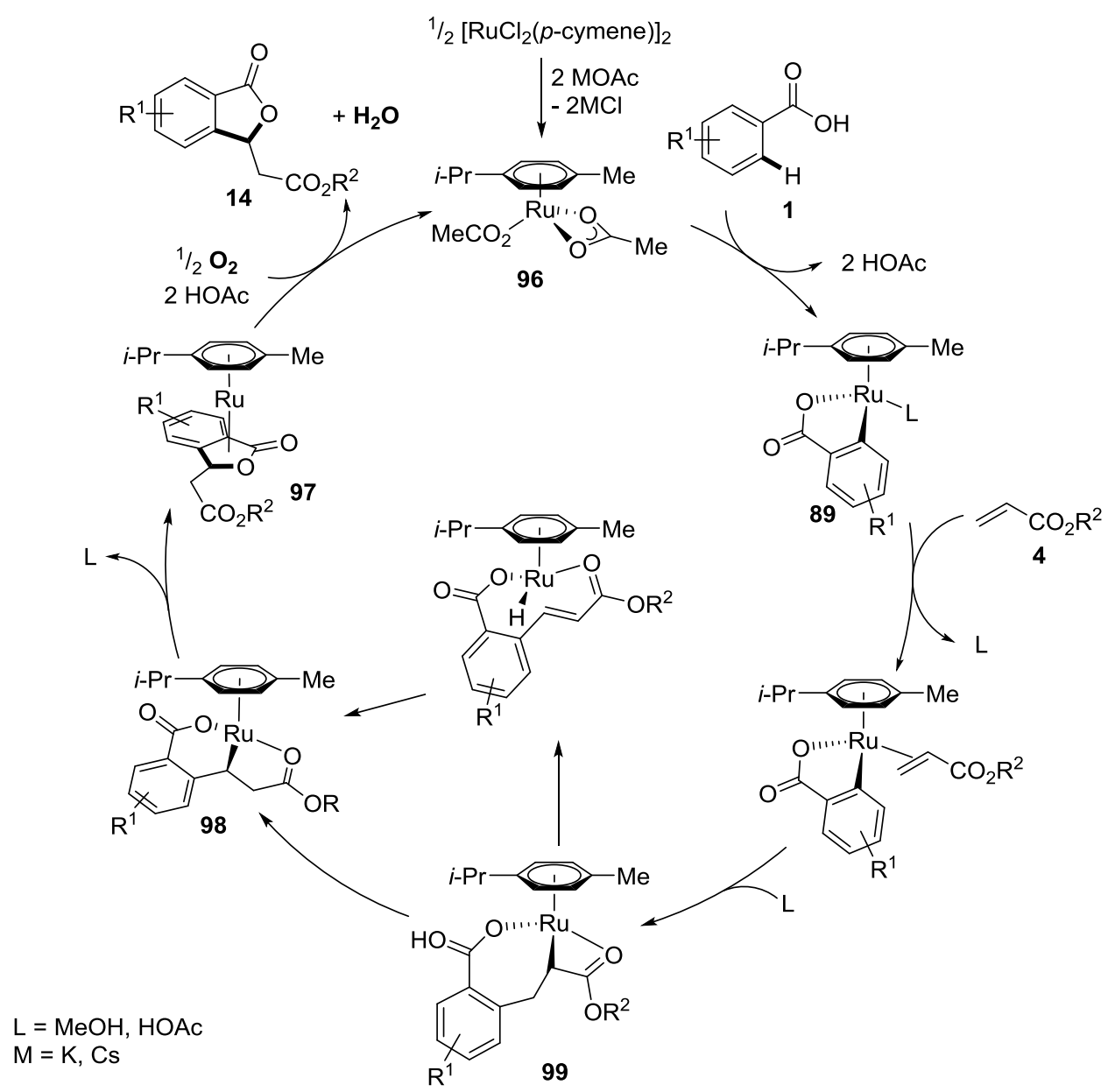

Scheme 80 . Proposed catalytic cycle for the oxidative ruthenium-catalyzed phthalide synthesis. 


\subsection{C-H Arylations Catalyzed by Single-Component Phosphinous Acid Ruthenium(II) Catalysts}

The transition metal-catalyzed direct arylation offers a green alternative for traditional cross-coupling reactions. Instead of organometallic nucleophiles simple arenes can be applied in the reaction. Thus, pre-functionalization steps are not required. Even though huge progress was achieved using ruthenium-catalyzed systems with carboxylate assistance, there is still a strong demand for more efficient catalysts. ${ }^{[3 e, 3 i, 3 p, 4 a, 113]}$

\subsubsection{Catalyst Design}

As shown previously by Ackermann ${ }^{[29]}$ not only carboxylates but also secondary phosphine oxides (SPOs) are viable additives in the direct arylation of phenylpyridines. Indeed, bis(1-adamantyl) phosphine oxide gave comparable yields to the adamantyl carboxylic acid. Encouraged by this early findings and also the beneficial ligand effect, which was achieved in palladium-catalyzed $\alpha$-arylation and cross-coupling reactions, ${ }^{[114]}$ we studied the effect of SPOs 100 in ruthenium-catalyzed C-H arylations with different directing groups.

As at that time no detailed mechanistic studies about the influence of SPOs in ruthenium-catalyzed $\mathrm{C}-\mathrm{H}$ activation reactions had been published, the first step was to isolate the well-defined complexes

84.

Most commonly the complexes are synthesized in $\mathrm{CH}_{2} \mathrm{Cl}_{2}{ }^{[115]}$ or tetrahydrofuran, ${ }^{[116]}$ one patent also claimed the synthesis in toluene. ${ }^{[117]}$ These conditions led to relatively low yields in case of alkyl-aryl phosphine oxide 100a (Scheme 81).

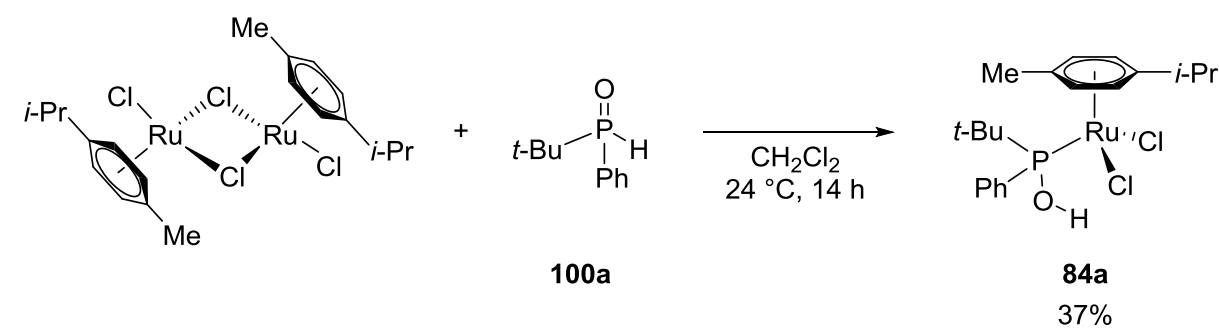

Scheme 81 . Synthesis of $84 a$ according to a literature procedure. ${ }^{[115 b]}$

Changing the solvent to hexane not only led to highly improved yields (Scheme 82), but also simplified the workup procedure, as the products precipitated from the solution and excess of SPO could be washed out with hexane. 


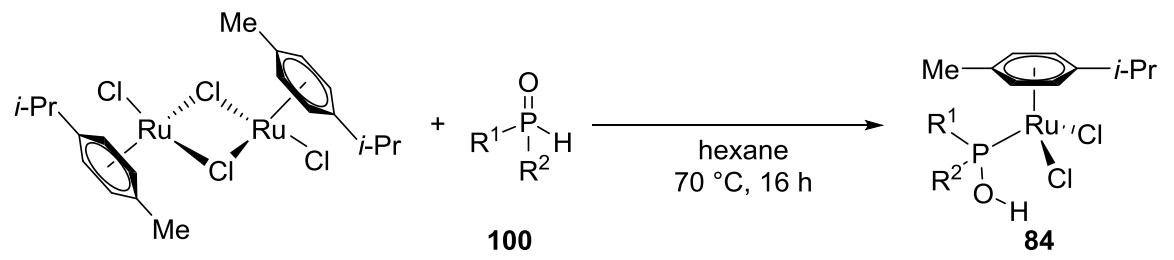

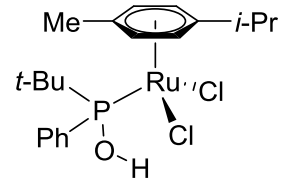

84a: $97 \%$

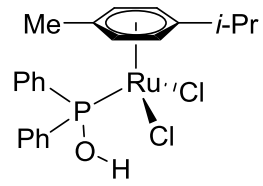

84d: $97 \%[a]$

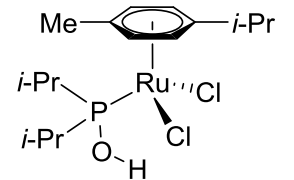

84b: $99 \%$

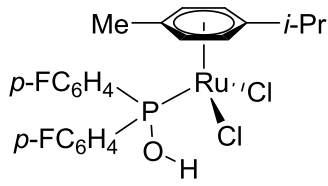

84e: $97 \%$ [a]

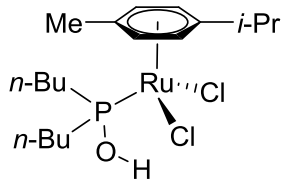

84c: $98 \%$

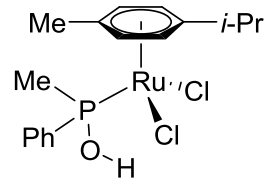

84f: $95 \%$ [a]

[a] Synthesized by T. Meyer

Scheme 82. Improved synthesis of phosphinous acid ruthenium(II) catalysts 84 .

The synthesis of complexes with sterically highly demanding tert-butyl $(\mathbf{1 0 0 g})$ and adamantyl (100h) substituted ligands was not possible. Also harsher reaction conditions could thus far not generate significant amounts of the desired products (Table 3).

Table 3. Attempts to synthesize sterically demanding ruthenium(II) phosphinous acid complexes. ${ }^{[a]}$

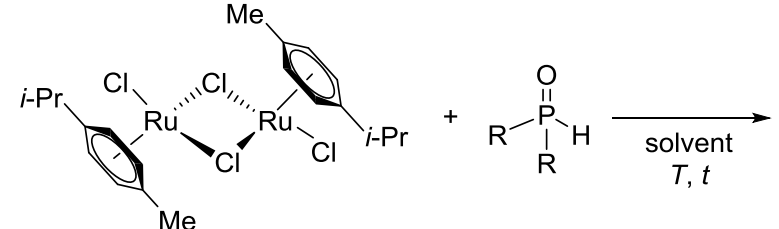

100<smiles>[R][PH]([R])(O)C1CC2CCC(C(C)C)C1[R]2(Cl)Cl</smiles>

84

\begin{tabular}{cccccc} 
entry & $\mathrm{R}$ & solvent & $T /{ }^{\circ} \mathrm{C}$ & $\mathrm{t} / \mathrm{h}$ & yield \\
\hline 1 & $t-\mathrm{Bu}$ & hexane & 70 & 16 & --- \\
2 & $t-\mathrm{Bu}$ & $\mathrm{CH}_{2} \mathrm{Cl}_{2}$ & 23 & 24 & --- \\
3 & $t-\mathrm{Bu}$ & $\mathrm{MeCN}$ & 23 & 24 & --- \\
4 & $t-\mathrm{Bu}$ & toluene & 120 & 20 & traces \\
5 & $1-\mathrm{Ad}$ & hexane & 70 & 16 & --- \\
6 & $1-\mathrm{Ad}$ & $\mathrm{CH}_{2} \mathrm{Cl}_{2}$ & 23 & 24 & --- \\
7 & $1-\mathrm{Ad}$ & $\mathrm{MeCN}^{2}$ & 23 & 24 & --- \\
8 & $1-\mathrm{Ad}$ & $\mathrm{CH}_{2} \mathrm{Cl}_{2} / \mathrm{MeCN} \mathrm{1:1}$ & 23 & 24 & --- \\
\hline
\end{tabular}


Attempts to attach two phosphorus ligands on the ruthenium, comparable to the work from Kläui, ${ }^{[118]}$ were not successful. Apparently, already the switch from $\eta^{6}$-hexamethylbenzene to $\eta^{6}$-paracymene hampers the reaction (Scheme 83). The addition of a base such as trimethylamine or potassium carbonate to trap the in situ formed hydrogen chloride and thus shift the equilibrium to the product side only delivered complex mixtures of different phosphorus species.

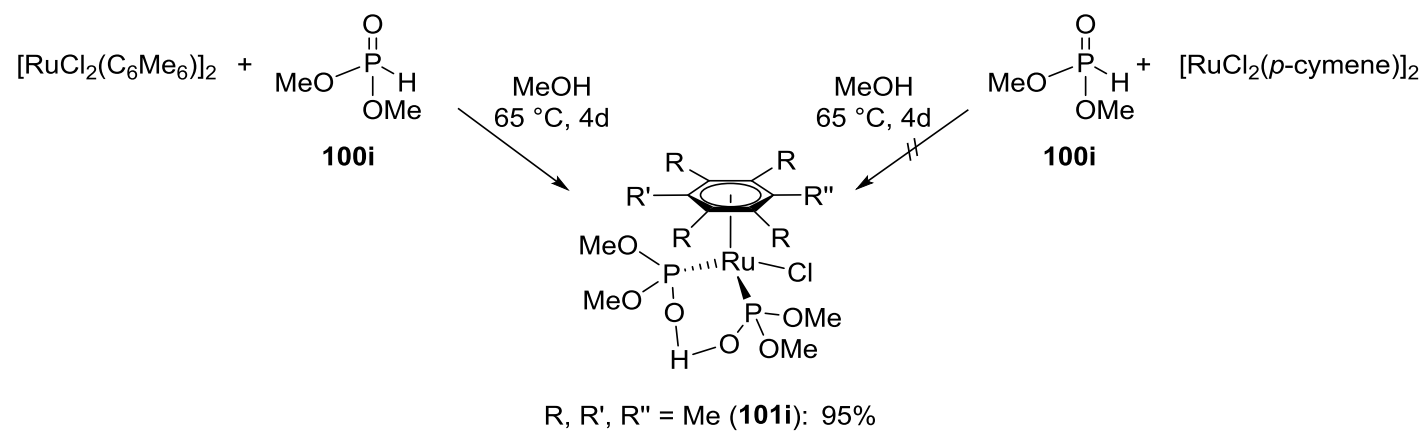

Scheme 83. Kläui ${ }^{[118]}$ (left) and own attempted synthesis (right) of complex 101.

\subsubsection{Optimization Studies}

The optimization studies were initiated using oxazoline and tetrazole as the directing groups. For sake of simplicity, initial tests were performed by in situ formation of the phosphinous acid ruthenium(II) catalyst 84. It turned out that in case of oxazolines aliphatic substituents on the phosphorus atom were superior to their aromatic counterparts (Scheme 84). Especially $n$-butyl substituted SPO 100c proved highly efficient. 
Results and Discussion<smiles>Cc1ccccc1C1=NCCO1</smiles>

$102 a$

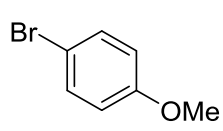

$25 a$

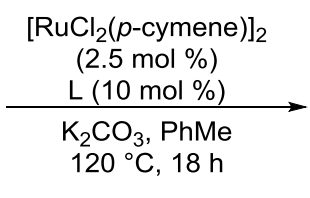

$120^{\circ} \mathrm{C}, 18 \mathrm{~h}$

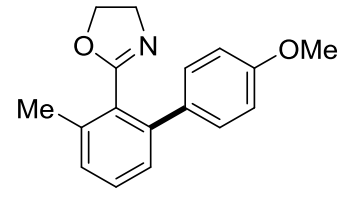

103aa<smiles>CCCCCCCCCC(C)(C)[Mg][PH](=O)CCCC</smiles><smiles>CC(C)P(=O)([In])C(F)(F)I</smiles><smiles>O=[PH](C1CCCCC1)C1CCCCC1</smiles>

Yield of 103aa: $\quad 98 \%$

$84 \%$

$72 \%$

$54 \%$<smiles>CC(C)(C)[PH](=O)c1ccccc1</smiles>

Yield of 103aa: $51 \%$<smiles>C[PH](=O)c1ccccc1</smiles>

$36 \%$<smiles>O=P(c1ccccc1)(c1ccc(F)cc1)c1ccc(F)cc1</smiles>

$48 \%$<smiles>O=[PH]([O-])([O-])[O-]</smiles>

$42 \%$<smiles>O=[PH](c1ccccc1)c1ccccc1</smiles>

$45 \%$

[a] Reaction conditions: $102 \mathrm{a}(0.50 \mathrm{mmol}), 25 \mathrm{a}(0.75 \mathrm{mmol}),\left[\mathrm{RuCl}_{2}(p \text {-cymene })\right]_{2}(5.0 \mathrm{~mol} \%)$, ligand $(10 \mathrm{~mol} \%), \mathrm{K}_{2} \mathrm{CO}_{3}(1.0 \mathrm{mmol}), \mathrm{PhMe}(0.25 \mathrm{M}), 120^{\circ} \mathrm{C}, 18 \mathrm{~h}$. Yields of isolated product $103 \mathrm{aa}$.

Scheme 84. Ligand screening for the $\mathrm{C}-\mathrm{H}$ arylation of phenyl oxazoline $102 \mathrm{a} .{ }^{[\mathrm{a}]}$

Triazole as well as tetrazole directing groups showed a different trend. Hence, in both cases the mixed alkyl-aryl substituted SPO 100a proved optimal (Scheme 85). 
a)

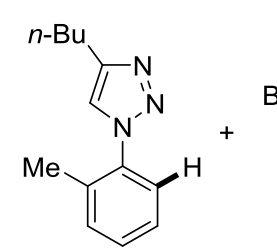

24a

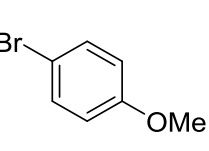

$25 a$

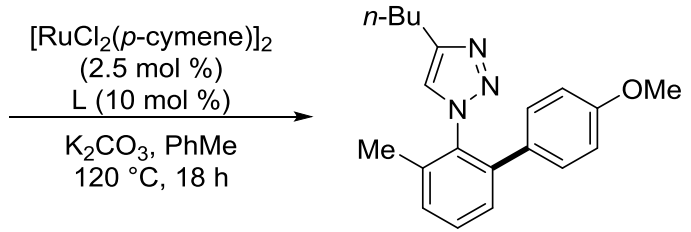

$26 a$

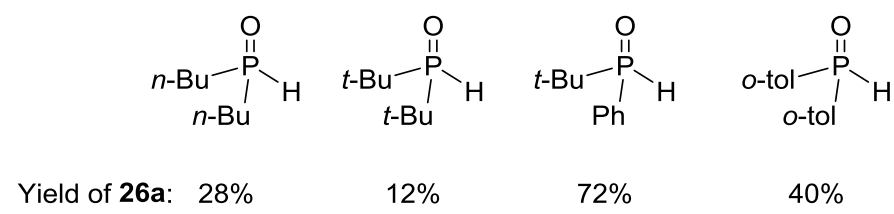

b)<smiles></smiles>

$104 a$<smiles>COc1ccc(Br)cc1</smiles>

25

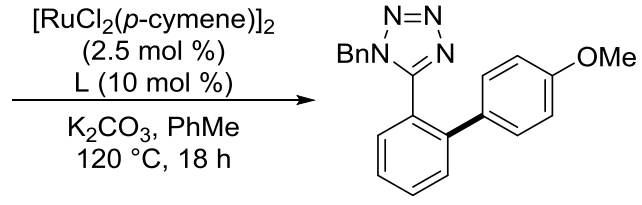

105aa

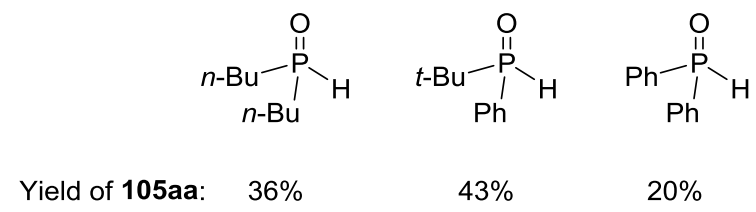

${ }^{[a]}$ Reaction conditions: $24 a$ or $104 a(0.50 \mathrm{mmol}), 25 a(0.75 \mathrm{mmol}),\left[\mathrm{RuCl}_{2}\left(p-\mathrm{cymene}_{2}\right]_{2}(2.5 \mathrm{~mol} \%)\right.$, ligand $(10 \mathrm{~mol} \%), \mathrm{K}_{2} \mathrm{CO}_{3}(1.0 \mathrm{mmol}), \mathrm{PhMe}(0.25 \mathrm{M}), 120^{\circ} \mathrm{C}, 18 \mathrm{~h}$. Yields of isolated product of $26 \mathrm{a}$ and NMR conversion of 105aa with 1,3,5-trimethoxybenzene as internal standard.

Scheme 85 . Ligand screening for the arylation of triazole $24 a$ and tetrazole $104 a{ }^{[a]}$

Testing the well-defined isolated phosphinous acid ruthenium(II) compounds $\mathbf{8 4}$ confirmed the aforementioned trends. Complex $\mathbf{8 4 c}$ is revealed as the optimal catalyst for the oxazoline-directed ruthenium-catalyzed $\mathrm{C}-\mathrm{H}$ arylation (Table 4 , entry 5). Ruthenium as catalyst is essential for the reaction and significant ligand acceleration is observed for phosphinous acid ligands (Table 4, entries $1,8-9)$.

Table 4. Optimization studies with oxazoline as the directing group. ${ }^{[a]}$<smiles>Cc1cccc([18F])c1C1=NCCO1</smiles>

$102 a$<smiles>COc1ccc(Br)cc1</smiles>

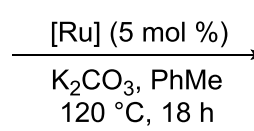
$120^{\circ} \mathrm{C}, 18 \mathrm{~h}$<smiles>COc1ccc(-c2cccc(C)c2C2=NCCO2)cc1</smiles>

103aa 


\begin{tabular}{|c|c|c|}
\hline entry & {$[\mathrm{Ru}]$} & yield / \%[b] \\
\hline 1 & $\mathrm{RuCl}_{3} \cdot \mathrm{H}_{2} \mathrm{O}$ & $<5^{[c, d]}$ \\
\hline 2 & {$\left[\mathrm{RuCl}_{2}\left(\mathrm{Ph}_{2} \mathrm{POH}\right)(p \text {-cymene })\right]_{2}(\mathbf{8 4 d})$} & 47 \\
\hline 3 & $\left[\mathrm{RuCl}_{2}\left(p-\mathrm{FC}_{6} \mathrm{H}_{4}\right)_{2} \mathrm{POH}\right)(p$-cymene $\left.)\right]_{2}(84 \mathrm{e})$ & 48 \\
\hline 4 & {$\left[\mathrm{RuCl}_{2}\left(i-\mathrm{Pr}_{2} \mathrm{POH}\right)(p \text {-cymene })\right]_{2}(\mathbf{8 4 b})$} & 72 \\
\hline 5 & {$\left[\mathrm{RuCl}_{2}\left(n-\mathrm{Bu}_{2} \mathrm{POH}\right)(p \text {-cymene })\right]_{2}(\mathbf{8 4 c})$} & 98 \\
\hline 6 & {$\left[\mathrm{RuCl}_{2}(\mathrm{MePhPOH})(p \text {-cymene })\right]_{2}$ (84f) } & 36 \\
\hline 7 & {$\left[\mathrm{RuCl}_{2}(t-\mathrm{BuPhPOH})(p \text {-cymene })\right]_{2}$ (84a) } & 50 \\
\hline 8 & {$\left[\mathrm{RuCl}_{2}(p \text {-cymene })\right]_{2}$} & 18 \\
\hline 9 & --- & $---[c]$ \\
\hline 10 & $84 c$ & $80 \%{ }^{[\mathrm{d}]}$ \\
\hline
\end{tabular}

[a] Reaction conditions: 102a $(0.5 \mathrm{mmol}), 25 \mathrm{a}(0.75 \mathrm{mmol}),[\mathrm{Ru}](5.0 \mathrm{~mol} \%), \mathrm{K}_{2} \mathrm{CO}_{3}$ $(1.0 \mathrm{mmol}), \mathrm{PhMe}(0.25 \mathrm{M}), 120^{\circ} \mathrm{C}, 18 \mathrm{~h} .{ }^{[\mathrm{b}]}$ Yields of isolated product 103aa. ${ }^{[\mathrm{cc}} \mathrm{n}-\mathrm{Bu}_{2} \mathrm{PHO}$ (5.0 mol \%), no $[\mathrm{Ru}] .{ }^{[\mathrm{dd}}$ At $80^{\circ} \mathrm{C}$.

As observed in the in situ system the catalyst of choice for the tetrazole-directed arylation is $\left[\mathrm{RuCl}_{2}(t-\right.$ BuPhPOH)(p-cymene) $]_{2}$ (84a) (Table 5, entry 7). For the present catalysis it proved highly beneficial to raise the reaction temperature to $140{ }^{\circ} \mathrm{C}$ (entry 8 ). The addition of cocatalytic amounts of an additive such as the pre-ligand 100 a or a potassium phosphate as published by Seki ${ }^{[27 a]}$ changed the ratio towards the mono-arylated product 105aa, albeit in reduced overall yield (entry 9-12), while the addition of an acetate source is shifting the selectivity strongly towards the diarylated product 105aa' (entry 13). Thus, conditions without additives were chosen for the standard conditions.

Table 5. Ligand optimization with tetrazole as directing group. ${ }^{[a]}$<smiles>c1ccc(-c2nnn[nH]2)cc1</smiles>

104a

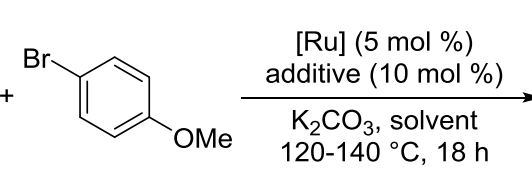

25a<smiles>COCCOC</smiles>

105aa<smiles></smiles>

105aa'

\begin{tabular}{|c|c|c|c|c|c|c|}
\hline entry & {$[\mathrm{Ru}]$} & additive & solvent & $\begin{array}{l}\mathrm{T} / \\
{ }^{\circ} \mathrm{C}\end{array}$ & $\begin{array}{l}\text { yield / } \\
\%^{[\mathrm{b}]}\end{array}$ & $\begin{array}{l}\text { 105aa } \\
: 105 a a '\end{array}$ \\
\hline 1 & {$\left[\mathrm{RuCl}_{3} \cdot \mathrm{H}_{2} \mathrm{O}\right]$} & --- & PhMe & 140 & 3 & $>95: 5$ \\
\hline 2 & $\begin{array}{c}{\left[\mathrm{RuCl}_{2}\left(\mathrm{Ph}_{2} \mathrm{POH}\right)(p-\right.} \\
\text { cymene })]_{2}\end{array}$ & --- & PhMe & 120 & 20 & $>95: 5$ \\
\hline 3 & $\begin{array}{c}{\left[\mathrm{RuCl}_{2}(p-\right.} \\
\left.\left.\mathrm{FC}_{6} \mathrm{H}_{4}\right)_{2} \mathrm{POH}\right)(p-\end{array}$ & --- & PhMe & 120 & 16 & $>95: 5$ \\
\hline
\end{tabular}




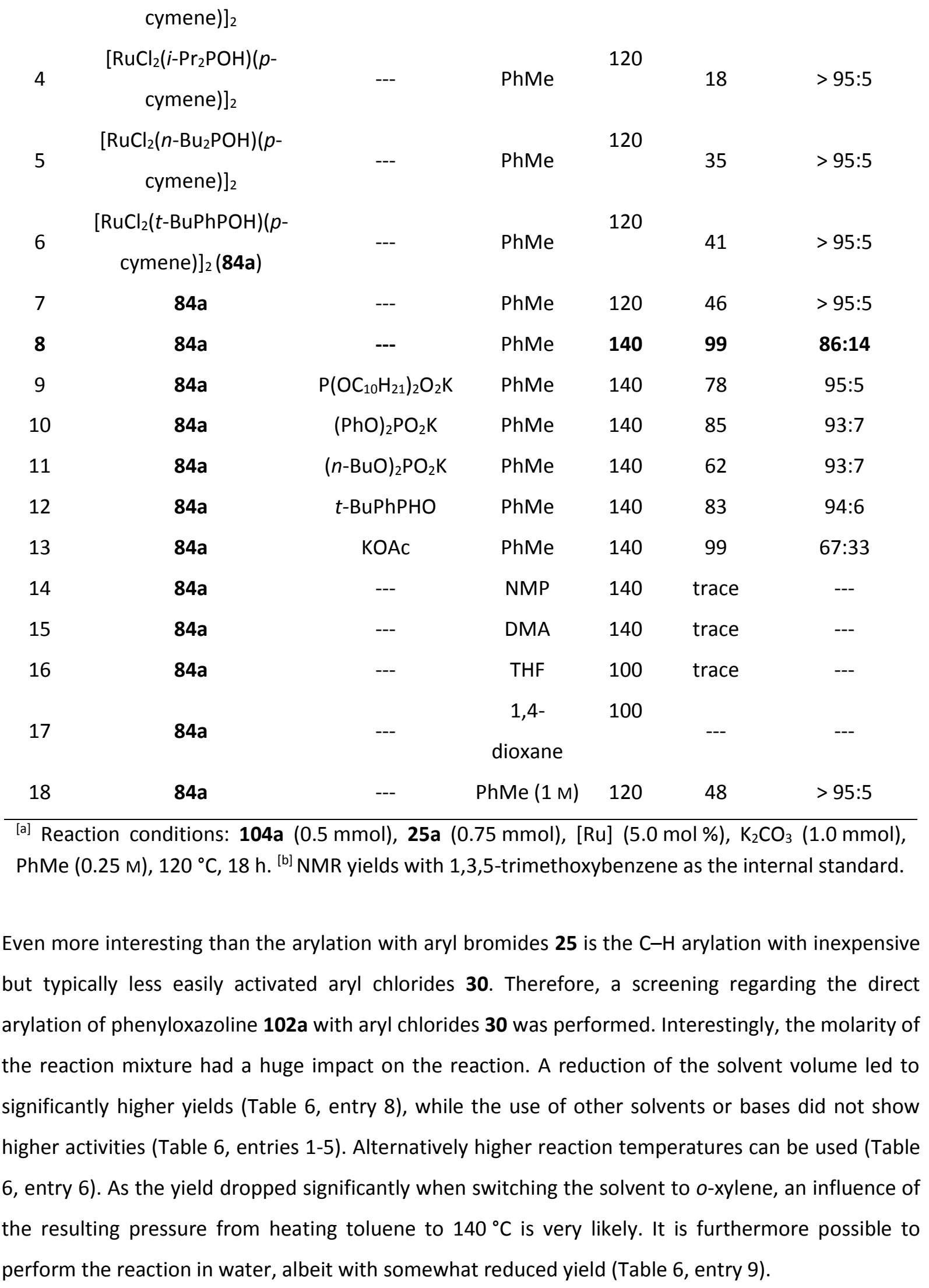


Table 6. Screening of reaction conditions with phenyloxazoline $102 \mathrm{a}$ and aryl chlorides $30{ }^{[a]}$<smiles>Cc1ccccc1C1=NCCO1</smiles>

$102 \mathrm{a}$<smiles>[R]c1ccc(Cl)cc1</smiles>

30

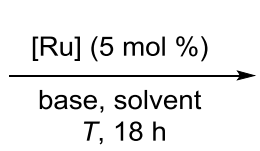

$T, 18 \mathrm{~h}$

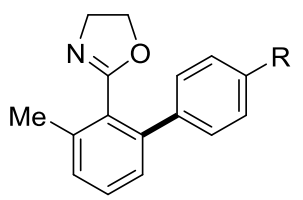

103

\begin{tabular}{|c|c|c|c|c|c|c|}
\hline entry & $\mathrm{R}$ & catalyst & solvent & base & $T /{ }^{\circ} \mathrm{C}$ & yield / \%[b] \\
\hline 1 & Me & $\begin{array}{c}{\left[\mathrm{RuCl}_{2}\left(n-\mathrm{Bu}_{2} \mathrm{POH}\right)(p-\right.} \\
\text { cymene })](84 \mathrm{c})\end{array}$ & PhMe (0.25 M) & $\mathrm{K}_{2} \mathrm{CO}_{3}$ & 120 & 52 \\
\hline 2 & OMe & $101 \mathrm{c}$ & PhMe (0.25 M) & $\mathrm{K}_{2} \mathrm{CO}_{3}$ & 120 & 8 \\
\hline 3 & OMe & $84 c$ & PhMe (0.25 M) & $n-\mathrm{Bu}_{4} \mathrm{NOAC}$ & 120 & $<5^{[c]}$ \\
\hline 4 & OMe & $\begin{array}{c}{\left[\mathrm{RuCl}_{3} \cdot \mathrm{H}_{2} \mathrm{O}\right]} \\
+\left(n-\mathrm{Bu}_{2} \mathrm{POH}\right)\end{array}$ & PhMe (0.25 M) & $\mathrm{K}_{2} \mathrm{CO}_{3}$ & 120 & $<5^{[c]}$ \\
\hline 5 & OMe & $84 c$ & DCE (0.25 M) & $\mathrm{K}_{2} \mathrm{CO}_{3}$ & 120 & $<5^{[c]}$ \\
\hline 6 & OMe & $84 c$ & $\operatorname{PhMe}(0.25 \mathrm{M})$ & $\mathrm{K}_{2} \mathrm{CO}_{3}$ & 140 & 80 \\
\hline 7 & OMe & $84 c$ & o-xylene $(0.25 \mathrm{M})$ & $\mathrm{K}_{2} \mathrm{CO}_{3}$ & 140 & 43 \\
\hline 8 & OMe & $84 c$ & PhMe (1 M) & $\mathrm{K}_{2} \mathrm{CO}_{3}$ & 120 & 96 \\
\hline 9 & OMe & $84 c$ & $\mathrm{H}_{2} \mathrm{O}(1 \mathrm{M})$ & $\mathrm{K}_{2} \mathrm{CO}_{3}$ & 120 & 60 \\
\hline
\end{tabular}

${ }^{[a]}$ Reaction conditions: 102a $(0.5 \mathrm{mmol}), 30(0.75 \mathrm{mmol}),[\mathrm{Ru}](5.0 \mathrm{~mol} \%), \mathrm{K}_{2} \mathrm{CO}_{3}(1.0 \mathrm{mmol})$, $18 \mathrm{~h} .{ }^{[b]}$ Yield of isolated product 103. ${ }^{[c]}$ Determined by GC with $n$-dodecane as internal standard.

Regarding the high efficiency of the catalytic system and the importance of small catalyst loadings for industrial applications, a screening of the required amount of catalyst was performed for aryloxazoline 102 and aryltetrazole 104.

Table 7. Impact of the catalyst loading on the ruthenium(II)-catalyzed C-H arylation of 102a. ${ }^{[a]}$

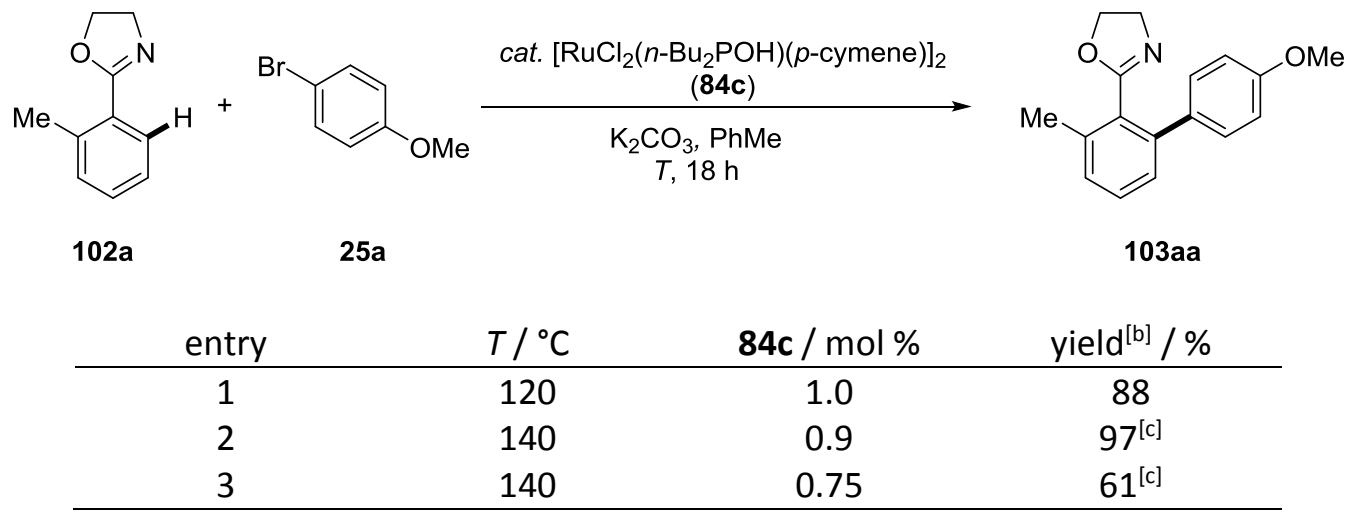




\begin{abstract}
[a] Reaction conditions: 102a $(0.50 \mathrm{mmol}), 25 a(0.75 \mathrm{mmol}),\left[\mathrm{RuCl}_{2}(n-\right.$ $\left.\mathrm{Bu}_{2} \mathrm{POH}\right)(p$-cymene $\left.)\right], \mathrm{K}_{2} \mathrm{CO}_{3}(1.0 \mathrm{mmol})$, PhMe $(1 \mathrm{M}), 18 \mathrm{~h}$. ${ }^{[b]}$ Yield of isolated product 103aa. ${ }^{[c]}$ Determined by GC with $n$-dodecane as internal standard.
\end{abstract}

It could be shown, that the catalyst loading can easily be reduced to $1 \mathrm{~mol} \%$ under the applied reaction conditions with only minor loss of product formation (Table 7 , entry 1 ). If the temperature was raised to $140{ }^{\circ} \mathrm{C}$ the reaction even worked efficiently with a catalyst loading as low as $0.75 \mathrm{~mol} \%$ (entry 3).

Table 8. Impact of the catalyst loading on the ruthenium(II)-catalyzed C-H arylation of 104a. ${ }^{[a]}$<smiles>[C+]c1ccccc1-c1nnn[nH]1</smiles>

$104 a$<smiles>COc1ccc(Br)cc1</smiles>

$25 a$<smiles>COc1ccc(-c2ccccc2-c2nnn[nH]2)cc1</smiles>

$105 a$

\begin{tabular}{ccc} 
entry & $\mathbf{8 4 a} / \mathrm{mol} \%$ & yield $^{[\mathrm{b}]} / \%$ \\
\hline 1 & 0.9 & 63 \\
2 & 0.75 & 48 \\
\hline${ }^{[a]}$ Reaction conditions: $104 a\left(0.5\right.$ mmol), 25a $\left(0.75\right.$ mmol), $\mathrm{K}_{2} \mathrm{CO}_{3}$ \\
$\left(1.0\right.$ mmol), PhMe (0.25 M), 18 h. ${ }^{[b]}$ Yield of isolated product $105 \mathrm{a}$
\end{tabular}

In case of the less reactive aryltetrazoles 104a a decrease of the catalyst loading caused an immediate drop in the yield. Nevertheless, when applying aryl bromide 25a good yields could be obtained with only $0.9 \mathrm{~mol} \%$ ruthenium (Table 8 ).

\title{
3.2.3 Scope of the Ruthenium(II)-Catalyzed C-H Arylation
}

To test the scope of the reaction various different aryl bromides were applied to the optimized reaction conditions (Scheme 86 ). The catalytic system proved very robust and many functional groups, such as ethers (25a), ketones (25c), esters (25g) and also thiophene (25d), on the aryl halide could be applied in the direct $\mathrm{C}-\mathrm{H}$ arylation. Furthermore, bromides, chlorides and pseudohalides proved suitable as the leaving groups of the arylating agent. 
(C)

102
$\left[\mathrm{RuCl}_{2}(p\right.$-cymene $\left.)\left(n-\mathrm{Bu}_{2} \mathrm{POH}\right)\right]$ (84c) $(5.0 \mathrm{~mol} \%)$

$\mathrm{K}_{2} \mathrm{CO}_{3}$

$\mathrm{PhMe}, 120^{\circ} \mathrm{C}, 18 \mathrm{~h}$

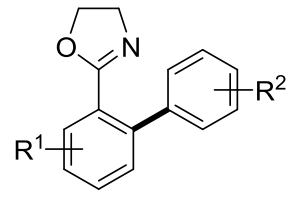

103

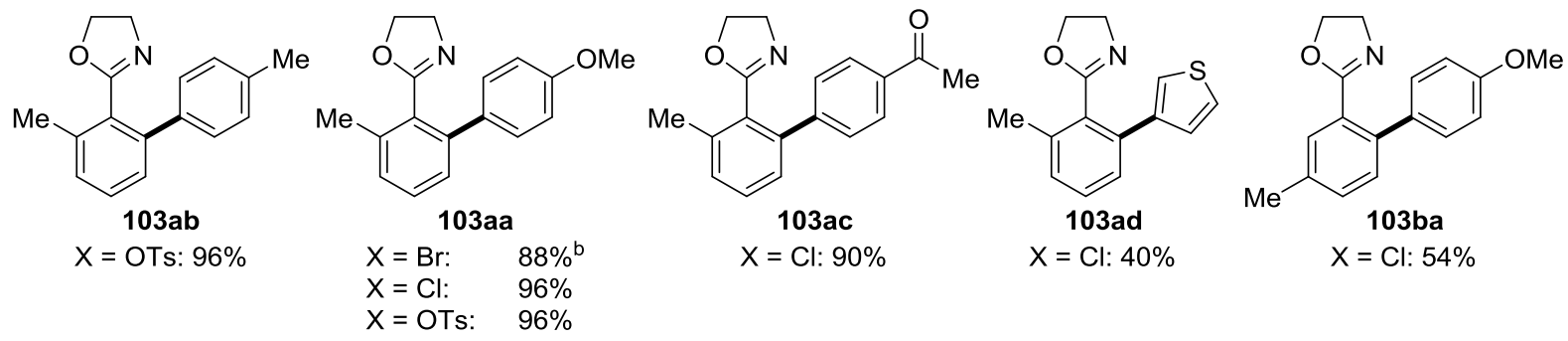

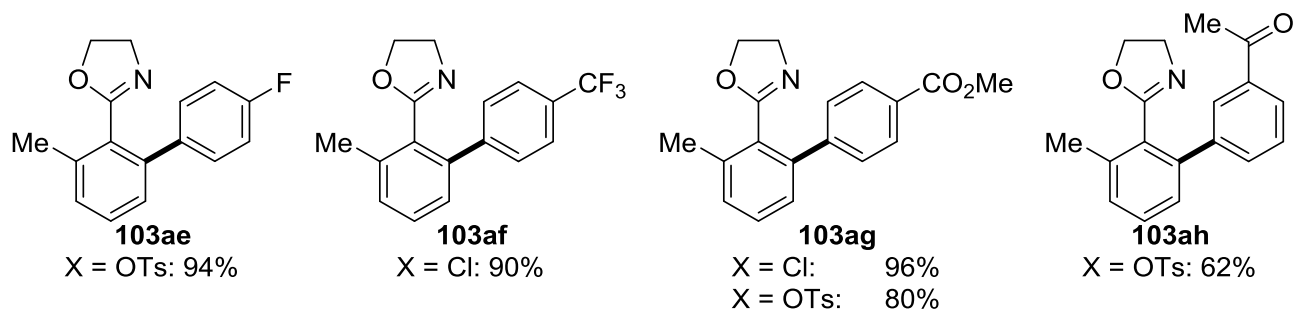<smiles></smiles>

$\mathrm{X}=\mathrm{Cl}: 98 \%$

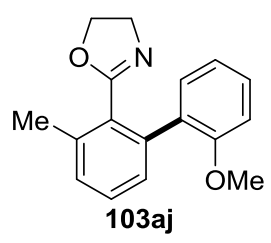

$\mathrm{X}=\mathrm{Cl}: 60 \%$<smiles>COc1ccc(-c2ccccc2-c2ccccc2)cc1</smiles>

$\mathrm{X}=\mathrm{Br}: 98 \%^{\mathrm{C}}$

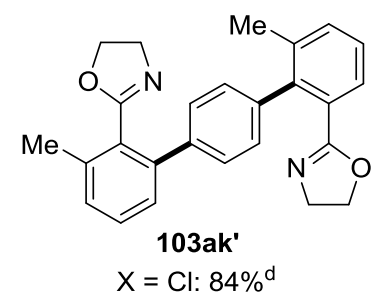

${ }^{[a]}$ Reaction conditions: 102 (0.50 mmol), 25/30/106 (0.75 mmol), $\left[\operatorname{RuCl}_{2}\left(n-\mathrm{Bu}_{2} \mathrm{POH}\right)(p\right.$-cymene)] (84c) (5.0 mol \%), $\mathrm{K}_{2} \mathrm{CO}_{3}(1.0 \mathrm{mmol})$, PhMe $(1 \mathrm{M}) 120^{\circ} \mathrm{C}, 18 \mathrm{~h}$. Yield of isolated product $103 .{ }^{[b]} 84 \mathrm{c}(1 \mathrm{~mol} \%) .{ }^{[\mathrm{c}]} 102 \mathrm{c}(0.50 \mathrm{mmol})$, 25a $(1.5 \mathrm{mmol}) .{ }^{[\mathrm{d}]}$ 102a $(0.50 \mathrm{mmol}), 30 \mathrm{k}(0.25 \mathrm{mmol})$.

Scheme 86. Scope of the ruthenium(II)-catalyzed oxazolinyl assisted $\mathrm{C}-\mathrm{H}$ arylation. ${ }^{[a]}$

The high conversion in case of the sterically demanding ortho-substituted aryl chloride $\mathbf{3 0 j}$ is noteworthy. In case of 1,4-dichlorobenzene (30k') two oxazoline units were connected. The yield of 103ak' was very high, even though no starting material was used in excess. Combined with the result of unsubstituted phenyl oxazoline 102c, which yielded the disubstituted phenyl oxazoline 103ca in high yield, it is most likely that the systems would also be suitable for polymerization reactions. A highlight was also the very low catalyst loading for aryl bromide 25a.

Restrictions of the reaction are shown in Scheme 87. These substrates were apparently not suitable for the reaction. 
Results and Discussion

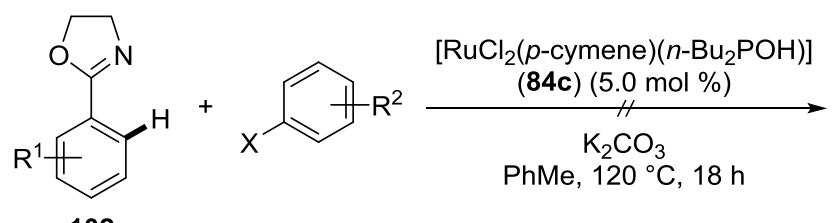

102

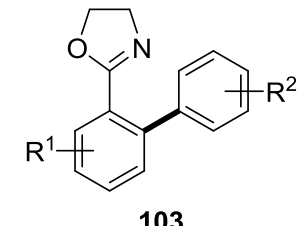

103<smiles>Cc1cccc(/C=C/c2ccccc2)c1C1=NCCO1</smiles>

$\mathrm{X}=\mathrm{Br}$<smiles>Cc1cccc(-c2ccccn2)c1C1=NCCO1</smiles>

$\mathrm{X}=$ OTs

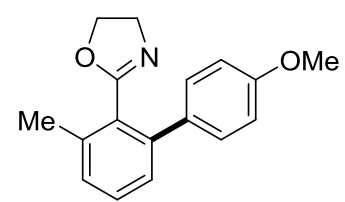

$\mathrm{X}=\mathrm{OS}(\mathrm{O})_{2} \mathrm{Me}$<smiles>COc1ccc(-c2cccc(OC)c2C2=NCCO2)cc1</smiles>

$\mathrm{X}=\mathrm{Cl}$<smiles>Cc1cccc(-c2ccc(C#N)cc2)c1C1=NCCO1</smiles>

$\mathrm{X}=\mathrm{OTs}$<smiles>COc1ccc(-c2cccc(F)c2C2=NCCO2)cc1</smiles>

$\mathrm{X}=\mathrm{Cl}$

Scheme 87. Challenging substrates in the ruthenium(II)-catalyzed direct arylation of 102.

The scope of the tetrazolyl-assisted $\mathrm{C}-\mathrm{H}$ arylation proved to be very versatile too. Thus, differently decorated tetrazoles 105 were obtained (Scheme 88). 
<smiles></smiles>

104<smiles>[R]c1ccc(Br)cc1</smiles>

25

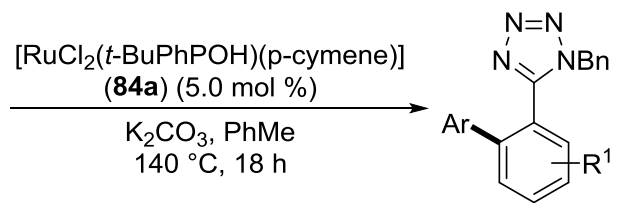

105

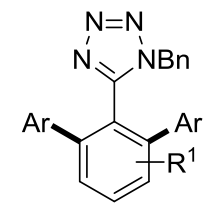

105'<smiles></smiles>

105aa: $80 \%$<smiles></smiles>

105al: $88 \%$ (+8\% 105al')<smiles>CC(=O)c1ccc(-c2ccccc2C2=NN=N[B]2)cc1</smiles>

105ac: $82 \%$ (+10\% 105ac')<smiles></smiles>

105am: $80 \%$<smiles></smiles>

105ak: $76 \%$<smiles>FC(F)(F)c1ccc(-c2ccccc2-c2nnnn2Cc2ccccc2)cc1</smiles>

105af: $78 \%$ (+10\% 105af')<smiles>COc1ccc(-c2nnnn2Cc2ccccc2)c(-c2ccc(C(C)=O)cc2)c1</smiles>

105bc: $76 \%$ (+16\% 105bc')<smiles></smiles>

105an: $72 \%(52 \%)^{[b]}$<smiles></smiles>

105ao: $72 \%$<smiles>COCc1ccc(-c2ccccc2-c2nnnn2Cc2ccccc2OC)cc1</smiles>

105cn: $76 \%$ (+14\% 105cn')

[a] Reaction conditions: $104(0.50 \mathrm{mmol}), 25$ (0.75 mmol), [RuCl${ }_{2}\left(t-\mathrm{BuPhPOH}^{\mathrm{a}}(p\right.$-cymene)] (84a) (5.0 mol \%), $\mathrm{K}_{2} \mathrm{CO}_{3}(1.0 \mathrm{mmol}), \mathrm{PhMe}(0.25 \mathrm{M}) 140{ }^{\circ} \mathrm{C}, 18 \mathrm{~h}$. Yield of isolated product $105{ }^{[\mathrm{b}]} 84 \mathrm{a}(2.0 \mathrm{~mol} \%)$.

Scheme 88. Scope of the tetrazole-directed ruthenium(II)-catalyzed $\mathrm{C}-\mathrm{H}$ arylation. ${ }^{[a]}$

Highlights of the scope were represented by the tolerance of an amine group (25m) and a chloro substituent (105ak), which allows further diversification of the product. Importantly, the synthesis of the building blocks 105an, $105 \mathrm{ao}$ and $105 \mathrm{cn}$, which are suitable for the synthesis of different angiotensin II receptor antagonists, ${ }^{[3 e, 119]}$ were possible in high yields.

Free alcohols or aldehydes were not tolerated in the reaction. Also the sterically demanding orthosubstituted arene $\mathbf{2 5}$ j only led to low conversions (Scheme $\mathbf{8 8 )}$ ). 
Results and Discussion

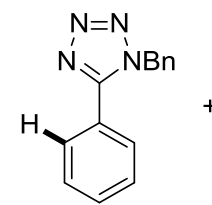

104a

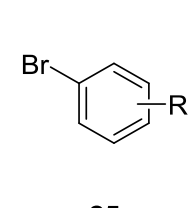

25

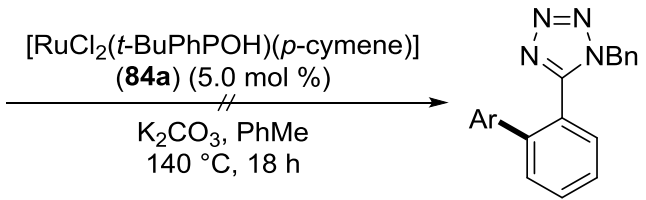

105<smiles></smiles>

$25 \%$ [a]<smiles></smiles>

$20 \%[$ [a]

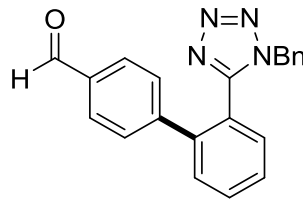

no product formation

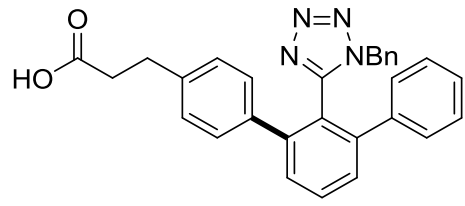

no product formation

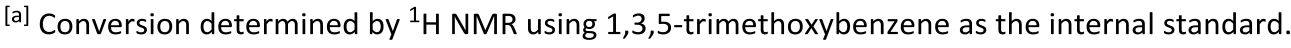

Scheme 89. Challenging substrates in the arylation of $104 a{ }^{[a]}$

\subsubsection{Synthesis of the Blockbuster Drug Valsartan}

Hypertension is one of the most prevalent diseases in developed countries and nonpeptidic angiotensin II receptor blockers (ARBs), such as Valsartan or Losartan (Figure 20), have emerged as highly effective antihypertensives. ${ }^{[120]}$ The ruthenium(II)-catalyzed $\mathrm{C}-\mathrm{H}$ arylation is a promising tool to synthesize these important drugs. ${ }^{[3 e, 119]}$<smiles>[CH]C(C)C(C(=O)O)N(Cc1ccc(-c2ccccc2-c2nnn[nH]2)cc1)C(=O)CCCC</smiles>

Valsartan<smiles>CCCCc1nc(Cl)c(CO)n1Cc1ccc(-c2ccccc2-c2nnn[nH]2)cc1</smiles>

Losartan

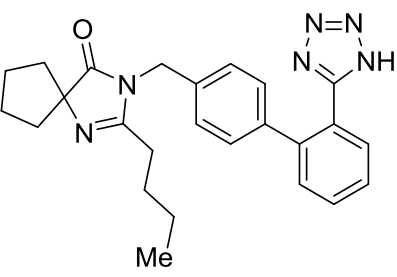

Irbesartan

Figure 20. Examples of tetrazole based ARBs.

Ackermann $^{[121]}$ and Seki ${ }^{[27 a, 119,122]}$ elegantly developed ruthenium(II)-catalyzed direct C-H arylation of phenyl tetrazoles 104 giving access to a precursor for these ARB drugs. The precursor had to be transformed to the corresponding arene, ${ }^{[119]}$ hence, several steps are required for deprotection, chlorination and further functionalization of the side chain. 


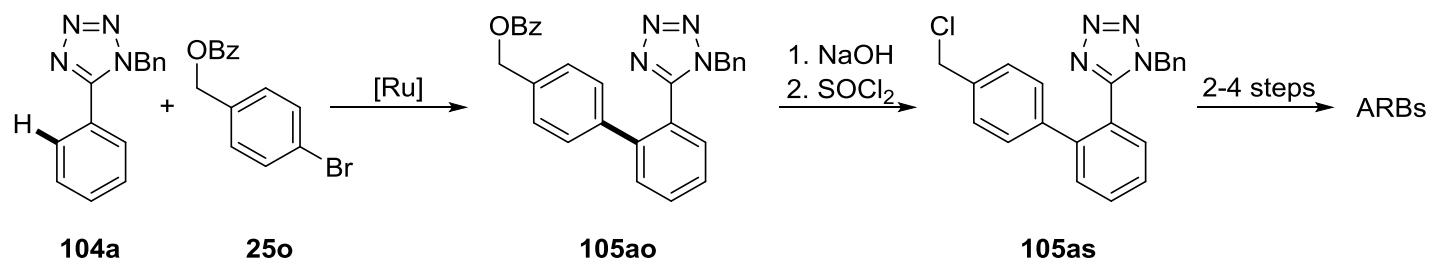

Scheme 90. Synthesis strategy to prepare ARBs. ${ }^{[119]}$

Therefore, the goal was to establish an alternative method, in which the fully functionalized arene is directly subjected to the reaction conditions. Valsartan was chosen as a model substrate, also in order to probe if the stereogenic information would be preserved.

As free alcohols, as well as acids are not tolerated in the reaction the acid was protected as methyl ester. Aryl bromide D-25t was synthesized according to literature procedures for similar products. ${ }^{[123]}$ Reductive amination was followed by an $\mathrm{N}$-acylation of the thus obtained product $\mathrm{D}-\mathbf{2 5 \mathrm { v }}$, whereby $\mathrm{D}$ $\mathbf{2 5 t}$ is formed, L-25t is synthesized analogous starting form L-valine. With this procedure in hand, the fully functionalized aryl bromide was obtained in $54 \%$ overall yield, without any optimization studies.
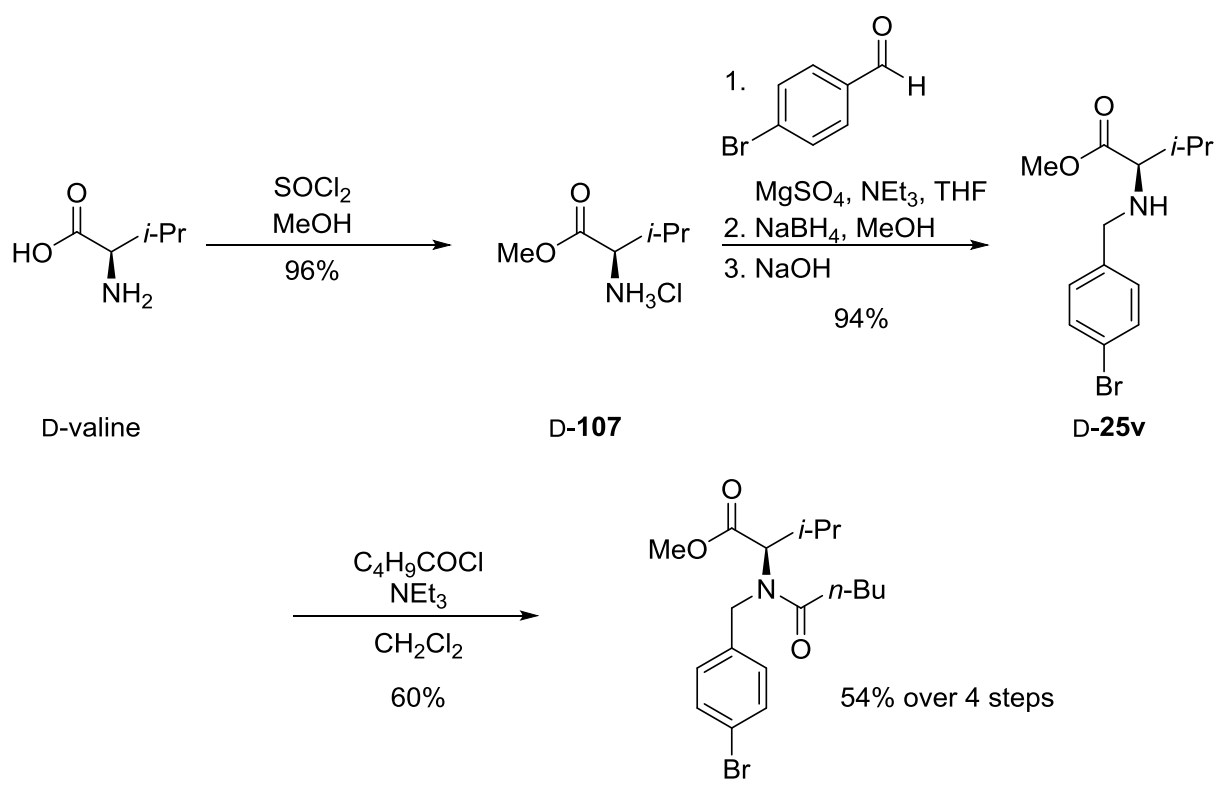

D-25t

Scheme 91. Synthesis of the starting material shown for D-25t.

Subsequently, the obtained aryl bromide $\mathbf{2 5 t}$ was tested in the optimized ruthenium(II)-catalyzed C$\mathrm{H}$ arylation. The reaction proceeded smoothly with $72 \%$ yield under the standard conditions. Furthermore, applying the functionalized aryl bromide $\mathbf{2 5 t}$ as limiting reagent with only small excess of tetrazole 104a gave even improved yields. 
Table 9. Synthesis of protected Valsartan 105at. ${ }^{[a]}$<smiles>Brc1ccccc1-c1nnn[nH]1</smiles>

104a<smiles>CCCCC(C(=O)OC)[C@@H](C(=O)OC)N(Cc1ccc(Br)cc1)C(=O)CC</smiles>

L-25t

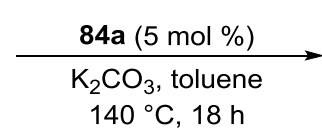

$140^{\circ} \mathrm{C}, 18 \mathrm{~h}$

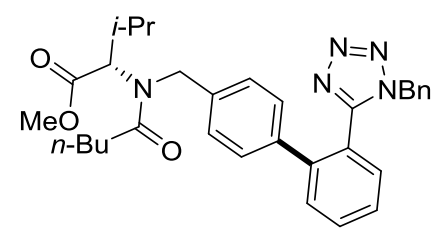

L-105at

\begin{tabular}{cccc}
\hline entry & 104a / equiv & L-25t / equiv & Yield L-105at / \% \\
\hline 1 & 1.0 & 1.5 & 72 \\
2 & 1.2 & 1.0 & 73 \\
3 & 1.2 & $1.0(D-25 t)$ & 80 (D-105at)
\end{tabular}

[a] Reaction conditions: 104a, 25t, [RuCl $2(t-\mathrm{BuPhPOH})(p$-cymene $)]$ (84a) (5.0 mol \%), $\mathrm{K}_{2} \mathrm{CO}_{3}(1.0 \mathrm{mmol}), \mathrm{PhMe}(0.25 \mathrm{M}), 140{ }^{\circ} \mathrm{C}, 18 \mathrm{~h}$. ${ }^{[b]}$ Yield of isolated product 105at.

Importantly, the ruthenium-catalyzed C-H functionalization worked without racemization (Figure 21) and therefore opens a possibility for the thus far most efficient synthesis of Valsartan.
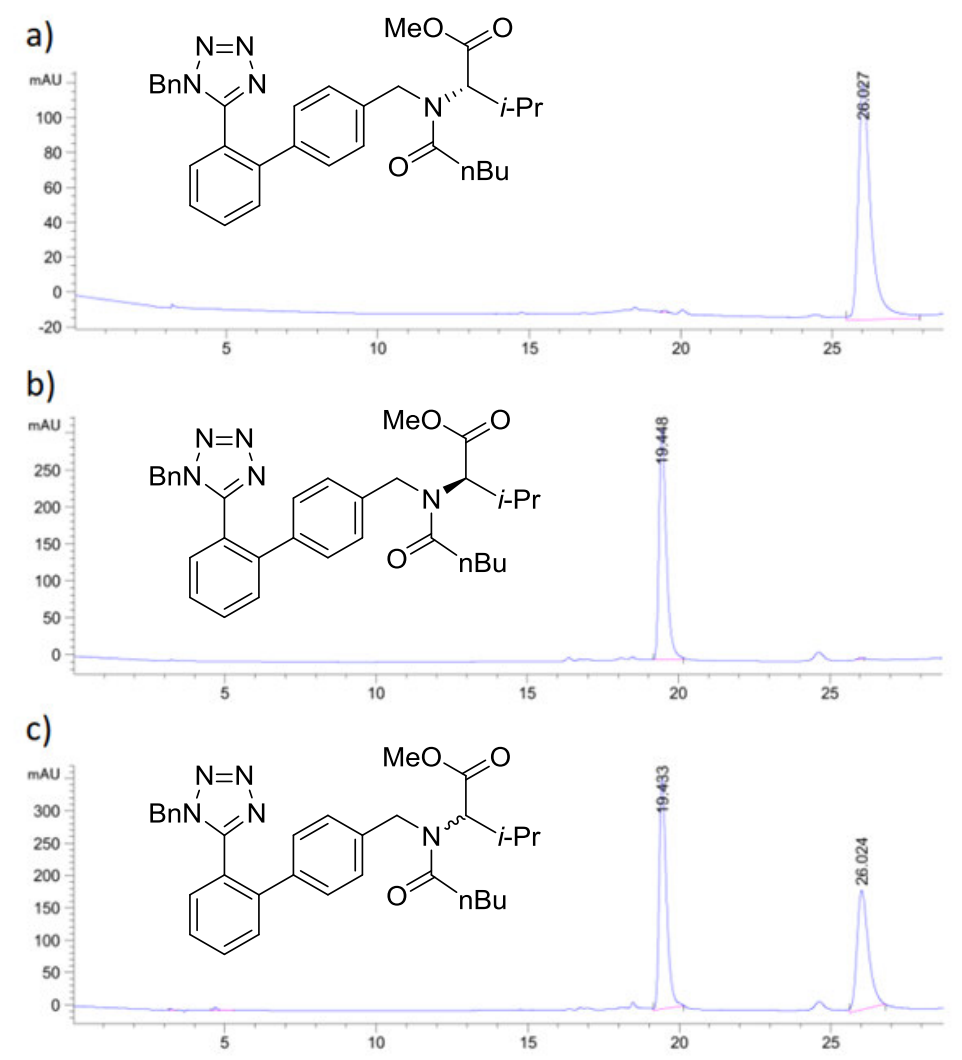

Figure 21. HPLC-chromatogram of a) L-105at, b) D-105at and c) a mixture of L- and D-105at. 
The removal of the protecting groups is literature known and can be easily performed in two steps. ${ }^{[124]}$

\subsubsection{Mechanistic Studies}

To study the transformation of the ruthenium species during the reaction several attempts to form the cyclometalated species were performed. Simple addition of different substrates such as oxazoline 102, phenylpyridine (32) or 2-styrylpyridine $(\mathbf{1 0 8})$, along with a base such as $\mathrm{K}_{2} \mathrm{CO}_{3}$ or $\mathrm{NaOAc}$, failed to deliver the cyclometalated species. Also a representative set of solvents $\left(\mathrm{CH}_{2} \mathrm{Cl}_{2}\right.$, $\mathrm{ClCH}_{2} \mathrm{CH}_{2} \mathrm{Cl}, \mathrm{MeOH}$, toluene, MeCN) and various reaction temperatures varying from $0{ }^{\circ} \mathrm{C}$ to $100^{\circ} \mathrm{C}$ could not provide the cyclometalated complex. Furthermore, attempts to abstract the chloride with different salts as additives, such as $\mathrm{AgSbF}_{6}, \mathrm{Ag}_{2} \mathrm{O}, \mathrm{KPF}_{6}$ and $\mathrm{AgNO}_{3}$, were not successful, even though the abstraction of the chloride worked cleanly in case of $\mathrm{AgSbF}_{6}{ }^{1} \mathrm{H}$ NMR spectroscopy showed no cycloruthenation. It appears that the ligand is deprotonated and acts as a chelating ligand.

When following the catalytic reaction via ${ }^{31} \mathrm{P} N M R$ studies a complex mixture of phosphorus resonances was observed, which could not be fully assigned to defined structures.

The reactions take place at rather high temperatures. Because high temperatures allow for the formation of metal nanoparticles ${ }^{[75]}$ and examples for heterogeneous $\mathrm{C}-\mathrm{H}$ functionalization are known, ${ }^{[73]}$ the question arose whether the reaction follows a homogeneous or heterogeneous pathway. To test the homogeneous nature of the reaction, mercury was added to the reaction. In case of a heterogeneous reaction the reaction should be stopped. ${ }^{[75,125]}$ Investigatons of both the tetrazolyl- and oxazolinyl-assisted $\mathrm{C}-\mathrm{H}$ arylation revealed the reaction to work in the presence of mercury without significant loss of activity (Scheme 92). Thus, indicating the reaction to occur in a homogeneous fashion.

a)

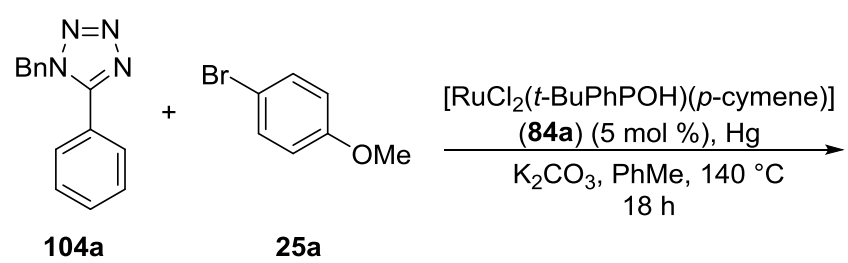

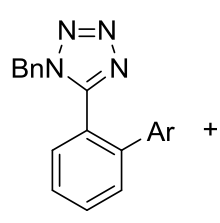

105aa: $83 \%$

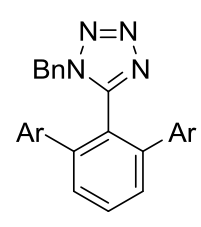

105aa': $5 \%$

b)

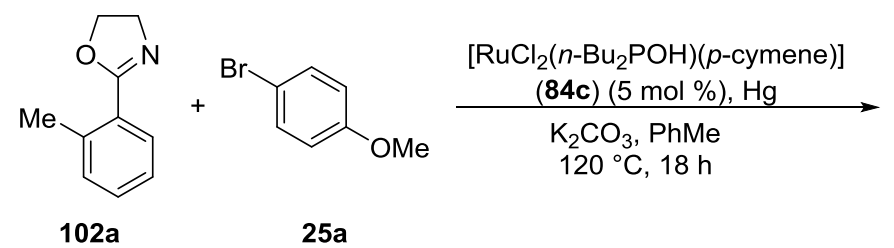<smiles>COc1ccc(-c2cccc(C)c2C2=NCCO2)cc1</smiles>

Scheme 92. Mercury test for the ruthenium-catalyzed direct arylation. 
Furthermore, intramolecular experiments showed the aryl chloride to be inherently more reactive than the aryl tosylate (Scheme 93). This trend was also shown by Ackermann previously. ${ }^{[90]}$
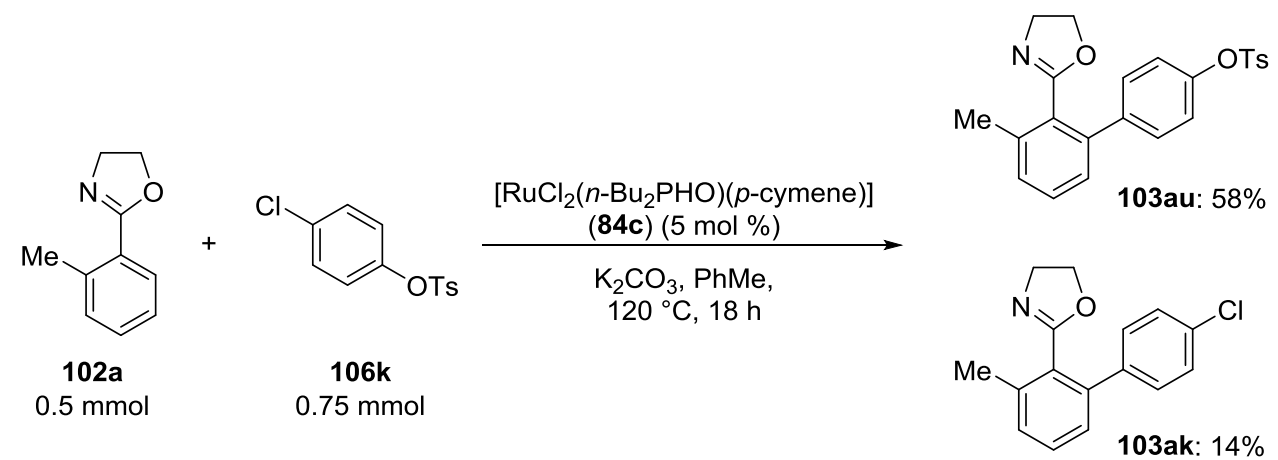

Scheme 93. Intramolecular competition experiment.

Studies regarding the deuterium incorporation with $\mathrm{D}_{2} \mathrm{O}$ as co-solvent under catalytic conditions showed that a facile H/D scrambling was observed. Hence, the cycloruthenation is reversible (Scheme 94).<smiles>COc1ccc(-c2ccccc2-c2cccc(-c3ccc(OC)cc3)c2-c2ccc(OC)cc2)cc1</smiles>

Scheme 94. H/D exchange experiment.

D. Zell ${ }^{[126]}$ studied the KIE of the reaction, which is roughly two and furthermore studied the relative reaction rates dependent on the applied aryl bromide. The thus obtained Hammett-Plot clearly showed a switch in the turnover determining step when going from electron-rich to electron-poor substrates $\mathbf{2 5}$. Studies of the kinetic order performed by $\mathrm{D}$. Zell clearly showed the reaction to be first order in ruthenium complex $\mathbf{8 4 c}$ and arene 108, while a saturation behavior was observed for the aryl bromide 25. He furthermore showed that radical scavengers, such as TEMPO and DPPH, hampered the reaction.

On the basis of these mechanistic findings the following catalytic cycle is proposed (Scheme 95). Coordination of phenyl oxazoline $\mathbf{1 0 2}$ is followed by a PA-assisted reversible cycloruthenation. A radical SET type $\mathrm{C}-\mathrm{X}$ cleavage forms a ruthenium(IV) species $\mathbf{1 1 0}$, which can then undergo reductive 
elimination to restore the catalytically active catalysts and release the arylated product 103 . The role of para-cymene is to this end still unknown and it cannot be excluded that it is cleaved or that a change of the hapticity occurs during the reaction. This hypothesis is supported by the facile $\mathrm{RuCl}_{3}-$ catalyzed $\mathrm{C}-\mathrm{H}$ arylation reported by Ackermann, which occurred in the absence of an arene ligand. ${ }^{[127]}$

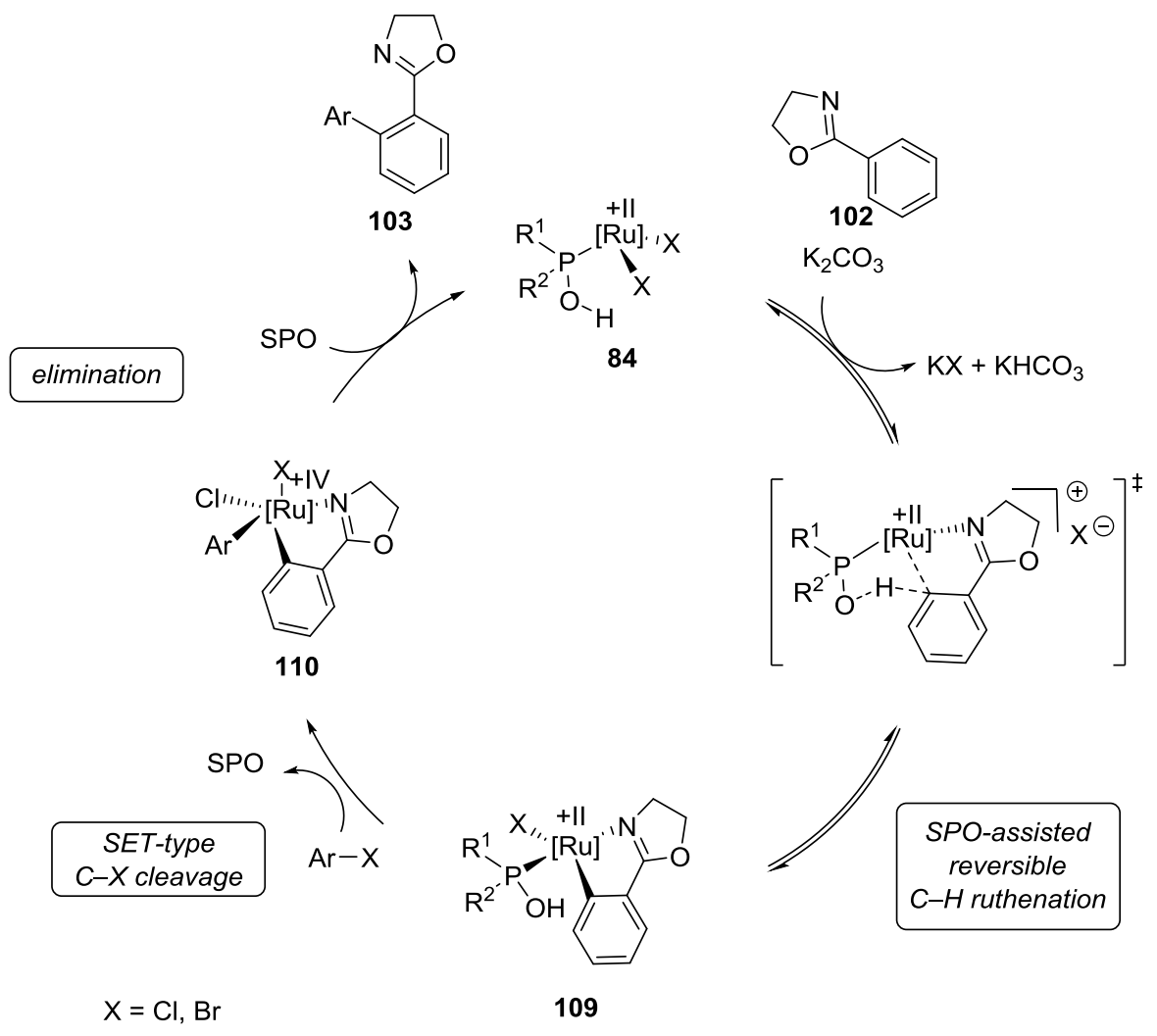

Scheme 95. Proposed catalytic cycle for the ruthenium(II) phosphinous acid-catalyzed C-H arylation. 


\subsection{Ruthenium(II)-Catalyzed meta-C-H Alkylations}

Achieving selectivity in $\mathrm{C}-\mathrm{H}$ functionalization reactions continues to be a major challenge. While

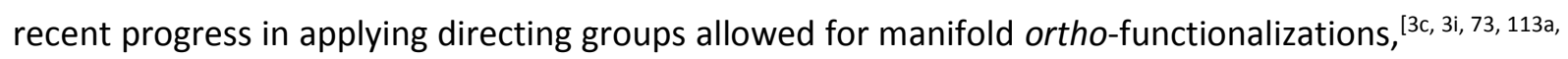

${ }^{128]}$ the examples for selective functionalization of remote positions are still scarce. ${ }^{[44 a, 44 c-g]}$ One early example for this selectivity was shown by Ackermann and N. Hofmann, ${ }^{[42]}$ who introduced the first ruthenium(II)-catalyzed meta-selective secondary alkylation (Scheme 22).

J. Li and Ackermann have developed a system for meta-selective alkylation which enabled the use of tertiary alkanes and also versatile directing groups based on pyrimidines and ketimines (Scheme 96). ${ }^{[129]}$ Interestingly, mono protected amino acids (MPAAs) performed excellent as ligands in the meta-selective $\mathrm{C}-\mathrm{H}$ alkylation.

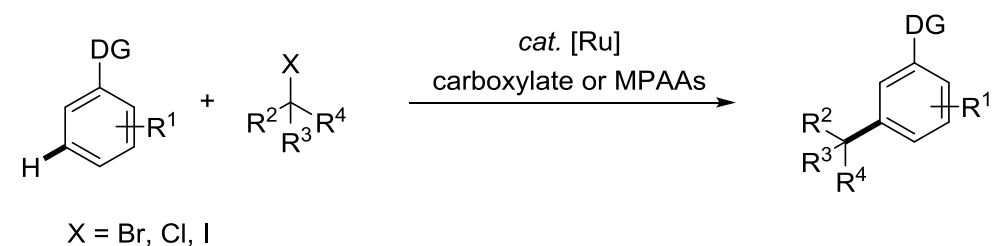

Scheme 96. Remote meta-C-H alkylations.

It should be mentioned that at the same time Frost $^{[130]}$ independently developed the meta-C-H alkylation of phenylpyridines 32 .

Regarding the high importance of this reaction, it is essential to understand the mode of action that results in this unique selectivity and to extend the synthetic value of this type of reaction. Therefore, within this thesis studies were performed to unravel the mechanism of this unique reaction.

\subsubsection{Synthesis of Ruthenium(II) MPAA Complexes}

Based on the discovery from J. Li and Ackermann, the amino acid ruthenium(II) complex $\mathbf{1 1 1}$ was synthesized. In a first attempt a procedure analogous to the synthesis of ruthenium(II) carboxylate complexes $^{[31]}$ was tested, but the direct use of mono protected amino acid $\mathbf{1 1 2}$ was not successful. In contrast, the use of the pre-formed sodium salt $\mathbf{1 1 3}$ delivered the product in excellent yield. The binding mode of the ligand is not fully understood yet, but based on literature known complexes ${ }^{[131]}$ the formation of a five-membered ring with oxygen and nitrogen coordinating to ruthenium(II) seems very likely (Scheme 97). 

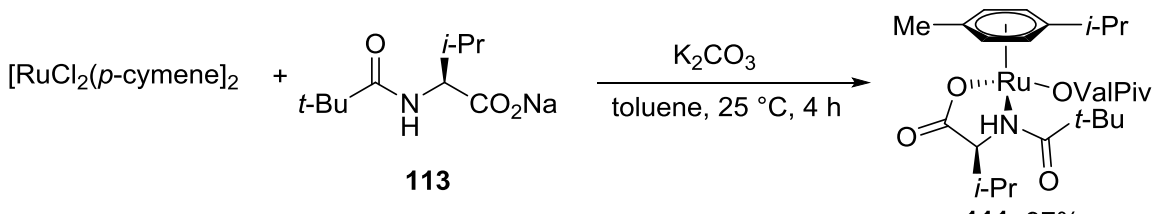

111: $97 \%$

Scheme 97. Synthesis of Ru(II) MPAA Complex 111.

The complex is very hygroscopic, which complicated its handling in catalytic quantities.

With this compound in hand, several attempts to form the cyclometalated complex were conducted, albeit with no success. It turned out that the replacement of the mono protected amino acid $\mathbf{1 1 2}$ as ligand is not as easy as in the case of carboxylate ligands.

One idea to circumvent that problem was to apply the complex with only one amino acid ligand attached. Decreasing the amount of ligand applied in the synthesis led to a mixture of starting material and two products as confirmed by ESI-MS studies. Most likely the complex 111 and the analogous compound $\mathbf{1 1 4}$ with one chloride ligand instead of the protected amino acid $\mathbf{1 1 2}$ were formed. Reaction time and temperature could not improve this result and separation of the mixture was not possible. Also following the procedure from Baird, ${ }^{[132]}$ thus for unprotected amino acids with methanol as solvent, did not give access to the pure desired complex 114.

Thus, an alternative strategy with the silver salt of $\mathbf{1 1 5}$ was developed (Scheme 98). This allowed the synthesis of mono-MPAA complex 114 in excellent yield.
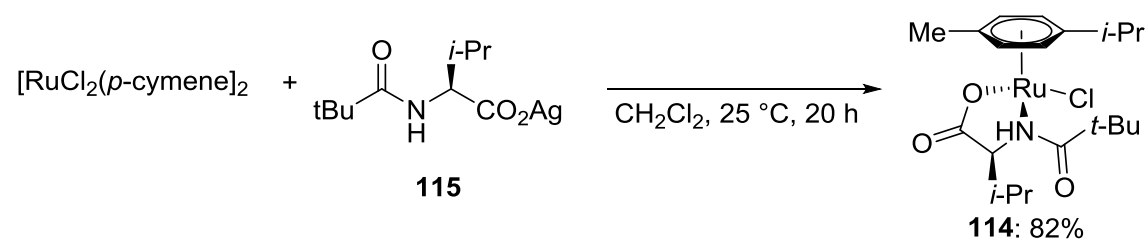

Scheme 98. Synthesis of Ru(II) MPAA 114.

With this complex in hand the cyclometalation with phenylpyridine 32a was studied (Scheme 99). The product was cleanly formed but isomer formation complicated the characterization of the complex. 


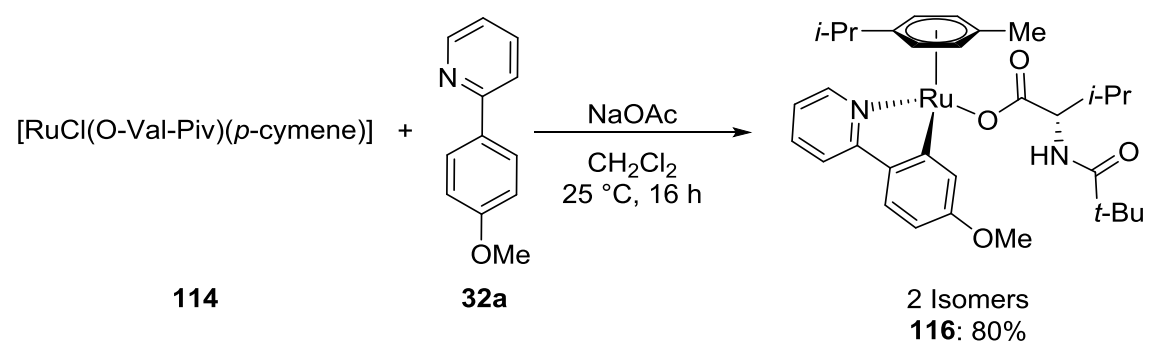

Scheme 99. Cyclometalation with complex 114.

Alternatively, it was possible to synthesize the same species from $\mathbf{1 1 1}$ via transmetallation, using the organomercury compound $\mathbf{1 1 7}^{[133]}$ (Scheme 100).

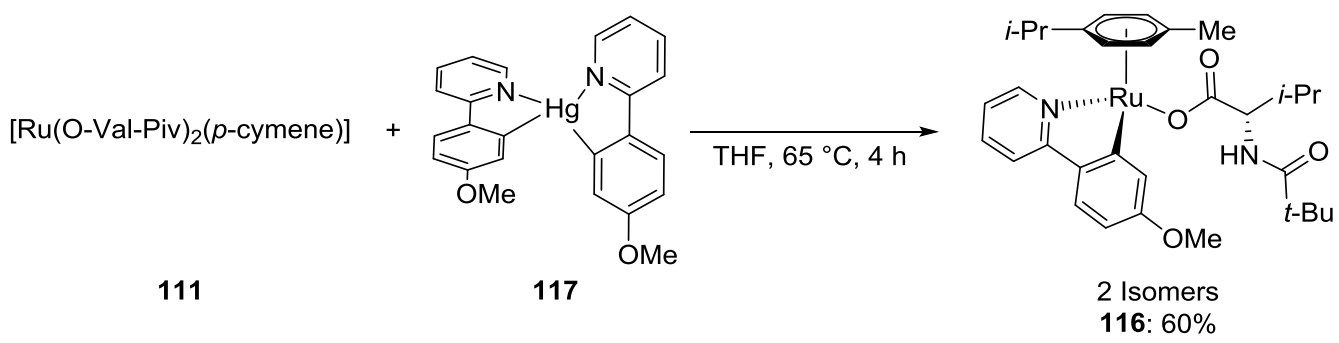

Scheme 100. Synthesis of 116 via transmetalation.

The stability of the thus obtained complexes $\mathbf{1 1 6}$ and $\mathbf{1 1 4}$ was investigated by thermogravimetric analysis and compared to the stability of complex 33 (Figure 22). The cyclometalated species 116 and 33 showed comparable behavior, both are stable up to around $150^{\circ} \mathrm{C}$. The stability of the cyclometalated compounds was reduced compared to $\mathbf{1 1 4}$, which was even stable up to a temperature of $180^{\circ} \mathrm{C}$. A detailed analysis of the TGA derived from 114 shows that immediately after the cleavage of para-cymene $\left(28 \mathrm{wt} \%, 180-226^{\circ} \mathrm{C}\right.$ ) the protected amino acid is cleaved ( $\left.43 \mathrm{wt} \%\right)$. Finally also chloride was eliminared, albeit very slowly, the mass loss stops at 21 weight \%, which equals the amount of ruthenium. In all cases the mass difference suggested that para-cymene is cleaved first, which is in analogy to $\left[\mathrm{RuCl}_{2}\left(p\right.\right.$-cymene) $\left.\left(\mathrm{PR}_{3}\right)\right]$ complexes. ${ }^{[134]}$ As the mass fragments are relatively close, especially in case of 116, TGA/DSC analysis coupled with a mass spectrometer would be needed for a definite assignment. 


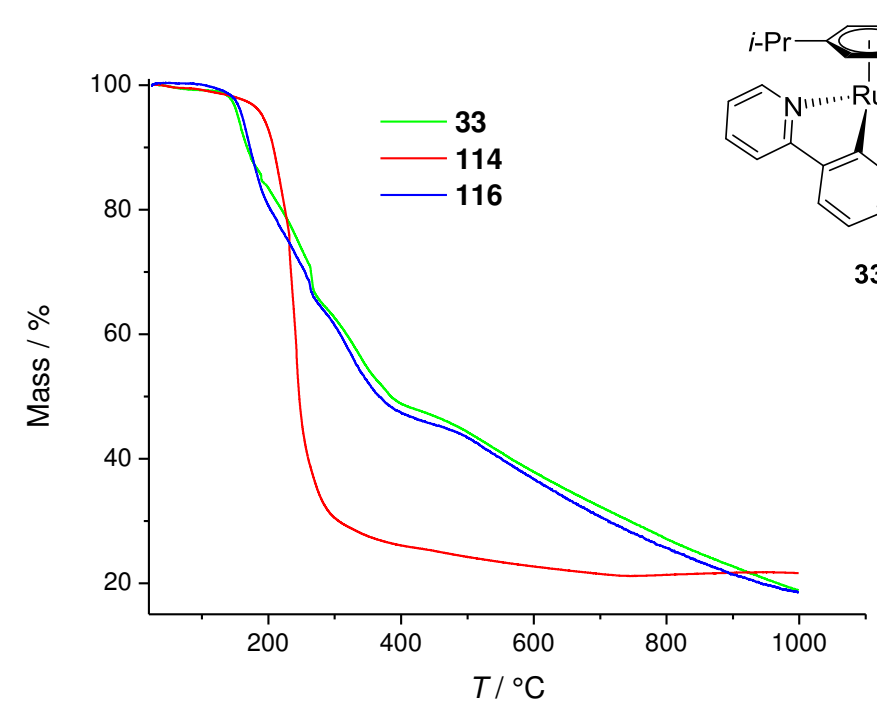

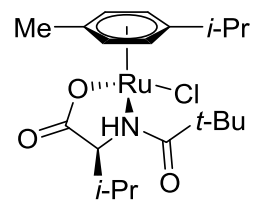

114

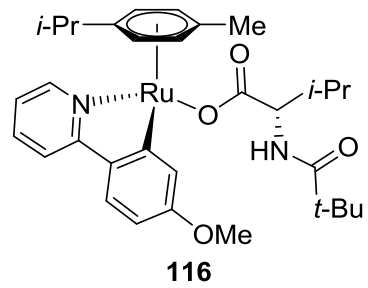

116

Figure 22. TGA analysis of 33, 116 and 114 .

\subsubsection{Optimization and Scope of the meta-Alkylation}

The optimization was performed for different directing groups by J. Li and Ackermann ${ }^{[129 a]}$ (Scheme 101). The isolated complex $\mathbf{1 1 4}$ proved to be highly active without any additional ligand. Thus, the amount of ligand was reduced by a factor of six.

a)

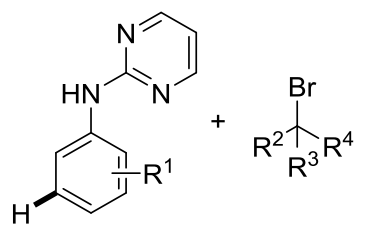

118

119

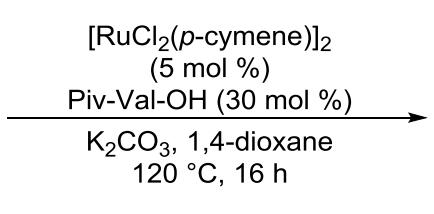

A: $\left[\mathrm{RuCl}_{2}(p \text {-cymene })\right]_{2}$ $(2.5 \mathrm{~mol} \%)$

Piv-Val-OH (30 mol \%) or

$\mathrm{B}:$ [RuCl(O-Val-Piv $)(p$-cymene $)]$
$(5.0 \mathrm{~mol} \%)$
$\mathrm{K}_{2} \mathrm{CO}_{3}, 1,4-$ dioxane
$120^{\circ} \mathrm{C}, 16 \mathrm{~h}$

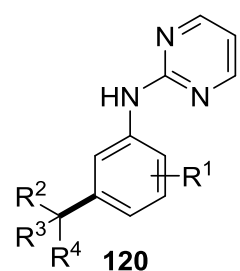<smiles>[R][C]1CC=C(C([R])([R])[R])C=C1c1ccccc1</smiles>

121

Scheme 101. Optimized conditions for meta-C-H alkylation with tertiary alkyl bromides $\mathbf{1 1 9 .}$

Further screening of soluble bases to generate a homogeneous reaction mixture was not successful (Table 10). 
Table 10. Probing soluble bases. ${ }^{[a]}$

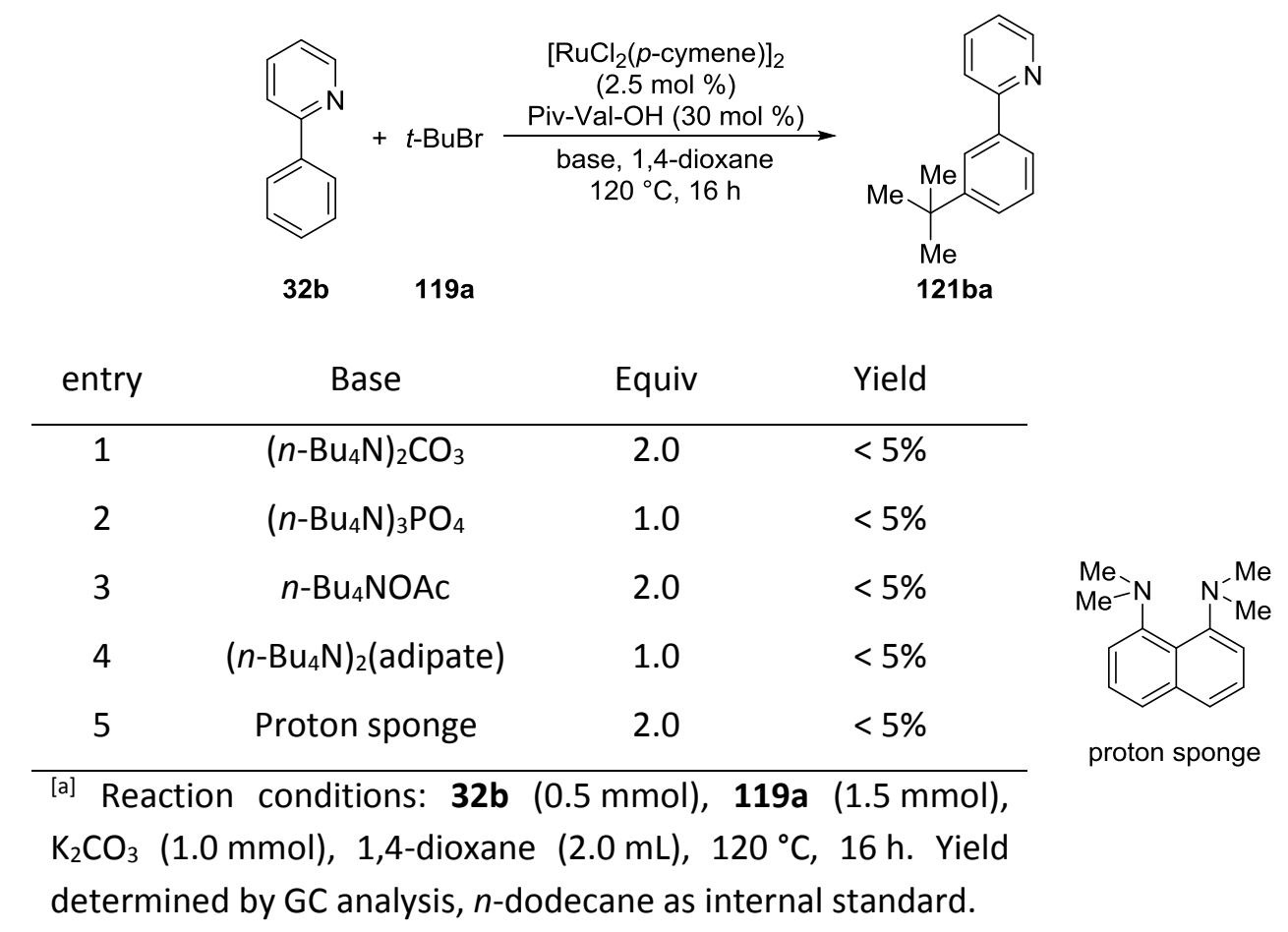

The scope of the reaction proved very broad, ${ }^{[129]}$ Scheme 102 shows selected substrates for the alkylation of phenylpyridines 32. Different substitution patterns were tolerated on phenyl as well as the pyridine moiety. Furthermore, different alkyl halides $\mathbf{1 1 9}$ were suitable for the transformation, thus allowing for the synthesis of diversely substituted products 121. 


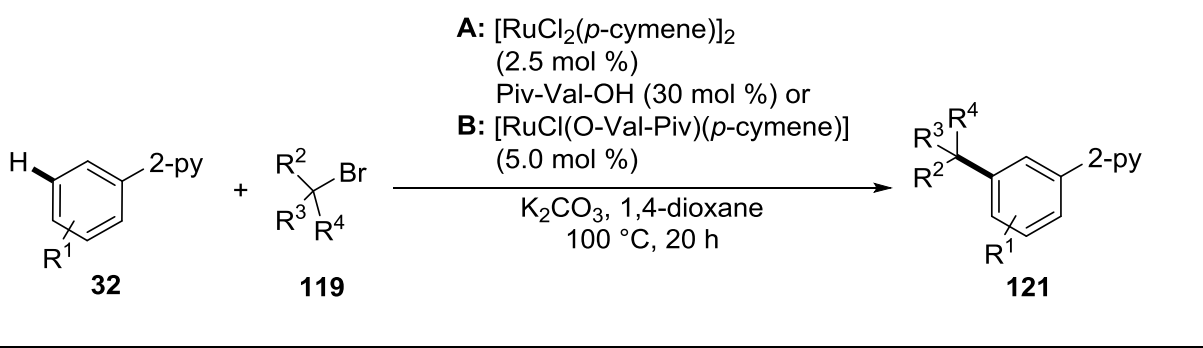

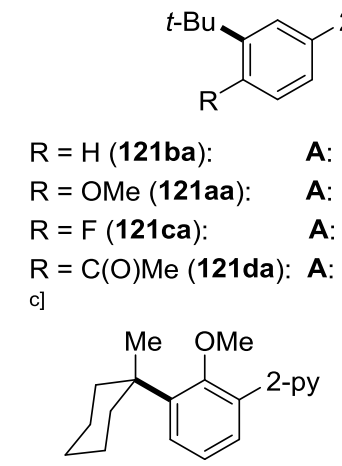

121fb: A: $46 \%,{ }^{[b, c]}$ B: $44 \%{ }^{[c]}$
A: $66 \%,{ }^{[b]}$ B: $59 \%{ }^{[b]}$

A: $76 \%,{ }^{[b]}$ B: $80 \%{ }^{[b]}$

A: $80 \%,{ }^{[b]}$ B: $81 \%$

A: $58 \%,{ }^{[b, c]}$ B: $55 \%{ }^{[b}$

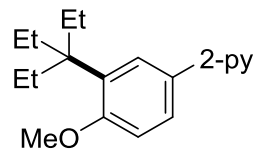

121ac: A: $52 \%,{ }^{[b]}$ B: $35 \%$<smiles>[R]c1ccc(-c2cccc(C([R15])(C)C)c2)nc1</smiles>

$R=A c(121 d a): A: 48 \%,{ }^{[b, c]} B: 56 \%{ }^{[c}$

$\mathrm{R}=\mathrm{F}$ (121ea): A: $56 \%,{ }^{[b, c]}$ B: $50 \%$

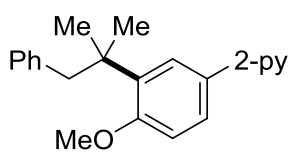

121ad: A: $59 \%,{ }^{[b]}$ B: $64 \%$

\footnotetext{
[a] Reaction conditions: 32 (0.5 mmol), 119 (1.5 mmol), $\mathrm{K}_{2} \mathrm{CO}_{3}(1.0 \mathrm{mmol}), 1$, -dioxane $(2.0 \mathrm{~mL}$ $120{ }^{\circ} \mathrm{C}, 16$ h. ${ }^{[\mathrm{b}]}$ Reaction performed by J. Li. ${ }^{[\mathrm{c}]}[\mathrm{Ru}](10 \mathrm{~mol} \%)$.
}

Scheme 102. Selected examples from the scope of the meta-C-H alkylation of phenylpyridines $32 .{ }^{[a]}$

Ketimines are important intermediates in organic synthesis, therefore the alkylation of ketimines $\mathbf{4 7}$ was studied. The reaction conditions were optimized by J. Li, S. De Sarkar and K. Korvorapun. ${ }^{[129 b]}$ In this case toluene as the solvent gave better conversions than 1,4-dioxane but a side product derived from benzylation of the ketimine $\mathbf{4 7}$ in ortho-position was observed. To prevent the formation of this S. De Sarkar used tert-butylbenzene as the solvent, which outperformed other solvents (Scheme 103).<smiles>[R][R](=[V])Br</smiles>

47

119

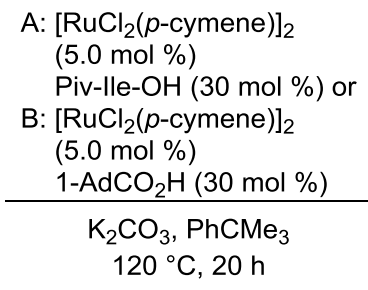

A: $\left[\mathrm{RuCl}_{2}(p \text {-cymene })\right]_{2}$ $(5.0 \mathrm{~mol} \%)$

Piv-lle-OH (30 mol \%) or

$\mathrm{B}:\left[\mathrm{RuCl}_{2}(p \text {-cymene })\right]_{2}$

$(5.0 \mathrm{~mol} \%)$

$1-\mathrm{AdCO}_{2} \mathrm{H}(30 \mathrm{~mol} \%)$

$\mathrm{K}_{2} \mathrm{CO}_{3}, \mathrm{PhCMe}_{3}$

$120^{\circ} \mathrm{C}, 20 \mathrm{~h}$

Scheme 103. Optimized conditions for the meta-C-H alkylation of ketimines 47 . 
In addition, the ability of other alkyl halides was probed and alkyl chloride 124a showed an equivalent efficiency as alkyl bromide 50a, while alkyl iodide 125a resulted in a drop of the yield (Table 11). An explanation could be the relatively weak C-I bond strength of alkyl iodides. They are therefore prone to undergo side reactions, like a fast elimination to isobutylene, thus the amount of active reagent is reduced.

Table 11. Screening of alkyl halides for the meta-C-H alkylation of ketimines. ${ }^{\text {[a] }}$
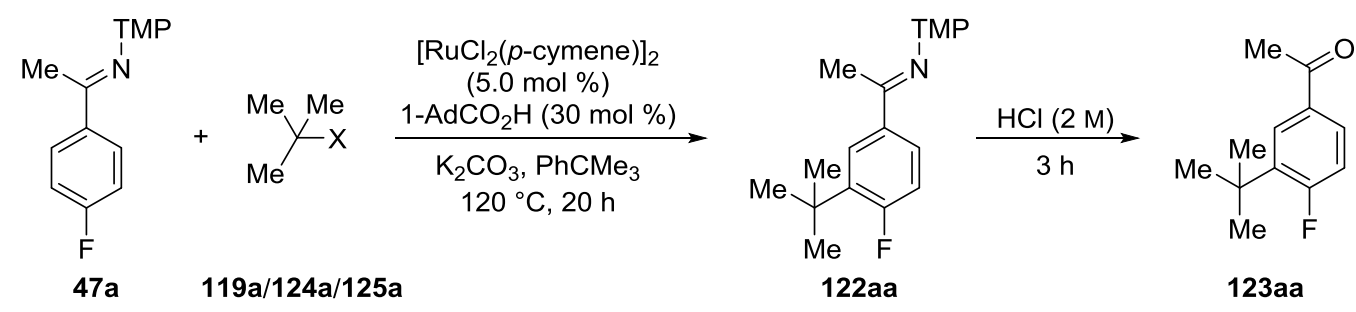

\begin{tabular}{ccc} 
entry & $\mathrm{X}$ & Yield /\% \\
\hline 1 & $\mathrm{I}(\mathbf{1 2 5 a})$ & 52 \\
2 & $\mathrm{Br}(\mathbf{1 1 9 a})$ & 72 \\
3 & $\mathrm{Cl}(\mathbf{1 2 4 a})$ & 72
\end{tabular}

[a] Reaction conditions: 1) 47a $(0.5 \mathrm{mmol}), t$-BuX (1.5 mmol), $\mathrm{K}_{2} \mathrm{CO}_{3}$ $\left.(1.0 \mathrm{mmol}), \mathrm{PhCMe}_{3}(2.0 \mathrm{~mL}), 120^{\circ} \mathrm{C}, 20 \mathrm{~h} .2\right) \mathrm{HCl}(2 \mathrm{M}, 3.0 \mathrm{~mL}), 23^{\circ} \mathrm{C}$, $3 \mathrm{~h}$. Yield of isolated product.

At the selected reaction conditions, an arene ligand exchange leading to a ruthenium(II) $\eta^{6}$-tertbutylbenzene complex cannot be excluded. In order to investigate if this complex is responsible for the increased activity when applying tert-butylbenzene as solvent, compound $\mathbf{1 2 6}$ was synthesized based on literature known procedures for similar materials (Scheme 104), ${ }^{[31,135]}$ starting from ruthenium(III) chloride and tert-butylcyclohexadiene (127). Complex 126 was isolated in excellent yield after reacting the dimer $\mathbf{1 2 8}$ with adamantyl carboxylic acid.

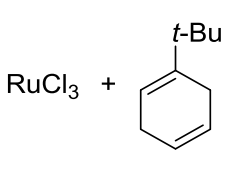

127

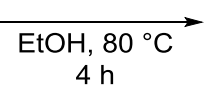

$4 \mathrm{~h}$

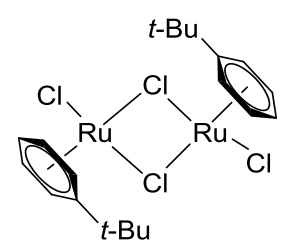

128: $76 \%$

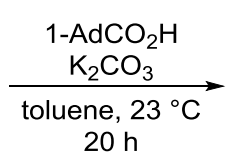

$20 \mathrm{~h}$

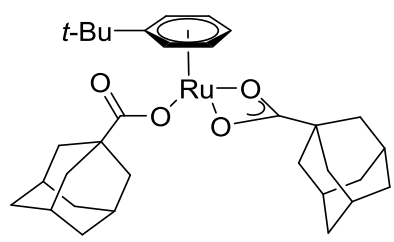

126: $99 \%$

Scheme 104. Synthesis of $\eta^{6}$-t-butylbenzene complex 126.

The catalytic activity of complex $\mathbf{1 2 6}$ was tested in the standard reaction and showed a comparable efficiency (Table 12, entries 1-2). Inspired by the good results with both catalysts, the required 
amount of catalyst was explored and fortunately, the catalyst loading could be reduced to $5 \mathrm{~mol} \%$ without a decrease in yield (entries 3-4). Unfortunately, further reduction of the catalyst yielded diminished yields (entries 5-7).

Table 12. Comparison of catalysts and their loading for the alkylation of ketimine $47 a^{[a]}$

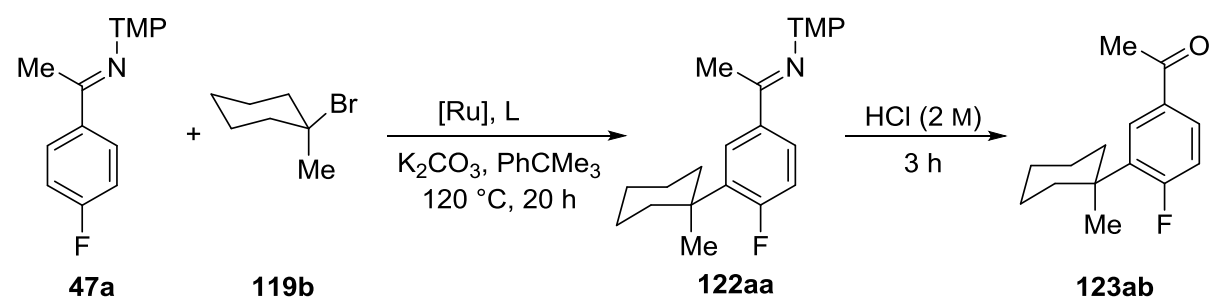

\begin{tabular}{|c|c|c|c|c|}
\hline entry & {$[\mathrm{Ru}]$} & {$[\mathrm{Ru}] \mathrm{mol} \%$} & Ligand & Yield / \% \\
\hline 1 & {$\left[\mathrm{RuCl}_{2}(p \text {-cymene })\right]_{2}$} & 5.0 & $\mathrm{AdCO}_{2} \mathrm{H}(30 \mathrm{~mol} \%)$ & $73^{[129 b]}$ \\
\hline 2 & {$\left[\mathrm{Ru}\left(\mathrm{O}_{2} \mathrm{CAd}\right)_{2}\left(t-\mathrm{BuC}_{6} \mathrm{H}_{5}\right)\right]$} & 10 & --- & 74 \\
\hline 3 & {$\left[\mathrm{RuCl}_{2}(p \text {-cymene })\right]_{2}$} & 2.5 & $\mathrm{AdCO}_{2} \mathrm{H}(15 \mathrm{~mol} \%)$ & 76 \\
\hline 4 & {$\left[\mathrm{Ru}\left(\mathrm{O}_{2} \mathrm{CAd}\right)_{2}\left(t-\mathrm{BuC}_{6} \mathrm{H}_{5}\right)\right]$} & 5.0 & $\mathrm{AdCO}_{2} \mathrm{H}(15 \mathrm{~mol} \%)$ & 75 \\
\hline 5 & {$\left[\mathrm{RuCl}_{2}(p \text {-cymene })\right]_{2}$} & 1.0 & $\mathrm{AdCO}_{2} \mathrm{H}(15 \mathrm{~mol} \%)$ & 24 \\
\hline 6 & {$\left[\mathrm{Ru}\left(\mathrm{O}_{2} \mathrm{CAd}\right)_{2}\left(t-\mathrm{BuC}_{6} \mathrm{H}_{5}\right)\right]$} & 2.0 & $\mathrm{AdCO}_{2} \mathrm{H}(15 \mathrm{~mol} \%)$ & 30 \\
\hline 7 & {$\left[\mathrm{Ru}\left(\mathrm{O}_{2} \mathrm{CAd}\right)_{2}\left(t-\mathrm{BuC}_{6} \mathrm{H}_{5}\right)\right]$} & 2.0 & $\mathrm{AdCO}_{2} \mathrm{H}(15 \mathrm{~mol} \%)$ & $20^{[b]}$ \\
\hline
\end{tabular}

\subsubsection{Well-defined Complexes as Catalyst}

In chapter 3.3.2 it was shown that the tert-butylbenzene complex $\mathbf{1 2 6}$ is equally active under standard conditions. Keeping in mind that tert-butylbenzene might be a non-innocent solvent, which could induce ligand exchange and therefore falsify a comparison of catalysts in tert-butylbenzene, the reaction in 1,4-dioxane was studied. The reaction was monitored by ${ }^{19} \mathrm{~F}$ NMR spectroscopy (Figure 23).

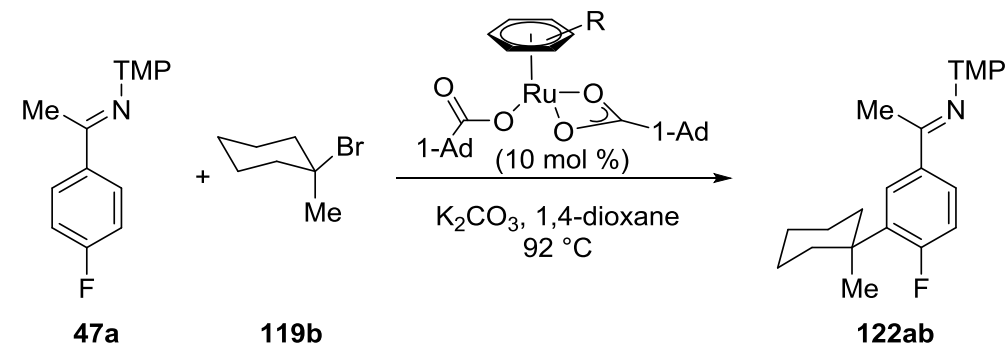



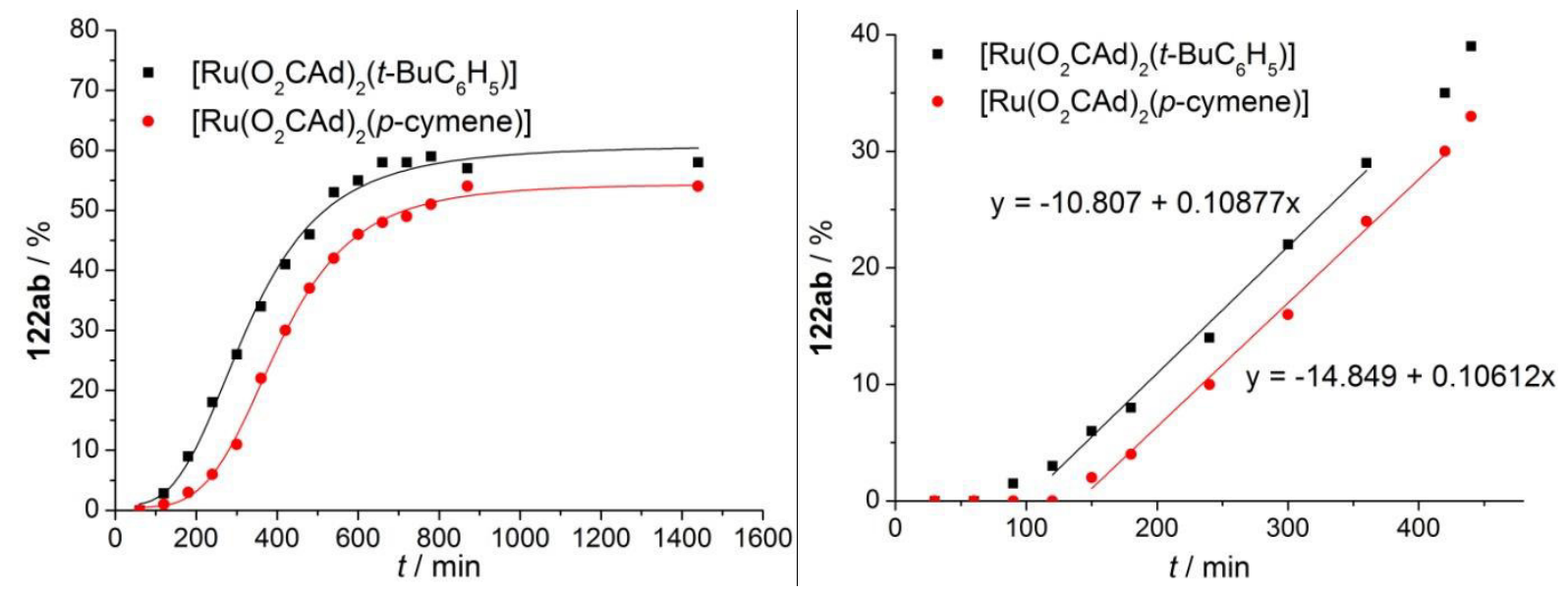

Figure 23. Comparison of the catalyric activity of $\left[\mathrm{Ru}\left(p-\mathrm{BuC}_{6} \mathrm{H}_{5}\right)\left(\mathrm{O}_{2} \mathrm{CAd}\right)_{2}\right]$ and $[\mathrm{Ru}(p$ cymene) $\left(\mathrm{O}_{2} \mathrm{CAd}\right)_{2}$ in the meta-alkylation of ketimine $47 \mathrm{a}$.

The tert-butylbenzene catalyst $\mathbf{1 2 6}$ indeed showed significantly higher conversion to the product. Interestingly, the initial rate appears to be nearly the same, but the induction period is significantly longer for para-cymene complex 129. Hence, a ligand effect is observed but it is not clear how this influences the reaction. One possible explanation is an effect of the electronics, which is especially prone in the para- (C4) position. As can be seen in the chemical shift in the ${ }^{13} \mathrm{CNMR}$, where a significant highfield shift is observed for C4 in $\mathbf{1 2 6}$ compared to 129 (Figure 24), thus indicating a stronger interaction to ruthenium. But the bulky tert-butyl substituent could also simply facilitate the dissociation of the $\eta^{6}$ arene ligand and thus far it is not completely clear if the $\eta^{6}$ arene ligand stays attached during the catalytic cycle.
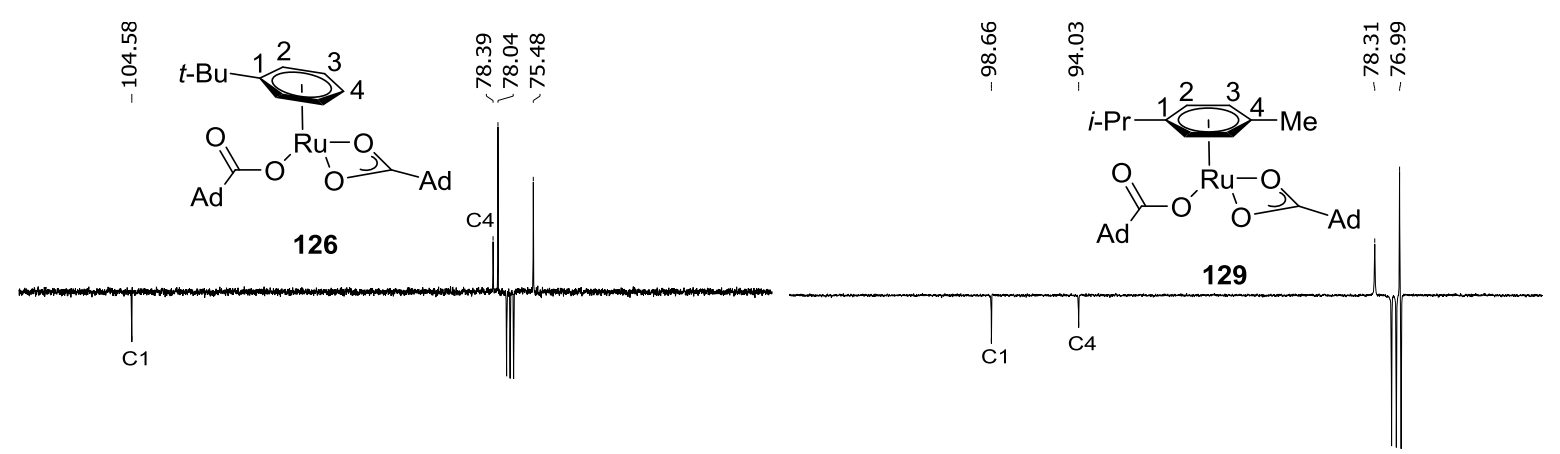

$\begin{array}{lllllllllllllllllllllllllll}110 & 105 & 100 & 95 & 90 & \begin{array}{c}85 \\ \mathrm{f} 1(\mathrm{ppm})\end{array} & 80 & 75 & 70 & 65 & 60 & 109 & 106 & 103 & 100 & 97 & 94 & 91 & 88 & 85 & 82 & 79 & 76 & 73 & 76\end{array}$

Figure 24. Comparison of ${ }^{13} \mathrm{C}$ NMR spectra of 126 and 129. 
To gain a deeper understanding of the mode of action, the alkylation of phenylpyridine $\mathbf{3 2}$ with potential reaction intermediates was probed.

First, catalyst $\mathbf{1 3 0}$ without carboxylate or mono-protected amino acid (MPAA) as ligand was subjected to the reaction (Scheme 105a) and no reaction was observed. Interestingly also no alkylation of the cyclometalated phenylpyridine was observed. Adding MPAA 112 restored the activity of the catalyst and the expected product 121ca as well as the alkylated ligand 121aa was observed (Scheme 105b). Hence, the MPAA, i.e. carboxylate, not only promotes the cycloruthenation as observed before, ${ }^{[31]}$ but also enables the alkylation of the already cyclometalated phenylpyridine.
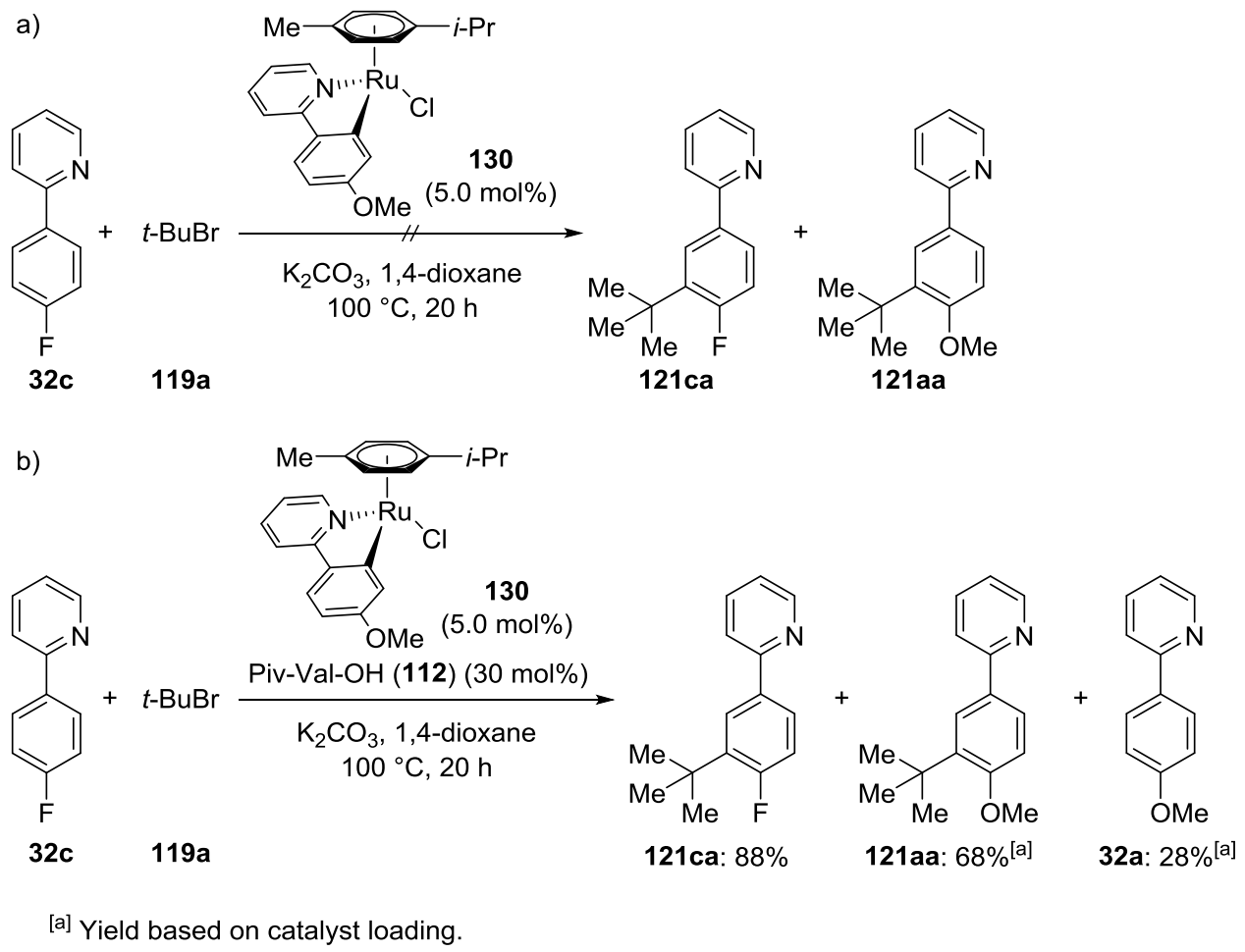

Scheme 105. Reactivity of ruthenium(II) complex $\mathbf{1 3 0}$ bearing a chloride ligand, a) without and b) with MPAA 112 as additive.

Catalysts with either a carboxylate or MPAA attached, efficiently transformed the phenylpyridine 32 (Scheme 106). Interestingly, in case of mesitylate complex $\mathbf{3 3}$ no alkylation of the ligand was observed. As the fluorinated substrate showed higher activity in the meta-alkylation, ${ }^{[129 a]}$ this could be caused by a faster ligand exchange in case of mesityl carboxylate as ligand than MPAA 112. 
a)
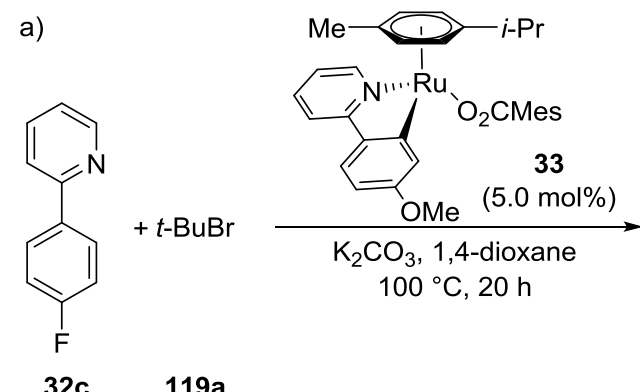

$32 c$

$119 a$

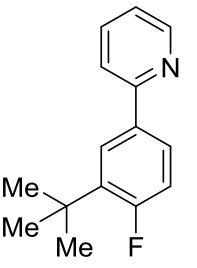

121ca: $92 \%$

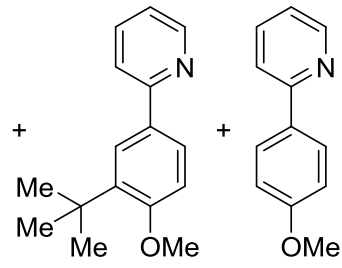

121aa: $<5 \%^{\text {a }}$ 32a: $80 \%^{[a]}$

b)<smiles>CC(C)(C)[14CH3]</smiles>

[Ru(O-Val-Piv $)_{2}(p$-cymene $\left.)\right]$ (111) $(5.0 \mathrm{~mol} \%)$

$\mathrm{K}_{2} \mathrm{CO}_{3}, 1,4$-dioxane $100^{\circ} \mathrm{C}, 20 \mathrm{~h}$

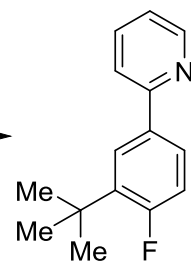

$32 \mathrm{C}$

$119 a$

121ca: $68 \%$

[a] Yield based on catalyst.

Scheme 106. Reactivity of ruthenium(II) complexes 33 and 111 bearing a carboxylate or MPAA ligand.

\subsubsection{Studies regarding the alkylation step}

The mechanistic studies discussed above suggested a CMD or AMLA type cyclometallation with carboxylate or MPAA assistance, as observed in similar ortho-alkylations. ${ }^{[4 a, 360,41]}$ But the following step leading to the alkylation is however not unfolded yet. Several modes of action were reasonable for the activation of the alkyl bromide $\mathbf{1 1 9}$ (Table 13). 
Table 13. Possible activation pathways for meta-alkylations.<smiles>[R]c1ccc(-c2ccccn2)c([R])c1</smiles>

\begin{tabular}{ccc} 
entry & Mode of activation & Substrate \\
\hline 1 & $\mathrm{~S}_{\mathrm{N}} 2$ & Radical \\
2 & Nucleophilic substitution at & pyridinium salt \\
4 & Hydroarylation & \\
5 & Activation by second ruthenium & species
\end{tabular}

With ruthenium attached to phenylpyridine, an activation of the phenyl ring is expected in ortho and meta-position for electrophilic aromatic substitution. This activation was observed before in the halogenation and nitration of cyclometalated phenylpyridines with osmium and ruthenium as the metal (Scheme 29 , page 16). ${ }^{[56-58]}$ Hence, the likelihood of an electrophilic aromatic substitution was studied. Already at an early point of these studies, N. Hofmann showed an $\mathrm{S}_{\mathrm{N}} 2$ reaction pathway to be unlikely as enantiopure secondary alkyl bromide 49a racemized during the reaction and thus suggested a planarization process during the reaction (Scheme 107a). ${ }^{[42]}$ S. De Sarkar probed if a $\mathrm{S}_{\mathrm{N}} 1$ mechanism via a cationic species is likely. Therefore, he subjected a substrate prone for WagnerMeerwein rearrangement in the catalytic reaction and no rearrangement was observable (Scheme 107b). ${ }^{[136]}$ Furthermore, Li showed that electron deficient arenes are more reactive (Scheme 107c), hence a simple electrophilic substitution appears to be unlikely. ${ }^{[129 a]}$ 
a)<smiles>COc1ccc([18O])cc1</smiles>

$32 a$

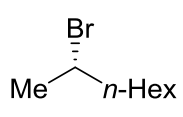

(S)-49a

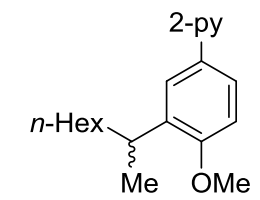

rac-131a: $53 \%$ racemic

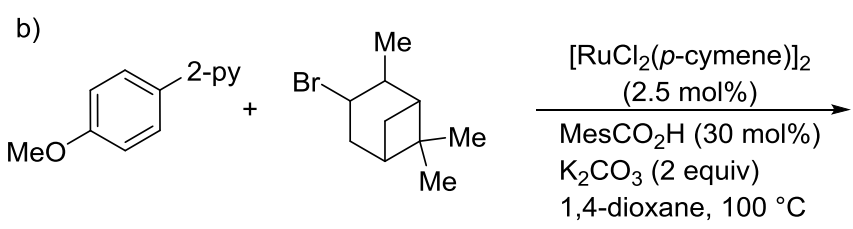

$32 a$

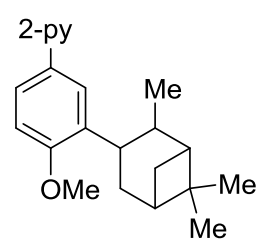

131b: $41 \%$

No rearrangement product was obtained

c)<smiles></smiles>

32c<smiles>COc1ccc([18O])cc1</smiles>

$32 a$
$t-\mathrm{BuBr}$

$\left[\mathrm{RuCl}_{2}(\mathrm{p} \text {-cymene })\right]_{2}$ (2.5 $\mathrm{mol} \%)$ $\underset{\mathrm{K}_{2} \mathrm{CO}_{3}, 1,4 \text {-dioxane }}{\stackrel{\text { Piv-Val-OH (30 mol \%) }}{\longrightarrow}}$ $100^{\circ} \mathrm{C}, 20 \mathrm{~h}$

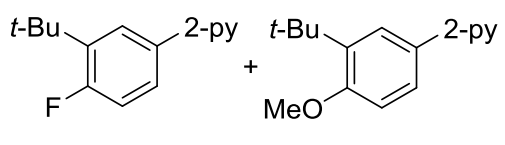

121ca: $26 \%$

121aa: $14 \%$

Scheme 107. Mechanistic studies performed to study the nature of the alkylation step by $\mathrm{N}$. Hofmann and J. Li.

Further tests approached the possibility of in situ formation of alternative active substrates derived from secondary or tertiary alkyl halides 49 and 119 (Scheme 108). First, the formation of a pyridinium salt 132 was tested and no conversion was observed (Scheme 108a). Another possibility is an elimination reaction, thus the corresponding alkenes $\mathbf{1 3 b}$ and $\mathbf{1 3 c}$ were tested (Scheme $108 \mathrm{~b}$ and $\mathrm{c}$ ). As $\mathrm{KHCO}_{3}$ would be formed during the elimination, also the influence of the latter as additive was tested. All reactions showed no conversion, hence this activation mode can be discarded. 
a)<smiles>COc1ccc([18O]c2ccc([18OH])cc2)cc1</smiles>

b)<smiles>COc1ccc([18O])cc1</smiles>

$32 a$<smiles>[X]C1=CCCCC1</smiles>

13b

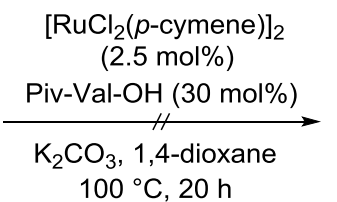

$100{ }^{\circ} \mathrm{C}, 20 \mathrm{~h}$

with or without $\mathrm{KHCO}_{3}$<smiles>COc1ccc([18O])cc1C1(C)CCCCC1</smiles>

$121 \mathrm{ab}$

c)<smiles>C=C1CCCCC1</smiles>

$\left[\operatorname{RuCl}_{2}(p \text {-cymene })\right]_{2}$

$(2.5 \mathrm{~mol} \%)$

$\underset{\mathrm{K}_{2} \mathrm{CO}_{3}, 1,4 \text {-dioxane }}{\stackrel{\text { Piv-Val-OH (30 mol\%) }}{\longrightarrow}}$

$100^{\circ} \mathrm{C}, 20 \mathrm{~h}$

with or without $\mathrm{KHCO}_{3}$

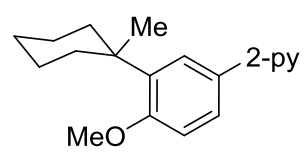

$121 \mathrm{ab}$

Scheme 108. Reactivity of possible in situ formed active substrates.

The radical inhibitor TEMPO was tested by $\mathrm{N}$ Hofmann ${ }^{[42]}$ and J. $\mathrm{Li}^{[129 a]}$ as a radical pathway could be envisioned. Hampering of the reaction was then observed. Additionally, S. De Sarkar subjected alkyl halide $49 \mathrm{c}$ with a cyclopropane moiety to the reaction, ${ }^{[129 a]}$ even though the product $131 \mathrm{~d}$ with intact cyclopropane is the major product, a minor product displaying ring-opening can be observed (Scheme 109). These results indicate a radical pathway with a very fast radical rebound, close to the reaction rate of the ring-opening of cyclopropylmethylene radical, which is reported to be $7.0 \cdot 10^{7} \mathrm{M}^{-}$ ${ }^{1} S^{-1} \cdot[137]$<smiles>COc1ccc([18O]c2ccc([18O])c([18OH])c2)cc1</smiles>

Scheme 109. Hints for a radical pathway, reactions performed by S. De Sarkar.

The question now arose how the radical is formed. Therefore, the stoichiometric alkylation was studied in more detail. 
Table 14. Alkylation of cyclometalated complex 33. ${ }^{[a]}$

\begin{tabular}{|c|c|c|c|c|}
\hline \multirow[b]{2}{*}{ entry } & OMe & $t-\mathrm{BuBr}$ & $\underset{\mathrm{Me}}{\mathrm{Me}} \underset{\mathrm{MeO}^{-}}{\mathrm{Me}}$ & \multirow[b]{2}{*}{ Note } \\
\hline & \multicolumn{2}{|c|}{ Additive (equiv) } & Yield & \\
\hline 1 & \multicolumn{2}{|c|}{--- } & --- & \multirow{7}{*}{ Without $\mathrm{K}_{2} \mathrm{CO}_{3}$} \\
\hline 2 & \multicolumn{2}{|c|}{--- } & --- & \\
\hline 3 & \multicolumn{2}{|c|}{$\mathrm{HO}_{2} \mathrm{CMes}(2.0)$} & --- & \\
\hline 4 & \multicolumn{2}{|c|}{$\left[\mathrm{Ru}\left(\mathrm{O}_{2} \mathrm{CMes}\right)_{2}(p\right.$-cymene $\left.)\right](1.0)$} & --- & \\
\hline 5 & \multicolumn{2}{|c|}{$\mathrm{RuCl}_{3}(4.0)$} & --- & \\
\hline 6 & \multicolumn{2}{|c|}{$\mathrm{FeBr}_{3}(2.0)$} & --- & \\
\hline 7 & \multicolumn{2}{|c|}{ DMAP (2.0) } & --- & \\
\hline 8 & \multicolumn{2}{|c|}{$\begin{array}{l}\text { 4-methoxy-2-phenylpyridine } \\
\text { (32a) (2.0) }\end{array}$} & $17 \%$ & $\begin{array}{l}\text { Combined yield of } \\
\text { ligand and additive }\end{array}$ \\
\hline
\end{tabular}

It appeared that no alkylation occured in the absence of additives, thus the active radical species is not formed under these conditions (Table 14, entries 1 and 2). Additional carboxylate as ligand or the catalyst also failed to provide the product 121aa (entries 3 and 4). Lewis acids, such as ruthenium(III) chloride or iron(III) bromide did not catalyze the reaction (entries 5 and 6), this further weakened the hypothesis of an electrophilic substitution manifold. To exclude problems of the reaction caused by different concentrations and dilutions compared to the catalytic reaction regarding the complex, additional phenylpyridine 32a was added. The product formed, albeit in a low yield (entry 8).

To probe the influence of phenylpyridine on the stoichiometric alkylation different phenylpyridines $\mathbf{3 2}$ and also pyridines $\mathbf{1 3 4}$ were tested and, besides sterically very demanding and free pyridine, all proved capable to facilitate the reaction (Table 15, entries 1-10). These results suggested that phenylpyridine in the catalytic reaction is not only a reagent but also functioned as ligand, which enabled the activation of the alkyl halide. Interestingly, no yields above $50 \%$ were obtained, which could suggest that a second ruthenium species with additional pyridine ligands acts as activator. Therefore, the bispyridine complex $\left[\mathrm{Ru}(\text { bipy })_{3} \mathrm{Cl}_{2}\right]$ was used instead of pyridine as additive but no product formation has been observed (entry 11). It also seemed that two equivalents of the ligand are required to obtain the optimum conversion (entries 1-3). Interestingly, the yield did not improve with additional ruthenium(II) complex (entries 12-14). 
Table 15. Stoichiometric alkylation with pyridines as additive. ${ }^{[a]}$

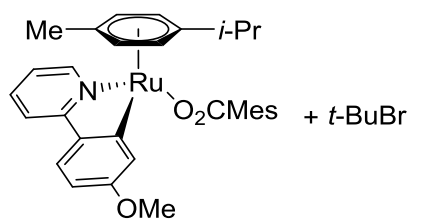

33

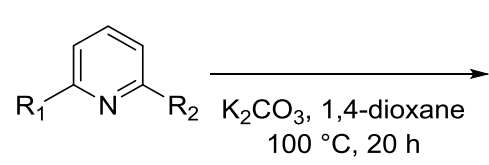

$32 / 134$<smiles>COc1ccc([Te])cc1C(C)(C)C</smiles>

121 aa

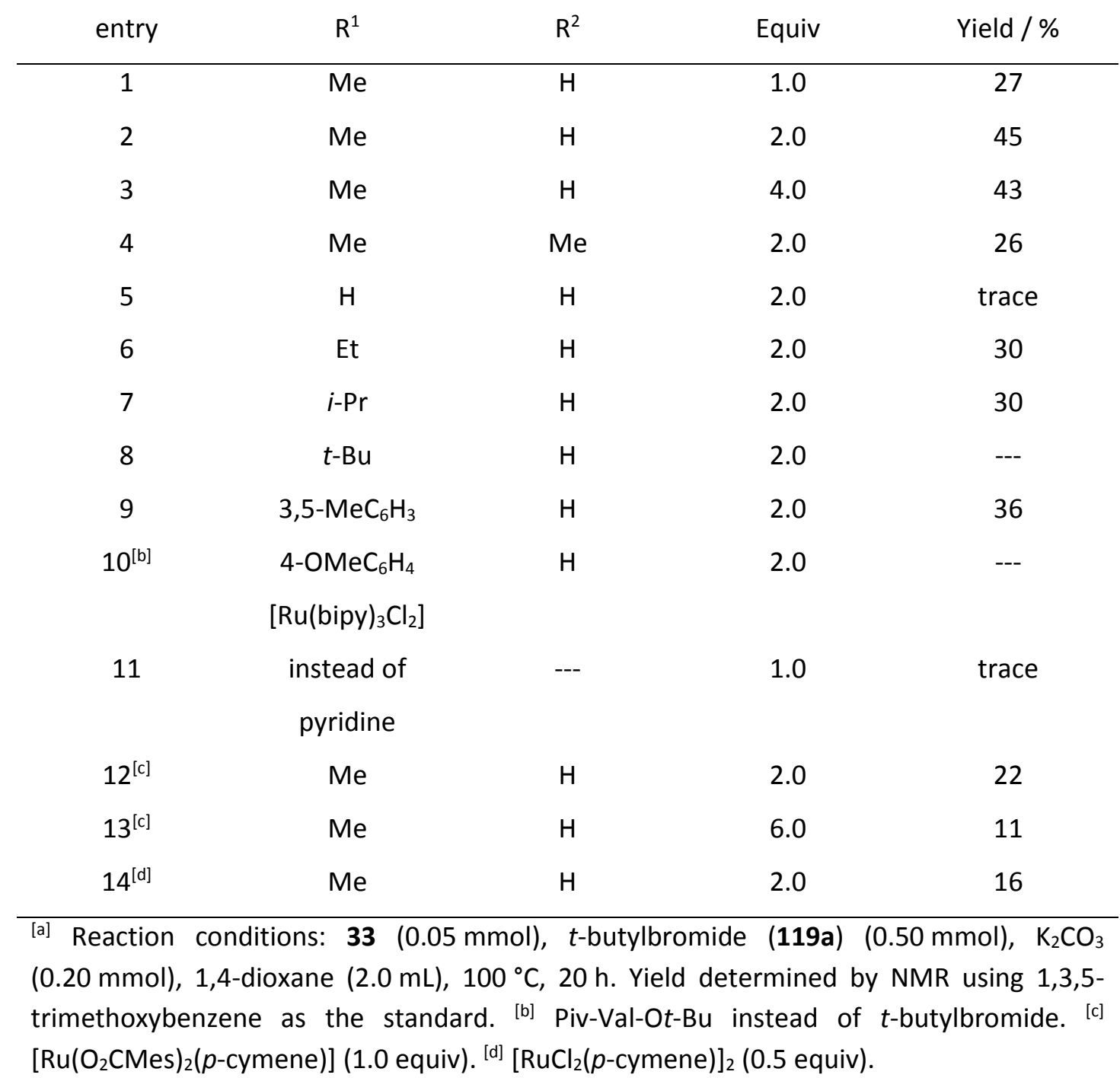

These results are in contrast to the observations by Frost in the meta-selective sulfonylation, where functionalization takes place by simply applying the cyclometalated complex instead of phenylpyridine to the reaction conditions. ${ }^{[59 b]}$ Thus, the same reaction was performed with tert-butyl bromide (119a) instead of sulfonyl chloride (63) but no conversion was observed, besides some ligand exchange derived from the solvent (Scheme 110). 
Results and Discussion

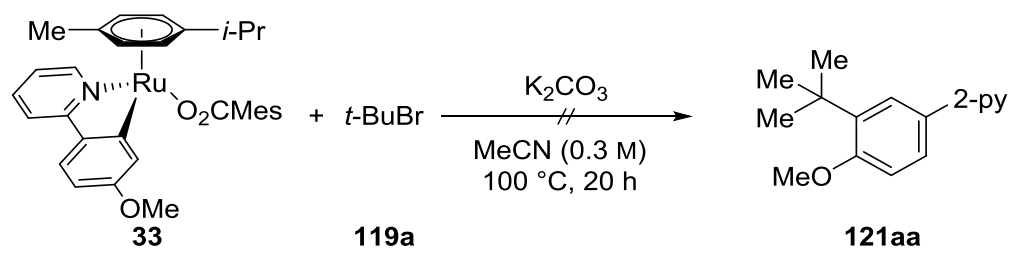

Scheme 110: Reactivity of cyclometalated complex 33 under Frosts conditions.

Attempts to install a $\sigma$-tert-butyl ligand on the cyclometalated complex $\mathbf{1 3 0}$, in order to test for the likelihood of such an intermediate, were thus far not successful (Scheme 111).
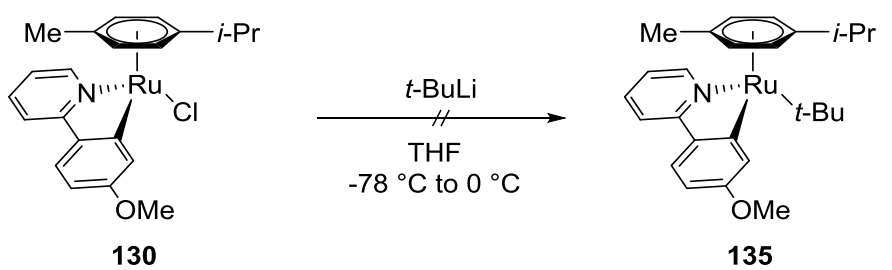

Scheme 111. Attempt to synthesize alkyl complex 135.

Further studies centered on the release of the alkylated product from ruthenium. The release via protodemetalation requires acidic conditions. Interestingly, tert-butyl bromide was efficient in the protonation, which is most likely caused by in situ formation of $\mathrm{HBr}$ by elimination. To release the product not only a proton source but also an additional ligand, like bispyridine, is required (Scheme 112). Besides tert-butyl bromide, hydrochloric acid was also able to induce protodemetalation. Potassium bicarbonate and tert-butyl chloride could not enable the Ru-C bond breakage.
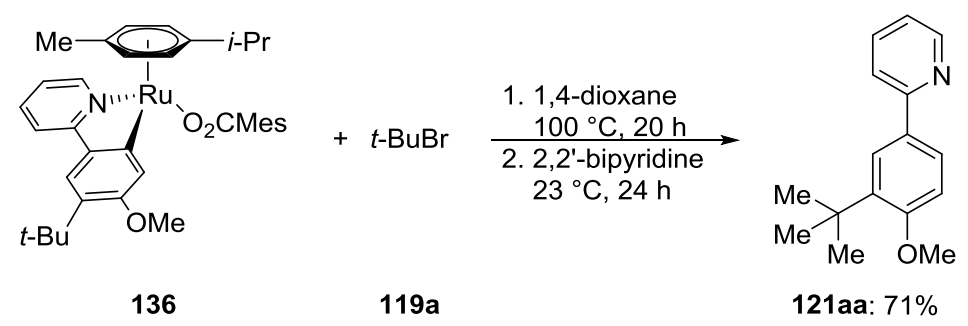

Scheme 112. Release of the alkylated product 121aa from ruthenium complex 136.

Studies with deuterated alkyl halide $\left[D_{9}\right]$-119a showed deuterium incorporation in the ortho-position of the product 121aa as well as the starting material 32a, showing the dual role of the alkyl halide as alkylating agent and proton source. Furthermore, the deuterium incorporation in the starting material and ortho to the alkyl group suggested the cyclometalation to be reversible, which was confirmed by J. Li upon using $\mathrm{D}_{2} \mathrm{O}$ as co-solvent. ${ }^{[129 a]}$ 


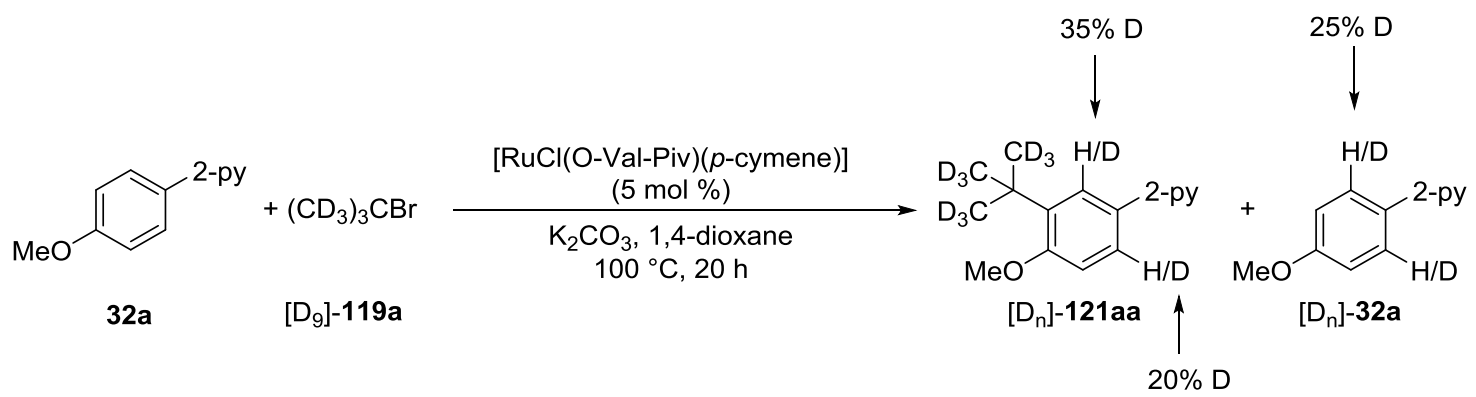

Scheme 113. Deuteration Study.

On the basis of this detailed mechanistic studies, the following catalytic cycle is proposed (Figure 25). First, the ruthenium(II) MPAA complex 114 undergoes cycloruthenation, the $\mathrm{C}-\mathrm{H}$ ruthenation is reversible. This complex $\mathbf{1 1 6}$ then reacts with a tertiary radical, which has probably been generated via SET processes with a yet undefined ruthenium species. This species most likely has more than one phenylpyridine as ligand attached. The radical on complex 137 is afterwards transferred to the previously formed ruthenium(III) species, reducing it to ruthenium(II). At the same time the aromaticity is restored by deprotonation. The last step consists of the proto-demetalation, the required proton can be released from the alkyl halide via elimination. The product is thereby released and the active catalyst restored. 
Results and Discussion

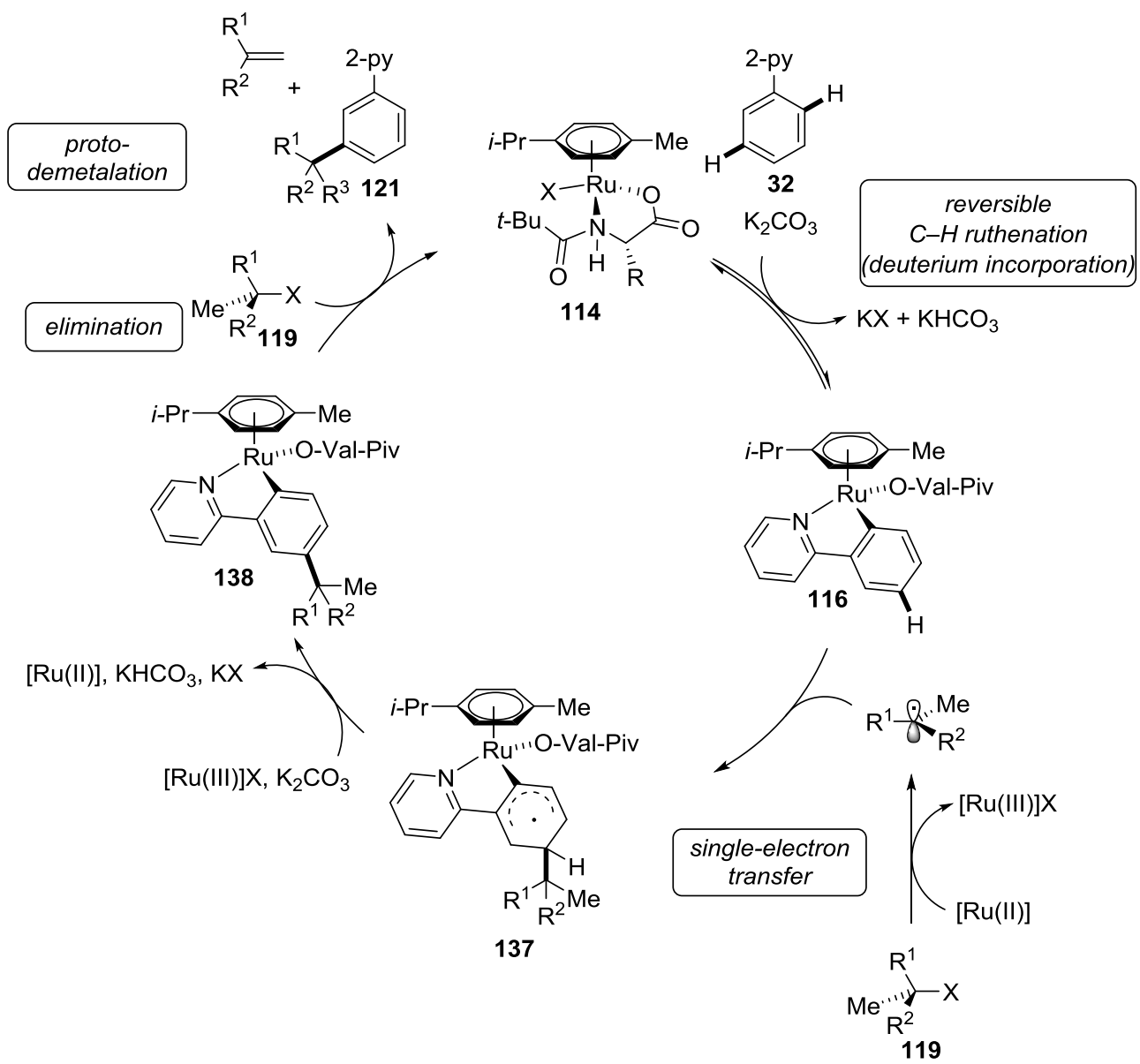

Figure 25. Proposed mechanistic cycle for the ruthenium(II)-catalyzed meta-alkylation. 


\subsection{Immobilization of Ruthenium Catalysts}

The design of recyclable catalysts is highly desirable as it can limit the required amount of transition metal by reusing the catalyst and furthermore contamination of the product by the catalyst is inherently reduced. ${ }^{[73]}$ Besides recent progress, heterogeneous, reusable catalysts for the functionalization of otherwise unreactive $\mathrm{C}-\mathrm{H}$ bonds are still scarce. ${ }^{[73]}$ Hence, one part of this thesis focused on the development of reusable ruthenium catalysts for $\mathrm{C}-\mathrm{H}$ bond functionalizations.

\subsubsection{Synthesis of Ruthenium-Sol-Gel Catalysts}

At the outset of this study, several sol-gel derived catalysts were synthesized according to standard literature procedures. ${ }^{[138]}$ Some synthetic procedures resulted in strong leaching and were therefore not suitable (Scheme 114).

$$
\begin{aligned}
& {\left[\mathrm{RuCl}_{2}(p \text {-cymene })\left(\mathrm{PPh}_{3}\right)\right]+\mathrm{Si}(\mathrm{OMe})_{4}} \\
& \underset{\mathrm{THF}}{\stackrel{\mathrm{NEt}_{2} \mathrm{O}}{\longrightarrow}} \mathrm{Ru@SiO} \\
& 23^{\circ} \mathrm{C}, 18 \mathrm{~h} \\
& {\left[\mathrm{RuCl}_{2}(p \text {-cymene })\right]_{2}+\mathrm{Si}(\mathrm{OMe})_{4}}
\end{aligned}
$$

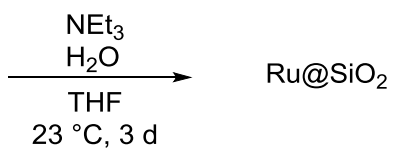

$$
\begin{aligned}
& {\left[\mathrm{RuCl}_{2}(p \text {-cymene })\right]_{2}+\mathrm{Si}(\mathrm{OMe})_{4}} \\
& \text { TBAF } \\
& \underset{\mathrm{THF}, \mathrm{CHCl}_{3}}{\longrightarrow} \\
& 23^{\circ} \mathrm{C}, 24 \mathrm{~h} \\
& {\left[\mathrm{RuCl}_{2}(p \text {-cymene })\right]_{2}+\mathrm{Si}(\mathrm{OEt})_{4}+\int_{\mathrm{HO}}^{\mathrm{OH}} \frac{\mathrm{H}_{2} \mathrm{O}}{\underset{\mathrm{EtOH}}{60-23{ }^{\circ} \mathrm{C}}}} \\
& \mathrm{Ru} @ \mathrm{SiO}_{2} \\
& \mathrm{Ru} @ \mathrm{SiO}_{2}
\end{aligned}
$$

Scheme 114. Strongly leaching sol-gel derived ruthenium catalysts.

Another attempt was to use a carboxylate ligand attached to silica particles. Unfortunately, also here strong leaching of the catalyst was observed (Scheme 115). 


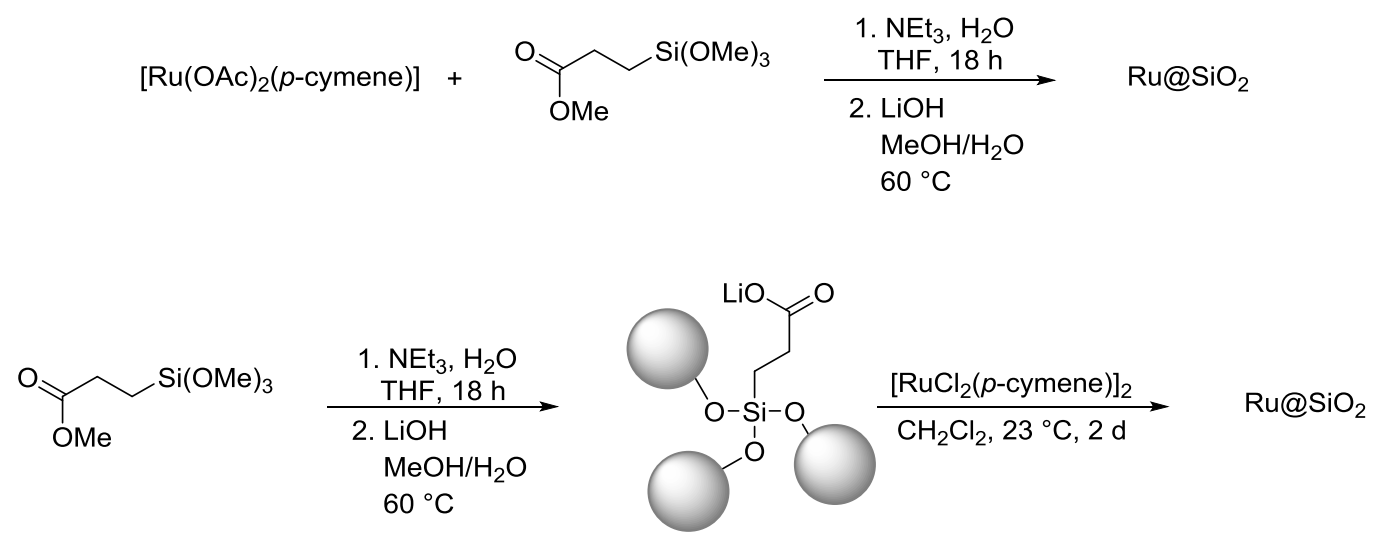

Scheme 115. Efforts to install ruthenium on ligands attached to silica.

Starting from carboxylate complexes or the cationic complex 139, no leaching was observed in the obtained products (Scheme 116). The base-catalyzed procedure is in accordance with a published procedure from Avnir, Schumann and Blum ${ }^{[138]}$ for similar compounds.

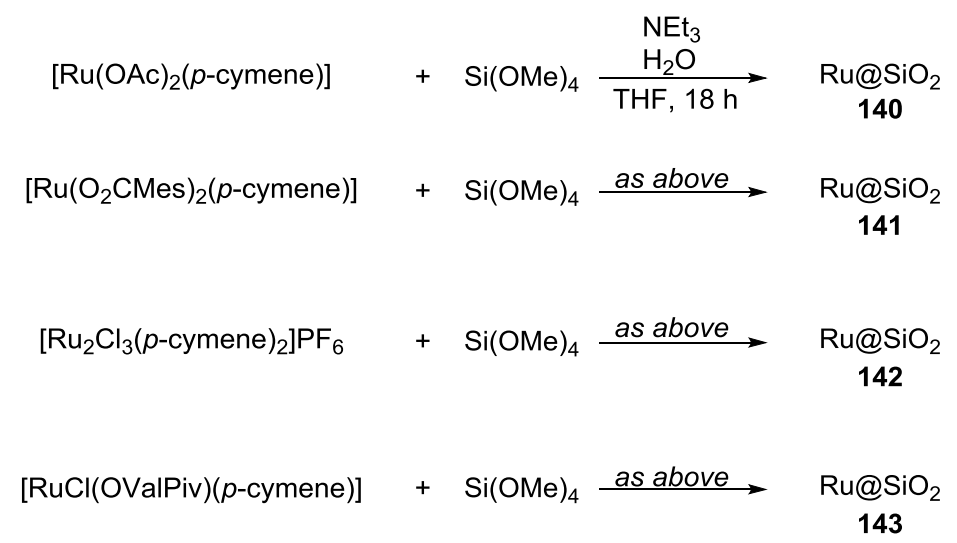

Scheme 116. Successful synthesis of ruthenium entrapped catalysts.

First trials showed no influence of the $O$-ligand (acetate, mesitylcarboxylate, MPAA) on the catalytic activity in the oxidative alkyne annulations. The catalyst 142, which was obtained from the cationic complex 139, delivered even reduced yields. As the yields of these reactions continued to be low, no further attempts regarding this oxidative transformation were made.

Furthermore, a synthesis analogue to a procedure published by Mizukami ${ }^{[82]}$ with ethylene glycol proved successful (Scheme 117). In this case only the last step, the reduction of ruthenium in a hydrogen stream was not performed. 


$$
\mathrm{RuCl}_{3} \cdot \mathrm{H}_{2} \mathrm{O}+\mathrm{Si}(\mathrm{OEt})_{4}+\int_{\mathrm{HO}}^{\mathrm{OH}} \stackrel{\mathrm{H}_{2} \mathrm{O}}{\mathrm{EtOH}} \underset{\begin{array}{c}
\mathrm{Ru} @ \\
\mathrm{SiO}_{2}
\end{array}}{144}
$$

Scheme 117. Polyol method for the synthesis of a heterogeneous ruthenium catalyst.

It is noteworthy that already small changes of the reaction conditions completely changed the appearance and catalytic potency of the catalyst 144. Analyses of the catalyst materials employing SEM and XPS were performed by J. Scholz. ${ }^{[139]}$ Images obtained with a SEM showed the particle size no to be completely homogeneous, besides small particles $(<100 \mathrm{~nm})$, also larger particles were observed.
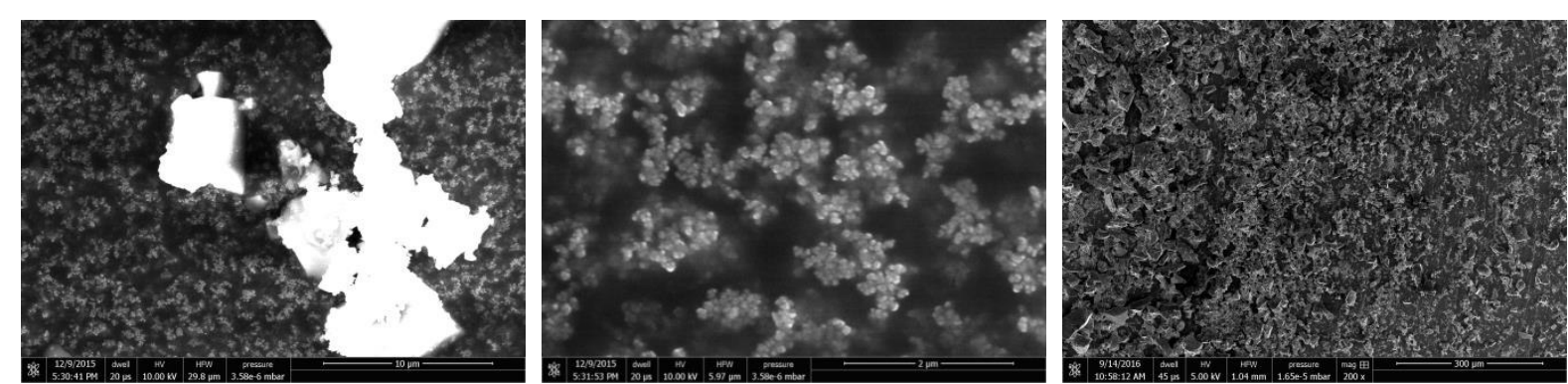

Figure 26. SEM analysis of 144.

XPS studies showed a second minor ruthenium species and traces of chloride (Figure 27). The oxidation state of ruthenium could not be clearly determined. IR analysis showed the Ru-O band to be shifted to higher wavenumbers compared to $\mathrm{RuO}_{2}$, indicating $\mathrm{Ru}-\mathrm{O}-\mathrm{Si}$ bonds. ${ }^{[140]}$

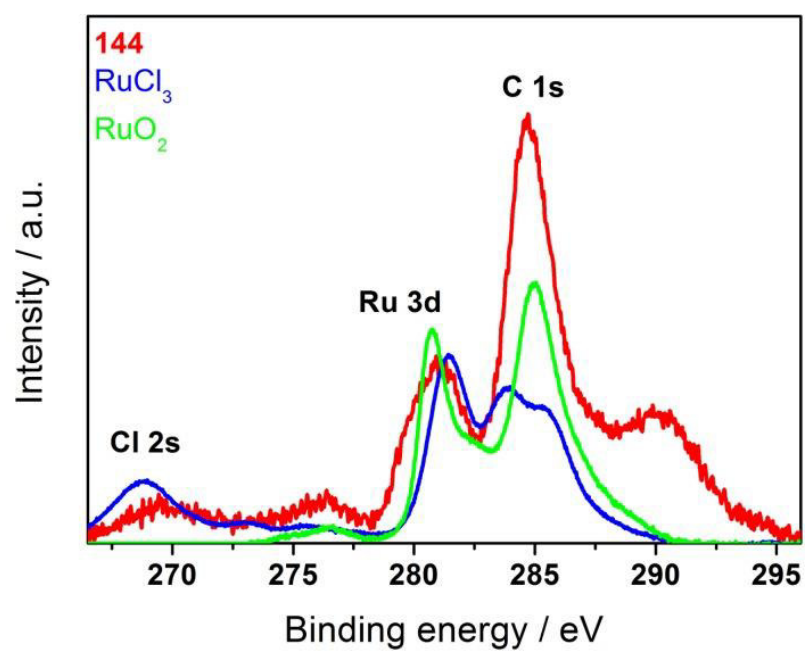

Figure 27. XPS study of catalyst 144 . 


\subsection{2 meta-Selective Bromination of Purine Bases}

Recent progress in transition metal-catalyzed $\mathrm{C}-\mathrm{H}$ functionalizations enabled selective remote transformations of otherwise unreactive $\mathrm{C}-\mathrm{H}$ bonds. $\left.{ }^{[44 a-c,}, 44 \mathrm{e}-\mathrm{g}\right]$ Especially halogenations provide interesting transformations, because aryl halides can be easily further functionalized. So far, this approach is limited to pyridines, pyrazoles and pyrimidines. ${ }^{[60]}$

Unnatural nucleosides are of major interest and can be applied, amongst others, as antivirals and anticancer agents. ${ }^{[91]}$ Therefore, the functionalization of purine bases is highly desirable to achieve differently functionalized structures, which could possibly show biological activity. D. J. Burns and Ackermann ${ }^{[141]}$ developed a homogeneous system for the meta-selective $\mathrm{C}-\mathrm{H}$ bromination of purine bases 85 (Scheme 118).

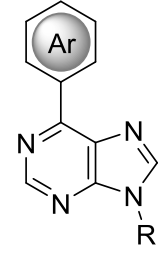

85

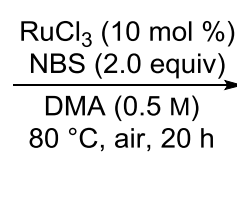

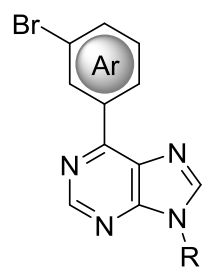

86: $53-77 \%$

Scheme 118. Optimized conditions for the homogeneous meta-bromination of purine bases 85 .

Intrigued by these findings several heterogeneous catalysts were probed in this reaction. The commercially available ruthenium on alox catalyst showed no reactivity at all and also literature known ruthenium on magnetite only gave low conversion (Table 16, entries 1-2). As the bromination worked with ruthenium(II) and ruthenium(III) catalysts in a homogeneous fashion, ruthenium(IV) oxide was also subjected to the reaction conditions, but did not show any activity (entry 3). However, sol-gel derived catalyst $\mathbf{1 4 4}$ led to the product in good yields (entry 5) and the catalyst loading could even be reduced, albeit with a slight decrease in the obtained yield (entries 10-11). Notably, a reduction of the catalyst was not viable in the homogeneous reaction.

Table 16. Optimization of the meta-bromination of phenylpurine $85 a{ }^{\text {[a] }}$

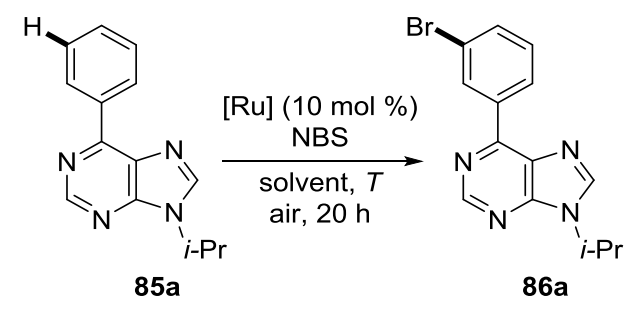

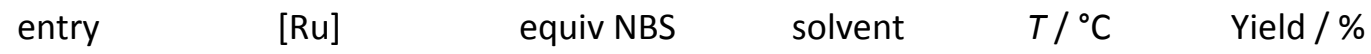




\begin{tabular}{|c|c|c|c|c|c|}
\hline 1 & $\mathrm{Ru} / \mathrm{Al}_{2} \mathrm{O}_{3}$ & & DMA & 80 & --- \\
\hline 2 & $\mathrm{Ru}(\mathrm{OH})_{3} \cdot \mathrm{Fe}_{3} \mathrm{O}_{4}$ & 2 & DMA & 80 & 5 (NMR) \\
\hline 3 & $\mathrm{RuO}_{2}$ & & DMA & 80 & --- \\
\hline 4 & 144 & 2 & DMA & 80 & $61(16 h)$ \\
\hline 5 & 144 & 2 & DMA & 80 & 73 \\
\hline 6 & 144 & 2 & DMA & 120 & --- \\
\hline 7 & 144 & $2+2$ & DMA & 80 & 54 \\
\hline 8 & 140 & 2 & DMA & 80 & 30 \\
\hline 9 & 144 & 2 & $\mathrm{DMA} / \mathrm{H}_{2} \mathrm{O}$ & 80 & --- \\
\hline $10^{[b]}$ & 144 (5 mol \%) & 2 & DMA & 80 & 68 \\
\hline $11^{[b]}$ & $144(2.5 \mathrm{~mol} \%)$ & 2 & DMA & 80 & 50 \\
\hline
\end{tabular}

[a] Reaction conditions: 85a $(0.25 \mathrm{mmol}), \mathrm{NBS}(0.50 \mathrm{mmol})$, catalyst $(10 \mathrm{~mol} \%), \mathrm{DMA}$ $(0.50 \mathrm{~mL}), 80^{\circ} \mathrm{C}, 20 \mathrm{~h}$ under air. Yield of isolated product. ${ }^{[\mathrm{b}]}$ Reaction performed by $\mathrm{K}$. Korvorapun. ${ }^{[141]}$

The scope of the homogeneous meta-bromination of phenyl purines 85 is shown in Scheme 119 , noteworthy is the direct drop in yield when reducing the catalyst loading to $5 \mathrm{~mol} \%$, while the heterogeneous catalyst still provided comparable yields (Table 16, entry 10).<smiles>c1ccc(-c2ncnc3[nH]cnc23)cc1</smiles>

$85 \mathrm{R}$

\section{$\mathrm{RuCl}_{3} \cdot \mathrm{H}_{2} \mathrm{O}(10 \mathrm{~mol} \%)$} NBS ( 2 equiv) DMA, $80^{\circ} \mathrm{C}$ air, $20 \mathrm{~h}$

$\mathrm{R}^{1}=\mathrm{H}(\mathbf{8 6 a}): 77 \%(25 \%)^{[\mathrm{b}]} \mathrm{R}^{2}=n-\mathrm{Bu}(\mathbf{8 6 c}): 62 \%$ $\mathrm{R}^{1}=\mathrm{F}(\mathbf{8 6 b}): 55 \%{ }^{\mathrm{c}} \quad \mathrm{R}^{2}=\mathrm{Ph}(\mathbf{8 6 d}): 53 \%{ }^{[\mathrm{c}]}$

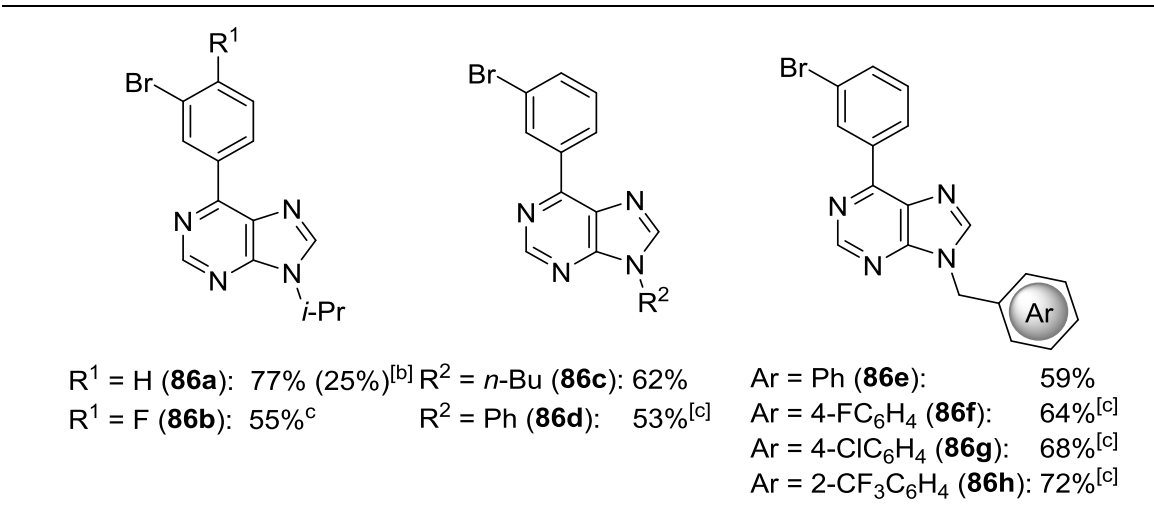<smiles>[R]n1cnc2c(-c3cccc(Br)c3)ncnc21</smiles>

86

[a] Reaction conditions: $85(0.25 \mathrm{mmol}), \mathrm{NBS}(0.50 \mathrm{mmol}), \mathrm{RuCl}_{3} \cdot \mathrm{H}_{2} \mathrm{O}(10 \mathrm{~mol} \%)$, DMA $(0.50 \mathrm{~mL}), 80^{\circ} \mathrm{C}, 20 \mathrm{~h}$ under air. Rections performed by D. J. Burns and C. Zhu. ${ }^{[b]} \mathrm{RuCl}_{3} \cdot \mathrm{H}_{2} \mathrm{O}(5 \mathrm{~mol} \%)$. ${ }^{[\mathrm{c}]}$ At $100{ }^{\circ} \mathrm{C}$.

Scheme 119. Scope of the homogeneous meta-bromination of phenyl purines 85 . Reactions performed by D. J. Burns and C. Zhu. ${ }^{[a]}$ 
The scope of the reaction proved comparable to the homogeneous one, while the substitution pattern on the aromatic motif was somewhat limited, the substituent on the nitrogen atom could be easily diversified (Scheme 120).

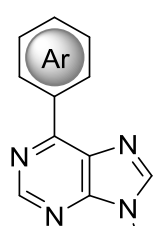

$85^{R}$

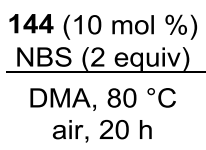

144 (10 mol \%) NBS ( 2 equiv) DMA, $80^{\circ} \mathrm{C}$ air, $20 \mathrm{~h}$

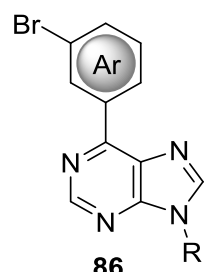<smiles>[R]c1ccc(-c2ncnc3c2ncn3C(C)C)cc1Br</smiles>

$\mathrm{R}^{1}=\mathrm{H}(\mathbf{8 6 a}): 70 \%$

$R^{1}=F(86 b): 48 \%[b]$
$\mathrm{Br}$<smiles>[R]n1cnc2c(-c3cccc(F)c3)ncnc21</smiles>

$\mathrm{Br}$<smiles>Fc1cccc(-c2ncnc3c2ncn3Cc2ccccc2)c1</smiles>

$\mathrm{R}^{2}=n-\mathrm{Bu}(\mathbf{8 6 \mathrm { c }}): 68 \%{ }^{[\mathrm{c}]} \quad \mathrm{Ar}=\mathrm{Ph}(\mathbf{8 6 e}):$

$57 \%$

$R^{2}=P h(86 d)$

Ar $=4-\mathrm{FC}_{6} \mathrm{H}_{4}(86 \mathrm{f})$ :

$\mathrm{Ar}=4-\mathrm{FC}_{6} \mathrm{H}_{4}(\mathbf{8 6 f}): \quad 64 \%{ }^{[\mathrm{c}}$ $\mathrm{Ar}=2-\mathrm{CF}_{3} \mathrm{C}_{6} \mathrm{H}_{4}(86 \mathrm{~h}): 66 \%{ }^{[\mathrm{c}]}$<smiles>Brc1cccc2c1ccc1cccnc12</smiles>

145: $68 \%$

[a] Reaction conditions: 85 (0.25 mmol), NBS (0.50 mmol), 144 (10 mol \%), DMA (0.50 mL), $80{ }^{\circ} \mathrm{C}, 20 \mathrm{~h}$ under air. ${ }^{[b]}$ At $100{ }^{\circ} \mathrm{C} .{ }^{[c]}$ Rection performed by K. Korvorapun.

Scheme 120. Scope of the meta-bromination. ${ }^{[a]}$

It should be noted that arenes with electron-donating substituents showed reactivity in the absence of a catalyst (Scheme 121), albeit in a reduced efficiency.
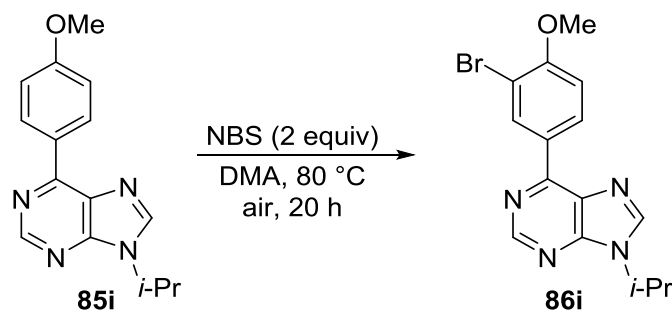

without Ru: $\quad 49 \%$

with $\mathrm{RuCl}_{3} \cdot \mathrm{H}_{2} \mathrm{O}(10 \mathrm{~mol} \%): 80 \%$

Scheme 121. Bromination of purine $85 \mathrm{i}$ in absence of a catalyst, reactions performed by C. Zhu. ${ }^{[141]}$

The reaction with unsubstituted 2-phenylpyridine (32b) gave mainly the meta-bromination but in a difficult to separate mixtures of mono- and di-brominated products. Furthermore, substrates in Scheme 122 were not suitable for the reaction. Delivering either no or very low conversion or 
unselective bromination. $\mathrm{N}$-benzyl-1-phenylethan-1-imine $\mathbf{4 7 d}$ was selectively brominated on the methyl group, which is activated by the neighboring imine.

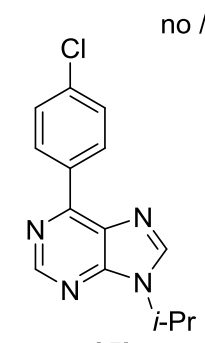

$85 \mathbf{j}$ no / low conversion

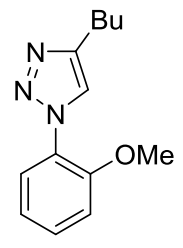

24b

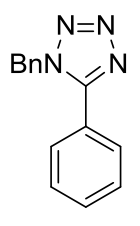

$104 a$ unselective bromination

$\mathrm{MeO}$<smiles>CN=C(C)c1ccccc1</smiles>

47c<smiles>c1ccc(Nc2ncccn2)cc1</smiles>

$118 a$ bromination in other position<smiles>C/C(=N\c1ccccc1)c1ccccc1</smiles>

47d<smiles>CNC(=O)c1ccccc1</smiles>

9a<smiles>c1ccc(C2=NCCO2)cc1</smiles>

$102 c$

Scheme 122. Unsuitable substrates for the meta-bromination.

The huge advantage of heterogeneous catalysts is the usually straightforward recyclability and the chance for reusability of the system. The catalyst could be reused three times with comparable isolated yields (Figure 28). For this purpose the reaction mixture was extracted three times with a hexane $/ \mathrm{CH}_{2} \mathrm{Cl}_{2}$ mixture and centrifuged to separate the solid from the liquid phase, followed by drying the catalyst under vacuum. No reactivation steps were necessary for reusing the catalyst. 
Results and Discussion

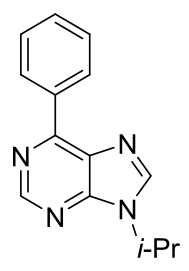

$85 a$

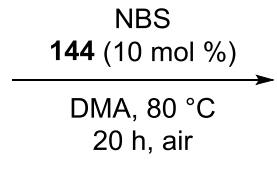

$20 \mathrm{~h}$, air

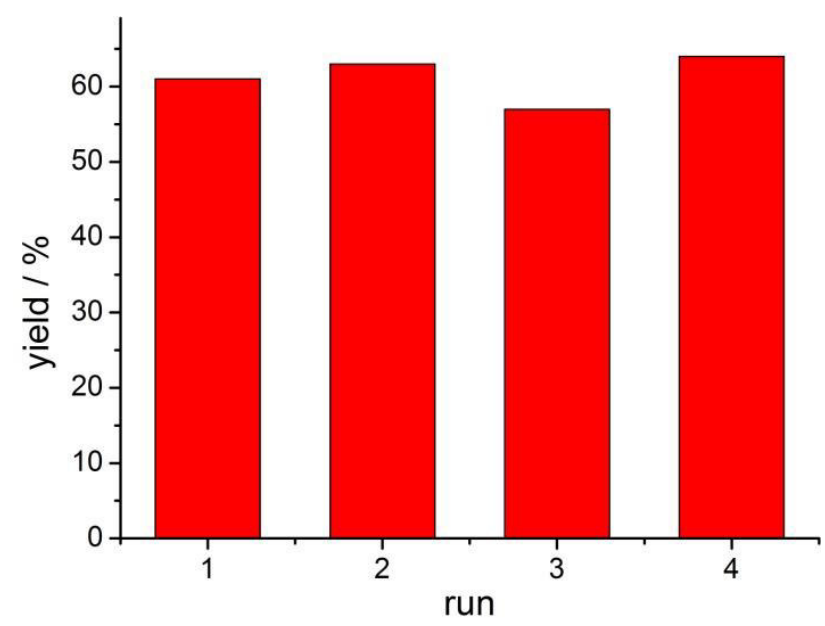

Figure 28. Recycling Studies of the meta-bromination of purine base 85a.

It is noteworthy that the conditions for the recycling are very important. If, on the one hand, the extraction solution of hexane and $\mathrm{CH}_{2} \mathrm{Cl}_{2}$ is altered from a 7:1 to a 5:1 ratio (hexane : $\mathrm{CH}_{2} \mathrm{Cl}_{2}$ ), the reusability of the catalysts is severely diminished, most probably due to a major leaching. Reducing the amount of $\mathrm{CH}_{2} \mathrm{Cl}_{2}$ on the other hand led to reduced efficiency regarding the extraction of the product (Table 17).

Table 17. Influence of solvent mixture for extraction.<smiles>CC(C)n1cnc2c(-c3ccccc3)ncnc21</smiles>

$85 a$

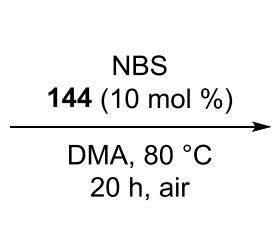

$2^{\text {nd }} \quad 3^{\text {rd }}$

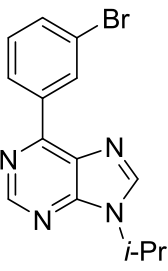

$86 a$

\begin{tabular}{ccccc} 
run & $1^{\text {st }}$ & $2^{\text {nd }}$ & $3^{\text {rd }}$ & Extraction solvent \\
\hline \multirow{2}{*}{ yield (86a) } & $70 \%$ & $61 \%$ & $48 \%$ & $5: 1$ hexane $/ \mathrm{CH}_{2} \mathrm{Cl}_{2}$ \\
& $63 \%$ & $65 \%$ & $55 \%$ & $7: 1$ hexane/ $\mathrm{CH}_{2} \mathrm{Cl}_{2}$ \\
\hline
\end{tabular}


To rule out that the reusability is simply achieved through catalyst precipitation, the same procedure was performed for the homogeneous catalyst ruthenium(III) chloride. The GC-conversion directly dropped by a factor of 1.6 (Scheme 123).<smiles>CC(C)n1cnc2c(-c3ccccc3)ncnc21</smiles>

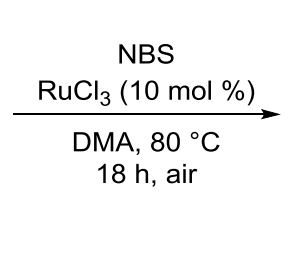<smiles>CC(C)[Pb]n1cnc2c(-c3cccc(Br)c3)ncnc21</smiles>

$1^{\text {st }}$ run $93 \%$ conversion $2^{\text {nd }}$ run $60 \%$ conversion

Scheme 123. Tested recycling of $\mathrm{RuCl}_{3}$.

Even though the heterogeneous catalyst 144 could be reused three times ICP-MS studies showed significant leaching of ruthenium into the crude product (Table 18). Furthermore XPS studies showed a slight difference in the oxidation state of ruthenium and a significant change in the nature of the silica.
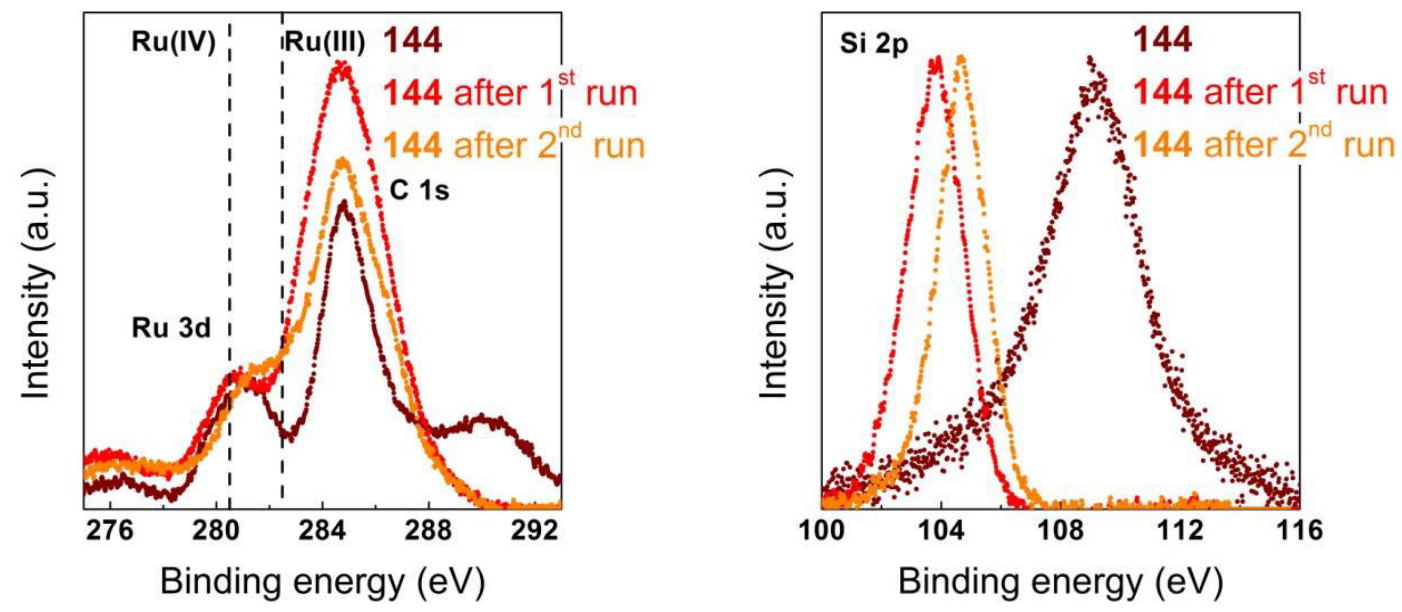

Figure 29. XPS study of the catalyst 144 before, after the first and second run.

Table 18. Leaching of ruthenium into crude product, determined prior to workup procedures.<smiles>CC(C)n1cnc2c(-c3ccccc3)ncnc21</smiles>

$85 a$

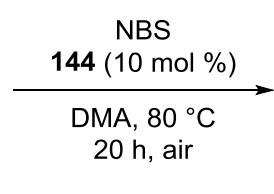<smiles>CC(C)n1cnc2c(-c3cccc(Br)c3)ncnc21</smiles>

$86 a$ 
Results and Discussion

\begin{tabular}{ccc} 
run & $1^{\text {st }}$ & $2^{\text {nd }}$ \\
\hline$[R u]$ & $756 p p m$ & $739 p p m$
\end{tabular}

The usability of the catalyst is limited by the leaching of the catalyst. Therefore, first tests regarding a system with PEG as reusable catalyst-solvent were conducted. The higher yield in the second run is most probably due to a poor extraction after the first run.

Table 19. Using a DMA/PEG mixture to enable recyclability of the system.

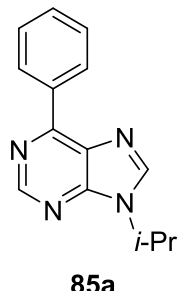

$85 a$

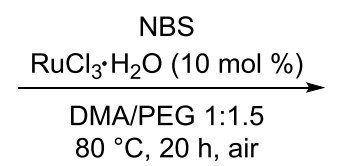

$80{ }^{\circ} \mathrm{C}, 20 \mathrm{~h}$, air

(a)

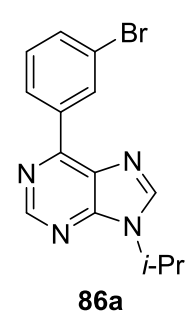

$2^{\text {nd }}$

\begin{tabular}{cll} 
Run & $1^{\text {st }}$ & $2^{\text {nd }}$ \\
\hline Yield / \% & 40 & 62
\end{tabular}

\subsubsection{Mechanistic Studies}

The strong leaching indicates that the reaction might proceed via a catch and release mechanism or fully in a homogeneous fashion. ${ }^{[75]}$ To probe the heterogeneity of the reaction, mercury and hotfiltration tests were performed (Figure 30). 
<smiles>CC(C)n1cnc2c(-c3ccccc3)ncnc21</smiles>

$85 \mathrm{a}$

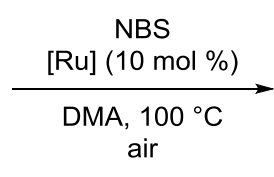

manipulation after $90 \mathrm{~min}$

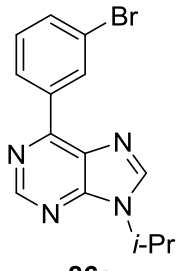

$86 a$

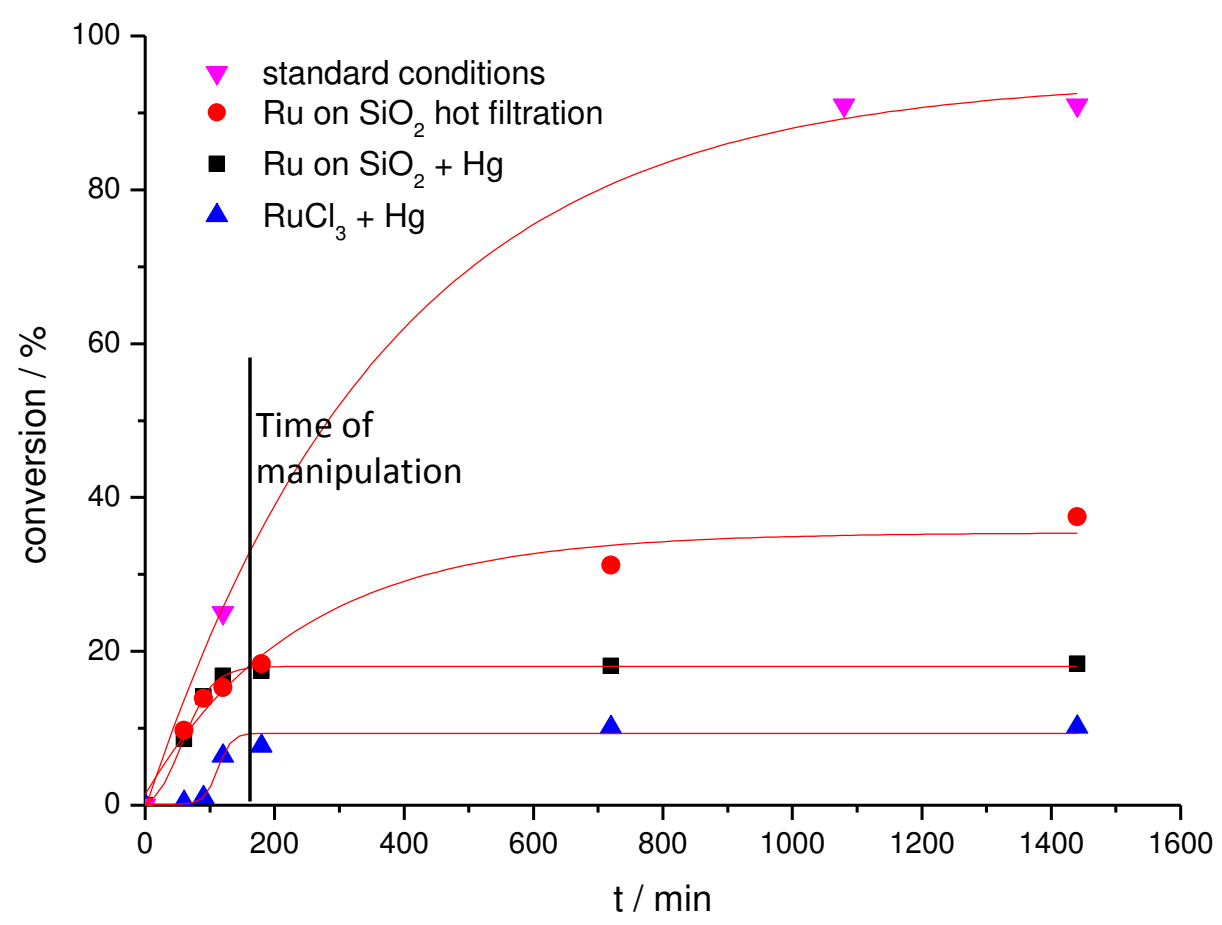

Figure 30. Heterogeneity tests.

The hot filtration test showed significantly reduced activity after filtration. The reason for this may either lie in the very inhomogeneous size of the particles and few very small particles passed the filter or the reactivity is solely reduced by the additional solvent required for the filtration. Both explanations are reasonable as the irregularity of the particle size was shown in SEM studies and the molarity of the reaction was shown to influence the reactivity. ${ }^{[141]}$ The addition of mercury directly stopped the reaction, speaking for a heterogeneous nature of the reaction. The mercury test could be hampered by a reaction of mercury with NBS, therefore future studies should include a threephase test to confirm the heterogeneous nature of the reaction. 



\section{Summary and Outlook}

Ruthenium(II)-catalyzed direct $\mathrm{C}-\mathrm{H}$ functionalizations have emerged as a powerful tool for organic chemists to construct $\mathrm{C}-\mathrm{C}$ and $\mathrm{C}-\mathrm{Het}$ bonds. In order to rationally improve the efficiency of these methods a mechanistic understanding of the underlying reactions is crucial. Within this thesis, studies to delineate the mode of powerful $\mathrm{C}-\mathrm{H}$ transformations have been performed and new methods based on the principles of green chemistry have been developed.

The first part of this thesis focused on aerobic oxidative transformations of benzoic acids (Scheme 124).

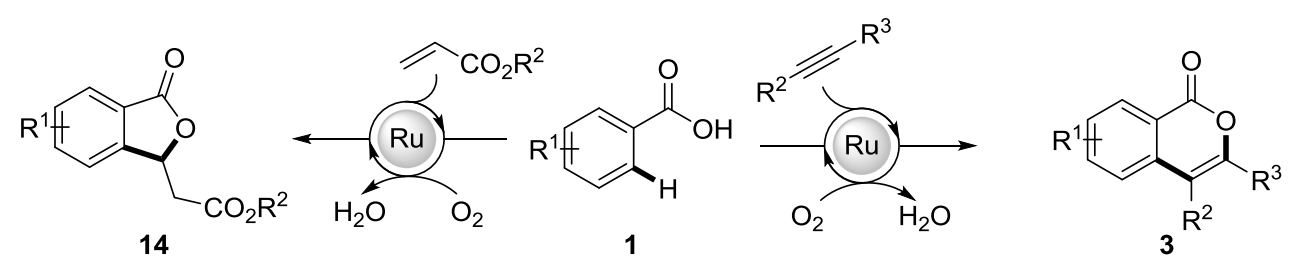

Scheme 124: Aerobic alkyne and alkene annulations of benzoic acids 1.

The alkyne annulation gave access to versatile isocoumarins 3 . To gain insights into the mechanistic cycle of the reaction, proposed reaction intermediates were isolated. Interestingly, alkyne insertion led to the formation of ruthenium(0) sandwich complex 91, while the seven-membered ruthenacycle $\mathbf{9 4}$ was only detectable through mass spectrometry. Both isolated complexes $\mathbf{8 9}$ and $\mathbf{9 1}$ proved active in the catalytic reaction.

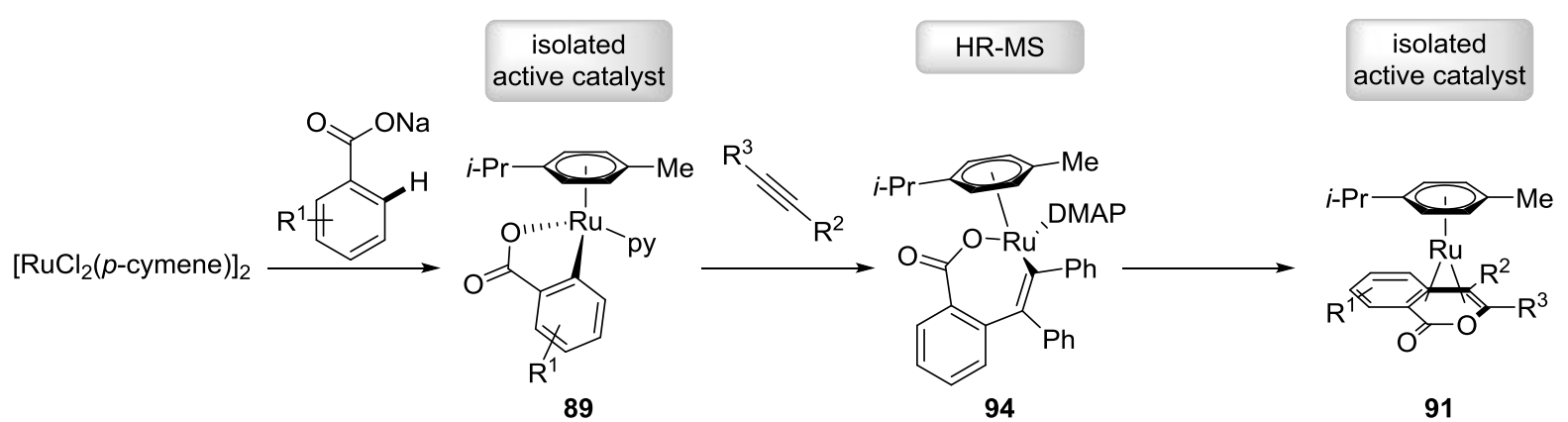

Scheme 125. Reaction intermediates in the aerobic alkyne annulation of benzoic acids 1 .

Further studies focused on the oxidation step and it could be shown that oxidation under aerobic conditions is possible in the absence of additional redox-active transition metals. Furthermore, acetic acid was found to be crucial for the oxidation. The influence of acetic acid on the oxidation potential was examined with cyclic voltammetry studies (Scheme 126). 


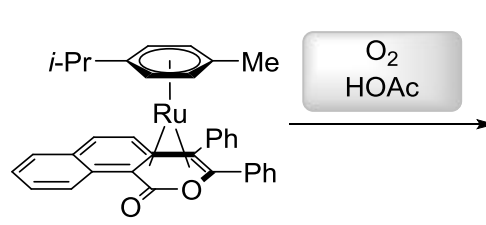

$91 \mathrm{ba}$

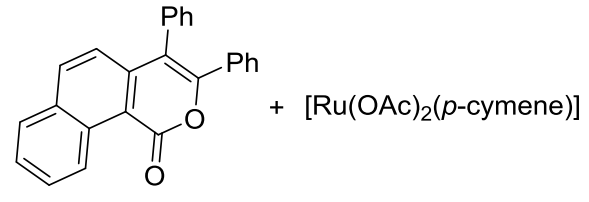

3 ba

96

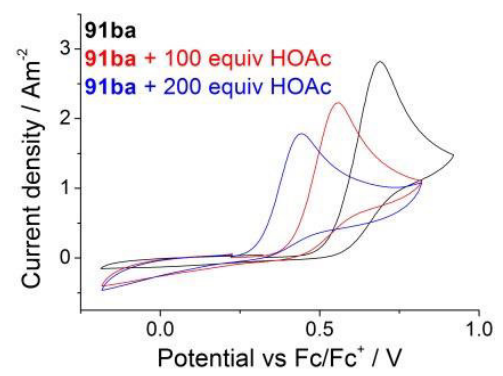

Scheme 126. Oxidation of the ruthenium(0) sandwich complex $91 \mathrm{ba}$.

This enabled the development of a catalytic method with oxygen as the sole oxidant performed by $\mathrm{C}$. Kornhaaß. ${ }^{[108]}$ The future development of this process may center on enabling the use of terminal alkynes.

Further studies focused on the related alkene annulation of benzoic acids $\mathbf{1}$, including the oxygen consumption during the reaction (Scheme 127). Also in this case important reaction intermediates were isolated and a ruthenium(0) complex 97 was observed. Following the reaction by NMR spectroscopy indicated the formation of the seven-membered ring $\mathbf{9 9}$ as an intermediate.

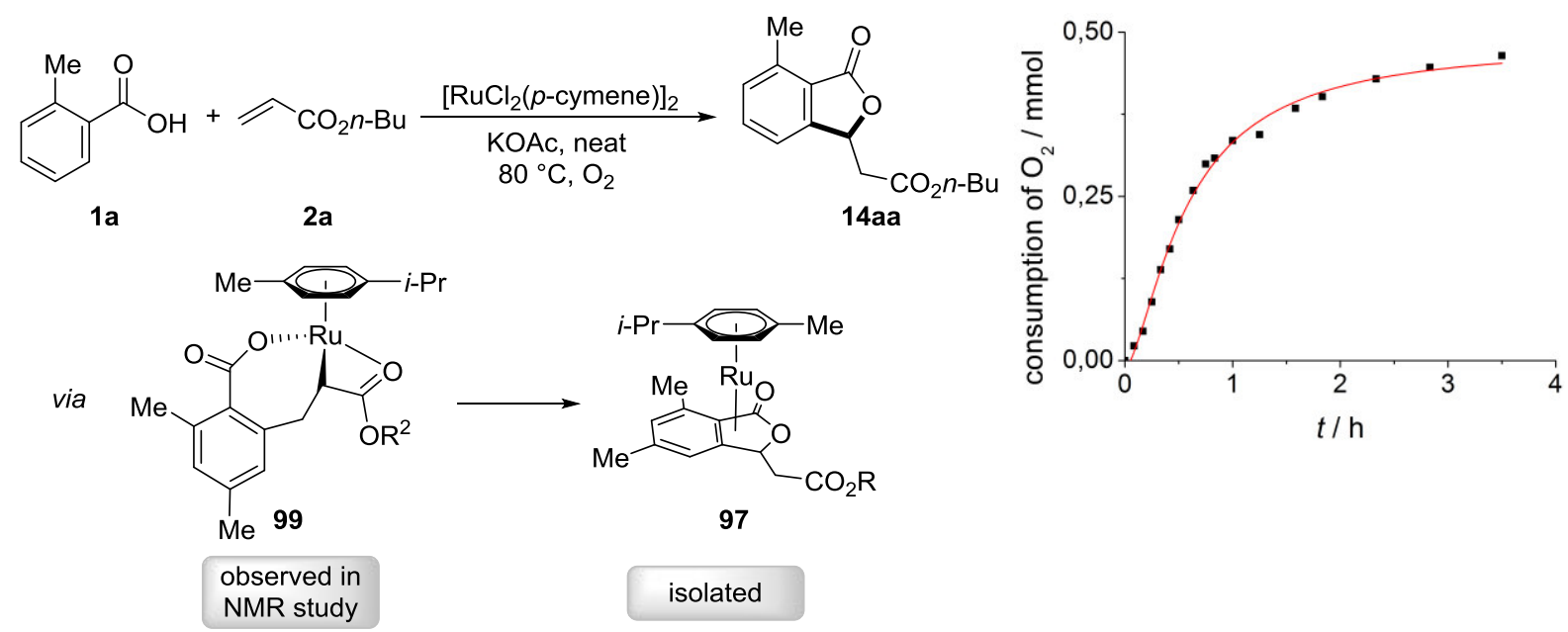

Scheme 127. Aerobic phthalide synthesis, observed intermediates and oxygen consumption.

More research should be carried out regarding the use of unactivated alkenes. Also the electrochemical oxidation of both alkyne and alkene annulation is highly desirable.

The third part of the thesis focused on the study of ruthenium-catalyzed direct arylations with secondary phosphine oxides as pre-ligands. For the first time the well-defined ruthenium(II) phosphinous acid complexes have been used in $\mathrm{C}-\mathrm{H}$ arylation reactions. Thus, very low catalyst 
loadings could be achieved and triazole, tetrazole and oxazoline proved as suitable directing groups (Scheme 128). Furthermore, the direct coupling of $104 a$ and $25 t$ to valsartan precursor 105at opened a very efficient new synthesis to the facile production of the blockbuster drug valsartan.

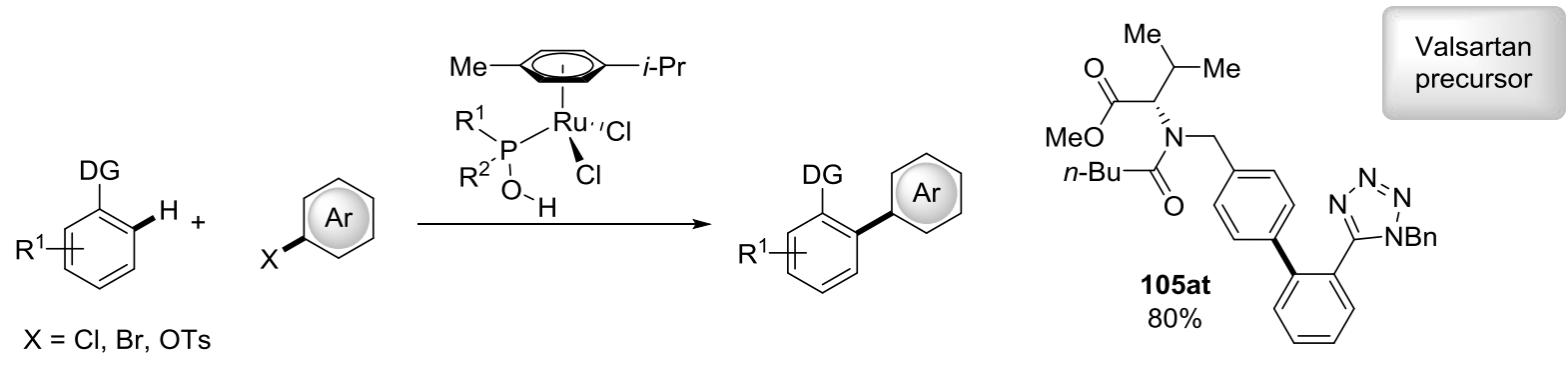

Scheme 128. C-H arylation with ruthenium(II) PA complexes.

A mercury test showed the homogeneous nature of the reaction and H/D studies revealed the cycloruthenation to be reversible.

Further studies have been performed later by J. Hubrich ${ }^{[142]}$ to further optimize the catalytic system. Additionally the reaction system could be used for polymerization reactions, as it was shown that dichlorobenzene reacts twice to give access to the dimeric oxazoline product 103ak' and unsubstituted oxazoline 102c easily undergoes twofold arylation to 103ca.

As the fourth part of this thesis meta-selective alkylations were studied. Hence, ruthenium catalysts with one and two MPAAs were successfully synthesized and performed efficiently as catalysts (Scheme 129).

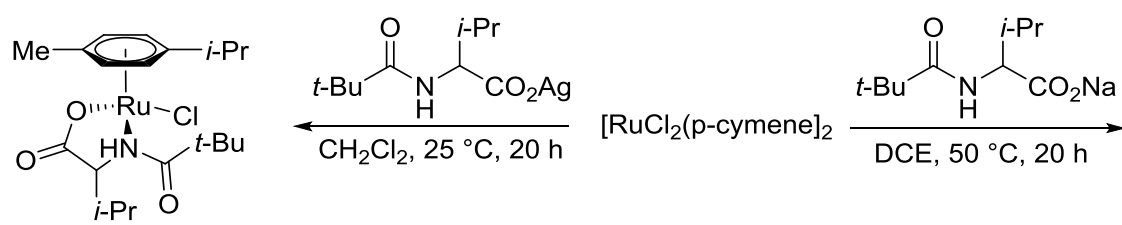

114: $82 \%$

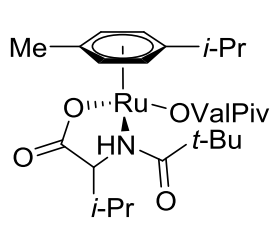

111: $97 \%$

Scheme 129. Synthesis of ruthenium(II) MPAA complexes 111 and 114.

Further studies investigated the influence of tert-butylbenzene as non-innocent solvent and it could indeed be shown that the well-defined $\eta^{6}$-tert-butylbenzene complex 126 outperformed the typically used para-cymene complex. 

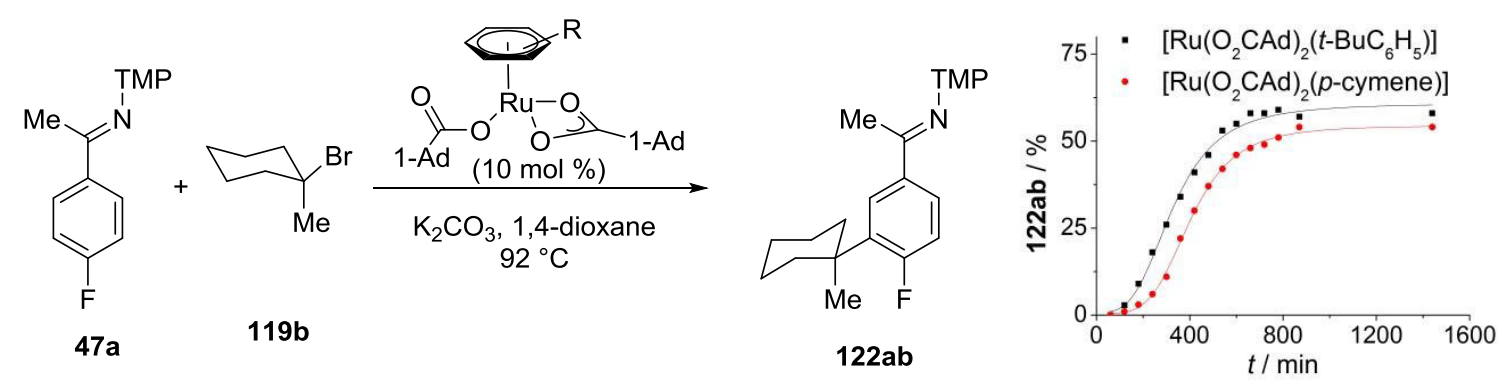

Scheme 130. Activity comparison of $\eta^{6}$-tert-butylbenzene and $\eta^{6}$-para-cymene derived ruthenium complex.

The system proved viable also for alkyl chlorides $\mathbf{1 2 4}$ and the catalyst loading could be decreased to $5 \mathrm{~mol} \%$.

Experiments regarding the activation of the alkyl halide bond suggested a second ruthenium complex to take part in the reaction and the alkylation apparently proceeds in a radical fashion. Activation via elimination of alkyl halide or the formation of a pyridinum salt was shown to be very unlikely. Furthermore, carboxylate assistance proved crucial not only for the $\mathrm{C}-\mathrm{H}$ activation but also the alkylation step itself. Interestingly, the product could be released with the alkyl halide as proton source via elimination of $\mathrm{HX}$.

The final project focused on recyclable and reusable heterogeneous catalysts. A sol-gel derived catalyst enabled the meta-selective bromination of purine derivatives $\mathbf{8 5}$. It is worth noting that the catalyst could be reused three times without a significant decrease in the isolated yield (Scheme 131).
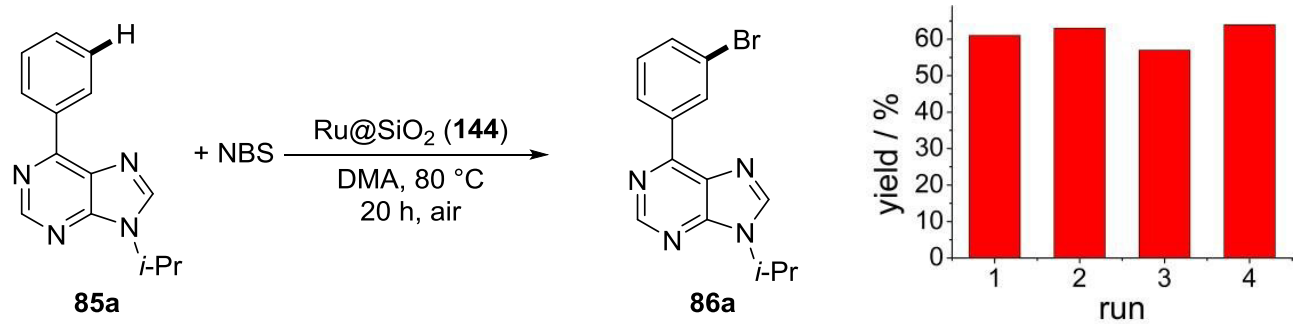

Scheme 131. meta-Selective bromination of purine base 85a.

Even though the catalyst can be reused the heterogeneous nature of the catalyst was not validated yet. The mercury test was inconclusive as mercury can also react with NBS and the hot filtration test only diminished the reactivity of the catalyst but did not inhibit the reaction completely. A threephase test may help to unravel the nature of the catalyst. Furthermore, experiments to improve the solid support and reduce the leaching of the catalyst should be performed in the future. A switch from DMA to a non-hazardous solvent would also be of advantage. 


\section{Experimental Part}

\subsection{General Remarks}

All reactions involving moisture- or air-sensitive reagents or products were performed under an atmosphere of Ar using pre-dried glassware and standard Schlenk techniques. If not otherwise mentioned yields refer to isolated compounds, estimated to be $>95 \%$ pure as determined by ${ }^{1} \mathrm{H}$ NMR and GC.

\section{Vacuum}

The following pressure was measured using a rotary vane pump RZ6 from Vacuubrand ${ }^{\circledR}: 9 \cdot 10^{-2} \mathrm{mbar}$ (medium vacuum, uncorrected value).

\section{Melting Points}

Melting points were measured using a Stuart ${ }^{\circledast}$ Melting Point Apparatus SMP3 from Barloworld Scientific. Values are uncorrected.

\section{Chromatography}

Analytical thin layer chromatography (TLC) was performed on Merck, silica gel $60 F_{254}$ aluminum sheets, detection was done under UV light at $254 \mathrm{~nm}$. Analytical High-Performance-LiquidChromatography (HPLC) to determine the enantiomeric purity was performed with an Agilent 1260 Infinity with Chiralpak IB-3 as column. Chromatographic purification of products was accomplished by flash column chromatography on MERCK silica gel, grade 60 (40-63 $\mu \mathrm{m}$ and 63-200 $\mu \mathrm{m}, 70-230$ mesh ASTM).

\section{Gas Chromatography}

Monitoring of reaction processes via gas chromatography or coupled gas chromatography-mass spectrometry was performed using a 5890 Series II GC-system with mass detector HP 5972 from Hewlett-Packard ${ }^{\circledR}$, a 7890 GC-system with/without mass detector 5975C (Triplex-Axis-Detector) or a 7890B GC-system coupled with a 5977A mass detector, both systems from Agilent Technologies ${ }^{\circledR}$. 


\section{Infrared Spectroscopy}

Infrared (IR) spectra were recorded using a Bruker ${ }^{\circledR}$ Alpha-P ATR spectrometer. Liquid samples were measured as film and solid samples neat. Spectra were recorded in the range from 4000 to $400 \mathrm{~cm}^{-1}$. Analyses of the spectral data were carried out using Opus 6. Absorption is given in wave numbers $\left(\tilde{v} / \mathrm{cm}^{-1}\right)$.

\section{Nuclear Magnetic Resonance Spectroscopy}

Nuclear magnetic resonance (NMR) spectra were recorded on Varian Inova 500, 600, Varian Mercury 300, VX 300, Varian Avance 300, Varian VNMRS 300 and Bruker Avance III 300, 400 and HD 500 spectrometers. Chemical shifts are reported as $\delta$-values in ppm. ${ }^{1} \mathrm{H}$ - and ${ }^{13} \mathrm{C}$ NMR spectra were calibrated using the residual proton or solvent carbon peak (see table), respectively. For ${ }^{31} \mathrm{P}$ - and ${ }^{19} \mathrm{~F}$ NMR spectra, $85 \%$ phosphoric acid and $\mathrm{CFCl}_{3}$ were used as external standards, respectively. ${ }^{13} \mathrm{C}$ NMR, ${ }^{31} \mathrm{P}\left\{{ }^{1} \mathrm{H}\right\}$ and ${ }^{19} \mathrm{~F}\left\{{ }^{1} \mathrm{H}\right\}$ were measured ${ }^{1} \mathrm{H}$ decoupled.

\begin{tabular}{ccc} 
& ${ }^{1} \mathrm{H} \mathrm{NMR}$ & ${ }^{13} \mathrm{C} \mathrm{NMR}$ \\
\hline $\mathrm{CDCl}_{3}$ & 7.26 & 77.16 \\
$\mathrm{CD}_{3} \mathrm{OD}$ & 3.31 & 49.00 \\
$\mathrm{DMSO}-\mathrm{d}_{6}$ & 2.50 & 39.52
\end{tabular}

The following abbreviations are used to describe the observed multiplicities: $s$ (singlet), $d$ (doublet), $t$ (triplet), q (quartet), hept (heptet), m (multiplet) or analogous representations. The coupling constants $J$ are reported in Hertz $(\mathrm{Hz})$. Analysis of the recorded spectra was carried out using MestReNova 10 software.

\section{Mass Spectrometry}

Electron ionization (EI), Field desorption (FD) and EI high resolution mass spectra (HR-MS) were measured on a time-of-flight mass spectrometer AccuTOF from JOEL. Electrospray ionization (ESI) mass spectra were recorded on an Ion-Trap mass spectrometer LCQ from Finnigan, a quadrupole time-of-flight maXis from Bruker Daltonic or on a time-of-flight mass spectrometer microTOF from Bruker Daltonic. ESI-HR-MS spectra were recorded on a Bruker Apex IV or a Bruker Daltonic 7T, fourier transform ion cyclotron resonance (FTICR) mass spectrometer. Inductively coupled plasma mass spectrometry was measured on a Perkin Elmer DRC II (Q-ICP-MS) in a $5 \% \mathrm{HCl}$ solution. The 
ratios of mass to charge $(\mathrm{m} / \mathrm{z})$ are indicated, intensities relative to the base peak $(I=100)$ are written in parentheses.

\section{Elemental Analysis}

Analysis of the relative $\mathrm{C}, \mathrm{H}, \mathrm{N}$ and $\mathrm{S}$ amounts of a compound was conducted with a 4.1 Vario EL 3 from Elementar.

\section{Cyclic Voltammetry}

Cyclic Voltammetry (CV) spectra were measured with the Potentiostat Autolab PGSTAT204 (Metrohm) usinga glassy Carbon disc electrode (3.0 mm diameter, $\mathrm{CH}$ Instruments) as working electrode, a platinum wire (1.0 mm diameter, $99.99 \%$, chempur) and a silver wire (1.0 mm diameter, 99.99\%, chempur) as pseudo-reference electrode. The CV spectra were measured with $n$-Bu $\mathrm{Bu}_{4} \mathrm{NP}_{6}$ $\left(0.1 \mathrm{M}, \mathrm{J} \& \mathrm{~K}\right.$ chemicals) as electrolyte and a sample concentration of $1 \cdot 10^{-3} \mathrm{M}$, at a $100 \mathrm{mV} / \mathrm{s}$ scanning speed applying a $4 \mathrm{mV}$ step size. The data were analysed with NOVA 2.0 (Metrohm).

\section{Electron Paramagnetic Resonance}

Continuous-wave (CW) Electron Paramagnetic Resonance (EPR) spectra were recorded at X-band microwave frequencies $(9 \mathrm{GHz})$ using a Bruker ElexSys E500 spectrometer with a Bruker SuperX CW bridge. The spectrometer was equipped with the Bruker SHQ rectangular microwave cavity (Bruker 4122 SHQ) and a helium flow cryostat (Oxford Instruments) for low temperature experiments.

\section{Thermo Gravimetric Analysis}

Thermo gravimetric analysis (TGA) was carried out using a STA 409PC Luxx or a TG 209 F3 Tarsus, both from Netzsch.

\section{Peroxide Detection}

To detect peroxides Quantofix ${ }^{\circledR}$ Peroxid 100 test stripes from Macherey Nagel were used. For that purpose the stripe is dipped into the solution of interest, after evaporation of the solvent a drop of water is added and the color of the stripe controlled.The detection limit is $1 \mathrm{mg}$ peroxide per liter. 


\section{Solvents}

Solvents for column chromatography were purified via distillation under reduced pressure prior to their use. All solvents for reactions involving moisture-sensitive reagents were dried, distilled and stored under inert atmosphere (Ar or $\mathrm{N}_{2}$ ) according to following standard procedures. ${ }^{[143]}$

Solvents purified by solvent purification system (SPS-800) from M. Braun: Dichloromethane, toluene, tetrahydrofurane, diethylether, dimethylformamide.

Solvents dried and distilled over $\mathrm{Na}$ using benzophenone as indicator: Methanol, $t$-amylalcohol, toluene, $o-, m$-, $p$-xylene, $n$-hexane, 1,4-dioxane.

Solvents dried and distilled over $\mathrm{CaH}_{2}$ : Triethylamine, dichloroethane, dimethylacetamide, dimethylformanide, dimethylsulfoxide, pyridine, $N$-methyl-2-pyrrolidone, $\gamma$-valerolactone.

Solvents dried over molecular sieve and degassed by freeze-pump-thaw cycles: $n$-Butanol (4 $)$ ), acetonitrile (3 ̊̊).

Water was degassed before its use applying repeated freeze-pump-thaw cycles.

\section{Reagents}

Chemicals obtained from commercial sources (with a purity $>95 \%$ ) were used without further purification. The following compounds are known and were synthesized according to previously described literature protocols:

[RuCl$_{2}$ (pyridine)(p-cymene)], ${ }^{[144]} \quad$ 1-(pyridin-2-yl)hept-2-yn-1-ol $\left.\quad(\mathbf{2 g})\right)^{[145]} \quad 3-\{(3-$ phenylprop-2-yn-1yl)oxy\}benzoic acid (1g), ${ }^{[146]}$ (3,3-dimethylbut-1-yn-1-yl)benzene $(\mathbf{2 h}),^{[16 w]}\left[\operatorname{Ru}(\mathrm{OAc})_{2}\left(p\right.\right.$-cymene)], ${ }^{[147]}$ $\left[D_{5}\right]$-benzoic acid $\left(\left[D_{5}\right]-1 h\right),{ }^{[108]}$ SPOs $100,{ }^{[148]}$ oxazolines $102,{ }^{[149]}$ 4-butyl-1-(o-tolyl)-1H-1,2,3-triazole (24a), ${ }^{[29]}$ tetrazoles 104, ${ }^{[122]}$ 1-(6-bromopyridin-3-yl)ethan-1-one (134a), ${ }^{[150]}$ phenyl pyridine 32, ${ }^{[151]}$ bis\{5-methoxy-2-(pyridin-2-yl)phenyl\}mercury (117), ${ }^{[133]}$ 1-bromo-1-methylcyclohexane (119b), ${ }^{[152]} 1$ (4-fluorophenyl)- $N$-(3,4,5-trimethoxyphenyl)ethan-1-imine $\quad(47 \mathrm{a}){ }_{,}^{[153]} \quad\left(n-\mathrm{Bu}_{4} \mathrm{~N}\right)_{2} \mathrm{CO}_{3},{ }^{[154]} \quad(n-$ $\left.\mathrm{Bu}_{4} \mathrm{~N}\right)_{3} \mathrm{PO}_{4}{ }^{[154]}\left(n-\mathrm{Bu}_{4} \mathrm{~N}\right) \mathrm{OAc}^{[154]}\left(n-\mathrm{Bu}_{4} \mathrm{~N}\right)_{2}$ (adipate), ${ }^{[154]} \quad\left[\mathrm{Ru}\left(\mathrm{O}_{2} \mathrm{CMes}\right)\left(4-\mathrm{OMeC}_{6} \mathrm{H}_{3}-2-\right.\right.$ py)$(p$-cymene $\left.)\right]$ (33), ${ }^{\left[{ }^{[3]}\right.} \quad\left[\mathrm{RuCl}_{2}\left(t-\mathrm{BuC}_{6} \mathrm{H}_{5}\right)\right]_{2} \quad(\mathbf{1 2 8}),{ }^{[155]} \quad 1$-(t-butyl)cyclohexa-1,4-diene $\left.\quad(127)\right)^{[135 a]} \quad 1$-isopropyl-2methylpyridin-1-ium bromide (132), ${ }^{[156]}$ methylenecyclohexane $(\mathbf{1 3 b}),{ }^{[157]} \quad\left[\mathrm{Ru}\left(\mathrm{O}_{2} \mathrm{CMes}\right)_{2}(p\right.$ cymene) $]{ }^{[31]}\left[\mathrm{Ru}_{2} \mathrm{Cl}_{3}(p \text {-cymene) })_{2}\right] \mathrm{PF}_{6}\left(\right.$ (139), ${ }^{[158]}$ methyl 3-(trimethoxysilyl)propanoate, ${ }^{[159]}$ 9-isopropyl6-phenyl-9H-purine (85a). ${ }^{[160]}$

The following chemicals were kindly provided by the persons named below: 
Karsten Rauch: $\left[\operatorname{RuCl}_{2}(p \text {-cymene })\right]_{2}, \quad\left[\mathrm{Ru}\left(\mathrm{O}_{2} \mathrm{CMes}\right)_{2}(p\right.$-cymene $\left.)\right], \quad t$-butyl(phenyl)phosphine oxide (100a).

Tjark Meyer: Diphenylphosphine oxide (100d), di-n-butylphosphine oxide (100c), di-ipropylphosphine oxide (100b), $\quad\left[\mathrm{RuCl}_{2}(p\right.$-cymene $\left.)\left\{\mathrm{Ph}_{2} \mathrm{P}(\mathrm{OH})\right\}\right] \quad(\mathbf{8 4 d}), \quad\left[\mathrm{RuCl}_{2}(p\right.$-cymene $)\{(p-\mathrm{F}-$ $\left.\left.\left.\mathrm{C}_{6} \mathrm{H}_{4}\right)_{2} \mathrm{P}(\mathrm{OH})\right\}\right](\mathbf{8 4 e})$, [RuCl $2(p$-cymene) $\{\mathrm{MePhP}(\mathrm{OH})\}]$ (84f), 2-(m-tolyl)-4,5-dihydrooxazole (102b), 1benzyl-5-phenyl-1H-tetrazole (104a), 1-(2-methoxybenzyl)-5-phenyl-1H-tetrazole (104c), 4bromobenzyl acetate (25n).

Yujiao Zhang: 2-(2-fluorophenyl)-4,5-dihydrooxazole (102a), 1-benzyl-5-phenyl-1H-tetrazole (104a), 4-bromobenzyl benzoate (250).

Ruhuai Mei: 2-(2-methoxyphenyl)-4,5-dihydrooxazole.

Sabine Fenner: aryl tosylates 106.

Karolina Graczyk: 1,2-bis(4-(trifluoromethyl)phenyl)ethyne (2b), 1,2-bis(4-methoxyphenyl)ethyne (2c).

Cuiju Zhu: 6-(4-fluorophenyl)-9-isopropyl-9H-purine (85b), 9-benzyl-6-phenyl-9H-purine (85e).

Jie Li: pivaloyl-L-valine (112), 3-bromo-3-ethylpentane (119c), (2-bromo-2-methylpropyl)benzene (119d)

Korkit Korvorapun: (E)-1-phenylethan-1-one $O$-methyl oxime (47c), $\mathrm{N}$-benzyl-1-phenylethan-1-imine (47d), $N$-benzylpyrimidin-2-amine (118a).

\subsection{General Procedures}

\subsubsection{General Procedure A: Synthesis of Ruthenacycles 89 via $\mathrm{C}-\mathrm{H}$ Metallation}

A solution of $\left[\operatorname{RuCl}_{2}(p \text {-cymene })\right]_{2}(100 \mathrm{mg}, 0.16 \mathrm{mmol}, 1.0$ equiv) and pyridine $(26 \mu \mathrm{L}, 0.32 \mathrm{mmol}$, 2.0 equiv) or DMAP (39.1 mg, $0.32 \mathrm{mmol}, 2.0$ equiv) in $\mathrm{CH}_{2} \mathrm{Cl}_{2}\left(5 \mathrm{~mL}, 0.03 \mathrm{M}\right.$ ) was stirred at $23^{\circ} \mathrm{C}$ for $2 \mathrm{~h}$. Subsequently, sodium benzoate $87\left(0.80 \mathrm{mmol}, 5.0\right.$ equiv) and $\mathrm{NEt}_{3}(0.4 \mathrm{~mL}, 2.9 \mathrm{mmol})$ were added and the suspension was stirred at $23^{\circ} \mathrm{C}$ for further $22 \mathrm{~h}$. Filtration over celite and purification by column chromatography $\left(\mathrm{CH}_{2} \mathrm{Cl}_{2} / \mathrm{MeOH}: 40 / 1 \rightarrow 20 / 1\right)$ yielded the ruthenapentacycles 89 as yellow to orange solids. 


\subsubsection{General Procedure B: Synthesis of Ruthenium(0) Sandwich Complex 91}

A solution of $\left[\mathrm{RuCl}_{2}(p \text {-cymene })\right]_{2}(31.1 \mathrm{mg}, 0.05 \mathrm{mmol}, 1.0$ equiv) and benzoic acid 1 ( $0.10 \mathrm{mmol}$, 2.0 equiv), alkyne 2 ( $0.20 \mathrm{mmol}, 4.0$ equiv) and $\mathrm{NaOAc}(16.4 \mathrm{mg}, 0.20 \mathrm{mmol}, 4.0$ equiv) in $\mathrm{MeOH}$ $(4.0 \mathrm{~mL}, 0.01 \mathrm{M})$ was stirred at $45^{\circ} \mathrm{C}$ for $2 \mathrm{~d}$. Filtration over celite and purification by column chromatography on silica gel $\left(\mathrm{CH}_{2} \mathrm{Cl}_{2}\right)$ yielded the ruthenium(0) sandwich complexes 91 as bright yellow solids or the elimination products as colorless solids.

\subsubsection{General Procedure C: Synthesis of Ruthenium(0) Sandwich Complex 91 via Alkyne Insertion}

Ruthenacycle 89 ( $15 \mu \mathrm{mol}, 1.0$ equiv), alkyne 2 ( $15 \mu \mathrm{mol}, 1.0$ equiv), 1,4-dimethoxybenzene $(2.1 \mathrm{mg}$, $15 \mu \mathrm{mol}, 1.0$ equiv) and $\mathrm{CD}_{3} \mathrm{OD}(0.6 \mathrm{~mL})$ were placed in a NMR tube and heated to $40-60{ }^{\circ} \mathrm{C}$. The reaction was followed by ${ }^{1} \mathrm{H}$ NMR spectroscopy. Filtration over celite and purification by column chromatography on silica gel $\left(\mathrm{CH}_{2} \mathrm{Cl}_{2}\right)$ yielded the complexes $91(5.4 \mathrm{mg}, 64 \%)$ as yellow solids.

\subsubsection{General Procedure D: Synthesis of Phthalides 14 via Ruthenium(II)- Catalyzed Aerobic Alkene Annulation}

Benzoic acid 1 (2.00 mmol, 2.0 equiv), $\left[\operatorname{RuCl}_{2}(p \text {-cymene })\right]_{2}(30.6 \mathrm{mg}, 0.05 \mathrm{mmol}, 5.0 \mathrm{~mol} \%)$ and CsOAc (178 mg, $1.00 \mathrm{mmol}, 1.0$ equiv) were placed in a pre-dried $25 \mathrm{~mL}$ Schlenk tube. The flask was evacuated and flushed with $\mathrm{O}_{2}$ three times. $\mathrm{MeOH}(3.0 \mathrm{~mL})$ and acrylate 4 ( $1.00 \mathrm{mmol}, 1.0$ equiv) were added and the reaction mixture was stirred at $60^{\circ} \mathrm{C}$ for $18 \mathrm{~h}$. At ambient temperature, all volatiles were removed in vacuo. The residue was purified by column chromatography on silica gel ( $n$-hexane/EtOAc) to yield the corresponding phthalides 14.

\subsubsection{General Procedure E: Synthesis of Ruthenium(II) Phosphinous Acid Catalysts 84}

A suspension of $\left[\mathrm{RuCl}_{2}(p \text {-cymene })\right]_{2}(100 \mathrm{mg}, 163 \mu \mathrm{mol}, 1.0$ equiv) and secondary phosphine oxide 100 (340 $\mu \mathrm{mol}, 2.1$ equiv) in $n$-hexane $(5.0 \mathrm{~mL})$ was stirred at $75^{\circ} \mathrm{C}$ for $16 \mathrm{~h}$. At ambient temperature, the red precipitate was filtered off and washed with $n$-hexane. The red solid was dissolved in $\mathrm{CH}_{2} \mathrm{Cl}_{2}$ and filtered, evaporation of the filtrate in vacuo yielded the according complexes $\mathbf{8 4}$ as red solids. 


\subsubsection{General Procedure F: PA-Ruthenium(II)-Catalyzed C-H Arylations of Oxazolines 102}

A mixture of oxazoline $102(0.50 \mathrm{mmol}, 1.0$ equiv), aryl halide $25 / 30$ or tosylate $106(0.75 \mathrm{mmol}$, 1.5 equiv), $\mathrm{K}_{2} \mathrm{CO}_{3}\left(138 \mathrm{mg}, 1.00 \mathrm{mmol}, 2.0\right.$ equiv) and $\left[\mathrm{RuCl}_{2}\left(p\right.\right.$-cymene) $\left.\left\{n-\mathrm{Bu}_{2} \mathrm{P}(\mathrm{OH})\right\}\right](84 \mathrm{c})(11.7 \mathrm{mg}$, $25 \mu \mathrm{mol}, 5 \mathrm{~mol} \%)$ in toluene $(0.5 \mathrm{~mL})$ was stirred at $120^{\circ} \mathrm{C}$ for $18 \mathrm{~h}$. Filtration over celite and purification by column chromatography on silica gel ( $n$-hexane/EtOAc) yielded the corresponding biaryls 103.

\subsubsection{General Procedure G: PA-Ruthenium(II)-Catalyzed C-H Arylations of Tetrazoles 104}

A mixture of tetrazole 104 ( $0.50 \mathrm{mmol}, 1.0$ equiv), aryl bromide 25 ( $0.75 \mathrm{mmol}, 1.5$ equiv), $\mathrm{K}_{2} \mathrm{CO}_{3}$ (138 mg, $1.00 \mathrm{mmol}, 2.0$ equiv) and $\left[\mathrm{RuCl}_{2}(p\right.$-cymene)\{t-BuPhP(OH$\left.\left.)\right\}\right]$ (84a) (12.2 mg, $25 \mu \mathrm{mol}$, $5 \mathrm{~mol} \%)$ in toluene $\left(2.0 \mathrm{~mL}\right.$ ) was stirred in a sealed tube at $140{ }^{\circ} \mathrm{C}$ for $18 \mathrm{~h}$. Filtration over celite and purification by column chromatography on silica gel ( $n$-hexane/EtOAc) yielded the corresponding arylated tetrazole 105.

\subsubsection{General Procedure H: Ruthenium(II)-Catalyzed direct meta-Alkylation of Phenylpyridines 32}

A mixture of phenylpyridine 32 (0.50 mmol, 1.0 equiv), [RuCl(O-Val-Piv)(p-cymene)] (114) (11.8 mg, $0.025 \mathrm{mmol}, 5.0 \mathrm{~mol} \%), \mathrm{K}_{2} \mathrm{CO}_{3}(138 \mathrm{mg}, 1.00 \mathrm{mmol}, 2.0$ equiv), tertiary alkyl bromide 119 (1.50 mmol, 3.0 equiv) in 1,4-dioxane $(2.0 \mathrm{~mL})$ was stirred in a sealed tube at $100{ }^{\circ} \mathrm{C}$ for $20 \mathrm{~h}$. Purification by column chromatography on silica gel ( $n$-hexane/EtOAc) yielded the alkylated phenylpyridine 121.

\subsubsection{General Procedure I: Ruthenium(II)-Catalyzed direct meta-Alkylation of Ketimines}

A mixture of ketimine 47 (0.50 mmol, 1.0 equiv), [Ru( $\left.\mathrm{O}_{2} \mathrm{CAd}\right)_{2}(p$-cymene)] (129) (29.8 mg, $0.05 \mathrm{mmol}$, $10 \mathrm{~mol} \%)$ or $\left[\mathrm{RuCl}_{2}(p \text {-cymene })\right]_{2}(15.3 \mathrm{mg}, 25.0 \mu \mathrm{mol}, 5.0 \mathrm{~mol} \%)$ and $1-\mathrm{AdCO}_{2} \mathrm{H}(27.3 \mathrm{mg}, 0.15 \mathrm{mmol}$, $30 \mathrm{~mol} \%), \mathrm{K}_{2} \mathrm{CO}_{3}(138 \mathrm{mg}, 1.00 \mathrm{mmol}, 2.0$ equiv) and alkyl halide 119 (1.50 mmol, 3.0 equiv) in $\mathrm{PhCMe}_{3}(2.0 \mathrm{~mL})$ was stirred at $120^{\circ} \mathrm{C}$ for $20 \mathrm{~h}$ in a sealed tube under an atmosphere of Ar. At 
ambient temperature, $2 \mathrm{~N} \mathrm{HCl}(3.0 \mathrm{~mL})$ was added, and the resulting mixture was stirred for $3 \mathrm{~h}$ and extracted with EtOAc $(3 \times 20 \mathrm{~mL})$. The combined organic layers were dried over $\mathrm{Na}_{2} \mathrm{SO}_{4}$ and concentrated in vacuo. Purification by column chromatography on silica gel ( $n$-pentane/Et ${ }_{2} \mathrm{O}$ ) yielded the alkylated ketones 123. 


\subsection{Experimental Procedures and Analytical Data}

\subsubsection{Synthesis of Starting Materials}

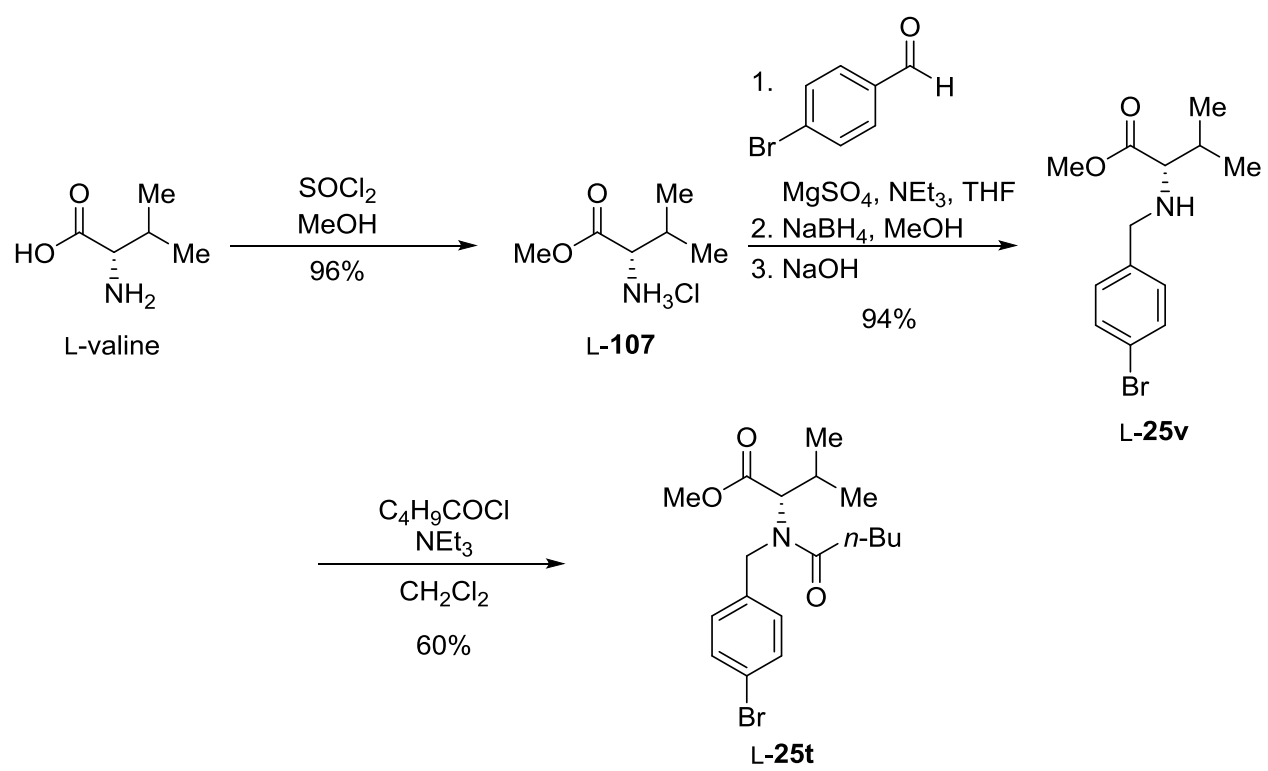

L-25t was synthesized via a modified literature procedure. ${ }^{[123]}$ A suspension of L-107 (3.35 g, $20.0 \mathrm{mmol}), \mathrm{MgSO}_{4}(4.10 \mathrm{~g}, 34.0 \mathrm{mmol}), 4$-bromoacetophenone $(7.40 \mathrm{~g}, 40.0 \mathrm{mmol})$ and $\mathrm{NEt}_{3}$ $(2.8 \mathrm{~mL}, 20 \mathrm{mmol})$ in THF $(100 \mathrm{~mL})$ was stirred at $60^{\circ} \mathrm{C}$ for $10 \mathrm{~h}$ and at $23^{\circ} \mathrm{C}$ for further $13 \mathrm{~h}$. Filtration and removal of the solvent provided the crude product, which was then directly dissolved in $\mathrm{MeOH}(60 \mathrm{~mL}) . \mathrm{NaBH}_{4}(1.51 \mathrm{~g}, 40.0 \mathrm{mmol})$ was added at $0{ }^{\circ} \mathrm{C}$. Purification by column chromatography ( $n$-hexane/EtOAc: $4 / 1)$ yielded the desired product L-25v as a colorless oil $(7.23 \mathrm{~g}$, 94\%).

To a solution of $\mathrm{L}-25 \mathrm{v}(3.00 \mathrm{~g}, 10.0 \mathrm{mmol})$ in $\mathrm{NEt}_{3}(24 \mathrm{~mL})$ and $\mathrm{CH}_{2} \mathrm{Cl}_{2}(25 \mathrm{~mL})$ was added pentanoyl chloride $(1.8 \mathrm{~mL}, 15 \mathrm{mmol})$ dropwise at $0{ }^{\circ} \mathrm{C}$ and stirred at $23^{\circ} \mathrm{C}$ for 2 days. The reaction was stopped by the addition of aqueous $\mathrm{HCl}(1 \mathrm{M}, 25 \mathrm{~mL})$ and extracted with $\mathrm{CH}_{2} \mathrm{Cl}_{2}$, washed with brine and dried over $\mathrm{Na}_{2} \mathrm{SO}_{4}$. Column chromatography ( $n$-hexane/EtOAc: $\left.6 / 1\right)$ yielded L-25t $(2.31 \mathrm{~g}, 60 \%, 54 \%$ over 4 steps) as a colorless oil.

${ }^{1} \mathrm{H}$ NMR (500 MHz, CDCl $): \delta=7.43(\mathrm{~d}, J=8.5 \mathrm{~Hz}, 2 \mathrm{H}), 7.22(\mathrm{~d}, J=8.5 \mathrm{~Hz}, 2 \mathrm{H}), 3.79(\mathrm{~d}, J=13.4 \mathrm{~Hz}, 1 \mathrm{H})$, $3.72(\mathrm{~s}, 3 \mathrm{H}), 3.51(\mathrm{~d}, J=13.4 \mathrm{~Hz}, 1 \mathrm{H}), 2.97(\mathrm{~d}, J=6.1 \mathrm{~Hz}, 1 \mathrm{H}), 1.96-1.85(\mathrm{~m}, 1 \mathrm{H}), 0.94(\mathrm{~d}, J=6.9 \mathrm{~Hz}$, 3H), $0.92(\mathrm{~d}, J=6.9 \mathrm{~Hz}, 3 \mathrm{H}) ;{ }^{13} \mathrm{C} \mathrm{NMR}\left(125 \mathrm{MHz}, \mathrm{CDCl}_{3}\right): \delta=176.0\left(\mathrm{C}_{\mathrm{q}}\right), 139.4\left(\mathrm{C}_{\mathrm{q}}\right), 131.6(\mathrm{CH}), 130.2$ (CH), $120.9\left(\mathrm{C}_{\mathrm{q}}\right), 66.6(\mathrm{CH}), 51.9\left(\mathrm{CH}_{2}\right), 51.6\left(\mathrm{CH}_{3}\right), 31.8(\mathrm{CH}), 19.4\left(\mathrm{CH}_{3}\right), 18.6\left(\mathrm{CH}_{3}\right)$; IR (ATR): $\tilde{v}=2959$, 1739, 1650, 1436, 1403, 1200, 1166, 1010, 795, $479 \mathrm{~cm}^{-1}$; MS (EI) m/z (relative intensity) 300 (99) [M$\mathrm{H}]^{+}\left({ }^{81} \mathrm{Br}\right), 298(100)[\mathrm{M}-\mathrm{H}]{ }^{+}\left({ }^{79} \mathrm{Br}\right), 242$ (49), 240 (57), 186 (45), 184 (46), 171 (94), 169 (97), 57 (33); 
HR-MS (ESI): $m / z$ calcd for $\left[\mathrm{C}_{18} \mathrm{H}_{27} \mathrm{BrNO}_{3}+\mathrm{H}\right]^{+} 386.1149$, found: $386.1155 ;$ HPLC: $t_{\mathrm{R}}(\mathrm{L}-25 \mathrm{t})=10.403, t_{\mathrm{R}}$ $(\mathrm{D}-\mathbf{2 5 t})=9.624($ flow rate $=1 \mathrm{~mL} / \mathrm{min} ; n$-hexane $/ \mathrm{i}-\mathrm{PrOH}$ 99:1)

The enantiomere was synthesized accordingly.

\subsubsection{Data for the Ruthenium-catalyzed Oxidative Annulation}

\subsubsection{Synthesis of 5-membered Ruthenacycles}

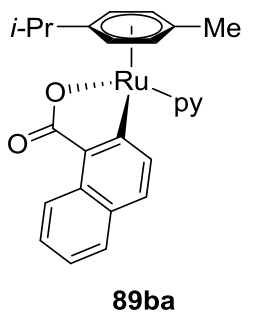

89ba: The representative procedure $\mathbf{A}$ was followed using $\left[\mathrm{RuCl}_{2}(p \text {-cymene })\right]_{2}(100 \mathrm{mg}, 0.16 \mathrm{mmol})$, pyridine $(26 \mu \mathrm{L}, 0.32 \mathrm{mmol})$, sodium naphthoat $(87 \mathrm{~b})(155 \mathrm{mg}, 0.80 \mathrm{mmol})$ and $\mathrm{NEt}_{3}(0.4 \mathrm{~mL}$, $1.44 \mathrm{mmol})$. Purification by column chromatography $\left(\mathrm{CH}_{2} \mathrm{Cl}_{2} / \mathrm{MeOH}: 40 / 1 \rightarrow 20 / 1\right)$ yielded 89ba (110 $\mathrm{mg}, 71 \%)$ as a dark yellow solid.

M.p. (decomp.): $147^{\circ} \mathrm{C} ;{ }^{1} \mathrm{H} N \mathrm{NMR}\left(400 \mathrm{MHz}, \mathrm{CDCl}_{3}\right): \delta=9.46(\mathrm{~d}, J=8.7 \mathrm{~Hz}, 1 \mathrm{H}), 8.50(\mathrm{~d}, J=5.4 \mathrm{~Hz}, 2 \mathrm{H})$, $8.19(\mathrm{~d}, J=8.2 \mathrm{~Hz}, 1 \mathrm{H}), 7.67(\mathrm{~d}, J=8.1 \mathrm{~Hz}, 2 \mathrm{H}), 7.40-7.27(\mathrm{~m}, 2 \mathrm{H}), 7.23$ (ddd, $J=8.3,6.9,1.3 \mathrm{~Hz}, 1 \mathrm{H}$ ), 6.92-6.86 (m, 2H), $5.58(\mathrm{~d}, J=5.1 \mathrm{~Hz}, 1 \mathrm{H}), 5.49(\mathrm{~d}, J=5.7 \mathrm{~Hz}, 1 \mathrm{H}), 5.27(\mathrm{~d}, J=6.0 \mathrm{~Hz}, 1 \mathrm{H}), 4.82(\mathrm{~d}, J=$ $5.7 \mathrm{~Hz}, 1 \mathrm{H}), 2.46-2.28(\mathrm{~m}, 1 \mathrm{H}), 1.67(\mathrm{~s}, 3 \mathrm{H}), 0.94(\mathrm{~d}, J=6.9 \mathrm{~Hz}, 3 \mathrm{H}), 0.94(\mathrm{~d}, J=6.9 \mathrm{~Hz}, 3 \mathrm{H}) ;{ }^{13} \mathrm{C} \mathbf{N M R}$ $\left(100 \mathrm{MHz}, \mathrm{CDCl}_{3}\right): \delta=181.5\left(\mathrm{C}_{\mathrm{q}}\right), 180.0\left(\mathrm{C}_{\mathrm{q}}\right), 153.6(\mathrm{CH}), 136.7(\mathrm{CH}), 135.8(\mathrm{CH}), 132.7\left(\mathrm{C}_{\mathrm{q}}\right), 131.5\left(\mathrm{C}_{\mathrm{q}}\right)$, $130.4\left(\mathrm{C}_{q}\right), 130.0(\mathrm{CH}), 127.6(\mathrm{CH}), 126.2(\mathrm{CH}), 124.3(\mathrm{CH}), 123.7(\mathrm{CH}), 123.3(\mathrm{CH}), 102.2\left(\mathrm{C}_{q}\right), 98.4\left(\mathrm{C}_{q}\right)$, $88.1(\mathrm{CH}), 87.3(\mathrm{CH}), 85.1(\mathrm{CH}), 80.1(\mathrm{CH}), 30.8(\mathrm{CH}), 22.5\left(\mathrm{CH}_{3}\right), 22.3\left(\mathrm{CH}_{3}\right), 18.0\left(\mathrm{CH}_{3}\right)$; IR (ATR): $\tilde{v}=$ $3045,2963,2211,1601,1267,819,728 \mathrm{~cm}^{-1}$; HR-MS (ESI): $\mathrm{m} / \mathrm{z}$ calcd for $\left[\mathrm{C}_{26} \mathrm{H}_{25} \mathrm{~N}_{1} \mathrm{O}{ }_{2} \mathrm{Ru}+\mathrm{H}\right]^{+}$ 486.1009, found 486.1001 .

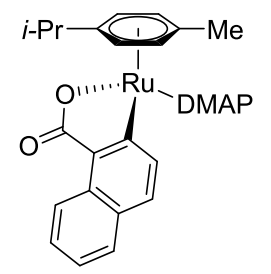

$89 b b$ 
89bb: The representative procedure $\mathbf{A}$ was followed using $\left[\mathrm{RuCl}_{2}(p \text {-cymene })\right]_{2}(100 \mathrm{mg}, 0.16 \mathrm{mmol})$, DMAP $(39.1 \mathrm{mg}, 0.32 \mathrm{mmol})$, sodium naphthoat $(\mathbf{8 7 b})(155 \mathrm{mg}, 0.80 \mathrm{mmol})$ and $\mathrm{NEt}_{3}(0.4 \mathrm{~mL}$, $1.44 \mathrm{mmol})$. Purification by column chromatography $\left(\mathrm{CH}_{2} \mathrm{Cl}_{2} / \mathrm{MeOH}: 40 / 1 \rightarrow 20 / 1\right)$ yielded 89bb (142 $\mathrm{mg}, 85 \%$ ) as an orange solid.

M.p. (decomp.): $154{ }^{\circ} \mathrm{C} ;{ }^{1} \mathrm{H} \mathrm{NMR}\left(500 \mathrm{MHz}, \mathrm{CDCl}_{3}\right): \delta=9.52(\mathrm{~d}, J=8.6 \mathrm{~Hz}, 1 \mathrm{H}), 8.20(\mathrm{~d}, J=8.1 \mathrm{~Hz}, 1 \mathrm{H})$, $7.87(\mathrm{~d}, J=6.2 \mathrm{~Hz}, 2 \mathrm{H}), 7.68(\mathrm{t}, J=7.3 \mathrm{~Hz}, 2 \mathrm{H}$ ), 7.35 (ddd, $J=8.5,6.7,1.5 \mathrm{~Hz}, 1 \mathrm{H}$ ), 7.21 (ddd, $J=7.9$, $6.7,1.1 \mathrm{~Hz}, 1 \mathrm{H}), 5.91(\mathrm{~d}, J=5.6 \mathrm{~Hz}, 2 \mathrm{H}), 5.56(\mathrm{~d}, J=5.5 \mathrm{~Hz}, 1 \mathrm{H}), 5.46(\mathrm{~d}, J=5.8 \mathrm{~Hz}, 1 \mathrm{H}), 5.22(\mathrm{~d}, J=$ $5.8 \mathrm{~Hz}, 1 \mathrm{H}), 4.77(\mathrm{~d}, J=5.3 \mathrm{~Hz}, 1 \mathrm{H}), 2.70(\mathrm{~s}, 6 \mathrm{H}), 2.36$ (hept, $J=6.1 \mathrm{~Hz}, 1 \mathrm{H}), 1.72(\mathrm{~s}, 3 \mathrm{H}), 1.00-0.94(\mathrm{~m}$, 6H); ${ }^{13}$ C NMR (125 MHz, CDCl $): \delta=181.5\left(\mathrm{C}_{\mathrm{q}}\right), 181.0\left(\mathrm{C}_{\mathrm{q}}\right), 153.4\left(\mathrm{C}_{\mathrm{q}}\right), 152.1(\mathrm{CH}), 136.1(\mathrm{CH}), 132.7$ $\left(\mathrm{C}_{\mathrm{q}}\right), 131.4\left(\mathrm{C}_{\mathrm{q}}\right), 130.5\left(\mathrm{C}_{\mathrm{q}}\right), 129.4(\mathrm{CH}), 127.4(\mathrm{CH}), 125.9(\mathrm{CH}), 123.9(\mathrm{CH}), 123.0(\mathrm{CH}), 106.9(\mathrm{CH})$, $101.5\left(\mathrm{C}_{\mathrm{q}}\right), 98.1\left(\mathrm{C}_{\mathrm{q}}\right), 87.6(\mathrm{CH}), 87.2(\mathrm{CH}), 84.6(\mathrm{CH}), 79.7(\mathrm{CH}), 38.9\left(\mathrm{CH}_{3}\right), 30.9(\mathrm{CH}), 22.7\left(\mathrm{CH}_{3}\right), 22.5$ $\left(\mathrm{CH}_{3}\right), 18.3\left(\mathrm{CH}_{3}\right)$; IR (ATR): $\tilde{v}=2959,1613,1529,1382,1224,1190,1136,811 \mathrm{~cm}^{-1} ;$ HR-MS (ESI): $\mathrm{m} / \mathrm{z}$ calcd for $\left[\mathrm{C}_{28} \mathrm{H}_{30} \mathrm{~N}_{2} \mathrm{O}_{2} \mathrm{Ru}+\mathrm{H}\right]^{+} 529.1431$, found 529.1428 .

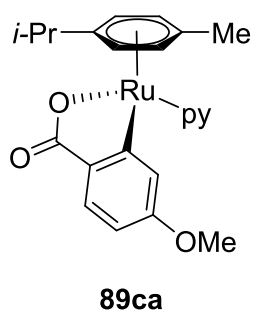

89ca: The representative procedure $\mathbf{A}$ was followed using $\left[\mathrm{RuCl}_{2}(p \text {-cymene })\right]_{2}(100 \mathrm{mg}, 0.16 \mathrm{mmol})$, pyridine $(26 \mu \mathrm{L}, 0.32 \mathrm{mmol})$, sodium 4-methoxybenzoate $(87 \mathrm{c})(139 \mathrm{mg}, 0.80 \mathrm{mmol})$ and $\mathrm{NEt}_{3}$ $(0.4 \mathrm{~mL}, 2.9 \mathrm{mmol})$. Purification by column chromatography $\left(\mathrm{CH}_{2} \mathrm{Cl}_{2} / \mathrm{MeOH}: 40 / 1 \rightarrow 20 / 1\right)$ yielded 89ca (104 $\mathrm{mg}, 70 \%$ ) as a yellow solid.

Alternatively a mixture of $\left[\mathrm{RuCl}_{2} \text { (pyridine)(p-cymene) }\right]_{2} \quad(90 \mathrm{a}) \quad(40.0 \mathrm{mg}, 0.13 \mathrm{mmol})$, sodium 4methoxybenzoate $(87 \mathrm{c})(45.3 \mathrm{mg}, 0.26 \mathrm{mmol})$ and $\mathrm{NEt}_{3}(0.2 \mathrm{~mL}, 1.4 \mathrm{mmol})$ was stirred at $23^{\circ} \mathrm{C}$ for $24 \mathrm{~h}$. Purification by column chromatography $\left(\mathrm{CH}_{2} \mathrm{Cl}_{2} / \mathrm{MeOH}: 40 / 1 \rightarrow 20 / 1\right)$ yielded 89ca $(44 \mathrm{mg}$, $73 \%)$ as a yellow solid.

M.p. (decomp.): $142{ }^{\circ} \mathrm{C} ;{ }^{1} \mathrm{H} \mathrm{NMR}\left(300 \mathrm{MHz}, \mathrm{CDCl}_{3}\right): \delta=8.51$ (d, $\left.J=4.6 \mathrm{~Hz}, 2 \mathrm{H}\right), 7.54(\mathrm{~d}, J=2.4 \mathrm{~Hz}, 1 \mathrm{H})$, $7.42(\mathrm{dd}, J=7.6,7.6 \mathrm{~Hz}, 1 \mathrm{H}$ ), 7.33 (d, $J=8.3 \mathrm{~Hz}, 1 \mathrm{H}), 7.02-6.92(\mathrm{~m}, 2 \mathrm{H}), 6.45$ (dd, $J=8.2,2.4 \mathrm{~Hz}, 1 \mathrm{H}$ ), $5.45(\mathrm{~d}, J=5.7 \mathrm{~Hz}, 1 \mathrm{H}), 5.39$ (d, J=6.0 Hz, 1H), 5.21 (d, J=6.0 Hz, 1H), 4.80 (d, J=5.6 Hz, 1H), 3.84 (s, 3H), $2.43-2.32(\mathrm{~m}, 1 \mathrm{H}), 1.70(\mathrm{~s}, 3 \mathrm{H}), 0.97(\mathrm{~d}, J=6.5 \mathrm{~Hz}, 3 \mathrm{H}), 0.97(\mathrm{~d}, J=6.9 \mathrm{~Hz}, 3 \mathrm{H}) ;{ }^{13} \mathrm{C}$ NMR $(125$ $\left.\mathrm{MHz}, \mathrm{CDCl}_{3}\right): \delta=180.9\left(\mathrm{C}_{\mathrm{q}}\right), 177.5\left(\mathrm{C}_{\mathrm{q}}\right), 160.9\left(\mathrm{C}_{\mathrm{q}}\right), 153.7(\mathrm{CH}), 136.8(\mathrm{CH}), 132.1\left(\mathrm{C}_{\mathrm{q}}\right), 129.4(\mathrm{CH}), 124.3$ $(\mathrm{CH}), 122.2(\mathrm{CH}), 106.8(\mathrm{CH}), 102.3\left(\mathrm{C}_{\mathrm{q}}\right), 97.7\left(\mathrm{C}_{\mathrm{q}}\right), 87.5(\mathrm{CH}), 86.3(\mathrm{CH}), 84.5(\mathrm{CH}), 80.4(\mathrm{CH}), 55.0$ 
$\left(\mathrm{CH}_{3}\right), 30.6(\mathrm{CH}), 22.4\left(\mathrm{CH}_{3}\right), 22.1\left(\mathrm{CH}_{3}\right), 17.8\left(\mathrm{CH}_{3}\right)$; IR (ATR): $\tilde{v}=3048,2968,1601,1443,1063,882$, $760,693 \mathrm{~cm}^{-1}$; HR-MS (ESI): $\mathrm{m} / z$ calcd for $\left[\mathrm{C}_{23} \mathrm{H}_{25} \mathrm{NO}_{3} \mathrm{Ru}+\mathrm{H}\right]^{+} 466.0958$, found 466.0954 .

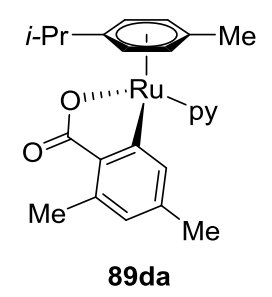

89da: The representative procedure $\mathbf{A}$ was followed using $\left[\mathrm{RuCl}_{2}(p \text {-cymene })\right]_{2}(61.2 \mathrm{mg}, 0.10 \mathrm{mmol})$, pyridine (18 $\mu \mathrm{L}, 0.22 \mathrm{mmol})$, sodium 2,4-dimethylbenzoat $(87 \mathrm{~d})(86.1 \mathrm{mg}, 0.50 \mathrm{mmol})$ and $\mathrm{KOAc}$ (98.1 mg, $1.0 \mathrm{mmol})$. Purification by column chromatography $\left(\mathrm{CH}_{2} \mathrm{Cl}_{2} / \mathrm{MeOH}: 20 / 1\right)$ yielded $89 \mathrm{da}$ (77.4 $\mathrm{mg}, 81 \%)$ as a yellow solid.

M.p. (decomp.): $\left.102{ }^{\circ} \mathrm{C} ;{ }^{1} \mathrm{H} \mathrm{NMR} \mathrm{(300} \mathrm{MHz,} \mathrm{CDCl}_{3}\right): \delta=8.59-8.53(\mathrm{~m}, 2 \mathrm{H}), 7.67(\mathrm{~s}, 1 \mathrm{H}), 7.43$ (dddd, $J=$ 7.6, 7.6, 1.6, 1.6 Hz, 1H), 7.04-6.95 (m, 2H), $6.53(\mathrm{~s}, 1 \mathrm{H}), 5.50$ (dd, $J=5.7,1.2 \mathrm{~Hz}, 1 \mathrm{H}), 5.41(\mathrm{dd}, J=$ 5.9, $1.2 \mathrm{~Hz}, 1 \mathrm{H}$ ), $5.21(\mathrm{dd}, J=5.9,1.2 \mathrm{~Hz}, 1 \mathrm{H}), 4.78(\mathrm{dd}, J=5.7,1.2 \mathrm{~Hz}, 1 \mathrm{H}), 2.42(\mathrm{~s}, 3 \mathrm{H}), 2.34$ (hept, $J=$ $6.9 \mathrm{~Hz}, 1 \mathrm{H}), 2.34(\mathrm{~s}, 3 \mathrm{H}), 1.67(\mathrm{~s}, 3 \mathrm{H}), 0.98(\mathrm{~d}, J=6.9 \mathrm{~Hz}, 3 \mathrm{H}), 0.97(\mathrm{~d}, J=6.9 \mathrm{~Hz}, 3 \mathrm{H}) ;{ }^{13} \mathrm{C}$ NMR $(125$ $\left.\mathrm{MHz}, \mathrm{CDCl}_{3}\right): \delta=181.6\left(\mathrm{C}_{\mathrm{q}}\right), 177.9\left(\mathrm{C}_{\mathrm{q}}\right), 153.8(\mathrm{CH}), 139.8\left(\mathrm{C}_{\mathrm{q}}\right), 139.3\left(\mathrm{C}_{\mathrm{q}}\right), 136.8(\mathrm{CH}), 135.3(\mathrm{CH}), 133.1$ $\left(\mathrm{C}_{\mathrm{q}}\right), 127.9(\mathrm{CH}), 124.4(\mathrm{CH}), 101.7\left(\mathrm{C}_{\mathrm{q}}\right), 97.7\left(\mathrm{C}_{\mathrm{q}}\right), 88.1(\mathrm{CH}), 87.4(\mathrm{CH}), 84.8(\mathrm{CH}), 80.4(\mathrm{CH}), 30.8(\mathrm{CH})$, $22.6\left(\mathrm{CH}_{3}\right), 22.4\left(\mathrm{CH}_{3}\right), 21.6\left(\mathrm{CH}_{3}\right), 19.7\left(\mathrm{CH}_{3}\right), 18.0\left(\mathrm{CH}_{3}\right)$; IR (ATR): $\tilde{v}=2961,1595,1445,1299,841$, $810,761,730,694,626 \mathrm{~cm}^{-1}$; HR-MS (ESI): $\mathrm{m} / \mathrm{z}$ calcd for $\left[\mathrm{C}_{24} \mathrm{H}_{27} \mathrm{NO}_{2} \mathrm{Ru}+\mathrm{H}\right]^{+} 464.1165$, found 464.1164.

\subsubsection{Synthesis of Ruthenium-Sandwich Complexes}

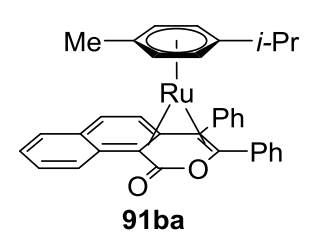

91ba: The representative procedure $\mathbf{B}$ was followed using $\left[\mathrm{RuCl}_{2}(p \text {-cymene })\right]_{2}(62.1 \mathrm{mg}, 0.10 \mathrm{mmol})$, naphthoic acid (1b) $(34.4 \mathrm{mg}, 0.20 \mathrm{mmol})$, diphenylacetylene (2a) $(35.6 \mathrm{mg}, 0.20 \mathrm{mmol}$ ) and $\mathrm{NaOAc}$ ( $32.8 \mathrm{mg}, 0.40 \mathrm{mmol}$ ) for $48 \mathrm{~h}$ at $45^{\circ} \mathrm{C}$. Purification by column chromatography $\left(\mathrm{CH}_{2} \mathrm{Cl}_{2}\right)$ yielded 91 ba (114 $\mathrm{mg}, 98 \%)$ as a yellow solid.

The representative procedure B was followed using $\left[\mathrm{RuCl}_{2}(p \text {-cymene })\right]_{2}(31.1 \mathrm{mg}, 0.05 \mathrm{mmol})$, naphthoic acid (1) $(13.8 \mathrm{mg}, 0.08 \mathrm{mmol})$, diphenylacetylene (2a) $(28.5 \mathrm{mg}, 0.16 \mathrm{mmol}), \mathrm{NaOAc}$ 
(13.1 $\mathrm{mg}, 0.16 \mathrm{mmol}$ ) and additionaly pyridine $(8.1 \mu \mathrm{L}, 0.10 \mathrm{mmol})$ for $48 \mathrm{~h}$ at $45^{\circ} \mathrm{C}$. Purification by column chromatography $\left(\mathrm{CH}_{2} \mathrm{Cl}_{2}\right)$ yielded 91 ba $(38.0 \mathrm{mg}, 81 \%)$ as a yellow solid.

The representative procedure $\mathbf{C}$ was followed using ruthenacycle $89 \mathrm{bb}(9.7 \mathrm{mg}, 20 \mu \mathrm{mol})$ and diphenylacetylene (2a) $(3.6 \mathrm{mg}, 20 \mu \mathrm{mol})$ at $60{ }^{\circ} \mathrm{C}$ for $48 \mathrm{~h}$ (NMR-yield: $87 \%$ ). Purification by column chromatography $\left(\mathrm{CH}_{2} \mathrm{Cl}_{2}\right)$ yielded $\mathbf{9 1 b a}(10.0 \mathrm{mg}, 86 \%)$ as a yellow solid.

M.p. (decomp.): $164{ }^{\circ} \mathrm{C} .{ }^{1} \mathrm{H} \mathrm{NMR}\left(300 \mathrm{MHz}, \mathrm{CDCl}_{3}\right): \delta=8.34$ (d, $\left.J=8.0 \mathrm{~Hz}, 1 \mathrm{H}\right), 7.84(\mathrm{~d}, J=7.6 \mathrm{~Hz}, 1 \mathrm{H})$, 7.60-7.42 (m, 3H), 7.39-7.32 (m, 1H), 7.29 (td, J = 7.6, 1.4 Hz, 1H), 7.24-7.14 (m, 4H), 7.13-6.95 (m, $5 \mathrm{H}), 5.49(\mathrm{~d}, J=5.9 \mathrm{~Hz}, 1 \mathrm{H}), 5.30(\mathrm{~d}, J=5.7 \mathrm{~Hz}, 1 \mathrm{H}), 3.79(\mathrm{~d}, J=5.8 \mathrm{~Hz}, 1 \mathrm{H}), 3.27(\mathrm{~d}, J=6.2 \mathrm{~Hz}, 1 \mathrm{H})$, 1.71 (hept, $J=6.9 \mathrm{~Hz}, 1 \mathrm{H}), 1.58(\mathrm{~s}, 3 \mathrm{H}), 1.23(\mathrm{~d}, J=6.8 \mathrm{~Hz}, 3 \mathrm{H}), 0.94(\mathrm{~d}, J=6.9 \mathrm{~Hz}, 3 \mathrm{H}) ;{ }^{13} \mathrm{C}$ NMR $(125$ $\left.\mathrm{MHz}, \mathrm{CDCl}_{3}\right): \delta=172.7\left(\mathrm{C}_{\mathrm{q}}\right), 142.1\left(\mathrm{C}_{\mathrm{q}}\right), 137.6\left(\mathrm{C}_{\mathrm{q}}\right), 135.5\left(\mathrm{C}_{\mathrm{q}}\right), 132.6(\mathrm{CH}), 132.0(\mathrm{CH}), 129.5\left(\mathrm{C}_{\mathrm{q}}\right), 129.4$ $(\mathrm{CH}), 128.8(\mathrm{CH}), 128.3(\mathrm{CH}), 127.9(\mathrm{CH}), 127.7(\mathrm{CH}), 127.5(\mathrm{CH}), 127.4(\mathrm{CH}), 126.9(\mathrm{CH}), 125.3(\mathrm{CH})$, $124.8(\mathrm{CH}), 124.3(\mathrm{CH}), 123.2(\mathrm{CH}), 111.2\left(\mathrm{C}_{\mathrm{q}}\right), 99.0\left(\mathrm{C}_{\mathrm{q}}\right), 91.9\left(\mathrm{C}_{\mathrm{q}}\right), 88.8\left(\mathrm{C}_{\mathrm{q}}\right), 87.8(\mathrm{CH}), 87.6(\mathrm{CH}), 85.5$ $(\mathrm{CH}), 83.9(\mathrm{CH}), 81.3\left(\mathrm{C}_{\mathrm{q}}\right), 57.1\left(\mathrm{C}_{\mathrm{q}}\right), 30.2(\mathrm{CH}), 24.6\left(\mathrm{CH}_{3}\right), 21.5\left(\mathrm{CH}_{3}\right), 17.3\left(\mathrm{CH}_{3}\right)$; IR (ATR): $\tilde{v}=3056$, 2958, 1711, 1494, 1205, 1007, 959, 837, 807, 763, 697, $584 \mathrm{~cm}^{-1}$; HR-MS (ESI): $\mathrm{m} / \mathrm{z}$ calcd for $\left[\mathrm{C}_{35} \mathrm{H}_{30} \mathrm{O}_{2} \mathrm{Ru}+\mathrm{H}\right]^{+}$585.1372, found 585.1369.

\section{Studies}



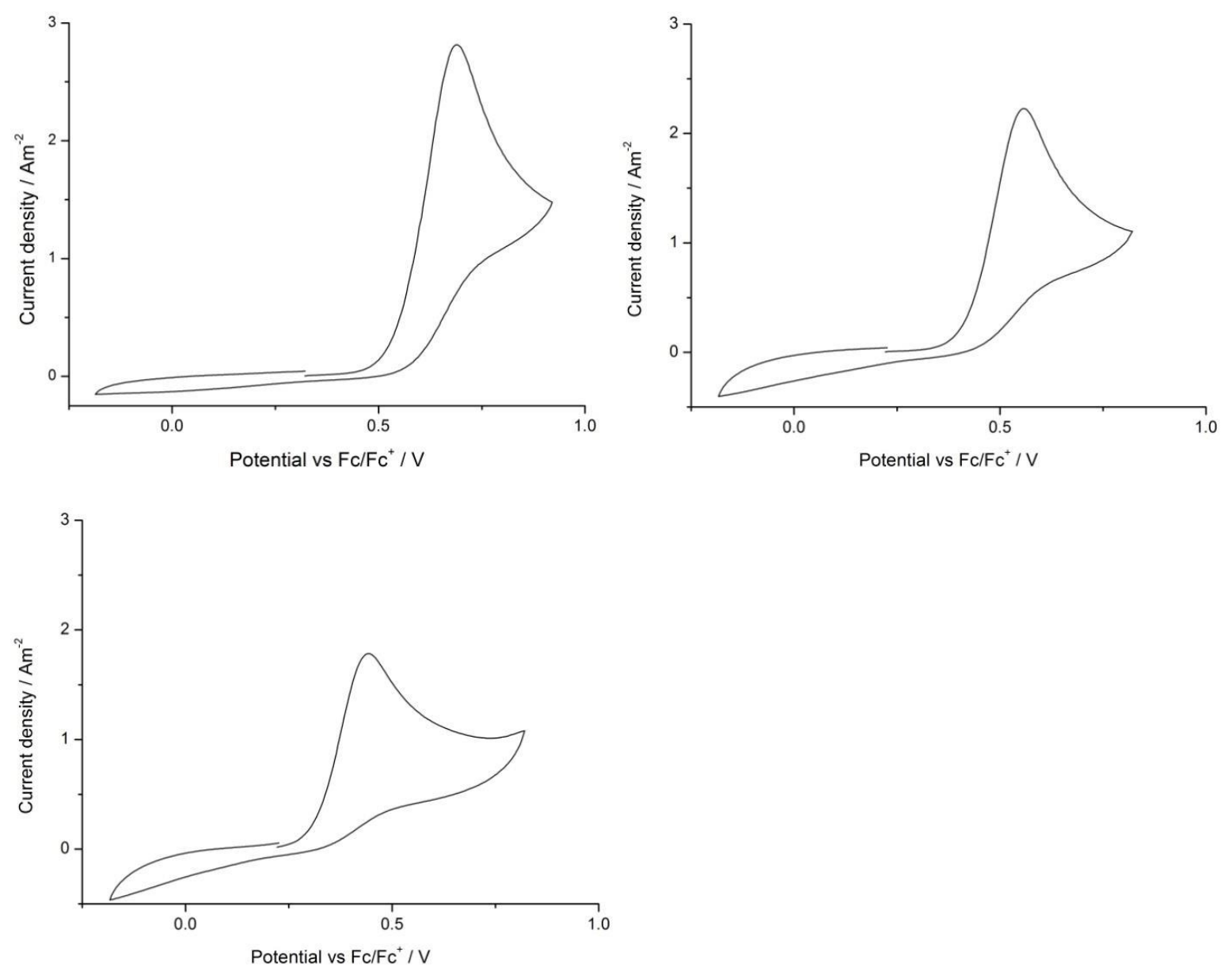

Figure 31. CV spectra of complex 91ba in acetonitrile top left: without acid, top right: with 100 equivalent acetic acid, bottom left: with 200 equivalent acetic acid.

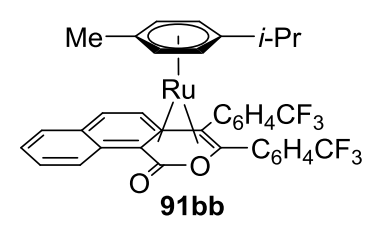

The representative procedure B was followed using $\left[\operatorname{RuCl}_{2}(p \text {-cymene })\right]_{2}(100 \mathrm{mg}, 0.16 \mathrm{mmol})$, naphthoic acid (1b) $(55.1 \mathrm{mg}, 0.32 \mathrm{mmol})$, 1,2-bis(4-(trifluoromethyl)phenyl)ethyne (2b) (101 mg, $0.32 \mathrm{mmol})$ and $\mathrm{NaOAc}(52.5 \mathrm{mg}, 0.64 \mathrm{mmol})$ for $48 \mathrm{~h}$ at $45^{\circ} \mathrm{C}$. Purification by column chromatography $\left(\mathrm{CH}_{2} \mathrm{Cl}_{2}\right)$ yielded $\mathbf{9 1 b b}(192 \mathrm{mg}, 84 \%)$ as a yellow solid.

The representative procedure $\mathbf{C}$ was followed using ruthenacycle $89 \mathrm{bb}(7.0 \mathrm{mg}, 20 \mu \mathrm{mol})$ and 1,2bis(4-(trifluoromethyl)phenyl)ethyne (2b) $(6.3 \mathrm{mg}, 20 \mu \mathrm{mol})$ for $48 \mathrm{~h}$ (NMR-yield: 95\%). Purification by column chromatography $\left(\mathrm{CH}_{2} \mathrm{Cl}_{2}\right)$ yielded $91 \mathrm{bb}(13.2 \mathrm{mg}, 92 \%)$ as a yellow solid.

M.p. (decomp.): $145^{\circ} \mathrm{C} ;{ }^{1} \mathrm{H}$ NMR $\left(300 \mathrm{MHz}, \mathrm{CDCl}_{3}\right): \delta=8.35(\mathrm{~d}, J=8.2 \mathrm{~Hz}, 1 \mathrm{H}), 7.97(\mathrm{~d}, J=8.0 \mathrm{~Hz}, 1 \mathrm{H})$, $7.85(\mathrm{~d}, J=7.8 \mathrm{~Hz}, 1 \mathrm{H}), 7.58-7.54(\mathrm{~m}, 1 \mathrm{H}), 7.51-7.47(\mathrm{~m}, 2 \mathrm{H}), 7.36-7.32(\mathrm{~m}, 3 \mathrm{H}), 7.29(\mathrm{~d}, J=7.5 \mathrm{~Hz}$, 
$1 \mathrm{H}), 7.25(\mathrm{~d}, J=9.4 \mathrm{~Hz}, 1 \mathrm{H}), 7.16(\mathrm{~d}, J=8.4 \mathrm{~Hz}, 2 \mathrm{H}), 7.07(\mathrm{~d}, J=9.3 \mathrm{~Hz}, 1 \mathrm{H}), 5.50(\mathrm{~d}, J=5.9 \mathrm{~Hz}, 1 \mathrm{H})$, $5.32(\mathrm{~d}, J=5.1 \mathrm{~Hz}, 1 \mathrm{H}), 3.81(\mathrm{~d}, J=5.1 \mathrm{~Hz}, 1 \mathrm{H}), 3.30(\mathrm{~d}, J=5.9 \mathrm{~Hz}, 1 \mathrm{H}), 1.73$ (hept, $J=6.8 \mathrm{~Hz}, 1 \mathrm{H}$ ), 1.61 $(\mathrm{s}, 3 \mathrm{H}), 1.22(\mathrm{~d}, J=6.8 \mathrm{~Hz}, 3 \mathrm{H}), 0.96(\mathrm{~d}, J=7.0 \mathrm{~Hz}, 3 \mathrm{H}) ;{ }^{13} \mathrm{C}$ NMR $\left(125 \mathrm{MHz}, \mathrm{CDCl}_{3}\right): \delta=172.0\left(\mathrm{C}_{\mathrm{q}}\right)$, $146.4\left(\mathrm{C}_{\mathrm{q}}\right) 139.6\left(\mathrm{C}_{\mathrm{q}}\right), 137.3\left(\mathrm{C}_{\mathrm{q}}\right), 132.9(\mathrm{CH}), 132.2(\mathrm{CH}), 129.8(\mathrm{CH}), 129.8\left(\mathrm{q}, J=32.6 \mathrm{~Hz}, \mathrm{C}_{\mathrm{q}}\right), 129.4$ $\left(\mathrm{C}_{q}\right), 129.4(\mathrm{CH}), 128.0(\mathrm{CH}), 127.9(\mathrm{CH}), 126.3\left(\mathrm{q}, J=32.3 \mathrm{~Hz}, \mathrm{C}_{\mathrm{q}}\right), 125.4(\mathrm{CH}), 125.3(\mathrm{CH}), 125.1(\mathrm{CH})$ $124.8\left(q, J=271.6 \mathrm{~Hz}, \mathrm{C}_{\mathrm{q}}\right.$ ), $124.0\left(\mathrm{q}, J=272.2 \mathrm{~Hz}, \mathrm{C}_{\mathrm{q}}\right), 124.0$ (q, J=3.8 Hz, CH), $111.6\left(\mathrm{C}_{\mathrm{q}}\right), 99.4\left(\mathrm{C}_{\mathrm{q}}\right)$, $92.6\left(\mathrm{C}_{\mathrm{q}}\right), 88.1(\mathrm{CH}), 88.1(\mathrm{CH}), 86.8\left(\mathrm{C}_{\mathrm{q}}\right), 85.9(\mathrm{CH}), 84.7(\mathrm{CH}), 80.2\left(\mathrm{C}_{\mathrm{q}}\right), 58.0\left(\mathrm{C}_{\mathrm{q}}\right), 30.4(\mathrm{CH}), 24.5$ $\left(\mathrm{CH}_{3}\right), 21.5\left(\mathrm{CH}_{3}\right), 17.3\left(\mathrm{CH}_{3}\right) ;{ }^{19} \mathrm{~F}$ NMR $\left(282 \mathrm{MHz}, \mathrm{CDCl}_{3}\right): \delta=-62.2$ (s), -62.4 (s); IR (ATR): $\tilde{v}=2968$, $1713,1612,1320,1109,1063,802 \mathrm{~cm}^{-1}$; HR-MS (ESI): $\mathrm{m} / z$ calcd for $\left[\mathrm{C}_{37} \mathrm{H}_{28} \mathrm{~F}_{6} \mathrm{O}_{2} \mathrm{Ru}+\mathrm{H}\right]^{+} 721.1120$, found 721.1113; as well as calcd for $\left[\mathrm{C}_{37} \mathrm{H}_{28} \mathrm{~F}_{6} \mathrm{O}_{2} \mathrm{Ru}+\mathrm{Na}\right]^{+} 743.0939$, found 743.0933 .

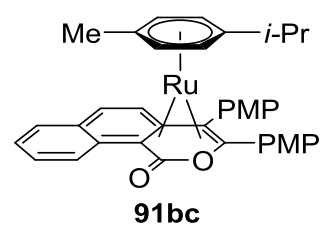

The representative procedure B was followed using $\left[\mathrm{RuCl}_{2}(p \text {-cymene })\right]_{2}(62.1 \mathrm{mg}, 0.10 \mathrm{mmol})$, naphthoic acid (1b) (34.4 mg, 0. $02 \mathrm{mmol})$, 1,2-bis(4-methoxyphenyl)ethyne (2c) $(47.7 \mathrm{mg}$, $0.20 \mathrm{mmol})$ and $\mathrm{NaOAc}(32.9 \mathrm{mg}, 0.40 \mathrm{mmol})$ for $48 \mathrm{~h}$ at $45^{\circ} \mathrm{C}$. Purification by column chromatography $\left(\mathrm{CH}_{2} \mathrm{Cl}_{2}\right)$ yielded $\mathbf{9 1 b c}(123 \mathrm{mg}, 95 \%)$ as a yellow solid.

The representative procedure $\mathbf{C}$ was followed using ruthenacycle $89 \mathrm{bb}(7.0 \mathrm{mg}, 20 \mu \mathrm{mol})$ and 1,2bis(4-methoxyphenyl)ethyne (2c) $(4.8 \mathrm{mg}, 20 \mu \mathrm{mol})$ for $24 \mathrm{~h}$ (NMR-yield: 76\%). Purification by column chromatography $\left(\mathrm{CH}_{2} \mathrm{Cl}_{2}\right)$ yielded $91 \mathrm{bc}(9.2 \mathrm{mg}, 71 \%)$ as a yellow solid.

M.p. (decomp.): $120{ }^{\circ} \mathrm{C} .{ }^{1} \mathrm{H} \mathrm{NMR}\left(300 \mathrm{MHz}, \mathrm{CDCl}_{3}\right): \delta=8.34-8.28(\mathrm{~m}, 1 \mathrm{H}), 7.72(\mathrm{~d}, J=8.5 \mathrm{~Hz}, 1 \mathrm{H})$, 7.53-7.46 (m, 1H), 7.43 (dd, J = 7.9, 1.4 Hz, 1H), 7.27 (ddd, J = 7.7, 7.2, 1.3 Hz, 1H), 7.15 (d, J = 2.7 Hz, 2H), 7.13-6.99 (m, 4H), 6.77-6.71 (m, 1H), $6.63(\mathrm{~d}, J=9.1 \mathrm{~Hz}, 2 \mathrm{H}), 5.44(\mathrm{dd}, J=5.9,1.2 \mathrm{~Hz}, 1 \mathrm{H}), 5.25$ (dd, $J=5.8,1.3 \mathrm{~Hz}, 1 \mathrm{H}), 3.85(\mathrm{~s}, 3 \mathrm{H}), 3.80(\mathrm{dd}, J=5.8,1.3 \mathrm{~Hz}, 1 \mathrm{H}), 3.76(\mathrm{~s}, 3 \mathrm{H}), 3.26(\mathrm{dd}, J=5.9,1.2 \mathrm{~Hz}$, 1H), 1.77 (hept, $J=6.9 \mathrm{~Hz}, 1 \mathrm{H}$ ), $1.59(\mathrm{~s}, 3 \mathrm{H}), 1.23$ (d, $J=6.8 \mathrm{~Hz}, 3 \mathrm{H}), 0.95$ (d, $J=6.9 \mathrm{~Hz}, 3 \mathrm{H}$ ); ${ }^{13} \mathrm{C}$ NMR $\left(125 \mathrm{MHz}, \mathrm{CDCl}_{3}\right): \delta=172.8\left(\mathrm{C}_{\mathrm{q}}\right), 158.9\left(\mathrm{C}_{\mathrm{q}}\right), 156.5\left(\mathrm{C}_{\mathrm{q}}\right), 137.7\left(\mathrm{C}_{\mathrm{q}}\right), 134.4\left(\mathrm{C}_{\mathrm{q}}\right), 133.8(\mathrm{CH}), 133.1(\mathrm{CH})$, $129.6\left(\mathrm{C}_{q}\right), 129.4(\mathrm{CH}), 128.6(\mathrm{CH}), 127.7(\mathrm{CH}), 127.6\left(\mathrm{C}_{q}\right), 127.4(\mathrm{CH}), 126.5(\mathrm{CH}), 124.7(\mathrm{CH}), 123.5$ $(\mathrm{CH}), 113.8(\mathrm{CH}), 113.3(\mathrm{CH}), 112.4(\mathrm{CH}), 111.2\left(\mathrm{C}_{q}\right), 99.1\left(\mathrm{C}_{q}\right), 91.4\left(\mathrm{C}_{q}\right), 89.7\left(\mathrm{C}_{q}\right), 87.4(\mathrm{CH}), 87.3(\mathrm{CH})$, 85.3 $(\mathrm{CH}), 83.7(\mathrm{CH}), 80.4\left(\mathrm{C}_{\mathrm{q}}\right), 56.6\left(\mathrm{C}_{\mathrm{q}}\right), 55.3\left(\mathrm{CH}_{3}\right), 55.1\left(\mathrm{CH}_{3}\right), 30.4(\mathrm{CH}), 24.7\left(\mathrm{CH}_{3}\right), 21.6\left(\mathrm{CH}_{3}\right), 17.4$ $\left(\mathrm{CH}_{3}\right)$; IR (ATR): $\tilde{v}=2698,2241,1713,1612,1320,1163,1109,1007,802 \mathrm{~cm}^{-1} ; \mathrm{HR}-\mathrm{MS}$ (ESI): $\mathrm{m} / \mathrm{z}$ calcd for $\left[\mathrm{C}_{37} \mathrm{H}_{34} \mathrm{O}_{4} \mathrm{Ru}+\mathrm{H}\right]^{+} 645.1584$, found 645.1576 . 


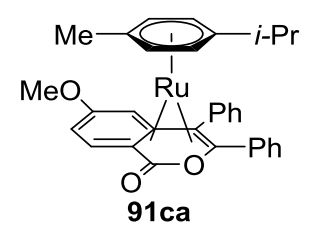

The representative procedure B was followed using $\left[\mathrm{RuCl}_{2}(p \text {-cymene })\right]_{2}(24.9 \mathrm{mg}, 0.04 \mathrm{mmol}), 4-$ methoxybenzoic acid (1c) $(12.1 \mathrm{mg}, 0.08 \mathrm{mmol})$, diphenylacetylene (2a) $(14.3 \mathrm{mg}, 0.08 \mathrm{mmol})$ and $\mathrm{NaOAc}(13.1 \mathrm{mg}, 0.16 \mathrm{mmol})$ for $48 \mathrm{~h}$ at $45{ }^{\circ} \mathrm{C}$. Purification by column chromatography $\left(\mathrm{CH}_{2} \mathrm{Cl}_{2}\right)$ yielded 91ca (42.5 $\mathrm{mg}, 94 \%$ ) as a yellow solid.

The representative procedure C was followed using ruthenacycle $89 \mathrm{ca}(8.4 \mathrm{mg}, 18 \mu \mathrm{mol})$ and diphenylacetylene (2a) $(3.2 \mathrm{mg}, 18 \mu \mathrm{mol})$ for $20 \mathrm{~h}$ to $40^{\circ} \mathrm{C}$ (NMR-yield: $71 \%$ ). Purification by filtration and washing with $n$-hexane yielded $91 \mathrm{ca}(5.4 \mathrm{mg}, 64 \%$ ) as a yellow solid.

M.p. (decomp.): $185^{\circ} \mathrm{C} ;{ }^{1} \mathrm{H} \mathrm{NMR}\left(600 \mathrm{MHz}, \mathrm{CDCl}_{3}\right): \delta=7.92(\mathrm{~d}, J=7.6 \mathrm{~Hz}, 1 \mathrm{H}), 7.61(\mathrm{~d}, J=9.6 \mathrm{~Hz}, 1 \mathrm{H})$, $7.55(\mathrm{dd}, J=7.5,7.5 \mathrm{~Hz}, 1 \mathrm{H}), 7.36-7.31(\mathrm{~m}, 1 \mathrm{H}), 7.19(\mathrm{t}, J=7.4 \mathrm{~Hz}, 1 \mathrm{H}), 7.14(\mathrm{~d}, J=7.7 \mathrm{~Hz}, 1 \mathrm{H}), 7.05-$ $6.99(\mathrm{~m}, 4 \mathrm{H}), 6.98-6.93(\mathrm{~m}, 1 \mathrm{H}), 6.39(\mathrm{dd}, J=9.6,2.4 \mathrm{~Hz}, 1 \mathrm{H}), 6.36(\mathrm{~d}, J=2.4 \mathrm{~Hz}, 1 \mathrm{H}), 5.61(\mathrm{~d}, J=$ $5.7 \mathrm{~Hz}, 1 \mathrm{H}), 5.34(\mathrm{~d}, J=5.7 \mathrm{~Hz}, 1 \mathrm{H}), 4.09(\mathrm{~d}, J=5.7 \mathrm{~Hz}, 1 \mathrm{H}), 3.98(\mathrm{~d}, J=5.8 \mathrm{~Hz}, 1 \mathrm{H}), 3.68(\mathrm{~s}, 3 \mathrm{H}), 1.84$ (hept, $J=6.8 \mathrm{~Hz}, 1 \mathrm{H}), 1.65(\mathrm{~s}, 3 \mathrm{H}), 1.19(\mathrm{~d}, J=6.8 \mathrm{~Hz}, 3 \mathrm{H}), 1.01(\mathrm{~d}, J=7.0 \mathrm{~Hz}, 3 \mathrm{H}) ;{ }^{13} \mathrm{C}$ NMR $(125 \mathrm{MHz}$, $\left.\mathrm{CDCl}_{3}\right): \delta=171.5\left(\mathrm{C}_{\mathrm{q}}\right), 159.1\left(\mathrm{C}_{\mathrm{q}}\right), 142.4\left(\mathrm{C}_{\mathrm{q}}\right), 137.1(\mathrm{CH}), 136.1\left(\mathrm{C}_{\mathrm{q}}\right), 132.0(\mathrm{CH}), 132.0(\mathrm{CH}), 128.4(\mathrm{CH})$, $127.9(\mathrm{CH}), 127.1(\mathrm{CH}), 126.7(\mathrm{CH}), 125.2(\mathrm{CH}), 124.1(\mathrm{CH}), 116.7(\mathrm{CH}), 110.0\left(\mathrm{C}_{\mathrm{q}}\right), 98.5\left(\mathrm{C}_{\mathrm{q}}\right), 98.3\left(\mathrm{C}_{\mathrm{q}}\right)$, $95.6(\mathrm{CH}), 88.4\left(\mathrm{C}_{q}\right), 87.1(\mathrm{CH}), 85.9(\mathrm{CH}), 84.4(\mathrm{CH}), 82.0(\mathrm{CH}), 77.9\left(\mathrm{C}_{\mathrm{q}}\right), 59.6\left(\mathrm{C}_{\mathrm{q}}\right), 54.9\left(\mathrm{CH}_{3}\right), 30.5$ (CH), $24.5\left(\mathrm{CH}_{3}\right), 21.8\left(\mathrm{CH}_{3}\right), 17.6\left(\mathrm{CH}_{3}\right)$; IR (ATR): $\tilde{v}=2920,1699,1235,811,765,698,576 \mathrm{~cm}^{-1}$; HRMS (ESI): $\mathrm{m} / \mathrm{z}$ calcd for $\left[\mathrm{C}_{32} \mathrm{H}_{30} \mathrm{O}_{3} \mathrm{Ru}+\mathrm{H}\right]^{+} 565.1320$, found 565.1314 .

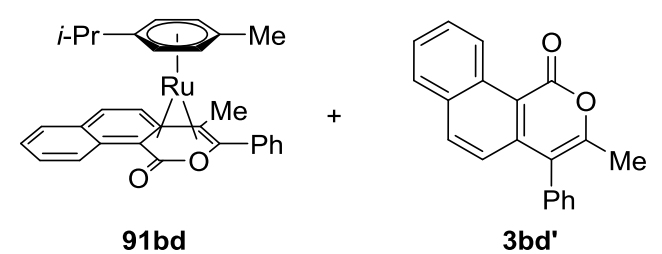

The representative procedure B was followed using $\left[\mathrm{RuCl}_{2}(p \text {-cymene })\right]_{2}(62.1 \mathrm{mg}, 0.10 \mathrm{mmol})$, naphthoic acid (1b) $(34.4 \mathrm{mg}, 0.20 \mathrm{mmol})$, prop-1-yn-1-ylbenzene (2d) $(23.2 \mathrm{mg}, 0.20 \mathrm{mmol})$ and $\mathrm{NaOAc}(32.9 \mathrm{mg}, 0.40 \mathrm{mmol})$. Purification by column chromatography $\left(\mathrm{CH}_{2} \mathrm{Cl}_{2}\right)$ yielded $91 \mathrm{bd}$ ( $82.3 \mathrm{mg}, 79 \%)$ and 3 bd' (11.9 $\mathrm{mg}, 21 \%)$ as a yellow and colorless solid, respectively.

91bd: M.p. (decomp.): $128{ }^{\circ} \mathrm{C}$; ${ }^{1} \mathrm{H}$ NMR $\left(300 \mathrm{MHz}, \mathrm{CDCl}_{3}\right.$ ): $\delta=8.31$ (d, $\left.J=8.3 \mathrm{~Hz}, 1 \mathrm{H}\right), 7.54-7.36$ (m, $5 \mathrm{H}), 7.34(\mathrm{~s}, 1 \mathrm{H}), 7.31(\mathrm{~s}, 1 \mathrm{H}), 7.29(\mathrm{~s}, 1 \mathrm{H}), 7.25-7.22(\mathrm{~m}, 1 \mathrm{H}), 7.21-7.12(\mathrm{~m}, 1 \mathrm{H}), 5.05(\mathrm{~d}, J=5.8 \mathrm{~Hz}$, $1 \mathrm{H}), 4.97(\mathrm{~d}, J=5.6 \mathrm{~Hz}, 1 \mathrm{H}), 3.94(\mathrm{~d}, J=5.8 \mathrm{~Hz}, 1 \mathrm{H}), 3.31(\mathrm{~d}, J=6.0 \mathrm{~Hz}, 1 \mathrm{H}), 2.45(\mathrm{~s}, 3 \mathrm{H}), 1.98(\mathrm{sept}, J=$ 
$6.9 \mathrm{~Hz}, 1 \mathrm{H}), 1.65(\mathrm{~s}, 3 \mathrm{H}), 1.15(\mathrm{~d}, J=6.9 \mathrm{~Hz}, 3 \mathrm{H}), 1.02(\mathrm{~d}, J=6.9 \mathrm{~Hz}, 3 \mathrm{H}) ;{ }^{13} \mathrm{C} \mathbf{N M R}\left(125 \mathrm{MHz}, \mathrm{CDCl}_{3}\right): \delta$ $=172.4\left(\mathrm{C}_{\mathrm{q}}\right), 142.9\left(\mathrm{C}_{\mathrm{q}}\right), 137.9\left(\mathrm{C}_{\mathrm{q}}\right), 129.3\left(\mathrm{C}_{\mathrm{q}}\right), 129.2(\mathrm{CH}), 128.5(\mathrm{CH}), 127.7(\mathrm{CH}), 127.4(\mathrm{CH}), 127.3$ $(\mathrm{CH}), 125.4(\mathrm{CH}), 124.7(\mathrm{CH}), 124.6(\mathrm{CH}), 122.8(\mathrm{CH}), 110.0\left(\mathrm{C}_{q}\right), 98.4\left(\mathrm{C}_{\mathrm{q}}\right), 91.2\left(\mathrm{C}_{\mathrm{q}}\right), 90.7\left(\mathrm{C}_{\mathrm{q}}\right), 87.1$ $(\mathrm{CH}), 87.0(\mathrm{CH}), 84.9(\mathrm{CH}), 84.7(\mathrm{CH}), 74.0\left(\mathrm{C}_{\mathrm{q}}\right), 57.5\left(\mathrm{C}_{\mathrm{q}}\right), 30.5(\mathrm{CH}), 24.4\left(\mathrm{CH}_{3}\right), 22.3\left(\mathrm{CH}_{3}\right), 17.6\left(\mathrm{CH}_{3}\right)$, $14.3\left(\mathrm{CH}_{3}\right)$; IR (ATR): $\tilde{v}=3054,2957,1696,1200,959,797,763,702,666,425 \mathrm{~cm}^{-1}$; HR-MS (ESI): $\mathrm{m} / \mathrm{z}$ calcd for $\left[\mathrm{C}_{30} \mathrm{H}_{28} \mathrm{O}_{2} \mathrm{Ru}+\mathrm{H}\right]^{+}$523.1214, found 523.1205.

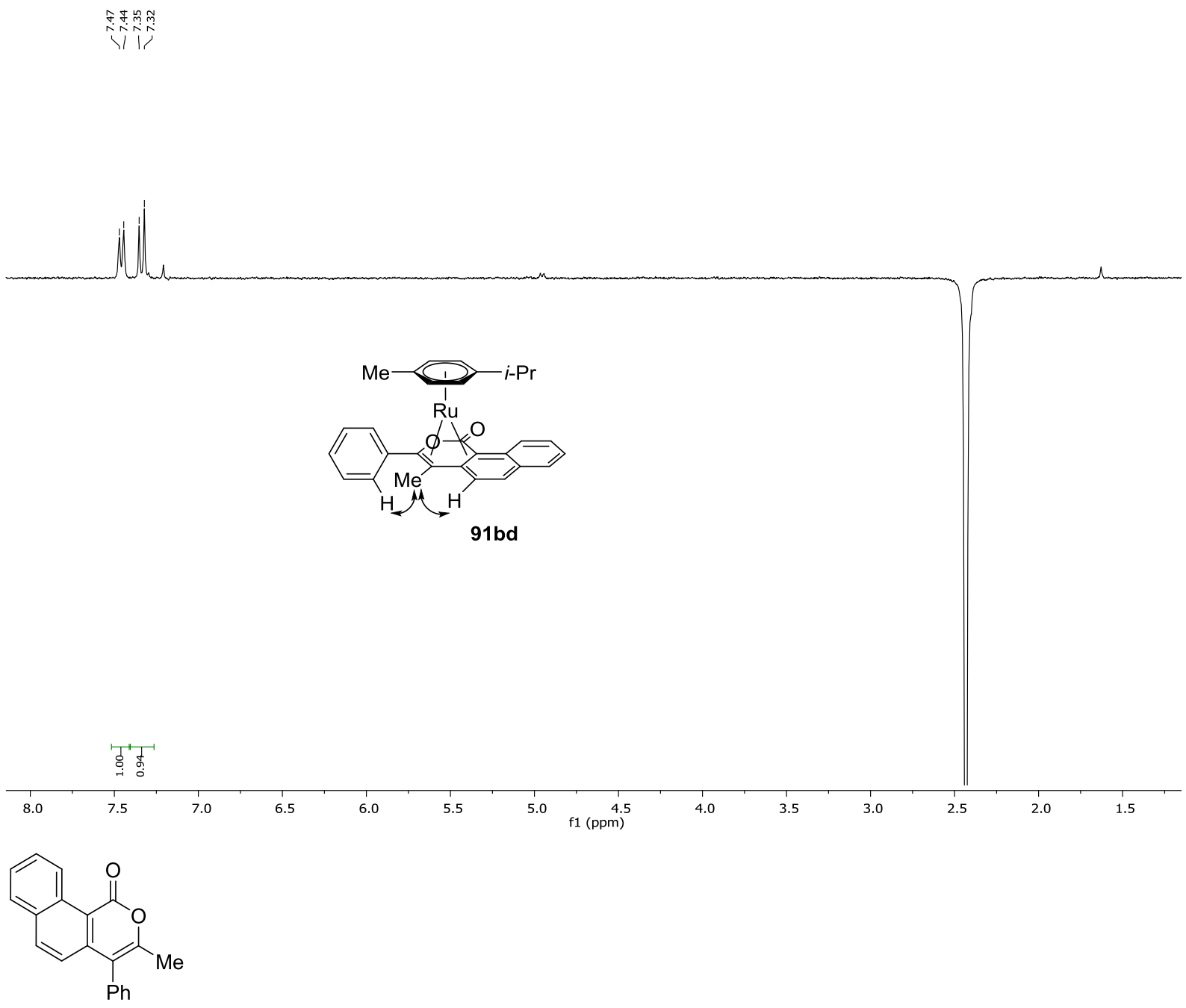

3bd': M.p.: $173{ }^{\circ} \mathrm{C} ;{ }^{1} \mathrm{H}$ NMR $\left(300 \mathrm{MHz}, \mathrm{CDCl}_{3}\right): \delta=9.84-9.79(\mathrm{~m}, 1 \mathrm{H}), 8.14(\mathrm{~d}, J=8.8 \mathrm{~Hz}, 1 \mathrm{H}), 7.89$ (dd, $J=8.1,1.5 \mathrm{~Hz}, 1 \mathrm{H}), 7.76(\mathrm{ddd}, J=8.6,6.9,1.5 \mathrm{~Hz}, 1 \mathrm{H}), 7.68-7.59(\mathrm{~m}, 4 \mathrm{H}), 7.53-7.44(\mathrm{~m}, 3 \mathrm{H}), 2.39(\mathrm{~s}$, $3 \mathrm{H}) ;{ }^{13} \mathrm{C}$ NMR $\left(125 \mathrm{MHz}, \mathrm{CDCl}_{3}\right) \delta=161.6\left(\mathrm{C}_{\mathrm{q}}\right), 152.7\left(\mathrm{C}_{\mathrm{q}}\right), 141.0\left(\mathrm{C}_{\mathrm{q}}\right), 136.1(\mathrm{CH}), 133.1\left(\mathrm{C}_{\mathrm{q}}\right), 132.4\left(\mathrm{C}_{\mathrm{q}}\right)$, $131.6\left(\mathrm{C}_{\mathrm{q}}\right), 129.5(\mathrm{CH}), 129.4(\mathrm{CH}), 129.3(\mathrm{CH}), 128.4(\mathrm{CH}), 128.2(\mathrm{CH}), 127.0(\mathrm{CH}), 126.8(\mathrm{CH}), 120.7$ $(\mathrm{CH}), 114.2\left(\mathrm{C}_{\mathrm{q}}\right), 109.4\left(\mathrm{C}_{\mathrm{q}}\right), 14.2\left(\mathrm{CH}_{3}\right)$; IR (ATR): $\tilde{v}=1700,1593,1547,1105,831,807,754,695,637$, $504 \mathrm{~cm}^{-1}$; MS (El) m/z (relative intensity) 286 (100) [M] ${ }^{+}, 258$ (98), 152 (37), 105 (45), 77 (38); HR-MS (EI) $\mathrm{m} / \mathrm{z}$ calcd for $\left[\mathrm{C}_{20} \mathrm{H}_{14} \mathrm{O}_{2}\right]^{+} 286.0994$, found 286.0991 . 


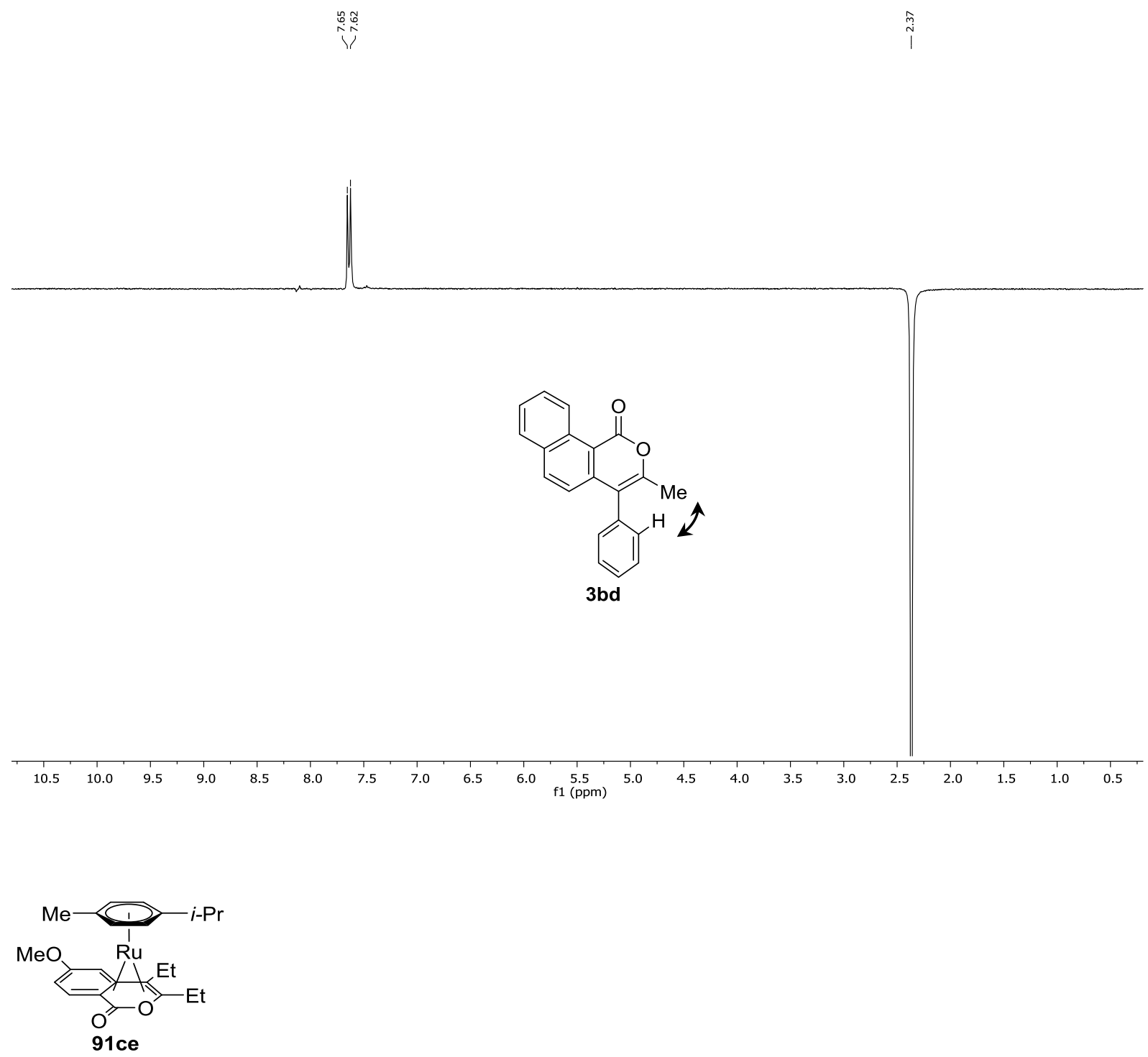

The representative procedure $\mathbf{C}$ was followed using ruthenacycle $89 \mathrm{cb}(8.4 \mathrm{mg}, 18 \mu \mathrm{mol})$ and 3 hexyne (2e) $(2.0 \mu \mathrm{L}, 18 \mu \mathrm{mol})$ at $45{ }^{\circ} \mathrm{C}$ for $18 \mathrm{~h}$ (NMR-yield: $75 \%$ ). Purification by filtration and washing with $n$-hexane yielded 91ce $(4.1 \mathrm{mg}, 49 \%)$ as a yellow oxygen-sensitive solid.

${ }^{1} \mathrm{H}$ NMR $\left(300 \mathrm{MHz}, \mathrm{CDCl}_{3}\right): \delta=7.44(\mathrm{~d}, J=9.7 \mathrm{~Hz}, 1 \mathrm{H}), 6.42(\mathrm{~d}, J=2.3 \mathrm{~Hz}, 1 \mathrm{H}), 6.28(\mathrm{dd}, J=9.6,2.3 \mathrm{~Hz}$, $1 \mathrm{H}), 5.08(\mathrm{~d}, J=5.6 \mathrm{~Hz}, 1 \mathrm{H}), 4.68(\mathrm{~d}, J=5.9 \mathrm{~Hz}, 1 \mathrm{H}), 4.61(\mathrm{~d}, J=5.6 \mathrm{~Hz}, 1 \mathrm{H}), 4.45(\mathrm{~d}, J=5.9 \mathrm{~Hz}, 1 \mathrm{H})$, $3.77(\mathrm{~s}, 3 \mathrm{H}$ ), 2.66 (dq, $J=15.0,7.5 \mathrm{~Hz}, 1 \mathrm{H}$ ), 2.47 (hept, $J=6.9 \mathrm{~Hz}, 1 \mathrm{H}$ ), 2.20-2.03 (m, 2H), 2.02-1.91 $(\mathrm{m}, 1 \mathrm{H}), 1.88(\mathrm{~s}, 3 \mathrm{H}), 1.32(\mathrm{t}, J=7.5 \mathrm{~Hz}, 3 \mathrm{H}), 1.25(\mathrm{~d}, J=6.9 \mathrm{~Hz}, 3 \mathrm{H}), 1.24(\mathrm{~d}, J=6.9 \mathrm{~Hz}, 3 \mathrm{H}), 1.12(\mathrm{t}, J=$ $7.3 \mathrm{~Hz}, 3 \mathrm{H}) ;{ }^{13} \mathrm{C}$ NMR $\left(75 \mathrm{MHz}, \mathrm{CDCl}_{3}\right): \delta=171.8\left(\mathrm{C}_{\mathrm{q}}\right), 158.4\left(\mathrm{C}_{\mathrm{q}}\right), 137.2(\mathrm{CH}), 115.4(\mathrm{CH}), 108.6\left(\mathrm{C}_{\mathrm{q}}\right)$, 96.4 $\left(\mathrm{C}_{\mathrm{q}}\right)$, 95.7 $\left(\mathrm{C}_{\mathrm{q}}\right), 94.6(\mathrm{CH}), 94.3\left(\mathrm{C}_{\mathrm{q}}\right), 86.8(\mathrm{CH}), 83.1(\mathrm{CH}), 82.1(\mathrm{CH}), 81.5(\mathrm{CH}), 74.4\left(\mathrm{C}_{q}\right), 60.2\left(\mathrm{C}_{q}\right)$, 54.8 $\left(\mathrm{CH}_{3}\right), 31.5(\mathrm{CH}), 29.3\left(\mathrm{CH}_{2}\right), 23.7\left(\mathrm{CH}_{3}\right), 23.2\left(\mathrm{CH}_{3}\right), 22.3\left(\mathrm{CH}_{2}\right), 18.6\left(\mathrm{CH}_{3}\right), 15.0\left(\mathrm{CH}_{3}\right), 12.4\left(\mathrm{CH}_{3}\right)$; HR-MS (ESI): $\mathrm{m} / z$ calcd for $\left[\mathrm{C}_{24} \mathrm{H}_{30} \mathrm{O}_{3} \mathrm{Ru}+\mathrm{H}\right]^{+} 469.1318$, found 469.1312 . 


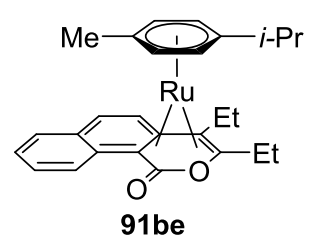

The representative procedure $\mathbf{C}$ was followed using ruthenacycle $89 \mathrm{bb}(9.7 \mathrm{mg}, 20 \mu \mathrm{mol})$ and 3hexyne (2e) $(2.3 \mu \mathrm{L}, 20 \mu \mathrm{mol})$ at $60^{\circ} \mathrm{C}$ for $46 \mathrm{~h}$ (NMR-yield: $67 \%$ ). Purification by filtration and washing with $n$-hexane yielded 91 be $(5.8 \mathrm{mg}, 59 \%)$ as an oxygen sensitive yellow solid.

${ }^{1} \mathrm{H}$ NMR $\left(300 \mathrm{MHz}, \mathrm{CDCl}_{3}\right): \delta=8.23(\mathrm{~d}, J=8.0 \mathrm{~Hz}, 1 \mathrm{H}), 7.45-7.36(\mathrm{~m}, 2 \mathrm{H}), 7.30(\mathrm{~d}, J=9.3 \mathrm{~Hz}, 1 \mathrm{H}), 7.21$ (ddd, $J=8.1,7.1,1.3 \mathrm{~Hz}, 1 \mathrm{H}), 7.06(\mathrm{~d}, J=9.3 \mathrm{~Hz}, 1 \mathrm{H}), 4.77(\mathrm{dd}, J=5.7,1.3 \mathrm{~Hz}, 1 \mathrm{H}), 4.54-4.48(\mathrm{~m}, 2 \mathrm{H})$, $4.05(\mathrm{dd}, J=5.8,1.2 \mathrm{~Hz}, 1 \mathrm{H}), 2.75-2.60(\mathrm{~m}, 1 \mathrm{H}), 2.47-2.33(\mathrm{~m}, 1 \mathrm{H}), 2.25-2.11(\mathrm{~m}, 2 \mathrm{H}), 2.11-1.97(\mathrm{~m}$, 1H), $1.85(\mathrm{~s}, 3 \mathrm{H}), 1.35$ (t, J=7.5 Hz, 3H), $1.23(\mathrm{~d}, J=6.9 \mathrm{~Hz}, 3 \mathrm{H}), 1.23(\mathrm{~d}, J=6.9 \mathrm{~Hz}, 3 \mathrm{H}), 1.20$ (t, $J=$ $7.4 \mathrm{~Hz}, 3 \mathrm{H}) ;{ }^{13} \mathrm{C}$ NMR $\left(125 \mathrm{MHz}, \mathrm{CDCl}_{3}\right): \delta=172.7\left(\mathrm{C}_{\mathrm{q}}\right), 138.2\left(\mathrm{C}_{\mathrm{q}}\right), 129.3\left(\mathrm{C}_{\mathrm{q}}\right), 129.0(\mathrm{CH}), 128.2(\mathrm{CH})$, $127.5(\mathrm{CH}), 127.0(\mathrm{CH}), 124.1(\mathrm{CH}), 122.5(\mathrm{CH}), 109.5\left(\mathrm{C}_{q}\right), 97.8\left(\mathrm{C}_{\mathrm{q}}\right), 94.6\left(\mathrm{C}_{\mathrm{q}}\right), 90.1\left(\mathrm{C}_{\mathrm{q}}\right), 86.7(\mathrm{CH})$, $84.5(\mathrm{CH}), 83.2(\mathrm{CH}), 83.0(\mathrm{CH}), 78.6\left(\mathrm{C}_{\mathrm{q}}\right), 57.6\left(\mathrm{C}_{\mathrm{q}}\right), 31.0(\mathrm{CH}), 29.3\left(\mathrm{CH}_{2}\right), 23.8\left(\mathrm{CH}_{3}\right), 23.6\left(\mathrm{CH}_{2}\right), 22.5$ $\left(\mathrm{CH}_{3}\right), 18.5\left(\mathrm{CH}_{3}\right), 15.9\left(\mathrm{CH}_{3}\right), 12.6\left(\mathrm{CH}_{3}\right) ; \mathrm{HR}-\mathrm{MS}(\mathrm{ESI}): \mathrm{m} / \mathrm{z}$ calcd for $\left[\mathrm{C}_{27} \mathrm{H}_{30} \mathrm{O}_{2} \mathrm{Ru}+\mathrm{H}\right]^{+} 489.1369$, found 489.1369 .

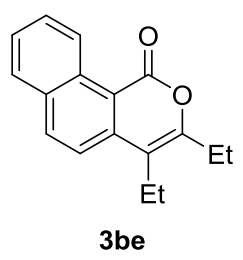

The representative procedure $\mathbf{B}$ was followed using $\left[\operatorname{RuCl}_{2}(p \text {-cymene })\right]_{2}(31.1 \mathrm{mg}, 0.05 \mathrm{mmol})$, naphthoic acid (1b) $(15.5 \mathrm{mg}, 0.09 \mathrm{mmol}), 3$-hexyne $(\mathbf{2 e})(14.8 \mathrm{mg}, 0.18 \mathrm{mmol})$ and $\mathrm{NaOAc}(14.8 \mathrm{mg}$, $0.18 \mathrm{mmol})$. Purification by column chromatography $\left(\mathrm{CH}_{2} \mathrm{Cl}_{2}\right)$ yielded 3 be $(15.2 \mathrm{mg}, 83 \%)$ as a colorless solid.

M.p.: $131{ }^{\circ} \mathrm{C} ;{ }^{1} \mathrm{H}$ NMR $\left(300 \mathrm{MHz}, \mathrm{CDCl}_{3}\right): \delta=9.83-9.74(\mathrm{~m}, 1 \mathrm{H}), 7.74(\mathrm{ddd}, J=8.6,6.9,1.5 \mathrm{~Hz}, 1 \mathrm{H})$, $8.13(\mathrm{~d}, J=8.8 \mathrm{~Hz}, 1 \mathrm{H}), 7.88(\mathrm{dd}, J=8.0,1.6 \mathrm{~Hz}, 1 \mathrm{H}), 7.63(\mathrm{~d}, J=9.1 \mathrm{~Hz}, 1 \mathrm{H}), 7.61-7.56(\mathrm{~m}, 1 \mathrm{H}), 2.75$ $(q, J=7.5 \mathrm{~Hz}, 2 \mathrm{H}), 2.71(\mathrm{q}, J=7.5 \mathrm{~Hz}, 2 \mathrm{H}), 1.34(\mathrm{t}, J=7.6 \mathrm{~Hz}, 3 \mathrm{H}), 1.25(\mathrm{t}, J=7.5 \mathrm{~Hz}, 3 \mathrm{H}) ;{ }^{13} \mathrm{C}$ NMR $(75$ $\left.\mathrm{MHz}, \mathrm{CDCl}_{3}\right): \delta=162.3\left(\mathrm{C}_{\mathrm{q}}\right), 157.1\left(\mathrm{C}_{\mathrm{q}}\right), 140.4\left(\mathrm{C}_{\mathrm{q}}\right), 136.2(\mathrm{CH}), 132.3\left(\mathrm{C}_{\mathrm{q}}\right), 132.2\left(\mathrm{C}_{\mathrm{q}}\right), 129.3(\mathrm{CH}), 128.4$ (CH), $127.0(\mathrm{CH}), 126.7(\mathrm{CH}), 120.4(\mathrm{CH}), 114.4\left(\mathrm{C}_{q}\right), 113.8\left(\mathrm{C}_{\mathrm{q}}\right), 24.4\left(\mathrm{CH}_{2}\right), 19.9\left(\mathrm{CH}_{2}\right), 14.7\left(\mathrm{CH}_{3}\right), 12.8$ $\left(\mathrm{CH}_{3}\right)$; IR (ATR): $\tilde{v}=2967,2923,1692,1640,1593,1112,931,757,505 \mathrm{~cm}^{-1}$; MS (EI) $\mathrm{m} / \mathrm{z}$ (relative intensity) 252 (100) [M] ${ }^{+}, 237$ (49), 209 (49), 195 (42), 181 (63), 165 (61), 152 (48); HR-MS (EI): m/z 
calcd for $\left[\mathrm{C}_{13} \mathrm{H}_{14} \mathrm{O}_{2}\right]^{+} 252.1150$, found 252.1147 . The spectral data are in accordance with those reported in the literature. ${ }^{[17]}$

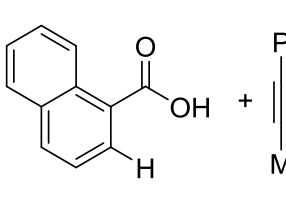

$1 b$

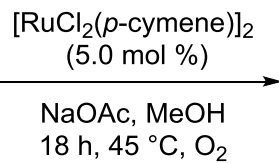

2d

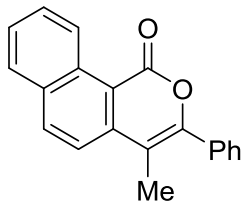

3bd: $59 \%$

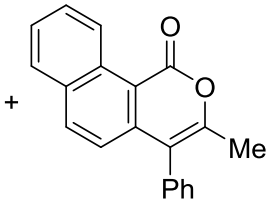

3bd': 2\%

3

Naphthoic acid (1b) (344 mg, 2.00 mmol, 2.0 equiv), prop-1-yn-1-ylbenzene (2d) (116 mg, 1.00 mmol, 1.0 equiv), [RuCl $2(p \text {-cymene) }]_{2}(30.6 \mathrm{mg}, 0.05 \mathrm{mmol}, 5.0 \mathrm{~mol} \%)$ and $\mathrm{NaOAc}(98.1 \mathrm{mg}, 1.00 \mathrm{mmol}$, 1.0 equiv) were placed in a $25 \mathrm{~mL}$ Schlenk tube. The mixture was degassed and purged with oxygen for three times. Dry $\mathrm{MeOH}(3.0 \mathrm{~mL}, 0.33 \mathrm{M})$ was added and the reaction mixture was stirred at $45^{\circ} \mathrm{C}$ for $18 \mathrm{~h}$. The crude product was purified by column chromatography on silica gel ( $n$-hexane/EtOAc: 20/1) to yield 3 bd (169 mg, 59\%) and 3bd' (6.9 mg, 2\%) as colorless solids (for characterization of 3bd' see page 125).<smiles>O=c1oc(-c2ccccc2)c([N+]#[W])c2ccc3ccccc3c12</smiles>

M.p.: $166^{\circ} \mathrm{C} ;{ }^{1} \mathrm{H}$ NMR $\left(300 \mathrm{MHz}, \mathrm{CDCl}_{3}\right): \delta=9.85(\mathrm{dd}, J=8.7,1.0 \mathrm{~Hz}, 1 \mathrm{H}), 8.21(\mathrm{~d}, J=8.8 \mathrm{~Hz}, 1 \mathrm{H}), 7.94$ (dd, $J=7.9,1.5 \mathrm{~Hz}, 1 \mathrm{H}), 7.79$ (ddd, $J=7.9,7.9,1.5 \mathrm{~Hz}, 1 \mathrm{H}), 7.74(\mathrm{~d}, J=8.8 \mathrm{~Hz}, 1 \mathrm{H}), 7.69-7.61(\mathrm{~m}, 3 \mathrm{H})$, 7.54-7.46 (m, 3H), $2.43(\mathrm{~s}, 3 \mathrm{H}) ;{ }^{13} \mathrm{C}$ NMR $\left(125 \mathrm{MHz}, \mathrm{CDCl}_{3}\right) \delta=162.0\left(\mathrm{C}_{\mathrm{q}}\right), 153.1\left(\mathrm{C}_{\mathrm{q}}\right), 141.4\left(\mathrm{C}_{\mathrm{q}}\right), 136.4$ $(\mathrm{CH}), 133.5\left(\mathrm{C}_{\mathrm{q}}\right), 132.8\left(\mathrm{C}_{\mathrm{q}}\right), 132.0\left(\mathrm{C}_{\mathrm{q}}\right), 129.8(\mathrm{CH}), 129.7(\mathrm{CH}), 129.7(\mathrm{CH}), 128.7(\mathrm{CH}), 128.5(\mathrm{CH})$, $127.3(\mathrm{CH}), 127.1(\mathrm{CH}), 121.0(\mathrm{CH}), 114.6\left(\mathrm{C}_{\mathrm{q}}\right), 109.6\left(\mathrm{C}_{\mathrm{q}}\right), 14.4\left(\mathrm{CH}_{3}\right)$; IR (ATR): $\tilde{v}=2923,1702,1593$, 1104, 1015, 830, 806, 753, 696, $504 \mathrm{~cm}^{-1}$; MS (EI) m/z (relative intensity) 286 (58) [M] $]^{+}, 258$ (43), 207 (100), 152 (21), 105 (26), 77 (21), 44 (59); HR-MS (ESI) m/z calcd for $\left[\mathrm{C}_{20} \mathrm{H}_{14} \mathrm{O}_{2}+\mathrm{H}\right]^{+}$287.1067, found 287.1060 


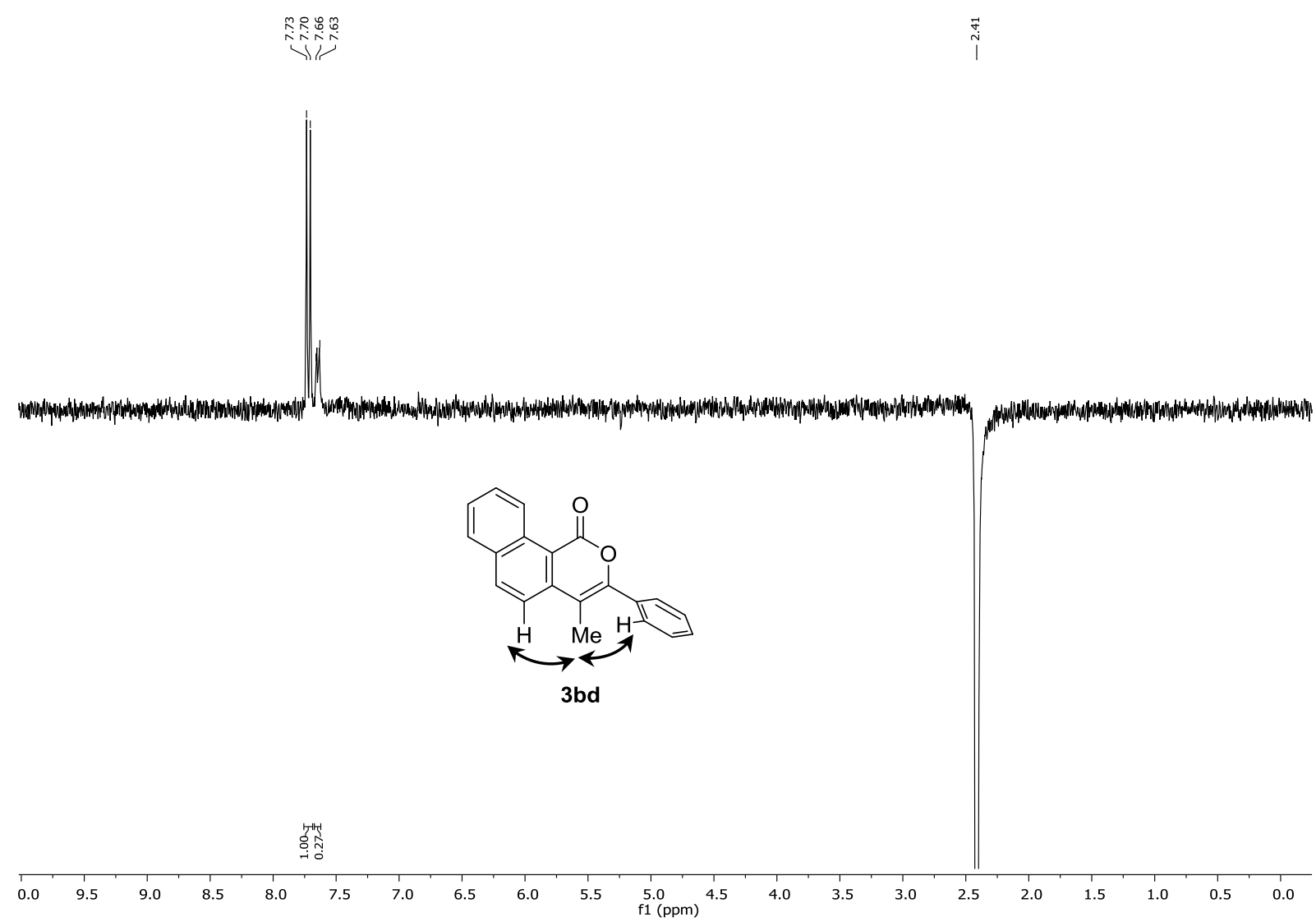

\subsubsection{Attempted Synthesis of 7-membered Ruthenacycle}

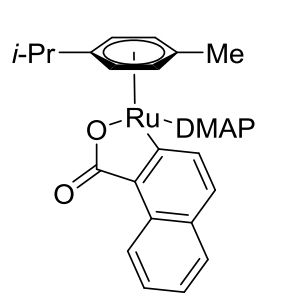

89bb
$\|_{\mathrm{Ph}}^{\mathrm{Ph}} \frac{10 \text { eqiv. DMAP }}{\mathrm{MeOH}, 40^{\circ} \mathrm{C}, 18 \mathrm{~h}}$

$2 a$

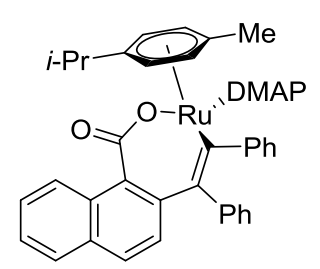

94ba

A solution of ruthenacycle $89 \mathrm{bb}(20.0 \mathrm{mg}, 38 \mu \mathrm{mol}, 1.0$ equiv), diphenylacetylene (2a) $(6.8 \mathrm{mg}$, $38 \mu \mathrm{mol}, 1.0$ equiv), and DMAP (46.4 mg, $380 \mu \mathrm{mol}, 10$ equiv) in $\mathrm{MeOH}(1.5 \mathrm{~mL})$ was stirred under an atmosphere of $\operatorname{Ar}$ at $40^{\circ} \mathrm{C}$ for $18 \mathrm{~h}$. No conversion was observable by ${ }^{1} \mathrm{H}$ NMR spectroscopy, the starting material $89 \mathrm{bb}$ could be reisolated $\left(18.3 \mathrm{mg}\right.$, 92\%) by column chromatography $\left(\mathrm{CH}_{2} \mathrm{Cl}_{2} / \mathrm{MeOH}\right.$ : 20/1). 
$\left[\mathrm{RuCl}_{2}(p \text {-cymene) }]_{2}+\right.$<smiles>COC(=O)C1=C[C+]C(C(=O)O[Na])=CC1</smiles>

$87 \mathrm{c}$

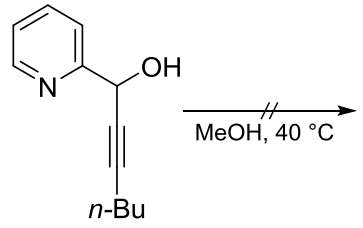

2g

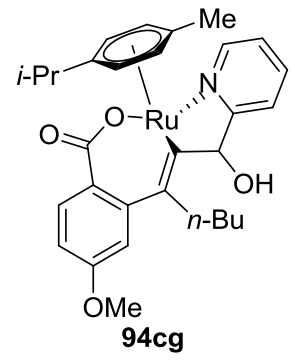

A solution of $\left[\mathrm{RuCl}_{2}(p \text {-cymene })\right]_{2}(24.9 \mathrm{mg}, 0.04 \mathrm{mmol}, 1.0$ equiv), sodium 4-methoxybenzoate (87c) (17.4 mg, $0.10 \mathrm{mmol}, 2.5$ equiv), $\mathrm{NEt}_{3}(13 \mu \mathrm{L}, 0.10 \mathrm{mmol}, 2.5$ equiv) and alkyne $2 \mathrm{~g}$ (7.6 mg, $0.04 \mathrm{mmol}, 1.0$ equiv) in $\mathrm{MeOH}(2.0 \mathrm{~mL})$ was stirred under an atmosphere of $\mathrm{Ar}$ at $40{ }^{\circ} \mathrm{C}$ for $48 \mathrm{~h}$ and afterwards to $80^{\circ} \mathrm{C}$ for $4 \mathrm{~h}$. No conversion to the product was observed by ${ }^{1} \mathrm{H}$ NMR spectroscopy.

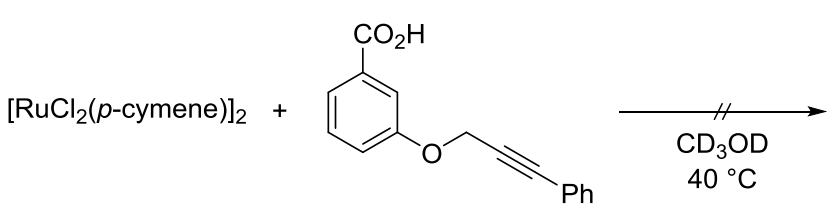

19

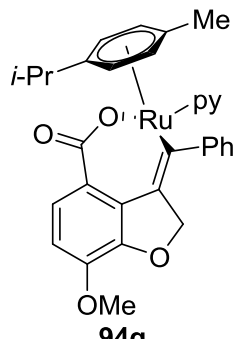

$94 \mathrm{~g}$

$\left[\mathrm{RuCl}_{2} \text { (pyridine)(p-cymene)}\right]_{2}(14.6 \mathrm{mg}, 38 \mu \mathrm{mol}, 1.0$ equiv), benzoic acid $1 \mathrm{~g}(10.0 \mathrm{mg}, 40 \mu \mathrm{mol}$, 1.1 equiv), $\mathrm{NaOAc}\left(6.2 \mathrm{mg}, 76 \mu \mathrm{mol}, 2.0\right.$ equiv) and $\mathrm{CD}_{3} \mathrm{OD}(0.6 \mathrm{~mL})$ were placed in a NMR tube and heated to $40^{\circ} \mathrm{C}$ for $39 \mathrm{~h}$. An unselective reaction with no hint for the formation of the desired product was observed as judged by ${ }^{1} \mathrm{H}$ NMR and ESI-MS.

$\left[\mathrm{RuCl}_{2}(p \text {-cymene })\right]_{2}$<smiles>O=C(O)c1ccc([N+](=O)[O-])cc1</smiles>

1e

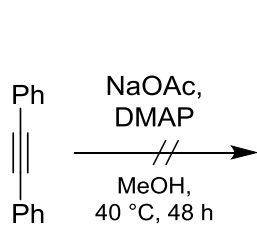

$2 a$

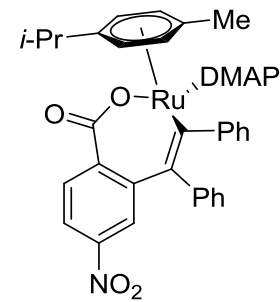

94ea

A solution of $\left[\mathrm{RuCl}_{2}(p \text {-cymene })\right]_{2}(31.1 \mathrm{mg}, 0.05 \mathrm{mmol}, 1.0$ equiv) and 4-nitrobenzoic acid (1e) (15.0 mg, $0.09 \mathrm{mmol}, 1.8$ equiv), diphenylacetylene (2a) $(32.1 \mathrm{mg}, 0.18 \mathrm{mmol}, 4.0$ equiv), DMAP (12.2 mg, $0.10 \mathrm{mmol}, 2.0$ equiv) and $\mathrm{NaOAc}(14.8 \mathrm{mg}, 0.18 \mathrm{mmol}, 4.0$ equiv) in $\mathrm{MeOH}$ ( $4 \mathrm{~mL}, 0.01 \mathrm{M}$ ) was stirred at $40{ }^{\circ} \mathrm{C}$ for $2 \mathrm{~d}$. The desired product was not obtained.

\section{Stoichiometric Reaction of Ruthenapentacycle 89bb with Diphenylacetylene (ESI-MS control)}


The representative procedure $\mathbf{C}$ was followed using ruthenacycle $89 \mathrm{bb}(9.2 \mathrm{mg}, 19 \mu \mathrm{mol})$ and diphenylacetylene (2a) $(3.4 \mu \mathrm{L}, 19 \mu \mathrm{mol})$ at $40^{\circ} \mathrm{C}$. But in this case the reaction was stopped after $13 \mathrm{~h}$, hence before completion of the reaction. The crude reaction mixture was directly subjected to ESI-MS analysis. In this case a third compound $\mathbf{9 4 b a}$, besides the starting material $\mathbf{8 9 b b}$ and the sandwich complex 91ba, could be observed, which has both DMAP and diphenylacteylene attached to the complex (HR-MS (ESI): $\mathrm{m} / \mathrm{z}=707.2217$ calcd for $\left[\mathrm{C}_{42} \mathrm{H}_{40} \mathrm{~N}_{2} \mathrm{O}_{2} \mathrm{Ru}+\mathrm{H}\right]^{+}$, found: 707.2212). To exclude a formation of the species during the ionization process, mixtures of the starting material 89bb and diphenylacetylene (2a) as well as a mixture of the sandwich complex 91ba with the ligand DMAP were subjected to the ESI-MS analysis under otherwise identical conditions. Here, the new product $94 \mathrm{ba}$ could not be detected.
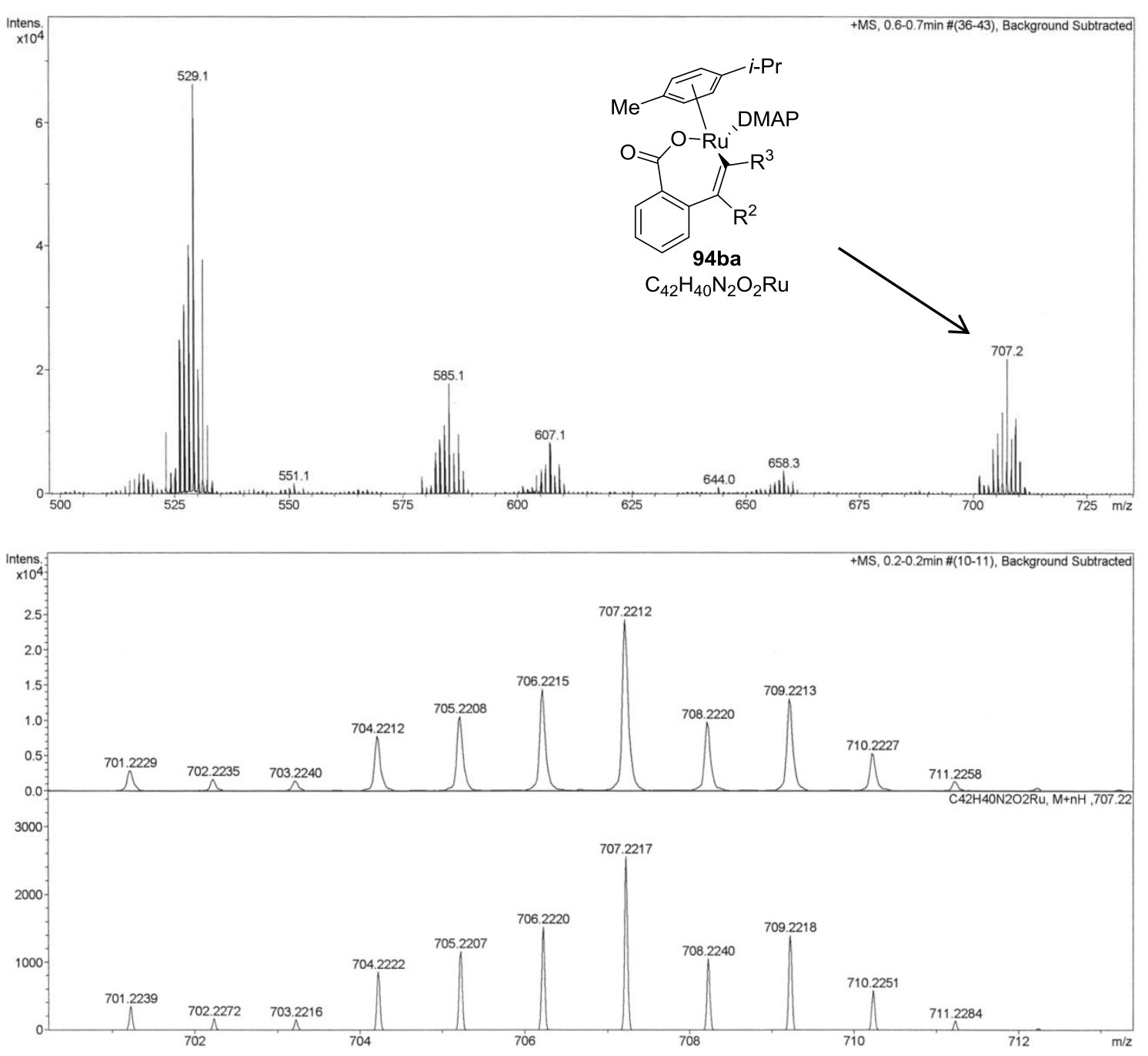

Figure 32. ESI-MS of the stoichiometric reaction of ruthenapentacycle $89 \mathrm{bb}$ with diphenylacetylene (2a). 


\subsubsection{Oxidation of Sandwich complex 91ba and Release of Isocoumarin}

\section{Attempted Oxidation of Sandwich Complex 91ba by $\mathrm{Cu}(\mathrm{OAc})_{2} \cdot \mathrm{H}_{2} \mathrm{O}$}

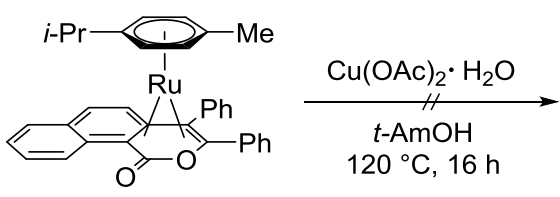

$91 \mathrm{ba}$

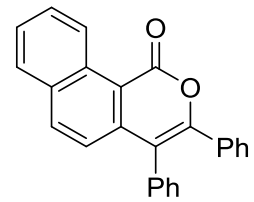

3 ba

A suspension of 91 ba $\left(20.0 \mathrm{mg}, 34 \mu \mathrm{mol}, 1.0\right.$ equiv) and $\mathrm{Cu}(\mathrm{OAc})_{2} \cdot \mathrm{H}_{2} \mathrm{O}(13.6 \mathrm{mg}, 68 \mu \mathrm{mol}, 2.0$ equiv) in $t$ - $\mathrm{AmOH}(2.0 \mathrm{~mL})$ was stirred at $120^{\circ} \mathrm{C}$ for $16 \mathrm{~h}$ in a pressure tube. TLC $\left(\mathrm{CH}_{2} \mathrm{Cl}_{2}\right)$, NMR and GC-MS analysis did not show conversion of the starting material to the product $3 \mathbf{b a}$.

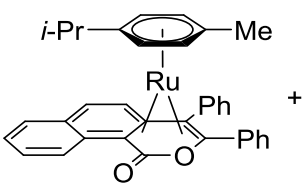

$91 \mathrm{ba}$

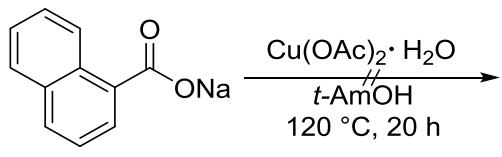

$87 b$<smiles>O=c1oc(-c2ccccc2)c(-c2ccccc2)c2ccc3ccccc3c12</smiles>

3ba

A suspension of 91ba (15.0 mg, $26 \mu \mathrm{mol}, 1.0$ equiv), sodium naphthoate (87b) (10.1 mg, $52 \mu \mathrm{mol}$, 2.0 equiv) and $\mathrm{Cu}(\mathrm{OAc})_{2} \cdot \mathrm{H}_{2} \mathrm{O}\left(13.6 \mathrm{mg}, 68 \mu \mathrm{mol}, 2.0\right.$ equiv), in $t-\mathrm{AmOH}(1.5 \mathrm{~mL})$ was stirred at $120^{\circ} \mathrm{C}$ for $20 \mathrm{~h}$ in a pressure tube. TLC $\left(\mathrm{CH}_{2} \mathrm{Cl}_{2}\right), \mathrm{NMR}$ and GC-MS analysis did not show conversion of the starting material to the product $\mathbf{3 b a}$.

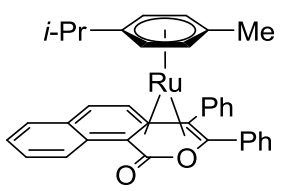

$91 \mathrm{ba}$

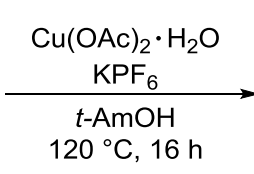

$120^{\circ} \mathrm{C}, 16 \mathrm{~h}$

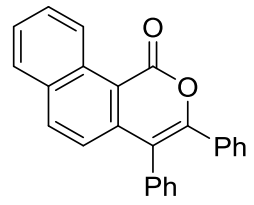

$3 \mathbf{b a}$ $99 \%$

91ba (20.0 mg, $34 \mu \mathrm{mol}, 1.0$ equiv), $\mathrm{Cu}(\mathrm{OAc})_{2} \cdot \mathrm{H}_{2} \mathrm{O}\left(13.6 \mathrm{mg}, 68 \mu \mathrm{mol}, 2.0\right.$ equiv) and $\mathrm{KPF}_{6}(12.5 \mathrm{mg}$, $68 \mu \mathrm{mol}, 2.0$ equiv) in $t$ - $\mathrm{AmOH}(2.0 \mathrm{~mL})$ was stirred at $120^{\circ} \mathrm{C}$ for $16 \mathrm{~h}$ in a pressure tube. Crystallization from EtOAc yielded 3 ba $(11.7 \mathrm{mg}, 99 \%)$ as a colorless solid.<smiles>O=c1oc(-c2ccccc2)c(-c2ccccc2)c2ccc3ccccc3c12</smiles> 
3,4-Diphenyl-1H-benzo[h]isochromen-1-one (3ba): M.p.: $192{ }^{\circ} \mathrm{C} ;{ }^{1} \mathrm{H}$ NMR $\left(300 \mathrm{MHz}, \mathrm{CDCl}_{3}\right): \delta=9.87$ (d, $J=8.7 \mathrm{~Hz}, 1 \mathrm{H}), 8.02(\mathrm{~d}, J=8.8 \mathrm{~Hz}, 1 \mathrm{H}), 7.89$ (d, $J=7.2 \mathrm{~Hz}, 1 \mathrm{H}), 7.85-7.73(\mathrm{~m}, 1 \mathrm{H}), 7.65$ (dd, $J=7.2$, $7.2 \mathrm{~Hz}, 1 \mathrm{H}), 7.55-7.17(\mathrm{~m}, 11 \mathrm{H}) ;{ }^{13} \mathrm{C}$ NMR $\left(125 \mathrm{MHz}, \mathrm{CDCl}_{3}\right): \delta=161.4\left(\mathrm{C}_{\mathrm{q}}\right), 152.5\left(\mathrm{C}_{\mathrm{q}}\right), 141.1\left(\mathrm{C}_{\mathrm{q}}\right)$, $135.9(\mathrm{CH}), 134.8\left(\mathrm{C}_{q}\right), 132.8\left(\mathrm{C}_{\mathrm{q}}\right), 132.7\left(\mathrm{C}_{\mathrm{q}}\right), 131.6\left(\mathrm{C}_{\mathrm{q}}\right), 131.5(\mathrm{CH}), 129.5(\mathrm{CH}), 129.2(\mathrm{CH}), 129.2$ (CH), $129.1(\mathrm{CH}), 128.5(\mathrm{CH}), 128.2(\mathrm{CH}), 127.9(\mathrm{CH}), 127.1(\mathrm{CH}), 127.1(\mathrm{CH}) 122.7(\mathrm{CH}), 117.4\left(\mathrm{C}_{\mathrm{q}}\right)$, $114.0\left(C_{q}\right)$; IR (ATR): $\tilde{v}=3055,1709,1591,1101,834,703,693,523 \mathrm{~cm}^{-1}$; MS (EI) $\mathrm{m} / \mathrm{z}$ (relative intensity) $348(100)[\mathrm{M}]^{+}, 215$ (50), 105 (42), 77 (25), 43 (43); HR-MS (EI): m/z calcd for $\left[\mathrm{C}_{25} \mathrm{H}_{16} \mathrm{O}_{2}\right]^{+}$ 348.1150, found 348.1146. The spectral data are in accordance with those reported in the literature. ${ }^{[109]}$

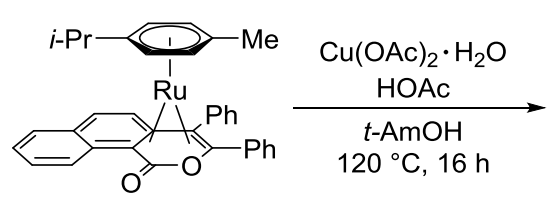

$91 \mathrm{ba}$<smiles>O=c1oc(-c2ccccc2)c(-c2ccccc2)c2ccc3ccccc3c12</smiles>

$3 \mathbf{b a}$

$92 \%$

91ba $\left(20.0 \mathrm{mg}, 34 \mu \mathrm{mol}, 1.0\right.$ equiv), $\mathrm{Cu}(\mathrm{OAc})_{2} \cdot \mathrm{H}_{2} \mathrm{O}(13.6 \mathrm{mg}, 68 \mu \mathrm{mol}, 2.0$ equiv) and $\mathrm{HOAc}(19 \mu \mathrm{L}$, $0.34 \mathrm{mmol}, 2.0$ equiv) in $t$ - $\mathrm{AmOH}(2.0 \mathrm{~mL})$ was stirred at $120^{\circ} \mathrm{C}$ for $16 \mathrm{~h}$ in a pressure tube. Purification by column chromatography ( $n$-hexane/EtOAc $5 / 1$ ) yielded 3 ba $(10.9 \mathrm{mg}, 92 \%$ ) as a colorless solid.

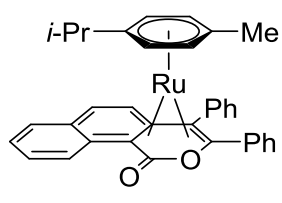

$91 \mathrm{ba}$

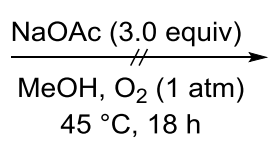
$45^{\circ} \mathrm{C}, 18 \mathrm{~h}$

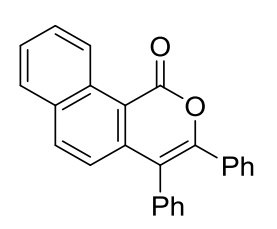

3 ba

91ba (20 mg, $34 \mu \mathrm{mol}, 1.0$ equiv) and $\mathrm{NaOAc}$ (14 mg, $68 \mu \mathrm{mol}, 2.0$ equiv) were placed in a pre-dried $25 \mathrm{~mL}$ Schlenk tube. The mixture was degassed and purged with oxygen for 3 times. Dry $\mathrm{MeOH}$ $(2.0 \mathrm{~mL})$ was added and the reaction mixture was stirred at $45^{\circ} \mathrm{C}$ for $18 \mathrm{~h}$. $\mathrm{TLC}\left(\mathrm{CH}_{2} \mathrm{Cl}_{2}\right), \mathrm{NMR}$ and GCMS analysis showed no conversion of the starting material to the product $\mathbf{3 b a}$.

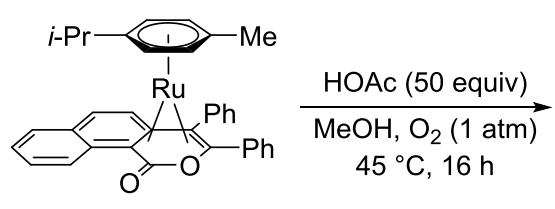

$91 \mathrm{ba}$

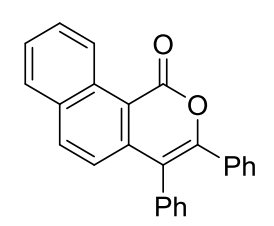

3 ba
$+\left[\mathrm{Ru}(\mathrm{OAc})_{2}(p\right.$-cymene $\left.)\right]$

96 
91ba (20.0 mg, $34 \mu \mathrm{mol}, 1.0$ equiv) and HOAc (97 $\mu \mathrm{L}, 1.7 \mathrm{mmol}, 50$ equiv) were placed in a predried $25 \mathrm{~mL}$ Schlenk tube. The mixture was degassed and purged with oxygen for 3 times. Dry $\mathrm{MeOH}$ $\left(2.0 \mathrm{~mL}\right.$ ) was added and the reaction mixture was stirred at $45^{\circ} \mathrm{C}$ for $16 \mathrm{~h} .{ }^{1} \mathrm{H}$ NMR analysis showed the formation of $\left[\mathrm{Ru}(\mathrm{OAc})_{2}(p\right.$-cymene)] (96) (56\%). Purification by column chromatography on silica gel ( $n$-hexane/EtOAc: $20 / 1)$ yielded 3 ba (11.0 mg, 94\%) as a colorless solid.

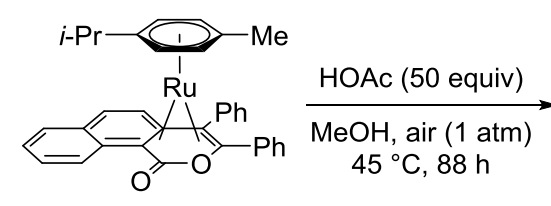

$91 \mathrm{ba}$

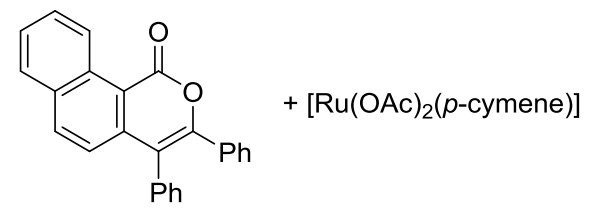

$3 \mathrm{ba}$
96

A solution of 91 ba ( $20.0 \mathrm{mg}, 34 \mu \mathrm{mol}, 1.0$ equiv) and $\mathrm{HOAc}(97 \mu \mathrm{L}, 1.7 \mathrm{mmol}, 50$ equiv) in $\mathrm{MeOH}$ $(2.0 \mathrm{~mL})$ was set up under air and stirred at $60^{\circ} \mathrm{C}$ for $18 \mathrm{~h}$. The ${ }^{1} \mathrm{H}$ NMR spectrum showed the formation of $\left[\mathrm{Ru}(\mathrm{OAc})_{2}(p\right.$-cymene)] (96) (66\%). Purification by column chromatography on silica gel ( $n$-hexane/EtOAc: $20 / 1)$ yielded 3 ba (11.1 mg, 94\%) as a colorless solid.

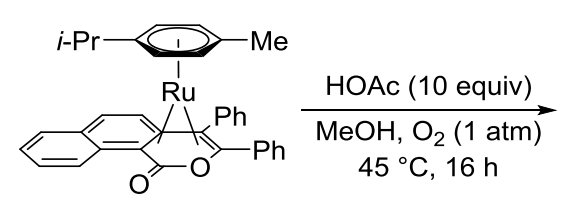

$91 \mathrm{ba}$

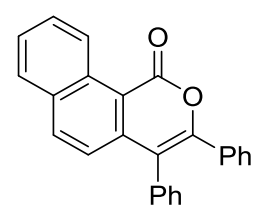

3ba

91ba (20.0 mg, $34 \mu \mathrm{mol}, 1.0$ equiv) and HOAc (19 $\mu \mathrm{L}, 0.34 \mathrm{mmol}, 10$ equiv) were placed in a predried $25 \mathrm{~mL}$ Schlenk tube. The mixture was degassed and purged with oxygen for 3 times. Dry $\mathrm{MeOH}$ $(2.0 \mathrm{~mL})$ was added and the reaction mixture was stirred at $45^{\circ} \mathrm{C}$ for $18 \mathrm{~h}$. The ${ }^{1} \mathrm{H}$ NMR analysis showed the formation of $\mathbf{3 b a}(17 \%)$.

91ba (20.0 mg, $34 \mu \mathrm{mol}, 1.0$ equiv) and HOAc (19 $\mu \mathrm{L}, 0.34 \mathrm{mmol}, 10$ equiv) were placed in a predried $25 \mathrm{~mL}$ Schlenk tube. The mixture was degassed and purged with oxygen for three times. Dry MeOH $(0.5 \mathrm{~mL})$ was added and the reaction mixture was stirred at $45^{\circ} \mathrm{C}$ for $18 \mathrm{~h} .{ }^{1} \mathrm{H}$ NMR analysis showed the formation of $3 \mathrm{ba}$ (62\%). 


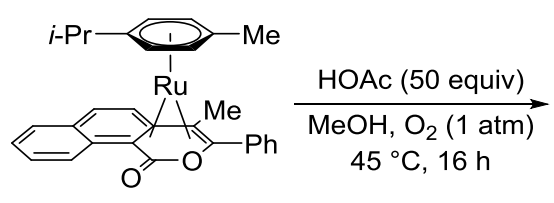

$91 \mathrm{bd}$

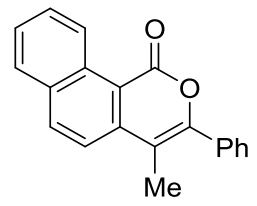

3bd

91bd ( $8.0 \mathrm{mg}, 15 \mu \mathrm{mol}, 1.0$ equiv) and $\mathrm{HOAc}$ ( $43 \mu \mathrm{L}, 0.75 \mathrm{mmol}, 50$ equiv) were placed in a predried $25 \mathrm{~mL}$ Schlenk tube. The mixture was degassed and purged with oxygen for three times. Dry $\mathrm{MeOH}$ $(2.0 \mathrm{~mL})$ was added and the reaction mixture was stirred at $45^{\circ} \mathrm{C}$ for $18 \mathrm{~h}$. Purification by column chromatography on silica gel ( $n$-hexane/EtOAc: $9 / 1)$ yielded 3bd $(2.9 \mathrm{mg}, 67 \%)$ as a colorless solid (for characterization see page 128).

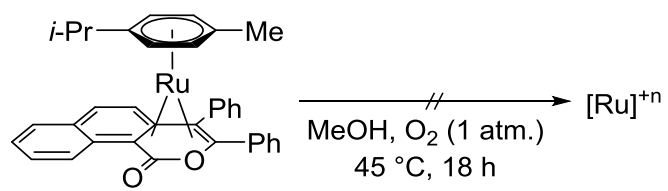

$91 \mathrm{ba}$

91ba (10.0 mg, $17 \mu \mathrm{mol}, 1.0$ equiv) was placed in a predried Schlenk tube. It was degassed and purged with oxygen for three times. $\mathrm{MeOH}(1.0 \mathrm{~mL})$ was added and the solution was stirred at $45^{\circ} \mathrm{C}$ for $18 \mathrm{~h}$. The ${ }^{1} \mathrm{H}$ NMR spectrum showed no conversion of the starting material 91ba.

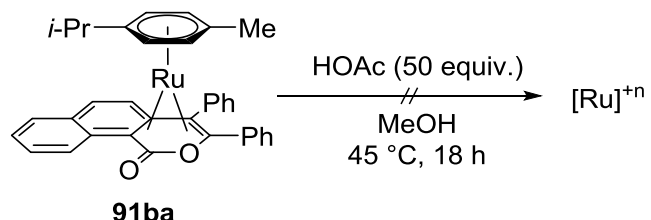

A solution of 91ba (16.2 mg, $28 \mu \mathrm{mol}, 1.0$ equiv) and HOAc ( $80 \mu \mathrm{L}, 1.4 \mathrm{mmol}, 50$ equiv) in methanol (1.5 mL) was stirred at $45^{\circ} \mathrm{C}$ for $18 \mathrm{~h}$ under an atmosphere of Ar. The ${ }^{1} \mathrm{H}$ NMR spectrum showed no conversion of the starting material 91ba.

\subsubsection{Synthesis of Isocoumarins 3 via Aerobic Ruthenium-Catalyzed Alkyne Annulations}<smiles>O=c1oc(-c2ccccc2)c(-c2ccccc2)c2cccc([N+](=O)[O-])c12</smiles>

3aa 
8-Methyl-3,4-diphenyl-1H-isochromen-1-one (3aa): ortho-Toluic acid (1a) $(272 \mathrm{mg}, 2.00 \mathrm{mmol}$, 2.0 equiv), diphenylacetylene (2a) (178 mg, $1.00 \mathrm{mmol}, 1.0$ equiv), $\left[\mathrm{RuCl}_{2}(p \text {-cymene) }]_{2}\right.$ (30.6 mg, $0.05 \mathrm{mmol}, 5.0 \mathrm{~mol} \%)$ and $\mathrm{KOAc}(98.1 \mathrm{mg}, 1.00 \mathrm{mmol}, 1.0$ equiv) were placed in a $25 \mathrm{~mL}$ Schlenk tube. The mixture was degassed and purged with oxygen for 3 times. Dry $\mathrm{MeOH}(3.0 \mathrm{~mL})$ was added and the reaction mixture was stirred at $45^{\circ} \mathrm{C}$ for $18 \mathrm{~h}$. The crude product was purified by column chromatography on silica gel ( $n$-hexane/EtOAc: $20 / 1$ ) to yield 3 aa $(280 \mathrm{mg}, 90 \%$ ) as a colorless solid.

M-p.: $142{ }^{\circ} \mathrm{C} ;{ }^{1} \mathrm{H}$ NMR $\left(300 \mathrm{MHz}, \mathrm{CDCl}_{3}\right): \delta=7.51-7.37(\mathrm{~m}, 4 \mathrm{H}), 7.35-7.28(\mathrm{~m}, 3 \mathrm{H}), 7.27-7.14(\mathrm{~m}, 5 \mathrm{H})$, $7.01(\mathrm{ddd}, J=8.1,1.3,0.7 \mathrm{~Hz}, 1 \mathrm{H}), 2.92(\mathrm{~s}, 3 \mathrm{H}) ;{ }^{13} \mathrm{C} \mathrm{NMR}\left(75 \mathrm{MHz}, \mathrm{CDCl}_{3}\right): \delta=161.4\left(\mathrm{C}_{\mathrm{q}}\right), 150.5\left(\mathrm{C}_{\mathrm{q}}\right)$, $143.4\left(C_{q}\right), 140.4\left(C_{q}\right), 134.9\left(C_{q}\right), 133.7(C H), 132.9\left(C_{q}\right), 131.3(\mathrm{CH}), 131.0(\mathrm{CH}), 129.0(\mathrm{CH}), 129.0$ $(\mathrm{CH}), 128.7(\mathrm{CH}), 128.0(\mathrm{CH}), 127.8(\mathrm{CH}), 123.6(\mathrm{CH}), 118.9\left(\mathrm{C}_{\mathrm{q}}\right), 116.9\left(\mathrm{C}_{\mathrm{q}}\right), 23.5\left(\mathrm{CH}_{3}\right)$; IR (ATR): 2929, 1727, 1564, 1487, 1467, 1443, 1304, 1089, 1028, 803, $670 \mathrm{~cm}^{-1}$; MS (EI) $\mathrm{m} / \mathrm{z}$ (relative intensity) 312 (100) [M+], 297 (10), 284 (25), 235 (15), 207 (8), 179 (25), 152 (11), 105 (46), 77 (35), 51 (6). HR-MS (EI): $\mathrm{m} / \mathrm{z}$ calcd for $\left[\mathrm{C}_{22} \mathrm{H}_{16} \mathrm{O}_{2}\right]^{+} 312.1150$, found 312.1145 . The spectral data are in accordance with those reported in the literature. ${ }^{[17]}$

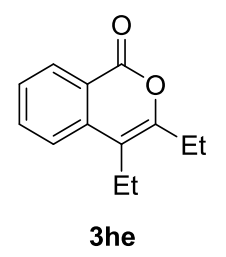

3,4-Diethyl-1H-isochromen-1-one (3he): A mixture of benzoic acid (1h) (122 mg, $2.00 \mathrm{mmol}$, 2.0 equiv), 3-hexyne (2e) (41.1 mg, $0.50 \mathrm{mmol}, 1.0$ equiv), 91ba (12.1 mg, $25 \mu \mathrm{mol}, 5.0 \mathrm{~mol} \%), \mathrm{KPF}_{6}$ (18.4 mg, $0.10 \mathrm{mmol}, 20 \mathrm{~mol} \%)$ and $\mathrm{Cu}(\mathrm{OAc})_{2} \cdot \mathrm{H}_{2} \mathrm{O}(150 \mathrm{mg}, 0.75 \mathrm{mmol}, 1.5$ equiv) in $t$-AmOH $(1.5 \mathrm{~mL})$ was stirred at $120^{\circ} \mathrm{C}$ for $16 \mathrm{~h}$. The product was purified by column chromatography on silica gel ( $n$-hexane/EtOAc: $50 / 1)$ to yield 3he $(3.9 \mathrm{mg}$, $44 \%$ based on catalyst, for characterization see page $133)$ and 3he $(69.4 \mathrm{mg}, 68 \%)$ as colorless solids.

A mixture of benzoic acid (1h) $(122 \mathrm{mg}, 2.00 \mathrm{mmol}, 2.0$ equiv), 3-hexyne (2e) $(41.1 \mathrm{mg}, 0.50 \mathrm{mmol}$, 1.0 equiv), $89 \mathrm{ba} \quad(30.6 \mathrm{mg}, 25 \mu \mathrm{mol}, 5.0 \mathrm{~mol} \%), \mathrm{KPF}_{6} \quad(18.4 \mathrm{mg}, 0.10 \mathrm{mmol}, 20 \mathrm{~mol} \%$ ) and $\mathrm{Cu}(\mathrm{OAc})_{2} \cdot \mathrm{H}_{2} \mathrm{O}$ (150 mg, $0.75 \mathrm{mmol}, 1.5$ equiv) in $t-\mathrm{AmOH}(1.5 \mathrm{~mL})$ was stirred at $120^{\circ} \mathrm{C}$ for $16 \mathrm{~h}$. The product was purified by column chromatography on silica gel ( $n$-hexane/EtOAc: $50 / 1$ ) to yield 3he (89.0 $\mathrm{mg}, 88 \%)$ as a colorless solid.

M.p.: $65{ }^{\circ} \mathrm{C} ;{ }^{1} \mathrm{H}$ NMR $\left(300 \mathrm{MHz}, \mathrm{CDCl}_{3}\right): \delta=8.30$ (ddd, $\left.J=8.1,1.5,0.8 \mathrm{~Hz}, 1 \mathrm{H}\right), 7.72$ (ddd, $J=8.1,7.2$, $1.5 \mathrm{~Hz}, 1 \mathrm{H}$ ), $7.53(\mathrm{~d}, J=8.1 \mathrm{~Hz}, 1 \mathrm{H}$ ), 7.44 (ddd, $J=8.1,7.2,0.8 \mathrm{~Hz}, 1 \mathrm{H}$ ), 2.64 (q, J = 7.5 Hz, 2H), 2.61 (q, $J=7.5 \mathrm{~Hz}, 2 \mathrm{H}), 1.27(\mathrm{t}, J=7.5 \mathrm{~Hz}, 3 \mathrm{H}), 1.19(\mathrm{t}, J=7.5 \mathrm{~Hz}, 3 \mathrm{H}) ;{ }^{13} \mathrm{C}$ NMR $\left(75 \mathrm{MHz}, \mathrm{CDCl}_{3}\right): \delta=163.1\left(\mathrm{C}_{\mathrm{q}}\right)$, 
$155.1\left(\mathrm{C}_{\mathrm{q}}\right), 137.9\left(\mathrm{C}_{\mathrm{q}}\right), 134.7(\mathrm{CH}), 130.0(\mathrm{CH}), 127.2(\mathrm{CH}), 122.6(\mathrm{CH}), 121.0\left(\mathrm{C}_{\mathrm{q}}\right), 113.2\left(\mathrm{C}_{\mathrm{q}}\right), 24.2\left(\mathrm{CH}_{2}\right)$, $19.4\left(\mathrm{CH}_{2}\right), 14.4\left(\mathrm{CH}_{3}\right), 12.7\left(\mathrm{CH}_{3}\right)$; IR (ATR): $\tilde{v}=2965,1698,1639,1470,1113,1073,1055,1027,772$, $703 \mathrm{~cm}^{-1}$; MS (EI) m/z (relative intensity) 202 (43) [M] , 187 (35), 131 (74), 69 (100), 57 (37), 43 (47); HR-MS (EI): $m / z$ calcd for $\left[\mathrm{C}_{13} \mathrm{H}_{14} \mathrm{O}_{2}\right]^{+} 202.0994$, found 202.0996. The spectral data are in accordance with those reported in the literature. ${ }^{[17]}$

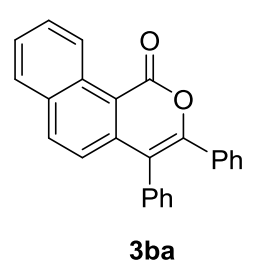

3,4-Diphenyl-1H-benzo[h]isochromen-1-one (3ba): Naphthoic acid (1b) (344 mg, $2.00 \mathrm{mmol}$, 2.0 equiv), diphenylacetylene (2a) (178 $\mathrm{mg}, 1.00 \mathrm{mmol}, 1.0$ equiv), $\left[\mathrm{RuCl}_{2}(p \text {-cymene) }]_{2}\right.$ (30.6 mg, $0.05 \mathrm{mmol}, 5.0 \mathrm{~mol} \%)$ and $\mathrm{NaOAc}(82.0 \mathrm{mg}, 1.00 \mathrm{mmol}, 1.0$ equiv) were placed in a $25 \mathrm{~mL}$ Schlenk tube. The mixture was degassed and purged with oxygen for three times. Dry $\mathrm{MeOH}(3.0 \mathrm{~mL})$ was added and the reaction mixture was stirred at $45^{\circ} \mathrm{C}$ for $18 \mathrm{~h}$. The crude product was purified by column chromatography on silica gel ( $n$-hexane/EtOAc: $20 / 1$ ) to yield 3 ba $(111 \mathrm{mg}, 32 \%$ ) as a colorless solid.

Naphthoic acid (1b) (344 mg, $2.00 \mathrm{mmol}, 2.0$ equiv), diphenylacetylene (2a) (178 mg, $1.00 \mathrm{mmol}$, 1.0 equiv), $\left[\mathrm{RuCl}_{2}(p \text {-cymene })\right]_{2} \quad(30.6 \mathrm{mg}, 0.05 \mathrm{mmol}, 5.0 \mathrm{~mol} \%)$, pyridine $(8.1 \mu \mathrm{L}, 0.10 \mathrm{mmol}$, $10 \mathrm{~mol} \%$ ) and $\mathrm{NaOAc}(82.0 \mathrm{mg}, 1.00 \mathrm{mmol}, 1.0$ equiv) were placed in a $25 \mathrm{~mL}$ Schlenk tube. The mixture was degassed and purged with oxygen for three times. Dry $\mathrm{MeOH}(3.0 \mathrm{~mL})$ was added and the reaction mixture was stirred at $45^{\circ} \mathrm{C}$ for $18 \mathrm{~h}$. The crude product was purified by column chromatography on silica gel ( $n$-hexane/EtOAc: $20 / 1)$ to yield $\mathbf{3 b a}(175 \mathrm{mg}, 50 \%)$ as a colorless solid.

\subsubsection{Ruthenium-catalyzed Phthalide Synthesis}

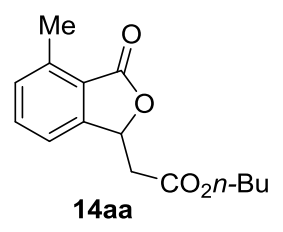

n-Butyl 2-(4-methyl-3-oxo-1,3-dihydroisobenzofuran-1-yl)acetate (14aa):

A solution of $o$-toluic acid (1a) (272 mg, $2.00 \mathrm{mmol}$ ), $n$-butyl acrylate (4a) (128 mg, $1.00 \mathrm{mmol}$ ), $\left[\operatorname{RuCl}_{2}(p \text {-cymene })\right]_{2}(30.6 \mathrm{mg}, 0.05 \mathrm{mmol}, 5.0 \mathrm{~mol} \%), \mathrm{KOAc}(108 \mathrm{mg}, 1.10 \mathrm{mmol})$ in $n-\mathrm{BuOH}(3.0 \mathrm{~mL})$ 
was frozen with liquid $\mathrm{N}_{2}$ and $\mathrm{KO}_{2}(142 \mathrm{mg}, 2.00 \mathrm{mmol})$ was added under an atmosphere of Ar. The reaction mixture was stirred at $80^{\circ} \mathrm{C}$ for $18 \mathrm{~h}$. Purification by column chromatography ( $n$ hexane/EtOAc: $4 / 1+5 \% \mathrm{NEt}_{3}$ ) yielded $14 \mathrm{aa}(33.0 \mathrm{mg}, 13 \%$ ) as a colorless oil.

o-Toluic acid (1a) $(272 \mathrm{mg}, 2.00 \mathrm{mmol}),\left[\mathrm{RuCl}_{2}(p \text {-cymene })\right]_{2}(30.6 \mathrm{mg}, 0.05 \mathrm{mmol}, 5.0 \mathrm{~mol} \%)$ and KOAc (108 mg, $1.10 \mathrm{mmol}$ ) were placed in a pre-dried $25 \mathrm{~mL}$ Schlenk tube. The flask was evacuated and flushed with $\mathrm{O}_{2}$ three times. $n-\mathrm{BuOH}(3.0 \mathrm{~mL})$ and $n$-butyl acrylate $(4 a)(128 \mathrm{mg}, 1.00 \mathrm{mmol})$ were added and the reaction mixture was stirred at $60^{\circ} \mathrm{C}$ for $18 \mathrm{~h}$. The crude reaction mixture was tested for peroxides with Quantofix ${ }^{\circledR}$ Peroxid 100 test stripes, no peroxide was detectable Purification by column chromatography ( $n$-hexane/EtOAc: $4 / 1+5 \% \mathrm{NEt}_{3}$ ) yielded 14aa (209 mg, 80\%) as a colorless oil.

${ }^{1} \mathrm{H}$ NMR $\left(500 \mathrm{MHz}, \mathrm{CDCl}_{3}\right): \delta=7.52(\mathrm{dd}, J=7.6,7.6 \mathrm{~Hz}, 1 \mathrm{H}), 7.30-7.26(\mathrm{~m}, 2 \mathrm{H}), 5.81(\mathrm{t}, J=6.5 \mathrm{~Hz}, 1 \mathrm{H})$, $4.15(\mathrm{t}, J=6.7 \mathrm{~Hz}, 2 \mathrm{H}), 2.88(\mathrm{dd}, J=16.4,7.0 \mathrm{~Hz}, 1 \mathrm{H}), 2.85(\mathrm{dd}, J=16.4,6.2 \mathrm{~Hz}, 1 \mathrm{H}), 2.68(\mathrm{~s}, 3 \mathrm{H}), 1.64-$ $1.58(\mathrm{~m}, 2 \mathrm{H}), 1.40-1.31(\mathrm{~m}, 2 \mathrm{H}), 0.92(\mathrm{t}, J=6.5 \mathrm{~Hz}, 3 \mathrm{H}) ;{ }^{13} \mathrm{C}$ NMR $\left(125 \mathrm{MHz}, \mathrm{CDCl}_{3}\right): \delta=170.2\left(\mathrm{C}_{\mathrm{q}}\right)$, $169.6\left(\mathrm{C}_{q}\right), 149.4\left(\mathrm{C}_{q}\right), 140.1\left(\mathrm{C}_{q}\right), 134.1(\mathrm{CH}), 131.3(\mathrm{CH}), 123.6\left(\mathrm{C}_{q}\right), 119.4(\mathrm{CH}), 76.2(\mathrm{CH}), 65.3\left(\mathrm{CH}_{2}\right)$, $39.9\left(\mathrm{CH}_{2}\right), 30.7\left(\mathrm{CH}_{2}\right), 19.2\left(\mathrm{CH}_{2}\right), 17.5\left(\mathrm{CH}_{3}\right), 13.8\left(\mathrm{CH}_{3}\right)$. IR (ATR): $\tilde{v}=2960,2932,2874,1755,1731$, 1201, 1168, 1046, 1006, $687 \mathrm{~cm}^{-1}$. MS (EI) $\mathrm{m} / z$ (relative intensity) 262 (8) [M], 206 (65), 163 (25), 160 (78), 147 (100), 132 (25), 119 (32), 91 (37), 65 (15), 41 (18). HR-MS (EI) m/z calcd for $\left[\mathrm{C}_{15} \mathrm{H}_{18} \mathrm{O}_{4}\right]^{+}$ 262.1205, found 262.1213. The spectral data are in accordance with those reported in the literature. ${ }^{[18]}$

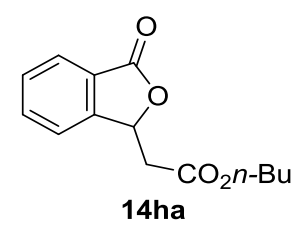

n-Butyl 2-(3-oxo-1,3-dihydroisobenzofuran-1-yl)acetate (14ha) and $n$-butyl (E)-3-\{1-(2-butoxy-2oxoethyl)-3-oxo-1,3-dihydroisobenzofuran-4-yl\}acrylate (5ha):

The representative procedure $\mathbf{D}$ was followed using benzoic acid (1h) $(244 \mathrm{mg}, 2.00 \mathrm{mmol})$ and $n$ butyl acrylate $(4 \mathrm{a})(128 \mathrm{mg}, 1.00 \mathrm{mmol})$. Purification by column chromatography ( $n$-hexane/EtOAc: $4 / 1+5 \% \mathrm{NEt}_{3}$ ) yielded $14 \mathrm{ha}(147 \mathrm{mg}, 59 \%)$ and $5 \mathrm{ha}(58 \mathrm{mg}, 15 \%)$ as colorless oils.

${ }^{1} \mathrm{H}$ NMR $\left(500 \mathrm{MHz}, \mathrm{CDCl}_{3}\right): \delta=7.91(\mathrm{~d}, J=7.7 \mathrm{~Hz}, 1 \mathrm{H}), 7.68$ (ddd, $\left.J=7.5,7.5,1.1 \mathrm{~Hz}, 1 \mathrm{H}\right), 7.58-7.48$ $(\mathrm{m}, 2 \mathrm{H}), 5.88(\mathrm{t}, J=6.6 \mathrm{~Hz}, 1 \mathrm{H}), 4.16(\mathrm{t}, J=6.7 \mathrm{~Hz}, 2 \mathrm{H}), 2.94(\mathrm{dd}, J=16.5,7.0 \mathrm{~Hz}, 1 \mathrm{H}), 2.87(\mathrm{dd}, J=$ 16.5, $6.2 \mathrm{~Hz}, 1 \mathrm{H}), 1.65-1.57(\mathrm{~m}, 2 \mathrm{H}), 1.42-1.32(\mathrm{~m}, 2 \mathrm{H}), 0.93(\mathrm{t}, J=7.4 \mathrm{~Hz}, 3 \mathrm{H}) ;{ }^{13} \mathrm{C} \mathrm{NMR}(125 \mathrm{MHz}$, $\left.\mathrm{CDCl}_{3}\right): \delta=170.0\left(\mathrm{C}_{\mathrm{q}}\right), 169.5\left(\mathrm{C}_{\mathrm{q}}\right), 149.0\left(\mathrm{C}_{\mathrm{q}}\right), 134.4(\mathrm{CH}), 129.7(\mathrm{CH}), 126.1\left(\mathrm{C}_{\mathrm{q}}\right), 126.0(\mathrm{CH}) 122.2(\mathrm{CH})$, 
$77.1(\mathrm{CH}), 65.3\left(\mathrm{CH}_{2}\right), 39.7\left(\mathrm{CH}_{2}\right), 30.7\left(\mathrm{CH}_{2}\right), 19.2\left(\mathrm{CH}_{2}\right), 13.8\left(\mathrm{CH}_{3}\right)$; IR (ATR): $\tilde{v}=2960,2873,1761$, 1729, 1337, 1170, 1047, 989, $585 \mathrm{~cm}^{-1}$; MS (EI) m/z (relative intensity) 248 (8) [M] ${ }^{+}, 192$ (60), 175 (10), 146 (54), 133 (100), 105 (35), 77 (29), 41 (18); HR-MS (EI): $m / z$ calcd for $\left[\mathrm{C}_{14} \mathrm{H}_{16} \mathrm{O}_{4}\right]^{+}$248.1055, found: 248.1055 .

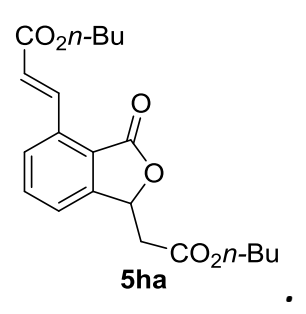

n-Butyl (E)-3-\{1-(2-butoxy-2-oxoethyl)-3-oxo-1,3-dihydroisobenzofuran-4-yl\}acrylate 5ha: ${ }^{1} \mathrm{H}$ NMR $\left(500 \mathrm{MHz}, \mathrm{CDCl}_{3}\right): \delta=8.71(\mathrm{~d}, J=16.2 \mathrm{~Hz}, 1 \mathrm{H}), 7.77(\mathrm{~d}, J=7.8 \mathrm{~Hz}, 1 \mathrm{H}), 7.66(\mathrm{dd}, J=7.9,7.9 \mathrm{~Hz}, 1 \mathrm{H})$, $7.48(\mathrm{~d}, J=7.6 \mathrm{~Hz}, 1 \mathrm{H}), 6.60(\mathrm{~d}, J=16.2 \mathrm{~Hz}, 1 \mathrm{H}), 5.85(\mathrm{t}, J=6.5 \mathrm{~Hz}, 1 \mathrm{H}), 4.24(\mathrm{t}, J=6.7 \mathrm{~Hz}, 2 \mathrm{H}), 4.15(\mathrm{t}$, $J=6.7 \mathrm{~Hz}, 2 \mathrm{H}), 2.92(\mathrm{dd}, J=16.5,6.9 \mathrm{~Hz}, 1 \mathrm{H}), 2.85(\mathrm{dd}, J=16.5,6.9 \mathrm{~Hz}, 1 \mathrm{H}), 1.72-1.67(\mathrm{~m}, 2 \mathrm{H}), 1.64-$ $1.57(\mathrm{~m}, 2 \mathrm{H}), 1.47-1.32(\mathrm{~m}, 4 \mathrm{H}), 0.94(\mathrm{t}, J=7.4 \mathrm{~Hz}, 3 \mathrm{H}), 0.92(\mathrm{t}, J=7.4 \mathrm{~Hz}, 3 \mathrm{H}) ;{ }^{13} \mathrm{C} \mathrm{NMR}(125 \mathrm{MHz}$, $\left.\mathrm{CDCl}_{3}\right): \delta=169.3\left(\mathrm{C}_{\mathrm{q}}\right), 169.0\left(\mathrm{C}_{\mathrm{q}}\right), 166.3\left(\mathrm{C}_{\mathrm{q}}\right), 149.9\left(\mathrm{C}_{\mathrm{q}}\right), 137.4(\mathrm{CH}), 135.2\left(\mathrm{C}_{\mathrm{q}}\right), 134.4(\mathrm{CH}), 126.8(\mathrm{CH})$, $123.4\left(\mathrm{C}_{\mathrm{q}}\right), 123.3(\mathrm{CH}), 123.1(\mathrm{CH}), 76.2(\mathrm{CH}), 65.4\left(\mathrm{CH}_{2}\right), 64.9\left(\mathrm{CH}_{2}\right), 39.6\left(\mathrm{CH}_{2}\right), 30.8\left(\mathrm{CH}_{2}\right), 30.6\left(\mathrm{CH}_{2}\right)$, $19.3\left(\mathrm{CH}_{2}\right), 19.2\left(\mathrm{CH}_{2}\right), 13.9\left(\mathrm{CH}_{3}\right), 13.8\left(\mathrm{CH}_{3}\right)$; IR (ATR): $\tilde{v}=2960,1712,1396,1281,1223,1173,1046$, 988, $583 \mathrm{~cm}^{-1}$; MS (El) m/z (relative intensity) 374 (14) [M] $]^{+}, 301$ (65), 273 (63), 244 (33), 199 (100), 171 (31), 157 (30), 57 (21), 41 (32); HR-MS (EI): $m / z$ calcd for $\left[\mathrm{C}_{21} \mathrm{H}_{26} \mathrm{O}_{6}\right]^{+} 374.1729$, found: 374.1735.

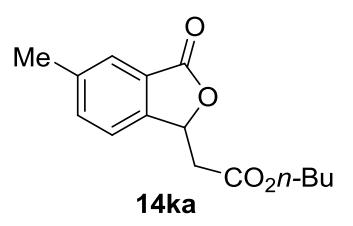

n-Butyl 2-(5-methyl-3-oxo-1,3-dihydroisobenzofuran-1-yl)acetate (14ka):

The representative procedure D was followed using $m$-toluic acid (1k) $(272 \mathrm{mg}, 2.00 \mathrm{mmol})$ and $n$ butyl acrylate (4a) $(128 \mathrm{mg}, 1.00 \mathrm{mmol})$. Purification by column chromatography ( $n$-hexane/EtOAc: $4 / 1+5 \% \mathrm{NEt}_{3}$ ) yielded $\mathbf{1 4 k a}(167 \mathrm{mg}, 63 \%$ ) as a colorless oil.

${ }^{1} \mathrm{H}$ NMR $\left(500 \mathrm{MHz}, \mathrm{CDCl}_{3}\right): \delta=7.70(\mathrm{~s}, 1 \mathrm{H}), 7.48(\mathrm{~d}, J=7.8 \mathrm{~Hz}, 1 \mathrm{H}), 7.37(\mathrm{~d}, J=7.8 \mathrm{~Hz}, 1 \mathrm{H}), 5.84(\mathrm{t}, J=$ $6.6 \mathrm{~Hz}, 1 \mathrm{H}), 4.16(\mathrm{t}, J=6.7 \mathrm{~Hz}, 2 \mathrm{H}), 2.91(\mathrm{dd}, J=16.4,7.0 \mathrm{~Hz}, 1 \mathrm{H}), 2.84(\mathrm{dd}, J=16.4,6.2 \mathrm{~Hz}, 1 \mathrm{H}$ ), 2.46 $(\mathrm{s}, 3 \mathrm{H}), 1.64-1.58(\mathrm{~m}, 2 \mathrm{H}), 1.40-1.32(\mathrm{~m}, 2 \mathrm{H}), 0.93(\mathrm{t}, J=6.5 \mathrm{~Hz}, 3 \mathrm{H}) ;{ }^{13} \mathrm{C}$ NMR $\left(125 \mathrm{MHz}, \mathrm{CDCl}_{3}\right): \delta=$ $170.2\left(C_{q}\right), 169.5\left(C_{q}\right), 146.3\left(C_{q}\right), 140.0\left(C_{q}\right), 135.5(C H), 126.3\left(C_{q}\right), 126.0(C H), 121.9(C H), 77.1(C H)$, 
$65.3\left(\mathrm{CH}_{2}\right), 39.8\left(\mathrm{CH}_{2}\right), 30.7\left(\mathrm{CH}_{2}\right), 21.4\left(\mathrm{CH}_{3}\right), 19.2\left(\mathrm{CH}_{2}\right), 13.8\left(\mathrm{CH}_{3}\right)$; IR (ATR): $\tilde{v}=2960,2873,1763$, 1730, 1287, 1153, 1057, 1006, 836, $638 \mathrm{~cm}^{-1}$; MS (EI) m/z (relative intensity) 262 (8) [M] ${ }^{+}, 206$ (75), 163 (38), 160 (96), 147 (100), 119 (44), 91 (28), 65 (15), 41 (12); HR-MS (EI) m/z calcd for [ $\left.\mathrm{C}_{15} \mathrm{H}_{18} \mathrm{O}_{4}\right]^{+}$ 262.1205, found 262.1207 .

\subsubsection{7 $O_{2}$-uptake Study for the Synthesis of Phthalides}<smiles>[X]c1ccccc1C(=O)O</smiles>

$1 a$

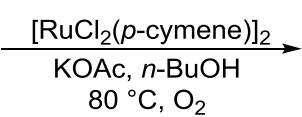
$80{ }^{\circ} \mathrm{C}, \mathrm{O}_{2}$<smiles>CCCCOCC1OC(=O)c2c1cccc2[N+](=O)[O-]</smiles>

14aa

o-Toluic acid (1a) (136 mg, $1.00 \mathrm{mmol}, 1.0$ equiv), [RuCl${ }_{2}(p \text {-cymene) }]_{2} \quad(30.6 \mathrm{mg}, 0.05 \mathrm{mmol}$, $5.0 \mathrm{~mol} \%$ ) and KOAc (108 mg, $1.10 \mathrm{mmol}, 1.1$ equiv) were placed in a pre-dried $25 \mathrm{~mL}$ Schlenk tube. The flask was evacuated and flushed with oxygen three times. $n-\mathrm{BuOH}(3.0 \mathrm{~mL})$ was added. The Schlenk tube was connected to a burette with a reservoir filled with oxygen-saturated water. The mixture was stirred at $80^{\circ} \mathrm{C}$ and the changes in volume were determined as shown in Table 20 .

Table 20. $\mathrm{O}_{2}$-uptake for the background oxidation of $n-\mathrm{BuOH}$.

\begin{tabular}{c|c|c|c}
$\mathrm{t} / \mathrm{h}$ & $\mathrm{V} / \mathrm{mL}$ & \multicolumn{1}{c}{$\Delta \mathrm{V} / \mathrm{mL}$} & $\mathrm{n} / \mathrm{mmol}$ \\
\hline 0 & 23,5 & 0 & 0 \\
0.08 & 22,7 & 0,8 & 0,03572705 \\
0.17 & 21 & 2,5 & 0,11164702 \\
0.25 & 19,8 & 3,7 & 0,16523758 \\
0.33 & 18,1 & 5,4 & 0,24115756 \\
0.42 & 16,6 & 6,9 & 0,30814577 \\
0.5 & 15,5 & 8 & 0,35727045 \\
0.58 & 14,7 & 8,8 & 0,3929975 \\
0.67 & 14,4 & 9,1 & 0,40639514 \\
0.75 & 13,8 & 9,7 & 0,43319043 \\
0.83 & 12,7 & 10,8 & 0,48231511 \\
1.00 & 11,6 & 11,9 & 0,5314398 \\
1.17 & 10,9 & 12,6 & 0,56270096 \\
1.42 & 9,9 & 13,6 & 0,60735977 \\
1.50 & 7 & 16,5 & 0,73687031 \\
1.75 & 6,2 & 17,3 & 0,77259736 \\
4.17 & 1,5 & 22 & 0,98249375 \\
4.67 & 0 & 23,5 & 1,04948196 \\
\hline
\end{tabular}




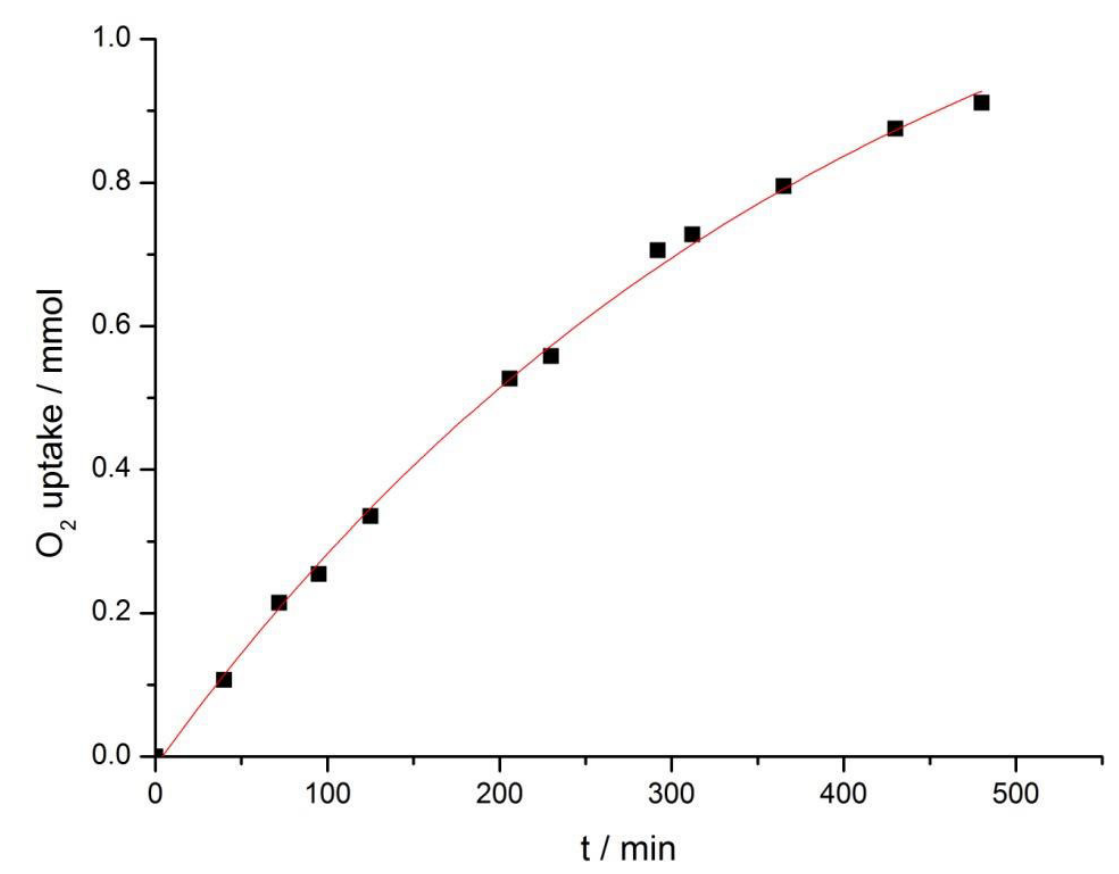

Figure 33. $\mathrm{O}_{2}$-uptake for the background oxidation of $n-\mathrm{BuOH}$

$\overbrace{\mathrm{OH}}^{\mathrm{MeO}}+\sim_{\mathrm{CO}_{2} n-\mathrm{Bu}}^{\mathrm{O}}$

1a

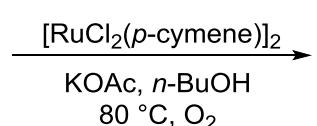

$80^{\circ} \mathrm{C}, \mathrm{O}_{2}$

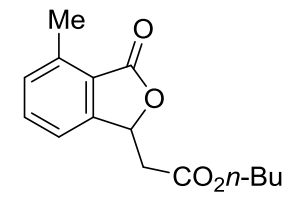

$14 a a$

isolated yield:

o-Toluic acid (1a) (136 mg, $1.00 \mathrm{mmol}, 1.0$ equiv), [RuCl $(p \text {-cymene) }]_{2} \quad(30.6 \mathrm{mg}, 0.05 \mathrm{mmol}$, $5.0 \mathrm{~mol} \%$ ) and KOAc (108 mg, $1.10 \mathrm{mmol}, 1.1$ equiv) were placed in a pre-dried $25 \mathrm{~mL}$ Schlenk tube. The flask was evacuated and flushed with oxygen three times. $n$-BuOH $(3.0 \mathrm{~mL})$ and $n$-butyl acrylate (4a) (192 mg, $1.5 \mathrm{mmol}, 1.5$ equiv) was added. The Schlenk tube was connected to a burette with a reservoir filled with oxygen-saturated water. The mixture was stirred at $80^{\circ} \mathrm{C}$ and the changes in volume were determined as shown in Table 21. Purification by column chromatography ( $n$ hexane/EtOAc: $4 / 1+5 \% \mathrm{NEt}_{3}$ ) yielded 14aa (200 mg, 81\%) as a colorless oil (for characterization of 14aa see page 138).

Table 21. $\mathrm{O}_{2}$-uptake for the oxidation in $n-\mathrm{BuOH}$.

\begin{tabular}{c|c|c|c|c}
$\mathrm{t} / \mathrm{h}$ & \multicolumn{1}{c}{$\mathrm{V} / \mathrm{mL}$} & \multicolumn{1}{c}{$\Delta \mathrm{V} / \mathrm{mL}$} & $\mathrm{n} / \mathrm{mmol}$ & $\mathrm{n}_{\text {cor }} / \mathrm{mmol}$ \\
\hline 0 & 23.4 & 0 & 0,00 & 0,00 \\
0.08 & 22.9 & 0.5 & 0,02 & 0,01 \\
0.17 & 21.5 & 1.9 & 0,08 & 0,05
\end{tabular}


Experimental Part

\begin{tabular}{c|c|c|c|c}
0.33 & 18.7 & 4.7 & 0,21 & 0,15 \\
0.42 & 17.6 & 5.8 & 0,26 & 0,18 \\
0.48 & 17.1 & 6.3 & 0,28 & 0,20 \\
0.58 & 15.6 & 7.8 & 0,35 & 0,24 \\
0.68 & 14.0 & 9.4 & 0,42 & 0,30 \\
0.88 & 12.2 & 11.2 & 0,50 & 0,35 \\
0.98 & 12.0 & 11.4 & 0,51 & 0,34 \\
1.08 & 11.3 & 12.1 & 0,54 & 0,35 \\
1.25 & 10.7 & 12.7 & 0,57 & 0,35 \\
1.42 & 10.0 & 13.4 & 0,60 & 0,36 \\
1.58 & 8.9 & 14.5 & 0,65 & 0,38 \\
2.08 & 7.6 & 15.8 & 0,71 & 0,36 \\
2.37 & 6.9 & 16.5 & 0,74 & 0,35 \\
2.62 & 6.4 & 17.0 & 0,76 & 0,34 \\
3.33 & 4.3 & 19.1 & 0,85 & 0,34 \\
4.47 & 2.9 & 20.5 & 0,92 & 0,27 \\
5.05 & 2.1 & 21.3 & 0,95 & 0,24 \\
5.48 & 1.2 & 22.2 & 0,99 & 0,24 \\
8.00 & -7.0 & 30.4 & 1,36 & 0,44 \\
\hline
\end{tabular}

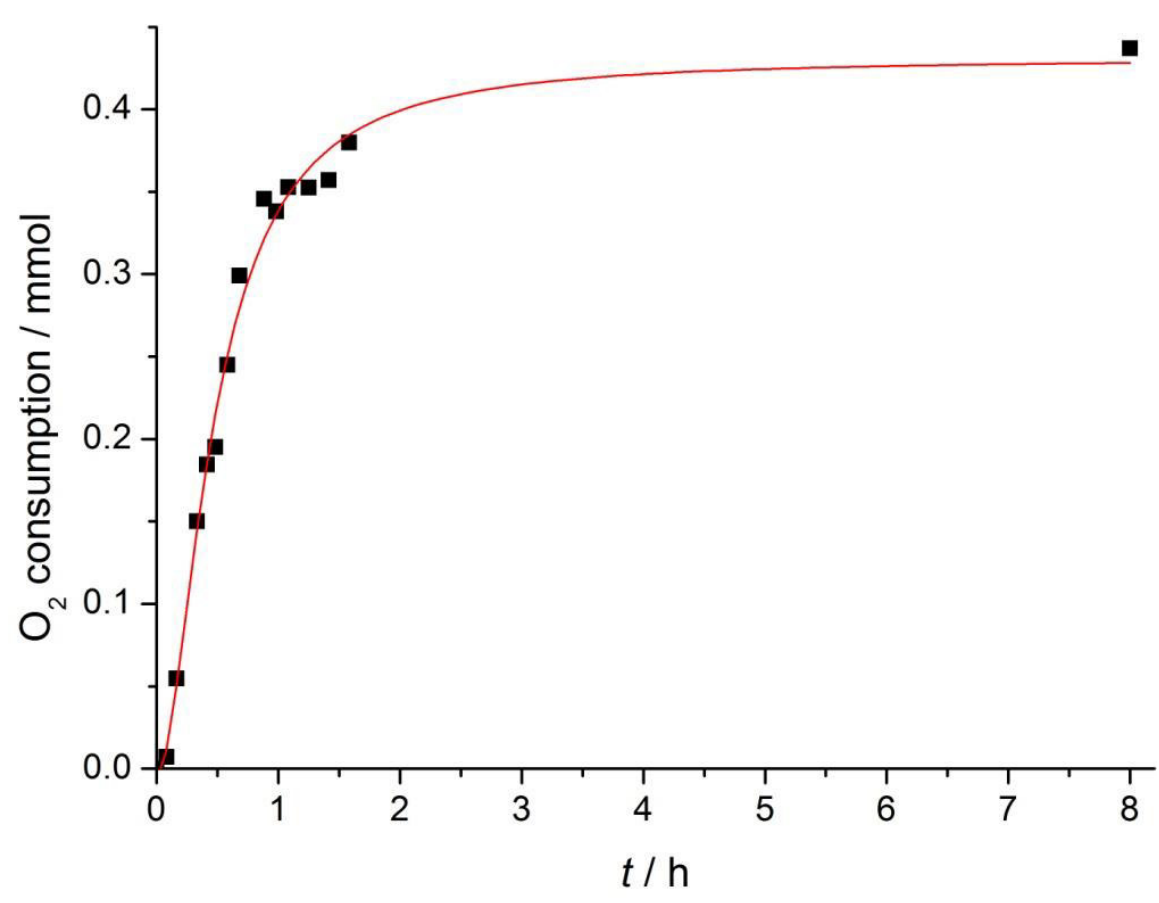

Figure 34. $\mathrm{O}_{2}$-uptake for the oxidation in $n-\mathrm{BuOH}$. 


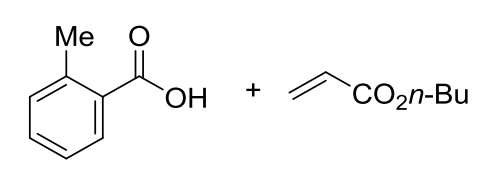

1a

4a

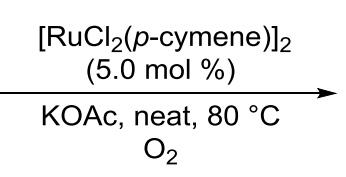

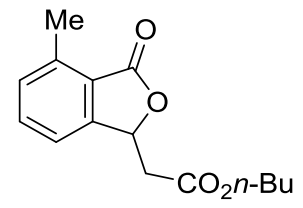

14aa

o-Toluic acid (1a) (136 mg, $1.00 \mathrm{mmol}, 1.0$ equiv), [RuCl$(p \text {-cymene) }]_{2} \quad(30.6 \mathrm{mg}, 0.05 \mathrm{mmol}$, $5.0 \mathrm{~mol} \%$ ) and KOAc (108 mg, $1.10 \mathrm{mmol}, 1.1$ equiv) were placed in a predried $25 \mathrm{~mL}$ Schlenk tube. The flask was evacuated and flushed with oxygen three times. $n$-Butyl acrylate $(4 a)(0.71 \mathrm{~mL}$, $5.0 \mathrm{mmol}, 5.0$ equiv) was added. The Schlenk tube was connected to a burette with a reservoir filled with oxygen-saturated water. The mixture was stirred at $80^{\circ} \mathrm{C}$ and the changes in volume were determined as shown in Table-S3. Purification by column chromatography ( $n$-hexane/EtOAc: 4/1 + $5 \% \mathrm{NEt}_{3}$ ) yielded 14aa (217 mg, 83\%) as a colorless oil (for characterization of 14aa see page 138).

Table-S3: $\mathrm{O}_{2}$-uptake for the oxidation under neat conditions.

\begin{tabular}{c|c|c|c}
$\mathrm{t} / \mathrm{h}$ & $\mathrm{V} / \mathrm{mL}$ & $\Delta \mathrm{V} / \mathrm{mL}$ & $\mathrm{n} / \mathrm{mmol}$ \\
\hline 0 & 22.7 & 0.00 & 0.00 \\
0.08 & 22.2 & 0.50 & 0.022 \\
0.17 & 21.7 & 1.00 & 0.045 \\
0.25 & 20.7 & 2.00 & 0.089 \\
0.33 & 19.6 & 3.10 & 0.14 \\
0.42 & 18.9 & 3.80 & 0.17 \\
0.50 & 17.9 & 4.80 & 0.21 \\
0.63 & 16.9 & 5.80 & 0.26 \\
0.75 & 16.0 & 6.70 & 0.30 \\
0.83 & 15.8 & 6.90 & 0.31 \\
1.00 & 15.2 & 7.50 & 0.33 \\
1.25 & 15.0 & 7.70 & 0.34 \\
1.58 & 14.1 & 8.60 & 0.38 \\
1.83 & 13.7 & 9.00 & 0.40 \\
2.33 & 13.1 & 9.60 & 0.43 \\
2.83 & 12.7 & 10.0 & 0.45 \\
3.5 & 12.3 & 10.4 & 0.46 \\
\hline
\end{tabular}




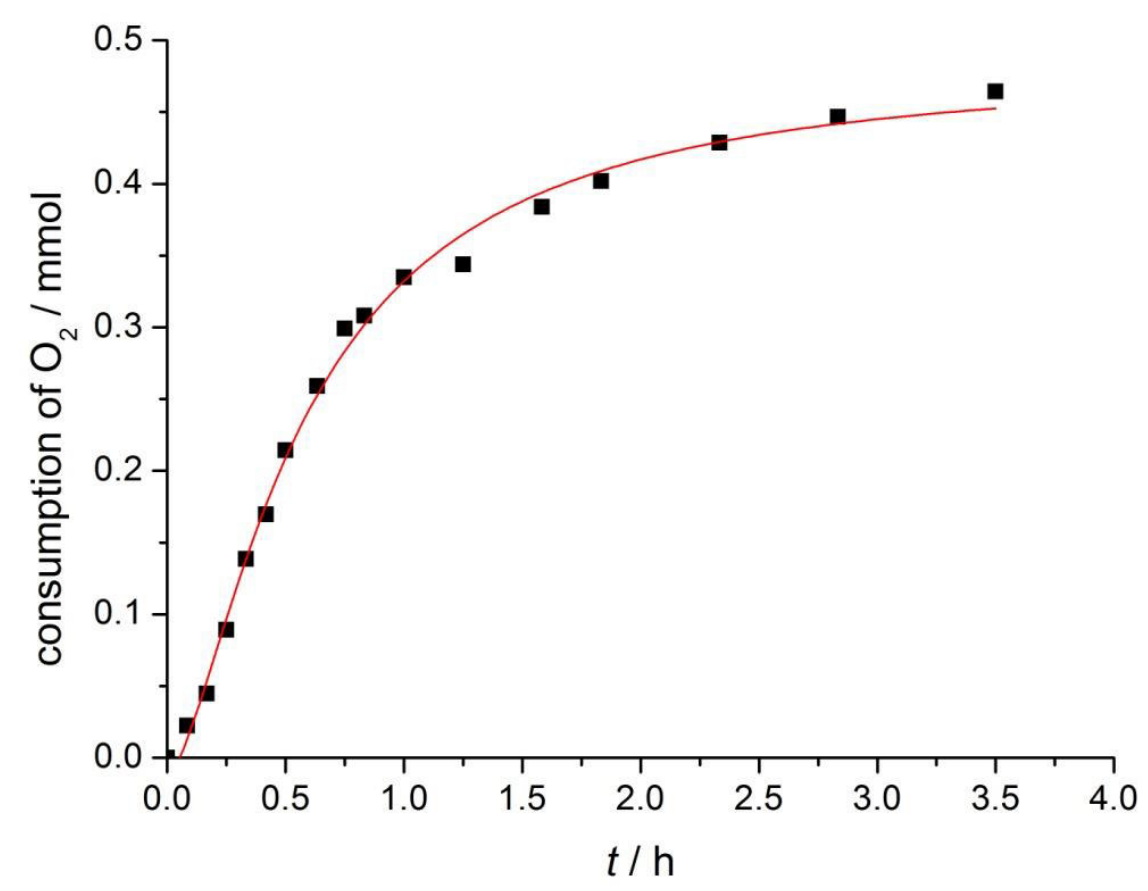

Figure 35. $\mathrm{O}_{2}$-uptake for the oxidation under neat conditions.

\subsubsection{Isotope Studies}

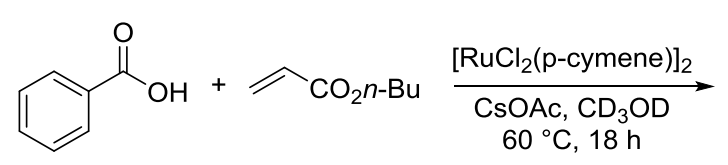

$1 \mathrm{~h}$

4a
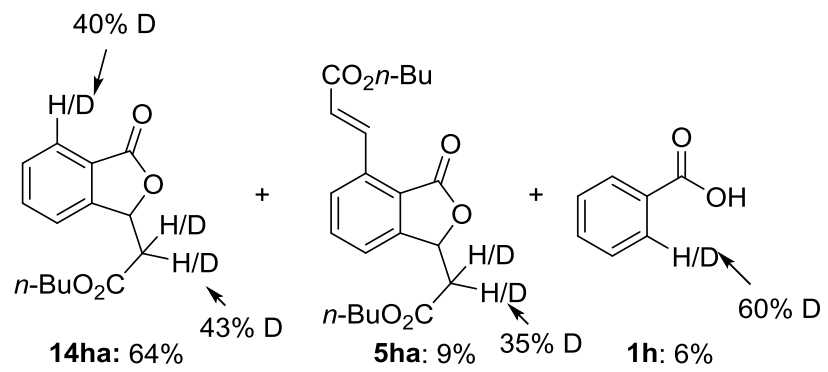

The representative procedure D was followed using benzoic acid (1h) $(244 \mathrm{mg}, 2.00 \mathrm{mmol})$ and $n$ butyl acrylate $(4 \mathrm{a})(128 \mathrm{mg}, 1.00 \mathrm{mmol})$ in $\mathrm{CD}_{3} \mathrm{OD}(3.0 \mathrm{~mL})$. Purification by column chromatography ( $n$-hexane/EtOAc: 4/1 + 5\% NEt ${ }_{3}$ ) yielded 14ha (160 mg, 64\%), 5ha (67 mg, 19\%) and 1 h (7.3 mg, 6\%) as colorless oils and colorless solid, respectively. Deuterium incorporation was determined by ${ }^{1} \mathrm{H}$ NMR spectroscopy. 
Experimental Part

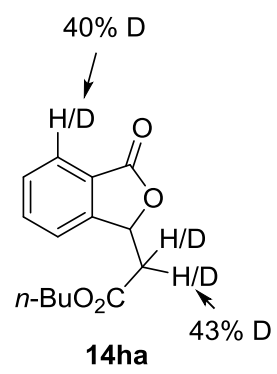

$\left(\mathrm{CDCl}_{3}, 300 \mathrm{MHz}\right)$
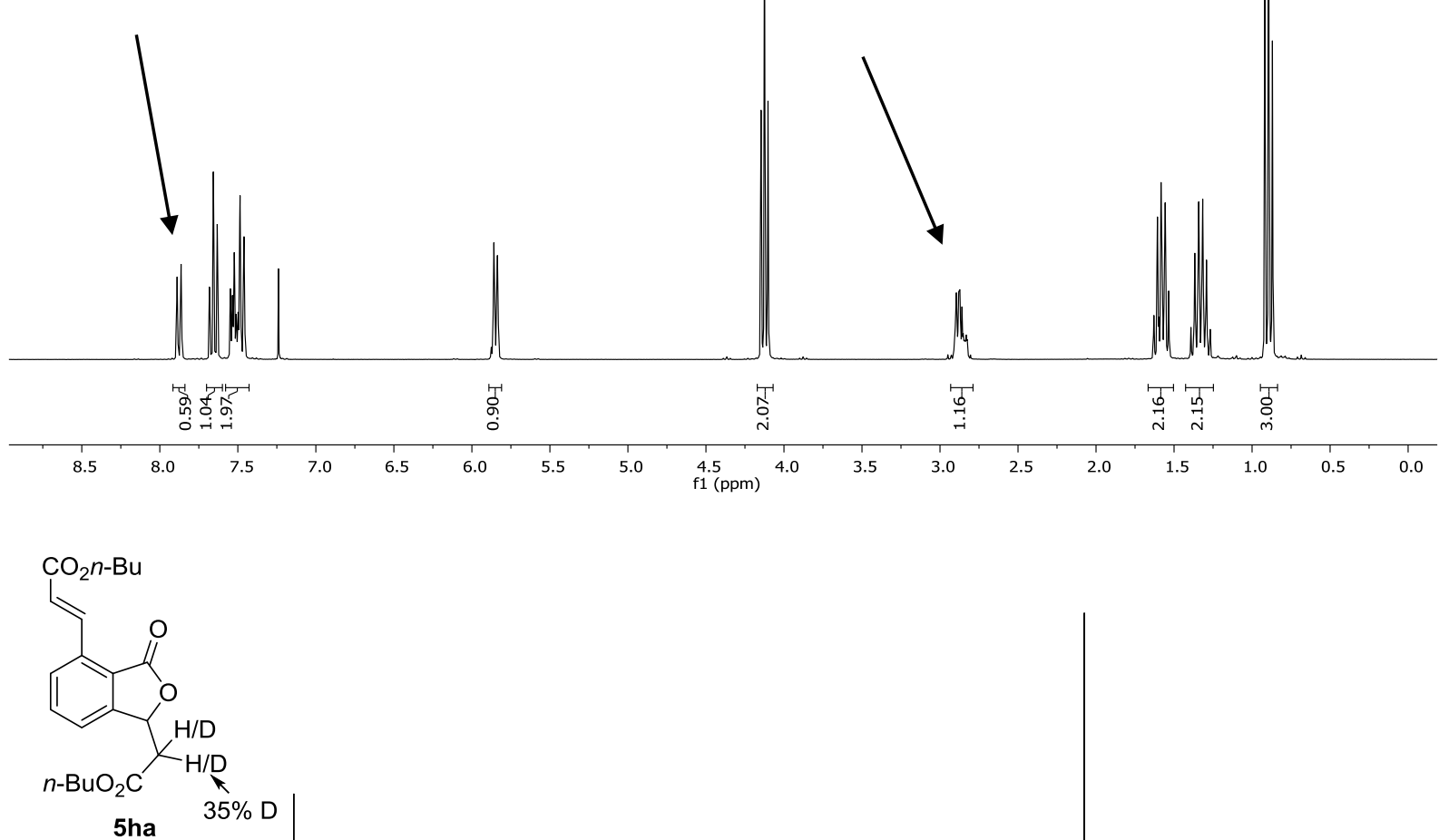

$\left(\mathrm{CDCl}_{3}, 300 \mathrm{MHz}\right)$

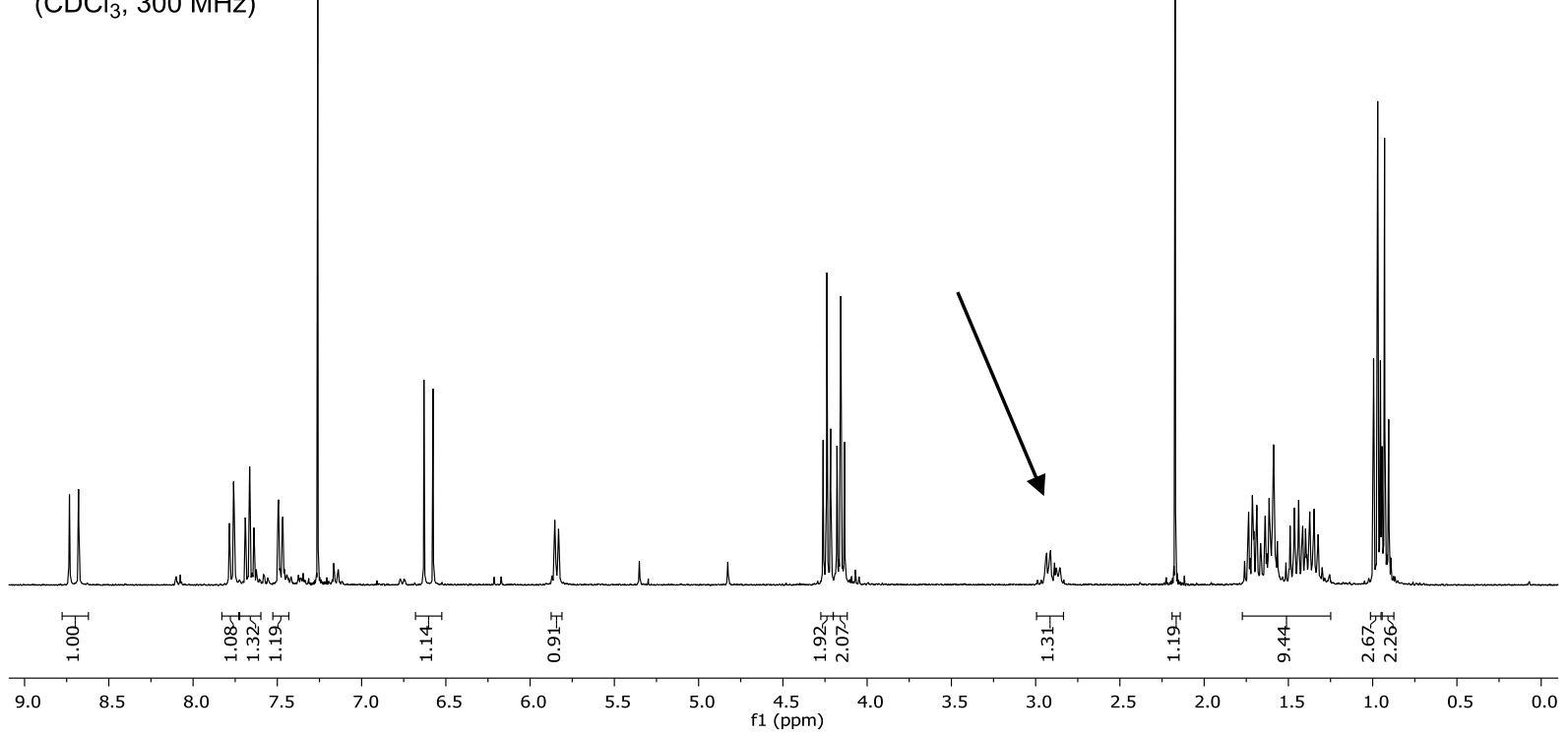




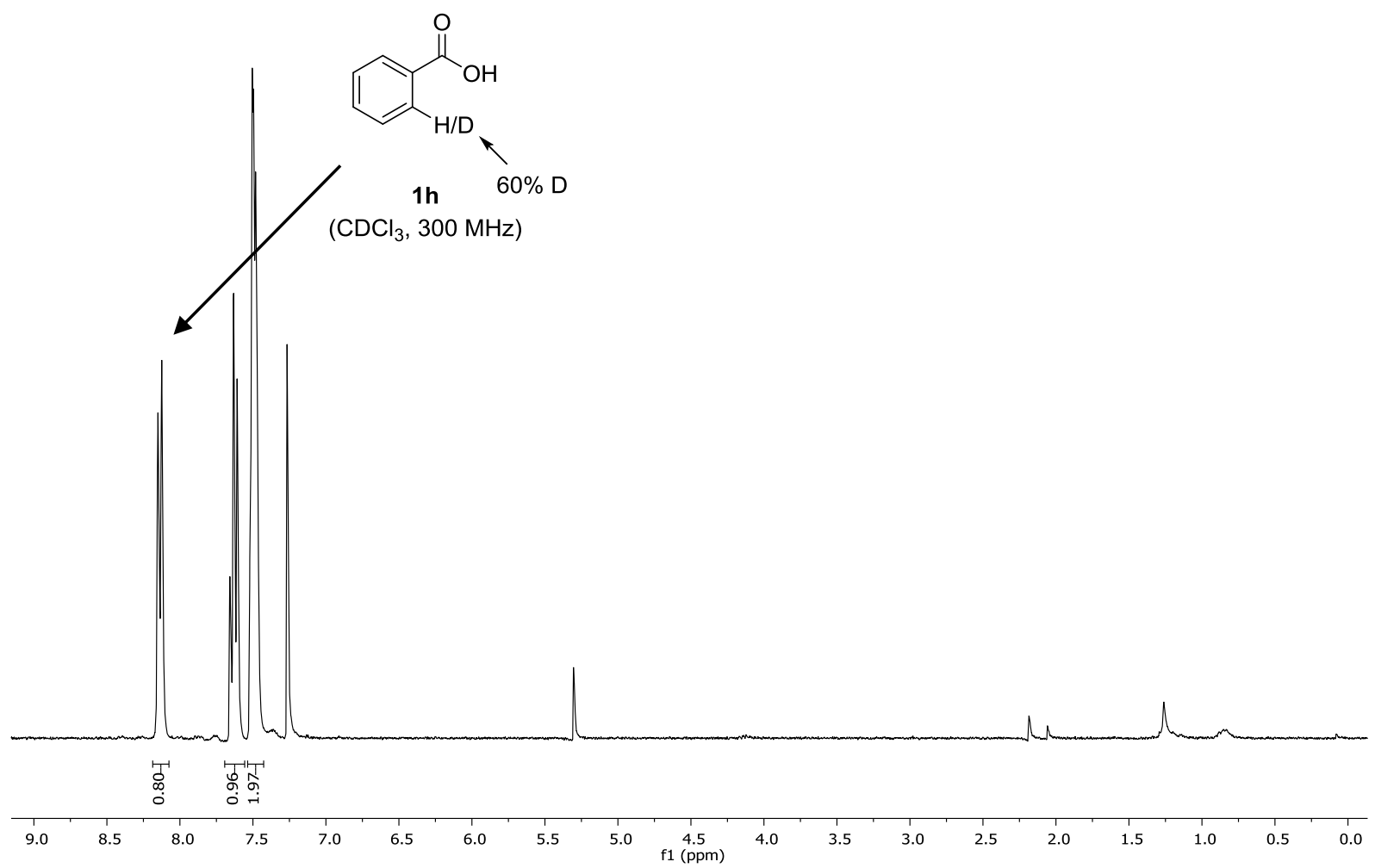<smiles>CCCCCC1OC(=O)c2ccccc21</smiles>

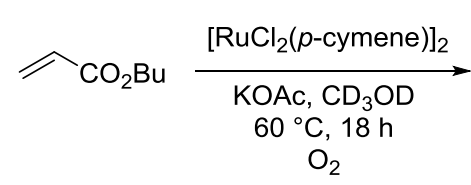

14ha

4a

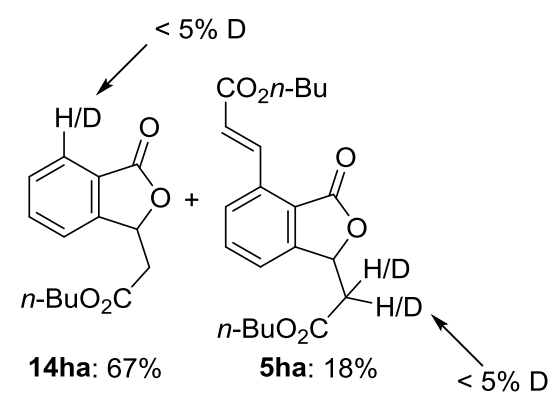

The representative procedure $\mathbf{D}$ was followed using phthalide 14 ha $(52.0 \mathrm{mg}, 0.21 \mathrm{mmol}), n$-butyl acrylate (4a) $(41.0 \mathrm{mg}, 0.32 \mathrm{mmol}),\left[\mathrm{RuCl}_{2}(p \text {-cymene }]_{2}(6.1 \mathrm{mg}, 0.01 \mathrm{mmol}, 5 \mathrm{~mol} \%)\right.$ and KOAc $(22.7 \mathrm{mg}, 0.23 \mathrm{mmol})$ in $\mathrm{CD}_{3} \mathrm{OD}(0.6 \mathrm{~mL})$. Purification by column chromatography ( $n$-hexane/EtOAc: $\left.4 / 1+5 \% \mathrm{NEt}_{3}\right)$ yielded phthalide $14 \mathrm{ha}(34.2 \mathrm{mg}, 66 \%)$ and $5 \mathrm{ha}(13.9 \mathrm{mg}, 18 \%)$ as colorless oils. The deuterium incorporation was determined via ${ }^{1} \mathrm{H}$ NMR spectroscopy. 
Experimental Part
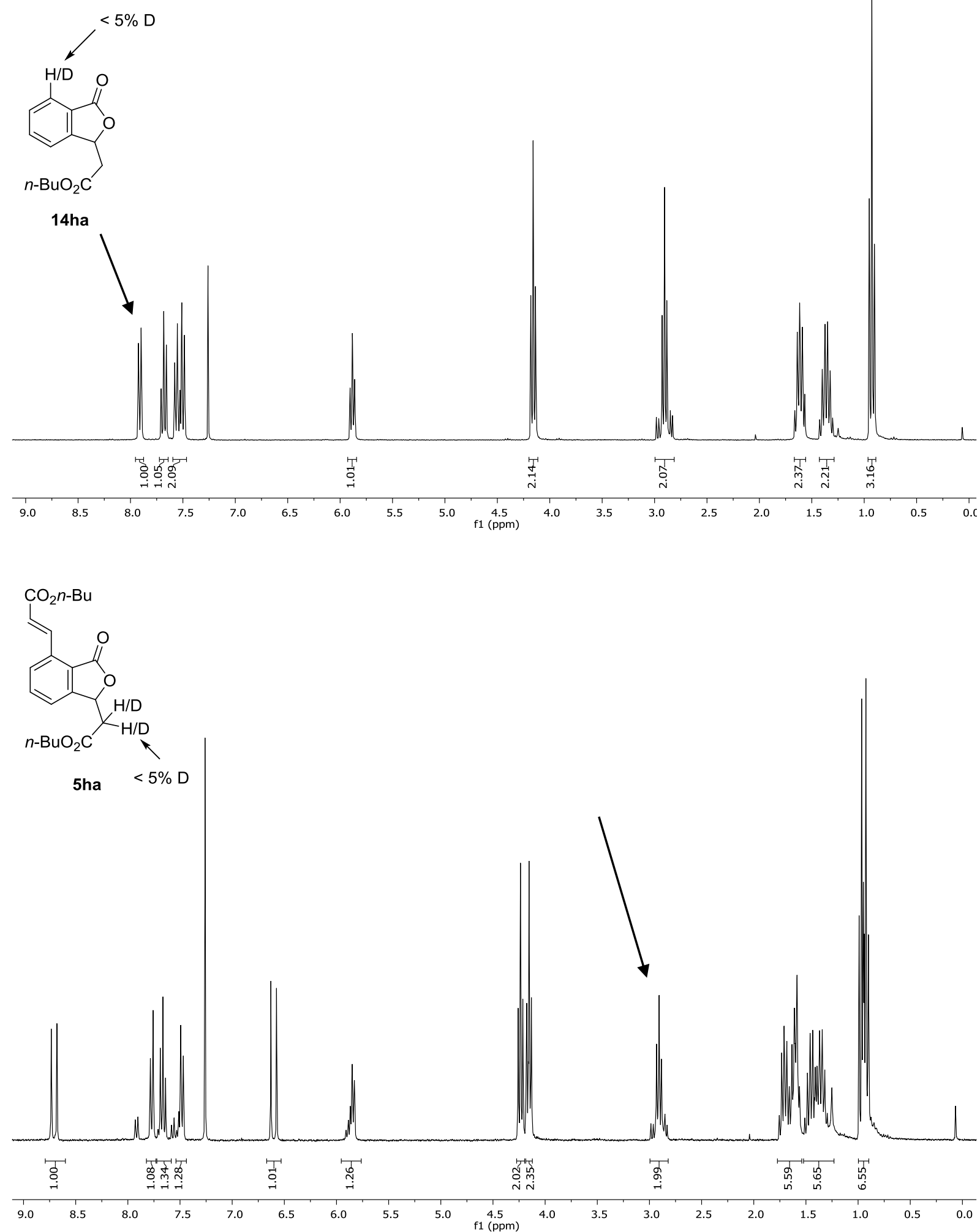


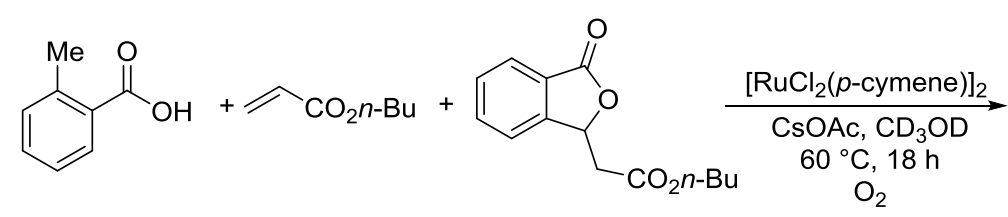

$1 \mathrm{a}$

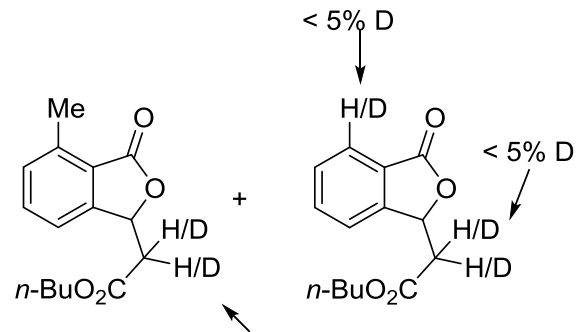

14aa: $52 \% \quad 46 \%$ D

The representative procedure $\mathbf{D}$ was followed using phthalide $14 \mathrm{ha}(52.0 \mathrm{mg}, 0.21 \mathrm{mmol})$ and $n$-butyl acrylate (4a) $(41.0 \mathrm{mg}, 0.32 \mathrm{mmol}),\left[\mathrm{RuCl}_{2}(p \text {-cymene })\right]_{2}(6.1 \mathrm{mg}, 0.01 \mathrm{mmol}, 5 \mathrm{~mol} \%)$ and $\mathrm{KOAc}$ (22.7 $\mathrm{mg}, 0.23 \mathrm{mmol}$ ) in $\mathrm{CD}_{3} \mathrm{OD}(0.6 \mathrm{~mL})$. Purification by column chromatography ( $n$-hexane/EtOAc: $4 / 1+5 \% \mathrm{NEt}_{3}$ ) yielded phthalide $14 \mathrm{aa}(68 \mathrm{mg}, 52 \%$ ) and $14 \mathrm{ha}(33 \mathrm{mg}, 83 \%$ ) as colorless oils. The deuterium incorporation was determined via ${ }^{1} \mathrm{H}$ NMR spectroscopy.
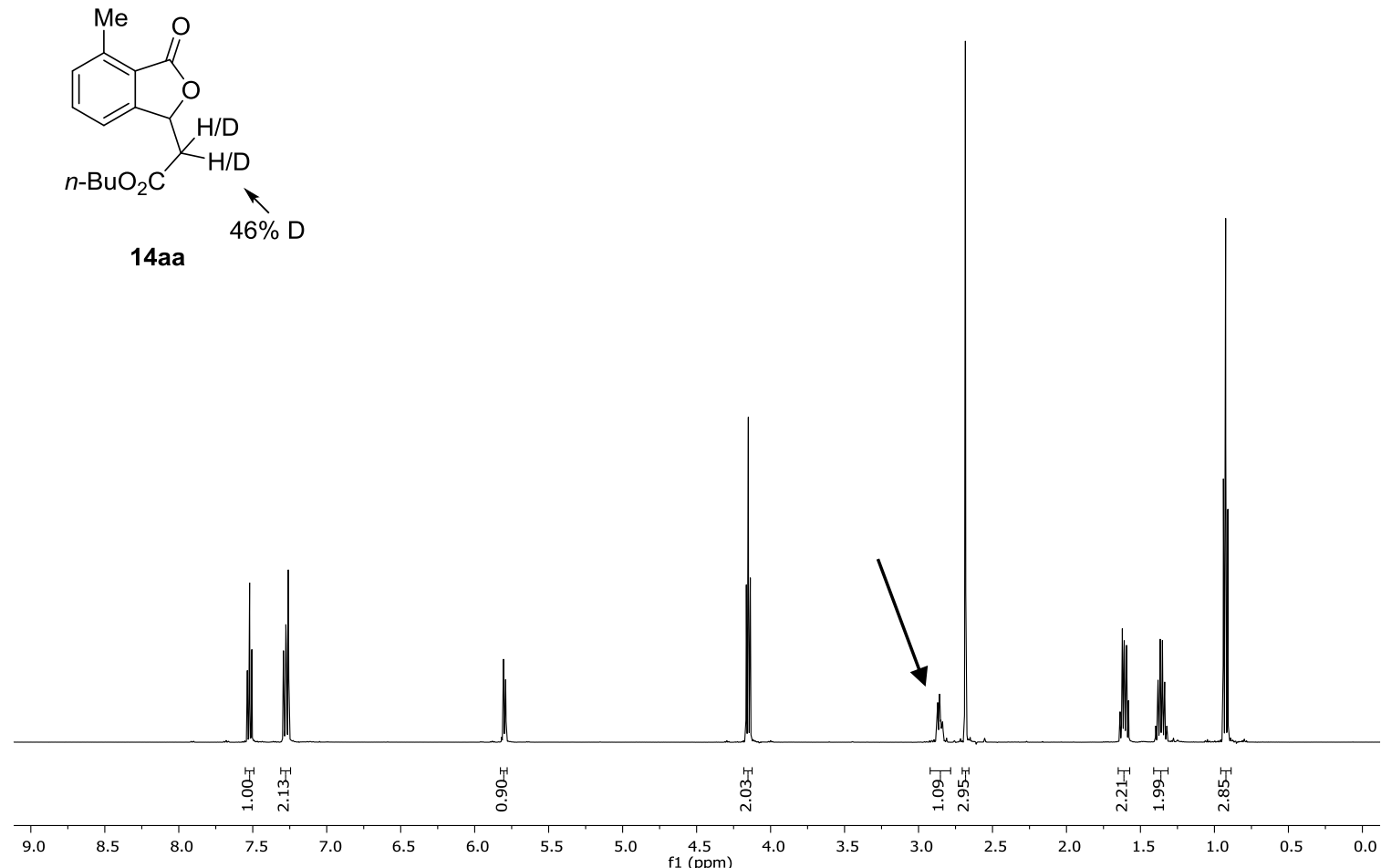


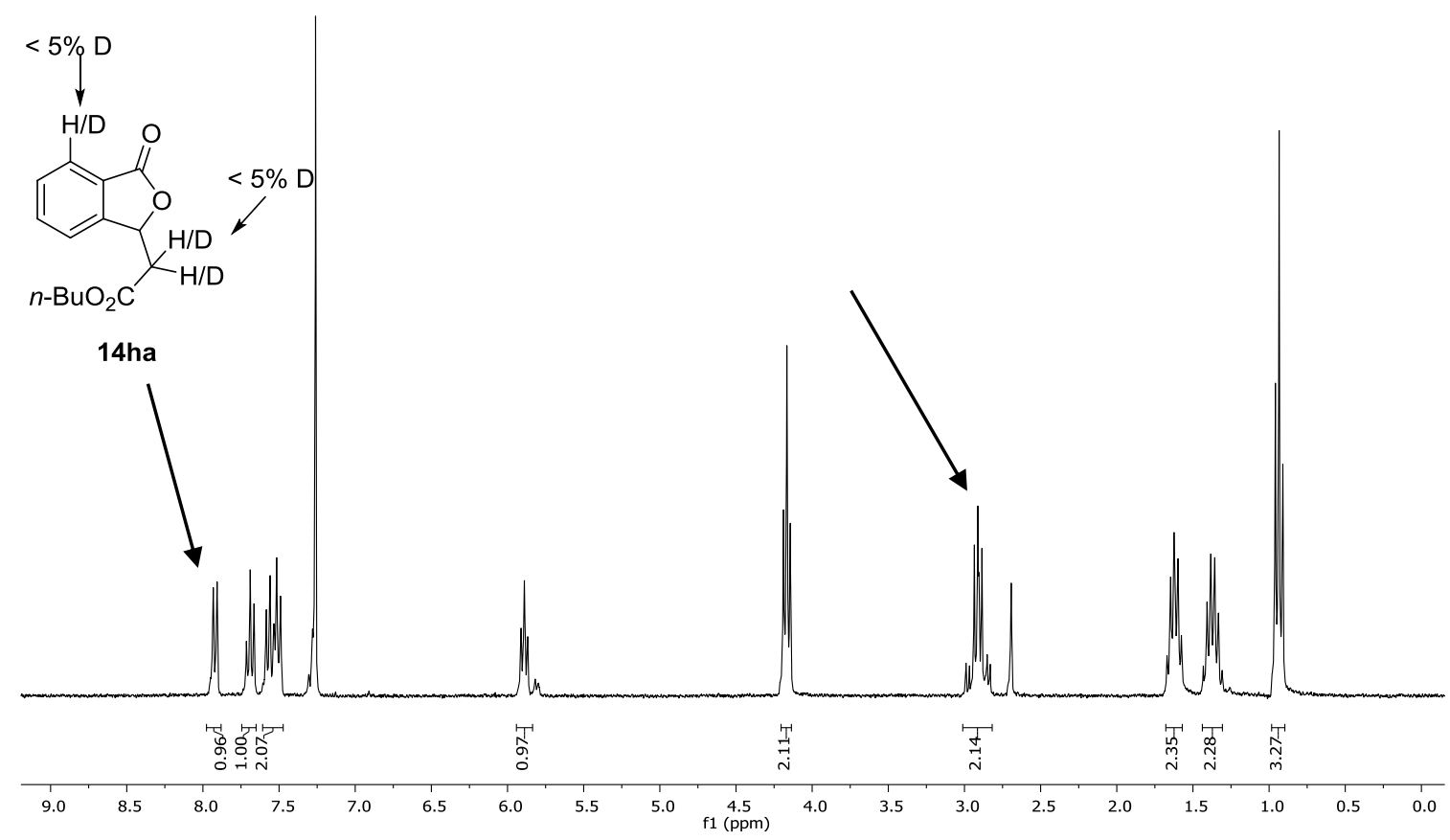

Kinetic Isotope Effect (KIE) Studies for the Synthesis of Phthalides

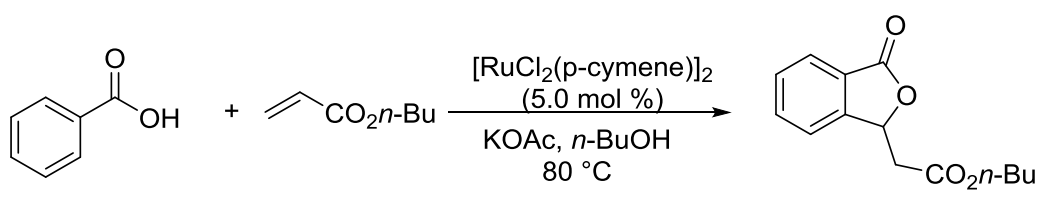

$1 \mathrm{~h}$

4a

14ha

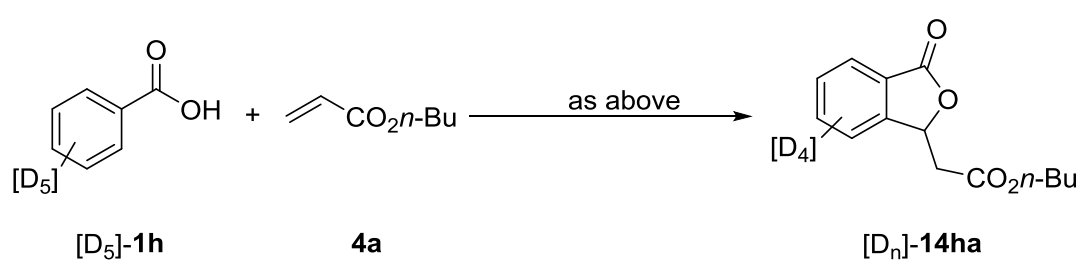

Two parallel reactions of $n$-butyl acrylate (4a) with benzoic acid (1h) and $\left[D_{5}\right]-\mathbf{1 h}$ were performed to determine the KIE value by comparison of the initial rates. The representative procedure $\mathbf{D}$ was applied using $1 \mathrm{~h}$ (122 mg, $1.0 \mathrm{mmol}$ ) or [ $\left.\mathrm{D}_{5}\right]-1 \mathrm{~h}$ (127 mg, $\left.1.0 \mathrm{mmol}\right)$, acrylate $4 \mathrm{a}$ (192 mg, $1.0 \mathrm{mmol}$ ), $\left[\operatorname{RuCl}_{2}(p \text {-cymene })\right]_{2}(30.6 \mathrm{mg}, 5.0 \mathrm{~mol} \%), n$-dodecane $(85.2 \mathrm{mg}, 0.50 \mathrm{mmol})$ and KOAc $(108 \mathrm{mg}$, $1.1 \mathrm{mmol}$ ) in $n-\mathrm{BuOH}(3.0 \mathrm{~mL})$ under ambient $\mathrm{O}_{2}$. The mixture was stirred at $80^{\circ} \mathrm{C}$, a periodic aliquot $(10 \mu \mathrm{L})$ was removed via a syringe and analyzed by GC providing the following data: 
Table 22. Conversion to 14 ha and $\left[D_{n}\right]-14 h a$.

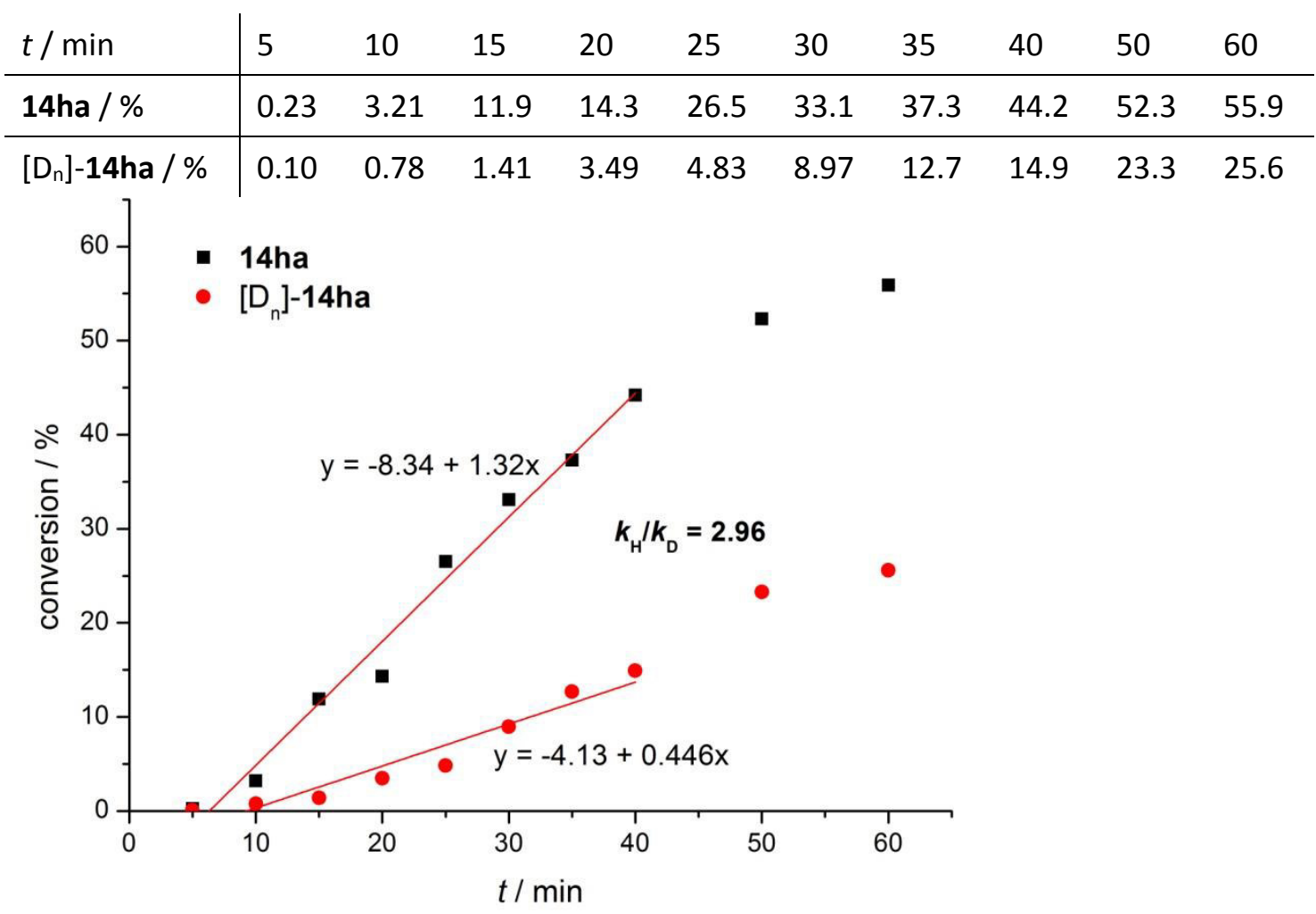

Figure 36. Conversion to $14 \mathrm{ha}$ and $\left[D_{n}\right]-14 h a$.

\subsubsection{Synthesis of Reaction Intermediates}

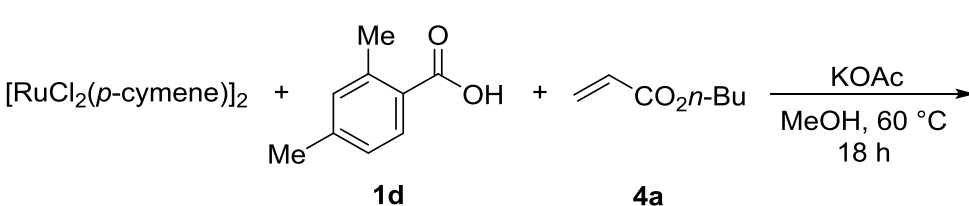

4a

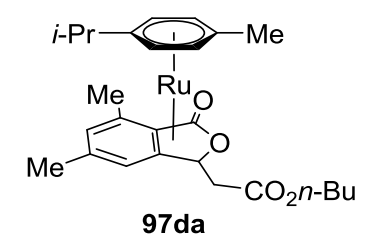

97da

A mixture of $\left[\mathrm{RuCl}_{2}(p \text {-cymene })\right]_{2}(61.2 \mathrm{mg}, 0.10 \mathrm{mmol})$, acid $1 \mathrm{~d}(31.5 \mathrm{mg}, 0.20 \mathrm{mmol}), n$-butyl acrylate (4a) $(28.2 \mathrm{mg}, 0.22 \mathrm{mmol})$ and $\mathrm{KOAc}(39.3 \mathrm{mg}, 0.40 \mathrm{mmol})$ in $\mathrm{MeOH}(5 \mathrm{~mL})$ was stirred under an atmosphere of $\mathrm{Ar}$ at $60^{\circ} \mathrm{C}$ for $18 \mathrm{~h}$. Removing the solvent, dissolving with $\mathrm{CH}_{2} \mathrm{Cl}_{2}$, filtration, removing the solvent and washing with $n$-hexane yielded crude $97 \mathrm{da}$. After confirming the stability of the complex, column chromatography on silica $\left(\mathrm{CH}_{2} \mathrm{Cl}_{2} / \mathrm{MeOH}\right.$ : $\left.20 / 1\right)$ yielded complex $97 \mathrm{da}$ (26.9 mg, $27 \%)$ as a red solid.

${ }^{1} \mathrm{H}$ NMR $\left(300 \mathrm{MHz}, \mathrm{CDCl}_{3}\right): \delta=6.98(\mathrm{~s}, 1 \mathrm{H}), 6.69(\mathrm{~s}, 1 \mathrm{H}), 5.53(\mathrm{~d}, J=5.6 \mathrm{~Hz}, 1 \mathrm{H}), 5.31(\mathrm{dd}, J=6.0$, $1.2 \mathrm{~Hz}, 1 \mathrm{H}), 5.02(\mathrm{~d}, J=6.0 \mathrm{~Hz}, 1 \mathrm{H}), 4.25-4.08(\mathrm{~m}, 3 \mathrm{H}), 3.46(\mathrm{dd}, J=14.7,7.5 \mathrm{~Hz}, 1 \mathrm{H}), 3.39(\mathrm{dd}, J=$ 14.7, $7.0 \mathrm{~Hz}, 1 \mathrm{H}$ ), $2.69(\mathrm{~s}, 3 \mathrm{H}$ ), 2.53 (hept, $J=6.9 \mathrm{~Hz}, 1 \mathrm{H}$ ), $2.28(\mathrm{~s}, 3 \mathrm{H}), 2.21$ (t, $J=7.2 \mathrm{~Hz}, 1 \mathrm{H}$ ), $1.70-$ $1.56(\mathrm{~m}, 2 \mathrm{H}), 1.45-1.31(\mathrm{~m}, 2 \mathrm{H}), 1.25(\mathrm{~d}, J=6.9 \mathrm{~Hz}, 3 \mathrm{H}), 1.23(\mathrm{~d}, J=6.9 \mathrm{~Hz}, 3 \mathrm{H}), 1.21(\mathrm{~s}, 3 \mathrm{H}), 0.92(\mathrm{t}, J$ 
$=7.3 \mathrm{~Hz}, 3 \mathrm{H}) ;{ }^{13} \mathrm{C}$ NMR $\left(125 \mathrm{MHz}, \mathrm{CDCl}_{3}\right): \delta=172.5\left(\mathrm{C}_{\mathrm{q}}\right), 168.7\left(\mathrm{C}_{\mathrm{q}}\right), 143.3\left(\mathrm{C}_{\mathrm{q}}\right), 141.9\left(\mathrm{C}_{\mathrm{q}}\right), 128.5(\mathrm{CH})$, 121.6 (CH), $105.4\left(\mathrm{C}_{\mathrm{q}}\right), 104.8\left(\mathrm{C}_{\mathrm{q}}\right), 90.3\left(\mathrm{C}_{\mathrm{q}}\right), 90.3\left(\mathrm{C}_{\mathrm{q}}\right), 86.3(\mathrm{CH}), 85.8(\mathrm{CH}), 82.8(\mathrm{CH}), 79.5(\mathrm{CH}), 65.0$ $\left(\mathrm{CH}_{2}\right), 54.7(\mathrm{CH}), 40.0\left(\mathrm{CH}_{2}\right), 31.2(\mathrm{CH}), 30.9\left(\mathrm{CH}_{2}\right), 23.2\left(\mathrm{CH}_{3}\right), 22.8\left(\mathrm{CH}_{3}\right), 22.1\left(\mathrm{CH}_{3}\right), 21.0\left(\mathrm{CH}_{3}\right), 19.4$ $\left(\mathrm{CH}_{2}\right), 16.2\left(\mathrm{CH}_{3}\right), 13.9\left(\mathrm{CH}_{3}\right)$; IR (ATR): $\tilde{v}=2965,1698,1639,1470,1113,1073,1055,1027,772$, $703 \mathrm{~cm}^{-1} ;$ HR-MS (ESI): $\mathrm{m} / z$ calcd for $\left[\mathrm{C}_{26} \mathrm{H}_{34} \mathrm{O}_{4} \mathrm{Ru}+\mathrm{H}\right]^{+} 513.1581$, found 513.1578 .
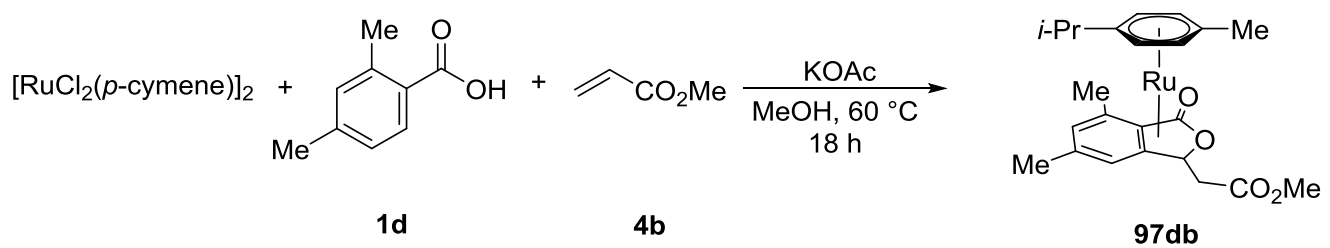

A mixture of $\left[\mathrm{RuCl}_{2}(p \text {-cymene })\right]_{2}(61.2 \mathrm{mg}, 0.10 \mathrm{mmol})$, benzoic acid $1 \mathrm{~d}(31.5 \mathrm{mg}, 0.20 \mathrm{mmol})$, methyl acrylate (4b) (18.9 mg, $0.22 \mathrm{mmol})$ and $\mathrm{KOAc}(39.3 \mathrm{mg}, 0.40 \mathrm{mmol})$ in $\mathrm{MeOH}(5 \mathrm{~mL})$ was stirred under an atmosphere of $\operatorname{Ar}$ at $60^{\circ} \mathrm{C}$ for $18 \mathrm{~h}$. Removal of the solvent followed by column chromatography on silica $\left(\mathrm{CH}_{2} \mathrm{Cl}_{2} / \mathrm{MeOH} 20: 1\right)$ yielded complex $97 \mathrm{db}(93.8 \mathrm{mg}, 99 \%)$ as a red solid.

M.p. (decomp.): $109{ }^{\circ} \mathrm{C} ;{ }^{1} \mathrm{H}$ NMR $\left(300 \mathrm{MHz}, \mathrm{CDCl}_{3}\right): \delta=6.99(\mathrm{~s}, 1 \mathrm{H}), 6.67$ (s, 1H), 5.54 (dd, J = 5.7, $1.2 \mathrm{~Hz}, 1 \mathrm{H}), 5.32(\mathrm{dd}, J=6.1,1.2 \mathrm{~Hz}, 1 \mathrm{H}), 5.06(\mathrm{~d}, J=5.8 \mathrm{~Hz}, 1 \mathrm{H}), 4.11(\mathrm{~d}, J=5.6 \mathrm{~Hz}, 1 \mathrm{H}), 3.76(\mathrm{~s}, 3 \mathrm{H})$, 3.49-3.37 (m, 2H), 2.69 (s, 3H), 2.55 (hept, $J=7.0 \mathrm{~Hz}, 1 \mathrm{H}$ ), $2.29(\mathrm{~s}, 3 \mathrm{H}), 2.21$ (t, $J=7.2 \mathrm{~Hz}, 1 \mathrm{H}$ ), 1.26 (d, $J=7.0 \mathrm{~Hz}, 3 \mathrm{H}), 1.24(\mathrm{~d}, J=7.0 \mathrm{~Hz}, 3 \mathrm{H}), 1.21(\mathrm{~s}, 3 \mathrm{H}) ;{ }^{13} \mathrm{C} \mathrm{NMR}\left(125 \mathrm{MHz}, \mathrm{CDCl}_{3}\right): \delta=173.0\left(\mathrm{C}_{\mathrm{q}}\right), 168.8$ $\left(\mathrm{C}_{\mathrm{q}}\right), 143.4\left(\mathrm{C}_{\mathrm{q}}\right), 142.1\left(\mathrm{C}_{\mathrm{q}}\right), 128.7(\mathrm{CH}), 121.6(\mathrm{CH}), 105.5\left(\mathrm{C}_{\mathrm{q}}\right), 104.8\left(\mathrm{C}_{\mathrm{q}}\right), 90.4\left(\mathrm{C}_{\mathrm{q}}\right), 90.4\left(\mathrm{C}_{\mathrm{q}}\right), 86.5(\mathrm{CH})$, 86.0 (CH), $82.9(\mathrm{CH}), 79.2(\mathrm{CH}), 54.5(\mathrm{CH}), 52.1\left(\mathrm{CH}_{3}\right), 39.6\left(\mathrm{CH}_{2}\right), 31.2(\mathrm{CH}), 23.2\left(\mathrm{CH}_{3}\right), 22.7\left(\mathrm{CH}_{3}\right), 22.0$ $\left(\mathrm{CH}_{3}\right), 20.9\left(\mathrm{CH}_{3}\right), 16.0\left(\mathrm{CH}_{3}\right)$; IR (ATR): $\tilde{v}=2957,1709,1630,1532,1435,1381,1322,1262,1169$, $854 \mathrm{~cm}^{-1} ;$ HR-MS (ESI): $\mathrm{m} / z$ calcd for $\left[\mathrm{C}_{23} \mathrm{H}_{28} \mathrm{O}{ }_{4} \mathrm{Ru}+\mathrm{H}\right]^{+} 471.1110$, found: 471.1108 .

\section{Studies}




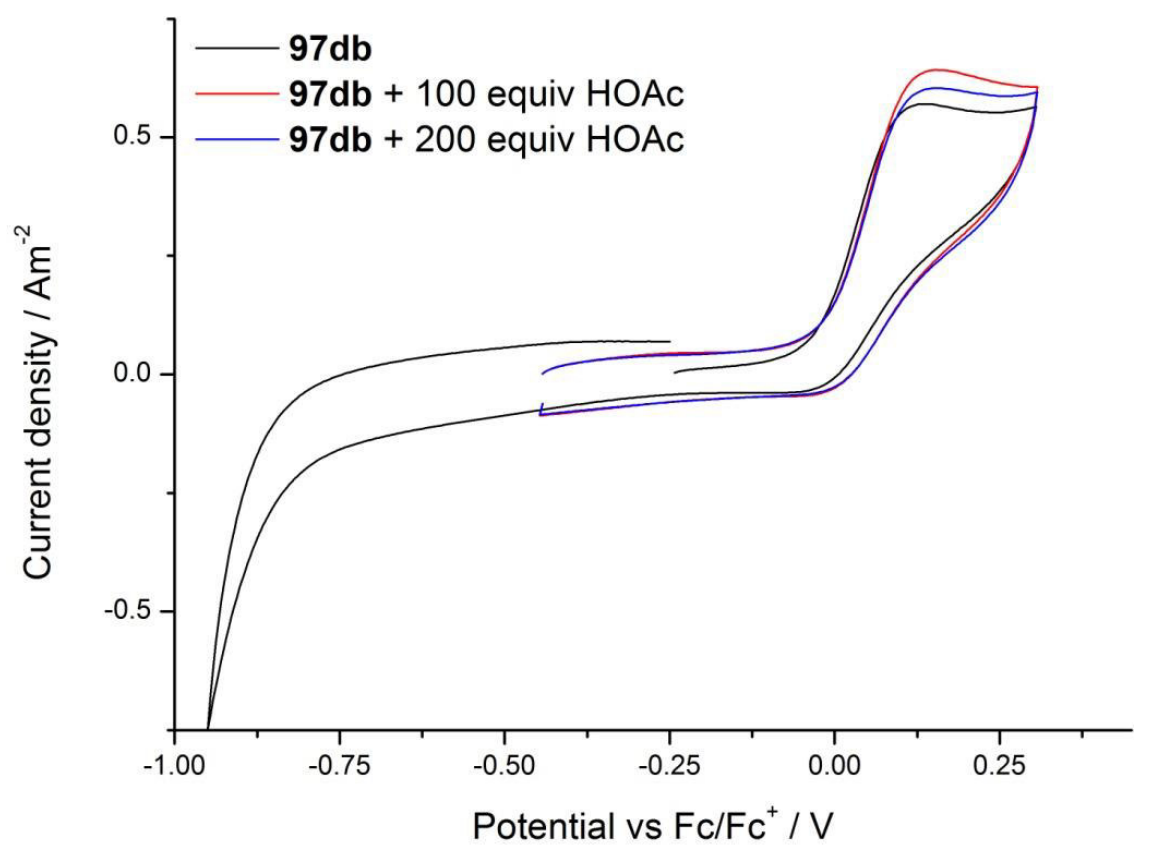

Figure 37. CV spectra of complex $\mathbf{9 7 d b}$ in acetonitrile.

\section{Oxidation of Reaction Intermediate}<smiles>CCCCC1OC(=O)c2c(C)cc(C)cc21</smiles>

n-Butyl 2-(4,6-dimethyl-3-oxo-1,3-dihydroisobenzofuran-1-yl)acetate (14da): 97da (15.0 mg, $29 \mu \mathrm{mol})$ was placed in a Schlenk tube and three times evacuated and filled with $\mathrm{O}_{2}$. HOAc $(17 \mu \mathrm{L}$, $0.29 \mathrm{mmol})$ and $\mathrm{MeOH}(0.5 \mathrm{~mL})$ were added and the solution was stirred at $60{ }^{\circ} \mathrm{C}$ for $18 \mathrm{~h}$. Removal of the solvent followed by column chromatography on silica ( $n$-hexane/EtOAc: $4 / 1$ ) yielded 14da (5.1 mg mg, 62\%) as a colorless oil.

${ }^{1} \mathrm{H}$ NMR $\left(500 \mathrm{MHz}, \mathrm{CDCl}_{3}\right): \delta=7.04(\mathrm{~d}, J=0.7 \mathrm{~Hz}, 1 \mathrm{H}), 7.02(\mathrm{~d}, J=0.7 \mathrm{~Hz}, 1 \mathrm{H}), 5.69(\mathrm{t}, J=6.5 \mathrm{~Hz}, 1 \mathrm{H})$, $4.10(\mathrm{td}, J=6.7,1.3 \mathrm{~Hz}, 2 \mathrm{H}), 2.84-2.75(\mathrm{~m}, 2 \mathrm{H}), 2.57(\mathrm{~s}, 3 \mathrm{H}), 2.37(\mathrm{~s}, 3 \mathrm{H}), 1.64-1.48(\mathrm{~m}, 2 \mathrm{H}), 1.37-$ $1.24(\mathrm{~m}, 2 \mathrm{H}), 0.87(\mathrm{t}, J=7.4 \mathrm{~Hz}, 3 \mathrm{H}) ;{ }^{13} \mathrm{C}$ NMR $\left(125 \mathrm{MHz}, \mathrm{CDCl}_{3}\right): \delta=169.8\left(\mathrm{C}_{\mathrm{q}}\right), 169.3\left(\mathrm{C}_{\mathrm{q}}\right), 149.7\left(\mathrm{C}_{\mathrm{q}}\right)$, $145.0\left(\mathrm{C}_{q}\right), 139.2\left(\mathrm{C}_{\mathrm{q}}\right), 132.0(\mathrm{CH}), 120.7\left(\mathrm{C}_{\mathrm{q}}\right), 119.5(\mathrm{CH}), 75.7(\mathrm{CH}), 64.8\left(\mathrm{CH}_{2}\right), 39.6\left(\mathrm{CH}_{2}\right), 30.3\left(\mathrm{CH}_{2}\right)$, $21.7\left(\mathrm{CH}_{3}\right), 18.9\left(\mathrm{CH}_{2}\right), 17.0\left(\mathrm{CH}_{3}\right), 13.5\left(\mathrm{CH}_{3}\right)$; IR (ATR): $\tilde{v}=2959,1753,1732,1613,1203,1170,1151$, 1054, 1013, $686 \mathrm{~cm}^{-1}$; MS (EI) m/z (relative intensity) 276 (20) [M] ${ }^{+}, 220$ (64), 174 (99), 161 (100), 146 (30), 133 (34), 105 (20), 77 (14), 43 (22); HR-MS (EI): $m / z=276.1362$ calcd for $\left[\mathrm{C}_{16} \mathrm{H}_{20} \mathrm{O}_{4}\right]^{+}$, found: 276.1372 . 


\subsubsection{Ruthenium(II)-Catalyzed Direct Arylation}

\subsubsection{Synthesis of Ruthenium(II) Phosphinous Acid Catalysts 84}

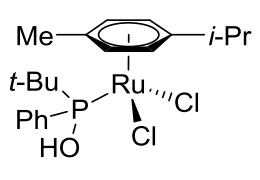

$84 a$

$\left[\mathrm{RuCl}_{2}(\boldsymbol{p}\right.$-cymene) $\{t-\mathrm{BuPhP}(\mathrm{OH})\}]$ (84a): The representative procedure $\mathbf{A}$ was followed using $\left[\mathrm{RuCl}_{2}(p-\right.$ cymene) $]_{2} \quad(200 \mathrm{mg}, 0.322 \mathrm{mmol}$ ) and tert-butyl(phenyl)phosphine oxide (100a) (148 mg, $0.805 \mathrm{mmol}$ ), yielding $84 \mathrm{a}$ (307 $\mathrm{mg}, 97 \%$ ) as a red solid.

M.p. (decomp.): $182^{\circ} \mathrm{C} ;{ }^{1} \mathrm{H}$ NMR $\left(300 \mathrm{MHz}, \mathrm{CDCl}_{3}\right): \delta=7.78-7.67(\mathrm{~m}, 2 \mathrm{H}), 7.54-7.42(\mathrm{~m}, 3 \mathrm{H}), 6.17(\mathrm{~s}$, $1 \mathrm{H}), 5.49(\mathrm{~d}, J=6.1 \mathrm{~Hz}, 1 \mathrm{H}), 5.53-5.46(\mathrm{~m}, 2 \mathrm{H}), 5.14(\mathrm{~d}, J=6.1 \mathrm{~Hz}, 1 \mathrm{H}), 2.73(\mathrm{sept}, J=6.9 \mathrm{~Hz}, 1 \mathrm{H}), 1.98$ (s, 3H), $1.18(\mathrm{~d}, J=15.1 \mathrm{~Hz}, 9 \mathrm{H}), 1.15(\mathrm{~d}, J=6.9 \mathrm{~Hz}, 3 \mathrm{H}), 0.98(\mathrm{~d}, J=6.9 \mathrm{~Hz}, 3 \mathrm{H}) ;{ }^{13} \mathrm{C} \mathrm{NMR}(125 \mathrm{MHz}$, $\left.\mathrm{CDCl}_{3}\right): \delta=136.8\left(\mathrm{~d}, J=46 \mathrm{~Hz}, \mathrm{C}_{\mathrm{q}}\right), 130.2(\mathrm{~d}, J=3 \mathrm{~Hz}, \mathrm{CH}), 129.7(\mathrm{~d}, J=10 \mathrm{~Hz}, \mathrm{CH}), 127.8(\mathrm{~d}, J=10 \mathrm{~Hz}$, $\mathrm{CH}), 107.4\left(\mathrm{C}_{\mathrm{q}}\right), 93.9\left(\mathrm{C}_{\mathrm{q}}\right), 92.2(\mathrm{~d}, J=5 \mathrm{~Hz}, \mathrm{CH}), 90.2(\mathrm{~d}, J=4 \mathrm{~Hz}, \mathrm{CH}), 86.3(\mathrm{~d}, J=6 \mathrm{~Hz}, \mathrm{CH}), 85.9(\mathrm{~d}, J=$ $6 \mathrm{~Hz}, \mathrm{CH}), 39.6(\mathrm{~d}, J=27 \mathrm{~Hz}, \mathrm{C}), 30.2(\mathrm{CH}), 26.1\left(\mathrm{~d}, J=4 \mathrm{~Hz}, \mathrm{CH}_{3}\right), 21.8\left(\mathrm{CH}_{3}\right), 21.5\left(\mathrm{CH}_{3}\right), 17.8\left(\mathrm{CH}_{3}\right)$; ${ }^{31} \mathrm{P}$ NMR $\left(121 \mathrm{MHz}, \mathrm{CDCl}_{3}\right): \delta=116.4$ (s); IR (ATR): $\tilde{v}=2964,1467,1144,1104,910,859,729,699$, $516 \mathrm{~cm}^{-1}$; MS (ESI) m/z (relative intensity) 494 (33), 453 (65), [M-Cl+], 407 (100), 371 (58), 313 (20); HR-MS (ESI): $m / z$ calcd for $\left[\mathrm{C}_{20} \mathrm{H}_{29} \mathrm{Cl}_{2} \mathrm{OPRu}-\mathrm{Cl}\right]^{+} 453.0685$, found 453.0686 .

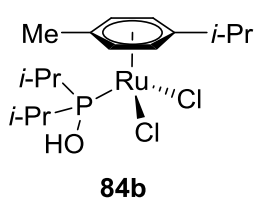

$\left[\mathrm{RuCl}_{2}\left(\boldsymbol{p}\right.\right.$-cymene) $\left.\left\{i-\mathrm{Pr}_{2} \mathrm{P}(\mathrm{OH})\right\}\right]$ (84b): The representative procedure $\mathbf{A}$ was followed using $\left[\mathrm{RuCl}_{2}(p\right.$ cymene) $]_{2}(100 \mathrm{mg}, 163 \mu \mathrm{mol})$ and diisopropylphosphine oxide (100b) $(64.4 \mathrm{mg}, 0.48 \mathrm{mmol})$, yielding 84b (113 mg, 73\%) as a red solid.

M.p. (decomp.): $131{ }^{\circ} \mathrm{C} ;{ }^{1} \mathrm{H} \mathrm{NMR}\left(300 \mathrm{MHz}, \mathrm{CDCl}_{3}\right): \delta=5.63(\mathrm{~d}, J=5.8 \mathrm{~Hz}, 2 \mathrm{H}), 5.59(\mathrm{~d}, J=5.8 \mathrm{~Hz}, 2 \mathrm{H})$, 2.78 (sept, $J=6.9 \mathrm{~Hz}, 1 \mathrm{H}$ ), 2.68 (sept, $J=7.1 \mathrm{~Hz}, 2 \mathrm{H}), 2.11(\mathrm{~s}, 3 \mathrm{H}), 1.35-1.29(\mathrm{~m}, 12 \mathrm{H}), 1.27(\mathrm{~d}, J=$ $6.9 \mathrm{~Hz}, 6 \mathrm{H}) ;{ }^{13} \mathrm{C}$ NMR $\left(100 \mathrm{MHz}, \mathrm{CDCl}_{3}\right): \delta=107.2\left(\mathrm{C}_{\mathrm{q}}\right), 94.0\left(\mathrm{C}_{\mathrm{q}}\right), 89.1(\mathrm{~d}, J=4 \mathrm{~Hz}, \mathrm{CH}), 84.6(\mathrm{~d}, J=$ $6 \mathrm{~Hz}, \mathrm{CH}$ ), $32.1(\mathrm{~d}, J=29 \mathrm{~Hz}, \mathrm{CH}), 30.8(\mathrm{CH}), 22.4\left(\mathrm{CH}_{3}\right), 18.2\left(\mathrm{CH}_{3}\right), 17.7\left(\mathrm{~d}, J=64 \mathrm{~Hz}, \mathrm{CH}_{3}\right) ;{ }^{31} \mathrm{P} \mathbf{N M R}$ $\left(121 \mathrm{MHz}, \mathrm{CDCl}_{3}\right): \delta=134.6$ (s); IR (ATR): $\tilde{v}=3267,2925,2871,1464,1377,1138,852,670,523$, $407 \mathrm{~cm}^{-1} ;$ HR-MS (ESI): $\mathrm{m} / z$ calcd for $\left[\mathrm{C}_{16} \mathrm{H}_{29} \mathrm{Cl}_{2} \mathrm{OPRu}-\mathrm{Cl}\right]^{+} 405.0684$, found 405.0690 . 


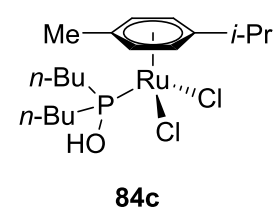

[RuCl $2\left(p\right.$-cymene) $\left.\left\{n-\mathrm{Bu}_{2} \mathrm{P}(\mathrm{OH})\right\}\right]$ (84c): The representative procedure $\mathbf{A}$ was followed using $\left[\mathrm{RuCl}_{2}(p\right.$ cymene) $]_{2}$ (500 mg, $0.816 \mathrm{mmol}$ ) and di- $n$-butylphosphine oxide (100c) (399 mg, $2.46 \mathrm{mmol}$ ), yielding 84c (753 mg, 98\%) as a red solid.

M.p. (decomp.): $140{ }^{\circ} \mathrm{C} ;{ }^{1} \mathrm{H}$ NMR $\left(400 \mathrm{MHz}, \mathrm{CDCl}_{3}\right): \delta=5.47(\mathrm{~d}, J=5.8 \mathrm{~Hz}, 2 \mathrm{H}), 5.43(\mathrm{~d}, J=5.8 \mathrm{~Hz}, 2 \mathrm{H}$ ), $2.78(\mathrm{sept}, J=6.9 \mathrm{~Hz}, 1 \mathrm{H}), 2.24-2.10(\mathrm{~m}, 4 \mathrm{H}), 2.07(\mathrm{~s}, 3 \mathrm{H}), 1.69-1.50(\mathrm{~m}, 4 \mathrm{H}), 1.47-1.39(\mathrm{~m}, 4 \mathrm{H}), 1.21$ $(\mathrm{d}, J=6.9 \mathrm{~Hz}, 6 \mathrm{H}), 0.93(\mathrm{t}, J=7.8 \mathrm{~Hz}, 6 \mathrm{H}) ;{ }^{13} \mathrm{C}$ NMR $\left(100 \mathrm{MHz}, \mathrm{CDCl}_{3}\right): \delta=107.0\left(\mathrm{C}_{\mathrm{q}}\right), 94.8\left(\mathrm{C}_{\mathrm{q}}\right), 89.3(\mathrm{~d}$, $J=5 \mathrm{~Hz}, \mathrm{CH}$ ), $85.5\left(\mathrm{~d}, J=6 \mathrm{~Hz}, \mathrm{CH}\right.$ ), $32.7\left(\mathrm{~d}, J=33 \mathrm{~Hz}, \mathrm{CH}_{2}\right.$ ), $30.7(\mathrm{CH}), 24.7$ (d, J=3 Hz, CH $\left.=13 \mathrm{~Hz}, \mathrm{CH}_{2}\right), 22.1\left(\mathrm{CH}_{3}\right), 18.4\left(\mathrm{CH}_{3}\right), 13.8\left(\mathrm{CH}_{3}\right) ;{ }^{31} \mathrm{P}$ NMR $\left(121 \mathrm{MHz}, \mathrm{CDCl}_{3}\right): \delta=124.4$ (s); IR (ATR): $\tilde{v}=$ 2958, 2929, 2870, 1462, 1137, 795, $481 \mathrm{~cm}^{-1}$; HR-MS (ESI): $\mathrm{m} / \mathrm{z}$ calcd for $\left[\mathrm{C}_{18} \mathrm{H}_{33} \mathrm{Cl}_{2} \mathrm{OPRu}\right]^{+} 468.0601$, found 468.0690 .

\section{Attempted Synthesis of $\left[\mathrm{Ru}(\mathrm{PA})_{2} \mathrm{Cl}\right]$}
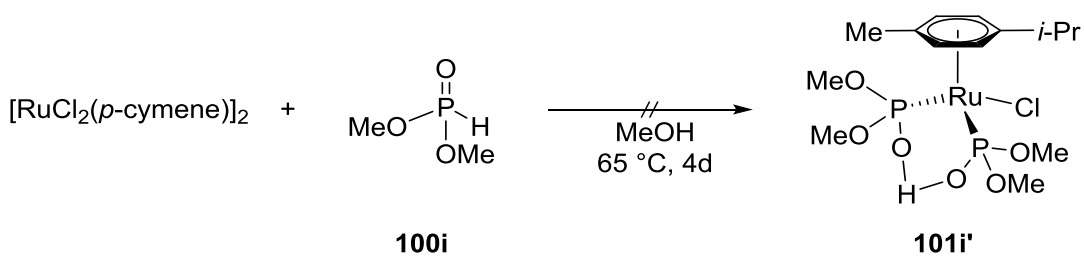

A solution of $\left[\mathrm{RuCl}_{2}(p \text {-cymene })\right]_{2}(62.1 \mathrm{mg}, 0.10 \mathrm{mmol}, 1.0$ equiv) and dimethyl phosphonate (100i) (42 $\mu \mathrm{L}, 0.45 \mathrm{mmol}, 4.5$ equiv) in $\mathrm{MeOH}\left(4.0 \mathrm{ml}\right.$ ) was stirred at $65^{\circ} \mathrm{C}$ for $64 \mathrm{~h}$ under an atmosphere of Ar. No formation of the desired product 101i was observed by ${ }^{31} \mathrm{P}$ NMR.

In independent reactions, the addition of $\mathrm{NEt}_{3}\left(0.10 \mathrm{~mL}, 0.72 \mathrm{mmol}, 7.2\right.$ equiv) or $\mathrm{Na}_{2} \mathrm{CO}_{3}(21.2 \mathrm{mg}$, $0.20 \mathrm{mmol}, 2.0$ equiv) did not lead to product formation.

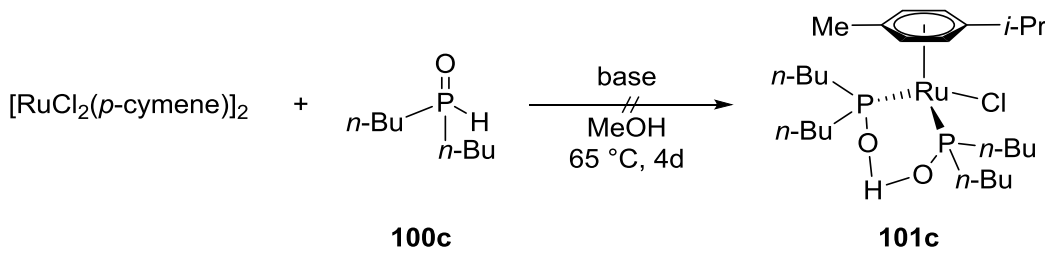


A mixture of $\left[\mathrm{RuCl}_{2}(p \text {-cymene) }]_{2}\right.$ (31.1 mg, $0.05 \mathrm{mmol}, 1.0$ equiv), di- $n$-butylphosphine oxide (100c) (48.7 mg, $0.30 \mathrm{mmol}, 6.0$ equiv) and $\mathrm{Na}_{2} \mathrm{CO}_{3}(10.6 \mathrm{mg}, 0.10 \mathrm{mmol}$ ) in $\mathrm{MeOH}(2.5 \mathrm{ml})$ was stirred at $65{ }^{\circ} \mathrm{C}$ for $66 \mathrm{~h}$ under an atmosphere of Ar. ${ }^{31} \mathrm{P}$ NMR spectroscopy of the crude reaction mixture showed three signals, corresponding to the starting material $100 \mathrm{c},\left[\operatorname{RuCl}_{2}\left(p\right.\right.$-cymene) $\left.\left\{n-\mathrm{Bu}_{2} \mathrm{P}(\mathrm{OH})\right\}\right]$ (84c) and a signal from an unknown new compound, which decomposed during crystallization attempts.

A mixture of $\left[\mathrm{RuCl}_{2}(p \text {-cymene) }]_{2}\right.$ (31.1 $\mathrm{mg}, 0.05 \mathrm{mmol}, 1.0$ equiv), di- $n$-butylphosphine oxide (100c) (81.1 mg, $0.50 \mathrm{mmol}, 10$ equiv) and $\mathrm{Na}_{2} \mathrm{CO}_{3}(21.2 \mathrm{mg}, 0.20 \mathrm{mmol})$ in $\mathrm{MeOH}(2.5 \mathrm{ml})$ was stirred at $65{ }^{\circ} \mathrm{C}$ for $66 \mathrm{~h}$ under an atmosphere of Ar. ${ }^{31} \mathrm{P}$ NMR spectroscopy showed two major signals, one corresponding to the starting material $100 \mathrm{c}$ and a signal from an unknown new compound, which was not isolable in a pure fashion.

\subsubsection{PA-Ruthenium(II)-catalyzed C-H Arylation of Oxazolines}<smiles>COc1ccc(-c2cccc(OC)c2C2=NCCO2)cc1</smiles>

2-(4'-Methoxy-3-methyl-[1,1'-biphenyl]-2-yl)-4,5-dihydrooxazoline (103aa):

The representative procedure $\mathbf{F}$ was followed using oxazoline $102 \mathrm{a}(80.6 \mathrm{mg}, 0.50 \mathrm{mmol})$ and aryl bromide 25a (140 mg, $0.75 \mathrm{mmol}$ ), yielding 103aa (131 mg, 98\%) as a colorless solid.

The representative procedure $\mathbf{F}$ was followed using oxazoline $102 \mathrm{a}(80.6 \mathrm{mg}, 0.50 \mathrm{mmol})$, aryl bromide $25 \mathrm{a}(140 \mathrm{mg}, 0.75 \mathrm{mmol})$ and $\left[\mathrm{RuCl}_{2}\left(p\right.\right.$-cymene) $\left.\left\{n-\mathrm{Bu}_{2} \mathrm{P}(\mathrm{OH})\right\}\right]$ (84c) (2.3 mg, $5 \mu \mathrm{mol}$, $1 \mathrm{~mol} \%$ ), yielding 103aa (127 mg, 88\%) as a colorless solid.

The representative procedure $\mathbf{F}$ was followed using oxazoline $102 \mathrm{a}(80.6 \mathrm{mg}, 0.50 \mathrm{mmol})$ and aryl chloride 30a (107 mg, $0.75 \mathrm{mmol}$ ), yielding 103aa (128 mg, 96\%) as a colorless solid.

The representative procedure $\mathbf{F}$ was followed using oxazoline $102 \mathrm{a}(80.6 \mathrm{mg}, 0.50 \mathrm{mmol})$ and aryl tosylate 106a (209 mg, $0.75 \mathrm{mmol}$ ), yielding 103aa (128 mg, 96\%) as a colorless solid.

M.p.: $169^{\circ} \mathrm{C} ;{ }^{1} \mathrm{H}$ NMR $\left(300 \mathrm{MHz}, \mathrm{CDCl}_{3}\right): \delta=7.39-7.30(\mathrm{~m}, 3 \mathrm{H}), 7.19(\mathrm{~d}, J=7.8 \mathrm{~Hz}, 2 \mathrm{H}), 6.91(\mathrm{~d}, J=$ $7.8 \mathrm{~Hz}, 2 \mathrm{H}), 4.17(\mathrm{t}, J=9.5 \mathrm{~Hz}, 2 \mathrm{H}), 3.88(\mathrm{t}, J=9.5 \mathrm{~Hz}, 2 \mathrm{H}), 3.84(\mathrm{~s}, 3 \mathrm{H}), 2.41(\mathrm{~s}, 3 \mathrm{H}) ;{ }^{13} \mathrm{C}$ NMR $(75 \mathrm{MHz}$, $\left.\mathrm{CDCl}_{3}\right): \delta=164.6\left(\mathrm{C}_{\mathrm{q}}\right), 158.8\left(\mathrm{C}_{\mathrm{q}}\right), 141.6\left(\mathrm{C}_{\mathrm{q}}\right), 137.4\left(\mathrm{C}_{\mathrm{q}}\right), 133.7\left(\mathrm{C}_{\mathrm{q}}\right), 129.5(\mathrm{CH}), 129.4(\mathrm{CH}), 128.6(\mathrm{CH})$, $128.1\left(\mathrm{C}_{\mathrm{q}}\right), 127.2(\mathrm{CH}), 113.5(\mathrm{CH}), 67.2\left(\mathrm{CH}_{2}\right), 55.2\left(\mathrm{CH}_{3}\right), 55.1\left(\mathrm{CH}_{2}\right), 19.8\left(\mathrm{CH}_{3}\right)$; IR $(\mathrm{ATR}): \tilde{v}=2992$, 
1880, 1669, 1608, 1510, 1478, 1330, 1301, 1180, $938 \mathrm{~cm}^{-1}$; MS (EI) $\mathrm{m} / \mathrm{z}$ (relative intensity) 267 (24) $[\mathrm{M}]^{+}, 266$ (100) [M-H] $, 251(8), 222$ (13), 152 (10); HR-MS (ESI): m/z calcd for $\left[\mathrm{C}_{17} \mathrm{H}_{17} \mathrm{NO}_{2}+\mathrm{H}\right]^{+}$ 268.1338, found 268.1332. The spectral data are in accordance with those reported in the literature. ${ }^{[90]}$<smiles>Cc1ccc(-c2cccc([N+](=O)[O-])c2C2=NCCO2)cc1</smiles>

2-(3,4'-Dimethyl-[1,1'-biphenyl]-2-yl)-4,5-dihydrooxazoline (103ab): The representative procedure F was followed using oxazoline $102 \mathrm{a}(80.6 \mathrm{mg}, 0.50 \mathrm{mmol})$ and 4-methylphenyl tosylate (106b) (197 mg, $0.75 \mathrm{mmol}$ ), yielding 103ab (120 mg, 96\%) as a colorless solid.

M.p.: $101{ }^{\circ} \mathrm{C} ;{ }^{1} \mathrm{H}$ NMR $\left(500 \mathrm{MHz}, \mathrm{CDCl}_{3}\right): \delta=7.38-7.29(\mathrm{~m}, 3 \mathrm{H}), 7.24-7.15(\mathrm{~m}, 4 \mathrm{H}), 4.16(\mathrm{t}, J=9.5 \mathrm{~Hz}$, 2H), $3.88(\mathrm{t}, J=9.5 \mathrm{~Hz}, 2 \mathrm{H}), 2.42(\mathrm{~s}, 3 \mathrm{H}), 2.38(\mathrm{~s}, 3 \mathrm{H}) ;{ }^{13} \mathrm{C}$ NMR $\left(125 \mathrm{MHz}, \mathrm{CDCl}_{3}\right): \delta=164.5\left(\mathrm{C}_{\mathrm{q}}\right), 141.9$ $\left(\mathrm{C}_{q}\right), 138.3\left(\mathrm{C}_{\mathrm{q}}\right), 137.4\left(\mathrm{C}_{\mathrm{q}}\right), 136.7\left(\mathrm{C}_{\mathrm{q}}\right), 129.4(\mathrm{CH}), 128.7(\mathrm{CH}), 128.7(\mathrm{CH}), 128.2(\mathrm{CH}), 128.1\left(\mathrm{C}_{\mathrm{q}}\right), 127.2$ (CH), $67.1\left(\mathrm{CH}_{2}\right), 55.1\left(\mathrm{CH}_{2}\right), 21.1\left(\mathrm{CH}_{3}\right), 19.8\left(\mathrm{CH}_{3}\right)$; IR (ATR): $\tilde{v}=2992,1880,1669,1608,1510,1478$, 1330, 1301, 1180, $938 \mathrm{~cm}^{-1}$. MS (El) m/z (relative intensity) 251 (22) [M] , 250 (100) [M-H] $]^{+}, 206(13)$, 165 (9). HR-MS (ESI): $m / z$ calcd for $\left[\mathrm{C}_{17} \mathrm{H}_{17} \mathrm{NO}+\mathrm{H}\right]^{+} 252.1383$, found 252.1387. The spectral data are in accordance with those reported in the literature. ${ }^{[29]}$<smiles>CC(=O)c1ccc(-c2cccc(C)c2C2=NCCO2)cc1</smiles>

1-\{2'-(4,5-Dihydrooxazolin-2-yl)-3'-methyl-[1,1'-biphenyl]-4-yl\}ethan-1-one (103ac): The representative procedure $\mathbf{F}$ was followed using oxazoline $102 \mathrm{a}(80.6 \mathrm{mg}, 0.50 \mathrm{mmol})$ and 4 chloroacetophenone (30c) (116 mg, $0.75 \mathrm{mmol}$ ), yielding 103ac (122 mg, 90\%) as a colorless solid.

M.p.: $90{ }^{\circ} \mathrm{C} ;{ }^{1} \mathrm{H}$ NMR $\left(500 \mathrm{MHz}, \mathrm{CDCl}_{3}\right): \delta=7.97(\mathrm{~d}, J=8.6 \mathrm{~Hz}, 2 \mathrm{H}), 7.50(\mathrm{~d}, J=8.6 \mathrm{~Hz}, 2 \mathrm{H}), 7.38(\mathrm{dd}, J$ $=7.7,7.7 \mathrm{~Hz}, 1 \mathrm{H}$ ), 7.26 (ddd, J = 7.7, 1.3, $0.7 \mathrm{~Hz}, 1 \mathrm{H}$ ), 7.21 (ddd, J=7.6, 1.2, $0.6 \mathrm{~Hz}, 1 \mathrm{H}), 4.15$ (t, $J=$ $9.6 \mathrm{~Hz}, 2 \mathrm{H}), 3.85(\mathrm{t}, J=9.6 \mathrm{~Hz}, 2 \mathrm{H}), 2.62(\mathrm{~s}, 3 \mathrm{H}), 2.42(\mathrm{~s}, 3 \mathrm{H}) ;{ }^{13} \mathrm{C} \mathrm{NMR}\left(125 \mathrm{MHz}, \mathrm{CDCl}_{3}\right): \delta=197.8\left(\mathrm{C}_{\mathrm{q}}\right)$, $164.1\left(C_{q}\right), 146.2\left(C_{q}\right), 140.8\left(C_{q}\right), 137.8\left(C_{q}\right), 135.7\left(C_{q}\right), 129.7(C H), 129.6(C H), 128.6(C H), 128.1(C H)$, $128.1\left(\mathrm{C}_{\mathrm{q}}\right), 127.0(\mathrm{CH}), 67.2\left(\mathrm{CH}_{2}\right), 55.2\left(\mathrm{CH}_{2}\right), 26.6\left(\mathrm{CH}_{3}\right), 19.8\left(\mathrm{CH}_{3}\right)$; IR (ATR): $\tilde{v}=2962,1680,1605$, 
1354, 1266, 1042, 936, 791, $601 \mathrm{~cm}^{-1}$; MS (ESI) m/z (relative intensity) 318 (4) [M+Na] $]^{+}, 280$ (100) $[\mathrm{M}+\mathrm{H}]^{+}, 149$ (4); HR-MS (ESI): $\mathrm{m} / z$ calcd for $\left[\mathrm{C}_{18} \mathrm{H}_{17} \mathrm{NO}_{2}+\mathrm{H}\right]^{+} 280.1332$, found 280.1332. The spectral data are in accordance with those reported in the literature. ${ }^{[90]}$<smiles>Cc1cccc(-c2ccsc2)c1C1=NCCO1</smiles>

103ad

2-\{2-Methyl-6-(thiophen-3-yl)phenyl\}-4,5-dihydrooxazoline (103ad): The representative procedure F was followed using oxazoline $102 \mathrm{a}(80.6 \mathrm{mg}, 0.50 \mathrm{mmol})$ and 3-chlorothiophene $(\mathbf{3 0 d})(88.9 \mathrm{mg}$, $0.75 \mathrm{mmol}$ ), yielding $103 \mathrm{ad}(48.7 \mathrm{mg}, 40 \%)$ as a yellowish oil.

${ }^{1} \mathrm{H}$ NMR $\left(500 \mathrm{MHz}, \mathrm{CDCl}_{3}\right): \delta=7.36-7.28(\mathrm{~m}, 3 \mathrm{H}), 7.30-7.24(\mathrm{~m}, 1 \mathrm{H}), 7.23-7.16(\mathrm{~m}, 2 \mathrm{H}), 4.23(\mathrm{t}, J=$ $9.6 \mathrm{~Hz}, 2 \mathrm{H}), 3.95(\mathrm{t}, J=9.4 \mathrm{~Hz}, 2 \mathrm{H}), 2.40(\mathrm{~s}, 3 \mathrm{H}) ;{ }^{13} \mathrm{C} \mathrm{NMR}\left(125 \mathrm{MHz}, \mathrm{CDCl}_{3}\right): \delta=164.5\left(\mathrm{C}_{\mathrm{q}}\right), 141.4\left(\mathrm{C}_{\mathrm{q}}\right)$, $137.5\left(\mathrm{C}_{\mathrm{q}}\right), 136.5\left(\mathrm{C}_{\mathrm{q}}\right), 129.5(\mathrm{CH}), 128.9(\mathrm{CH}), 128.2(\mathrm{CH}), 128.0\left(\mathrm{C}_{\mathrm{q}}\right), 126.9(\mathrm{CH}), 125.0(\mathrm{CH}), 122.3$ (CH), $67.3\left(\mathrm{CH}_{2}\right), 55.2\left(\mathrm{CH}_{2}\right), 19.7\left(\mathrm{CH}_{3}\right)$; IR (ATR): $\tilde{v}=2925,1664,1464,1238,1042,936,777,651 \mathrm{~cm}^{-}$ 1; MS (EI) $\mathrm{m} / \mathrm{z}$ (relative intensity) 243 (34) [M] ${ }^{+}, 242$ (100) [M-H] $]^{+} .198$ (24). HR-MS (ESI): $\mathrm{m} / z$ calcd for $\left[\mathrm{C}_{14} \mathrm{H}_{13} \mathrm{NOS}+\mathrm{H}\right]^{+} 244.0791$, found 244.0790 . The spectral data are in accordance with those reported in the literature. ${ }^{[26 a]}$<smiles>COc1ccc(-c2ccc(C)cc2C2=NCCO2)cc1</smiles>

2-(3'-Methoxy-4-methyl-[1,1'-biphenyl]-2-yl)-4,5-dihydrooxazoline (103ba): The representative procedure $\mathbf{F}$ was followed using oxazoline $103 \mathrm{~b}(80.6 \mathrm{mg}, 0.50 \mathrm{mmol}$ ) and 4-chloroanisole (30a) (107 mg, $0.75 \mathrm{mmol}$ ), yielding 103 ba (72 mg, 54\%) as a colorless oil.

${ }^{1} \mathrm{H}$ NMR $\left(500 \mathrm{MHz}, \mathrm{CDCl}_{3}\right): \delta=7.58(\mathrm{dd}, J=1.1,0.6 \mathrm{~Hz}, 1 \mathrm{H}), 7.34-7.27(\mathrm{~m}, 4 \mathrm{H}), 6.93(\mathrm{~d}, J=8.8 \mathrm{~Hz}, 2 \mathrm{H})$, $4.15(\mathrm{t}, J=9.4 \mathrm{~Hz}, 2 \mathrm{H}), 3.94(\mathrm{t}, J=9.4 \mathrm{~Hz}, 2 \mathrm{H}), 3.85(\mathrm{~s}, 3 \mathrm{H}), 2.40(\mathrm{~s}, 3 \mathrm{H}) ;{ }^{13} \mathrm{C} \mathbf{N M R}\left(125 \mathrm{MHz}, \mathrm{CDCl}_{3}\right): \delta=$ $166.6\left(\mathrm{C}_{\mathrm{q}}\right), 158.9\left(\mathrm{C}_{\mathrm{q}}\right), 138.7\left(\mathrm{C}_{\mathrm{q}}\right), 136.6\left(\mathrm{C}_{\mathrm{q}}\right), 133.8\left(\mathrm{C}_{\mathrm{q}}\right), 131.4(\mathrm{CH}), 130.8(\mathrm{CH}), 130.3(\mathrm{CH}), 129.5(\mathrm{CH})$, $127.3\left(\mathrm{C}_{\mathrm{q}}\right), 113.6(\mathrm{CH}), 67.9\left(\mathrm{CH}_{2}\right), 55.4\left(\mathrm{CH}_{3}\right), 55.1\left(\mathrm{CH}_{2}\right), 20.9\left(\mathrm{CH}_{3}\right)$; IR (ATR): $\tilde{v}=1649$, 1609, 1487, 1245, 1180, 1037, 822, $543 \mathrm{~cm}^{-1}$; MS (EI) $\mathrm{m} / \mathrm{z}$ (relative intensity) $267(21)[\mathrm{M}]^{+}, 266(100)[\mathrm{M}-\mathrm{H}]^{+}, 222$ (10); HR-MS (ESI): $m / z$ calcd for $\left[\mathrm{C}_{17} \mathrm{H}_{17} \mathrm{NO}_{2}+\mathrm{H}\right]^{+} 268.1332$, found 268.1335 . The spectral data are in accordance with those reported in the literature. ${ }^{[31]}$ 
<smiles>Cc1cccc(-c2ccc(F)cc2)c1C1=NCCO1</smiles>

2-(4'-Fluoro-3-methyl-[1,1'-biphenyl]-2-yl)-4,5-dihydrooxazoline (103ae): The representative procedure $\mathbf{F}$ was followed using oxazoline $102 \mathrm{a}(80.6 \mathrm{mg}, 0.50 \mathrm{mmol})$ and 4-fluorophenyl tosylate (106e) (200 mg, $0.75 \mathrm{mmol}$ ), yielding 103ae (119 mg, 94\%) as a colorless solid.

M.p.: $107^{\circ} \mathrm{C} ;{ }^{1} \mathrm{H}$ NMR $\left(500 \mathrm{MHz}, \mathrm{CDCl}_{3}\right): \delta=7.40-7.33(\mathrm{~m}, 3 \mathrm{H}), 7.23(\mathrm{~d}, J=7.2 \mathrm{~Hz}, 1 \mathrm{H}), 7.18(\mathrm{~d}, J=$ $7.6 \mathrm{~Hz}, 1 \mathrm{H}), 7.08-7.03(\mathrm{~m}, 2 \mathrm{H}), 4.15(\mathrm{t}, J=9.6 \mathrm{~Hz}, 2 \mathrm{H}), 3.87(\mathrm{t}, J=9.6 \mathrm{~Hz}, 2 \mathrm{H}), 2.41(\mathrm{~s}, 3 \mathrm{H}) ;{ }^{13} \mathrm{C}$ NMR $\left(125 \mathrm{MHz}, \mathrm{CDCl}_{3}\right): \delta=164.3\left(\mathrm{C}_{\mathrm{q}}\right), 162.3\left(\mathrm{~d}, J=246 \mathrm{~Hz}, \mathrm{C}_{\mathrm{q}}\right), 140.9\left(\mathrm{C}_{\mathrm{q}}\right), 137.6\left(\mathrm{C}_{\mathrm{q}}\right), 137.2\left(\mathrm{~d}, J=3 \mathrm{~Hz}, \mathrm{C}_{\mathrm{q}}\right)$, 130.1 (d, J = 8 Hz, CH), $129.5(\mathrm{CH}), 129.1(\mathrm{CH}), 128.3\left(\mathrm{C}_{\mathrm{q}}\right), 127.1(\mathrm{CH}), 114.9$ (d, J = $\left.21 \mathrm{~Hz}, \mathrm{CH}\right), 67.2$ $\left(\mathrm{CH}_{2}\right), 55.1\left(\mathrm{CH}_{2}\right), 19.8\left(\mathrm{CH}_{3}\right) ;{ }^{19} \mathrm{~F}$ NMR $\left(282 \mathrm{MHz}, \mathrm{CDCl}_{3}\right): \delta=-(115.7-115.8)(\mathrm{m})$; IR (ATR): $\tilde{v}=1661$, 1509, 1461, 1216, 1036, 932, 844, 792, 759, $579 \mathrm{~cm}^{-1}$; MS (EI) $\mathrm{m} / z$ (relative intensity) 255 (21) [M] ${ }^{+}$, $254(100)[\mathrm{M}-\mathrm{H}]^{+}, 210$ (26), 183 (21); HR-MS (ESI): m/z calcd for $\left[\mathrm{C}_{16} \mathrm{H}_{14} \mathrm{NOF}+\mathrm{H}\right]^{+}$256.1132, found 256.1140. The spectral data are in accordance with those reported in the literature. ${ }^{[161]}$<smiles>COc1cccc(-c2ccc(C(F)(F)F)cc2)c1C1=NCCO1</smiles>

2-\{3-Methyl-4'-(trifluoromethyl)-[1,1'-biphenyl]-2-yl\}-4,5-dihydrooxazole $\quad$ (103af): The representative procedure $\mathbf{F}$ was followed using oxazoline $102 \mathrm{a}(80.6 \mathrm{mg}, 0.50 \mathrm{mmol})$ and 1-chloro-4(trifluoromethyl)benzene (30f) (135 mg, $0.75 \mathrm{mmol})$, yielding 103af $(132 \mathrm{mg}, 90 \%)$ as a pale yellow oil.

${ }^{1} \mathrm{H}$ NMR $\left(300 \mathrm{MHz}, \mathrm{CDCl}_{3}\right): \delta=7.66-7.60(\mathrm{~m}, 2 \mathrm{H}), 7.55-7.50(\mathrm{~m}, 2 \mathrm{H}), 7.39(\mathrm{dd}, J=7.6,7.6 \mathrm{~Hz}, 1 \mathrm{H})$, 7.30-7.24 (m, 1H), 7.20 (ddd, $J=7.6,1.3,0.5 \mathrm{~Hz}, 1 \mathrm{H}$ ), 4.15 (td, $J=9.4,1.0 \mathrm{~Hz}, 2 \mathrm{H}$ ), 3.87 (td, $J=9.5$, $1.0 \mathrm{~Hz}, 2 \mathrm{H}), 2.43(\mathrm{~s}, 3 \mathrm{H}) ;{ }^{13} \mathrm{C}$ NMR $\left(125 \mathrm{MHz}, \mathrm{CDCl}_{3}\right): \delta=164.2\left(\mathrm{C}_{\mathrm{q}}\right), 145.0\left(\mathrm{C}_{\mathrm{q}}\right), 140.7\left(\mathrm{C}_{\mathrm{q}}\right), 138.0\left(\mathrm{C}_{\mathrm{q}}\right)$, $129.9(\mathrm{CH}), 129.8(\mathrm{CH}), 129.4\left(\mathrm{q}, J=32.4 \mathrm{~Hz}, \mathrm{C}_{\mathrm{q}}\right), 128.9(\mathrm{CH}), 128.3\left(\mathrm{C}_{\mathrm{q}}\right), 127.2(\mathrm{CH}), 125.1$ (q, $J=$ $3.8 \mathrm{~Hz}, \mathrm{CH}), 124.4(\mathrm{q}, J=271.9 \mathrm{~Hz}, \mathrm{C} q), 67.4\left(\mathrm{CH}_{2}\right), 55.3\left(\mathrm{CH}_{2}\right), 20.0\left(\mathrm{CH}_{2}\right) ;{ }^{19} \mathrm{~F} \mathrm{NMR}\left(282 \mathrm{MHz}, \mathrm{CDCl}_{3}\right): \delta$ $=-62.4$ (s); IR (ATR): $\tilde{v}=1662,1321,1163,1110,1062,1041,936,844,790,608 \mathrm{~cm}^{-1}$; MS (EI) $\mathrm{m} / \mathrm{z}$ (relative intensity) 306 (29) [M+H] $]^{+}, 275$ (7), 155 (91), 91 (100), 65 (16); HR-MS (ESI): m/z calcd for 
$\left[\mathrm{C}_{17} \mathrm{H}_{14} \mathrm{NOF}_{3}+\mathrm{H}\right]^{+} 306.1100$, found 306.1102. The spectral data are in accordance with those reported in the literature. ${ }^{[161]}$<smiles>COC(=O)c1ccc(-c2cccc(C)c2C2=NCCO2)cc1</smiles>

Methyl 2'-(4,5-dihydrooxazolin-2-yl)-3'-methyl-[1,1'-biphenyl]-4-carboxylate (103ag): The representative procedure $\mathbf{F}$ was followed using oxazoline $102 \mathrm{a}(80.6 \mathrm{mg}, 0.50 \mathrm{mmol})$ and methyl 4(tosyloxy)benzoate (106g) (230 mg, $0.75 \mathrm{mmol})$, yielding 103ag (119 mg, 80\%) as a colorless solid.

M.p.: $12{ }^{\circ} \mathrm{C} ;{ }^{1} \mathrm{H}$ NMR $\left(500 \mathrm{MHz}, \mathrm{CDCl}_{3}\right): \delta=8.04(\mathrm{~d}, J=8.6 \mathrm{~Hz}, 2 \mathrm{H}), 7.48(\mathrm{~d}, J=8.6 \mathrm{~Hz}, 2 \mathrm{H}), 7.38$ (dd, $J$ = 7.6, 7.6 Hz, 1H), 7.28-7.24 (m, 1H), 7.23-7.20 (m, 1H), $4.13(\mathrm{t}, J=9.6 \mathrm{~Hz}, 2 \mathrm{H}), 3.93(\mathrm{~s}, 3 \mathrm{H}), 3.85(\mathrm{t}, J$ $=9.6 \mathrm{~Hz}, 2 \mathrm{H}), 2.42(\mathrm{~s}, 3 \mathrm{H}) ;{ }^{13} \mathrm{C} \mathrm{NMR}\left(125 \mathrm{MHz}, \mathrm{CDCl}_{3}\right): \delta=167.0\left(\mathrm{C}_{\mathrm{q}}\right), 164.1\left(\mathrm{C}_{\mathrm{q}}\right), 146.0\left(\mathrm{C}_{\mathrm{q}}\right), 141.0\left(\mathrm{C}_{\mathrm{q}}\right)$, $137.8\left(\mathrm{C}_{\mathrm{q}}\right), 129.7(\mathrm{CH}), 129.6(\mathrm{CH}), 129.3(\mathrm{CH}), 128.8\left(\mathrm{C}_{\mathrm{q}}\right), 128.5(\mathrm{CH}), 128.1\left(\mathrm{C}_{\mathrm{q}}\right), 127.0(\mathrm{CH}), 67.2$ $\left(\mathrm{CH}_{2}\right), 55.2\left(\mathrm{CH}_{2}\right), 52.1\left(\mathrm{CH}_{3}\right), 19.8\left(\mathrm{CH}_{3}\right) ; \operatorname{IR}(\mathrm{ATR}): \tilde{v}=1719,1634,1435,1275,1106,1043,769,730$, $707 \mathrm{~cm}^{-1}$; MS (EI) m/z (relative intensity) 295 (4) [M]+, 278 (100), 236 (13), 165 (12); HR-MS (ESI): m/z calcd for $\left[\mathrm{C}_{18} \mathrm{H}_{17} \mathrm{NO}_{3}+\mathrm{H}\right]^{+} 296.1281$, found 296.1276. The spectral data are in accordance with those reported in the literature. ${ }^{[90]}$<smiles>COc1cccc(-c2cccc(C(C)=O)c2)c1C1=NCCO1</smiles>

1-\{2'-(4,5-Dihydrooxazolin-2-yl)-3'-methyl-[1,1'-biphenyl]-3-yl\}ethan-1-one $\quad$ (103ah): The representative procedure $\mathbf{F}$ was followed using oxazoline $102 \mathrm{a}(80.6 \mathrm{mg}, 0.50 \mathrm{mmol})$ and 3 acetylphenyl tosylate $(\mathbf{1 0 6 h})(218 \mathrm{mg}, 0.75 \mathrm{mmol})$, yielding $103 \mathrm{ah}(85.4 \mathrm{mg}, 62 \%)$ as a slightly yellow solid.

M.p.: $110{ }^{\circ} \mathrm{C} ;{ }^{1} \mathrm{H}$ NMR $\left(500 \mathrm{MHz}, \mathrm{CDCl}_{3}\right): \delta=8.05-8.02(\mathrm{~m}, 1 \mathrm{H}), 7.92(\mathrm{~d}, J=8.0 \mathrm{~Hz}, 1 \mathrm{H}), 7.62(\mathrm{~d}, J=$ $8.0 \mathrm{~Hz}, 1 \mathrm{H}), 7.47(\mathrm{dd}, J=7.9,7.9 \mathrm{~Hz}, 1 \mathrm{H}), 7.38(\mathrm{dd}, J=7.7,7.7 \mathrm{~Hz}, 1 \mathrm{H}), 7.28-7.20(\mathrm{~m}, 2 \mathrm{H}), 4.16(\mathrm{t}, J=$ $9.5 \mathrm{~Hz}, 2 \mathrm{H}), 3.84(\mathrm{t}, J=9.5 \mathrm{~Hz}, 2 \mathrm{H}), 2.60(\mathrm{~s}, 3 \mathrm{H}), 2.42(\mathrm{~s}, 3 \mathrm{H}) ;{ }^{13} \mathrm{C}$ NMR $\left(125 \mathrm{MHz}, \mathrm{CDCl}_{3}\right): \delta=197.9\left(\mathrm{C}_{\mathrm{q}}\right)$, $164.2\left(C_{q}\right), 141.5\left(C_{q}\right), 140.8\left(C_{q}\right), 137.7\left(C_{q}\right), 136.9\left(C_{q}\right), 133.0(\mathrm{CH}), 129.6(C H), 129.4(C H), 128.6(C H)$, 128.3 $(\mathrm{CH}), 128.2\left(\mathrm{C}_{\mathrm{q}}\right), 127.1(\mathrm{CH}), 126.9(\mathrm{CH}), 67.2\left(\mathrm{CH}_{2}\right), 55.2\left(\mathrm{CH}_{2}\right), 26.6\left(\mathrm{CH}_{3}\right), 19.8\left(\mathrm{CH}_{3}\right)$; IR (ATR): $\tilde{v}$ $=1681,1658,1599,1237,1040,935,897,788 \mathrm{~cm}^{-1}$; MS (EI) $\mathrm{m} / z$ (relative intensity) 279 (28) [M] 
278 (100) $[\mathrm{M}-\mathrm{H}]^{+} ; \mathrm{HR}-\mathrm{MS}(\mathrm{ESI}): \mathrm{m} / \mathrm{z}$ calcd for $\left[\mathrm{C}_{18} \mathrm{H}_{17} \mathrm{NO}_{2}+\mathrm{H}\right]^{+} 280.1332$, found 280.1335 . The spectral data are in accordance with those reported in the literature. ${ }^{[161]}$

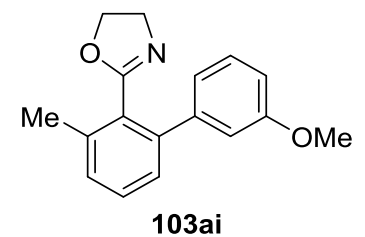

2-(3'-Methoxy-3-methyl-[1,1'-biphenyl]-2-yl)-4,5-dihydrooxazoline (103ai): The representative procedure $\mathbf{F}$ was followed using oxazoline $102 \mathrm{a}(80.6 \mathrm{mg}, 0.50 \mathrm{mmol})$ and 1-chloro-3methoxybenzene (30i) (107 mg, $0.75 \mathrm{mmol}$ ), yielding 103ai (131 mg, 98\%) as a colorless oil.

${ }^{1} \mathrm{H}$ NMR $\left(500 \mathrm{MHz}, \mathrm{CDCl}_{3}\right): \delta=7.37-7.33(\mathrm{~m}, 1 \mathrm{H}), 7.30-7.25(\mathrm{~m}, 1 \mathrm{H}), 7.24-7.20(\mathrm{~m}, 2 \mathrm{H}), 7.00(\mathrm{ddd}, J=$ 7.5, 1.6, 1.0 Hz, 1H), 6.99-6.98 (m, 1H), $6.87(\mathrm{ddd}, J=8.3,2.6,1.0 \mathrm{~Hz}, 1 \mathrm{H}), 4.16(\mathrm{t}, J=9.2 \mathrm{~Hz}, 2 \mathrm{H}), 3.88$ $(\mathrm{t}, J=9.7 \mathrm{~Hz}, 2 \mathrm{H}), 3.81(\mathrm{~s}, 3 \mathrm{H}), 2.42(\mathrm{~s}, 3 \mathrm{H}) ;{ }^{13} \mathrm{C} \mathrm{NMR}\left(125 \mathrm{MHz}, \mathrm{CDCl}_{3}\right): \delta=164.7\left(\mathrm{C}_{\mathrm{q}}\right), 159.5\left(\mathrm{C}_{\mathrm{q}}\right)$, $142.8\left(\mathrm{C}_{\mathrm{q}}\right), 142.1\left(\mathrm{C}_{\mathrm{q}}\right), 137.7\left(\mathrm{C}_{\mathrm{q}}\right), 129.7(\mathrm{CH}), 129.3(\mathrm{CH}), 129.2(\mathrm{CH}), 128.3\left(\mathrm{C}_{\mathrm{q}}\right), 127.4(\mathrm{CH}), 121.1$ $(\mathrm{CH}), 113.9(\mathrm{CH}), 113.4(\mathrm{CH}), 67.4\left(\mathrm{CH}_{2}\right), 55.3\left(\mathrm{CH}_{3}\right), 55.3\left(\mathrm{CH}_{2}\right), 19.9\left(\mathrm{CH}_{3}\right)$; IR (ATR): $\tilde{v}=2930,1632$, 1579, 1465, 1424, 1299, 1226, 1043, 780, $699 \mathrm{~cm}^{-1}$; MS (EI) m/z (relative intensity) 267 (20) [M], 266 (100) $[\mathrm{M}-\mathrm{H}]^{+}, 222$ (8),165 (7), 152 (7); HR-MS (ESI): m/z calcd for $\left[\mathrm{C}_{17} \mathrm{H}_{17} \mathrm{NO}_{2}+\mathrm{H}\right]^{+}$268.1332, found 268.1335. The spectral data are in accordance with those reported in the literature. ${ }^{[161]}$<smiles>COc1ccccc1-c1ccccc1C1=NCCO1</smiles>

2-(2'-Methoxy-3-methyl-[1,1'-biphenyl]-2-yl)-4,5-dihydrooxazoline (103aj): The representative procedure $\mathbf{F}$ was followed using oxazoline $102 \mathrm{a}(80.6 \mathrm{mg}, 0.50 \mathrm{mmol})$ and 2-chloroanisole (30j) (107 mg, $0.75 \mathrm{mmol}$ ), yielding 103aj $(79.2 \mathrm{mg}, 60 \%$ ) as a pale yellow solid.

M.p.: $62{ }^{\circ} \mathrm{C} ;{ }^{1} \mathrm{H}$ NMR $\left(400 \mathrm{MHz}, \mathrm{CDCl}_{3}\right): \delta=7.36-7.31(\mathrm{~m}, 1 \mathrm{H}), 7.29$ (ddd, $\left.J=8.2,7.4,1.8 \mathrm{~Hz}, 1 \mathrm{H}\right)$, 7.23-7.18 (m, 3H), 6.95 (ddd, $J=7.5,7.5,1.1 \mathrm{~Hz}, 1 \mathrm{H}), 6.93-6.90(\mathrm{~m}, 1 \mathrm{H}), 4.05(\mathrm{t}, J=9.5 \mathrm{~Hz}, 2 \mathrm{H}), 3.79$ $(\mathrm{d}, J=9.5 \mathrm{~Hz}, 2 \mathrm{H}), 3.75(\mathrm{~s}, 3 \mathrm{H}), 2.43(\mathrm{~s}, 3 \mathrm{H}) ;{ }^{13} \mathrm{C} \mathrm{NMR}\left(100 \mathrm{MHz}, \mathrm{CDCl}_{3}\right): \delta=164.5\left(\mathrm{C}_{\mathrm{q}}\right), 156.5\left(\mathrm{C}_{\mathrm{q}}\right)$, $138.7\left(\mathrm{C}_{\mathrm{q}}\right), 137.2\left(\mathrm{C}_{\mathrm{q}}\right), 130.7(\mathrm{CH}), 130.1\left(\mathrm{C}_{\mathrm{q}}\right), 129.0(\mathrm{CH}), 129.0(\mathrm{CH}), 128.9\left(\mathrm{C}_{\mathrm{q}}\right), 128.6(\mathrm{CH}), 128.2$ (CH), $120.1(\mathrm{CH}), 110.6(\mathrm{CH}), 66.9\left(\mathrm{CH}_{2}\right), 55.6\left(\mathrm{CH}_{3}\right), 55.1\left(\mathrm{CH}_{2}\right), 20.1\left(\mathrm{CH}_{3}\right)$; IR (ATR): $\tilde{v}=1626,1464$, 1240, 1045, 906, 724, $645 \mathrm{~cm}^{-1}$; MS (EI) $\mathrm{m} / z$ (relative intensity) 267 (3) [M] ${ }^{+}, 236$ (100), 192 (100), 
165 (15), 152 (10); HR-MS (ESI): $\mathrm{m} / z$ calcd for $\left[\mathrm{C}_{17} \mathrm{H}_{17} \mathrm{NO}_{2}+\mathrm{H}\right]^{+} 268.1332$, found 268.1329 . The spectral data are in accordance with those reported in the literature. ${ }^{[90]}$<smiles>COc1ccc(-c2cccc(-c3ccc(OC)cc3)c2C2=NCCO2)cc1</smiles>

$103 \mathrm{ca}$

2-(4,4"-Dimethoxy-[1,1':3',1"-terphenyl]-2'-yl)-4,5-dihydrooxazoline (103ca): The representative procedure $\mathbf{F}$ was followed using oxazoline $102 \mathrm{c}(73.6 \mathrm{mg}, 0.50 \mathrm{mmol}, 1.0$ equiv) and 4-bromoanisole (25a) (280 mg, $1.5 \mathrm{mmol}, 3.0$ equiv), yielding $103 \mathrm{ca}$ (176 mg, 98\%) as a colorless solid.

M.p.: $159^{\circ} \mathrm{C} ;{ }^{1} \mathrm{H}$ NMR $\left(500 \mathrm{MHz}, \mathrm{CDCl}_{3}\right): \delta=7.47(\mathrm{dd}, J=8.1,7.3 \mathrm{~Hz}, 1 \mathrm{H}), 7.41-7.37(\mathrm{~m}, 4 \mathrm{H}), 7.34(\mathrm{~d}, J$ $=7.7 \mathrm{~Hz}, 2 \mathrm{H}), 6.94-6.89(\mathrm{~m}, 4 \mathrm{H}), 3.94(\mathrm{t}, J=9.5 \mathrm{~Hz}, 2 \mathrm{H}), 3.84(\mathrm{~s}, 6 \mathrm{H}), 3.63(\mathrm{t}, J=9.4 \mathrm{~Hz}, 2 \mathrm{H}) ;{ }^{13} \mathrm{C} \mathrm{NMR}$ $\left(125 \mathrm{MHz}, \mathrm{CDCl}_{3}\right): \delta=164.2\left(\mathrm{C}_{\mathrm{q}}\right), 158.9\left(\mathrm{C}_{\mathrm{q}}\right), 141.9\left(\mathrm{C}_{\mathrm{q}}\right), 133.4\left(\mathrm{C}_{\mathrm{q}}\right), 129.7(\mathrm{CH}), 129.4(\mathrm{CH}), 128.5(\mathrm{CH})$, $127.5\left(\mathrm{C}_{\mathrm{q}}\right), 113.4(\mathrm{CH}), 67.2\left(\mathrm{CH}_{2}\right), 55.2\left(\mathrm{CH}_{3}\right), 55.0\left(\mathrm{CH}_{2}\right)$; IR (ATR): $\tilde{v}=2999,1609,1513,1457,1245$, 1179, 1037, 835, $804 \mathrm{~cm}^{-1}$; MS (EI) m/z (relative intensity) 359 (22) [M] $]^{+}, 358[\mathrm{M}-\mathrm{H}]^{+}$(100), 179 (6); HR-MS (ESI): $\mathrm{m} / \mathrm{z}$ calcd for $\left[\mathrm{C}_{23} \mathrm{H}_{21} \mathrm{NO}_{3}+\mathrm{H}\right]^{+} 360.1594$, found 360.1595 . The spectral data are in accordance with those reported in the literature. ${ }^{[162]}$<smiles>Cc1cccc(-c2ccc(-c3cccc(C)c3C3=NCCO3)cc2)c1C1=NCCO1</smiles>

2,2'-(3,3"--Dimethyl-[1,1':4',1"-terphenyl]-2,2"-diyl)bis(4,5-dihydrooxazoline)（103ak'): The representative procedure $\mathbf{F}$ was followed using oxazoline $102 \mathrm{a}(80.6 \mathrm{mg}, 0.50 \mathrm{mmol}, 1.0$ equiv) and 1,4-dichlorobenzene (30k') (37.0 mg, $0.25 \mathrm{mmol}, 1.5$ equiv). Column chromatography on silica gel $\left(\mathrm{CH}_{2} \mathrm{Cl}_{2} / \mathrm{MeOH} 95 / 5\right)$ yielded 103ak' (81.0 mg, 84\%) as a colorless solid.

M.p.: $212{ }^{\circ} \mathrm{C}$; ${ }^{1} \mathrm{H}$ NMR $\left(500 \mathrm{MHz}, \mathrm{CDCl}_{3}\right): \delta=7.42(\mathrm{~s}, 4 \mathrm{H}), 7.37$ (dd, $\left.J=7.7,7.7 \mathrm{~Hz}, 2 \mathrm{H}\right), 7.28-7.25(\mathrm{~m}$, $2 \mathrm{H}), 7.23(\mathrm{dd}, J=7.6,1.1 \mathrm{~Hz}, 2 \mathrm{H}), 4.15(\mathrm{t}, J=9.5 \mathrm{~Hz}, 4 \mathrm{H}), 3.86(\mathrm{t}, J=9.5 \mathrm{~Hz}, 4 \mathrm{H}), 2.43(\mathrm{~s}, 6 \mathrm{H}) ;{ }^{13} \mathrm{C} \mathrm{NMR}$ (125 MHz, $\mathrm{CDCl}_{3}$ ): $\delta=164.5\left(\mathrm{C}_{\mathrm{q}}\right), 141.8\left(\mathrm{C}_{\mathrm{q}}\right), 140.0\left(\mathrm{C}_{\mathrm{q}}\right), 137.5\left(\mathrm{C}_{\mathrm{q}}\right), 129.5(\mathrm{CH}), 129.0(\mathrm{CH}), 128.2\left(\mathrm{C}_{\mathrm{q}}\right)$, $128.1(\mathrm{CH}), 127.1(\mathrm{CH}), 67.2\left(\mathrm{CH}_{2}\right), 55.2\left(\mathrm{CH}_{2}\right), 19.8\left(\mathrm{CH}_{3}\right)$; IR (ATR): $\tilde{v}=1656,1250,1041,933,787$, 690, $593 \mathrm{~cm}^{-1}$; MS (EI) m/z (relative intensity) 396 (36) [M] ${ }^{+}, 395$ (100) [M-H] ${ }^{+}$. HR-MS (ESI): m/z calcd for $\left[\mathrm{C}_{26} \mathrm{H}_{24} \mathrm{~N}_{2} \mathrm{O}_{2}+\mathrm{H}\right]^{+}$397.1911, found 397.1914. 
<smiles>Cc1cccc(-c2ccc(OCCNC(=O)c3ccccc3)cc2)c1C1=NCCO1</smiles>

2'-(4,5-dihydrooxazolin-2-yl)-3'-methyl-[1,1'-biphenyl]-4-yl 4-methylbenzenesulfonate (103au) and 2-(4'-chloro-3-methyl-[1,1'-biphenyl]-2-yl)-4,5-dihydrooxazoline (103ak): The representative procedure $\mathbf{F}$ was followed using oxazoline $102 \mathrm{a}(80.6 \mathrm{mg}, 0.50 \mathrm{mmol}, 1.0$ equiv) and 4-chlorophenyl 4-methylbenzenesulfonate (106k) (211 mg, 0.75 mmol, 1.5 equiv), yielding 103au (118 mg, 58\%) and 103ak (19 mg, 14\%) as a colorless solid and oil, respectively.<smiles>Cc1cccc(-c2ccc(O)cc2)c1C1=NCCO1</smiles>

2'-(4,5-Dihydrooxazolin-2-yl)-3'-methyl-[1,1'-biphenyl]-4-yl 4-methylbenzenesulfonate (103au):

M.p.: $157^{\circ} \mathrm{C}$; ${ }^{1} \mathrm{H}$ NMR $\left(500 \mathrm{MHz}, \mathrm{CDCl}_{3}\right): \delta=7.72(\mathrm{~d}, J=8.5 \mathrm{~Hz}, 2 \mathrm{H}), 7.36-7.28(\mathrm{~m}, 5 \mathrm{H}), 7.22(\mathrm{~d}, J=$ $7.7 \mathrm{~Hz}, 1 \mathrm{H}), 7.15(\mathrm{~d}, J=7.7 \mathrm{~Hz}, 1 \mathrm{H}), 6.98(\mathrm{~d}, J=8.5 \mathrm{~Hz}, 2 \mathrm{H}), 4.10(\mathrm{t}, J=9.6 \mathrm{~Hz}, 2 \mathrm{H}), 3.82(\mathrm{t}, J=9.4 \mathrm{~Hz}$, 2H), $2.44(\mathrm{~s}, 3 \mathrm{H}), 2.39(\mathrm{~s}, 3 \mathrm{H}) ;{ }^{13} \mathrm{C}$ NMR $\left(125 \mathrm{MHz}, \mathrm{CDCl}_{3}\right): \delta=164.4\left(\mathrm{C}_{\mathrm{q}}\right), 149.0\left(\mathrm{C}_{\mathrm{q}}\right), 145.6\left(\mathrm{C}_{\mathrm{q}}\right), 140.8$ $\left(\mathrm{C}_{\mathrm{q}}\right), 140.4\left(\mathrm{C}_{\mathrm{q}}\right), 137.9\left(\mathrm{C}_{\mathrm{q}}\right), 132.7\left(\mathrm{C}_{\mathrm{q}}\right), 129.9(\mathrm{CH}), 129.8(\mathrm{CH}), 129.7(\mathrm{CH}), 129.6(\mathrm{CH}), 128.7(\mathrm{CH})$, 128.4 $\left(\mathrm{C}_{\mathrm{q}}\right), 127.2(\mathrm{CH}), 122.1(\mathrm{CH}), 67.3\left(\mathrm{CH}_{2}\right), 55.2\left(\mathrm{CH}_{2}\right), 21.7\left(\mathrm{CH}_{3}\right), 19.8\left(\mathrm{CH}_{3}\right)$; IR (ATR): $\tilde{v}=1653$, $1368,1174,1149,854,795,756,660,578,550 \mathrm{~cm}^{-1}$; MS (EI) $\mathrm{m} / \mathrm{z}$ (relative intensity) 407 (14) [M] 406 (32) [M-H] $]^{+}, 252$ (100), 91.1 (21); HR-MS (ESI): m/z calcd for $\left[\mathrm{C}_{23} \mathrm{H}_{21} \mathrm{NO}_{4} \mathrm{~S}+\mathrm{H}\right]^{+}$408.1264, found 408.1264<smiles>Cc1cccc(-c2ccc(Cl)cc2)c1C1=NCCO1</smiles>

\section{2-(4'-Chloro-3-methyl-[1,1'-biphenyl]-2-yl)-4,5-dihydrooxazoline (103ak):}

${ }^{1} \mathrm{H}$ NMR $\left(300 \mathrm{MHz}, \mathrm{CDCl}_{3}\right): \delta=7.36-7.30(\mathrm{~m}, 5 \mathrm{H}), 7.23-7.19(\mathrm{~m}, 1 \mathrm{H}), 7.17-7.13(\mathrm{~m}, 1 \mathrm{H}), 4.14(\mathrm{t}, J=$ $9.5 \mathrm{~Hz}, 2 \mathrm{H}), 3.85(\mathrm{t}, J=9.5 \mathrm{~Hz}, 2 \mathrm{H}), 2.39(\mathrm{~s}, 3 \mathrm{H}) ;{ }^{13} \mathrm{C} \mathrm{NMR}\left(75 \mathrm{MHz}, \mathrm{CDCl}_{3}\right): \delta=164.4\left(\mathrm{C}_{\mathrm{q}}\right), 140.9\left(\mathrm{C}_{\mathrm{q}}\right)$, $139.8\left(\mathrm{C}_{\mathrm{q}}\right), 137.8\left(\mathrm{C}_{\mathrm{q}}\right), 133.4\left(\mathrm{C}_{\mathrm{q}}\right), 129.9(\mathrm{CH}), 129.7(\mathrm{CH}), 129.5(\mathrm{CH}), 128.3(\mathrm{CH}), 128.3\left(\mathrm{C}_{\mathrm{q}}\right), 127.2$ (CH), $67.4\left(\mathrm{CH}_{2}\right), 55.3\left(\mathrm{CH}_{2}\right), 20.0\left(\mathrm{CH}_{3}\right)$; IR (ATR): $\tilde{v}=1656,1491,1450,1261,1091,1039,1013,800$, 
759, $699 \mathrm{~cm}^{-1}$; MS (EI) m/z (relative intensity) 271 (44) [M] , 270 (100), 226 (17), 191 (15), 165 (15); HR-MS (ESI): $m / z$ calcd for $\left[\mathrm{C}_{16} \mathrm{H}_{14} \mathrm{NOCl}+\mathrm{H}\right]^{+} 272.0837$, found 272.0838 .

\subsubsection{PA-Ruthenium(II)-catalyzed C-H Arylation of Triazole}<smiles>CCCCc1cn(-c2c(OC)cccc2-c2ccc(OC)cc2)nn1</smiles>

$26 a$

4-n-Butyl-1-(4'-methoxy-3-methyl-[1,1'-biphenyl]-2-yl)-1H-1,2,3-triazole (26a): A mixture of triazole 24 (108 mg, $0.50 \mathrm{mmol}, 1.0$ equiv), aryl bromide 25a ( $140 \mathrm{mg}, 0.75 \mathrm{mmol}, 1.5$ equiv), $\mathrm{K}_{2} \mathrm{CO}_{3}$ (138 mg, $1.00 \mathrm{mmol}, 2.0$ equiv) and $\left[\mathrm{RuCl}_{2}(p\right.$-cymene $\left.)\{t-\mathrm{BuPhP}(\mathrm{OH})\}\right](12.2 \mathrm{mg}, 25 \mu \mathrm{mol}, 5 \mathrm{~mol} \%)$ in toluene $(2.0 \mathrm{~mL})$ was heated in a sealed tube to $120^{\circ} \mathrm{C}$ for $18 \mathrm{~h}$. Filtration over celite and purification by column chromatography on silica gel ( $n$-hexane/EtOAc: 6/1) yielded $\mathbf{2 6 a}(116 \mathrm{mg}, \mathbf{7 2 \%}$ ) as a colorless oil.

${ }^{1} \mathrm{H}$ NMR $\left(300 \mathrm{MHz}, \mathrm{CDCl}_{3}\right): \delta=7.44(\mathrm{dd}, J=8.0,7.1 \mathrm{~Hz}, 1 \mathrm{H}), 7.34-7.29(\mathrm{~m}, 2 \mathrm{H}), 7.02-6.93(\mathrm{~m}, 3 \mathrm{H})$, 6.80-6.66 (m, 2H), $3.75(\mathrm{~s}, 3 \mathrm{H}), 2.65(\mathrm{t}, J=7.5 \mathrm{~Hz}, 2 \mathrm{H}), 2.12(\mathrm{~s}, 3 \mathrm{H}), 1.61-1.47(\mathrm{~m}, 2 \mathrm{H}), 1.31-1.12(\mathrm{~m}$, $2 \mathrm{H}), 0.85(\mathrm{t}, J=7.2 \mathrm{~Hz}, 3 \mathrm{H}) ;{ }^{13} \mathrm{C} \mathrm{NMR}\left(100 \mathrm{MHz}, \mathrm{CDCl}_{3}\right): \delta=159.2\left(\mathrm{C}_{\mathrm{q}}\right), 148.0\left(\mathrm{C}_{\mathrm{q}}\right), 139.3\left(\mathrm{C}_{\mathrm{q}}\right), 136.3$ $\left(\mathrm{C}_{\mathrm{q}}\right), 134.8\left(\mathrm{C}_{\mathrm{q}}\right), 130.2\left(\mathrm{C}_{\mathrm{q}}\right), 129.9(\mathrm{CH}), 129.8(\mathrm{CH}), 129.5(\mathrm{CH}), 128.3(\mathrm{CH}), 123.2(\mathrm{CH}), 113.8(\mathrm{CH}), 55.3$ $\left(\mathrm{CH}_{3}\right), 31.6\left(\mathrm{CH}_{2}\right), 25.1\left(\mathrm{CH}_{2}\right), 22.0\left(\mathrm{CH}_{2}\right), 17.8\left(\mathrm{CH}_{3}\right), 13.9\left(\mathrm{CH}_{3}\right)$; IR (ATR): $\tilde{v}=2929,1609,1514,1465$, 1248, 1179, 1035, 834, 789, $756 \mathrm{~cm}^{-1}$; MS (El) m/z (relative intensity) 321 (5) [M]', 292 (63), 278 (28), 250 (100), 237 (29), 207 (31), 153 (24); HR-MS (ESI+): m/z calcd for $\left[\mathrm{C}_{20} \mathrm{H}_{23} \mathrm{~N}_{3} \mathrm{O}+\mathrm{H}\right]^{+}$322.1914, found 322.1915 .

\subsubsection{PA-Ruthenium(II)-catalyzed C-H Arylations of Tetrazoles}

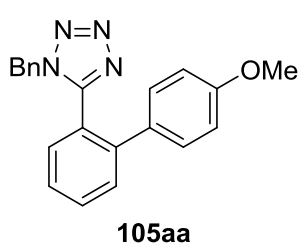

1-Benzyl-5-(4'-methoxy-[1,1'-biphenyl]-2-yl)-1H-tetrazole (105aa): The representative procedure $\mathbf{G}$ was followed using tetrazole 104a (118 $\mathrm{mg}, 0.50 \mathrm{mmol}$ ) and aryl bromide $25 \mathrm{a}$ (140 mg, $0.75 \mathrm{mmol}$ ), yielding 105aa (147 mg, 86\%) as a colorless solid. 
M.p.: $113{ }^{\circ} \mathrm{C} ;{ }^{1} \mathrm{H}$ NMR $\left(500 \mathrm{MHz}, \mathrm{CDCl}_{3}\right): \delta=7.60$ (ddd, $\left.J=7.8,7.3,1.5 \mathrm{~Hz}, 1 \mathrm{H}\right), 7.54$ (ddd, $J=7.8,1.3$, $0.5 \mathrm{~Hz}, 1 \mathrm{H}$ ), 7.38 (ddd, J = 7.5, 7.5, 1.3 Hz, 1H), 7.33 (ddd, J = 7.7, 1.4, 0.5 Hz, 1H), 7.22-7.17 (m, 1H), 7.16-7.12 (m, 2H), 7.09-7.05 (m, 2H), $6.82(\mathrm{~d}, J=8.9 \mathrm{~Hz}, 2 \mathrm{H}), 6.78-6.74(\mathrm{~m}, 2 \mathrm{H}), 4.79(\mathrm{~s}, 2 \mathrm{H}), 3.80(\mathrm{~s}$, 3H); ${ }^{13} \mathrm{C}$ NMR (125 MHz, $\left.\mathrm{CDCl}_{3}\right): \delta=159.5\left(\mathrm{C}_{\mathrm{q}}\right), 154.8\left(\mathrm{C}_{\mathrm{q}}\right), 141.4\left(\mathrm{C}_{\mathrm{q}}\right), 133.1\left(\mathrm{C}_{\mathrm{q}}\right), 131.5(\mathrm{CH}), 131.3$ $(\mathrm{CH}), 131.1\left(\mathrm{C}_{\mathrm{q}}\right), 130.0(\mathrm{CH}), 129.8(\mathrm{CH}), 128.6(\mathrm{CH}), 128.5(\mathrm{CH}), 127.8(\mathrm{CH}), 127.3(\mathrm{CH}), 122.5\left(\mathrm{C}_{\mathrm{q}}\right)$, $114.4(\mathrm{CH}), 55.3\left(\mathrm{CH}_{3}\right), 50.8\left(\mathrm{CH}_{2}\right)$; IR (ATR): $\tilde{v}=1609,1514,1467,1249,1180,837,767,721$, $699 \mathrm{~cm}^{-1}$; MS (EI) m/z (relative intensity) 342 (53) [M], 265 (46), 249 (58), 222 (61), 178 (88), 132 (100); HR-MS (ESI): $m / z$ calcd for $\left[\mathrm{C}_{21} \mathrm{H}_{18} \mathrm{~N}_{4} \mathrm{O}+\mathrm{H}\right]^{+} 343.1553$, found 343.1554 .

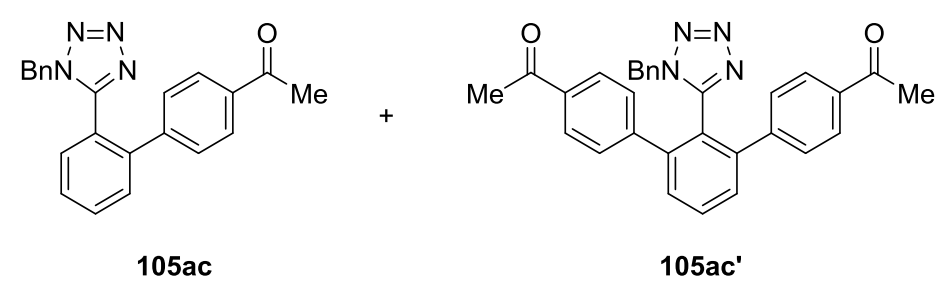

1-\{2'-(1-Benzyl-1H-tetrazol-5-yl)-[1,1'-biphenyl]-4-yl\}ethan-1-one (105ac) and 1,1'-(2'-\{1-Benzyl-1Htetrazol-5-yl)-[1,1':3',1"-terphenyl]-4,4"-diyl\}bis(ethan-1-one) (105ac'): The representative procedure $\mathbf{D}$ was followed using tetrazole $104 \mathrm{a}(118 \mathrm{mg}, 0.50 \mathrm{mmol})$ and 4-bromoacetophenone (25c) (149 mg, $0.75 \mathrm{mmol}$ ), yielding 105ac (147 mg, 82\%) and 105ac' (23 mg, 10\%) as colorless solids. 105ac: M.p.: $158^{\circ} \mathrm{C} ;{ }^{1} \mathrm{H}$ NMR $\left(500 \mathrm{MHz}, \mathrm{CDCl}_{3}\right): \delta=7.85-7.81(\mathrm{~m}, 2 \mathrm{H}), 7.67$ (ddd, J = 7.7, 7.6, $1.3 \mathrm{~Hz}$, 1H), 7.59-7.55 (m, 1H), 7.49 (ddd, J = 7.6, 7.6, 1.3 Hz, 1H), 7.36 (dd, J = 7.7, 1.3 Hz, 1H), 7.23-7.12 (m, $5 \mathrm{H}), 6.77(\mathrm{~d}, J=7.2 \mathrm{~Hz}, 2 \mathrm{H}), 4.88(\mathrm{~s}, 2 \mathrm{H}), 2.57(\mathrm{~s}, 3 \mathrm{H}) ;{ }^{13} \mathrm{C} \mathrm{NMR}\left(125 \mathrm{MHz}, \mathrm{CDCl}_{3}\right): \delta=197.3\left(\mathrm{C}_{\mathrm{q}}\right), 154.2$ $\left(\mathrm{C}_{q}\right), 143.3\left(\mathrm{C}_{\mathrm{q}}\right), 140.7\left(\mathrm{C}_{\mathrm{q}}\right), 136.3\left(\mathrm{C}_{\mathrm{q}}\right), 132.8\left(\mathrm{C}_{\mathrm{q}}\right), 131.6(\mathrm{CH}), 131.2(\mathrm{CH}), 130.3(\mathrm{CH}), 128.8(\mathrm{CH}), 128.8$ $(\mathrm{CH}), 128.7(\mathrm{CH}), 128.6(\mathrm{CH}), 128.5(\mathrm{CH}), 127.7(\mathrm{CH}), 122.7\left(\mathrm{C}_{\mathrm{q}}\right), 50.9\left(\mathrm{CH}_{2}\right), 26.6\left(\mathrm{CH}_{3}\right)$; IR (ATR): $\tilde{v}=$ 3065, 1617, 1322, 1404, 1165, 1113, 1069, 846, 769, $721 \mathrm{~cm}^{-1}$; MS (EI) $\mathrm{m} / \mathrm{z}$ (relative intensity) 354 (12) $[\mathrm{M}]^{+}, 353$ (35), 91 (100), 43 (38); HR-MS (ESI): $\mathrm{m} / \mathrm{z}$ calcd for $\left[\mathrm{C}_{22} \mathrm{H}_{18} \mathrm{~N}_{4} \mathrm{O}+\mathrm{H}\right]^{+}$355.1553, found 355.1550. The spectral data are in accordance with those reported in the literature. ${ }^{[121]}$<smiles>CC(=O)c1ccc(-c2cccc(-c3ccc(C(C)=O)cc3)c2-c2nnn[nH]2)cc1</smiles>

1,1'-\{2'-(1-Benzyl-1H-tetrazol-5-yl)-[1,1':3',1"-terphenyl]-4,4"-diyl\}bis(ethan-1-one) (105ac'):

M.p.: $220^{\circ} \mathrm{C}$; ${ }^{1} \mathrm{H}$ NMR $\left(500 \mathrm{MHz}, \mathrm{CDCl}_{3}\right): \delta=7.75(\mathrm{~d}, J=8.2 \mathrm{~Hz}, 4 \mathrm{H}), 7.54(\mathrm{~d}, J=7.7 \mathrm{~Hz}, 2 \mathrm{H}), 7.28-7.23$ (m, 2H), 7.16-7.11 (m, 2H), $7.05(\mathrm{~d}, J=8.2 \mathrm{~Hz}, 4 \mathrm{H}), 6.69(\mathrm{~d}, J=7.0 \mathrm{~Hz}, 2 \mathrm{H}), 4.72(\mathrm{~s}, 2 \mathrm{H}), 2.55(\mathrm{~s}, 6 \mathrm{H})$; 
${ }^{13} \mathrm{C}$ NMR $\left(125 \mathrm{MHz}, \mathrm{CDCl}_{3}\right): \delta=197.4\left(\mathrm{C}_{\mathrm{q}}\right), 152.3\left(\mathrm{C}_{\mathrm{q}}\right), 143.2\left(\mathrm{C}_{\mathrm{q}}\right), 142.6\left(\mathrm{C}_{\mathrm{q}}\right), 136.2\left(\mathrm{C}_{\mathrm{q}}\right), 132.3\left(\mathrm{C}_{\mathrm{q}}\right)$, $131.5(\mathrm{CH}), 129.9(\mathrm{CH}), 129.2(\mathrm{CH}), 128.9(\mathrm{CH}), 128.9(\mathrm{CH}), 128.3(\mathrm{CH}), 128.1(\mathrm{CH}), 121.3\left(\mathrm{C}_{\mathrm{q}}\right), 50.9$ $\left(\mathrm{CH}_{2}\right), 26.6\left(\mathrm{CH}_{3}\right) ;$ IR (ATR): $\tilde{v}=2923,1682,1597,1353,1266,1211,839,728,609 \mathrm{~cm}^{-1} ;$ MS (EI) $\mathrm{m} / \mathrm{z}$ (relative intensity) 472 (37) [M] ${ }^{+}, 471$ (35), 239 (19), 91 (100), 43 (74); HR-MS (ESI): m/z calcd for $\left[\mathrm{C}_{30} \mathrm{H}_{24} \mathrm{~N}_{4} \mathrm{O}_{2}+\mathrm{H}\right]^{+} 473.1972$, found 473.1968 . The spectral data are in accordance with those reported in the literature. ${ }^{[121]}$

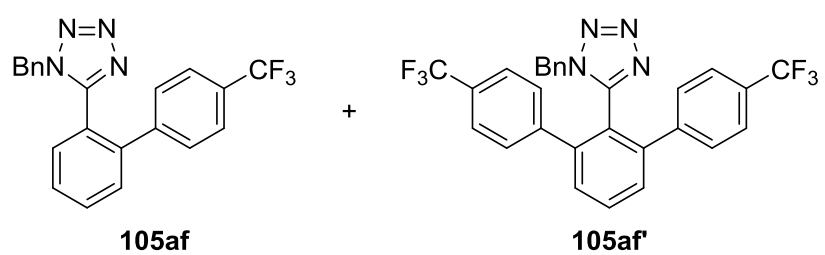

1-Benzyl-5-\{4'-(trifluoromethyl)-[1,1'-biphenyl]-2-yl\}-1H-tetrazole (105af) and 1-Benzyl-5-(4,4"bis(trifluoromethyl)-[1,1':3',1"-terphenyl]-2'-yl)-1H-tetrazole (105af'): The representative procedure D was followed using tetrazole $104 \mathrm{a}(118 \mathrm{mg}, 0.50 \mathrm{mmol})$ and 1-bromo-4-(trifluoromethyl)benzene (25f) (169 mg, $0.75 \mathrm{mmol}$ ), yielding 105af (131 mg, 68\%) and 105af' (22 mg, 10\%) as colorless solids. 105af: M.p.: $120{ }^{\circ} \mathrm{C} ;{ }^{1} \mathrm{H}$ NMR $\left(300 \mathrm{MHz}, \mathrm{CDCl}_{3}\right): \delta=7.77$ (ddd, $\left.J=7.8,7.5,1.4 \mathrm{~Hz} 1 \mathrm{H}\right), 7.57-7.46(\mathrm{~m}$, $4 \mathrm{H}), 7.37$ (ddd, $J=7.7,1.4,0.5 \mathrm{~Hz}, 2 \mathrm{H}), 7.26-7.12(\mathrm{~m}, 5 \mathrm{H}), 6.79-6.72(\mathrm{~m}, 1 \mathrm{H}), 4.93(\mathrm{~s}, 2 \mathrm{H}) ;{ }^{13} \mathrm{C} \mathrm{NMR}$ $\left(125 \mathrm{MHz}, \mathrm{CDCl}_{3}\right): \delta=154.1\left(\mathrm{C}_{\mathrm{q}}\right), 142.3\left(\mathrm{C}_{\mathrm{q}}\right), 140.5\left(\mathrm{C}_{\mathrm{q}}\right), 132.8\left(\mathrm{C}_{\mathrm{q}}\right), 131.7(\mathrm{CH}), 131.2(\mathrm{CH}), 130.5(\mathrm{CH})$, $130.1\left(\mathrm{q}, J=33 \mathrm{~Hz}, \mathrm{C}_{\mathrm{q}}\right.$ ), $129.1(\mathrm{CH}), 128.8(\mathrm{CH}), 128.7(\mathrm{CH}), 128.5(\mathrm{CH}), 127.6(\mathrm{CH}), 125.7(\mathrm{q}, J=4 \mathrm{~Hz}$, $\mathrm{CH}), 123.9\left(\mathrm{q}, J=273 \mathrm{~Hz}, \mathrm{C}_{\mathrm{q}}\right), 122.8\left(\mathrm{C}_{\mathrm{q}}\right), 51.0\left(\mathrm{CH}_{2}\right) ;{ }^{19} \mathrm{~F} \mathrm{NMR}\left(282 \mathrm{MHz}, \mathrm{CDCl}_{3}\right): \delta=-62.3$ (s); IR (ATR): $\tilde{v}=2925,1618,1322,1165,1131,1066,850,724 \mathrm{~cm}^{-1}$; MS (ESI) $\mathrm{m} / \mathrm{z}$ (relative intensity) 419 (100) $[\mathrm{M}+\mathrm{K}]^{+}, 403(33)[\mathrm{M}+\mathrm{Na}]^{+}, 381(64)[\mathrm{M}+\mathrm{H}]^{+}$; HR-MS (ESI): $\mathrm{m} / \mathrm{z}$ calcd for $\left[\mathrm{C}_{21} \mathrm{H}_{15} \mathrm{~F}_{3} \mathrm{~N}_{4}+\mathrm{H}\right]^{+} 381.1322$, found 381.1319 .<smiles>FC(F)(F)c1ccc(-c2cccc(-c3ccc(C(F)(F)F)cc3)c2-c2nnn[nH]2)cc1</smiles>

1-Benzyl-5-\{4,4"-bis(trifluoromethyl)-[1,1':3',1"-terphenyl]-2'-yl\}-1H-tetrazole (105af'): M.p.: $169^{\circ} \mathrm{C} ;{ }^{1} \mathrm{H}$ NMR $\left(500 \mathrm{MHz}, \mathrm{CDCl}_{3}\right): \delta=7.77$ (dd, $\left.J=7.8,7.8 \mathrm{~Hz} 1 \mathrm{H}\right), 7.54(\mathrm{~d}, J=7.8 \mathrm{~Hz}, 2 \mathrm{H}), 7.43(\mathrm{~d}, J=$ $8.0 \mathrm{~Hz}, 4 \mathrm{H}), 7.29-7.23(\mathrm{~m}, 1 \mathrm{H}), 7.16-7.10(\mathrm{~m}, 2 \mathrm{H}), 7.09(\mathrm{~d}, \mathrm{~J}=8.0 \mathrm{~Hz}, 4 \mathrm{H}), 6.67-6.62(\mathrm{~m}, 2 \mathrm{H}), 4.75(\mathrm{~s}$, 2H); ${ }^{13} \mathrm{C}$ NMR $\left(125 \mathrm{MHz}, \mathrm{CDCl}_{3}\right): \delta=152.2\left(\mathrm{C}_{\mathrm{q}}\right), 142.3\left(\mathrm{C}_{\mathrm{q}}\right), 142.1\left(\mathrm{C}_{\mathrm{q}}\right), 142.0\left(\mathrm{C}_{\mathrm{q}}\right), 142.0(\mathrm{CH}), 130.1$ $(\mathrm{CH}), 130.1\left(\mathrm{q}, \mathrm{J}=32.7 \mathrm{~Hz}, \mathrm{C}_{\mathrm{q}}\right.$ ), $129.3(\mathrm{CH}), 128.9(\mathrm{CH}), 128.9(\mathrm{CH}), 127.8(\mathrm{CH}), 125.3(\mathrm{q}, J=3.7 \mathrm{~Hz}, \mathrm{CH})$, 
$123.8\left(\mathrm{q}, J=272.3 \mathrm{~Hz}, \mathrm{C}_{\mathrm{q}}\right), 121.4\left(\mathrm{C}_{\mathrm{q}}\right), 50.8\left(\mathrm{CH}_{2}\right) ;{ }^{19} \mathrm{~F} \mathrm{NMR}\left(376 \mathrm{MHz} \mathrm{CDCl}_{3}\right): \delta=-62.7$ (s); IR (ATR): $\tilde{v}=$ 2925, 1618, 1322, 1165, 1131, 1066, 850, $724 \mathrm{~cm}^{-1}$; MS (ESI) m/z (relative intensity) 563 (100) $[\mathrm{M}+\mathrm{K}]^{+}, 547(36)[\mathrm{M}+\mathrm{Na}]^{+}, 525(98)[\mathrm{M}+\mathrm{H}]^{+} ;$HR-MS (ESI): $\mathrm{m} / z$ calcd for $\left[\mathrm{C}_{28} \mathrm{H}_{18} \mathrm{~N}_{4}+\mathrm{H}\right]^{+} 525.1508$, found 525.1512.<smiles>Clc1ccc(-c2ccccc2-c2nnnn2Br)cc1</smiles>

1-Benzyl-5-(4'-chloro-[1,1'-biphenyl]-2-yl)-1H-tetrazole (105ak): The representative procedure D was followed using tetrazole $104 \mathrm{a}(118 \mathrm{mg}, 0.50 \mathrm{mmol}$ ) and 1-bromo-4-chlorobenzene (25k) (144 mg, $0.75 \mathrm{mmol}$ ), yielding 105ak (131 mg, 76\%) as a colorless solid.

M.p.: $169{ }^{\circ} \mathrm{C} ;{ }^{1} \mathbf{H}$ NMR $\left(500 \mathrm{MHz}, \mathrm{CDCl}_{3}\right): \delta=7.64$ (ddd, $\left.J=7.6,7.61 .4 \mathrm{~Hz}, 1 \mathrm{H}\right), 7.53$ (ddd, $J=7.6,1.3$, $0.5 \mathrm{~Hz}, 1 \mathrm{H}), 7.45$ (ddd, $J=7.6,7.6,1.3 \mathrm{~Hz}, 1 \mathrm{H}), 7.34$ (ddd, $J=7.6,1.4,0.5 \mathrm{~Hz}, 1 \mathrm{H}), 7.25-7.20(\mathrm{~m}, 3 \mathrm{H})$, 7.19-7.14 (m, 2H), $7.02(\mathrm{~d}, J=8.7 \mathrm{~Hz}, 2 \mathrm{H}), 6.78-6.74(\mathrm{~m}, 2 \mathrm{H}), 4.89(\mathrm{~s}, 2 \mathrm{H}) ;{ }^{13} \mathrm{C} \mathrm{NMR}\left(125 \mathrm{MHz}^{\mathrm{C}} \mathrm{CDCl}_{3}\right)$ : $\delta=154.3\left(\mathrm{C}_{\mathrm{q}}\right), 140.6\left(\mathrm{C}_{\mathrm{q}}\right), 137.1\left(\mathrm{C}_{\mathrm{q}}\right), 134.4\left(\mathrm{C}_{\mathrm{q}}\right), 132.9\left(\mathrm{C}_{\mathrm{q}}\right), 131.6(\mathrm{CH}), 131.2(\mathrm{CH}), 130.2(\mathrm{CH}), 129.9$ (CH), $129.1(\mathrm{CH}), 128.8(\mathrm{CH}), 128.6(\mathrm{CH}), 128.1(\mathrm{CH}), 127.7(\mathrm{CH}), 122.7\left(\mathrm{C}_{q}\right), 50.9\left(\mathrm{CH}_{2}\right)$; IR (ATR): $\tilde{v}=$ 1711, 1494, 1643, 1092, 1006, 834, 764, 722, 696, $526 \mathrm{~cm}^{-1}$; MS (EI) m/z (relative intensity) 347 (25) $[\mathrm{M}+\mathrm{H}]^{+}, 346(24)[\mathrm{M}]^{+}, 345(66)[\mathrm{M}-\mathrm{H}]^{+}, 91$ (100); HR-MS (ESI): m/z calcd for $\left[\mathrm{C}_{20} \mathrm{H}_{15} \mathrm{~N}_{4} \mathrm{Cl}+\mathrm{H}\right]^{+}$ 347.1058, found 347.1057.

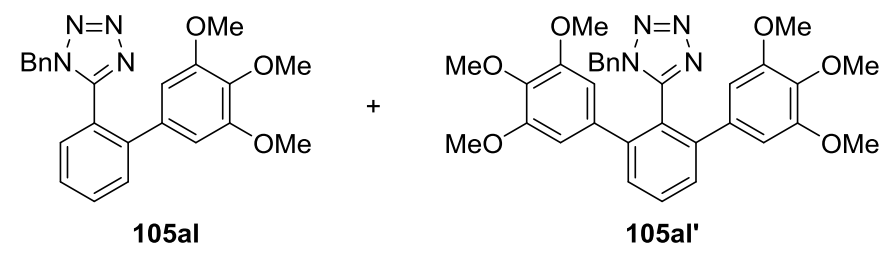

1-Benzyl-5-(3',4',5'-trimethoxy-[1,1'-biphenyl]-2-yl)-1H-tetrazole (105al) and 1-Benzyl-5(3,3",4,4",5,5"-hexamethoxy-[1,1':3',1"-terphenyl]-2'-yl)-1H-tetrazole (105al'): The representative procedure D was followed using tetrazole 104a (118 mg, $0.50 \mathrm{mmol}$ ) and 5-bromo-1,2,3trimethoxybenzene (25l) (185 mg, $0.75 \mathrm{mmol})$, yielding 105al (178 mg, 88\%) and 105al' (26 mg, 8\%) as a colorless oil and solid, respectively. 
105al: ${ }^{1} \mathrm{H}$ NMR $\left(500 \mathrm{MHz}, \mathrm{CDCl}_{3}\right.$ ): $\delta=7.63-7.57(\mathrm{~m}, 2 \mathrm{H}), 7.40$ (ddd, $J=7.8,6.8,1.9 \mathrm{~Hz}, 1 \mathrm{H}$ ), 7.32 (ddd, $J=7.8,1.3,0.6 \mathrm{~Hz}, 1 \mathrm{H}), 7.22-7.10(\mathrm{~m}, 3 \mathrm{H}), 6.77-6.73(\mathrm{~m}, 2 \mathrm{H}), 6.33(\mathrm{~s}, 2 \mathrm{H}), 4.82(\mathrm{~s}, 2 \mathrm{H}), 3.82(\mathrm{~s}, 3 \mathrm{H})$, $3.66(\mathrm{~s}, 6 \mathrm{H}) ;{ }^{13} \mathrm{C}$ NMR $\left(125 \mathrm{MHz}, \mathrm{CDCl}_{3}\right): \delta=154.8\left(\mathrm{C}_{\mathrm{q}}\right), 153.4\left(\mathrm{C}_{\mathrm{q}}\right), 141.5\left(\mathrm{C}_{\mathrm{q}}\right), 137.9\left(\mathrm{C}_{\mathrm{q}}\right), 134.0\left(\mathrm{C}_{\mathrm{q}}\right)$, $133.0\left(\mathrm{C}_{\mathrm{q}}\right), 131.6(\mathrm{CH}), 131.3(\mathrm{CH}), 129.9(\mathrm{CH}), 128.7(\mathrm{CH}), 128.6(\mathrm{CH}), 127.8(\mathrm{CH}), 127.7(\mathrm{CH}), 122.6$ $\left(\mathrm{C}_{\mathrm{q}}\right), 105.8(\mathrm{CH}), 60.9\left(\mathrm{CH}_{3}\right), 56.1\left(\mathrm{CH}_{3}\right), 50.8\left(\mathrm{CH}_{2}\right)$; IR (ATR): $\tilde{v}=2938,2835,1585,1508,1468,1409$,

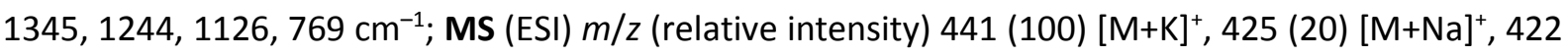
(10), 403 (55) $[\mathrm{M}+\mathrm{H}]^{+}$; HR-MS (ESI): $\mathrm{m} / z$ calcd for $\left[\mathrm{C}_{23} \mathrm{H}_{22} \mathrm{~N}_{4} \mathrm{O}_{3}+\mathrm{H}\right]^{+} 403.1765$, found 403.1766. The spectral data are in accordance with those reported in the literature. ${ }^{[121]}$<smiles>COc1cc(-c2cccc(-c3cc(OC)c(OC)c(OC)c3)c2-c2nnn[nH]2)cc(OC)c1OC</smiles>

1-Benzyl-5-(3,3",4,4",5,5"-hexamethoxy-[1,1':3',1"-terphenyl]-2'-yl)-1H-tetrazole (105al'): M.p.: $182{ }^{\circ} \mathrm{C} ;{ }^{1} \mathrm{H}$ NMR $\left(500 \mathrm{MHz}, \mathrm{CDCl}_{3}\right): \delta=7.71(\mathrm{dd}, J=8.2,7.3 \mathrm{~Hz}, 1 \mathrm{H}), 7.56(\mathrm{~d}, J=7.7 \mathrm{~Hz}, 2 \mathrm{H}), 7.24-7.19$ $(\mathrm{m}, 1 \mathrm{H}), 7.17-7.11(\mathrm{~m}, 2 \mathrm{H}), 6.75-6.69(\mathrm{~m}, 2 \mathrm{H}), 6.30(\mathrm{~s}, 4 \mathrm{H}), 4.76(\mathrm{~s}, 2 \mathrm{H}), 3.81(\mathrm{~s}, 6 \mathrm{H}), 3.65(\mathrm{~s}, 12 \mathrm{H}) ;{ }^{13} \mathrm{C}$ NMR (125 MHz, CDCl $\left.)_{3}\right): \delta=153.3\left(C_{q}\right), 152.9\left(C_{q}\right), 143.4\left(C_{q}\right), 137.7\left(C_{q}\right), 134.2\left(C_{q}\right), 132.7\left(C_{q}\right), 131.4$ $(\mathrm{CH}), 129.4(\mathrm{CH}), 128.8(\mathrm{CH}), 128.7(\mathrm{CH}), 128.1(\mathrm{CH}), 121.0\left(\mathrm{C}_{\mathrm{q}}\right), 106.5(\mathrm{CH}), 60.9\left(\mathrm{CH}_{3}\right), 56.1\left(\mathrm{CH}_{3}\right)$, $50.6\left(\mathrm{CH}_{2}\right)$; IR (ATR): $\tilde{v}=2938,2836,1576,1506,1460,1395,1241,1123,1003,725 \mathrm{~cm}^{-1}$; MS (ESI) $\mathrm{m} / \mathrm{z}$ (relative intensity) $607(100)[\mathrm{M}+\mathrm{K}]^{+}, 591(36)[\mathrm{M}+\mathrm{Na}]^{+}, 569(40)[\mathrm{M}+\mathrm{H}]^{+} ;$HR-MS (ESI): $\mathrm{m} / \mathrm{z}$ calcd for $\left[\mathrm{C}_{32} \mathrm{H}_{32} \mathrm{~N}_{4} \mathrm{O}_{6}+\mathrm{H}\right]^{+} 569.2395$, found 569.2391 .

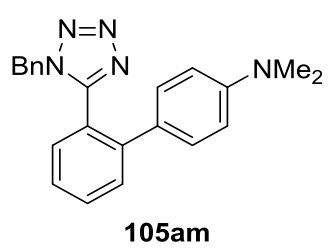

2'-(1-Benzyl-1H-tetrazol-5-yl)-N,N-dimethyl-[1,1'-biphenyl]-4-amine (105am): The representative procedure D was followed using tetrazole $104 \mathrm{a}(118 \mathrm{mg}, 0.50 \mathrm{mmol})$ and 4-bromo- $\mathrm{N}, \mathrm{N}-$ dimethylaniline (25m) (150 mg, $0.75 \mathrm{mmol})$, yielding 105am (142 mg, 80\%) as a colorless oil.

${ }^{1} \mathbf{H}$ NMR $\left(500 \mathrm{MHz}, \mathrm{CDCl}_{3}\right): \delta=7.59-7.52(\mathrm{~m}, 2 \mathrm{H}), 7.32-7.28(\mathrm{~m}, 2 \mathrm{H}), 7.19-7.15(\mathrm{~m}, 1 \mathrm{H}), 7.14-7.09$ $(\mathrm{m}, 2 \mathrm{H}), 7.02(\mathrm{~d}, J=8.9 \mathrm{~Hz}, 2 \mathrm{H}), 6.77-6.73(\mathrm{~m}, 2 \mathrm{H}), 6.61(\mathrm{~d}, J=8.9 \mathrm{~Hz} 2 \mathrm{H}), 4.76(\mathrm{~s}, 2 \mathrm{H}), 2.95(\mathrm{~s}, 6 \mathrm{H})$; ${ }^{13} \mathrm{C}$ NMR $\left(125 \mathrm{MHz}, \mathrm{CDCl}_{3}\right): \delta=155.1\left(\mathrm{C}_{\mathrm{q}}\right), 149.9\left(\mathrm{C}_{\mathrm{q}}\right), 141.7\left(\mathrm{C}_{\mathrm{q}}\right), 133.2\left(\mathrm{C}_{\mathrm{q}}\right), 131.3(\mathrm{CH}), 131.2(\mathrm{CH})$, $129.7(\mathrm{CH}), 129.3(\mathrm{CH}), 128.5(\mathrm{CH}), 128.3(\mathrm{CH}), 127.8(\mathrm{CH}), 126.6(\mathrm{CH}), 126.1\left(\mathrm{C}_{\mathrm{q}}\right), 122.1\left(\mathrm{C}_{\mathrm{q}}\right), 112.4$ 
(CH), $50.7\left(\mathrm{CH}_{2}\right), 40.1\left(\mathrm{CH}_{3}\right)$; IR (ATR): $\tilde{v}=1608,1523,1356,1104,945,821,765,722,697,528 \mathrm{~cm}^{-1}$; MS (ESI) m/z (relative intensity) 378 (35) [M+Na] $]^{+}, 356(100)[\mathrm{M}+\mathrm{H}]^{+}, 265$ (6), 237 (6); HR-MS (ESI): $\mathrm{m} / \mathrm{z}$ calcd for $\left[\mathrm{C}_{22} \mathrm{H}_{21} \mathrm{~N}_{5}+\mathrm{H}\right]^{+} 356.1870$, found 356.1870 .
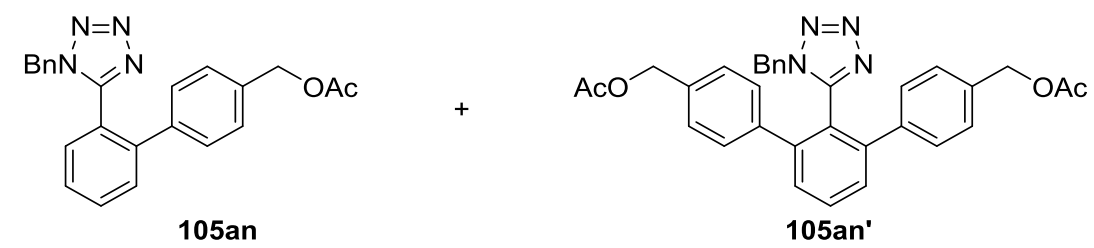

\{2'-(1-Benzyl-1H-tetrazol-5-yl)-[1,1'-biphenyl]-4-yl\}methyl acetate (105an) and \{2'-(1-Benzyl-1Htetrazol-5-yl)-[1,1':3',1"-terphenyl]-4,4"-diyl\}bis(methylene) diacetate (105an'): The representative procedure D was followed using tetrazole 104a $(118 \mathrm{mg}, 0.50 \mathrm{mmol})$ and 4-bromobenzyl acetate (25n) (172 mg, $0.75 \mathrm{mmol}$ ), yielding 105an (139 mg, 72\%) and 105an' (15 mg, 6\%) as colorless solids.

105an: M.p.: $75^{\circ} \mathrm{C} ;{ }^{1} \mathrm{H}$ NMR $\left(300 \mathrm{MHz}, \mathrm{CDCl}_{3}\right): \delta=7.63$ (ddd, $\left.J=7.6,7.6,1.4 \mathrm{~Hz}, 1 \mathrm{H}\right), 7.57-7.51(\mathrm{~m}$, 1H), 7.43 (ddd, $J=7.5,7.51 .3 \mathrm{~Hz}, 1 \mathrm{H}), 7.33(\mathrm{dd}, J=7.7,1.1 \mathrm{~Hz}, 1 \mathrm{H}), 7.30-7.07(\mathrm{~m}, 7 \mathrm{H}), 6.79-6.70(\mathrm{~m}$, 2H), $5.07(\mathrm{~s}, 2 \mathrm{H}), 4.82(\mathrm{~s}, 2 \mathrm{H}), 2.11(\mathrm{~s}, 3 \mathrm{H}) ;{ }^{13} \mathrm{C} \mathrm{NMR}\left(75 \mathrm{MHz}, \mathrm{CDCl}_{3}\right): \delta=170.7\left(\mathrm{C}_{\mathrm{q}}\right), 154.5\left(\mathrm{C}_{\mathrm{q}}\right), 141.2$ $\left(C_{q}\right), 138.6\left(C_{q}\right), 135.9\left(C_{q}\right), 132.9\left(C_{q}\right), 131.5(C H), 131.2(C H), 130.2(C H), 128.8(C H), 128.7(C H)$, $128.5(\mathrm{CH}), 128.5(\mathrm{CH}), 127.9(\mathrm{CH}), 127.7(\mathrm{CH}), 122.6\left(\mathrm{C}_{\mathrm{q}}\right), 65.5\left(\mathrm{CH}_{2}\right), 50.8\left(\mathrm{CH}_{2}\right), 20.9\left(\mathrm{CH}_{3}\right) ; \mathrm{IR}(\mathrm{ATR})$ : $\tilde{v}=1738,1406,1361,1223,1026,828,765,721,699,526 \mathrm{~cm}^{-1} ;$ MS (ESI) $\mathrm{m} / \mathrm{z}$ (relative intensity) 407 (100) $[\mathrm{M}+\mathrm{Na}]^{+}, 385(27)[\mathrm{M}+\mathrm{H}]^{+}, 325$ (33), 297 (6); HR-MS (ESI): $\mathrm{m} / z$ calcd for $\left[\mathrm{C}_{23} \mathrm{H}_{20} \mathrm{~N}_{4} \mathrm{O}_{2}+\mathrm{H}\right]^{+}$ 385.1659, found 385.1650. The spectral data are in accordance with those reported in the literature. ${ }^{[121]}$<smiles>CC(=O)OCc1ccc(-c2cccc(-c3ccc(COC(C)=O)cc3)c2-c2nnn[nH]2)cc1</smiles>

\{2'-(1-Benzyl-1H-tetrazol-5-yl)-[1,1':3',1"-terphenyl]-4,4"-diyl\}bis(methylene) diacetate (105an'): M.p.: $152{ }^{\circ} \mathrm{C}$; ${ }^{1} \mathrm{H}$ NMR $\left(300 \mathrm{MHz}, \mathrm{CDCl}_{3}\right): \delta=7.69(\mathrm{~d}, J=7.3 \mathrm{~Hz}, 1 \mathrm{H}), 7.49(\mathrm{~d}, J=7.7 \mathrm{~Hz}, 2 \mathrm{H}), 7.25-7.20$ (m, 1H), 7.19-7.09 (m, 2H), $7.16(\mathrm{~d}, J=8.2 \mathrm{~Hz}, 4 \mathrm{H}), 6.96(\mathrm{~d}, J=8.2 \mathrm{~Hz}, 4 \mathrm{H}), 6.69(\mathrm{~d}, J=7.3 \mathrm{~Hz}, 2 \mathrm{H})$, $5.03(\mathrm{~s}, 4 \mathrm{H}), 4.72(\mathrm{~s}, 2 \mathrm{H}), 2.11(\mathrm{~s}, 6 \mathrm{H}) ;{ }^{13} \mathrm{C} \mathrm{NMR}\left(125 \mathrm{MHz}, \mathrm{CDCl}_{3}\right): \delta=170.8\left(\mathrm{C}_{\mathrm{q}}\right), 152.8\left(\mathrm{C}_{\mathrm{q}}\right), 143.1\left(\mathrm{C}_{\mathrm{q}}\right)$, $138.7\left(\mathrm{C}_{\mathrm{q}}\right), 135.5\left(\mathrm{C}_{\mathrm{q}}\right), 132.5\left(\mathrm{C}_{\mathrm{q}}\right), 131.3(\mathrm{CH}), 129.7(\mathrm{CH}), 129.1(\mathrm{CH}), 128.8(\mathrm{CH}), 128.7(\mathrm{CH}), 128.2$ (CH), $128.0(\mathrm{CH}), 121.3\left(\mathrm{C}_{\mathrm{q}}\right), 65.7\left(\mathrm{CH}_{2}\right), 50.8\left(\mathrm{CH}_{2}\right), 21.0\left(\mathrm{CH}_{3}\right)$; IR (ATR): $\tilde{v}=1735,1456,1362,1224$, 1024, 802, $721 \mathrm{~cm}^{-1}$; MS (ESI) m/z (relative intensity) $555(100)[\mathrm{M}+\mathrm{Na}]^{+}, 533(20)[\mathrm{M}+\mathrm{H}]^{+}, 473$ (7); 
HR-MS (ESI): $m / z$ calcd for $\left[\mathrm{C}_{32} \mathrm{H}_{28} \mathrm{~N}_{4} \mathrm{O}_{4}+\mathrm{H}\right]^{+} 533.2183$, found 533.2182 . The spectral data are in accordance with those reported in the literature. ${ }^{[163]}$

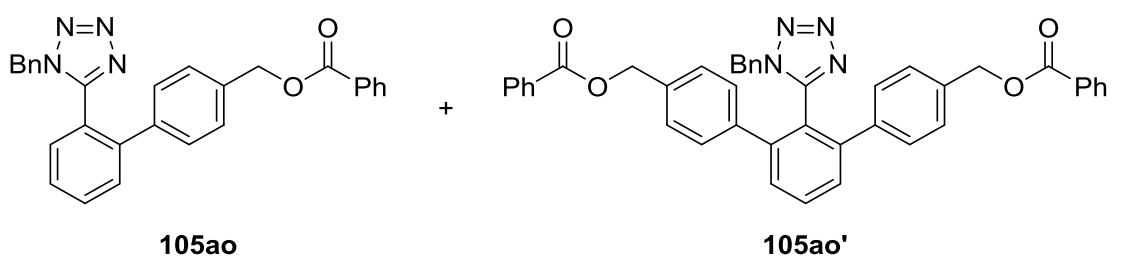

\{2'-(1-Benzyl-1H-tetrazol-5-yl)-[1,1'-biphenyl]-4-yl\}methyl benzoate (1085ao) and \{2'-(1-Benzyl-1Htetrazol-5-yl)-[1,1':3',1"-terphenyl]-4,4"-diyl\}bis(methylene) dibenzoate (105ao'): The representative procedure D was followed using tetrazole $104 \mathrm{a}(118 \mathrm{mg}, 0.50 \mathrm{mmol})$ and 4bromobenzyl benzoate (25o) (218 mg, $0.75 \mathrm{mmol}$ ), yielding 105ao (160 mg, 72\%) and 105ao' (37 mg, $11 \%)$ as colorless solids.

105ao: M.p.: $117^{\circ} \mathrm{C} ;{ }^{1} \mathrm{H}$ NMR (300 MHz, $\left.\mathrm{CDCl}_{3}\right): \delta=8.12-8.06(\mathrm{~m}, 2 \mathrm{H}), 7.68-7.54(\mathrm{~m}, 3 \mathrm{H}), 7.49-7.40$ $(\mathrm{m}, 3 \mathrm{H}), 7.39-7.32(\mathrm{~m}, 3 \mathrm{H}), 7.23-7.10(\mathrm{~m}, 5 \mathrm{H}), 6.79-6.73(\mathrm{~m}, 2 \mathrm{H}), 5.35(\mathrm{~s}, 2 \mathrm{H}), 4.83(\mathrm{~s}, 2 \mathrm{H}) ;{ }^{13} \mathrm{C} \mathrm{NMR}$ $\left(125 \mathrm{MHz}, \mathrm{CDCl}_{3}\right): \delta=166.3\left(\mathrm{C}_{\mathrm{q}}\right), 154.5\left(\mathrm{C}_{\mathrm{q}}\right), 141.2\left(\mathrm{C}_{\mathrm{q}}\right), 138.6\left(\mathrm{C}_{\mathrm{q}}\right), 136.1\left(\mathrm{C}_{\mathrm{q}}\right), 133.1(\mathrm{CH}), 133.0\left(\mathrm{C}_{\mathrm{q}}\right)$, $131.6(\mathrm{CH}), 131.2(\mathrm{CH}), 130.3(\mathrm{CH}), 129.9\left(\mathrm{C}_{\mathrm{q}}\right), 129.7(\mathrm{CH}), 128.9(\mathrm{CH}), 128.7(\mathrm{CH}), 128.5(\mathrm{CH}), 128.5$ $(\mathrm{CH}), 128.4(\mathrm{CH}), 127.9(\mathrm{CH}), 127.8(\mathrm{CH}), 122.7\left(\mathrm{C}_{\mathrm{q}}\right), 65.9\left(\mathrm{CH}_{2}\right), 50.9\left(\mathrm{CH}_{2}\right)$; IR (ATR): $\tilde{v}=1710,1452$, $1359,1268,1221,1103,1070,803,713,529 \mathrm{~cm}^{-1}$; MS (ESI) $\mathrm{m} / \mathrm{z}$ (relative intensity) 485 (100) [M+K] 469 (11) $[\mathrm{M}+\mathrm{Na}]^{+}, 447$ (12) $[\mathrm{M}+\mathrm{H}]^{+}, 325$ (15); HR-MS (ESI): $\mathrm{m} / z$ calcd for $\left[\mathrm{C}_{28} \mathrm{H}_{22} \mathrm{~N}_{4} \mathrm{O}_{2}+\mathrm{K}\right]^{+}$485.1374, found 485.1367 . The spectral data are in accordance with those reported in the literature. ${ }^{[163]}$<smiles>O=C(OCc1ccc(-c2cccc(-c3ccc(COC(=O)c4ccccc4)cc3)c2-c2nnn[nH]2)cc1)c1ccccc1</smiles>

\{2'-(1-Benzyl-1H-tetrazol-5-yl)-[1,1':3',1"-terphenyl]-4,4"-diyl\}bis(methylene) dibenzoate (105ao'): M.p.: $156^{\circ} \mathrm{C} ;{ }^{1} \mathrm{H}$ NMR $\left(400 \mathrm{MHz}, \mathrm{CDCl}_{3}\right): \delta=8.14-8.06(\mathrm{~m}, 4 \mathrm{H}), 7.71(\mathrm{dd}, J=8.1,7.4 \mathrm{~Hz}, 1 \mathrm{H}), 7.62-$ $7.54(\mathrm{~m}, 2 \mathrm{H}), 7.54-7.42(\mathrm{~m}, 6 \mathrm{H}), 7.23-7.17(\mathrm{~m}, 4 \mathrm{H}), 7.16-7.09(\mathrm{~m}, 3 \mathrm{H}), 7.06-6.97(\mathrm{~m}, 4 \mathrm{H}), 6.74-6.66$ $(\mathrm{m}, 2 \mathrm{H}), 5.30(\mathrm{~s}, 4 \mathrm{H}), 4.74(\mathrm{~s}, 2 \mathrm{H}) ;{ }^{13} \mathrm{C}$ NMR $\left(100 \mathrm{MHz}, \mathrm{CDCl}_{3}\right): \delta=166.4\left(\mathrm{C}_{\mathrm{q}}\right), 152.9\left(\mathrm{C}_{\mathrm{q}}\right), 143.1\left(\mathrm{C}_{\mathrm{q}}\right)$, $138.8\left(\mathrm{C}_{\mathrm{q}}\right), 135.7\left(\mathrm{C}_{\mathrm{q}}\right), 133.1(\mathrm{CH}), 132.5\left(\mathrm{C}_{\mathrm{q}}\right), 131.3(\mathrm{CH}), 123.0\left(\mathrm{C}_{\mathrm{q}}\right), 129.7(\mathrm{CH}), 129.7(\mathrm{CH}), 129.2$ $(\mathrm{CH}), 128.8(\mathrm{CH}), 128.7(\mathrm{CH}), 128.4(\mathrm{CH}), 128.1(\mathrm{CH}), 127.9(\mathrm{CH}), 121.3\left(\mathrm{C}_{\mathrm{q}}\right), 66.0\left(\mathrm{CH}_{2}\right), 50.8\left(\mathrm{CH}_{2}\right)$; IR (ATR): $\tilde{v}=1715,1450,1269,1103,1070,829,766,713,527 \mathrm{~cm}^{-1}$; MS (ESI) $\mathrm{m} / z$ (relative intensity) 
716 (100), 679 (33) [M+Na] $]^{+}, 657(30)[\mathrm{M}+\mathrm{H}]^{+}$; HR-MS (ESI): $\mathrm{m} / z$ calcd for $\left[\mathrm{C}_{42} \mathrm{H}_{32} \mathrm{~N}_{4} \mathrm{O}_{4}+\mathrm{H}\right]^{+}$657.2496, found 657.2479 . The spectral data are in accordance with those reported in the literature. ${ }^{[163]}$<smiles>COc1ccc(-c2nnnn2Cc2ccccc2)c(-c2ccc(C(C)=O)cc2)c1</smiles>

$105 \mathrm{bc}$

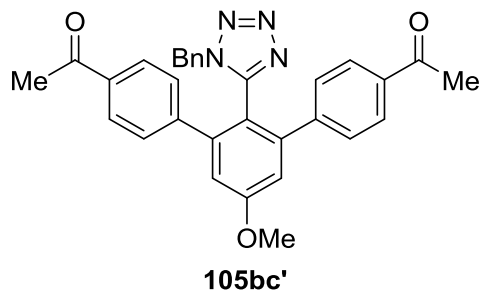

$105 b^{\prime}$

1-\{2'-(1-Benzyl-1H-tetrazol-5-yl)-5'-methoxy-[1,1'-biphenyl]-4-yl\}ethan-1-onetetrazole (105bc) and 1,1'-\{2'-(1-Benzyl-1H-tetrazol-5-yl)-5'-methoxy-[1,1':3',1"-terphenyl]-4,4"'-diyl\}bis(ethan-1-one)

(105bc'): The representative procedure $\mathbf{D}$ was followed using 1-benzyl-5-(4-methoxyphenyl)-1Htetrazole (104b) (133 mg, $0.50 \mathrm{mmol}$ ) and 4-bromoacetophenone (25c) (149 mg, $0.75 \mathrm{mmol}$ ), yielding $105 \mathrm{bc}(149 \mathrm{mg}, 78 \%)$ and $105 \mathrm{bc}^{\prime}(40 \mathrm{mg}, 16 \%)$ as colorless solids.

105bc: M.p.: $123{ }^{\circ} \mathrm{C} ;{ }^{1} \mathrm{H}$ NMR $\left(500 \mathrm{MHz}, \mathrm{CDCl}_{3}\right): \delta=7.82(\mathrm{~d}, J=8.5 \mathrm{~Hz}, 2 \mathrm{H}), 7.30(\mathrm{~d}, J=8.5 \mathrm{~Hz}, 1 \mathrm{H})$, 7.24-7.19 (m, 1H), 7.18-7.13 (m, 4H), $7.06(\mathrm{~d}, J=2.6 \mathrm{~Hz}, 1 \mathrm{H}), 7.00(\mathrm{dd}, J=8.5,2.6 \mathrm{~Hz}, 1 \mathrm{H}), 6.82-6.78$ $(\mathrm{m}, 2 \mathrm{H}), 4.87(\mathrm{~s}, 2 \mathrm{H}), 3.91(\mathrm{~s}, 3 \mathrm{H}), 2.56(\mathrm{~s}, 3 \mathrm{H}) ;{ }^{13} \mathrm{C}$ NMR $\left(125 \mathrm{MHz}, \mathrm{CDCl}_{3}\right): \delta=197.3\left(\mathrm{C}_{\mathrm{q}}\right), 161.9\left(\mathrm{C}_{\mathrm{q}}\right)$, 154.2 $\left(\mathrm{C}_{\mathrm{q}}\right), 143.4\left(\mathrm{C}_{\mathrm{q}}\right), 142.3\left(\mathrm{C}_{\mathrm{q}}\right), 136.3\left(\mathrm{C}_{\mathrm{q}}\right), 133.0\left(\mathrm{C}_{\mathrm{q}}\right), 132.7(\mathrm{CH}), 128.8(\mathrm{CH}), 128.8(\mathrm{CH}), 128.7(\mathrm{CH})$, 128.6 (CH), $127.7(\mathrm{CH}), 115.9(\mathrm{CH}), 114.6\left(\mathrm{C}_{\mathrm{q}}\right), 113.8(\mathrm{CH}), 55.6\left(\mathrm{CH}_{3}\right), 50.8\left(\mathrm{CH}_{2}\right), 26.6\left(\mathrm{CH}_{3}\right)$; IR (ATR): $\tilde{v}=1681,1604,1468,1267,1123,838,724,599 \mathrm{~cm}^{-1}$; MS (ESI) m/z (relative intensity) 423 (100) $[\mathrm{M}+\mathrm{K}]^{+}, 407$ (12) $[\mathrm{M}+\mathrm{Na}]^{+}, 385(46)[\mathrm{M}+\mathrm{H}]^{+} ; \mathrm{HR}-\mathrm{MS}(\mathrm{ESI}): \mathrm{m} / \mathrm{z}$ calcd for $\left[\mathrm{C}_{23} \mathrm{H}_{20} \mathrm{~N}_{4} \mathrm{O}_{2}+\mathrm{H}\right]^{+}$385.1659, found 385.1659. The spectral data are in accordance with those reported in the literature. ${ }^{[121]}$<smiles>COc1cc(-c2ccc(C(C)=O)cc2)c(-c2nnn[nH]2)c(-c2ccc(C(C)=O)cc2)c1</smiles>

1,1'-\{2'-(1-Benzyl-1H-tetrazol-5-yl)-5'-methoxy-[1,1':3',1"-terphenyl]-4,4"'-diyl)bis(ethan-1-one\} (105bc'): M.p.: $187^{\circ} \mathrm{C} ;{ }^{1} \mathrm{H}$ NMR $\left(500 \mathrm{MHz}, \mathrm{CDCl}_{3}\right): \delta=7.76-7.72(\mathrm{~m}, 4 \mathrm{H}), 7.27-7.23(\mathrm{~m}, 1 \mathrm{H}), 7.18-$ $7.12(\mathrm{~m}, 2 \mathrm{H}), 7.07-7.03(\mathrm{~m}, 6 \mathrm{H}), 6.74-6.70(\mathrm{~m}, 2 \mathrm{H}), 4.71(\mathrm{~s}, 2 \mathrm{H}), 3.95(\mathrm{~s}, 3 \mathrm{H}), 2.54(\mathrm{~s}, 6 \mathrm{H}) ;{ }^{13} \mathrm{C}$ NMR $\left(125 \mathrm{MHz}, \mathrm{CDCl}_{3}\right): \delta=197.3\left(\mathrm{C}_{\mathrm{q}}\right), 161.4\left(\mathrm{C}_{\mathrm{q}}\right), 152.4\left(\mathrm{C}_{\mathrm{q}}\right), 144.2\left(\mathrm{C}_{\mathrm{q}}\right), 143.3\left(\mathrm{C}_{\mathrm{q}}\right), 136.3\left(\mathrm{C}_{\mathrm{q}}\right), 132.4\left(\mathrm{C}_{\mathrm{q}}\right)$, $129.1(\mathrm{CH}), 128.9(\mathrm{CH}), 128.8(\mathrm{CH}), 128.2(\mathrm{CH}), 128.0(\mathrm{CH}), 115.5(\mathrm{CH}), 113.2\left(\mathrm{C}_{\mathrm{q}}\right), 55.8\left(\mathrm{CH}_{3}\right), 50.7$ $\left(\mathrm{CH}_{2}\right), 26.6\left(\mathrm{CH}_{3}\right)$; IR (ATR): $\tilde{v}=1682,1597,1398,1353,1266,1211,839,728,609 \mathrm{~cm}^{-1} ; \mathrm{MS}$ (ESI) $\mathrm{m} / \mathrm{z}$ 
(relative intensity) $541(100)[\mathrm{M}+\mathrm{K}]^{+}, 525(43)[\mathrm{M}+\mathrm{Na}]^{+}, 503(75)[\mathrm{M}+\mathrm{H}]^{+}$; HR-MS (ESI): $\mathrm{m} / z$ calcd for $\left[\mathrm{C}_{31} \mathrm{H}_{26} \mathrm{~N}_{4} \mathrm{O}_{3}+\mathrm{H}\right]^{+}$503.2078, found 503.2078.

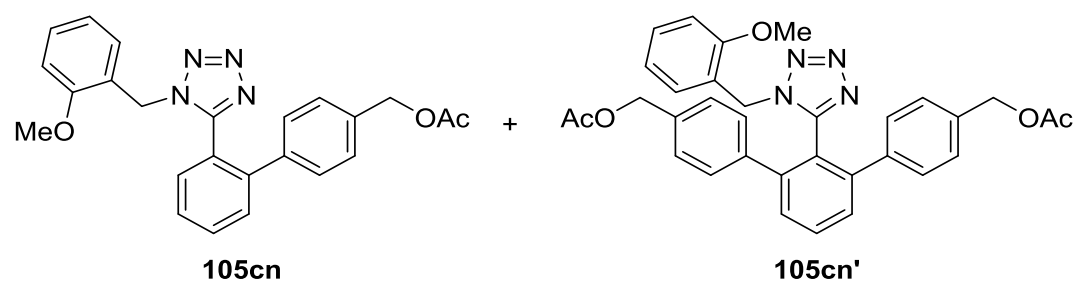

[2'-\{1-(2-Methoxybenzyl)-1H-tetrazol-5-yl\}-[1,1'-biphenyl]-4-yl]methyl (105cn) acetate and [2'-\{1(2-methoxybenzyl)-1H-tetrazol-5-yl\}-[1,1':3',1"-terphenyl]-4,4"-diyl]bis(methylene) diacetate (105cn'):

The representative procedure $\mathbf{D}$ was followed using tetrazole $104 \mathrm{c}(133 \mathrm{mg}, 0.50 \mathrm{mmol})$ and 4bromobenzyl acetate (25n) (172 mg, 0.75 mmol), yielding 105cn (157 mg, 76\%) and 105cn' (39.8 mg, $14 \%)$ as colorless solids.

105cn: M.p.: $120^{\circ} \mathrm{C} ;{ }^{1} \mathrm{H}$ NMR $\left(500 \mathrm{MHz}, \mathrm{CDCl}_{3}\right): \delta=7.63$ (ddd, $J=7.8,7.1,1.7 \mathrm{~Hz}, 1 \mathrm{H}$ ), 7.55 (ddd, $J=$ 7.8, 1.3, $0.6 \mathrm{~Hz}, 1 \mathrm{H}), 7.48-7.41(\mathrm{~m}, 2 \mathrm{H}), 7.27-7.24(\mathrm{~m}, 2 \mathrm{H}), 7.19$ (ddd, J = 8.3, 7.3, 2.0 Hz, 1H), 7.13$7.11(\mathrm{~m}, 2 \mathrm{H}), 6.80-6.74(\mathrm{~m}, 2 \mathrm{H}), 6.68(\mathrm{~d}, \mathrm{~J}=8.8 \mathrm{~Hz}, 1 \mathrm{H}), 5.08(\mathrm{~s}, 2 \mathrm{H}), 4.76(\mathrm{~s}, 2 \mathrm{H}), 3.51(\mathrm{~s}, 3 \mathrm{H}), 2.13(\mathrm{~s}$, $3 \mathrm{H}) ;{ }^{13} \mathrm{C}$ NMR $\left(125 \mathrm{MHz}, \mathrm{CDCl}_{3}\right): \delta=170.6\left(\mathrm{C}_{\mathrm{q}}\right), 156.6\left(\mathrm{C}_{\mathrm{q}}\right), 154.5\left(\mathrm{C}_{\mathrm{q}}\right), 141.3\left(\mathrm{C}_{\mathrm{q}}\right), 138.8\left(\mathrm{C}_{\mathrm{q}}\right), 135.6\left(\mathrm{C}_{\mathrm{q}}\right)$, $131.2(\mathrm{CH}), 131.1(\mathrm{CH}), 130.0(\mathrm{CH}), 130.0(\mathrm{CH}), 129.8(\mathrm{CH}), 128.7(\mathrm{CH}), 128.3(\mathrm{CH}), 127.6(\mathrm{CH}), 123.1$ (C $\left.\mathrm{C}_{\mathrm{q}}\right), 121.4\left(\mathrm{C}_{\mathrm{q}}\right), 120.4(\mathrm{CH}), 110.2(\mathrm{CH}), 65.6\left(\mathrm{CH}_{2}\right), 55.1\left(\mathrm{CH}_{3}\right), 46.1\left(\mathrm{CH}_{2}\right), 21.0\left(\mathrm{CH}_{3}\right)$; IR (ATR): $\tilde{v}=$ 2943, 1734, 1496, 1466, 1373, 1224, 1024, 836, $754 \mathrm{~cm}^{-1}$; MS (EI) $\mathrm{m} / \mathrm{z}$ (relative intensity) 413 (27) [M-H] $]^{+}, 205$ (37), 178 (20), 177 (52), 121 (100), 91 (84); HR-MS (ESI): m/z calcd for $\left[\mathrm{C}_{24} \mathrm{H}_{22} \mathrm{~N}_{4} \mathrm{O}_{3}+\mathrm{H}\right]^{+}$ 415.1765, found 415.1760. The spectral data are in accordance with those reported in the literature. ${ }^{[121]}$<smiles>COc1ccccc1-n1nnnc1-c1c(-c2ccc(COC(C)=O)cc2)cccc1-c1ccc(OC(C)=O)cc1</smiles>

(2'-(1-(2-methoxybenzyl)-1H-tetrazol-5-yl)-[1,1':3',1"-terphenyl]-4,4"-diyl)bis(methylene) diacetate (105cn'):

M.p.: $153^{\circ} \mathrm{C} ;{ }^{1} \mathrm{H}$ NMR $\left(500 \mathrm{MHz}, \mathrm{CDCl}_{3}\right): \delta=7.67$ (ddd, $\left.J=8.0,7.4,0.5 \mathrm{~Hz}, 1 \mathrm{H}\right), 7.47(\mathrm{~d}, J=7.7 \mathrm{~Hz}, 2 \mathrm{H})$, $7.24-7.20(\mathrm{~m}, 1 \mathrm{H}), 7.16-7.14(\mathrm{~m}, 4 \mathrm{H}), 6.98-6.94(\mathrm{~m}, 4 \mathrm{H}), 6.70$ (ddd, $J=8.2,6.1,1.1 \mathrm{~Hz}, 2 \mathrm{H}), 6.61-$ 
$6.56(\mathrm{~m}, 1 \mathrm{H}), 5.03(\mathrm{~s}, 4 \mathrm{H}), 4.75(\mathrm{~s}, 2 \mathrm{H}), 3.48(\mathrm{~s}, 3 \mathrm{H}), 2.09(\mathrm{~s}, 6 \mathrm{H}) ;{ }^{13} \mathrm{C} \mathrm{NMR}\left(125 \mathrm{MHz}, \mathrm{CDCl}_{3}\right): \delta=170.6$ $\left(C_{q}\right), 156.6\left(C_{q}\right), 152.6\left(C_{q}\right), 143.0\left(C_{q}\right), 138.9\left(C_{q}\right), 135.2\left(C_{q}\right), 130.9(C H), 130.1(C H), 130.0(C H), 129.4$ $(\mathrm{CH}), 129.0(\mathrm{CH}), 127.9(\mathrm{CH}), 121.5\left(\mathrm{C}_{q}\right), 120.8\left(\mathrm{C}_{\mathrm{q}}\right), 120.5(\mathrm{CH}), 110.4(\mathrm{CH}), 65.7\left(\mathrm{CH}_{2}\right), 55.2\left(\mathrm{CH}_{3}\right), 45.4$ $\left(\mathrm{CH}_{2}\right), 21.0\left(\mathrm{CH}_{3}\right)$; IR (ATR): $\tilde{v}=2954,1735,1496,1461,1378,1225,1026,802,756,731 \mathrm{~cm}^{-1}$; MS (EI) m/z (relative intensity) 562 (15) [M] ${ }^{+}, 353$ (29), 325 (30), 265 (80), 121 (100), 91 (81), 43 (32); HR-MS (ESI): $m / z$ calcd for $\left[\mathrm{C}_{33} \mathrm{H}_{30} \mathrm{~N}_{4} \mathrm{O}_{5}+\mathrm{H}\right]^{+} 563.2289$, found 563.2282 .

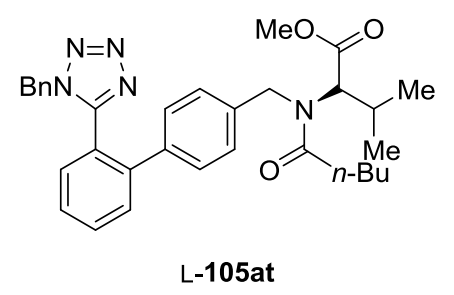

Methyl $\quad N$-\{(2'-(1-benzyl-1H-tetrazol-5-yl)-[1,1'-biphenyl]-4-yl)methyl\}-N-pentanoyl-L-valinate (L105at): The representative procedure $D$ was followed using tetrazole 104a $(59 \mathrm{mg}, 0.25 \mathrm{mmol}$, 1.0 equiv) and aryl bromide L-25t (146 mg, $0.38 \mathrm{mmol}, 1.5$ equiv), yielding L-105at (97.1 mg, 72\%).

Alternatively the representative procedure $D$ was followed with tetrazole $104 a$ (161 mg, $0.68 \mathrm{mmol}$, 1.2 equiv) and aryl bromide L-25t ( $220 \mathrm{mg}, 0.57 \mathrm{mmol}, 1.0$ equiv), yielding L-105at ( $222 \mathrm{mg}, 74 \%$ ).

M.p.: $75^{\circ} \mathrm{C}$; ${ }^{1} \mathrm{H}$ NMR $\left(300 \mathrm{MHz}\right.$, DMSO-d $\left.6,120^{\circ} \mathrm{C}\right): \delta=7.70$ (ddd, $\left.J=7.8,7.3,1.5 \mathrm{~Hz}, 1 \mathrm{H}\right), 7.57$ (ddd, $J$ $=7.8,1.3,0.7 \mathrm{~Hz}, 1 \mathrm{H}$ ), 7.52 (dd, $J=7.4,1.3 \mathrm{~Hz}, 1 \mathrm{H}$ ), 7.44 (ddd, $J=7.7,1.5,0.6 \mathrm{~Hz}, 1 \mathrm{H}), 7.30-7.19$ (m, $3 \mathrm{H}), 7.10(\mathrm{~d}, J=8.4 \mathrm{~Hz}, 2 \mathrm{H}), 7.00(\mathrm{~d}, J=8.2 \mathrm{~Hz}, 2 \mathrm{H}), 6.90-6.85(\mathrm{~m}, 2 \mathrm{H}), 5.08(\mathrm{~s}, 2 \mathrm{H}), 4.67(\mathrm{~d}, J=$ $16.9 \mathrm{~Hz}, 1 \mathrm{H}), 4.55-4.38(\mathrm{~m}, 2 \mathrm{H}), 2.88(\mathrm{~s}, 3 \mathrm{H}), 2.45-2.20(\mathrm{~m}, 3 \mathrm{H}), 1.63-1.46(\mathrm{~m}, 2 \mathrm{H}), 1.38-1.23(\mathrm{~m}$, $2 \mathrm{H}), 0.95(\mathrm{~d}, J=6.5 \mathrm{~Hz}, 3 \mathrm{H}), 0.90-0.80(\mathrm{~m}, 6 \mathrm{H}) ;{ }^{13} \mathrm{C}$ NMR (75 MHz, DMSO-d $)$ : $\delta=173.0\left(\mathrm{C}_{\mathrm{q}}\right), 169.7$ $\left(C_{q}\right), 153.6\left(C_{q}\right), 141.0\left(C_{q}\right), 137.3\left(C_{q}\right), 136.8\left(C_{q}\right), 133.0\left(C_{q}\right), 130.8(C H), 130.1(C H), 129.7(C H), 128.0$ $(\mathrm{CH}), 127.8(\mathrm{CH}), 127.7(\mathrm{CH}), 127.2(\mathrm{CH}), 127.1(\mathrm{CH}), 126.2(\mathrm{CH}), 122.0\left(\mathrm{C}_{\mathrm{q}}\right), 50.6\left(\mathrm{CH}_{3}\right), 50.0\left(\mathrm{CH}_{2}\right)$, $31.9\left(\mathrm{CH}_{2}\right), 27.0(\mathrm{CH}), 26.4\left(\mathrm{CH}_{2}\right), 21.1\left(\mathrm{CH}_{2}\right), 19.1\left(\mathrm{CH}_{3}\right), 18.0\left(\mathrm{CH}_{3}\right), 12.8(\mathrm{CH})$; IR (ATR): $\tilde{v}=2960,1738$, $1711,1651,1407,1359,1218,766,721,700 \mathrm{~cm}^{-1}$; HR-MS (ESI): $\mathrm{m} / \mathrm{z}$ calcd for $\left[\mathrm{C}_{32} \mathrm{H}_{37} \mathrm{~N}_{5} \mathrm{O}_{3}+\mathrm{H}\right]^{+}$ 540.2969, found 540.2975; HPLC: $t_{\mathrm{R}}(\mathrm{L}-105 \mathrm{at})=26.027$.

HPLC-chromatogram of the product L-105at: 


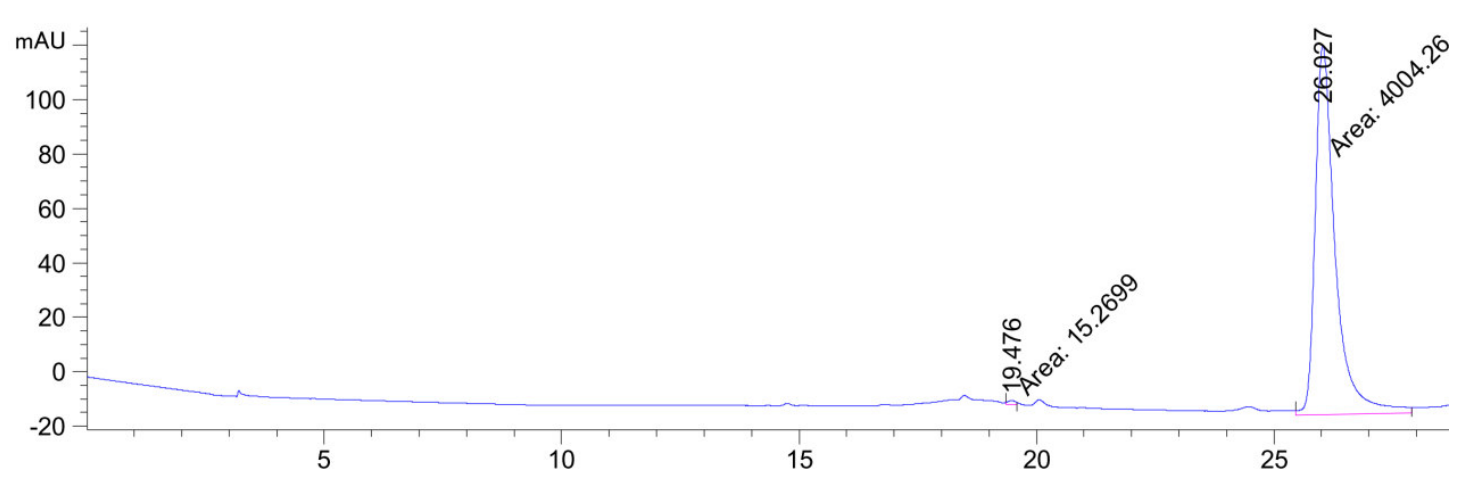

HPLC-chromatogram of independently synthesized D-105at:

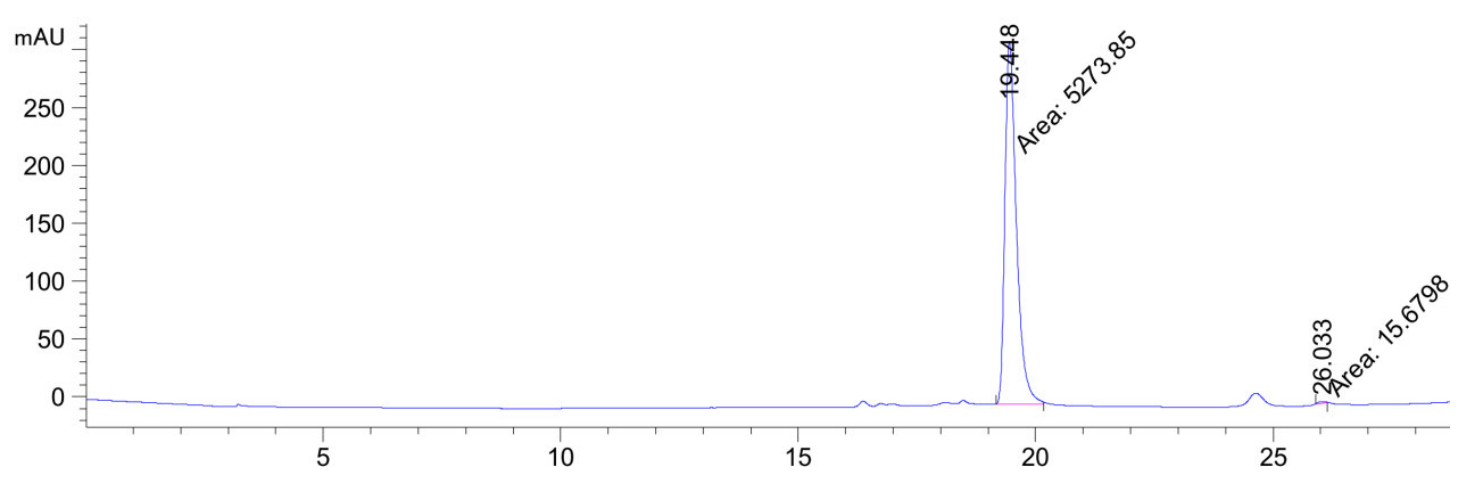

HPLC-chromotgram of a mixture of L- and D-105at:

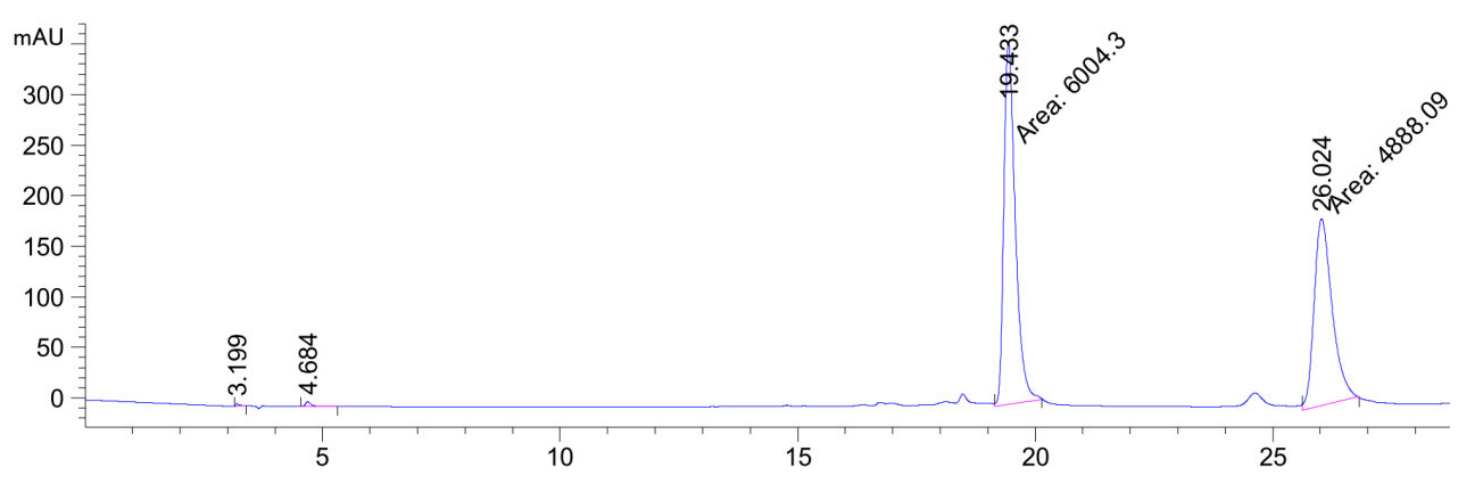

Mercury test and H/D-Exchange Experiment 
<smiles>c1ccc(-c2nnnn2-c2ccccc2)cc1</smiles>

104a<smiles>COc1ccc(Br)cc1</smiles>

25a<smiles></smiles>

105aa: $83 \%$

The representative procedure $\mathbf{G}$ was followed using 104a (118 $\mathrm{mg}, 0.50 \mathrm{mmol}$ ), 4-bromoanisole (25a) (140 mg, $0.75 \mathrm{mmol}$ ) and mercury ( $250 \mathrm{mg}, 2.5$ equiv) was added. The reaction was stopped after $18 \mathrm{~h}$, filtered through celite und purified by column chromatography on silica gel ( $n$-hexane/EtOAc: $2 / 1$ to $1 / 1$ ), yielding $105 \mathrm{aa}$ (142 $\mathrm{mg}, 88 \%$ ) as a colorless solid.<smiles>Cc1ccccc1C1=NCCO1</smiles>

103a<smiles>COc1ccc(Br)cc1</smiles>

25a

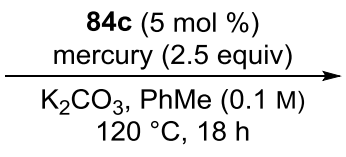
$120^{\circ} \mathrm{C}, 18 \mathrm{~h}$<smiles>COc1ccc(-c2cccc(C)c2C2=NCCO2)cc1</smiles>

103aa: $97 \%$

The representative procedure $\mathbf{F}$ was followed using $102 \mathrm{a}(118 \mathrm{mg}, 0.50 \mathrm{mmol})$ and 4-bromoanisole (25a) $(140 \mathrm{mg}, 0.75 \mathrm{mmol})$, after $30 \mathrm{~min}$ reaction time (GC-conversion: $29 \%)$ mercury (250 $\mathrm{mg}$, 2.5 equiv) was added. The reaction was stopped after $18 \mathrm{~h}$, filtered through celite und purified by column chromatography on silica gel ( $n$-hexane/EtOAc: $2 / 1$ to $1 / 1$ ), yielding 103aa (130 mg, 97\%) as a colorless solid.

At the same time, the reaction was carried out as above but without the addition of mercury, yielding 103aa (131 $\mathrm{mg}, 98 \%$ ) as a colorless solid.

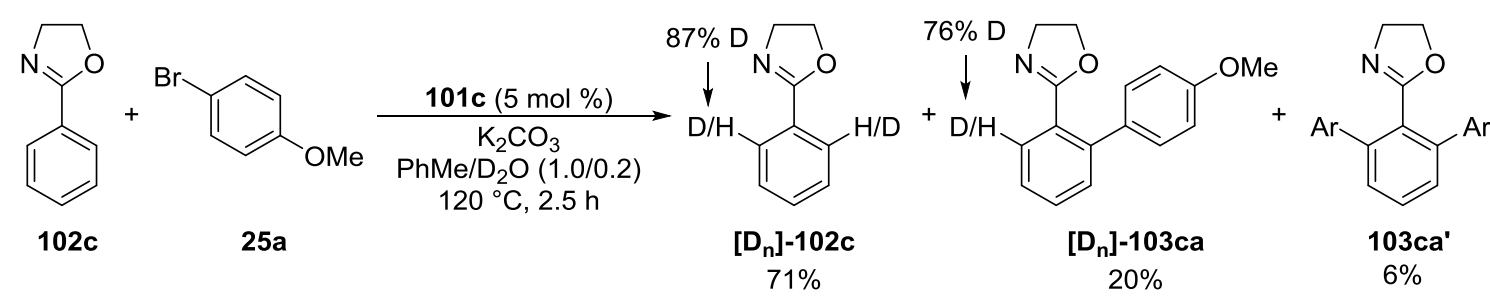

$\mathrm{Ar}=4$-methoxybenzene

The representative procedure $\mathbf{C}$ was followed using oxazoline $102 \mathrm{c}(80.6 \mathrm{mg}, 0.50 \mathrm{mmol}, 1.0$ equiv) and aryl bromide $25 \mathrm{a}$ (140 mg, $0.75 \mathrm{mmol}, 1.5$ equiv) in a toluene $(0.5 \mathrm{~mL}) / \mathrm{D}_{2} \mathrm{O}(0.1 \mathrm{~mL})$ mixture for $2.5 \mathrm{~h}$, yielding 102c (53 mg, 71\%), 103ca (25 mg, 20\%) and 103ca' (12 mg, 6\%). The deuterium incorporation was determined by ${ }^{1} \mathrm{H}$ NMR spectroscopy. 
Experimental Part
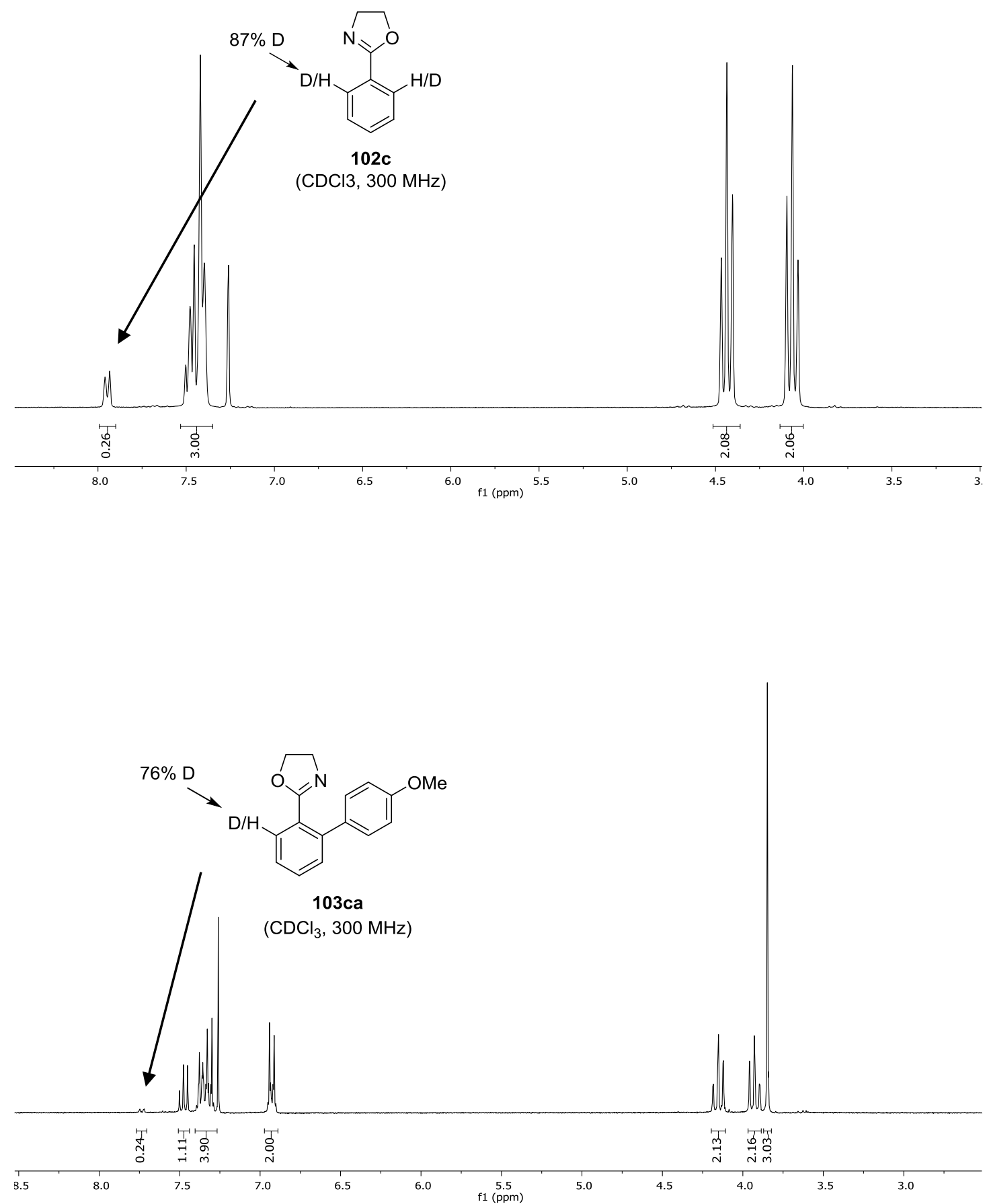


\subsubsection{Meta-C-H Alkylation}

\subsubsection{Synthesis of Complexes}

\section{Synthesis of $\left[\mathrm{Ru}(\mathrm{O}-\mathrm{Val}-\mathrm{Piv})_{2}(p\right.$-cymene $\left.)\right](111)$}

A suspension of $\left[\mathrm{RuCl}_{2}(p \text {-cymene })\right]_{2}(612 \mathrm{mg}, 1.0 \mathrm{mmol})$ and sodium pivaloyl-L-valinate $(839 \mathrm{mg}$, $2.05 \mathrm{mmol})$ in $\mathrm{CH}_{2} \mathrm{Cl}_{2}(50 \mathrm{~mL})$ was stirred at $23^{\circ} \mathrm{C}$ for $20 \mathrm{~h}$ in the dark. Then the residue was filtered over celite and the filtrate was dried under vacuum to obtain [Ru(O-Val-Piv $)_{2}(p$-cymene)] (111) (1.23 $\mathrm{g}, 97 \%)$ as a red hygroscopic solid.

M.p.: $69{ }^{\circ} \mathrm{C}$ (under atmosphere of air); ${ }^{1} \mathbf{H}$ NMR (400 MHz, $\mathrm{CDCl}_{3}$, mixture of isomers): $\delta=6.21$ and 5.99 (bs, 2H), $5.86-5.69(\mathrm{~m}, 1 \mathrm{H}), 5.64(\mathrm{~d}, J=5.6 \mathrm{~Hz})$ and $5.60(\mathrm{~d}, J=5.5 \mathrm{~Hz}, 2 \mathrm{H}), 5.43(\mathrm{~d}, J=5.6 \mathrm{~Hz})$ and $5.39(\mathrm{~d}, J=5.5 \mathrm{~Hz}, 1 \mathrm{H}$ ), $4.32(\mathrm{bs}, 2 \mathrm{H}), 2.89$ (hept, $J=6.9 \mathrm{~Hz}$ ) and 2.78 (hept, $J=6.9 \mathrm{~Hz}, 1 \mathrm{H}$ ), 2.28 (s) and $2.20(\mathrm{~s}, 3 \mathrm{H}), 2.14-2.00(\mathrm{~m}, 2 \mathrm{H}) 1.35(\mathrm{~d}, J=6.9 \mathrm{~Hz}), 1.34(\mathrm{~d}, J=6.9 \mathrm{~Hz}), 1.31(\mathrm{~d}, J=6.9 \mathrm{~Hz}), 1.31$ $(\mathrm{d}, J=6.9 \mathrm{~Hz}, 6 \mathrm{H}), 1.19(\mathrm{~s}, 18 \mathrm{H}), 0.94-0.74(\mathrm{~m}, 12 \mathrm{H}) ;{ }^{13} \mathrm{C} \mathrm{NMR}\left(101 \mathrm{MHz}, \mathrm{CDCl}_{3}\right.$, mixture of isomers): $\delta$ $=183.7\left(\mathrm{bs}, \mathrm{C}_{\mathrm{q}}\right), 178.3\left(\mathrm{C}_{\mathrm{q}}\right), 100.3$ and $98.4\left(\mathrm{C}_{\mathrm{q}}\right), 94.0\left(\mathrm{C}_{\mathrm{q}}\right), 79.2,79.1,78.7,78.6,78.2,77.7$ and $77.4(4$ $\mathrm{CH}), 58.4$ (bs, $\mathrm{CH}$ ), $39.0\left(\mathrm{C}_{\mathrm{q}}\right), 31.6$ and $31.6(\mathrm{CH}), 31.4(\mathrm{bs}, \mathrm{CH}), 27.7\left(\mathrm{CH}_{3}\right), 22.6,22.5,22.5$ and $22.4(2$ $\left.\mathrm{CH}_{3}\right), 19.3$ and $17.8\left(\mathrm{CH}_{3}\right), 18.8$ and $18.6\left(\mathrm{CH}_{3}\right)$; IR (ATR): $\tilde{v}=3444,2961,1650,1500,1366,1317$, $1198,875,769,572 \mathrm{~cm}^{-1}$; HR-MS (ESI): $\mathrm{m} / z$ calcd for $\left[\mathrm{C}_{30} \mathrm{H}_{50} \mathrm{~N}_{2} \mathrm{O}_{6} \mathrm{Ru}+\mathrm{H}\right]^{+} 637.2794$, found 637.2780; Elemental analysis $111+2 \mathrm{H}_{2} \mathrm{O}$ : calcd C 53.63\% H 8.10\% N 4.17\%; found C 53.41\% H 7.69\% N 3.99\%.

\section{Synthesis of [RuCl(O-Val-Piv)(p-cymene)] (114)}

Synthesis of silver pivaloyl-L-valinate (115): A mixture of silveroxide $(1.16 \mathrm{~g}, 5.0 \mathrm{mmol})$ and pivaloyl-Lvalinol $(1.21 \mathrm{~g}, 6.0 \mathrm{mmol})$ in deionized water $(40 \mathrm{~mL})$ was sonicated for $38 \mathrm{~h}$ at $23^{\circ} \mathrm{C}$ in the dark. Then the residue was filtered off and the filtrate was dried under vacuum to obtain the light-sensitive product as a colorless solid in a quantitative yield. The compound was directly used in the synthesis of complex 114: A suspension of $\left[\mathrm{RuCl}_{2}(p \text {-cymene })\right]_{2}(612 \mathrm{mg}, 1.0 \mathrm{mmol})$ and silver pivaloyl-L-valinate (632 mg, $2.05 \mathrm{mmol})$ in $\mathrm{CH}_{2} \mathrm{Cl}_{2}(50 \mathrm{~mL})$ was stirred at $23^{\circ} \mathrm{C}$ for $20 \mathrm{~h}$ in the dark. Then the residue was filtered over celite and the filtrate was dried under vacuum to obtain [RuCl(O-Val-Piv)( $p$-cymene)] (114) (386 $\mathrm{mg}, 82 \%$ ) as a red hygroscopic solid.

M.p. (decomp.): $158-160{ }^{\circ} \mathrm{C} ;{ }^{1} \mathrm{H}$ NMR (400 MHz, $\mathrm{CDCl}_{3}$, mixture of isomers): $\delta=6.22$ and 5.99 (bs, $1 \mathrm{H}), 5.63(\mathrm{~d}, J=5.8 \mathrm{~Hz})$ and $5.60(\mathrm{~d}, J=5.9 \mathrm{~Hz})$ and $5.46(\mathrm{~d}, J=5.9 \mathrm{~Hz}, 2 \mathrm{H}), 5.43(\mathrm{~d}, J=5.8 \mathrm{~Hz})$ and $5.39(\mathrm{~d}, J=5.8 \mathrm{~Hz}$ ) and $5.33(\mathrm{~d}, J=5.9 \mathrm{~Hz}, 2 \mathrm{H}$ ), 4.31 (bs, $1 \mathrm{H}), 2.90$ (hept, $J=7.0 \mathrm{~Hz}$ ) and 2.83 (hept, $J=$ $7.0 \mathrm{~Hz}, 1 \mathrm{H}), 2.29(\mathrm{~s})$ and $2.20(\mathrm{~s})$ and $2.14(\mathrm{~s}, 3 \mathrm{H}), 2.04(\mathrm{bs}, 1 \mathrm{H}), 1.38-1.23(\mathrm{~m}, 6 \mathrm{H}), 1.20(\mathrm{~s}, 9 \mathrm{H}), 0.85$ $(\mathrm{d}, J=6.6 \mathrm{~Hz}, 3 \mathrm{H}), 0.81(\mathrm{~d}, J=6.6 \mathrm{~Hz}, 3 \mathrm{H}) ;{ }^{13} \mathrm{C} \mathrm{NMR}\left(125 \mathrm{MHz}, \mathrm{CDCl}_{3}\right.$, mixture of isomers): $\delta=178.1$ $\left(C_{q}\right), 177.7$ (bs, $\left.C_{q}\right), 101.2$ and $100.1\left(C_{q}\right), 96.7$ and $93.9\left(C_{q}\right), 81.3$ and 79.0 and $78.5(C H), 80.5$ and 
78.1 and $77.5(\mathrm{CH}), 58.5(\mathrm{CH}), 38.9\left(\mathrm{C}_{\mathrm{q}}\right), 31.5(\mathrm{CH}), 30.9$ and $30.7(\mathrm{CH}), 27.6\left(\mathrm{CH}_{3}\right), 22.5$ and $22.4\left(\mathrm{CH}_{3}\right)$, 22.4 and $22.2\left(\mathrm{CH}_{3}\right), 19.3$ and $18.9\left(\mathrm{CH}_{3}\right), 18.8$ and $17.6\left(\mathrm{CH}_{3}\right)$; IR (ATR): $\tilde{v}=3425,3056,2871,1657$, 1566, 1497, 1450, 1388, 1320, $1199 \mathrm{~cm}^{-1}$; HR-MS (ESI): $\mathrm{m} / z$ calcd for $\left[\mathrm{C}_{20} \mathrm{H}_{32} \mathrm{NO}_{3} \mathrm{RuCl}-\mathrm{Cl}\right]^{+} 436.1426$, found 436.1426; Elemental analysis: calcd C 51.00\% H 6.85\% N 2.97\%; found C 51.00\% H 6.95\% N $2.98 \%$.

\section{Cyclometalation}

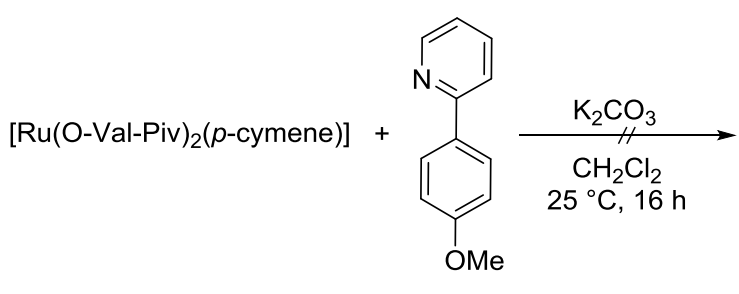

111

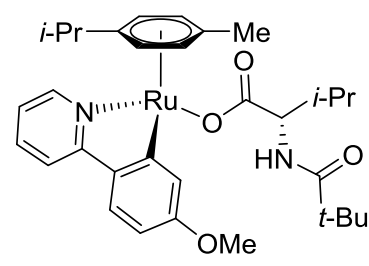

116

A mixture of $\quad\left[\mathrm{Ru}(\mathrm{O}-\mathrm{V} \text { al-Piv })_{2}(p\right.$-cymene $\left.)\right] \quad$ (111) $\quad(40.0 \mathrm{mg}, \quad 60 \mu \mathrm{mol}, \quad 1.0$ equiv), $2-(4-$ methoxyphenyl)pyridine $(11.1 \mathrm{mg}, 60 \mu \mathrm{mol})$ and $\mathrm{K}_{2} \mathrm{CO}_{3}(16.6 \mathrm{mg}, 120 \mu \mathrm{mol})$ in $\mathrm{CH}_{2} \mathrm{Cl}_{2}(3.0 \mathrm{~mL})$ was stirred at $65{ }^{\circ} \mathrm{C}$ for $4 \mathrm{~h}$ under an atmosphere of Ar. ${ }^{1} \mathrm{H}$ NMR and ESI-MS analysis showed no product formation.

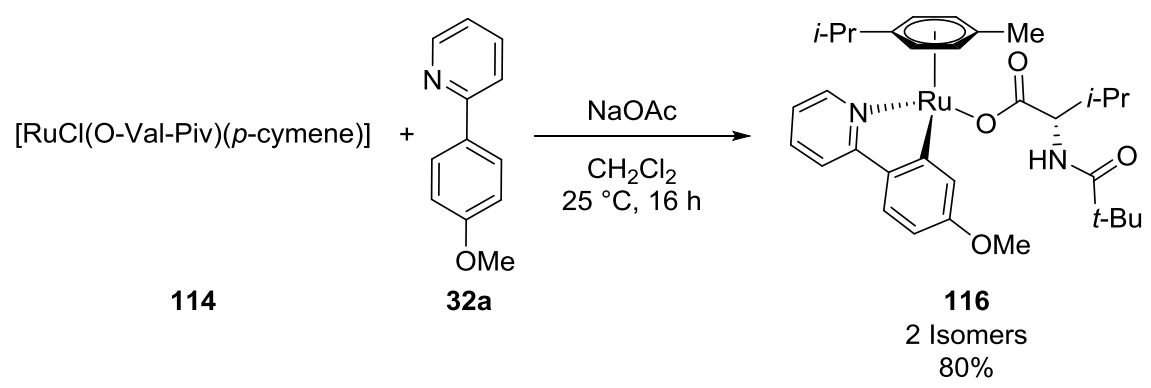

A mixture of [RuCl(O-Val-Piv)(p-cymene)] (114) $(32.8 \mathrm{mg}, 60 \mu \mathrm{mol}), 2$-(4-methoxyphenyl)pyridine (32a) $(11.1 \mathrm{mg}, 60 \mu \mathrm{mol})$ and $\mathrm{K}_{2} \mathrm{CO}_{3}(16.6 \mathrm{mg}, 0.12 \mathrm{mmol})$ in $\mathrm{CH}_{2} \mathrm{Cl}_{2}(3.0 \mathrm{~mL})$ was stirred at $65^{\circ} \mathrm{C}$ for $4 \mathrm{~h}$ under an atmosphere of Ar. Filtration over celite and purification by column chromatography $\left(\mathrm{CH}_{2} \mathrm{Cl}_{2} / \mathrm{MeOH}: 20 / 1\right)$ yielded the cyclometalated complex as a mixture of isomers (29.8 $\left.\mathrm{mg}, 80 \%\right)$.

${ }^{1} \mathrm{H}$ NMR $\left(600 \mathrm{MHz}, \mathrm{CDCl}_{3}\right): \delta=9.15$ (ddd, $\left.J=5.7,1.6,0.8 \mathrm{~Hz}, 1 \mathrm{H}\right), 7.69(\mathrm{~d}, J=2.5 \mathrm{~Hz}, 1 \mathrm{H}), 7.60$ (ddd, $J$ $=8.5,7.0,1.6 \mathrm{~Hz}, 1 \mathrm{H}), 7.58-7.53(\mathrm{~m}, 2 \mathrm{H}), 6.96(\mathrm{ddd}, J=7.2,5.7,1.6 \mathrm{~Hz}, 1 \mathrm{H}), 6.58(\mathrm{dd}, J=8.5,2.5 \mathrm{~Hz}$, $1 \mathrm{H}), 6.08(\mathrm{~d}, J=8.5 \mathrm{~Hz}, 1 \mathrm{H}), 5.56(\mathrm{dd}, J=5.8,1.3 \mathrm{~Hz}, 1 \mathrm{H}), 5.53(\mathrm{dd}, J=5.9,1.2 \mathrm{~Hz}, 1 \mathrm{H}), 5.17(\mathrm{dd}, J=$ 6.0, $1.3 \mathrm{~Hz}, 1 \mathrm{H}$ ), 4.98 (dd, $J=6.0,1.3 \mathrm{~Hz}, 1 \mathrm{H}), 4.59$ (dd, J = 8.6, $4.8 \mathrm{~Hz}, 1 \mathrm{H}), 3.90(\mathrm{~s}, 3 \mathrm{H}), 2.44$ (sept, $J=$ $6.9 \mathrm{~Hz}, 1 \mathrm{H}), 2.21(\mathrm{septd}, J=6.9,4.8 \mathrm{~Hz}, 1 \mathrm{H}), 2.04(\mathrm{~s}, 3 \mathrm{H}), 1.23(\mathrm{~s}, 10 \mathrm{H}), 0.98(\mathrm{~d}, J=6.9 \mathrm{~Hz}, 3 \mathrm{H}), 0.96$ (d, $J=6.9 \mathrm{~Hz}, 3 \mathrm{H}), 0.93(\mathrm{~d}, J=6.9 \mathrm{~Hz}, 3 \mathrm{H}), 0.88(\mathrm{~d}, J=6.9 \mathrm{~Hz}, 3 \mathrm{H}) ;{ }^{13} \mathrm{C} \mathrm{NMR}\left(125 \mathrm{MHz}, \mathrm{CDCl}_{3}\right): \delta=183.3$ 
$\left(\mathrm{C}_{q}\right), 171.9\left(\mathrm{C}_{\mathrm{q}}\right), 165.0\left(\mathrm{C}_{\mathrm{q}}\right), 159.7\left(\mathrm{C}_{\mathrm{q}}\right), 154.4(\mathrm{CH}), 136.7\left(\mathrm{C}_{\mathrm{q}}\right), 136.5(\mathrm{CH}), 125.0(\mathrm{CH}), 124.0(\mathrm{CH}), 120.3$ $(\mathrm{CH}), 118.2(\mathrm{CH}), 108.8(\mathrm{CH}), 100.6\left(\mathrm{C}_{q}\right), 100.5\left(\mathrm{C}_{q}\right), 90.7(\mathrm{CH}), 89.7(\mathrm{CH}), 84.5(\mathrm{CH}), 82.5(\mathrm{CH}), 64.8$ $\left(\mathrm{C}_{\mathrm{q}}\right), 57.0(\mathrm{CH}), 55.3\left(\mathrm{CH}_{3}\right), 41.5\left(\mathrm{C}_{\mathrm{q}}\right) 31.5(\mathrm{CH}), 31.0(\mathrm{CH}), 27.7\left(\mathrm{CH}_{3}\right), 22.8\left(\mathrm{CH}_{3}\right), 21.9\left(\mathrm{CH}_{3}\right), 19.2\left(\mathrm{CH}_{3}\right)$, $19.0\left(\mathrm{CH}_{3}\right), 18.0\left(\mathrm{CH}_{3}\right) ;$ IR (ATR): $\tilde{v}=2963,1741,1663,1583,1509,1463,1275,1211,1185,775 \mathrm{~cm}^{-1}$; HR-MS (ESI) $\mathrm{m} / \mathrm{z}$ calcd for $\left[\mathrm{C}_{32} \mathrm{H}_{42} \mathrm{~N}_{2} \mathrm{O}_{4} \mathrm{Ru}+\mathrm{H}\right]^{+} 621.2270$; found 621.2261 .

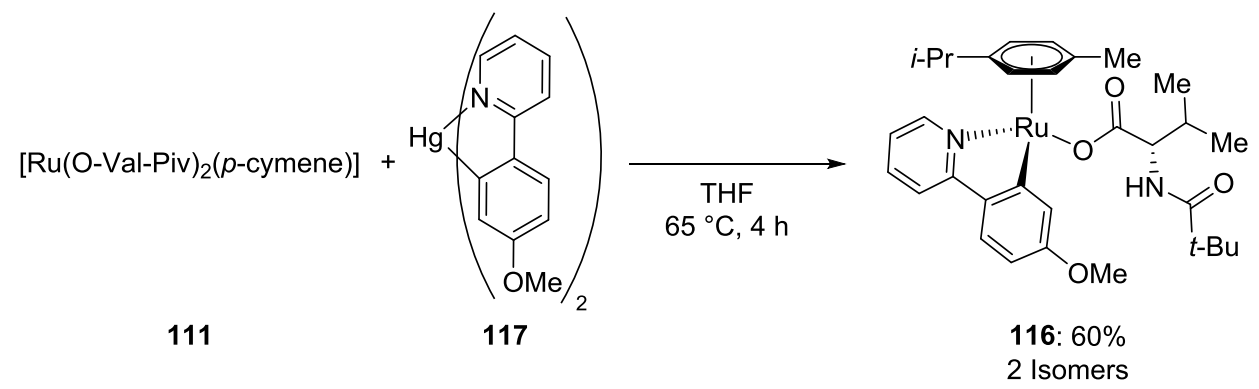

A solution of [Ru(O-Val-Piv) ${ }_{2}(p$-cymene $\left.)\right](111)(40.0 \mathrm{mg}, 60 \mu \mathrm{mol})$ and $117(17.1 \mathrm{mg}, 30 \mu \mathrm{mol})$ in thf was stirred at $65^{\circ} \mathrm{C}$ for $4 \mathrm{~h}$ under an atmosphere of Ar. Purification by column chromatography $\left(\mathrm{CH}_{2} \mathrm{Cl}_{2} / \mathrm{MeOH}: 20 / 1\right)$ yielded the cyclometalated complex 116 as a mixture of isomers (22.4 mg, 60\%) as a yellow gluey solid (for characterization see page 177).

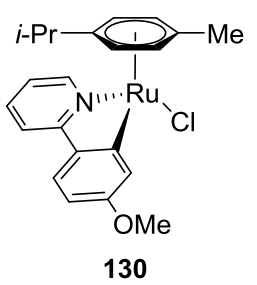

\section{Synthesis of ruthenium(II) complex 130}

Following a literature procedure ${ }^{[164]}$ a suspension of $\left[\mathrm{RuCl}_{2}(p \text {-cymene })\right]_{2}(31.1 \mathrm{mg}, 0.05 \mathrm{mmol}), 32 \mathrm{a}$ (18.5 mg, $0.10 \mathrm{mmol}$ ) and $\mathrm{NaOAc}(9.9 \mathrm{mg}, 0.12 \mathrm{mmol})$ in $\mathrm{CH}_{2} \mathrm{Cl}_{2}(5 \mathrm{~mL})$ was stirred at $23^{\circ} \mathrm{C}$ for $20 \mathrm{~h}$. Column chromatography (EtOAc/n-hexane: $2 / 1 \rightarrow 4 / 1$ ) of the crude product yielded complex 130 (28 $\mathrm{mg}, 66 \%$ ) as an orange solid.

M.p. (decomp.): $192{ }^{\circ} \mathrm{C} ;{ }^{1} \mathrm{H}$ NMR $\left(400 \mathrm{MHz}, \mathrm{CDCl}_{3}\right): \delta=9.17-9.12(\mathrm{~m}, 1 \mathrm{H}), 7.69(\mathrm{~d}, J=2.5 \mathrm{~Hz}, 1 \mathrm{H})$, 7.60-7.50 (m, 3H), 6.92 (ddd, $J=6.0,6.0,2.4 \mathrm{~Hz}, 1 \mathrm{H}$ ), 6.57 (dd, $J=8.5,2.5 \mathrm{~Hz}, 1 \mathrm{H}), 5.54(\mathrm{~d}, J=6.0 \mathrm{~Hz}$, 1H), $5.51(\mathrm{~d}, J=6.0 \mathrm{~Hz}, 1 \mathrm{H}), 5.16(\mathrm{~d}, J=5.9 \mathrm{~Hz}, 1 \mathrm{H}), 4.96(\mathrm{~d}, J=5.9 \mathrm{~Hz}, 1 \mathrm{H}), 3.89(\mathrm{~s}, 3 \mathrm{H}), 2.42$ (hept $J=$ $6.9 \mathrm{~Hz}, 1 \mathrm{H}), 2.02(\mathrm{~s}, 3 \mathrm{H}), 0.96(\mathrm{~d}, J=6.9 \mathrm{~Hz}, 3 \mathrm{H}), 0.87(\mathrm{~d}, J=6.9 \mathrm{~Hz}, 3 \mathrm{H}) ;{ }^{13} \mathrm{C} \mathrm{NMR}\left(125 \mathrm{MHz}, \mathrm{CDCl}_{3}\right): \delta$ $=183.5\left(\mathrm{C}_{\mathrm{q}}\right), 165.1\left(\mathrm{C}_{\mathrm{q}}\right), 159.7\left(\mathrm{C}_{\mathrm{q}}\right), 154.5(\mathrm{CH}), 136.8\left(\mathrm{C}_{\mathrm{q}}\right), 136.6(\mathrm{CH}), 125.0(\mathrm{CH}), 124.0(\mathrm{CH}), 120.4$ $(\mathrm{CH}), 118.2(\mathrm{CH}), 108.8(\mathrm{CH}), 100.6\left(\mathrm{C}_{q}\right), 100.3\left(\mathrm{C}_{q}\right), 90.6(\mathrm{CH}), 89.6(\mathrm{CH}), 84.4(\mathrm{CH}), 82.4(\mathrm{CH}), 55.2$ 
$\left(\mathrm{CH}_{3}\right), 30.7(\mathrm{CH}), 22.5\left(\mathrm{CH}_{3}\right), 21.6\left(\mathrm{CH}_{3}\right), 18.7\left(\mathrm{CH}_{3}\right)$; IR (ATR): $\tilde{v}=2963,1583,1545,1453,1274,1204$, $1169,1031,856 \mathrm{~cm}^{-1} ; \mathrm{HR}-\mathrm{MS}$ (ESI) m/z calcd for $\left[\mathrm{C}_{22} \mathrm{H}_{24} \mathrm{NO}_{3} \mathrm{RuCl}+\mathrm{Na}\right]^{+} 478.0485$; found 478.0477 .

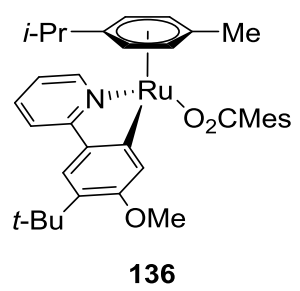

Synthesis of ruthenium complex $\left[\mathrm{Ru}\left(\mathrm{O}_{2} \mathrm{CMes}\right)\left(5-t-\mathrm{Bu}, 4-\mathrm{OMeC}_{6} \mathrm{H}_{2}\right.\right.$-pyridine $)(p$-cymene $\left.)\right]$ 136:

Following a literature procedure ${ }^{[31]}$ for a similar complex a suspension of $\left[\mathrm{Ru}\left(\mathrm{O}_{2} \mathrm{CMes}\right)_{2}(p\right.$-cymene $\left.)\right]$ (112 mg, $0.20 \mathrm{mmol}$ ) and 121aa (48.3 mg, $0.20 \mathrm{mmol})$ in $\mathrm{CH}_{2} \mathrm{Cl}_{2}(8 \mathrm{~mL})$ was stirred at $23^{\circ} \mathrm{C}$ for $18 \mathrm{~h}$, and stirred for further $2 \mathrm{~h}$ after addition of $\mathrm{K}_{2} \mathrm{CO}_{3}(55.3 \mathrm{mg}, 0.40 \mathrm{mmol})$. Column chromatography (EtOAc/n-hexane: $1 / 1 \rightarrow 4 / 1$ ) of the crude product yielded complex 136 (132 mg, 99\%) as an orange solid.

M.p. (decomp.): $116^{\circ} \mathrm{C} ;{ }^{1} \mathrm{H}$ NMR $\left(400 \mathrm{MHz}, \mathrm{CDCl}_{3}\right): \delta=9.53$ (ddd, $\left.J=5.8,1.6,0.8 \mathrm{~Hz}, 1 \mathrm{H}\right), 7.85(\mathrm{~s}, 1 \mathrm{H})$, $7.58-7.48(\mathrm{~m}, 2 \mathrm{H}), 7.41$ (s, 1H), 6.88 (ddd, $J=7.2,5.7,1.6 \mathrm{~Hz}, 1 \mathrm{H}), 6.47$ (d, $J=0.6 \mathrm{~Hz}, 2 \mathrm{H}$ ), 5.73 (dd, $J=$ 5.9, $1.3 \mathrm{~Hz}, 2 \mathrm{H}$ ), $5.46(\mathrm{dd}, J=6.1,1.2 \mathrm{~Hz}, 1 \mathrm{H}), 5.28(\mathrm{dd}, J=5.9,1.2 \mathrm{~Hz}, 1 \mathrm{H}), 4.00(\mathrm{~s}, 3 \mathrm{H}), 2.40$ (hept, $J=$ $6.9 \mathrm{~Hz}, 1 \mathrm{H}), 2.06(\mathrm{~s}, 3 \mathrm{H}), 2.02(\mathrm{~s}, 3 \mathrm{H}), 1.62(\mathrm{~d}, J=0.6 \mathrm{~Hz}, 6 \mathrm{H}), 1.37(\mathrm{~s}, 9 \mathrm{H}), 0.96(\mathrm{~d}, J=6.9 \mathrm{~Hz}, 3 \mathrm{H}), 0.92$ $(\mathrm{d}, J=6.9 \mathrm{~Hz}, 3 \mathrm{H}) ;{ }^{13} \mathrm{C}$ NMR $\left(101 \mathrm{MHz}, \mathrm{CDCl}_{3}\right): \delta=180.5\left(\mathrm{C}_{\mathrm{q}}\right), 176.2\left(\mathrm{C}_{\mathrm{q}}\right), 166.4\left(\mathrm{C}_{\mathrm{q}}\right), 158.6\left(\mathrm{C}_{\mathrm{q}}\right), 156.1$ $(\mathrm{CH}), 137.5\left(\mathrm{C}_{\mathrm{q}}\right), 136.5(\mathrm{CH}), 136.3\left(\mathrm{C}_{\mathrm{q}}\right), 135.5\left(\mathrm{C}_{\mathrm{q}}\right), 133.5\left(\mathrm{C}_{\mathrm{q}}\right), 132.9\left(\mathrm{C}_{\mathrm{q}}\right), 127.6(\mathrm{CH}), 122.2(\mathrm{CH}), 121.1$ $(\mathrm{CH}), 119.0(\mathrm{CH}), 117.0(\mathrm{CH}), 99.6\left(\mathrm{C}_{q}\right), 97.9\left(\mathrm{C}_{\mathrm{q}}\right), 88.8(\mathrm{CH}), 88.7(\mathrm{CH}), 85.5(\mathrm{CH}), 82.3(\mathrm{CH}), 55.1\left(\mathrm{CH}_{3}\right)$, 34.4 $\left(\mathrm{C}_{\mathrm{q}}\right), 31.1(\mathrm{CH}), 30.0\left(\mathrm{CH}_{3}\right), 22.9\left(\mathrm{CH}_{3}\right), 22.2\left(\mathrm{CH}_{3}\right), 20.8\left(\mathrm{CH}_{3}\right), 19.1\left(\mathrm{CH}_{3}\right), 19.0\left(\mathrm{CH}_{3}\right)$; IR (ATR): $\tilde{v}=$ 2955, 2917, 1708, 1588, 1528, 1426, 1355, 1274, 1211, 1178, $1031 \mathrm{~cm}^{-1}$; HR-MS (ESI) m/z calcd for $\left[\mathrm{C}_{36} \mathrm{H}_{43} \mathrm{NO}_{3} \mathrm{Ru}+\mathrm{H}\right]^{+} 640.2365$, found 640.2359 .

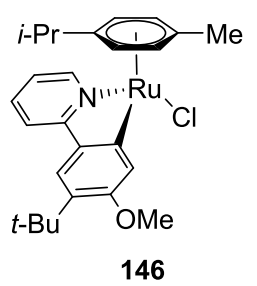

\section{Synthesis of ruthenium complex 146:}

A suspension of $\quad\left[\mathrm{RuCl}_{2}(p \text {-cymene })\right]_{2} \quad(31.1 \mathrm{mg}, \quad 0.05 \mathrm{mmol}), \quad 2-\{3-($ tert-butyl)-4methoxyphenyl\}pyridine 121aa $(24.1 \mathrm{mg}, 0.10 \mathrm{mmol})$ and $\mathrm{NaOAc}(9.9 \mathrm{mg}, 0.12 \mathrm{mmol})$ in $\mathrm{CH}_{2} \mathrm{Cl}_{2}$ 
$\left(5 \mathrm{~mL}\right.$ ) was stirred at $23^{\circ} \mathrm{C}$ for $20 \mathrm{~h}$. Column chromatography (EtOAc/n-hexane 2/1) of the crude product yielded complex 146 (37.1 mg, 73\%) as an orange solid.

M.p. (decomp.): $174{ }^{\circ} \mathrm{C} ;{ }^{1} \mathrm{H}$ NMR $\left(300 \mathrm{MHz}, \mathrm{CDCl}_{3}\right): \delta=9.14$ (ddd, $\left.J=5.8,1.2,1.2 \mathrm{~Hz}, 1 \mathrm{H}\right), 7.62(\mathrm{~s}, 1 \mathrm{H})$, 7.62-7.52 (m, 2H), $7.48(\mathrm{~s}, 1 \mathrm{H}), 6.97-6.88(\mathrm{~m}, 1 \mathrm{H}), 5.57(\mathrm{~d}, J=5.9 \mathrm{~Hz}, 1 \mathrm{H}), 5.48(\mathrm{~d}, J=5.9 \mathrm{~Hz}, 1 \mathrm{H})$, $5.19(\mathrm{~d}, J=5.8 \mathrm{~Hz}, 1 \mathrm{H}), 5.00(\mathrm{~d}, J=5.8 \mathrm{~Hz}, 1 \mathrm{H}), 4.00(\mathrm{~s}, 3 \mathrm{H}), 2.48$ (hept, $J=7.0 \mathrm{~Hz}, 1 \mathrm{H}), 2.01(\mathrm{~s}, 3 \mathrm{H})$, $1.37(\mathrm{~s}, 9 \mathrm{H}), 1.01(\mathrm{~d}, J=7.0 \mathrm{~Hz}, 3 \mathrm{H}), 0.92(\mathrm{~d}, J=7.0 \mathrm{~Hz}, 3 \mathrm{H}) ;{ }^{13} \mathrm{C}$ NMR $\left(125 \mathrm{MHz}, \mathrm{CDCl}_{3}\right): \delta=180.3\left(\mathrm{C}_{\mathrm{q}}\right)$, $165.6\left(\mathrm{C}_{\mathrm{q}}\right), 159.0\left(\mathrm{C}_{\mathrm{q}}\right), 154.3(\mathrm{CH}), 136.2(\mathrm{CH}), 135.4\left(\mathrm{C}_{\mathrm{q}}\right), 132.5\left(\mathrm{C}_{\mathrm{q}}\right), 122.0(\mathrm{CH}), 121.3(\mathrm{CH}), 119.7$ $(\mathrm{CH}), 117.9(\mathrm{CH}), 100.5\left(\mathrm{C}_{\mathrm{q}}\right), 99.4\left(\mathrm{C}_{\mathrm{q}}\right), 89.6(\mathrm{CH}), 89.6(\mathrm{CH}), 84.1(\mathrm{CH}), 82.6(\mathrm{CH}), 55.0\left(\mathrm{CH}_{3}\right), 34.4\left(\mathrm{C}_{\mathrm{q}}\right)$, $30.8(\mathrm{CH}), 29.9\left(\mathrm{CH}_{3}\right), 22.6\left(\mathrm{CH}_{3}\right), 21.7\left(\mathrm{CH}_{3}\right), 18.7\left(\mathrm{CH}_{3}\right)$; IR (ATR): $\tilde{v}=3062,2949,1587,1467,1426$, $1216,1098,1026,774,745 \mathrm{~cm}^{-1}$; HR-MS (ESI): $\mathrm{m} / \mathrm{z}$ calcd for $\left[\mathrm{C}_{26} \mathrm{H}_{32} \mathrm{CINORu}+\mathrm{Na}\right]^{+} 534.1112$, found 534.1113.

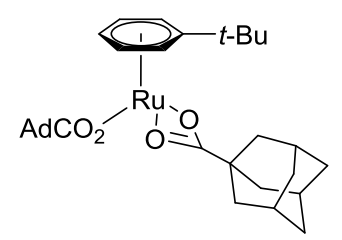

\section{Synthesis of Ruthenium(II) complex 126}

A suspension of $\left[\mathrm{RuCl}_{2}\left(t-\mathrm{BuC}_{6} \mathrm{H}_{5}\right)\right]_{2}(\mathbf{1 2 8})(153 \mathrm{mg}, 0.25 \mathrm{mmol}), 1$-adamantylcarboxylic acid $(270 \mathrm{mg}$, $1.5 \mathrm{mmol})$ and $\mathrm{K}_{2} \mathrm{CO}_{3}(346 \mathrm{mg}, 2.5 \mathrm{mmol})$ in toluene $(20 \mathrm{~mL})$ was stirred at $23^{\circ} \mathrm{C}$ for $42 \mathrm{~h}$. Removal of the solvent, dissolution in $\mathrm{CH}_{2} \mathrm{Cl}_{2}$ and filtration over celite yielded 126 (294 mg, 99\%) as an orange solid.

M.p.: $187^{\circ} \mathrm{C} ;{ }^{1} \mathbf{H}$ NMR $\left(300 \mathrm{MHz}, \mathrm{CDCl}_{3}\right): \delta=5.92-5.85(\mathrm{~m}, 1 \mathrm{H}), 5.82-5.72(\mathrm{~m}, 4 \mathrm{H}), 1.99-1.54(\mathrm{~m}$, 30H), $1.42(\mathrm{~s}, 9 \mathrm{H}) ;{ }^{13} \mathrm{C}$ NMR (125 MHz, $\left.\mathrm{CDCl}_{3}\right): \delta=191.4\left(\mathrm{C}_{\mathrm{q}}\right), 104.6\left(\mathrm{C}_{\mathrm{q}}\right), 78.4(\mathrm{CH}), 78.0(\mathrm{CH}), 75.5$ $(\mathrm{CH}), 42.2\left(\mathrm{C}_{q}\right), 39.4\left(\mathrm{CH}_{2}\right), 36.9\left(\mathrm{CH}_{2}\right), 34.6\left(\mathrm{C}_{q}\right), 30.3\left(\mathrm{CH}_{3}\right), 28.4(\mathrm{CH})$; IR (ATR): $\tilde{v}=2901,2849,1611$, $1482,1449,1335,1295,813,679,488 \mathrm{~cm}^{-1}$; MS (LIFDI) $\mathrm{m} / \mathrm{z}$ calcd for $\left[\mathrm{C}_{32} \mathrm{H}_{44} \mathrm{O}_{4} \mathrm{Ru}\right]^{+} 594.2$, found 594.1.

\subsubsection{Ruthenium(II)-catalyzed direct meta-Alkylation}

\section{Ruthenium(II)-catalyzed direct meta-Alkylation using [RuCl(O-Val-Piv)(p-cymene)]}




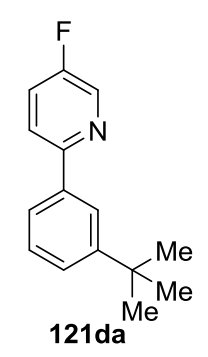

2-[3-(tert-Butyl)phenyl]-5-fluoropyridine (121da): The general procedure $\mathbf{H}$ was followed using substrate 32d (87 mg, $0.50 \mathrm{mmol}$ ) and bromide 119a (206 mg, $1.50 \mathrm{mmol})$. After $20 \mathrm{~h}$, purification by column chromatography ( $n$-hexane/EtOAc: 100/1) yielded 121da (57 mg, 50\%) as a colorless oil.

${ }^{1} \mathrm{H} \mathrm{NMR}\left(300 \mathrm{MHz}, \mathrm{CDCl}_{3}\right): \delta=8.54(\mathrm{~d}, J=3.0 \mathrm{~Hz}, 1 \mathrm{H}), 7.98(\mathrm{dd}, J=2.0,2.0 \mathrm{~Hz}, 1 \mathrm{H}), 7.73-7.67(\mathrm{~m}, 2 \mathrm{H})$, 7.48-7.36 (m, 3H), $1.38(\mathrm{~s}, 9 \mathrm{H}) ;{ }^{13} \mathrm{C}$ NMR $\left(75 \mathrm{MHz}, \mathrm{CDCl}_{3}\right): \delta=158.7$ (d, $\left.J=257 \mathrm{~Hz}, \mathrm{C}_{\mathrm{q}}\right), 154.3$ (d, $J=$ $\left.4 \mathrm{~Hz}, \mathrm{C}_{\mathrm{q}}\right), 151.7\left(\mathrm{C}_{\mathrm{q}}\right), 138.2\left(\mathrm{C}_{\mathrm{q}}\right), 137.6(\mathrm{~d}, \mathrm{~J}=24 \mathrm{~Hz}, \mathrm{CH}), 128.5(\mathrm{CH}), 126.0(\mathrm{CH}), 124.0(\mathrm{CH}), 123.8$ (CH), $123.4(\mathrm{~d}, J=19 \mathrm{~Hz}, \mathrm{CH}), 121.5(\mathrm{~d}, J=4 \mathrm{~Hz}, \mathrm{CH}), 34.8\left(\mathrm{C}_{\mathrm{q}}\right), 31.4\left(\mathrm{CH}_{3}\right) ;{ }^{19} \mathrm{~F}$ NMR $\left\{{ }^{1} \mathrm{H}\right\}(282 \mathrm{MHz}$, $\mathrm{CDCl}_{3}$ ): $\delta=-130.2$ (s). IR (ATR): $\tilde{v}=3065,2962,1671,1579,1468,1224,1017,834 \mathrm{~cm}^{-1} ;$ MS (EI) $\mathrm{m} / \mathrm{z}$ (relative intensity) 229 (38) [M] $]^{+}, 214$ (100), 199 (23), 185 (21); HR-MS (EI): m/z calcd for [ $\left.\mathrm{C}_{15} \mathrm{H}_{16} \mathrm{FN}\right]^{+}$ 229.1261, found 229.1260 .

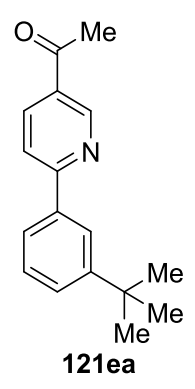

1-\{2-[3-(tert-Butyl)phenyl]pyridin-4-yl\}ethan-1-one (121ea): The general procedure $\mathbf{H}$ was followed using [RuCl(O-Val-Piv)(p-cymene)] $(23.6 \mathrm{mg}, 10.0 \mathrm{~mol} \%)$, substrate $32 \mathrm{e}(99 \mathrm{mg}, 0.50 \mathrm{mmol})$ and bromide 119a (206 mg, $1.50 \mathrm{mmol})$. After $20 \mathrm{~h}$, purification by column chromatography ( $n$ hexane/EtOAc: $20 / 1$ ) yielded 121 ea (70 $\mathrm{mg}, 56 \%)$ as a colorless solid.

M.p.: $86^{\circ} \mathrm{C} ;{ }^{1} \mathrm{H}$ NMR $\left(300 \mathrm{MHz}, \mathrm{CDCl}_{3}\right): \delta=9.22(\mathrm{dd}, J=2.3,0.9 \mathrm{~Hz}, 1 \mathrm{H}), 8.26(\mathrm{dd}, J=8.4,2.3 \mathrm{~Hz}, 1 \mathrm{H})$, 8.10 (dd, $J=1.9,1.9 \mathrm{~Hz}, 1 \mathrm{H}), 7.84-7.79(\mathrm{~m}, 2 \mathrm{H}), 7.50$ (ddd, $J=7.9,2.1,1.2 \mathrm{~Hz}, 1 \mathrm{H}), 7.41$ (dd, $J=7.7$, $7.7 \mathrm{~Hz}, 1 \mathrm{H}), 2.64(\mathrm{~s}, 3 \mathrm{H}), 1.38(\mathrm{~s}, 9 \mathrm{H}) ;{ }^{13} \mathrm{C} \mathrm{NMR}\left(75 \mathrm{MHz}, \mathrm{CDCl}_{3}\right): \delta=196.5\left(\mathrm{C}_{\mathrm{q}}\right), 161.5\left(\mathrm{C}_{\mathrm{q}}\right), 151.9\left(\mathrm{C}_{\mathrm{q}}\right)$, $150.1(\mathrm{CH}), 137.9\left(\mathrm{C}_{\mathrm{q}}\right), 136.2(\mathrm{CH}), 130.4\left(\mathrm{C}_{q}\right), 128.6(\mathrm{CH}), 127.2(\mathrm{CH}), 124.6(\mathrm{CH}), 124.4(\mathrm{CH}), 120.3$ (CH), $34.9\left(\mathrm{C}_{\mathrm{q}}\right), 31.3\left(\mathrm{CH}_{3}\right), 26.7\left(\mathrm{CH}_{3}\right)$; IR (ATR): $\tilde{v}=3024,2959,1593,1494,1453,1044,1027,809$ $\mathrm{cm}^{-1}$; MS (EI) m/z (relative intensity) 253 (15) [M] ${ }^{+}, 238$ (45), 210 (6), 197 (6); HR-MS (EI): m/z calcd for $\left[\mathrm{C}_{17} \mathrm{H}_{19} \mathrm{NO}\right]^{+} 253.1461$, found 253.1463. 


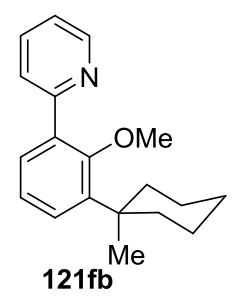

2-[2-Methoxy-3-(1-methylcyclohexyl)phenyl]pyridine (121fb): The general procedure H was followed, using [RuCl(O-Val-Piv)(p-cymene)] (23.6 mg, $10.0 \mathrm{~mol} \%), 32 \mathrm{f}(93 \mathrm{mg}, 0.50 \mathrm{mmol}$ ) and 119b (266 mg, $1.50 \mathrm{mmol}$ ). After $20 \mathrm{~h}$, purification by column chromatography ( $n$-hexane/EtOAc: 20/1) yielded $121 \mathrm{fb}$ (63 $\mathrm{mg}, 44 \%$ ) as a colorless oil.

${ }^{1} \mathrm{H}$ NMR $\left(300 \mathrm{MHz}, \mathrm{CDCl}_{3}\right): \delta=8.71(\mathrm{~d}, J=4.7 \mathrm{~Hz}, 1 \mathrm{H}), 7.74-7.65(\mathrm{~m}, 2 \mathrm{H}), 7.43(\mathrm{dd}, J=7.5,1.7 \mathrm{~Hz}, 1 \mathrm{H})$, 7.35 (dd, $J=8.0,1.7 \mathrm{~Hz}, 1 \mathrm{H}$ ), 7.20 (ddd, $J=6.5,4.9,2.2 \mathrm{~Hz}, 1 \mathrm{H}$ ), 7.12 (dd, $J=7.8,7.8 \mathrm{~Hz}, 1 \mathrm{H}$ ), 3.28 (s, $3 \mathrm{H}), 2.20-2.11(\mathrm{~m}, 2 \mathrm{H}), 1.74-1.64(\mathrm{~m}, 2 \mathrm{H}), 1.59-1.40(\mathrm{~m}, 6 \mathrm{H}), 1.31(\mathrm{~s}, 3 \mathrm{H}) ;{ }^{13} \mathrm{C} \mathrm{NMR}\left(75 \mathrm{MHz}, \mathrm{CDCl}_{3}\right)$ : $\delta=158.1\left(\mathrm{C}_{\mathrm{q}}\right), 157.9\left(\mathrm{C}_{\mathrm{q}}\right), 149.7(\mathrm{CH}), 142.0\left(\mathrm{C}_{\mathrm{q}}\right), 136.1(\mathrm{CH}), 134.5\left(\mathrm{C}_{\mathrm{q}}\right), 129.6(\mathrm{CH}), 128.5(\mathrm{CH}), 124.7$ $(\mathrm{CH}), 123.5(\mathrm{CH}), 121.6(\mathrm{CH}), 61.2\left(\mathrm{CH}_{3}\right), 38.8\left(\mathrm{C}_{\mathrm{q}}\right), 37.9\left(\mathrm{CH}_{2}\right), 27.5\left(\mathrm{CH}_{3}\right), 26.6\left(\mathrm{CH}_{2}\right), 23.0\left(\mathrm{CH}_{2}\right)$; IR (ATR): $\tilde{v}=3058,2923,1586,1407,1211,1005,775 \mathrm{~cm}^{-1}$; MS (EI) $\mathrm{m} / \mathrm{z}$ (relative intensity) 281 (43) $[\mathrm{M}]^{+}, 266$ (90), 248 (47), 222 (36); HR-MS (EI): $\mathrm{m} / z$ calcd for $\left[\mathrm{C}_{19} \mathrm{H}_{23} \mathrm{NO}^{+}\right.$281.1774, found 281.1785.

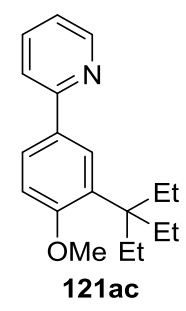

2-[3-(3-Ethylpentan-3-yl)-4-methoxyphenyl]pyridine (121ac): The general procedure $\mathbf{H}$ was followed using substrate 32a (93 mg, $0.50 \mathrm{mmol})$ and bromide $119 \mathrm{c}(269 \mathrm{mg}, 1.50 \mathrm{mmol})$. After $20 \mathrm{~h}$, purification by column chromatography ( $n$-hexane/EtOAc: $20 / 1$ ) yielded 121ac (50 mg, 35\%) as a colorless solid.

M.p.: $80{ }^{\circ} \mathrm{C} ;{ }^{1} \mathrm{H}$ NMR $\left(300 \mathrm{MHz}, \mathrm{CDCl}_{3}\right): \delta=8.66(\mathrm{~d}, J=4.9 \mathrm{~Hz}, 1 \mathrm{H}), 7.88(\mathrm{~d}, J=2.3 \mathrm{~Hz}, 1 \mathrm{H}), 7.83(\mathrm{dd}, J$ $=8.4,2.3 \mathrm{~Hz}, 1 \mathrm{H}), 7.73-7.64(\mathrm{~m}, 2 \mathrm{H}), 7.13(\mathrm{ddd}, J=6.8,4.6,2.3 \mathrm{~Hz}, 1 \mathrm{H}), 6.92(\mathrm{~d}, J=8.4 \mathrm{~Hz}, 1 \mathrm{H}), 3.84$ $(\mathrm{s}, 3 \mathrm{H}), 1.86(\mathrm{q}, J=7.3 \mathrm{~Hz}, 6 \mathrm{H}), 0.64(\mathrm{t}, J=7.3 \mathrm{~Hz}, 9 \mathrm{H}) ;{ }^{13} \mathrm{C}$ NMR $\left(75 \mathrm{MHz}, \mathrm{CDCl}_{3}\right): \delta=159.6\left(\mathrm{C}_{\mathrm{q}}\right), 157.9$ $\left(\mathrm{C}_{\mathrm{q}}\right), 149.5(\mathrm{CH}), 136.5(\mathrm{CH}), 134.8\left(\mathrm{C}_{\mathrm{q}}\right), 131.1\left(\mathrm{C}_{\mathrm{q}}\right), 128.3(\mathrm{CH}), 125.5(\mathrm{CH}), 121.1(\mathrm{CH}), 119.9(\mathrm{CH})$, $111.5(\mathrm{CH}), 55.2\left(\mathrm{CH}_{3}\right), 44.6\left(\mathrm{C}_{\mathrm{q}}\right), 26.1\left(\mathrm{CH}_{2}\right), 8.5\left(\mathrm{CH}_{3}\right)$; IR (ATR): $\tilde{v}=2961,2938,2873,1562,1460$, 1439, 1270, 1238, 1088, $816 \mathrm{~cm}^{-1}$; MS (EI) m/z (relative intensity) 283 (23) [M]+, 284 (76), 212 (60), 198 (100), 167 (27); HR-MS (EI): $m / z$ calcd for $\left[\mathrm{C}_{19} \mathrm{H}_{25} \mathrm{NO}\right]^{+} 283.1931$, found 283.1933. 


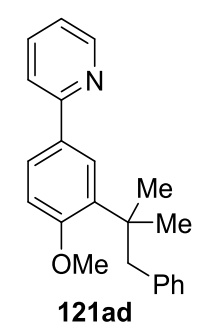

2-[4-Methoxy-3-(2-methyl-1-phenylpropan-2-yl)phenyl]pyridine (121ad): The general procedure H was followed, using 32a (93 mg, $0.50 \mathrm{mmol}$ ) and 119d (320 mg, $1.50 \mathrm{mmol})$. After $20 \mathrm{~h}$, purification by column chromatography ( $n$-hexane/EtOAc: $40 / 1$ ) yielded 121ad (101 mg, 64\%) as a colorless oil. ${ }^{1} \mathrm{H}$ NMR $\left(300 \mathrm{MHz}, \mathrm{CDCl}_{3}\right): \delta=8.61(\mathrm{~d}, J=4.9 \mathrm{~Hz}, 1 \mathrm{H}), 7.86(\mathrm{dd}, J=8.5,2.3 \mathrm{~Hz}, 1 \mathrm{H}), 7.69-7.62(\mathrm{~m}, 2 \mathrm{H})$, $7.56(\mathrm{~d}, J=8.1 \mathrm{~Hz}, 1 \mathrm{H}), 7.16-7.06(\mathrm{~m}, 4 \mathrm{H}), 7.03(\mathrm{~d}, J=8.5 \mathrm{~Hz}, 1 \mathrm{H}), 6.93-6.87(\mathrm{~m}, 2 \mathrm{H}), 3.99(\mathrm{~s}, 3 \mathrm{H})$, $3.19(\mathrm{~s}, 2 \mathrm{H}), 1.43(\mathrm{~s}, 6 \mathrm{H}) ;{ }^{13} \mathrm{C} \mathrm{NMR}\left(75 \mathrm{MHz}, \mathrm{CDCl}_{3}\right): \delta=159.3\left(\mathrm{C}_{\mathrm{q}}\right), 157.7\left(\mathrm{C}_{\mathrm{q}}\right), 149.4(\mathrm{CH}), 139.9\left(\mathrm{C}_{\mathrm{q}}\right)$, $136.5(\mathrm{CH}), 136.4\left(\mathrm{C}_{\mathrm{q}}\right), 131.5\left(\mathrm{C}_{\mathrm{q}}\right), 130.3(\mathrm{CH}), 127.1(\mathrm{CH}), 126.6(\mathrm{CH}), 126.0(\mathrm{CH}), 125.5(\mathrm{CH}), 121.2$ (CH), $120.0(\mathrm{CH}), 111.5(\mathrm{CH}), 55.2\left(\mathrm{CH}_{3}\right), 46.0\left(\mathrm{CH}_{2}\right), 39.3\left(\mathrm{C}_{\mathrm{q}}\right), 28.0\left(\mathrm{CH}_{3}\right)$; IR (ATR): $\tilde{v}=3002,2959$, 1586, 1462, 1270, 1236, 1086, 1025, $779 \mathrm{~cm}^{-1}$; MS (EI) $\mathrm{m} / \mathrm{z}$ (relative intensity) 317 (5) [M] , 226 (98), 198 (13), 167 (18), 91 (17); HR-MS (EI): $m / z$ calcd for [ $\left.\mathrm{C}_{22} \mathrm{H}_{23} \mathrm{NO}\right]^{+} 317.1774$, found 317.1793.

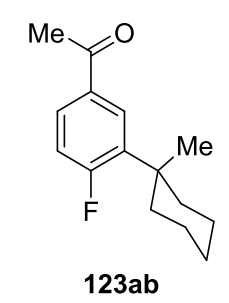

1-[4-Fluoro-3-(1-methylcyclohexyl)phenyl]ethan-1-one (123ab):

The general procedure I was followed using ketimine $47 \mathrm{a}(152 \mathrm{mg}, 0.50 \mathrm{mmol}),\left[\mathrm{Ru}\left(\mathrm{O}_{2} \mathrm{CAd}\right)_{2}(t-\right.$ $\left.\left.\mathrm{BuC}_{6} \mathrm{H}_{5}\right)\right](29.7 \mathrm{mg}, 50 \mu \mathrm{mol}, 10 \mathrm{~mol} \%)$ and 1-bromo-1-methylcyclohexane (119b) (266 mg, 1.50 $\mathrm{mmol}$ ). Purification by column chromatography ( $n$-pentane/Et $2 \mathrm{O}: 50 / 1)$ yielded 123ab $(87.0 \mathrm{mg}, 74 \%)$ as a colorless oil.

The general procedure I was followed using ketimine $47 a(152 \mathrm{mg}, 0.50 \mathrm{mmol}),\left[\operatorname{Ru}\left(\mathrm{O}_{2} \mathrm{CAd}\right)_{2}(t-\right.$ $\left.\left.\mathrm{BuC}_{6} \mathrm{H}_{5}\right)\right](14.9 \mathrm{mg}, 25 \mu \mathrm{mol}, 5.0 \mathrm{~mol} \%)$, 1- $\mathrm{AdCO}_{2} \mathrm{H} \quad(13.5 \mathrm{mg}, 75 \mu \mathrm{mol}, 15 \mathrm{~mol} \%)$, 1-bromo-1methylcyclohexane (119b) $(266 \mathrm{mg}, 1.50 \mathrm{mmol}$ ). Purification by column chromatography ( $n$ pentane/Et $2 \mathrm{O}: 50 / 1$ ) yielded $123 \mathrm{ab}(88.3 \mathrm{mg}, 75 \%)$ as a colorless oil.

The general procedure I was followed using ketimine $47 \mathrm{a}(152 \mathrm{mg}, 0.50 \mathrm{mmol}),\left[\operatorname{Ru}\left(\mathrm{O}_{2} \mathrm{CAd}\right)_{2}(t-\right.$ $\left.\left.\mathrm{BuC}_{6} \mathrm{H}_{5}\right)\right](7.7 \mathrm{mg}, 10 \mu \mathrm{mol}, 2.0 \mathrm{~mol} \%), 1-\mathrm{AdCO}_{2} \mathrm{H}(5.4 \mathrm{mg}, 30 \mu \mathrm{mol}, 6 \mathrm{~mol} \%)$ and 1-bromo-1methylcyclohexane (119b) $(266 \mathrm{mg}, 1.50 \mathrm{mmol})$. Purification by column chromatography ( $n$ pentane/Et ${ }_{2} \mathrm{O}: 50 / 1$ ) yielded $123 \mathrm{ab}(34.0 \mathrm{mg}, 30 \%)$ as a colorless oil. 
The general procedure I was followed using ketimine $47 \mathrm{a}(152 \mathrm{mg}, 0.50 \mathrm{mmol}),\left[\mathrm{Ru}\left(\mathrm{O}_{2} \mathrm{CAd}\right)_{2}(t-\right.$ $\left.\left.\mathrm{BuC}_{6} \mathrm{H}_{5}\right)\right](7.7 \mathrm{mg}, 10 \mu \mathrm{mol}, 2.0 \mathrm{~mol} \%), 1-\mathrm{AdCO}_{2} \mathrm{H}(5.4 \mathrm{mg}, 30 \mu \mathrm{mol}, 6 \mathrm{~mol} \%)$ and 1-bromo-1methylcyclohexane (119b) (266 mg, $1.50 \mathrm{mmol}$ ) in $\mathrm{PhCMe}_{3}(0.4 \mathrm{~mL})$. Purification by column chromatography ( $n$-pentane/Et ${ }_{2} \mathrm{O}: 50 / 1$ ) yielded 123ab (23.3 mg, 20\%) as a colorless oil.

The general procedure I was followed using ketimine $47 \mathrm{a}(152 \mathrm{mg}, 0.50 \mathrm{mmol})$, $\left[\mathrm{RuCl}_{2}(p \text {-cymene })\right]_{2}$ (7.7 mg, $13 \mu \mathrm{mol}, 2.5 \mathrm{~mol} \%), \quad 1-\mathrm{AdCO}_{2} \mathrm{H} \quad(13.5 \mathrm{mg}, \quad 75 \mu \mathrm{mol}, 15 \mathrm{~mol} \%)$ and 1-bromo-1methylcyclohexane (19b) (266 mg, $1.50 \mathrm{mmol}$ ). Purification by column chromatography ( $n$ pentane/Et $\left.{ }_{2} \mathrm{O}: 50 / 1\right)$ yielded $123 \mathrm{ab}(90.5 \mathrm{mg}, 76 \%)$ as a colorless oil.

The general procedure I was followed using ketimine $47 \mathrm{a}(152 \mathrm{mg}, 0.50 \mathrm{mmol}),\left[\operatorname{RuCl}_{2}(p-c y m e n e)\right]_{2}$ (3.1 mg, $5.0 \mu \mathrm{mol}, \quad 1.0 \mathrm{~mol} \%), \quad 1-\mathrm{AdCO}_{2} \mathrm{H} \quad(5.4 \mathrm{mg}, \quad 30 \mu \mathrm{mol}, \quad 6 \mathrm{~mol} \%)$ and 1-bromo-1methylcyclohexane (119b) (266 mg, $1.50 \mathrm{mmol}$ ). Purification by column chromatography ( $n$ pentane/Et $\left.{ }_{2} \mathrm{O}: 50 / 1\right)$ yielded $123 \mathrm{ab}(28.0 \mathrm{mg}, 24 \%)$ as a colorless oil.

${ }^{1} \mathrm{H}$ NMR $\left(400 \mathrm{MHz}, \mathrm{CDCl}_{3}\right): \delta=7.97(\mathrm{dd}, J=8.1,2.3 \mathrm{~Hz}, 1 \mathrm{H}$ ), 7.76 (ddd, $J=8.4,4.5,2.3 \mathrm{~Hz}, 1 \mathrm{H}), 7.02$ (dd, $J=12.4,8.4 \mathrm{~Hz}, 1 \mathrm{H}), 2.55(\mathrm{~s}, 3 \mathrm{H}), 2.11-1.99(\mathrm{~m}, 2 \mathrm{H}), 1.71-1.51(\mathrm{~m}, 4 \mathrm{H}), 1.51-1.31(\mathrm{~m}, 4 \mathrm{H}), 1.27$ $(\mathrm{d}, J=1.1 \mathrm{~Hz}, 3 \mathrm{H}) ;{ }^{13} \mathrm{C}$ NMR $\left(100 \mathrm{MHz}, \mathrm{CDCl}_{3}\right): \delta=196.9\left(\mathrm{C}_{\mathrm{q}}\right), 165.2\left(\mathrm{~d}, J=257 \mathrm{~Hz}, \mathrm{C}_{\mathrm{q}}\right), 136.8$ (d, $J=$ $12 \mathrm{~Hz}, \mathrm{C}_{\mathrm{q}}$ ), 133.2 (d, J = $3 \mathrm{~Hz}, \mathrm{C}_{\mathrm{q}}$ ), 129.1 (d, J = 8 Hz, CH), 128.3 (d, J = $\left.11 \mathrm{~Hz}, \mathrm{CH}\right), 116.7$ (d, J = $26 \mathrm{~Hz}$, $\mathrm{CH}), 37.9\left(\mathrm{~d}, J=4 \mathrm{~Hz}, \mathrm{C}_{\mathrm{q}}\right), 37.0\left(\mathrm{~d}, J=4 \mathrm{~Hz}, \mathrm{CH}_{2}\right), 26.5\left(\mathrm{CH}_{3}\right), 26.4\left(\mathrm{CH}_{3}\right), 26.2\left(\mathrm{CH}_{2}\right), 22.5\left(\mathrm{CH}_{2}\right) ;{ }^{19} \mathrm{~F} \mathrm{NMR}$ (376 MHz, $\mathrm{CDCl}_{3}$ ): $\delta=-101.0$ (ddd, J = 12.7, 7.9, $4.6 \mathrm{~Hz}$ ); IR (ATR): $\tilde{v}=2953,2870,1687,1590,1340$, 1280, 1067, $830 \mathrm{~cm}^{-1}$; MS (EI) m/z (relative intensity) 234 (24) [M] $]^{+}, 219$ (60), 178 (35), 163 (62); HRMS (EI): $m / z$ calcd for $\left[\mathrm{C}_{15} \mathrm{H}_{19} \mathrm{FO}\right]^{+} 234.1414$, found 234.1420 .

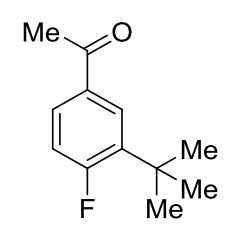

123aa

\section{1-[3-(tert-Butyl)-4-fluorophenyl]ethan-1-one (123aa):}

The general procedure I was followed using ketimine $47 \mathrm{a}(152 \mathrm{mg}, 0.50 \mathrm{mmol})$, $\left[\mathrm{RuCl}_{2}(p \text {-cymene })\right]_{2}$ (15.3 mg, $25.0 \mu \mathrm{mol}, 5.0 \mathrm{~mol} \%), 1-\mathrm{AdCO}_{2} \mathrm{H}(27.3 \mathrm{mg}, 0.15 \mathrm{mmol}, 30 \mathrm{~mol} \%)$ and tert-butyl iodide (125a) (179 $\mu \mathrm{L}, 1.50 \mathrm{mmol})$. Purification by column chromatography ( $n$-pentane/Et ${ }_{2} \mathrm{O}: 50 / 1$ ) yielded 123aa $(50.6 \mathrm{mg}, 52 \%)$ as a colorless oil.

The general procedure I was followed using ketimine $47 \mathrm{a}(152 \mathrm{mg}, 0.50 \mathrm{mmol})$, $\left[\mathrm{RuCl}_{2}(p \text {-cymene })\right]_{2}$ (15.3 mg, $25.0 \mu \mathrm{mol}, 5.0 \mathrm{~mol} \%), 1-\mathrm{AdCO}_{2} \mathrm{H}(27.3 \mathrm{mg}, 0.15 \mathrm{mmol}, 30 \mathrm{~mol} \%$ ) and tert-butyl bromide 
(119a) (168 $\mu \mathrm{L}, 1.50 \mathrm{mmol})$. Purification by column chromatography ( $n$-pentane/Et $\mathrm{E}_{2} \mathrm{O}: 50 / 1$ ) yielded 123aa (69.6 mg, 72\%) as a colorless oil.

The general procedure I was followed using ketimine $47 \mathrm{a}(152 \mathrm{mg}, 0.50 \mathrm{mmol})$, $\left[\operatorname{RuCl}_{2}(p-c y m e n e)\right]_{2}$ (15.3 mg, $25.0 \mu \mathrm{mol}, 5.0 \mathrm{~mol} \%), 1-\mathrm{AdCO}_{2} \mathrm{H}(27.3 \mathrm{mg}, 0.15 \mathrm{mmol}, 30 \mathrm{~mol} \%$ ) and freshly distilled tertbutyl chloride (124a) $(163 \mu \mathrm{L}, 1.50 \mathrm{mmol})$. Purification by column chromatography ( $n$-pentane/ $\mathrm{Et}_{2} \mathrm{O}$ : $50 / 1$ ) yielded 123aa (70.0 $\mathrm{mg}, 72 \%$ ) as a colorless oil.

${ }^{1} \mathrm{H}$ NMR $\left(300 \mathrm{MHz}, \mathrm{CDCl}_{3}\right): \delta=7.95(\mathrm{dd}, J=8.1,2.3 \mathrm{~Hz}, 1 \mathrm{H}$ ), 7.78 (ddd, $J=8.4,4.5,2.3 \mathrm{~Hz}, 1 \mathrm{H}), 7.04$ (dd, $J=12.0,8.4 \mathrm{~Hz}, 1 \mathrm{H}), 2.57$ (s, 3H), 1.39 (d, $J=1.1 \mathrm{~Hz}, 9 \mathrm{H}) ;{ }^{13} \mathrm{C} \mathrm{NMR}\left(125 \mathrm{MHz}, \mathrm{CDCl}_{3}\right): \delta=196.8$ ( $\left.C_{q}\right), 165.0\left(d, J=257 \mathrm{~Hz}, C_{q}\right), 137.5\left(d, J=12 \mathrm{~Hz}, C_{q}\right), 133.1$ (d, J = 3 Hz, $\left.C_{q}\right), 128.5$ (d, J=10 Hz, CH), $127.9(\mathrm{~d}, J=8 \mathrm{~Hz}, \mathrm{CH}), 116.4(\mathrm{~d}, J=25 \mathrm{~Hz}, \mathrm{CH}), 34.5\left(\mathrm{~d}, J=3 \mathrm{~Hz}, \mathrm{C}_{\mathrm{q}}\right), 29.8\left(\mathrm{~d}, J=3 \mathrm{~Hz}, \mathrm{CH}_{3}\right), 26.6\left(\mathrm{CH}_{3}\right)$; ${ }^{19} \mathrm{~F}$ NMR (376 MHz, CDCl $): \delta=-(101.5-101.8)(\mathrm{m}) ;$ IR (ATR): $\tilde{v}=2961,2873,1683,1606,1490,1355$, 1235, 1094, $817 \mathrm{~cm}^{-1}$; MS (EI) m/z (relative intensity) 194 (18) [M] ${ }^{+}, 179$ (100), 151 (58), 136 (10); HRMS (EI): $m / z$ calcd for $\left[\mathrm{C}_{12} \mathrm{H}_{15} \mathrm{FO}\right]^{+} 194.1101$, found 194.1106 .

\subsubsection{Mechanistic Studies}

\section{Reaction with Well-Defined Ruthenium (II)-complexes}

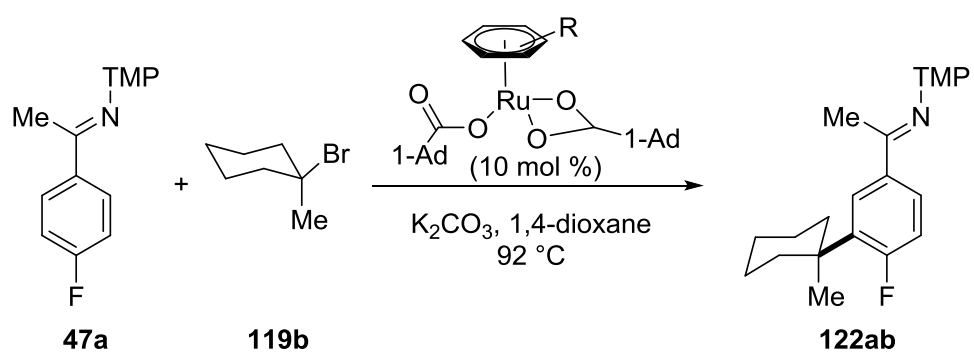

The reaction was set up in the glovebox following the general procedure I using ketimine 47a (303 mg, 1.00 mmol, 1.0 equiv), [Ru( $\left.\left.{ }_{2} \mathrm{CAd}\right)_{2}\left(t-\mathrm{BuC}_{6} \mathrm{H}_{5}\right)\right](59.5 \mathrm{mg}, 0.10 \mathrm{mmol}, 10 \mathrm{~mol} \%), 1$-bromo-1methylcyclohexane (119b) (531 mg, $3.00 \mathrm{mmol}, 3.0$ equiv), MS (4 $\AA, 25 \mathrm{mg}$ ) and 1-fluornonane (45 $\mu \mathrm{L}, 0.25 \mathrm{mmol}$ ). Aliquots of $0.01 \mathrm{~mL}$ were taken out after a defined time and analyzed by ${ }^{19} \mathrm{~F} \mathrm{NMR}$ (Table 23 and Table 24).

The reaction was set up in the glovebox following the general procedure I using ketimine 47a (303 mg, $1.00 \mathrm{mmol}, 1.0$ equiv), [Ru( $\left.\mathrm{O}_{2} \mathrm{CAd}\right)_{2}(p$-cymene)] (59.4 mg, $0.10 \mathrm{mmol}, 10 \mathrm{~mol} \%)$ 1-bromo-1methylcyclohexane (119b) (531 mg, $3.00 \mathrm{mmol}, 3.0$ equiv), MS (4 $\AA, 25 \mathrm{mg}$ ) and 1-fluornonane $(45 \mu \mathrm{L}, 0.25 \mathrm{mmol})$. Aliquots of $0.01 \mathrm{~mL}$ were taken out after a defined time and analyzed by ${ }^{19} \mathrm{~F} N \mathrm{NMR}$ (Table 23 and Table 24). 
Table 23. Conversion to $122 \mathrm{ab}$ determined by ${ }^{19} \mathrm{~F}$ NMR spectroscopy.

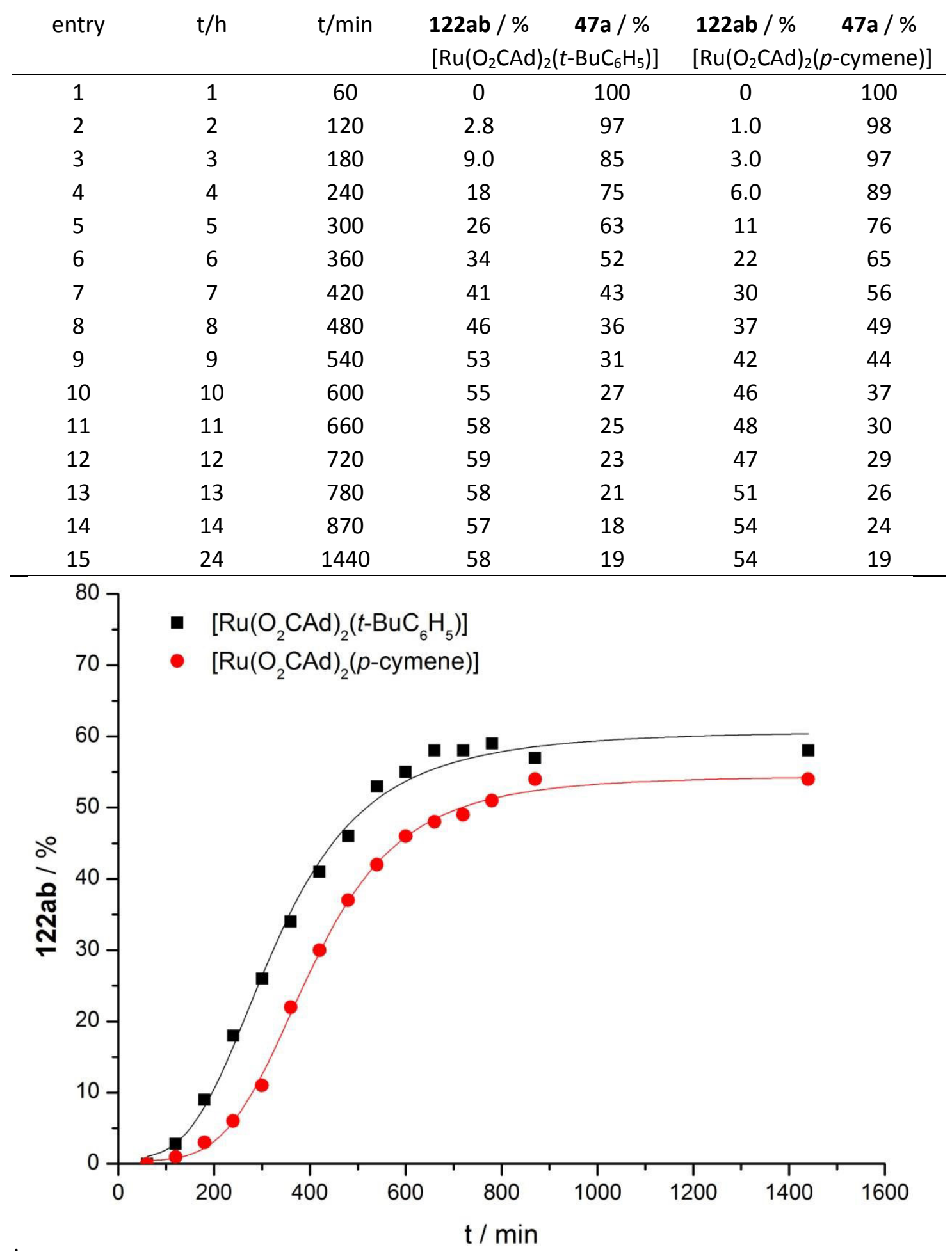

Figure 38. Conversion to $122 \mathrm{ab}$ determined by ${ }^{19} \mathrm{~F}$ NMR spectroscopy.

Table 24. Initial conversion to $122 \mathrm{ab}$ determined by ${ }^{19} \mathrm{~F}$ NMR spectroscopy.

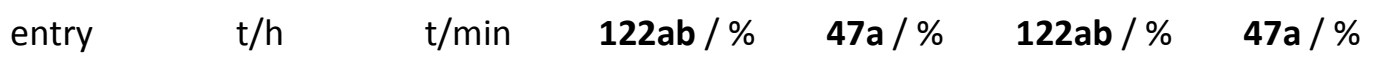


Experimental Part

\begin{tabular}{|c|c|c|c|c|c|c|}
\hline \multirow[b]{2}{*}{1} & \multirow[b]{2}{*}{0.5} & \multirow[b]{2}{*}{30} & \multicolumn{2}{|c|}{$\left[\mathrm{Ru}\left(\mathrm{O}_{2} \mathrm{CAd}\right)_{2}\left(t-\mathrm{BuC}_{6} \mathrm{H}_{5}\right)\right]$} & \multicolumn{2}{|c|}{$\left[\mathrm{Ru}\left(\mathrm{O}_{2} \mathrm{CAd}\right)_{2}(p\right.$-cymene $)$} \\
\hline & & & 0 & 100 & 0 & 100 \\
\hline 2 & 1 & 60 & 0 & 100 & 0 & 100 \\
\hline 3 & 1.5 & 90 & 1,5 & 97 & 0 & 100 \\
\hline 4 & 2 & 120 & 3 & 95 & 0 & 100 \\
\hline 5 & 2.5 & 150 & 6 & 91 & 2 & 97 \\
\hline 6 & 3 & 180 & 8 & 89 & 4 & 94 \\
\hline 7 & 4 & 240 & 14 & 79 & 10 & 85 \\
\hline 8 & 5 & 300 & 22 & 70 & 16 & 78 \\
\hline 9 & 6 & 360 & 29 & 58 & 24 & 69 \\
\hline 10 & 7 & 420 & 35 & 47 & 30 & 60 \\
\hline 11 & 7.3 & 440 & 39 & 45 & 33 & 57 \\
\hline
\end{tabular}

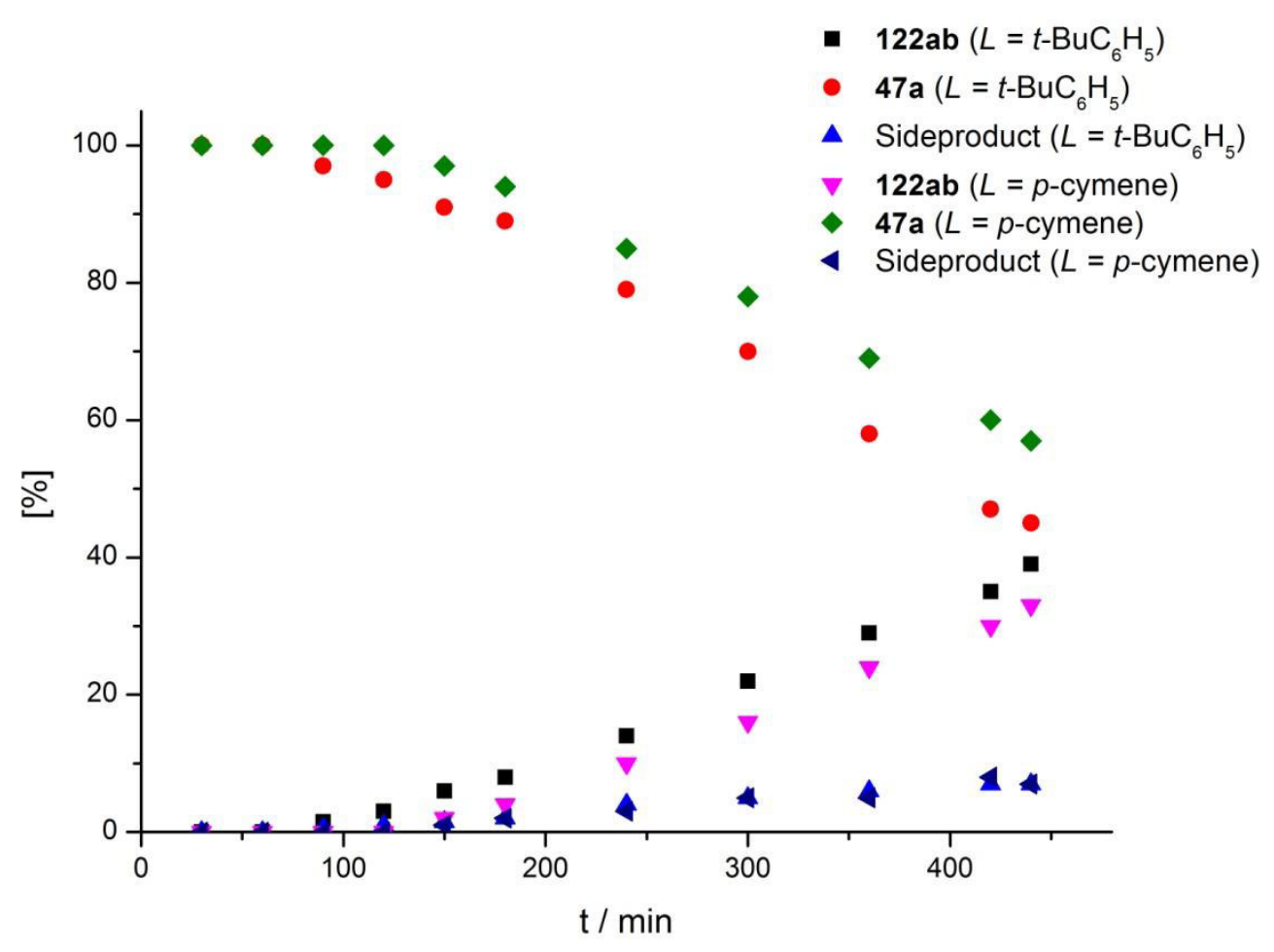

Figure 39. Initial conversion to $122 \mathrm{ab}$ determined by ${ }^{19} \mathrm{~F}$ NMR spectroscopy. 


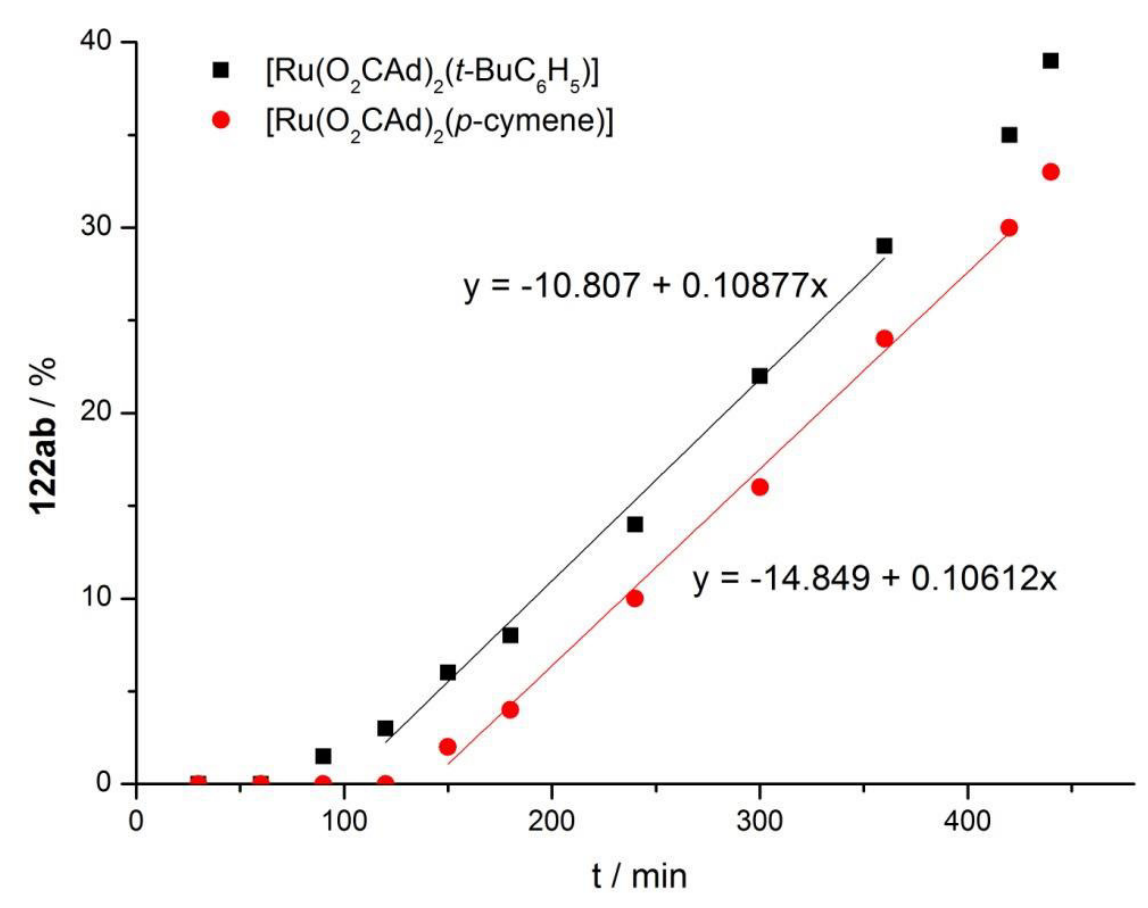

Figure 40. Initial rate for the conversion of $47 \mathrm{a}$ to $122 \mathrm{ab}$ determined by ${ }^{19} \mathrm{~F}$ NMR spectroscopy.

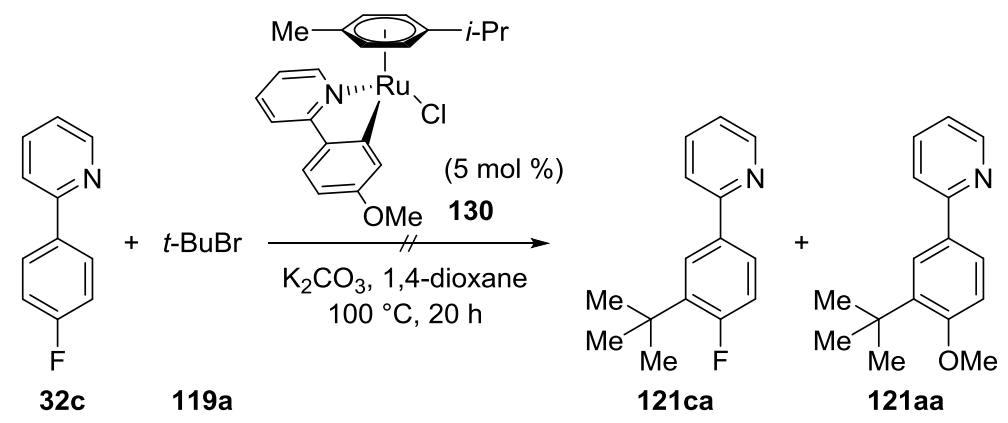

General procedure $\mathbf{H}$ was followed using substrate $32 \mathrm{c}(87 \mathrm{mg}, 0.50 \mathrm{mmol})$, catalyst 130 (10.6 mg, $25 \mu \mathrm{mol}, 5 \mathrm{~mol} \%$ ) and tert-butyl bromide (119a) (206 mg, $1.50 \mathrm{mmol}$ ). After stirring the reaction mixture at $100{ }^{\circ} \mathrm{C}$ for $20 \mathrm{~h}$, product formation was observed neither from phenylpyridine 32c nor from the phenylpyridine ligand 32a originating from complex 130. 


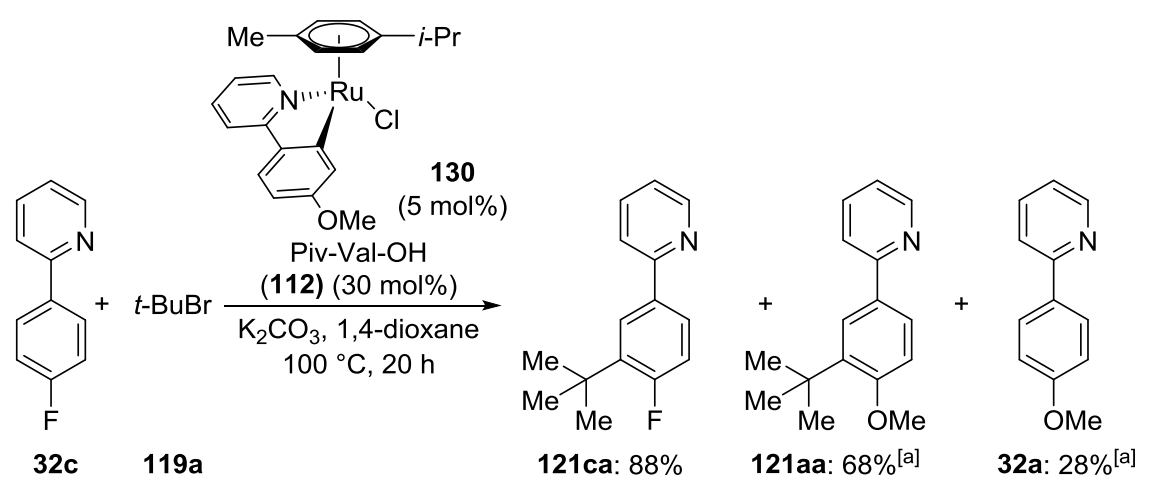

[a] Yield based on catalyst loading.

General procedure $\mathbf{H}$ was followed using substrate $32 \mathrm{c}(86.5 \mathrm{mg}, 0.50 \mathrm{mmol})$, complex 130 (10.6 mg, $25 \mu \mathrm{mol}, 5 \mathrm{~mol} \%)$, Piv-Val-OH (112) $(30.0 \mathrm{mg}, 30 \mathrm{~mol} \%)$ and tert-butyl bromide (119a) (206 mg, $1.50 \mathrm{mmol}$ ). Purification by column chromatography ( $n$-hexane/EtOAc: $80 / 1 \rightarrow 10 / 1$ ) yielded 121ca (101 mg, 88\%) and 121aa (4.2 mg, 68\% based on Ru) as colorless oils.<smiles>CC(C)(C)c1cc(-c2ccccn2)ccc1F</smiles>

\section{2-\{3-(tert-Butyl)-4-fluorophenyl\}pyridine (121ca):}

${ }^{1} \mathrm{H}$ NMR $\left(300 \mathrm{MHz}, \mathrm{CDCl}_{3}\right): \delta=8.66(\mathrm{ddd}, J=4.9,1.9,0.9 \mathrm{~Hz}, 1 \mathrm{H}), 7.98(\mathrm{dd}, J=8.1,2.6 \mathrm{~Hz}, 1 \mathrm{H}), 7.79-$ $7.64(\mathrm{~m}, 3 \mathrm{H}), 7.19$ (ddd, $J=7.4,4.7,1.3 \mathrm{~Hz}, 1 \mathrm{H}), 7.09$ (ddd, $J=12.3,8.5,1.1 \mathrm{~Hz}, 1 \mathrm{H}), 1.43$ (d, $J=1.0$ $\mathrm{Hz}, 9 \mathrm{H}) ;{ }^{13} \mathrm{C}$ NMR $\left(75 \mathrm{MHz}, \mathrm{CDCl}_{3}\right): \delta=162.7$ (d, $\left.J_{\mathrm{C}-\mathrm{F}}=251 \mathrm{~Hz}, \mathrm{C}_{\mathrm{q}}\right), 157.1\left(\mathrm{C}_{\mathrm{q}}\right), 149.6(\mathrm{CH}), 137.3(\mathrm{~d}, J=$ $12 \mathrm{~Hz}, \mathrm{C}_{\mathrm{q}}$ ), $136.7(\mathrm{CH}), 135.1$ (d, J = $\left.3 \mathrm{~Hz}, \mathrm{C}_{\mathrm{q}}\right), 126.2$ (d, J = 2 Hz, CH), 126.1 (d, J = 5 Hz, CH), $121.8(\mathrm{CH})$, $120.4(\mathrm{CH}), 116.5(\mathrm{~d}, J=24 \mathrm{~Hz}, \mathrm{CH}), 34.4\left(\mathrm{~d}, J=3 \mathrm{~Hz}, \mathrm{C}_{\mathrm{q}}\right), 29.9\left(\mathrm{~d}, J=3 \mathrm{~Hz}, \mathrm{CH}_{3}\right) ;{ }^{19} \mathrm{~F}$ NMR $\left\{{ }^{1} \mathrm{H}\right\}(282$ $\mathrm{MHz}, \mathrm{CDCl}_{3}$ ): $\delta=-109.4$ (s); IR (neat): $\tilde{v}=3050,2958,1590,1460,1432,1364,1214,1088,778 \mathrm{~cm}^{-1}$; MS (EI) m/z (relative intensity) 229 (40) [M] ${ }^{+}, 214$ (100), 186 (36), 173 (10); HR-MS (EI): m/z calcd for $\left[\mathrm{C}_{15} \mathrm{H}_{16} \mathrm{FN}-\mathrm{H}\right]^{+}$228.1183, found 228.1191.

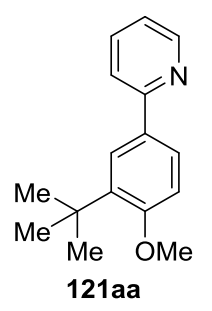

2-\{3-(tert-Butyl)-4-methoxyphenyl\}pyridine (121aa): 
${ }^{1} \mathrm{H}$ NMR $\left(300 \mathrm{MHz}, \mathrm{CDCl}_{3}\right): \delta=8.66(\mathrm{~d}, J=4.9 \mathrm{~Hz}, 1 \mathrm{H}), 7.97(\mathrm{~d}, J=2.3 \mathrm{~Hz}, 1 \mathrm{H}), 7.81$ (dd, $J=8.5,2.3 \mathrm{~Hz}$, 1H), 7.73-7.64 (m, 2H), 7.15 (ddd, J = 6.8, 4.9, 1.9 Hz, 1H), 6.97 (d, J = 8.6 Hz, 1H), $3.90(\mathrm{~s}, 3 \mathrm{H}), 1.46(\mathrm{~s}$, 9H); ${ }^{13} \mathrm{C} \mathrm{NMR}\left(75 \mathrm{MHz}, \mathrm{CDCl}_{3}\right): \delta=159.4\left(\mathrm{C}_{\mathrm{q}}\right), 157.8\left(\mathrm{C}_{\mathrm{q}}\right), 149.5(\mathrm{CH}), 138.4\left(\mathrm{C}_{\mathrm{q}}\right), 136.5(\mathrm{CH}), 131.4\left(\mathrm{C}_{\mathrm{q}}\right)$, $125.7(\mathrm{CH}), 125.4(\mathrm{CH}), 121.1(\mathrm{CH}), 120.0(\mathrm{CH}), 111.6(\mathrm{CH}), 55.1\left(\mathrm{CH}_{3}\right), 35.0\left(\mathrm{C}_{\mathrm{q}}\right), 29.7\left(\mathrm{CH}_{3}\right)$; IR (ATR): $\tilde{v}$ $=3077,2954,1586,1463,1270,1091,819,741 \mathrm{~cm}^{-1}$; MS (EI) m/z (relative intensity) 241 (42) [M] 226 (100), 210 (15), 167 (15); HR-MS (EI): $\mathrm{m} / z$ calcd for [ $\left.\mathrm{C}_{16} \mathrm{H}_{19} \mathrm{NO}\right]^{+} 241.1461$, found 241.1457.

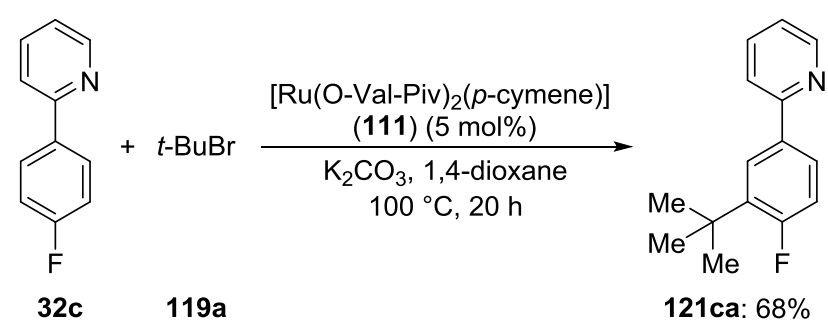

General procedure $\mathbf{H}$ was followed using substrate $32 \mathrm{c}(86.5 \mathrm{mg}, 0.50 \mathrm{mmol})$, [Ru(O-Val-Piv $)_{2}(p$ cymene)] (111) (15.9 mg, $25 \mu \mathrm{mol}, 5 \mathrm{~mol} \%$ ) and tert-butyl bromide (119a) (206 mg, $1.50 \mathrm{mmol}$ ). Purification by column chromatography ( $n$-hexane/EtOAc: $80 / 1$ ) yielded $121 \mathrm{ca}(78.0 \mathrm{mg}, 68 \%$ ) as a colorless oil.
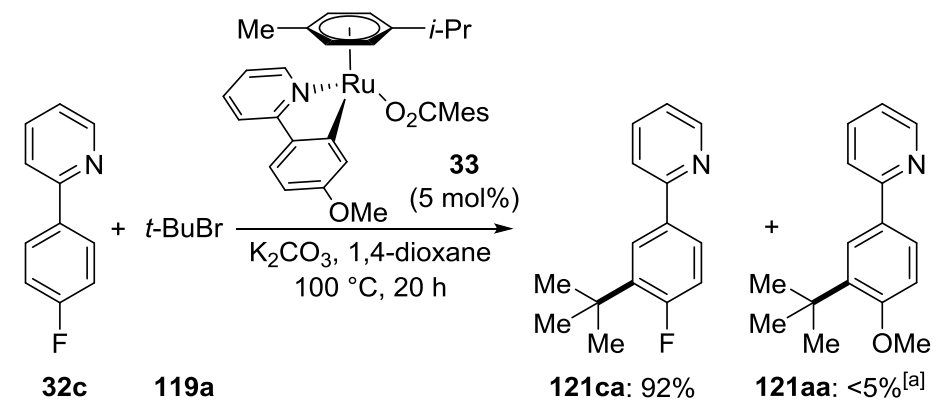<smiles>COc1ccc(-c2ccccn2)cc1</smiles>

32a: $80 \%$ [a]

[a] Yield based on catalyst.

General procedure $\mathbf{H}$ was followed using substrate $32 \mathrm{c}(86.5 \mathrm{mg}, 0.50 \mathrm{mmol})$, complex 33 (14.6 $\mathrm{mg}$, $5 \mathrm{~mol} \%$ ) and tert-butyl bromide (119a) (206 mg, $1.50 \mathrm{mmol})$. Purification by column chromatography ( $n$-hexane/EtOAc: 80/1 $\rightarrow$ 10/1) yielded 121ca (107 mg, 92\%) and 32a (3.7 mg, 80\% based on ligand of 33) as colorless oils.

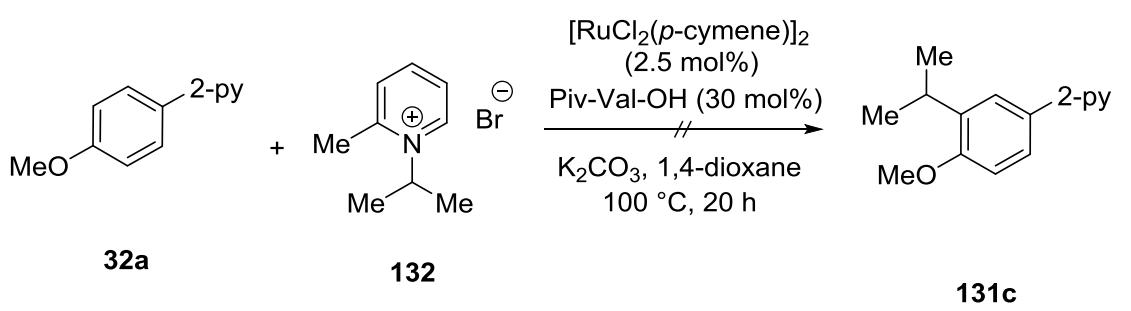

\section{Reaction with Pyridinium bromide 132}


The general procedure $\mathbf{H}$ was followed using substrate $32 \mathrm{a}(92.5 \mathrm{mg}, 0.50 \mathrm{mmol})$, $\left[\mathrm{RuCl}_{2}(p \text {-cymene })\right]_{2}$ (15.3 mg, $25 \mu \mathrm{mol}, 5.0 \mathrm{~mol} \%$ ), Piv-Val-OH (112) (30.0 mg, $0.15 \mathrm{mmol}, 30 \mathrm{~mol} \%$ ) and pyridinium bromide 132 (303 mg, $1.50 \mathrm{mmol}$ ). After $20 \mathrm{~h}$ no conversion was observed by ${ }^{1} \mathrm{H}$ NMR analysis of the crude reaction mixture.

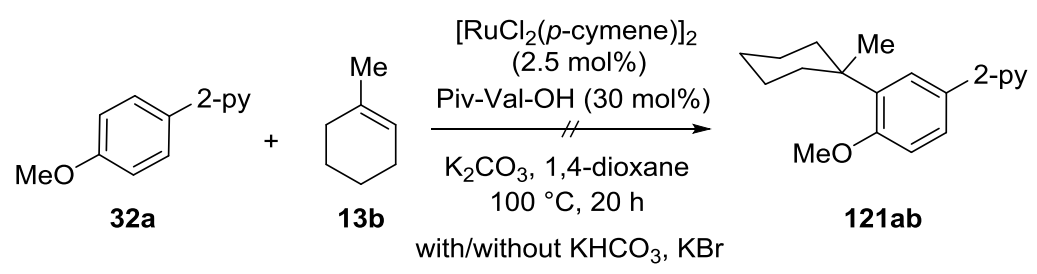

\section{Reaction with 1-Methylcyclohex-1-ene}

The general procedure $\mathbf{H}$ was followed using substrate $32 \mathrm{a}(92.5 \mathrm{mg}, 0.50 \mathrm{mmol})$, $\left[\mathrm{RuCl}_{2}(p \text {-cymene })\right]_{2}$ (15.3 mg, $25 \mu \mathrm{mol}, 5.0 \mathrm{~mol} \%$ ), Piv-Val-OH (30.0 mg, $0.15 \mathrm{mmol}, 30 \mathrm{~mol} \%$ ) and 1-methylcyclohex-1ene (13b) (144 mg, $1.50 \mathrm{mmol}$ ). After $20 \mathrm{~h}$ no conversion was observed by GC-MS and ${ }^{1} \mathrm{H}$ NMR analysis of the crude reaction mixture.

The general procedure $\mathbf{H}$ was followed using substrate $32 \mathrm{a}(92.5 \mathrm{mg}, 0.50 \mathrm{mmol})$, methylene cyclohexane (144 mg, $1.50 \mathrm{mmol})$, [RuCl$(2 \text {-cymene) }]_{2}(15.3 \mathrm{mg}, 25 \mu \mathrm{mol}, 5.0 \mathrm{~mol} \%)$, Piv-Val-OH (30.0 mg, $0.15 \mathrm{mmol}, 30 \mathrm{~mol} \%), \mathrm{KBr}(59,5 \mathrm{mg}, 0.50 \mathrm{mmol})$ and $\mathrm{KHCO}_{3}(100 \mathrm{mg}, 1.0 \mathrm{mmol})$. After $20 \mathrm{~h}$ no conversion was observed by GC-MS and ${ }^{1} \mathrm{H}$ NMR analysis of the crude reaction mixture.

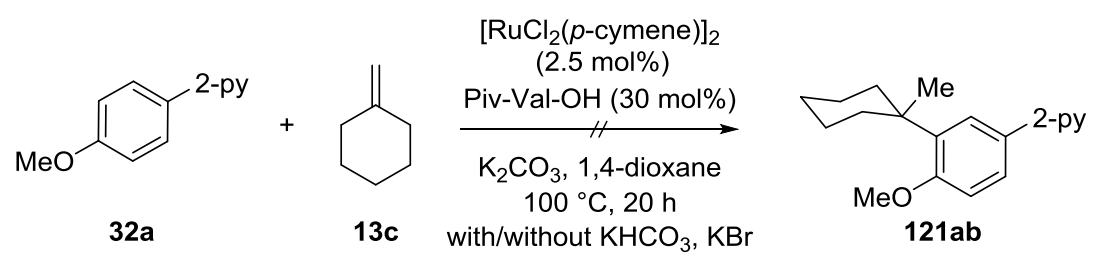

\section{Reaction with Methylene Cyclohexane 19a}

The general procedure $\mathbf{H}$ was followed using substrate $32 \mathrm{a}(92.5 \mathrm{mg}, 0.50 \mathrm{mmol})$, $\left[\mathrm{RuCl}_{2}(p-\mathrm{cymene})\right]_{2}$ (15.3 mg, 25 umol, $5.0 \mathrm{~mol} \%$ ), Piv-Val-OH (112) (30.0 mg, $0.15 \mathrm{mmol}, 30 \mathrm{~mol} \%$ ) and methylene cyclohexane (13c) $(144 \mathrm{mg}, 1.50 \mathrm{mmol})$. After $20 \mathrm{~h}$ no conversion was observed by GCMS and ${ }^{1} \mathrm{H}$ NMR analysis of the crude reaction mixture.

The general procedure $\mathbf{H}$ was followed using substrate $32 \mathrm{a}(92.5 \mathrm{mg}, 0.50 \mathrm{mmol})$, $\left[\mathrm{RuCl}_{2}(p-c y m e n e)\right]_{2}$ (15.3 mg, $5.0 \mathrm{~mol} \%)$, Piv-Val-OH (112) $(30.0 \mathrm{mg}, 30 \mathrm{~mol} \%)$, methylene cyclohexane (13c) (144 mg, $1.50 \mathrm{mmol}), \mathrm{KBr}(59.5 \mathrm{mg}, 0.50 \mathrm{mmol})$ and $\mathrm{KHCO}_{3}(100 \mathrm{mg}, 1.0 \mathrm{mmol})$. After $20 \mathrm{~h}$ no conversion was observed by GC-MS and ${ }^{1} \mathrm{H}$ NMR analysis of the crude reaction mixture. 


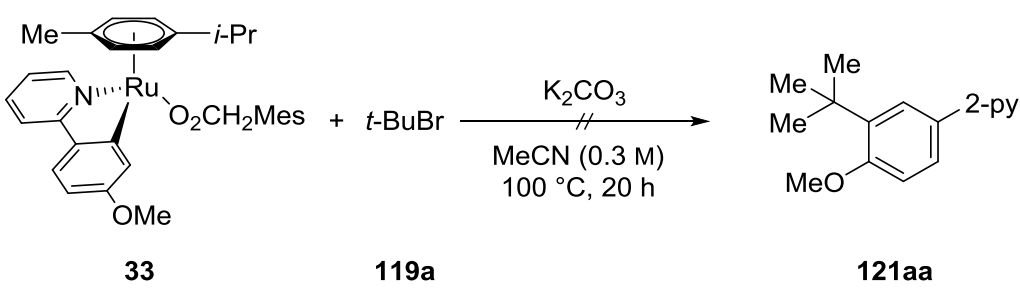

A mixture of complex $33(29.1 \mathrm{mg}, 50 \mu \mathrm{mol})$ tert-butyl bromide $(34.3 \mathrm{mg}, 0.25 \mathrm{mmol})$ and $\mathrm{K}_{2} \mathrm{CO}_{3}$ (13.8 $\mathrm{mg}, 0.10 \mathrm{mmol})$ in MeCN $(0.2 \mathrm{~mL}$ ) was stirred in a microwave vial, under an atmosphere of Ar at $100{ }^{\circ} \mathrm{C}$ for $20 \mathrm{~h}$. No conversion was observed by GC-MS and ${ }^{1} \mathrm{H}$ NMR analysis of the crude reaction mixture.

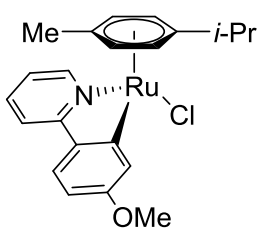

130

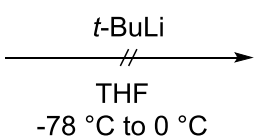

$-78^{\circ} \mathrm{C}$ to $0^{\circ} \mathrm{C}$

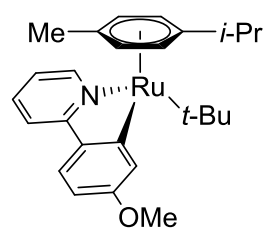

135

To a solution of $130(22.7 \mathrm{mg}, 50 \mu \mathrm{mol})$ in THF $(2.5 \mathrm{~mL})$ at $-78{ }^{\circ} \mathrm{C}$ was added $t$-BuLi $(1.9 \mathrm{M}, 0.07 \mathrm{~mL}$, $0.1 \mathrm{mmol}$ ) dropwise. The mixture was allowed to warm to $0{ }^{\circ} \mathrm{C}$ followed by removing all volatiles in vacuo and crystallization from $\mathrm{Et}_{2} \mathrm{O} /$ hexane. A new set of signals can be seen but no pure product was isolated. Mass analysis showed no product formation.
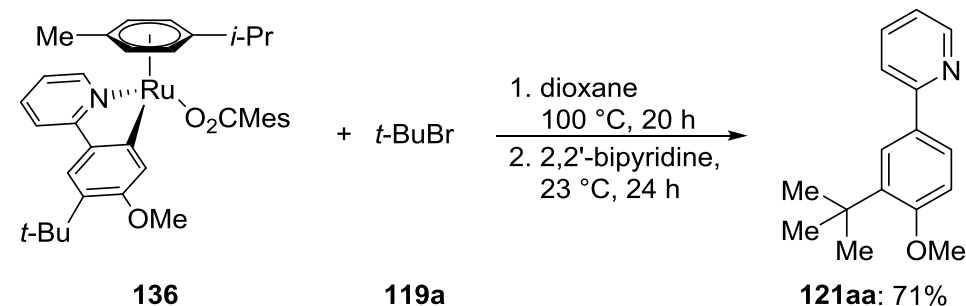

\section{Release of reaction product 121aa:}

Complex 136 (22.2 mg, $0.035 \mathrm{mmol})$ was placed in a pre-dried Schlenk tube, which was degassed and purged with Ar three times, tert-butyl bromide (119a) $(48 \mathrm{mg}, 0.35 \mathrm{mmol})$ and 1,4-dioxane $(1.0 \mathrm{~mL})$ were then added, and the mixture was stirred at $100{ }^{\circ} \mathrm{C}$ for $20 \mathrm{~h}$. At ambient temperature, 2,2'bipyridine $(6.1 \mathrm{mg}, 0.04 \mathrm{mmol})$ was added and the reaction mixture stirred for additional $24 \mathrm{~h}$ at $23^{\circ} \mathrm{C}$. EtOAc $(15 \mathrm{~mL})$ was added, and the reaction mixture was filtered through a pad of silica gel. The solvents were removed in vacuo and purification of the residue by column chromatography ( $n$ hexane/EtOAc: 6/1) yielded 121aa (6 mg, 71\%) as a colorless oil. 


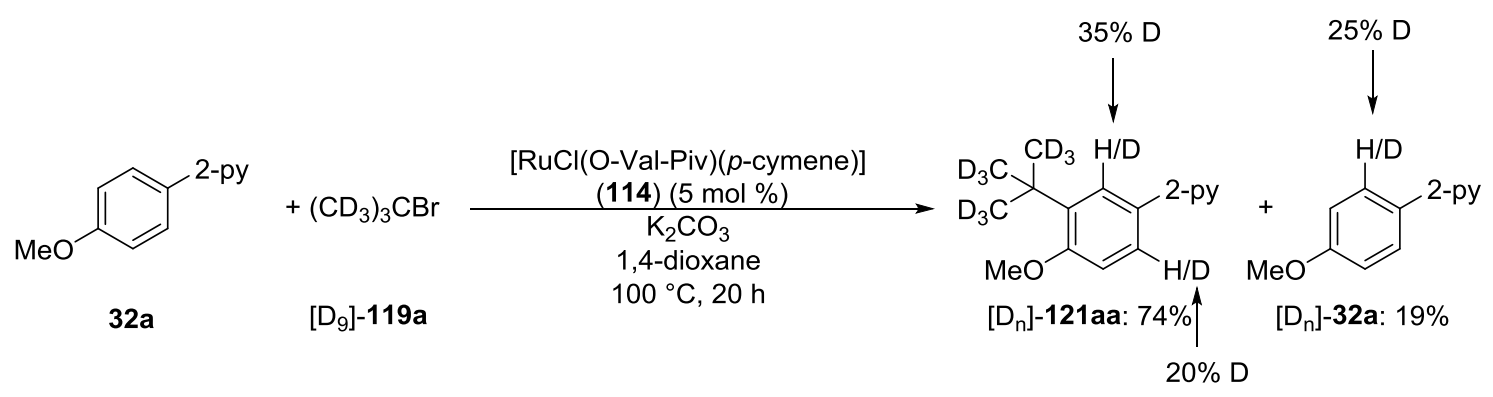

The general procedure $\mathbf{H}$ was followed using substrate $32 \mathrm{a}(92.5 \mathrm{mg}, 0.50 \mathrm{mmol})$ and $\left[\mathrm{D}_{9}\right]$-tert-butyl bromide ([Dg]-119a) $(219 \mathrm{mg}, 1.50 \mathrm{mmol})$. Purification by column chromatography ( $n$-hexane/EtOAc: $14 / 1$ to

9/1) yielded $\left[D_{n}\right]-121$ aa $(93.0 \mathrm{mg}, 74 \%)$ and $\left[D_{n}\right]-32 a(17.4 \mathrm{mg}, 19 \%)$ as colorless oils. The deuterium incorporation was determined via $^{1} \mathrm{H}$ NMR analysis.

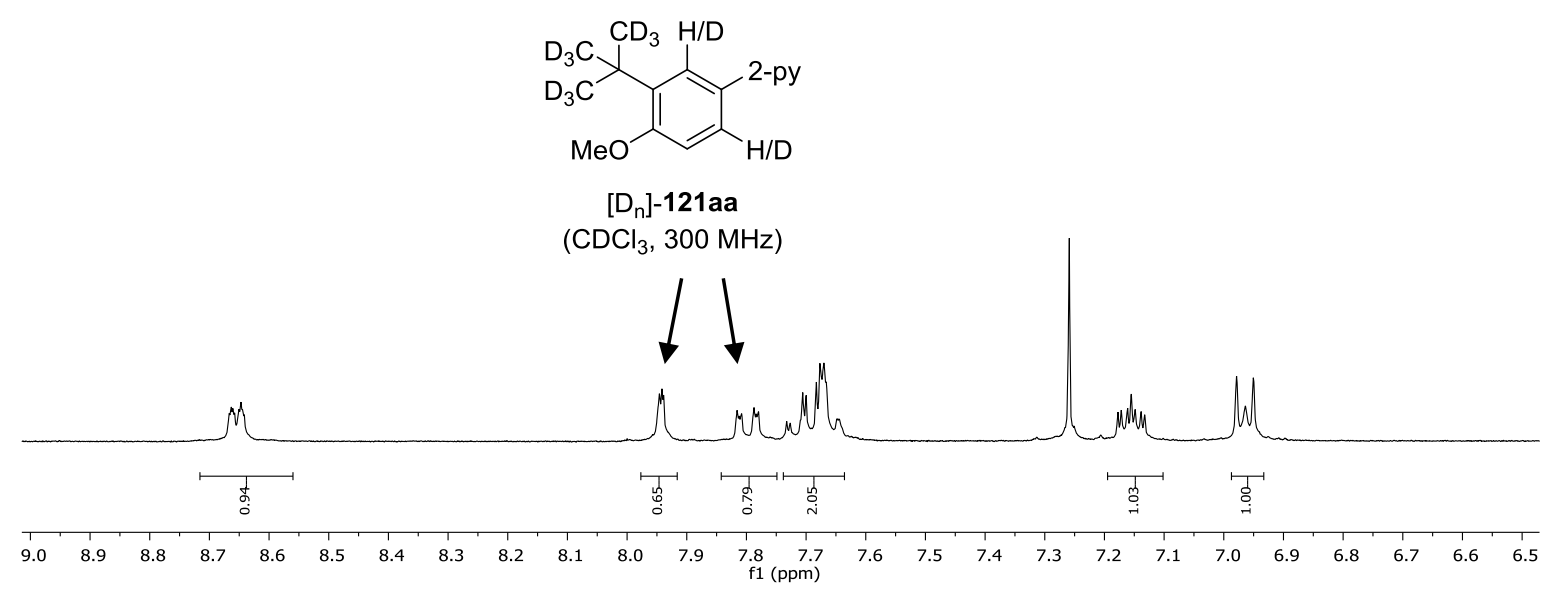




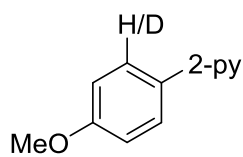

[D $]-32 a$

$\left(\mathrm{CDCl}_{3}, 300 \mathrm{MHz}\right)$

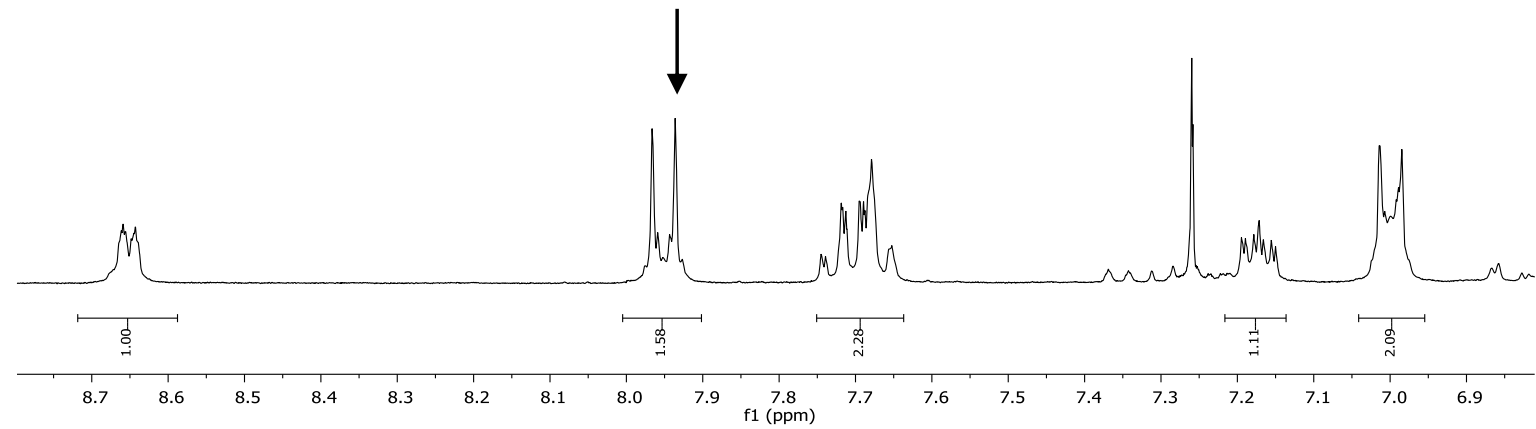

\subsubsection{Immobilized Ruthenium Catalysts}

\section{Synthesis of Sol-Gel derived ruthenium catalysts}

\section{Base-Catalyzed Condensation}

To a suspension of $\left[\mathrm{RuCl}_{2}\left(\mathrm{PPh}_{3}\right)(p\right.$-cymene $\left.)\right](30.0 \mathrm{mg}, 0.10 \mathrm{mmol})$ in THF $(4.0 \mathrm{~mL})$ was added $\mathrm{NEt}_{3}$ $(0.5 \mathrm{~mL})$. After stirring the obtained solution for $15 \mathrm{~min}, \mathrm{H}_{2} \mathrm{O}(0.5 \mathrm{~mL})$ was added and the solution was stirred for additional $5 \mathrm{~min}$ at $23^{\circ} \mathrm{C}$. After dropwise addition of $\mathrm{Si}(\mathrm{OMe})_{4}(1.2 \mathrm{~mL}, 8.1 \mathrm{mmol})$ and stirring at $23^{\circ} \mathrm{C}$ for $24 \mathrm{~h}$, the volatiles were removed in vacuo and the thus obtained complex washed with $\mathrm{CH}_{2} \mathrm{Cl}_{2}(5.0 \mathrm{~mL})$. Strong leaching was observed.

To a suspension of $\left[\mathrm{RuCl}_{2}(p \text {-cymene })\right]_{2}(61.1 \mathrm{mg}, 0.10 \mathrm{mmol})$ in THF $(8.0 \mathrm{~mL})$ was added $\mathrm{NEt}_{3}(1.0 \mathrm{~mL})$. After stirring the obtained solution for $15 \mathrm{~min}, \mathrm{H}_{2} \mathrm{O}(1.0 \mathrm{~mL})$ was added and the solution was stirred for additional $5 \mathrm{~min}$ at $23^{\circ} \mathrm{C}$. After dropwise addition of $\mathrm{Si}(\mathrm{OMe})_{4}(2.5 \mathrm{~mL}, 17 \mathrm{mmol})$ and stirring at $23^{\circ} \mathrm{C}$ for $24 \mathrm{~h}$, the volatiles were removed in vacuo and the thus obtained complex washed with $\mathrm{MeOH}(5.0 \mathrm{~mL})$. Strong leaching was observed.

140: To a suspension of $\left[\mathrm{Ru}(\mathrm{OAc})_{2}(p\right.$-cymene $\left.)\right](30.0 \mathrm{mg}, 0.08 \mathrm{mmol})$ in THF $(4.0 \mathrm{~mL})$ was added $\mathrm{NEt}_{3}$ $(0.5 \mathrm{~mL})$. After stirring the obtained solution for $15 \mathrm{~min}, \mathrm{H}_{2} \mathrm{O}(0.5 \mathrm{~mL})$ was added and the solution was stirred for $5 \mathrm{~min}$ at $23^{\circ} \mathrm{C}$. After dropwise addition of $\mathrm{Si}(\mathrm{OMe})_{4}(1.2 \mathrm{~mL}, 8.1 \mathrm{mmol})$ and stirring at 
$23^{\circ} \mathrm{C}$ for $24 \mathrm{~h}$, the volatiles were removed in vacuo and the thus obtained complex washed with $\mathrm{CH}_{2} \mathrm{Cl}_{2}(3 \times 7.5 \mathrm{~mL})$, centrifugation was used to separate the solid. No leaching was observed, the catalyst was dried under vacuum and isolated as a yellow powder (678 mg), the loading was determined to be $0.12 \mathrm{mmol}[\mathrm{Ru}] \cdot \mathrm{g}^{-1}$.

141: To a suspension of $\left[\mathrm{Ru}\left(\mathrm{O}_{2} \mathrm{CMes}\right)_{2}(p\right.$-cymene $\left.)\right](30.0 \mathrm{mg}, 0.06 \mathrm{mmol})$ in THF $(4.0 \mathrm{~mL})$ was added $\mathrm{NEt}_{3}(0.5 \mathrm{~mL})$. After stirring the obtained solution for $15 \mathrm{~min}, \mathrm{H}_{2} \mathrm{O}(0.5 \mathrm{~mL})$ was added and the solution was stirred for $5 \mathrm{~min}$ at $23^{\circ} \mathrm{C}$. After dropwise addition of Si(OMe $)_{4}(1.2 \mathrm{~mL}, 8.1 \mathrm{mmol})$ and stirring at $23^{\circ} \mathrm{C}$ for $24 \mathrm{~h}$, the volatiles were removed in vacuo and the thus obtained complex washed with $\mathrm{CH}_{2} \mathrm{Cl}_{2}(3 \times 7.5 \mathrm{~mL})$, centrifugation was used to separate the solid. No leaching was observed, the catalyst was dried under vacuum and isolated as a yellow powder (629 mg), the loading was determined to be $0.10 \mathrm{mmol}[\mathrm{Ru}] \cdot \mathrm{g}^{-1}$.

142: To a suspension of $\left[\mathrm{Ru}_{2} \mathrm{Cl}_{3}(p \text {-cymene })_{2}\right] \mathrm{PF}_{6}(30.0 \mathrm{mg}, 0.04 \mathrm{mmol})$ in THF $(4.0 \mathrm{~mL})$ was added $\mathrm{NEt}_{3}$ $(0.5 \mathrm{~mL})$. After stirring the obtained solution for $15 \mathrm{~min}, \mathrm{H}_{2} \mathrm{O}(0.5 \mathrm{~mL})$ was added and the solution was stirred for $5 \mathrm{~min}$ at $23^{\circ} \mathrm{C}$. After dropwise addition of Si(OMe $)_{4}(1.2 \mathrm{~mL}, 8.1 \mathrm{mmol})$ and stirring at $23^{\circ} \mathrm{C}$ for $24 \mathrm{~h}$ then, the volatiles were removed in vacuo and the thus obtained complex washed with $\mathrm{CH}_{2} \mathrm{Cl}_{2}(3 \times 7.5 \mathrm{~mL})$, centrifugation was used to separate the solid. No leaching was observed, the catalyst was dried under vacuum and isolated as a yellow powder $(552 \mathrm{mg})$, the loading was determined to be $0.07 \mathrm{mmol}[\mathrm{Ru}] \cdot \mathrm{g}^{-1}$.

To a suspension of $\left[\mathrm{RuCl}_{2}(p \text {-cymene })\right]_{2}(30.0 \mathrm{mg}, 0.05 \mathrm{mmol})$ in THF $(2.0 \mathrm{~mL})$ was added $\mathrm{NEt}_{3}(0.4 \mathrm{~mL})$. After stirring the obtained solution for $15 \mathrm{~min}, \mathrm{H}_{2} \mathrm{O}(1.0 \mathrm{~mL})$ was added and the solution was stirred for $5 \mathrm{~min}$ at $23^{\circ} \mathrm{C}$. After dropwise addition of methyl 3-(trimethoxysilyl)propanoate $(83.0 \mathrm{mg}$, $0.4 \mathrm{mmol})$ and $\mathrm{Si}(\mathrm{OMe})_{4}(0.6 \mathrm{~mL}, 4 \mathrm{mmol})$ and stirring at $23^{\circ} \mathrm{C}$ for $24 \mathrm{~h}$, the volatiles were removed. Addition of $\mathrm{LiOH}(84.0 \mathrm{mg}, 2.0 \mathrm{mmol})$ in $\mathrm{MeOH}(6.0 \mathrm{~mL})$ and $\mathrm{H}_{2} \mathrm{O}(2.0 \mathrm{~mL})$ was followed by stirring at $23^{\circ} \mathrm{C}$ for $16 \mathrm{~h}$. The obtained complex was washed with $\mathrm{CH}_{2} \mathrm{Cl}_{2}(7.5 \mathrm{~mL})$. Strong leaching was observed.

A solution of methyl 3-(trimethoxysilyl)propanoate $\left(1.75 \mathrm{~g}, 8.4 \mathrm{mmol}^{2}, \mathrm{NEt}_{3}(0.5 \mathrm{~mL})\right.$ in THF $(2.0 \mathrm{~mL})$ and $\mathrm{H}_{2} \mathrm{O}(0.5 \mathrm{~mL})$ was stirred at $23^{\circ} \mathrm{C}$ for $24 \mathrm{~h}$, the volatiles were removed. IR analysis shows a signal at $1736 \mathrm{~cm}^{-1}$. A suspension of the obtained Sol-Gel, $\mathrm{LiOH}(2.69 \mathrm{~g}, 64 \mathrm{mmol})$ in $\mathrm{MeOH}(6.0 \mathrm{~mL})$ and $\mathrm{H}_{2} \mathrm{O}$ $\left(2.0 \mathrm{~mL}\right.$ ) was stirred at $60{ }^{\circ} \mathrm{C}$ for $18 \mathrm{~h}$. The obtained compound was washed with $\mathrm{H}_{2} \mathrm{O}(7.5 \mathrm{~mL}) 3$ times. IR analysis showed no signal at $1736 \mathrm{~cm}^{-1}$ and a new signal at $1557 \mathrm{~cm}^{-1}$. A suspension of the thus obtained powder $(400 \mathrm{mg})$ and $\left[\mathrm{RuCl}_{2}(p \text {-cymene })\right]_{2}(15.0 \mathrm{mg}, 0.024 \mathrm{mmol})$ in $\mathrm{CH}_{2} \mathrm{Cl}_{2}(5.0 \mathrm{~mL})$ was stirred for $2 \mathrm{~d}$ at $23^{\circ} \mathrm{C}$. No absorption was observed. 


\section{Acid-Catalyzed}

To a solution of $\left[\mathrm{RuCl}_{2}(p \text {-cymene })\right]_{2}(61.1 \mathrm{mg}, 0.10 \mathrm{mmol})$ in $\mathrm{CHCl}_{3}(2.0 \mathrm{~mL})$ was added $\mathrm{Si}(\mathrm{OMe})_{4}$ (0.96 mL, $6.5 \mathrm{mmol}), \mathrm{H}_{2} \mathrm{O}(0.65 \mathrm{~mL}, 36 \mathrm{mmol})$ and TBAF $(1 \mathrm{M}, 0.2 \mathrm{~mL}, 0.2 \mathrm{~mol})$ dropwise. The obtained solution was stirred for $24 \mathrm{~h}$ at $23^{\circ} \mathrm{C}$. The volatiles were removed in vacuum and the thus obtained complex washed with $\mathrm{MeOH}$. Strong leaching was observed.

\section{Polyol Method}

\section{$\mathrm{RuCl}_{3} @ \mathrm{SiO}_{2}$}

The catalyst 144 was synthesized according to a modified literature procedure. ${ }^{\left[{ }^{82]}\right.}$ Therefore, $\mathrm{RuCl}_{3} \cdot 3 \mathrm{H}_{2} \mathrm{O}$ (150 mg, $\left.0.53 \mathrm{mmol}\right)$ was dissolved in $\mathrm{EtOH}(2.4 \mathrm{~mL})$. After addition of ethylene glycol ( $6.0 \mathrm{~mL}, 99.5 \%$ purity) and $\mathrm{H}_{2} \mathrm{O}(0.1 \mathrm{~mL})$ the deep red solution was stirred at $65^{\circ} \mathrm{C}$ for $0.5 \mathrm{~h}$ in which time the color changed to lighter red. Si $(\mathrm{OEt})_{4}(6.0 \mathrm{~mL}, 26.9 \mathrm{mmol})$ was added and the mixture stirred at $65^{\circ} \mathrm{C}$ for additional $3 \mathrm{~h}$, followed by the addition of $\mathrm{H}_{2} \mathrm{O}(3.0 \mathrm{~mL}, 167 \mathrm{mmol})$. After stirring at $65^{\circ} \mathrm{C}$ for further $1.25 \mathrm{~h}$ the oil bath was changed to $27^{\circ} \mathrm{C}$ and stirred for $24 \mathrm{~h}$. Removal of the volatiles at high vacuum followed by heating the mixture to $100{ }^{\circ} \mathrm{C}$ over night, the catalyst was completely dried at $100{ }^{\circ} \mathrm{C}$ and high vacuum. The catalyst was purified by first grinding it to a fine powder and washing three times with $\mathrm{CH}_{2} \mathrm{Cl}_{2}(7 \mathrm{~mL}$ ), the solid was separated by decanting after centrifugation (40 min, $8000 \mathrm{rpm})$. The washing phase was checked for residues, as this was not the case the ruthenium amount was determined by the amount of $\mathrm{RuCl}_{3}$ per achieved catalyst. Thereby catalysts with a loading between 0.13 and $0.15 \mathrm{mmol}[\mathrm{Ru}] \cdot \mathrm{g}^{-1}$ in form of a yellowish beige powder were obtained (3.5-4.1 g).

IR (neat): $\tilde{v}=3301,2939,2883,1459,1039,968,879,789,579 \mathrm{~cm}^{-1}$

\section{$\left[\mathrm{RuCl}_{2}(p \text {-cymene) }]_{2} @ \mathrm{SiO}_{2}\right.$}

According to a modified literature procedure ${ }^{[82]}$ a mixtue of $\left[\mathrm{RuCl}_{2}(p \text {-cymene })\right]_{2}(306 \mathrm{mg}, 0.5 \mathrm{mmol})$, EtOH $(10 \mathrm{~mL})$ and ethylene glycol $\left(10 \mathrm{~mL}, 99.5 \%\right.$ purity) was stirred at $65^{\circ} \mathrm{C}$ for $0.5 \mathrm{~h}$, in which time a solution was obtained. $\mathrm{Si}(\mathrm{OEt})_{4}(10 \mathrm{~mL}, 44.8 \mathrm{mmol})$ was added and the mixture stirred at $65^{\circ} \mathrm{C}$ for additional $3 \mathrm{~h}$, followed by the addition of $\mathrm{H}_{2} \mathrm{O}(5.0 \mathrm{~mL}, 167 \mathrm{mmol})$. After stirring at $65^{\circ} \mathrm{C}$ for further $1.25 \mathrm{~h}$ the oil bath was changed to $27^{\circ} \mathrm{C}$ and stirred for $24 \mathrm{~h}$. Removal of the volatiles at high vacuum followed by heating the mixture to $100{ }^{\circ} \mathrm{C}$ over night, the catalyst was completely dried at $100{ }^{\circ} \mathrm{C}$ and high vacuum. The catalyst was purified by first grinding it to a fine powder and washing with $\mathrm{CH}_{2} \mathrm{Cl}_{2}$ $(7 \mathrm{~mL})$, the catalyst showed heavy leaching during washing. 


\subsubsection{1 meta-Selective C-H Bromination}

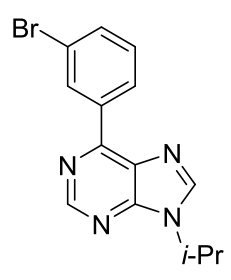

$86 a$

\section{6-(3-Bromophenyl)-9-isopropyl-9H-purine (86a):}

A mixture of purine $85 \mathrm{a}(71.5 \mathrm{mg}, 0.30 \mathrm{mmol}), \mathrm{NBS}(107 \mathrm{mg}, 0.60 \mathrm{mmol})$ and $144\left(0.14 \mathrm{mmol}[\mathrm{Ru}] \cdot \mathrm{g}^{-1}\right.$, $214 \mathrm{mg}, 10 \mathrm{~mol} \%)$ in DMA $(0.6 \mathrm{~mL})$ was stirred open to air for $20 \mathrm{~h}$ at $80^{\circ} \mathrm{C}$. Aqueous workup, followed by extraction with $\mathrm{CH}_{2} \mathrm{Cl}_{2}$ and purification by column chromatography ( $n$ hexane/EtOAc/NEt 3 : 4:1:0.02) yielded $86 a(66.7 \mathrm{mg}, 70 \%)$ as a colorless solid.

M.p.: $121{ }^{\circ} \mathrm{C} ;{ }^{1} \mathrm{H}$ NMR $\left(300 \mathrm{MHz}, \mathrm{CDCl}_{3}\right): \delta=8.99$ (s, $1 \mathrm{H}$ ), 8.94 (ddd, $\left.J=2.1,1.6,0.4 \mathrm{~Hz}, 1 \mathrm{H}\right), 8.78$ (ddd, $J=7.9,1.6,1.1 \mathrm{~Hz}, 1 \mathrm{H}$ ), 8.18 (s, 1H), 7.62 (ddd, $J=7.9,2.1,1.1 \mathrm{~Hz}, 1 \mathrm{H}$ ), 7.41 (ddd, $J=7.9,7.9,0.4 \mathrm{~Hz}$, $1 \mathrm{H}), 4.97$ (hept, $J=6.8 \mathrm{~Hz}, 1 \mathrm{H}), 1.66(\mathrm{~d}, J=6.8 \mathrm{~Hz}, 6 \mathrm{H}) ;{ }^{13} \mathrm{C} \mathrm{NMR}\left(75 \mathrm{MHz}, \mathrm{CDCl}_{3}\right): \delta=153.0\left(\mathrm{C}_{\mathrm{q}}\right), 152.4$ ( $\left.\mathrm{C}_{\mathrm{q}}\right), 152.1(\mathrm{CH}), 142.4(\mathrm{CH}), 137.9\left(\mathrm{C}_{\mathrm{q}}\right), 133.8(\mathrm{CH}), 132.5(\mathrm{CH}), 131.6\left(\mathrm{C}_{\mathrm{q}}\right), 130.2(\mathrm{CH}), 128.6(\mathrm{CH})$, $123.0\left(\mathrm{C}_{\mathrm{q}}\right), 47.5(\mathrm{CH}), 22.7\left(\mathrm{CH}_{3}\right)$; IR (ATR): $\tilde{v}=2977,1576,1553,1447,1324,1217,786,736,698$, $646 \mathrm{~cm}^{-1}$; MS (EI) $\mathrm{m} / \mathrm{z}$ (relative intensity) $318(68)[\mathrm{M}]^{+}\left({ }^{81} \mathrm{Br}\right.$ ), $316(69)[\mathrm{M}]^{+}\left({ }^{79} \mathrm{Br}\right), 276$ (92), 274 (94), 195 (100), 141 (27), 44 (48); HR-MS (ESI): $m / z$ calcd for $\left[\mathrm{C}_{14} \mathrm{H}_{13}{ }^{79} \mathrm{BrN}_{4}+\mathrm{H}\right]^{+} 317.0396$, found 317.0399. 
Experimental Part
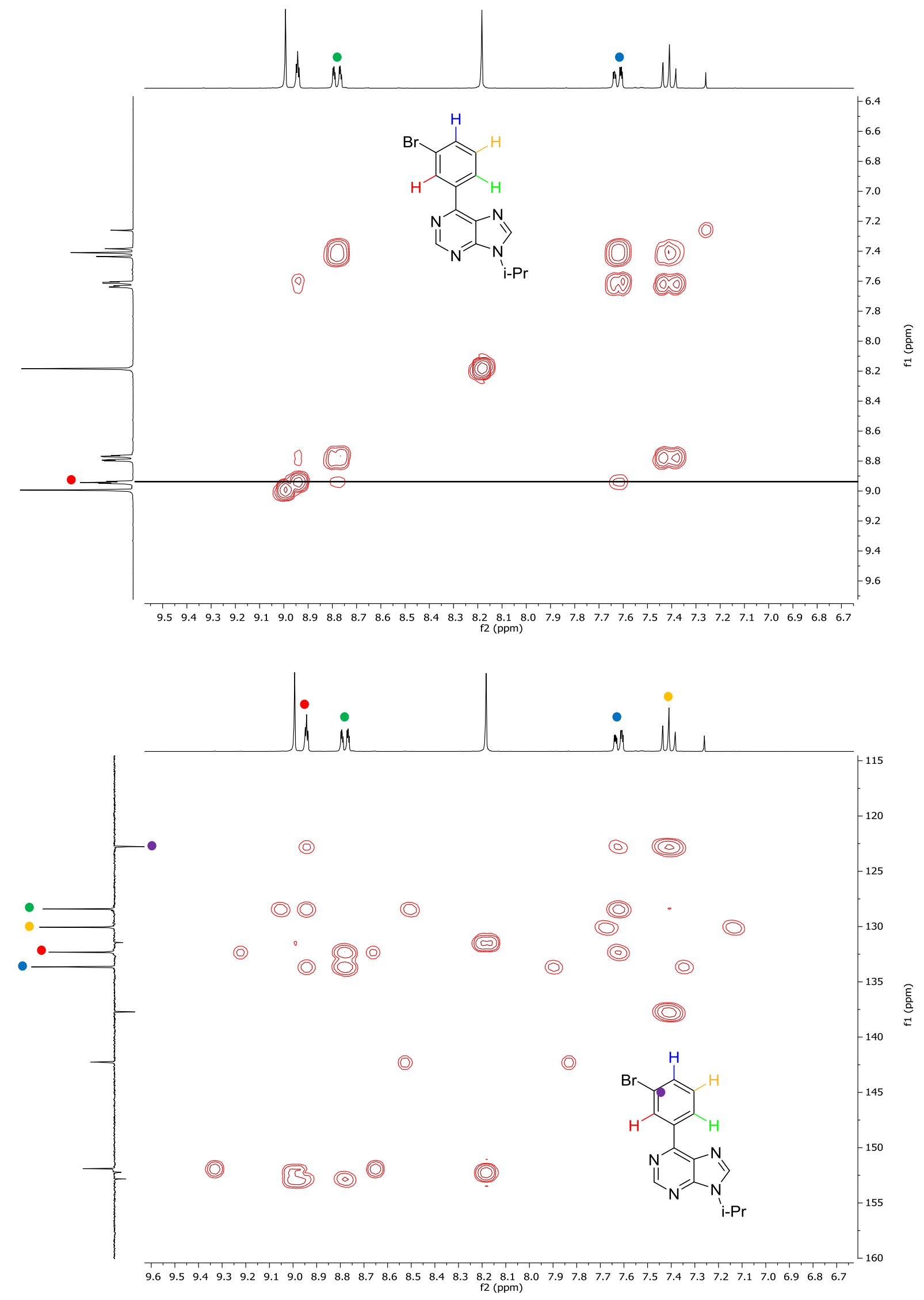


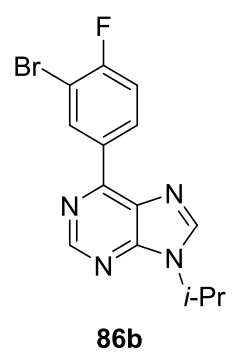

6-(3-Bromo-4-fluorophenyl)-9-isopropyl-9H-purine (86b): A mixture of purine 85b (76.8 mg, $0.30 \mathrm{mmol}$ ), NBS (107 mg, $0.60 \mathrm{mmol})$ and 144 (0.14 mmol [Ru]. $\left.\mathrm{g}^{-1}, 214 \mathrm{mg}, 10 \mathrm{~mol} \%\right)$ in DMA $(0.6 \mathrm{~mL})$ was stirred open to air for $20 \mathrm{~h}$ at $100^{\circ} \mathrm{C}$. Aqueous workup, followed by extraction with $\mathrm{CH}_{2} \mathrm{Cl}_{2}$ and purification by column chromatography ( $n$-hexane/EtOAc/NEt 3 : 1/1/0.02) yielded 86b (55.2 $\mathrm{mg}, 55 \%)$ as a colorless solid.

M.p.: $144-145{ }^{\circ} \mathrm{C} ;{ }^{1} \mathrm{H}$ NMR $\left(300 \mathrm{MHz}, \mathrm{CDCl}_{3}\right): \delta=9.11(\mathrm{dd}, J=6.9,2.2 \mathrm{~Hz}, 1 \mathrm{H}), 8.99(\mathrm{~s}, 1 \mathrm{H}), 8.82-8.92$ $(\mathrm{m}, 1 \mathrm{H}), 8.17-8.23(\mathrm{~m}, 1 \mathrm{H}), 7.21-7.33(\mathrm{~m}, 1 \mathrm{H}), 4.99$ (hept, $J=6.8 \mathrm{~Hz}, 1 \mathrm{H}), 1.69(\mathrm{~d}, J=6.8 \mathrm{~Hz}, 6 \mathrm{H})$; ${ }^{13} \mathrm{C}$ NMR $\left(101 \mathrm{MHz}, \mathrm{CDCl}_{3}\right): \delta=160.6\left(\mathrm{~d}, J=252.4 \mathrm{~Hz}, \mathrm{C}_{\mathrm{q}}\right), 152.4\left(\mathrm{C}_{\mathrm{q}}\right), 152.0(\mathrm{CH}), 152.0\left(\mathrm{C}_{\mathrm{q}}\right), 142.2$ (CH), $134.9(\mathrm{CH}), 133.4$ (d, J = 3.7 Hz, $\mathrm{C}_{\mathrm{q}}$ ), $131.2\left(\mathrm{C}_{\mathrm{q}}\right), 130.8$ (d, J= $\left.7.9 \mathrm{~Hz}, \mathrm{CH}\right), 116.5$ (d, J=22.5 Hz, $\mathrm{CH}), 109.4\left(\mathrm{~d}, J=21.2 \mathrm{~Hz}, \mathrm{C}_{\mathrm{q}}\right), 47.4(\mathrm{CH}), 22.5\left(\mathrm{CH}_{3}\right) ;{ }^{19} \mathrm{~F} \mathrm{NMR}\left\{{ }^{1} \mathrm{H}\right\}\left(282 \mathrm{MHz}, \mathrm{CDCl}_{3}\right): \delta=-103.73$; IR (ATR): $\tilde{v}=3065,1578,1556,1498,1449,1324,785,724,697,647 \mathrm{~cm}^{-1}$; MS (El) m/z (relative intensity) 336 (62) [M] ${ }^{+}\left({ }^{81} \mathrm{Br}\right), 334(65)[\mathrm{M}]^{+}\left({ }^{79} \mathrm{Br}\right), 294$ (98), 292 (100), 213 (97), 159 (26), 132 (24); HR-MS (EI): $\mathrm{m} / z$ calcd for $\mathrm{C}_{14} \mathrm{H}_{12}{ }^{79} \mathrm{BrFN}_{4}{ }^{+}[\mathrm{M}]^{+} 334.0224$, found 334.0234 .

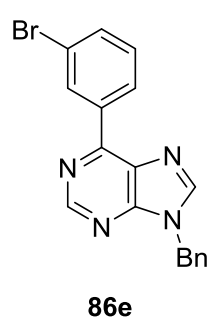

9-Benzyl-6-(3-bromophenyl)-9H-purine (86e): A mixture of purine $85 \mathrm{e}(85.9 \mathrm{mg}, 0.30 \mathrm{mmol}), \mathrm{NBS}$ (107 mg, $0.60 \mathrm{mmol}$ ) and $144\left(0.14 \mathrm{mmol}[\mathrm{Ru}] \cdot \mathrm{g}^{-1}, 214 \mathrm{mg}, 10 \mathrm{~mol} \%\right)$ in DMA (0.6 mL) was stirred open to air for $20 \mathrm{~h}$ at $80^{\circ} \mathrm{C}$. Aqueous workup, followed by extraction with $\mathrm{CH}_{2} \mathrm{Cl}_{2}$ and purification by column chromatography ( $n$-hexane/EtOAc/NEt 3 : 4/1/0.02) yielded $\mathbf{x x}(62.3 \mathrm{mg}, 57 \%)$ as a colorless solid.

M.p.: $149{ }^{\circ} \mathrm{C} ;{ }^{1} \mathrm{H}$ NMR $\left(400 \mathrm{MHz}, \mathrm{CDCl}_{3}\right): \delta=9.05(\mathrm{~s}, 1 \mathrm{H}), 8.97$ (dd, $\left.J=1.9,1.5 \mathrm{~Hz}, 1 \mathrm{H}\right), 8.80$ (ddd, $J=$ 7.9, 1.5, $1.2 \mathrm{~Hz}, 1 \mathrm{H}$ ), $8.11(\mathrm{~s}, 1 \mathrm{H}), 7.64$ (ddd, $J=7.9,1.9,1.2 \mathrm{~Hz}, 1 \mathrm{H}$ ), 7.42 (dd, $J=7.9,7.9 \mathrm{~Hz}, 1 \mathrm{H}$ ), 7.40-7.30 (m, 5H), $5.48(\mathrm{~s}, 2 \mathrm{H}) ;{ }^{13} \mathrm{C}$ NMR $\left(100 \mathrm{MHz}, \mathrm{CDCl}_{3}\right): \delta=153.2\left(\mathrm{C}_{\mathrm{q}}\right), 152.9\left(\mathrm{C}_{\mathrm{q}}\right), 152.7(\mathrm{CH})$, 
$144.6(\mathrm{CH}), 137.8\left(\mathrm{C}_{\mathrm{q}}\right), 135.2\left(\mathrm{C}_{\mathrm{q}}\right), 134.0(\mathrm{CH}), 132.6(\mathrm{CH}), 131.1\left(\mathrm{C}_{\mathrm{q}}\right), 130.3(\mathrm{CH}), 129.3(\mathrm{CH}), 128.8$ (CH), $128.6(\mathrm{CH}), 128.0(\mathrm{CH}), 123.0\left(\mathrm{C}_{\mathrm{q}}\right), 47.5\left(\mathrm{CH}_{2}\right)$; IR (ATR): $\tilde{v}=3064,1575,1553,1439,1320,1199$, 781, 717, 692, $648 \mathrm{~cm}^{-1}$; MS (EI) $\mathrm{m} / \mathrm{z}$ (relative intensity) 366 (13) [M] ${ }^{+}\left({ }^{81} \mathrm{Br}\right.$ ), 365 (17), 364 (14) [M] ${ }^{+}$ ( $\left.{ }^{79} \mathrm{Br}\right), 363$ (16), 281 (14), 207 (100), 91 (30), 44 (57); HR-MS (ESI): m/z calcd for $\left[\mathrm{C}_{18} \mathrm{H}_{13}{ }^{79} \mathrm{BrN}_{4}+\mathrm{H}\right]^{+}$ 365.0396 , found 365.0396 .

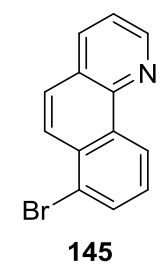

7-bromobenzo[h]quinoline (145): A mixture of benzo[ $h$ ]quinoline (65) $(44.8 \mathrm{mg}, 0.25 \mathrm{mmol}), \mathrm{NBS}$ (71.2 mg, $0.40 \mathrm{mmol})$ and $144\left(0.14 \mathrm{mmol}[\mathrm{Ru}] \cdot \mathrm{g}^{-1}, 179 \mathrm{mg}, 10 \mathrm{~mol} \%\right)$ in DMA (0.5 mL) was stirred open to air for $20 \mathrm{~h}$ at $80^{\circ} \mathrm{C}$. Aqueous workup, followed by extraction with $\mathrm{CH}_{2} \mathrm{Cl}_{2}$ and purification by column chromatography ( $n$-hexane/EtOAc: 9/1) yielded 145 (43.5 mg, 68\%) as a colorless oil.

${ }^{1} \mathrm{H}$ NMR $\left(300 \mathrm{MHz}, \mathrm{CDCl}_{3}\right): \delta=9.33(\mathrm{ddd}, J=8.3,1.0,1.0 \mathrm{~Hz}, 1 \mathrm{H}$ ), $9.03(\mathrm{dd}, J=4.4,1.8 \mathrm{~Hz}, 1 \mathrm{H}), 8.27$ (dd, $J=9.2,0.8 \mathrm{~Hz}, 1 \mathrm{H}$ ), $8.22(\mathrm{dd}, J=8.1,1.8 \mathrm{~Hz}, 1 \mathrm{H}$ ), 7.98 (dd, $J=7.6,1.2 \mathrm{~Hz}, 1 \mathrm{H}$ ), $7.80(\mathrm{~d}, J=9.2 \mathrm{~Hz}$, 1H), 7.63-7.54 (m, 2H); ${ }^{13} \mathrm{C}$ NMR (125 MHz, CDCl $): \delta=149.4(\mathrm{CH}), 146.2\left(\mathrm{C}_{\mathrm{q}}\right), 136.0(\mathrm{CH}), 133.4\left(\mathrm{C}_{\mathrm{q}}\right)$, $132.3(\mathrm{CH}), 132.2\left(\mathrm{C}_{\mathrm{q}}\right), 127.5(\mathrm{CH}), 126.9(\mathrm{CH}), 126.3(\mathrm{CH}), 126.2\left(\mathrm{C}_{\mathrm{q}}\right), 124.3(\mathrm{CH}), 122.9\left(\mathrm{C}_{\mathrm{q}}\right), 122.5$ (CH); IR (ATR): $\tilde{v}=1423,1099,1024,877,762,710,634,482,416 \mathrm{~cm}^{-1} ;$ MS (EI) $\mathrm{m} / \mathrm{z}$ (relative intensity) 259 (98) [M] ${ }^{+}\left({ }^{81} \mathrm{Br}\right), 257$ (100) [M] ${ }^{+}\left({ }^{79} \mathrm{Br}\right), 178$ (59), 150 (19), 89 (23), 75 (14); HR-MS (ESI): $\mathrm{m} / \mathrm{z}$ calcd for $\left[\mathrm{C}_{13} \mathrm{H}_{8}{ }^{79} \mathrm{BrN}+\mathrm{H}\right]^{+} 257.9913$, found 257.9918 .

\section{Recycling Studies}

\section{Procedure for Recycling of the Catalyst}

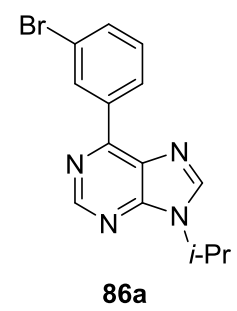

The reaction was performed as above using purine $85 \mathrm{a}(44.8 \mathrm{mg}, 0.25 \mathrm{mmol}), \mathrm{NBS}(71.2 \mathrm{mg}$, $0.40 \mathrm{mmol}$ ) and 144 (0.14 mmol [Ru]. $\left.\mathrm{g}^{-1}, 179 \mathrm{mg}, 10 \mathrm{~mol} \%\right)$ in DMA (0.5 mL) (see page 197). After $20 \mathrm{~h}$ the reaction was allowed to cool to ambient temperature and was then extracted with $n$ - 
hexane/ $\mathrm{CH}_{2} \mathrm{Cl}_{2}(7: 1,5 \mathrm{~mL})$. After centrifugation (10 $\left.\mathrm{min}, 8000 \mathrm{rpm}\right)$ the liquid was separated. This procedure was repeated three times. The product was purified as described above and the catalyst was dried under high vacuum at $80^{\circ} \mathrm{C}$ for $2 \mathrm{~h}$ and reused for the next reaction. Thereby $86 \mathrm{a}$ could be obtained as a colorless solid; yields are given in Table 25.

Table 25. Recycling Study.

\begin{tabular}{c|cccc} 
Run & $1^{\text {st }}$ & $2^{\text {nd }}$ & $3^{\text {rd }}$ & $4^{\text {th }}$ \\
\hline Amount of 86a & $48.7 \mathrm{mg}$ & $50.1 \mathrm{mg}$ & $45.2 \mathrm{mg}$ & $50.4 \mathrm{mg}$ \\
Yield of 86a & $61 \%$ & $63 \%$ & $57 \%$ & $64 \%$
\end{tabular}

\section{Recycling with $\mathrm{RuCl}_{3}$ as Catalyst}

A mixture of purine $85 \mathrm{a}(59.6 \mathrm{mg}, 0.25 \mathrm{mmol})$, NBS $\left(89.0 \mathrm{mg}, 0.50 \mathrm{mmol}, 2.0\right.$ equiv) and $\mathrm{RuCl}_{3} \cdot \mathrm{H}_{2} \mathrm{O}$ (10.6 mg, $25 \mu \mathrm{mol}, 10 \mathrm{~mol} \%)$ in DMA $(0.5 \mathrm{~mL})$ was stirred under air at $80^{\circ} \mathrm{C}$ for $20 \mathrm{~h}$. The reaction mixture was allowed to cool to ambient temperature and was then extracted with $n$-hexane/ $\mathrm{CH}_{2} \mathrm{Cl}_{2}$ (7:1, $5 \mathrm{~mL}$ ). After centrifugation (10 min, $8000 \mathrm{rpm})$ the liquid was separated. GC-analysis showed $93 \%$ conversion to $86 a$ in the first and $60 \%$ conversion in the second run.

\section{PEG as solvent}<smiles>CC(C)n1cnc2c(-c3ccccc3)ncnc21</smiles>

$85 a$

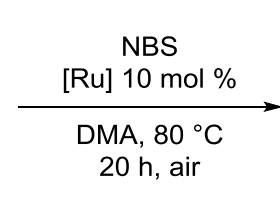

DMA, $80^{\circ} \mathrm{C}$ 集<smiles>CC(C)n1cnc2c(-c3cccc(Br)c3)ncnc21</smiles>

$86 a$

A mixture of purine $85 \mathrm{a}(59.6 \mathrm{mg}, 0.25 \mathrm{mmol}, 1.0$ equiv), NBS $(89.0 \mathrm{mg}, 0.50 \mathrm{mmol}, 2.0$ equiv) and $\mathrm{RuCl}_{3} \cdot \mathrm{H}_{2} \mathrm{O}(10.6 \mathrm{mg}, 25 \mu \mathrm{mol}, 10 \mathrm{~mol} \%)$ in DMA $(0.3 \mathrm{~mL})$ and PEG8000 (200 mg) was stirred under air at $80^{\circ} \mathrm{C}$ for $20 \mathrm{~h}$ the reaction was allowed to cool down to ambient temperature and was then extracted with $n$-hexane/ $\mathrm{CH}_{2} \mathrm{Cl}_{2}(7: 1,5 \mathrm{~mL})$ four times. All volatiles of the upper phase were removed and the crude product purified by column chromatography ( $n$-hexane/EtOAc/NEt ${ }_{3}$ : 4/1/0.02) to give the product (see Table 26 for yield). The decant was dried under vacuum and reused, therefore purine $86 \mathrm{a}$ ( $59.6 \mathrm{mg}, 0.25 \mathrm{mmol}, 1.0$ equiv), NBS ( $89.0 \mathrm{mg}, 0.50 \mathrm{mmol}, 2.0$ equiv) and DMA $(0.5 \mathrm{~mL})$ were added and the reaction performed as before. 
Table 26. Recycling with PEG as solvent.

\begin{tabular}{cll} 
Run & $1^{\text {st }}$ & $2^{\text {nd }}$ \\
\hline Yield $/ \%$ & 40 & 62
\end{tabular}

\subsubsection{ICP-MS Analysis}

The reaction was performed as above using purine $85 \mathrm{a}(23.8 \mathrm{mg}, 0.10 \mathrm{mmol}, 1.0$ equiv), NBS (35.6 mg, $0.20 \mathrm{mmol}, 2.0$ equiv) and $144\left(0.14 \mathrm{mmol}[\mathrm{Ru}] \cdot \mathrm{g}^{-1}, 71.4 \mathrm{mg}, 10 \mathrm{~mol} \%\right)$ in DMA (0.2 mL) (see page 197). After $20 \mathrm{~h}$ the reaction mixture was allowed to cool to ambient temperature and was then extracted with $n$-hexane $/ \mathrm{CH}_{2} \mathrm{Cl}_{2}(7: 1,5 \mathrm{~mL})$. All volatiles were removed and the crude product was subjected to ICP-MS analysis.

\begin{tabular}{|c|c|c|c|c|}
\hline & isotope & cps & std & Amount Ru \\
\hline \multicolumn{5}{|c|}{ blank } \\
\hline $\mathrm{Ru}$ & 96 & 324.6 & 20.815 & \\
\hline $\mathrm{Ru}$ & 98 & 155.4 & 25.351 & \\
\hline $\mathrm{Ru}$ & 99 & 507.5 & 20.685 & \\
\hline $\mathrm{Ru}$ & 100 & 582.7 & 18.449 & \\
\hline $\mathrm{Ru}$ & 101 & 690.5 & 11.777 & \\
\hline $\mathrm{Ru}$ & 102 & 1303.1 & 16.224 & \\
\hline $\mathrm{Ru}$ & 104 & 812.4 & 26.53 & \\
\hline \multicolumn{5}{|c|}{$50 \mathrm{ppm} \mathrm{Ru}$} \\
\hline $\mathrm{Ru}$ & 96 & 28164 & 367.007 & \\
\hline $\mathrm{Ru}$ & 98 & 10409.2 & 114.158 & \\
\hline $\mathrm{Ru}$ & 99 & 69256 & 894.936 & \\
\hline $\mathrm{Ru}$ & 100 & 70609.2 & 942.967 & \\
\hline $\mathrm{Ru}$ & 101 & 97120.5 & 1281.141 & \\
\hline $\mathrm{Ru}$ & 102 & 183192.8 & 2388.605 & \\
\hline $\mathrm{Ru}$ & 104 & 112493.2 & 1824.831 & \\
\hline \multicolumn{5}{|c|}{100 ppm Ru } \\
\hline $\mathrm{Ru}$ & 96 & 55717.1 & 873.329 & \\
\hline $\mathrm{Ru}$ & 98 & 19947.5 & 361.472 & \\
\hline $\mathrm{Ru}$ & 99 & 138445.9 & 2330.544 & \\
\hline $\mathrm{Ru}$ & 100 & 140138.8 & 2563.329 & \\
\hline $\mathrm{Ru}$ & 101 & 193622.1 & 3554.66 & \\
\hline $\mathrm{Ru}$ & 102 & 363608.5 & 6188.062 & \\
\hline $\mathrm{Ru}$ & 104 & 224411.1 & 3865.658 & \\
\hline \multicolumn{5}{|c|}{ After $1^{\text {st }}$ recycling } \\
\hline $\mathrm{Ru}$ & 96 & 71867.8 & 1336.947 & \\
\hline $\mathrm{Ru}$ & 98 & 21141.9 & 512.41 & \\
\hline $\mathrm{Ru}$ & 99 & 188340.6 & 3711.464 & \\
\hline $\mathrm{Ru}$ & 100 & 188229.4 & 3570.607 & \\
\hline $\mathrm{Ru}$ & 101 & 263366.7 & 5281.462 & \\
\hline $\mathrm{Ru}$ & 102 & 496252.9 & 9322.347 & \\
\hline
\end{tabular}


Experimental Part

\begin{tabular}{ccccc}
$\mathrm{Ru}$ & 104 & 305163 & 6946.828 & $756 \mathrm{ppm}$ \\
\hline $\mathrm{Ru}$ & After $2^{\text {nd }}$ recycling & \\
$\mathrm{Ru}$ & 96 & 71028.8 & 748.483 & \\
$\mathrm{Ru}$ & 98 & 21603.7 & 293.604 & \\
$\mathrm{Ru}$ & 99 & 184882.9 & 2002.844 & \\
$\mathrm{Ru}$ & 100 & 185879.9 & 2110.214 & \\
$\mathrm{Ru}$ & 101 & 258644 & 2522.971 & \\
$\mathrm{Ru}$ & 102 & 486629.9 & 5102.198 & \\
\hline \hline
\end{tabular}

\subsubsection{Tests for Heterogeneity}<smiles>CC(C)n1cnc2c(-c3ccccc3)ncnc21</smiles>

$85 a$

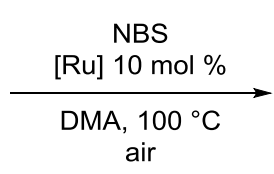

air

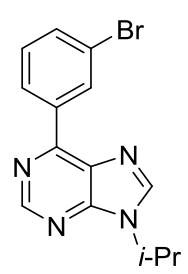

$86 a$

3 Reactions were set up as following: A mixture of purine $85 \mathrm{a}(23.8 \mathrm{mg}, 0.10 \mathrm{mmol}, 1.0$ equiv), NBS (35.6 mg, $0.20 \mathrm{mmol}, 2.0$ equiv), $n$-dodecane $\left(20 \mu \mathrm{L}\right.$ ) and 144 (0.14 mmol [Ru]. $\left.\mathrm{g}^{-1}, 71.4 \mathrm{mg}, 10 \mathrm{~mol} \%\right)$ in DMA $(0.2 \mathrm{~mL})$ was stirred open to air at $80^{\circ} \mathrm{C}$. An aliquot of the reaction mixture was removed and the conversion determined by GC analysis see Table 27 . After 90 min the reactions were treated differently:

1) No manipulation of the reaction was carried out.

2) The hot mixture was filtered over a small pad of celite.

3) $\mathrm{Hg}$ (40 $\mathrm{mg}, 0.2 \mathrm{mmol}$ ) was added to the reaction mixture.

Furthermore a reaction was set up in analogy but with $\mathrm{RuCl}_{3} 3 \mathrm{H}_{2} \mathrm{O}(2.9 \mathrm{mg}, 10 \mathrm{~mol} \%)$ as catalyst. After $90 \mathrm{~min} \mathrm{Hg}(40 \mathrm{mg}, 0.20 \mathrm{mmol}$ ) was added to the reaction mixture.

Table 27. Conversion to $\mathbf{8 6 a}$ determined by GC analysis.

\begin{tabular}{cccccc} 
entry & $\mathrm{t} / \mathrm{min}$ & $\begin{array}{c}\text { Standard } \\
\text { conditions }\end{array}$ & Hot Filtration & Mercury & Mercury RuCl 3 \\
\hline 1 & 60 & --- & 9.7 & 8.6 & 0.4 \\
2 & 90 & -- & 13.9 & 14.1 & 1.0 \\
3 & 120 & 25 & 15.3 & 16.8 & 6.4 \\
4 & 180 & --- & 18.4 & 17.5 & 7.7 \\
5 & 720 & --- & 31.2 & 18.1 & 10.1 \\
6 & 1080 & 91 & --- & --- & -- \\
7 & 1440 & 91 & 37.5 & 18.4 & 10.2 \\
\hline
\end{tabular}




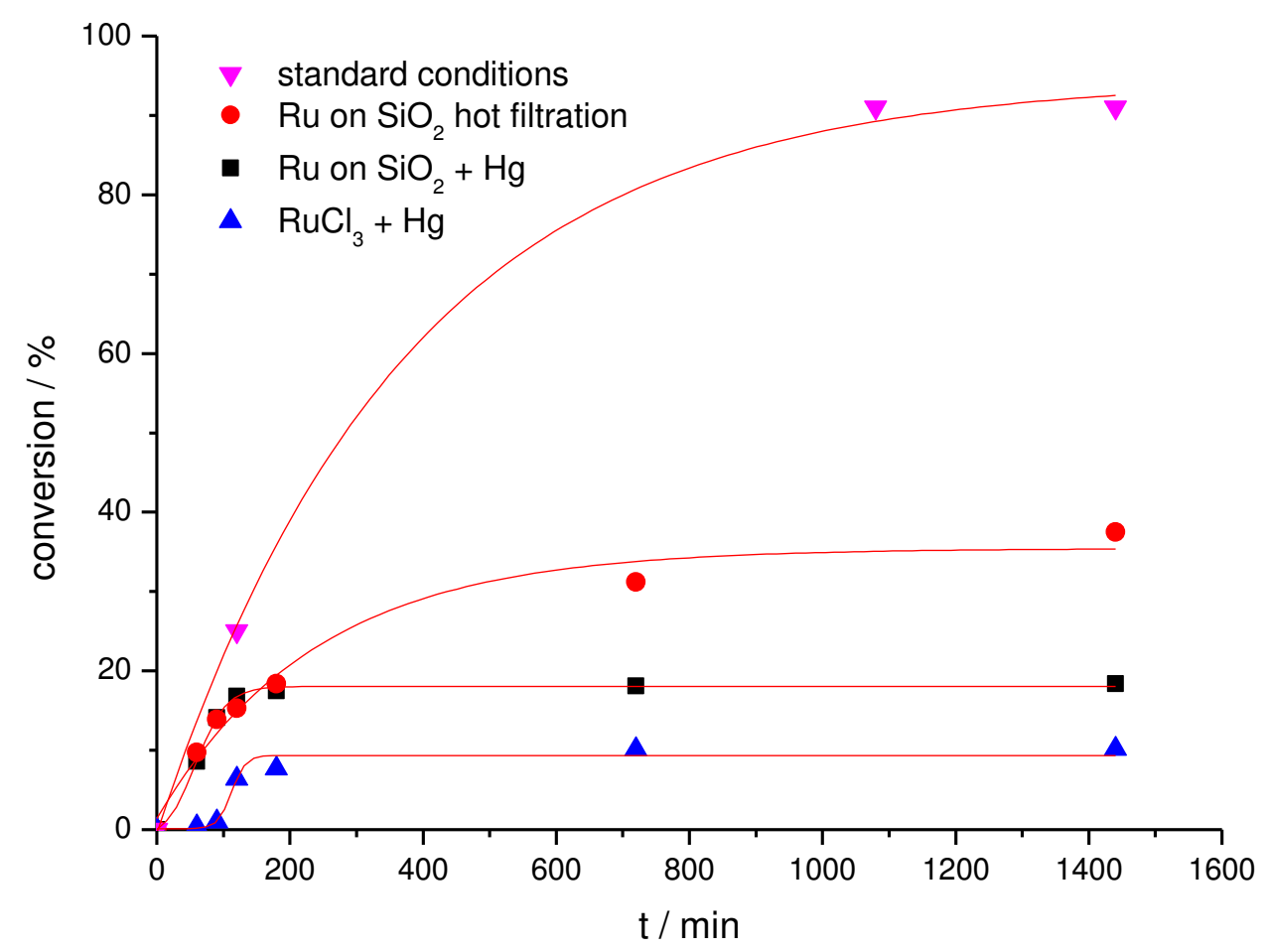

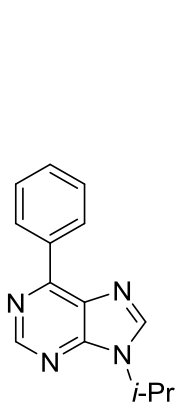

$85 a$

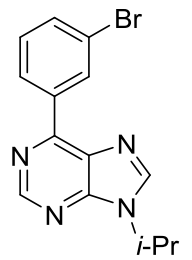

$86 a$

A mixture of NBS (71.2 mg, $0.40 \mathrm{mmol}, 2.0$ equiv) and $\mathrm{Hg}(80 \mathrm{mg}, 0.40 \mathrm{mmol})$ in DMA $(0.4 \mathrm{~mL})$ was stirred at $80^{\circ} \mathrm{C}$ under air for $1 \mathrm{~h}$. The mixture was allowed to settle and $0.2 \mathrm{~mL}$ of the upper solution was added to a mixture of purine $85 \mathrm{a}\left(23.8 \mathrm{mg}, 0.10 \mathrm{mmol}, 1.0\right.$ equiv) and $144\left(0.14 \mathrm{mmol}[\mathrm{Ru}] \cdot \mathrm{g}^{-1}\right.$, $71.4 \mathrm{mg}, 10 \mathrm{~mol} \%)$. No conversion was observed after $20 \mathrm{~h}$ at $80^{\circ} \mathrm{C}$.

\subsection{Crystallographic Data}

Table 28. Crystal data and structure refinement for $91 \mathrm{be:}$

\begin{tabular}{|l|c|}
\hline Compound & 6f \\
\hline Empirical formula & $\mathrm{C} 27 \mathrm{H} 30 \mathrm{O} 2 \mathrm{Ru}$
\end{tabular}


Experimental Part

\begin{tabular}{|c|c|}
\hline CCDC no. & 1044827 \\
\hline Molecular weight & 487.58 \\
\hline Crystal size [mm] & $0.140 \times 0.080 \times 0.050$ \\
\hline Wavelength $[\AA]$ & 0.71073 \\
\hline Crystal system & monoclinic \\
\hline Space group & $\mathrm{P} 22_{1} / \mathrm{c}$ \\
\hline$a[\AA]$ & $1731.1(3)$ \\
\hline$b[\AA]$ & $842.0(2)$ \\
\hline$c[\AA ̊]$ & $1627.3(2)$ \\
\hline$\beta\left[^{\circ}\right]$ & $113.03(2)^{\circ}$ \\
\hline$V\left[\mathrm{~nm}^{3}\right]$ & $2.1829(8)$ \\
\hline$Z$ & 4 \\
\hline Temperature [K] & $100(2)$ \\
\hline$\rho\left[\mathrm{Mgm}^{-3}\right]$ & 1.484 \\
\hline$\mu\left[\mathrm{mm}^{-1}\right]$ & 0.739 \\
\hline$F(000)$ & 1008 \\
\hline$\theta$-area $\left[^{\circ}\right]$ & 1.278 to $28.731^{\circ}$. \\
\hline Total number reflect. & 52104 \\
\hline Unique reflections & 5655 \\
\hline$R_{\text {int }}$ & 0.0534 \\
\hline Number of restraints & 135 \\
\hline Parameters & 304 \\
\hline$R 1[I>2 \sigma(I)]$ & 0.0246 \\
\hline$w R 2[I>2 \sigma(I)]$ & 0.0569 \\
\hline$R 1$ [all data] & 0.0306 \\
\hline$w R 2$ [all data] & 0.0597 \\
\hline GooF & $1.056-$ \\
\hline Extinction coefficient & \\
\hline Largest diff. peak / hole & \\
\hline $\max . / \min .\left[10^{3} \cdot \mathrm{e} \cdot \mathrm{nm}^{-3}\right]$ & 0.510 and -0.538 \\
\hline
\end{tabular}




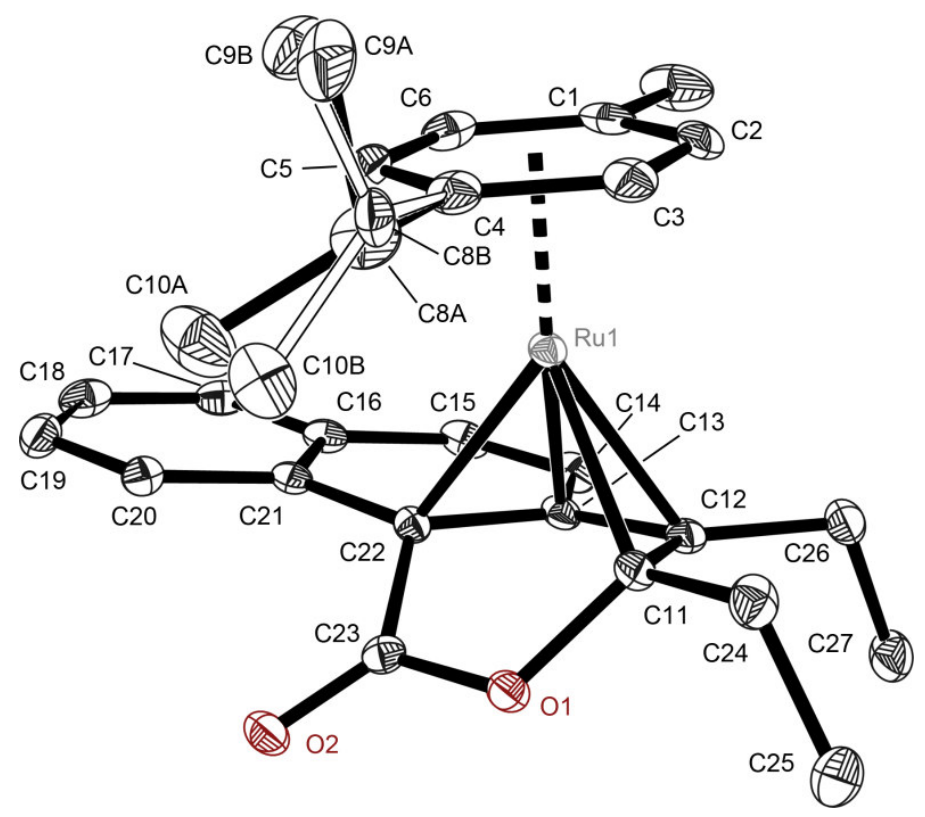

Figure 41. Molecular structure of $\mathbf{9 1 b e}$ in the crystal. Anisotropic displacement parameters are depicted at the $50 \%$ probability level 


\begin{tabular}{|c|c|c|c|}
\hline $\mathrm{Ru}(1)-\mathrm{C}(11)$ & $210.87(17)$ & $C(12)-C(26)$ & $150.9(2)$ \\
\hline $\mathrm{Ru}(1)-\mathrm{C}(12)$ & 213.71(17) & $C(13)-C(14)$ & $145.4(2)$ \\
\hline $\mathrm{Ru}(1)-\mathrm{C}(13)$ & $215.08(16)$ & $C(13)-C(22)$ & $146.5(2)$ \\
\hline$R u(1)-C(3)$ & $218.82(17)$ & $C(14)-C(15)$ & $134.1(3)$ \\
\hline$R u(1)-C(22)$ & $219.20(16)$ & $C(15)-C(16)$ & $144.9(2)$ \\
\hline $\mathrm{Ru}(1)-\mathrm{C}(2)$ & $222.52(17)$ & $C(16)-C(17)$ & $140.9(2)$ \\
\hline$R u(1)-C(5)$ & $222.55(18)$ & $C(16)-C(21)$ & $141.5(2)$ \\
\hline $\mathrm{Ru}(1)-\mathrm{C}(4)$ & $223.49(17)$ & $C(17)-C(18)$ & $137.8(3)$ \\
\hline $\mathrm{Ru}(1)-C(6)$ & $223.83(18)$ & $C(18)-C(19)$ & $139.5(3)$ \\
\hline $\mathrm{Ru}(1)-\mathrm{C}(1)$ & $226.11(18)$ & $C(19)-C(20)$ & $138.4(2)$ \\
\hline$O(1)-C(23)$ & $134.7(2)$ & $C(20)-C(21)$ & $140.6(2)$ \\
\hline $\mathrm{O}(1)-\mathrm{C}(11)$ & $146.7(2)$ & $C(21)-C(22)$ & $147.4(2)$ \\
\hline$C(1)-C(2)$ & $140.8(3)$ & $C(22)-C(23)$ & $149.6(2)$ \\
\hline$C(1)-C(6)$ & $141.2(3)$ & $C(24)-C(25)$ & $153.5(2)$ \\
\hline$C(1)-C(7)$ & $150.7(3)$ & $C(26)-C(27)$ & $153.4(2)$ \\
\hline$C(2)-C(3)$ & $141.2(3)$ & & \\
\hline$O(2)-C(23)$ & $120.8(2)$ & $C(11)-R u(1)-C(12)$ & $39.79(6)$ \\
\hline$C(6)-C(5)$ & $142.4(3)$ & $C(11)-R u(1)-C(13)$ & $67.65(7)$ \\
\hline$C(3)-C(4)$ & $142.3(3)$ & $C(12)-R u(1)-C(13)$ & $39.08(6)$ \\
\hline$C(5)-C(4)$ & 141.1(3) & $C(11)-R u(1)-C(3)$ & $101.62(7)$ \\
\hline$C(4)-C(8 B)$ & $150.9(15)$ & $C(12)-R u(1)-C(3)$ & $121.41(7)$ \\
\hline$C(4)-C(8 A)$ & $151.6(3)$ & $C(13)-R u(1)-C(3)$ & $158.85(7)$ \\
\hline$C(8 A)-C(10 A)$ & $152.9(5)$ & $C(11)-R u(1)-C(22)$ & $73.42(6)$ \\
\hline$C(8 A)-C(9 A)$ & $153.4(4)$ & $C(12)-R u(1)-C(22)$ & $68.83(7)$ \\
\hline$C(8 B)-C(10 B)$ & $150.8(15)$ & $C(13)-R u(1)-C(22)$ & $39.42(6)$ \\
\hline$C(8 B)-C(9 B)$ & $150.9(15)$ & $C(3)-R u(1)-C(22)$ & $157.75(7)$ \\
\hline$C(11)-C(12)$ & $144.5(2)$ & $C(11)-R u(1)-C(2)$ & $116.29(7)$ \\
\hline$C(11)-C(24)$ & $150.5(2)$ & $C(12)-R u(1)-C(2)$ & $109.47(7)$ \\
\hline$C(12)-C(13)$ & $143.4(2)$ & $C(13)-R u(1)-C(2)$ & $129.59(7)$ \\
\hline
\end{tabular}




\begin{tabular}{|c|c|c|c|}
\hline$C(3)-R u(1)-C(2)$ & $37.30(7)$ & $C(5)-R u(1)-C(1)$ & $66.77(7)$ \\
\hline$C(22)-R u(1)-C(2)$ & $163.71(7)$ & $C(4)-R u(1)-C(1)$ & $80.02(7)$ \\
\hline$C(11)-R u(1)-C(5)$ & $140.13(7)$ & $C(6)-R u(1)-C(1)$ & $36.56(7)$ \\
\hline$C(12)-R u(1)-C(5)$ & $171.97(6)$ & $C(23)-O(1)-C(11)$ & $113.91(13)$ \\
\hline$C(13)-R u(1)-C(5)$ & $133.70(7)$ & $C(2)-C(1)-C(6)$ & $117.67(17)$ \\
\hline$C(3)-R u(1)-C(5)$ & $66.30(7)$ & $C(2)-C(1)-C(7)$ & $121.32(18)$ \\
\hline$C(22)-R u(1)-C(5)$ & 103.17(7) & $C(6)-C(1)-C(7)$ & $121.01(18)$ \\
\hline$C(2)-R u(1)-C(5)$ & $77.98(7)$ & $C(2)-C(1)-R u(1)$ & $70.33(10)$ \\
\hline$C(11)-R u(1)-C(4)$ & $111.06(7)$ & $C(6)-C(1)-R u(1)$ & $70.84(10)$ \\
\hline$C(12)-R u(1)-C(4)$ & $148.15(7)$ & $C(7)-C(1)-R u(1)$ & $129.48(12)$ \\
\hline$C(13)-R u(1)-C(4)$ & $162.45(7)$ & $C(1)-C(2)-C(3)$ & $121.30(17)$ \\
\hline$C(3)-R u(1)-C(4)$ & $37.53(7)$ & $C(1)-C(2)-R u(1)$ & $73.10(10)$ \\
\hline$C(22)-R u(1)-C(4)$ & $123.03(7)$ & $C(3)-C(2)-R u(1)$ & $69.92(10)$ \\
\hline$C(2)-R u(1)-C(4)$ & $67.43(7)$ & $C(1)-C(6)-C(5)$ & $121.06(17)$ \\
\hline$C(5)-R u(1)-C(4)$ & $36.89(7)$ & $C(1)-C(6)-R u(1)$ & $72.59(10)$ \\
\hline$C(11)-R u(1)-C(6)$ & 177.11(7) & $C(5)-C(6)-R u(1)$ & $70.90(10)$ \\
\hline$C(12)-R u(1)-C(6)$ & $142.53(7)$ & $C(2)-C(3)-C(4)$ & $121.65(17)$ \\
\hline$C(13)-R u(1)-C(6)$ & $113.28(7)$ & $C(2)-C(3)-R u(1)$ & $72.77(10)$ \\
\hline$C(3)-R u(1)-C(6)$ & $78.39(7)$ & $C(4)-C(3)-R u(1)$ & $73.02(10)$ \\
\hline$C(22)-R u(1)-C(6)$ & $105.47(7)$ & $C(4)-C(5)-C(6)$ & $121.53(17)$ \\
\hline$C(2)-R u(1)-C(6)$ & $65.44(7)$ & $C(4)-C(5)-R u(1)$ & $71.92(10)$ \\
\hline$C(5)-R u(1)-C(6)$ & $37.22(7)$ & $C(6)-C(5)-R u(1)$ & $71.88(10)$ \\
\hline$C(4)-R u(1)-C(6)$ & $67.17(7)$ & $C(5)-C(4)-C(3)$ & $116.76(16)$ \\
\hline$C(11)-R u(1)-C(1)$ & 146.09(7) & $C(5)-C(4)-C(8 B)$ & $125.9(12)$ \\
\hline$C(12)-R u(1)-C(1)$ & 117.27(7) & $C(3)-C(4)-C(8 B)$ & $117.0(11)$ \\
\hline$C(13)-R u(1)-C(1)$ & 111.11(7) & $C(5)-C(4)-C(8 A)$ & $123.0(3)$ \\
\hline$C(3)-R u(1)-C(1)$ & $67.05(7)$ & $C(3)-C(4)-C(8 A)$ & $120.2(3)$ \\
\hline$C(22)-R u(1)-C(1)$ & 128.63(7) & $C(5)-C(4)-R u(1)$ & $71.19(10)$ \\
\hline$C(2)-R u(1)-C(1)$ & $36.57(7)$ & $C(3)-C(4)-R u(1)$ & $69.46(10)$ \\
\hline
\end{tabular}




\begin{tabular}{|c|c|c|c|}
\hline$C(8 B)-C(4)-R u(1)$ & $135.5(9)$ & $C(17)-C(16)-C(15)$ & $120.11(16)$ \\
\hline$C(8 A)-C(4)-R u(1)$ & $129.9(2)$ & $C(21)-C(16)-C(15)$ & $120.16(16)$ \\
\hline$C(4)-C(8 A)-C(10 A)$ & $113.8(3)$ & $C(18)-C(17)-C(16)$ & $120.56(17)$ \\
\hline$C(4)-C(8 A)-C(9 A)$ & $108.9(4)$ & $C(17)-C(18)-C(19)$ & $120.03(17)$ \\
\hline$C(10 A)-C(8 A)-C(9 A)$ & $110.9(4)$ & $C(20)-C(19)-C(18)$ & $120.29(17)$ \\
\hline$C(10 B)-C(8 B)-C(4)$ & $112.7(14)$ & $C(19)-C(20)-C(21)$ & $120.96(17)$ \\
\hline$C(10 B)-C(8 B)-C(9 B)$ & $117(2)$ & $C(20)-C(21)-C(16)$ & $118.44(16)$ \\
\hline$C(4)-C(8 B)-C(9 B)$ & $115(2)$ & $C(20)-C(21)-C(22)$ & $121.99(15)$ \\
\hline$C(12)-C(11)-O(1)$ & $115.74(14)$ & $C(16)-C(21)-C(22)$ & $119.57(15)$ \\
\hline$C(12)-C(11)-C(24)$ & $123.31(15)$ & $C(13)-C(22)-C(21)$ & $117.54(15)$ \\
\hline $\mathrm{O}(1)-\mathrm{C}(11)-\mathrm{C}(24)$ & $106.38(14)$ & $C(13)-C(22)-C(23)$ & $116.30(14)$ \\
\hline$C(12)-C(11)-R u(1)$ & $71.16(10)$ & $C(21)-C(22)-C(23)$ & $118.39(14)$ \\
\hline $\mathrm{O}(1)-\mathrm{C}(11)-\mathrm{Ru}(1)$ & $112.41(11)$ & $C(13)-C(22)-R u(1)$ & $68.77(9)$ \\
\hline$C(24)-C(11)-R u(1)$ & $124.81(12)$ & $C(21)-C(22)-R u(1)$ & $119.54(11)$ \\
\hline$C(13)-C(12)-C(11)$ & $110.89(15)$ & $C(23)-C(22)-R u(1)$ & $106.01(10)$ \\
\hline$C(13)-C(12)-C(26)$ & $122.66(16)$ & $\mathrm{O}(2)-\mathrm{C}(23)-\mathrm{O}(1)$ & $119.23(15)$ \\
\hline$C(11)-C(12)-C(26)$ & $126.42(16)$ & $O(2)-C(23)-C(22)$ & $126.41(16)$ \\
\hline$C(13)-C(12)-R u(1)$ & 70.97(9) & $\mathrm{O}(1)-\mathrm{C}(23)-\mathrm{C}(22)$ & $114.33(14)$ \\
\hline$C(11)-C(12)-R u(1)$ & $69.04(9)$ & $C(11)-C(24)-C(25)$ & $113.67(14)$ \\
\hline$C(26)-C(12)-R u(1)$ & $125.33(12)$ & \multicolumn{2}{|c|}{$C(12)-C(26)-C(27) 112.59(14)$} \\
\hline$C(12)-C(13)-C(14)$ & $125.04(15)$ & & \\
\hline$C(12)-C(13)-C(22)$ & $115.13(15)$ & & \\
\hline$C(14)-C(13)-C(22)$ & 119.69(15) & & \\
\hline$C(12)-C(13)-R u(1)$ & 69.94(9) & & \\
\hline$C(14)-C(13)-R u(1)$ & $124.09(12)$ & & \\
\hline$C(22)-C(13)-R u(1)$ & $71.81(9)$ & & \\
\hline$C(15)-C(14)-C(13)$ & $120.85(16)$ & & \\
\hline$C(14)-C(15)-C(16)$ & $121.86(16)$ & & \\
\hline$C(17)-C(16)-C(21)$ & $119.71(16)$ & & \\
\hline
\end{tabular}




\section{checkCIF/PLATON report}

Structure factors have been supplied for datablock(s) p21_c_a

THIS REPORT IS FOR GUIDANCE ONLY. IF USED AS PART OF A REVIEW PROCEDURE FOR PUBLICATION, IT SHOULD NOT REPLACE THE EXPERTISE OF AN EXPERIENCED CRYSTALLOGRAPHIC REFEREE.

No syntax errors found.

CIF dictionary

Interpreting this report

\section{Datablock: p21_c_a}

$\begin{array}{llll}\text { Bond precision: } & C-C=0.0025 \AA & \text { Wavelength }=0.71073 \\ \text { Cell: } & a=17.311(3) & b=8.420(2) & c=16.273(2) \\ & \text { alpha }=90 & \text { beta }=113.03(2) & \text { gamma }=90\end{array}$

Temperature: $100 \mathrm{~K}$

\begin{tabular}{lll} 
& Calculated & Reported \\
Volume & $2182.9(8)$ & $2182.9(8)$ \\
Space group & P 21/c & P 21/c \\
Hall group & $-\mathrm{P} 2 \mathrm{ybc}$ & $-\mathrm{P} 2 \mathrm{ybc}$ \\
Moiety formula & $\mathrm{C} 27 \mathrm{H} 30 \mathrm{O} 2 \mathrm{Ru}$ & $\mathrm{C} 27 \mathrm{H} 30 \mathrm{O} 2 \mathrm{Ru}$ \\
Sum formula & $\mathrm{C} 27 \mathrm{H} 30 \mathrm{O} 2 \mathrm{Ru}$ & $\mathrm{C} 27 \mathrm{H} 30 \mathrm{O} 2 \mathrm{Ru}$ \\
Mr & 487.58 & 487.58 \\
Dx,g cm-3 & 1.484 & 1.484 \\
Z & 4 & 4 \\
Mu (mm-1) & 0.739 & 0.739 \\
F000 & 1008.0 & 1008.0 \\
F000' & 1003.29 & \\
h,k,Imax & $23,11,22$ & $23,11,22$ \\
Nref & 5657 & 5655 \\
Tmin,Tmax & $0.932,0.964$ & $0.707,0.746$ \\
Tmin' & 0.902 & \\
\hline
\end{tabular}

Correction method= \# Reported T Limits: $\mathrm{Tmin}=0.707 \mathrm{Tmax}=0.746$

AbsCorr $=$ MULTI-SCAN

Data completeness $=1.000$

$R($ reflections $)=0.0246(4915)$

$S=1.056$

Npar $=304$
$\operatorname{Theta}(\max )=28.731$

$w R 2($ reflections $)=0.0597(5655)$ 
The following ALERTS were generated. Each ALERT has the format

test-name_ALERT_alert-type_alert-level.

Click on the hyperlinks for more details of the test.

\section{Alert level G}

PLAT002_ALERT_2_G Number of Distance or Angle Restraints on AtSite 9 Note

PLAT003_ALERT_2_G Number of Uiso or Uij Restrained non-H Atoms ... 7 Report

PLAT175_ALERT_4_G The CIF-Embedded .res File Contains SAME Records 2 Report

PLAT176_ALERT_4_G The CIF-Embedded .res File Contains SADI Records 7 Report

PLAT178_ALERT_4_G The CIF-Embedded .res File Contains SIMU Records 1 Report

PLAT187_ALERT_4_G The CIF-Embedded .res File Contains RIGU Records 1 Report

PLAT301_ALERT_3_G Main Residue Disorder ............ Percentage $=10$ Note

PLAT333_ALERT_2_G Check Large Av C6-Ring C-C Dist. C13 -C22 1.44 Ang.

PLAT343_ALERT_2_G Unusual sp? Angle Range in Main Residue for C11 Check

PLAT367_ALERT_2_G Long? C(sp?)-C(sp?) Bond C11 - C24 .. 1.50 Ang.

PLAT860_ALERT_3_G Number of Least-Squares Restraints ............. 135 Note

PLAT912_ALERT_4_G Missing \# of FCF Reflections Above STh/L= $0.600 \quad 4$ Note

PLAT978_ALERT_2_G Number C-C Bonds with Positive Residual Density 19 Note

0 ALERT level $\mathbf{A}=$ Most likely a serious problem - resolve or explain

0 ALERT level B = A potentially serious problem, consider carefully

0 ALERT level $\mathbf{C}=$ Check. Ensure it is not caused by an omission or oversight

13 ALERT level G = General information/check it is not something unexpected

0 ALERT type 1 CIF construction/syntax error, inconsistent or missing data

6 ALERT type 2 Indicator that the structure model may be wrong or deficient

2 ALERT type 3 Indicator that the structure quality may be low

5 ALERT type 4 Improvement, methodology, query or suggestion

0 ALERT type 5 Informative message, check 


\section{Literature}

[1] Green Chemistry, Theory and Practice, (Eds.: P. T. Anastas, J. C. Warner), Oxford University Press, Oxford, 1998.

[2] C-H Bond Activation in Organic Synthesis, (Ed.: J. J. Li), CRC Press, 2015, and refernces cited therein.

[3] a) M. Gulías, J. L. Mascareñas, Angew. Chem. Int. Ed. 2016, 55, 11000-11019; b) D. Intrieri, D. M. Carminati, E. Gallo, J. Porphyrins Phthalocyanines 2016, 20, 190-203; c) B. Li, B. Wang, in Transition Metal-Catalyzed Heterocycle Synthesis via C-H Activation (Ed.: X.-F. Wu), WileyVCH, Weinheim, 2016, pp. 187-232; d) V. P. Boyarskiy, D. S. Ryabukhin, N. A. Bokach, A. V. Vasilyev, Chem. Rev. 2016, 116, 5894-5986; e) L. Ackermann, Org. Process Res. Dev. 2015, 19, 260-269; f) P. Gandeepan, C.-H. Cheng, Chem. Asian J. 2015, 10, 824-838; g) K. Shin, H. Kim, S. Chang, Acc. Chem. Res. 2015, 48, 1040-1052; h) L. Huang, M. Arndt, K. Gooßen, H. Heydt, L. J. Gooßen, Chem. Rev. 2015, 115, 2596-2697; i) O. Daugulis, J. Roane, L. D. Tran, Acc. Chem. Res. 2015, 48, 1053-1064; j) D. Morton, S. B. Blakey, ChemCatChem 2015, 7, 577-578; k) Z. Chen, B. Wang, J. Zhang, W. Yu, Z. Liu, Y. Zhang, Org. Chem. Front. 2015, 2, 1107-1295; I) K. Yuan, J.-F. Soulé, H. Doucet, ACS Catal. 2015, 5, 978-991; m) J. Miao, H. Ge, Eur. J. Org. Chem. 2015, 2015, 7859-7868; n) M. Itazaki, H. Nakazawa, in Iron Catalysis II (Ed.: E. Bauer), Springer, Cham, 2015, pp. 47-81; o) L. Ackermann, Acc. Chem. Res. 2014, 47, 281-295; p) S. De Sarkar, W. Liu, S. I. Kozhushkov, L. Ackermann, Adv. Synth. Catal. 2014, 356, 1461-1479; q) V. S. Thirunavukkarasu, S. I. Kozhushkov, L. Ackermann, Chem. Commun. 2014, 50, 29-39; r) C. Bruneau, in Ruthenium in Catalysis (Eds.: H. P. Dixneuf, C. Bruneau), Springer, Cham, 2014, pp. 195-236; s) B. Li, P. H. Dixneuf, in Ruthenium in Catalysis (Eds.: H. P. Dixneuf, C. Bruneau), Springer, Cham, 2014, pp. 119-193; t) R. He, Z.-T. Huang, Q.-Y. Zheng, C. Wang, Tetrahedron Lett. 2014, 55, 5705-5713, and refernces cited therein.

[4] a) L. Ackermann, Chem. Rev. 2011, 111, 1315-1345; b) D. Balcells, E. Clot, O. Eisenstein, Chem. Rev. 2010, 110, 749-823; c) J. A. Labinger, J. E. Bercaw, Nature 2002, 417, 507-514.

[5] J. R. Webb, S. A. Burgess, T. R. Cundari, T. B. Gunnoe, Dalton Trans. 2013, 42, 16646-16665.

[6] L. David, F. Keith, Chem. Lett. 2010, 39, 1118-1126.

[7] a) Y. Boutadla, D. L. Davies, S. A. Macgregor, A. I. Poblador-Bahamonde, Dalton Trans. 2009, 5820-5831; b) Y. Boutadla, D. L. Davies, S. A. Macgregor, A. I. Poblador-Bahamonde, Dalton Trans. 2009, 5887-5893.

[8] J. Oxgaard, W. J. Tenn, R. J. Nielsen, R. A. Periana, W. A. Goddard, Organometallics 2007, 26, 1565-1567.

[9] a) H. Wang, M. Moselage, M. J. González, L. Ackermann, ACS Catal. 2016, 6, 2705-2709; b) D. Santrač, S. Cella, W. Wang, L. Ackermann, Eur. J. Org. Chem. 2016, DOI: 10.1002/ejoc.201601045; c) R. Mei, J. Loup, L. Ackermann, ACS Catal. 2016, 6, 793-797; d) W. Ma, R. Mei, G. Tenti, L. Ackermann, Chem. Eur. J. 2014, 20, 15248-15251.

[10] L. Ackermann, Top. Organomet. Chem. 2007, 24, 35-60.

[11] J. M. Kisenyi, G. J. Sunley, J. A. Cabeza, A. J. Smith, H. Adams, N. J. Salt, P. M. Maitlis, J. Chem. Soc., Dalton Trans. 1987, 2459-2466.

[12] K. Ueura, T. Satoh, M. Miura, Org. Lett. 2007, 9, 1407-1409.

[13] a) L. Li, W. W. Brennessel, W. D. Jones, J. Am. Chem. Soc. 2008, 130, 12414-12419; b) D. R. Stuart, M. Bertrand-Laperle, K. M. N. Burgess, K. Fagnou, J. Am. Chem. Soc. 2008, 130, 1647416475; c) K. Ueura, T. Satoh, M. Miura, J. Org. Chem. 2007, 72, 5362-5367, and refernces cited therein.

[14] Average price in August in $\$$ per Oz: Pt 1135, Pd 706, Rh 638, Ir 590, Ru 42, http://www.platinum.matthey.com/prices/price-charts, 26.08.2016

[15] L. Ackermann, A. V. Lygin, N. Hofmann, Angew. Chem. Int. Ed. 2011, 50, 6379-6382. 
[16] a) Y. Zhao, Z. He, S. Li, J. Tang, G. Gao, J. Lan, J. You, Chem. Commun. 2016, 52, 4613-4616; b) K. S. Singh, S. G. Sawant, P. H. Dixneuf, ChemCatChem 2016, 8, 1046-1050; c) S. Rajkumar, S. Antony Savarimuthu, R. Senthil Kumaran, C. M. Nagaraja, T. Gandhi, Chem. Commun. 2016, 52, 2509-2512; d) K.-H. He, W.-D. Zhang, M.-Y. Yang, K.-L. Tang, M. Qu, Y.-S. Ding, Y. Li, Org. Lett. 2016, 18, 2840-2843; e) Z. Zuo, X. Yang, J. Liu, J. Nan, L. Bai, Y. Wang, X. Luan, J. Org. Chem. 2015, 80, 3349-3356; f) Y. Zheng, W.-B. Song, S.-W. Zhang, L.-J. Xuan, Org. Biomol. Chem. 2015, 13, 6474-6478; g) J. Wu, W. Xu, Z.-X. Yu, J. Wang, J. Am. Chem. Soc. 2015, 137, 9489-9496; h) R. Prakash, K. Shekarrao, S. Gogoi, Org. Lett. 2015, 17, 5264-5267; i) H. Miura, K. Tsutsui, K. Wada, T. Shishido, Chem. Commun. 2015, 51, 1654-1657; j) R. Manoharan, M. Jeganmohan, Chem. Commun. 2015, 51, 2929-2932; k) R. Li, Y. Hu, R. Liu, R. Hu, B. Li, B. Wang, Adv. Synth. Catal. 2015, 357, 3885-3892; I) J. Li, L. Ackermann, Org. Chem. Front. 2015, 2, 1035-1039; m) X.-F. Dong, J. Fan, X.-Y. Shi, K.-Y. Liu, P.-M. Wang, J.-F. Wei, J. Organomet. Chem. 2015, 779, 55-61; n) A. Banerjee, S. K. Santra, P. R. Mohanta, B. K. Patel, Org. Lett. 2015, 17, 5678-5681; o) S. Allu, K. C. Kumara Swamy, Adv. Synth. Catal. 2015, 357, 26652680; p) Z. Zhang, H. Jiang, Y. Huang, Org. Lett. 2014, 16, 5976-5979; q) F. Yang, L. Ackermann, J. Org. Chem. 2014, 79, 12070-12082; r) S. Nakanowatari, L. Ackermann, Chem. Eur. J. 2014, 20, 5409-5413; s) C. Ma, C. Ai, Z. Li, B. Li, H. Song, S. Xu, B. Wang, Organometallics 2014, 33, 5164-5172; t) C.-H. Hung, P. Gandeepan, C.-H. Cheng, ChemCatChem 2014, 6, 2692-2697; u) S. De Sarkar, L. Ackermann, Chem. Eur. J. 2014, 20, 13932-13936; v) R. K. Arigela, R. Kumar, T. Joshi, R. Mahar, B. Kundu, RSC Adv. 2014, 4, 57749-57753; w) J. D. Dooley, S. Reddy Chidipudi, H. W. Lam, J. Am. Chem. Soc. 2013, 135, 10829-10836.

[17] L. Ackermann, J. Pospech, K. Graczyk, K. Rauch, Org. Lett. 2012, 14, 930-933.

[18] L. Ackermann, J. Pospech, Org. Lett. 2011, 13, 4153-4155.

[19] L. Wang, L. Ackermann, Org. Lett. 2013, 15, 176.

[20] N. Guimond, C. Gouliaras, K. Fagnou, J. Am. Chem. Soc. 2010, 132, 6908-6909.

[21] B. Li, H. Feng, S. Xu, B. Wang, Chem. Eur. J. 2011, 17, 12573-12577.

[22] L. Ackermann, S. Fenner, Org. Lett. 2011, 13, 6548-6551.

[23] Z. Shi, C. Zhang, S. Li, D. Pan, S. Ding, Y. Cui, N. Jiao, Angew. Chem. Int. Ed. 2009, 48, 45724576.

[24] a) Y. Lu, H.-W. Wang, J. E. Spangler, K. Chen, P.-P. Cui, Y. Zhao, W.-Y. Sun, J.-Q. Yu, Chem. Sci. 2015, 6, 1923-1927; b) G. Zhang, H. Yu, G. Qin, H. Huang, Chem. Commun. 2014, 50, 43314334; c) G. Zhang, L. Yang, Y. Wang, Y. Xie, H. Huang, J. Am. Chem. Soc. 2013, 135, 8850-8853.

[25] Modern Arylation Methods, (Ed.: L. Ackermann), Wiley-VCH, Weinheim, 2009, and refernces cited therein.

[26] a) S. Oi, R. Funayama, T. Hattori, Y. Inoue, Tetrahedron 2008, 64, 6051-6059; b) S. Oi, E. Aizawa, Y. Ogino, Y. Inoue, J. Org. Chem. 2005, 70, 3113-3119; c) S. Oi, Y. Ogino, S. Fukita, Y. Inoue, Org. Lett. 2002, 4, 1783-1785; d) S. Oi, S. Fukita, N. Hirata, N. Watanuki, S. Miyano, Y. Inoue, Org. Lett. 2001, 3, 2579-2581.

[27] a) M. Seki, RSC Adv. 2014, 4, 29131-29133; b) S. G. Ouellet, A. Roy, C. Molinaro, R. Angelaud, J.-F. Marcoux, P. D. O'Shea, I. W. Davies, J. Org. Chem. 2011, 76, 1436-1439.

[28] a) L. Ackermann, Isr. J. Chem. 2010, 50, 652; b) L. Ackermann, Org. Lett. 2005, 7, 3123-3125.

[29] L. Ackermann, R. Vicente, A. Althammer, Org. Lett. 2008, 10, 2299-2302.

[30] H. Grounds, J. C. Anderson, B. Hayter, A. J. Blake, Organometallics 2009, 28, 5289-5292.

[31] L. Ackermann, R. Vicente, H. K. Potukuchi, V. Pirovano, Organic Letters 2010, 12, 5032-5035.

[32] a) Catalytic Asymmetric Friedel-Crafts Alkylations, (Eds.: M. Bandini, A. Umani-Ronchi), Wiley VCH, Weinheim, 2009; b) C. Friedel, J.-M. Crafts, Compt. Rend. 1877, 84, 1392.

[33] M. Rueping, B. J. Nachtsheim, Beilstein J. Org. Chem. 2010, 6, 6.

[34] A. Yamamoto, Y. Nishimura, Y. Nishihara, in Applied Cross-Coupling Reactions (Ed.: Y. Nishihara), Springer, Berlin, Heidelberg, 2013, pp. 203-229, and refernces cited therein.

[35] G. Cahiez, C. Chaboche, M. Jézéquel, Tetrahedron 2000, 56, 2733-2737. 
[36] a) Z. Ruan, S. Lackner, L. Ackermann, Angew. Chem. Int. Ed. 2016, 55, 3153-3157; b) G. Cera, T. Haven, L. Ackermann, Angew. Chem. Int. Ed. 2016, 55, 1484-1488; c) S.-Y. Zhang, Q. Li, G. He, W. A. Nack, G. Chen, J. Am. Chem. Soc. 2015, 137, 531-539; d) R.-Y. Zhu, J. He, X.-C. Wang, J.-Q. Yu, J. Am. Chem. Soc. 2014, 136, 13194-13197; e) X. Wu, J. W. T. See, K. Xu, H. Hirao, J. Roger, J.-C. Hierso, J. Zhou, Angew. Chem. Int. Ed. 2014, 53, 13573-13577; f) W. Song, S. Lackner, L. Ackermann, Angew. Chem. Int. Ed. 2014, 53, 2477-2480; g) L. Ilies, T. Matsubara, S. Ichikawa, S. Asako, E. Nakamura, J. Am. Chem. Soc. 2014, 136, 13126-13129; h) E. R. Fruchey, B. M. Monks, S. P. Cook, J. Am. Chem. Soc. 2014, 136, 13130-13133; i) L. Ackermann, J. Org. Chem. 2014, 79, 8948-8954; j) B. Punji, W. Song, G. A. Shevchenko, L. Ackermann, Chem. Eur. J. 2013, 19, 10605-10610; k) K. Gao, N. Yoshikai, J. Am. Chem. Soc. 2013, 135, 9279-9282; I) T. Yao, K. Hirano, T. Satoh, M. Miura, Angew. Chem. Int. Ed. 2012, 51, 775-779; m) L. Ackermann, B. Punji, W. Song, Adv. Synth. Catal. 2011, 353, 3325-3329; n) T. Yao, K. Hirano, T. Satoh, M. Miura, Chem. Eur. J. 2010, 16, 12307-12311; review: o) L. Ackermann, Chem. Commun. 2010, 46, 4866-4877.

[37] S. J. Tremont, R. Hayat Ur, J. Am. Chem. Soc. 1984, 106, 5759-5760.

[38] L. N. Lewis, J. F. Smith, J. Am. Chem. Soc. 1986, 108, 2728-2735.

[39] S. Murai, F. Kakiuchi, S. Sekine, Y. Tanaka, A. Kamatani, M. Sonoda, N. Chatani, Nature 1993, 366, 529-531.

[40] M. Schinkel, I. Marek, L. Ackermann, Angew. Chem. Int. Ed. 2013, 52, 3977-3980.

[41] a) L. Ackermann, N. Hofmann, R. Vicente, Org. Lett. 2011, 13, 1875-1877; b) L. Ackermann, P. Novák, R. Vicente, N. Hofmann, Angew. Chem. Int. Ed. 2009, 48, 6045-6048.

[42] N. Hofmann, L. Ackermann, J. Am. Chem. Soc. 2013, 135, 5877-5884.

[43] a) Z. Qureshi, C. Toker, M. Lautens, Synthesis 2016, DOI: 10.1055/s-0035-1561625; b) E. O. Muimhneachain, G. P. McGlacken, in Organomet. Chem., Vol. 40, The Royal Society of Chemistry, 2016, pp. 33-53; c) C. Li, D. Chen, W. Tang, Synlett 2016, 27, 2183-2200; d) D. Haas, J. M. Hammann, R. Greiner, P. Knochel, ACS Catal. 2016, 6, 1540-1552; e) P. G. Gildner, T. J. Colacot, Organometallics 2015, 34, 5497-5508, and references cited therein.

[44] a) J. Li, S. De Sarkar, L. Ackermann, Top. Organomet. Chem. 2016, 55, 217-257; b) G. Yang, N. Butt, W. Zhang, Chin. J. Catal. 2016, 37, 98-101; c) S. De Sarkar, Angew. Chem. Int. Ed. 2016, 55, 10558-10560; d) J. Yang, Org. Biomol. Chem. 2015, 13, 1930-1941; e) C. G. Frost, A. J. Paterson, ACS Cent. Sci. 2015, 1, 418-419; f) L. Ackermann, J. Li, Nat. Chem. 2015, 7, 686-687; g) J. Schranck, A. Tlili, M. Beller, Angew. Chem. Int. Ed. 2014, 53, 9426-9428.

[45] a) S. Mochida, K. Hirano, T. Satoh, M. Miura, J. Org. Chem. 2011, 76, 3024-3033; b) S. Mochida, K. Hirano, T. Satoh, M. Miura, Org. Lett. 2010, 12, 5776-5779.

[46] J. Cornella, M. Righi, I. Larrosa, Angew. Chem. Int. Ed. 2011, 50, 9429-9432.

[47] N. Y. P. Kumar, A. Bechtoldt, K. Raghuvanshi, L. Ackermann, Angew. Chem. Int. Ed. 2016, 55, 6929-6932.

[48] a) T. Ishiyama, Y. Nobuta, J. F. Hartwig, N. Miyaura, Chem. Commun. 2003, 2924-2925; b) J.-Y. Cho, M. K. Tse, D. Holmes, R. E. Maleczka, M. R. Smith, Science 2002, 295, 305-308; c) T. Ishiyama, J. Takagi, K. Ishida, N. Miyaura, N. R. Anastasi, J. F. Hartwig, J. Am. Chem. Soc. 2002, 124, 390; d) T. Ishiyama, J. Takagi, J. F. Hartwig, N. Miyaura, Angew. Chem., Int. Ed. 2002, 41, 3056.

[49] a) C. Cheng, J. F. Hartwig, J. Am. Chem. Soc. 2014, 136, 12064-12072; b) C. Cheng, J. F. Hartwig, Science 2014, 343, 853-857.

[50] D. Leow, G. Li, T.-S. Mei, J.-Q. Yu, Nature 2012, 486, 518-522.

[51] a) M. Bera, S. K. Sahoo, D. Maiti, ACS Catal. 2016, 6, 3575-3579; b) S. Bag, D. Maiti, Synthesis 2016, 48, 804-815; c) A. Maji, B. Bhaskararao, S. Singha, R. B. Sunoj, D. Maiti, Chem. Sci. 2016, 7, 3147-3153; d) S. Li, L. Cai, H. Ji, L. Yang, G. Li, Nat. Commun. 2016, 7, 10443; e) A. Dey, S. Agasti, D. Maiti, Org. Biomol. Chem. 2016, 14, 5440-5453; f) S. Bag, T. Patra, A. Modak, A. Deb, S. Maity, U. Dutta, A. Dey, R. Kancherla, A. Maji, A. Hazra, M. Bera, D. Maiti, J. Am. Chem. Soc. 2015, 137, 11888-11891; g) L. Chu, M. Shang, K. Tanaka, Q. Chen, N. Pissarnitski, E. Streckfuss, J.-Q. Yu, ACS Cent. Sci. 2015, 1, 394-399; h) M. Bera, A. Modak, T. Patra, A. Maji, 
D. Maiti, Org. Lett. 2014, 16, 5760-5763; i) Y.-F. Yang, G.-J. Cheng, P. Liu, D. Leow, T.-Y. Sun, P. Chen, X. Zhang, J.-Q. Yu, Y.-D. Wu, K. N. Houk, J. Am. Chem. Soc. 2014, 136, 344-355; j) G. Yang, P. Lindovska, D. Zhu, J. Kim, P. Wang, R.-Y. Tang, M. Movassaghi, J.-Q. Yu, J. Am. Chem. Soc. 2014, 136, 10807-10813; k) R.-Y. Tang, G. Li, J.-Q. Yu, Nature 2014, 507, 215-220; I) H.-X. Dai, G. Li, X.-G. Zhang, A. F. Stepan, J.-Q. Yu, J. Am. Chem. Soc. 2013, 135, 7567-7571.

[52] Y. Kuninobu, H. Ida, M. Nishi, M. Kanai, Nat. Chem. 2015, 7, 712-717.

[53] M. Catellani, F. Frignani, A. Rangoni, Angew. Chem. Int. Ed. Engl. 1997, 36, 119-122.

[54] a) N. Della Ca', M. Fontana, E. Motti, M. Catellani, Acc. Chem. Res. 2016, 49, 1389-1400; b) P. Wang, M. E. Farmer, X. Huo, P. Jain, P.-X. Shen, M. Ishoey, J. E. Bradner, S. R. Wisniewski, M. D. Eastgate, J.-Q. Yu, J. Am. Chem. Soc. 2016, 138, 9269-9276; c) T. Wilhelm, M. Lautens, Org. Lett. 2005, 7, 4053-4056.

[55] Z. Dong, J. Wang, G. Dong, J. Am. Chem. Soc. 2015, 137, 5887-5890.

[56] J.-P. Sutter, D. M. Grove, M. Beley, J.-P. Collin, N. Veldman, A. L. Spek, J.-P. Sauvage, G. van Koten, Angew. Chem. Int. Ed. Engl. 1994, 33, 1282-1285.

[57] C. Coudret, S. Fraysse, Chem. Commun. 1998, 663-664.

[58] a) A. M. Clark, C. E. F. Rickard, W. R. Roper, L. J. Wright, J. Organomet. Chem. 2000, 598, 262275; b) A. M. Clark, C. E. F. Rickard, W. R. Roper, L. J. Wright, Organometallics 1999, 18, 28132820.

[59] a) P. Marce, A. J. Paterson, M. F. Mahon, C. G. Frost, Catal. Sci. Technol. 2016; b) O. Saidi, J. Marafie, A. E. W. Ledger, P. M. Liu, M. F. Mahon, G. Kociok-Köhn, M. K. Whittlesey, C. G. Frost, J. Am. Chem. Soc. 2011, 133, 19298-19301.

[60] a) C. J. Teskey, A. Y. W. Lui, M. F. Greaney, Angew. Chem. Int. Ed. 2015, 54, 11677-11680; b) Q. Yu, L. a. Hu, Y. Wang, S. Zheng, J. Huang, Angew. Chem. Int. Ed. 2015, 54, 15284-15288.

[61] Z. Fan, J. Ni, A. Zhang, J. Am. Chem. Soc. 2016, 138, 8470-8475.

[62] A. Dumrath, C. Lübbe, M. Beller, in Palladium-Catalyzed Coupling Reactions, Wiley-VCH Verlag GmbH \& Co. KGaA, 2013, pp. 445-489.

[63] A. R. Dick, K. L. Hull, M. S. Sanford, J. Am. Chem. Soc. 2004, 126, 2300-2301.

[64] L. G. Voskressensky, N. E. Golantsov, A. M. Maharramov, Synthesis 2016, 48, 615-643, and refernces cited therein.

[65] D. C. Powers, D. Y. Xiao, M. A. L. Geibel, T. Ritter, J. Am. Chem. Soc. 2010, 132, 14530-14536.

[66] F. Kakiuchi, T. Kochi, H. Mutsutani, N. Kobayashi, S. Urano, M. Sato, S. Nishiyama, T. Tanabe, J. Am. Chem. Soc. 2009, 131, 11310-11311.

[67] W. Hao, Y. Liu, Beilstein J. Org. Chem. 2015, 11, 2132-2144.

[68] X. Chen, X.-S. Hao, C. E. Goodhue, J.-Q. Yu, J. Am. Chem. Soc. 2006, 128, 6790-6791.

[69] D.-G. Yu, T. Gensch, F. de Azambuja, S. Vásquez-Céspedes, F. Glorius, J. Am. Chem. Soc. 2014, 136, 17722-17725.

[70] L. Wang, L. Ackermann, Chem. Commun. 2014, 50, 1083-1085.

[71] V. Pascanu, F. Carson, M. V. Solano, J. Su, X. Zou, M. J. Johansson, B. Martín-Matute, Chem. Eur. J. 2016, 22, 3729-3737.

[72] A. T. Bell, Science 2003, 299, 1688-1691, and refernces cited therein.

[73] S. Santoro, S. I. Kozhushkov, L. Ackermann, L. Vaccaro, Green Chem. 2016, 18, 3471-3493.

[74] N. Nakamura, Y. Tajima, K. Sakai, Heterocycles 1982, 17, 235-245.

[75] R. H. Crabtree, Chem. Rev. 2012, 112, 1536-1554.

[76] J. Lee, J. Chung, S. M. Byun, B. M. Kim, C. Lee, Tetrahedron 2013, 69, 5660-5664.

[77] a) X. Tian, F. Yang, D. Rasina, M. Bauer, S. Warratz, F. Ferlin, L. Vaccaro, L. Ackermann, Chem. Commun. 2016, 52, 9777-9780; b) D. Rasina, A. Kahler-Quesada, S. Ziarelli, S. Warratz, H. Cao, S. Santoro, L. Ackermann, L. Vaccaro, Green Chem. 2016, 18, 5025-5030.

[78] a) Q.-Y. Meng, Q. Liu, J.-J. Zhong, H.-H. Zhang, Z.-J. Li, B. Chen, C.-H. Tung, L.-Z. Wu, Org. Lett. 2012, 14, 5992-5995; b) A. Khorshidi, CCL 2012, 23, 903-906; c) S. Verma, S. L. Jain, B. Sain, ChemCatChem 2011, 3, 1329-1332; d) H. Miura, K. Wada, S. Hosokawa, M. Inoue, Chem. Eur. J. 2010, 16, 4186-4189; e) H. Miura, K. Wada, S. Hosokawa, M. Inoue, ChemCatChem 2010, 2, 1223-1225. 
[79] P. d. Jongh, in Catalysis: From Principles to Applications (Eds.: M. Beller, A. Renken, R. v. Santen), Wiley-VCH, Weinheim, Germany, 2012.

[80] D. W. Lee, B. R. Yoo, J. Ind. Eng. Chem. 2014, 20, 3947-3959.

[81] S. Takasaki, H. Suzuki, K. Takahashi, S. Tanabe, A. Ueno, Y. Kotera, Journal of the Chemical Society, Faraday Transactions 1: Physical Chemistry in Condensed Phases 1984, 80, 803-811.

[82] S.-I. Niwa, F. Mizukami, S. Isoyama, T. Tsuchiya, K. Shimizu, S. Imai, J. Imamura, J. Chem. Technol. Biotechnol. 1986, 36, 236-246.

[83] U. Schubert, in The Sol-Gel Handbook, Wiley-VCH Verlag GmbH \& Co. KGaA, 2015, pp. 1-28.

[84] a) Y. Holade, N. Sahin, K. Servat, T. Napporn, K. Kokoh, Catalysts 2015, 5, 310; b) H. Yue, Y. Zhao, X. Ma, J. Gong, Chem. Soc. Rev. 2012, 41, 4218-4244.

[85] a) R. Ciriminna, V. Pandarus, A. Fidalgo, L. M. Ilharco, F. Béland, M. Pagliaro, Org. Process Res. Dev. 2015, 19, 755-768; b) M. P. Conley, C. Copéret, C. Thieuleux, ACS Catal. 2014, 4, 14581469 , and refernces cited therein.

[86] a) H. Jahangiri, J. Bennett, P. Mahjoubi, K. Wilson, S. Gu, Catal. Sci. Technol. 2014, 4, 22102229; b) L. Shi, J. Chen, K. Fang, Y. Sun, Fuel 2008, 87, 521-526; c) K. Okabe, I. Takahara, M. Inaba, K. Murata, Y. Yoshimura, J. Jpn. Petrol. Inst. 2007, 50, 65-68, and refernces cited therein.

[87] C. Tanyu, Z. Qiankun, Z. Dacheng, L. Guohua, Curr. Org. Chem. 2015, 19, 667-680, and refernces cited therein.

[88] S. Ruiz, P. Villuendas, E. P. Urriolabeitia, Tetrahedron Lett. 2016, 57, 3413-3432.

[89] M. Deponti, S. I. Kozhushkov, D. S. Yufit, L. Ackermann, Org. Biomol. Chem. 2013, 11, 142148.

[90] L. Ackermann, A. Althammer, R. Born, Angew. Chem. Int. Ed. 2006, 45, 2619-2622.

[91] V. Gayakhe, Y. S. Sanghvi, I. J. S. Fairlamb, A. R. Kapdi, Chem. Commun. 2015, 51, 1194411960.

[92] Modern Heterocyclic Chemistry, Vol. 4, (Eds.: J. Alvarez-Builla, J. J. Vaquero, J. Barluenga), Wiley-VCH, Weinheim, 2011.

[93] a) S. Pal, V. Chatare, M. Pal, Curr. Org. Chem. 2011, 15, 782-800; b) G. Zeni, R. C. Larock, Chem. Rev. 2004, 104, 2285-2310; c) Heterocyclic Chemistry, 4th ed., (Eds.: J. A. Joule, K. Mills), Blackwell Science Ltd., Oxford, 2000.

[94] B. M. Trost, Science 1991, 254, 1471-1477.

[95] a) L. Ackermann, A. V. Lygin, Org. Lett. 2012, 14, 764; b) R. K. Chinnagolla, M. Jeganmohan, Chem. Commun. 2012, 48, 2030-2032.

[96] L. Yang, G. Zhang, H. Huang, Adv. Synth. Catal. 2014, 356, 1509-1515.

[97] R. Giri, J.-Q. Yu, J. Am. Chem. Soc. 2008, 130, 14082-14083.

[98] a) N. Wang, B. Li, H. Song, S. Xu, B. Wang, Chem. Eur. J. 2013, 19, 358-364; b) Z. Liang, L. Ju, Y. Xie, L. Huang, Y. Zhang, Chem. Eur. J. 2012, 18, 15816-15821.

[99] D. A. Frasco, C. P. Lilly, P. D. Boyle, E. A. Ison, ACS Catal. 2013, 3, 2421-2429.

[100] a) B. Li, H. Feng, N. Wang, J. Ma, H. Song, S. Xu, B. Wang, Chem. Eur. J. 2012, 18, 1287312879; b) W. Ferstl, I. K. Sakodinskaya, N. Beydoun-Sutter, G. Le Borgne, M. Pfeffer, A. D. Ryabov, Organometallics 1997, 16, 411-418; c) H. C. L. Abbenhuis, M. Pfeffer, J. P. Sutter, A. de Cian, J. Fischer, H. L. Ji, J. H. Nelson, Organometallics 1993, 12, 4464-4472.

[101] L. Cuesta, T. Soler, E. P. Urriolabeitia, Chem. Eur. J. 2012, 18, 15178-15189.

[102] The crystal structure was measured and solved by Dr. Christian Niepötter and approved by Prof. Dietmar Stalke.

[103] M. Pfeffer, J.-P. Sutter, E. P. Urriolabeitia, Bull. Soc. Chim. Fr. 1997, 134, 947-954.

[104] J. A. Cabeza, M. Damonte, P. García-Álvarez, E. Pérez-Carreño, Organometallics 2013, 32, 4382-4390.

[105] S. Ueno, E. Mizushima, N. Chatani, F. Kakiuchi, J. Am. Chem. Soc. 2006, 128, 16516-16517.

[106] a) A. Takaoka, M.-E. Moret, J. C. Peters, J. Am. Chem. Soc. 2012, 134, 6695-6706; b) R. Poli, Angew. Chem. Int. Ed. 2011, 50, 43-45; c) A. Takaoka, L. C. H. Gerber, J. C. Peters, Angew. Chem. Int. Ed. 2010, 49, 4088-4091. 
[107] H. Yu, Y. Fu, Q. Guo, Z. Lin, Organometallics 2009, 28, 4443-4451.

[108] C. Kornhaaß, PhD thesis, Georg-August-Universität Göttingen 2014.

[109] S. Warratz, C. Kornhaaß, A. Cajaraville, B. Niepötter, D. Stalke, L. Ackermann, Angew. Chem. Int. Ed. 2015, 54, 5513-5517.

[110] A. Bechtoldt, C. Tirler, K. Raghuvanshi, S. Warratz, C. Kornhaaß, L. Ackermann, Angew. Chem. Int. Ed. 2016, 55, 264-267.

[111] D. C. Fabry, M. A. Ronge, J. Zoller, M. Rueping, Angew. Chem. Int. Ed. 2015, 54, 2801-2805.

[112] A. Bechtoldt, L. Ackermann, unpublished results.

[113] a) Y. Segawa, T. Maekawa, K. Itami, Angew. Chem. Int. Ed. 2015, 54, 66-81; b) L. G. Mercier, M. Leclerc, Acc. Chem. Res. 2013, 46, 1597-1605; c) J. Wencel-Delord, F. Glorius, Nat. Chem. 2013, 5, 369-375.

[114] a) L. Ackermann, Isr. J. Chem. 2010, 50, 652-663; b) L. Ackermann, R. Vicente, N. Hofmann, Org. Lett. 2009, 11, 4274-4276.

[115] a) S. M. M. Knapp, T. J. Sherbow, R. B. Yelle, J. J. Juliette, D. R. Tyler, Organometallics 2013, 32, 3744-3752; b) E. Y. Y. Chan, Q.-F. Zhang, Y.-K. Sau, S. M. F. Lo, H. H. Y. Sung, I. D. Williams, R. K. Haynes, W.-H. Leung, Inorg. Chem. 2004, 43, 4921-4926.

[116] a) E. Tomás-Mendivil, V. Cadierno, M. I. Menéndez, R. López, Chem. Eur. J. 2015, 21, 1687416886; b) E. Tomas-Mendivil, L. Menendez-Rodriguez, J. Francos, P. Crochet, V. Cadierno, RSC Adv. 2014, 4, 63466-63474.

[117] T. Oshiki, M. Muranaka, WO/2012/017966, 2012.

[118] W. Kläui, E. Buchholz, Angew. Chem. Int. Ed. Engl. 1988, 27, 580-581.

[119] M. Seki, Org. Process Res. Dev. 2016, 20, 867-877.

[120] a) K. Kubo, Y. Kohara, Y. Yoshimura, Y. Inada, Y. Shibouta, Y. Furukawa, T. Kato, K. Nishikawa, T. Naka, J. Med. Chem. 1993, 36, 2343-2349; b) J. V. Duncia, A. T. Chiu, D. J. Carini, G. B. Gregory, A. L. Johnson, W. A. Price, G. J. Wells, P. C. Wong, J. C. Calabrese, P. B. M. W. M. Timmermans, J. Med. Chem. 1990, 33, 1312-1329.

[121] E. Diers, N. Y. Phani Kumar, T. Mejuch, I. Marek, L. Ackermann, Tetrahedron 2013, 69, 44454453.

[122] M. Seki, M. Nagahama, J. Org. Chem. 2011, 76, 10198-10206.

[123] a) Q. Lu, X. Huang, G. Song, C.-M. Sun, J. P. Jasinski, A. C. Keeley, W. Zhang, ACS Comb. Sci. 2013, 15, 350-355; b) R. Yendapally, J. G. Hurdle, E. I. Carson, R. B. Lee, R. E. Lee, J. Med. Chem. 2008, 51, 1487-1491.

[124] a) M. Seki, Synthesis 2014, 3249-3255; b) K. Senthil, S. B. Reddy, B. K. Sinha, D. Mukkanti, R. Dandala, Org. Process Res. Dev. 2009, 13, 1185.

[125] a) E. E. Finney, R. G. Finke, Inorg. Chim. Acta 2006, 359, 2879-2887; b) G. M. Whitesides, M. Hackett, R. L. Brainard, J. P. P. M. Lavalleye, A. F. Sowinski, A. N. Izumi, S. S. Moore, D. W. Brown, E. M. Staudt, Organometallics 1985, 4, 1819-1830.

[126] D. Zell, S. Warratz, D. Gelman, S. J. Garden, L. Ackermann, Chem. Eur. J. 2016, 22, 1248-1252.

[127] a) L. Ackermann, A. Althammer, R. Born, Synlett 2007, 2007, 2833-2836; b) L. Ackermann, A. Althammer, R. Born, Tetrahedron 2008, 64, 6115-6124.

[128] a) P. H. Dixneuf, H. Doucet, Top. Organomet. Chem. 2016, 55; b) G. Cera, L. Ackermann, Top. Curr. Chem. 2016, 374, 1-34; c) M. Moselage, J. Li, L. Ackermann, ACS Catal. 2016, 6, 498-525; d) W. Liu, L. Ackermann, ACS Catal. 2016, 6, 3743-3752; e) G. Song, X. Li, Acc. Chem. Res. 2015, 48, 1007-1020.

[129] a) J. Li, S. Warratz, D. Zell, S. De Sarkar, E. E. Ishikawa, L. Ackermann, J. Am. Chem. Soc. 2015, 137, 13894-13901; b) K. Korvorapun, J. Li, S. D. Sarkar, T. Rogge, L. Ackermann, unpublished results.

[130] A. J. Paterson, S. St John-Campbell, M. F. Mahon, N. J. Press, C. G. Frost, Chem. Commun. 2015, 51, 12807-12810.

[131] a) G. W. Karpin, J. S. Merola, J. O. Falkinham, Antimicrob. Agents Chemother. 2013, 57, 3434 3436; b) K. S. Singh, P. H. Dixneuf, ChemCatChem 2013, 5, 1313-1316; c) G. Ciancaleoni, I. Di Maio, D. Zuccaccia, A. Macchioni, Organometallics 2007, 26, 489-496; d) A. Habtemariam, M. 
Melchart, R. Fernández, S. Parsons, I. D. H. Oswald, A. Parkin, F. P. A. Fabbiani, J. E. Davidson, A. Dawson, R. E. Aird, D. I. Jodrell, P. J. Sadler, J. Med. Chem. 2006, 49, 6858-6868; e) K. Severin, R. Bergs, W. Beck, Angew. Chem. Int. Ed. 1998, 37, 1634-1654; f) W. S. Sheldrick, S. Heeb, Inorg. Chim. Acta 1990, 168, 93-100.

[132] D. F. Dersnah, M. C. Baird, J. Organomet. Chem. 1977, 127, C55-C58.

[133] D. Black, G. Deacon, G. Edwards, B. Gatehouse, Aust. J. Chem. 1993, 46, 1323-1336.

[134] A. Hafner, A. Mühlebach, P. A. Van Der Schaaf, Angew. Chem. 1997, 109, 2213-2216.

[135] a) P. W. Rabideau, Z. Marcinow, in Organic Reactions, Vol. 42 (Ed.: L. A. Paquette), John Wiley \& Sons, Inc., 2004; b) E. Hodson, S. J. Simpson, Polyhedron 2004, 23, 2695-2707.

[136] S. De Sarkar, L. Ackermann, unpublished results.

[137] V. W. Bowry, J. Lusztyk, K. U. Ingold, J. Am. Chem. Soc. 1991, 113, 5687-5698.

[138] F. Gelman, D. Avnir, H. Schumann, J. Blum, J. Mol. Catal. A: Chem. 1999, 146, 123-128.

[139] J. Scholz, C. Jooß, unpublished results.

[140] T. Lopez, P. Bosch, M. Asomoza, R. Gomez, J. Catal. 1992, 133, 247-259.

[141] S. Warratz, D. J. Burns, C. Zhu, K. Korvorapun, T. Rogge, L. Ackermann, unpublished results.

[142] J. Hubrich, L. Ackermann, Eur. J. Org. Chem. 2016, 3700-3704.

[143] W. L. F. Armarego, C. L. L. Chai, in Purification of Laboratory Chemicals (Sixth Edition), Butterworth-Heinemann, Oxford, 2009.

[144] M. A. Bennett, A. K. Smith, J. Chem. Soc., Dalton Trans. 1974, 233-241.

[145] M. N. Pennell, P. G. Turner, T. D. Sheppard, Chem. Eur. J. 2012, 18, 4748-4758.

[146] M. Rivara, M. K. Patel, L. Amori, V. Zuliani, Bioorg. Med. Chem. Lett. 2012, 22, 6401-6404.

[147] B. Li, C. Darcel, T. Roisnel, P. H. Dixneuf, J. Organomet. Chem. 2015, 793, 200-209.

[148] C. A. Busacca, J. C. Lorenz, N. Grinberg, N. Haddad, M. Hrapchak, B. Latli, H. Lee, P. Sabila, A. Saha, M. Sarvestani, S. Shen, R. Varsolona, X. Wei, C. H. Senanayake, Org. Lett. 2005, 7, 42774280.

[149] D. S. Clarke, R. Wood, Synth. Commun. 1996, 26, 1335-1340.

[150] I. El-Deeb, J. Ryu, S. Lee, Molecules 2008, 13, 818-830.

[151] a) V. P. W. Böhm, T. Weskamp, C. W. K. Gstöttmayr, W. A. Herrmann, Angew. Chem. Int. Ed. 2000, 39, 1602-1604; b) J. Y. Kim, S. H. Park, J. Ryu, S. H. Cho, S. H. Kim, S. Chang, J. Am. Chem. Soc. 2012, 134, 9110-9113.

[152] M. Hiromitsu, M. Yoshiharu, Bull. Chem. Soc. Jpn. 1980, 53, 1181-1182.

[153] M. Periasamy, G. Srinivas, P. Bharathi, J. Org. Chem. 1999, 64, 4204-4205.

[154] C.-T. Yang, Y. Fu, Y.-B. Huang, J. Yi, Q.-X. Guo, L. Liu, Angew. Chem. Int. Ed. 2009, 48, 73987401.

[155] M. A. Bennett, T. N. Huang, T. W. Matheson, A. K. Smith, S. Ittel, W. Nickerson, in Inorg. Synth., John Wiley \& Sons, Inc., 2007, pp. 74-78.

[156] E. M. Kosower, P. E. Klinedinst, J. Am. Chem. Soc. 1956, 78, 3493-3497.

[157] R. Greenwald, M. Chaykovsky, E. J. Corey, J. Org. Chem. 1963, 28, 1128-1129.

[158] L. Ackermann, A. V. Lygin, Org. Lett. 2012, 14, 764-767.

[159] R. Takeuchi, N. Ishii, M. Sugiura, N. Sato, J. Org. Chem. 1992, 57, 4189-4194.

[160] a) M. Havelková, D. Dvořák, M. Hocek, Synthesis 2001, 1704-1710; b) L.-L. Gundersen, A. Kristin Bakkestuen, A. Jørgen Aasen, H. Øverås, F. Rise, Tetrahedron 1994, 50, 9743-9756.

[161] L. Ackermann, M. Mulzer, Org. Lett. 2008, 10, 5043-5045.

[162] B. Li, K. Devaraj, C. Darcel, P. H. Dixneuf, Tetrahedron 2012, 68, 5179-5184.

[163] M. Seki, ACS Catal. 2014, 4, 4047-4050.

[164] Y. Boutadla, O. Al-Duaij, D. L. Davies, G. A. Griffith, K. Singh, Organometallics 2009, 28, 433440. 